\title{
Hydrological, Geochemical, and Ecological Characterization of Kesterson Reservoir
}

\author{
Annual Report \\ October 1, 1988 through September 30, 1989
}

\author{
Earth Sciences Division \\ Lawrence Berkeley Laboratory \\ University of Calfornia \\ Berkeley, CA 94720 \\ Division of Agriculture and \\ Natural Resources \\ University of California
}

June 1990

This work was supported by the U. S. Bureau of Reclamation, under U. S. Department of Interior Interagency Agrcement 9-AA-20-20, through U. S. Department of Energy Contract No. DE-AC03-76SF00098. 


\section{Table of Contents}

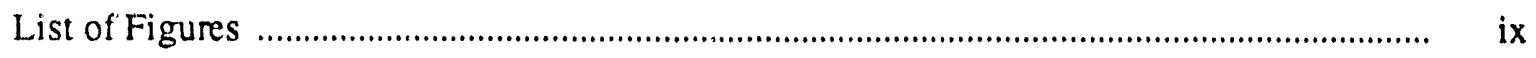

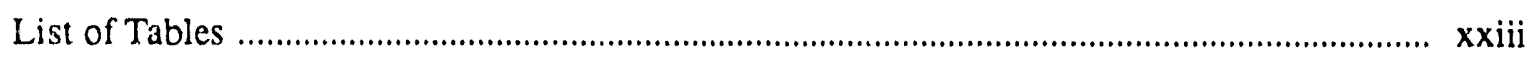

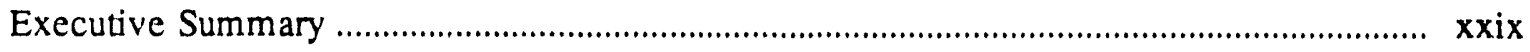

1.0. INTRODUCTION ……………....................................................................

2.0. HYDROLOGY AND GEOPHYSICS ........................................................................

2.1. Water Table Elevations and Annual Fluctuations .................................................... 5

2.1.1. Current and Historic Water Table Fluctuations ……………………......... 5

2.1.2. Anticipated Future Hydrologic Conditions ............................................... 8

2.1.3. Numerical Simulation of Water Table Fluctuations ................................... $\quad 14$

2.2. Electro-magnetic Monitoring of Plume Migration ................................................. 21

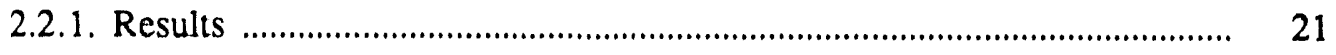

2.2.2. Data Analysis ................................................................................ 26

3.0. VADOSE ZONE MONITORING AND EVALUATION ............................................... 37

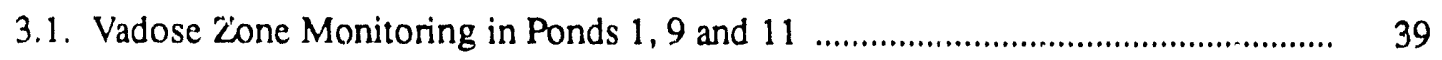

3.1.1. Pond 9 ............................................................................................... 39

3.1.2. Pond 11 Soil Water Selenium and Salinity Changes ............................... 42

3.1.3. Pond 1 Soil Water Selenium and Salinity Changes .................................. 47

3.2. Ephemeral Ptol Water Quality .......................................................................... 57

3.3. Bare Soil Evaporation Rates at Kesterson Reservoir ........................................... 63

3.3.1. Impetus for Research ............................................................................ 63

3.3.2. Local and Site-Sperific Hydrology and Hydrogeology ........................... 65

3.3.3. Measurement of Bare Soil Evaporation Rates ......................................... 68

3.3.3.1. Important Aspects of Bare Soil Evaporation .............................. 68

3.3.3.2. Methods for Measuring Bare Soil Evaporation ........................... $\quad 75$ 
3.3.3.3. Bare Soil Evaporation Rates in Plots 8EP and 9BE:

Field Data and Analysis

3.3.3.4. Errors Involved in Bare Soil Evaporation Rate Measurement

3.3.4. Measurement of Chemical Changes in Near-Surface Soils

100

3.3.4.1. Species Mobility and Reactivity

100

3.3.4.2. Procedures for Sample Collection

103

3.3.4.3. Methods for Sample Preparation and Analysis

103

3.3.4.4. Qualitative Analysis of Changes in Species Concentrations in the Upper $9 \mathrm{~cm}$ of the Soil Profile

3.3.4.5. Quantitative Analysis of Chloride Accumulation:

Calculation of Seasonal Evaporation Rates

3.3.4.5.1. Approach

3.3.4.5.2. Results

3.3.4.5.3. Analysis of Trend Significance and Errors Involved

3.3.5. Conclusions

3.4. Capillary Rise of Kesterson Reservoir Soil Solutes into

Fill Dirt

4.0. SOIL AND VEGETATION MANAGEMENT

4.1. Soil, Plant and Volatilization Studies

4.1.1. Studies at Kesterson

4.1.1.1. Main rist

4.1.1.2. Satellite Plot

4.1.2. Volatilization Studies

4.1.2.1. Sampling Procedure 147

4.1.2.2. Data Collected

4.1.2.3. Extraction Procedure

4.1.2.4. Drip Method

4.1.3. Soil and Plant Studies

4.1.3.1. Main Plot

4.1.3.2. Satellite Plot

4.1.4. Discussion

4.2. Ground Water and Vadose Zone Moisture Related to Selenium Removal by Irrigated Vegetation 
4.2.1.1. Description of Experimental Sites ............................................ 164

4.2.1.2. Field Measurements ................................................................ 168

4.2.1.3. Laboratory Experiments ......................................................... 168

4.2.1.4. Computer Simulations .......................................................... 171

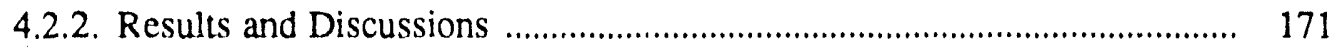

4.2.2.1. Field Measurements .............................................................. 171

4.2.2.2. Laboratory Experiments .......................................................... 182

4.2.2.3. Computer Simulations .............................................................. 184

4.3. Biomass, Species Diversity and Selenium Concentration

in Kesterson Plants .................................................................................... 189

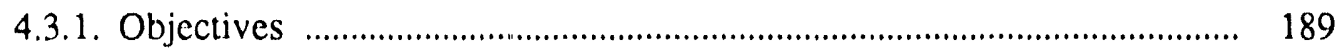

4.3.2. Materials and Methods ....................................................................... 189

4.3.3. Results and Conclusions ................................................................. 190

4.4. The Effect of Evaporite Formation and Dissolution on Salinity and Toxic

Element Management in Surface Soils .............................................................. 201

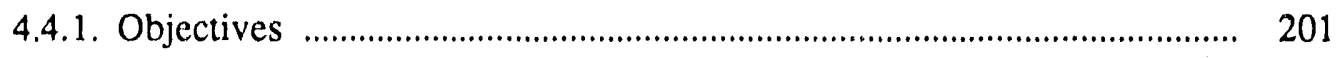

4.4.2. Sampling Procedures .......................................................................... 202

4.4.3. Projects in Progress ............................................................................... 202

4.4.3.1. Chemical Speciation of Soil Extracts _........................................ 202

4.4.3.2. Particle Size Analysis and Clay Mineralogy ............................... 225

4.4.3.3. Formation of Salt Crusts on Clods .............................................. 225

4.4.3.4. Identification of Field Evaporite Samples ................................... 225

4.4.3.5. Leaching Studies .................................................................. 226

4.5. The Effect of Irrigation Strategy on Dissipation of Selenium .............................. 235

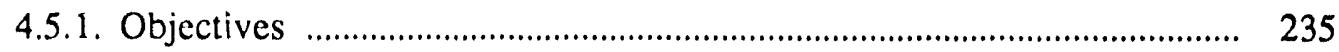

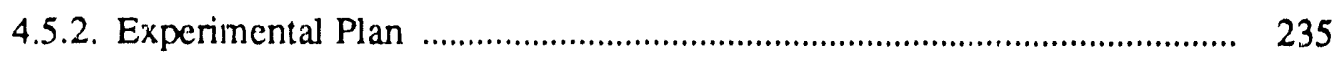

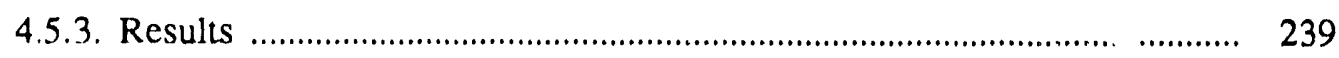

4.6. Salt and Boron Tolerance of Prospective Forage Species for

Reclamation of Selenium-Contaminated Soils ................................................. 251

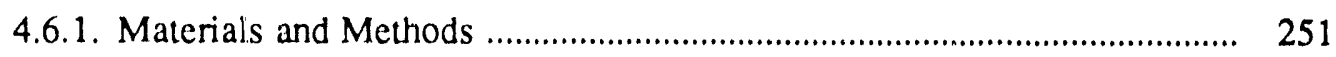

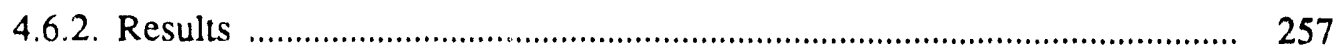

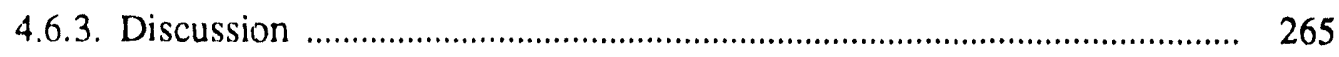

4.7. Volatilization of Selenium from Different Types of Plants

for the Removal of Selenium from Kesterson Reservoir .................................... 269 


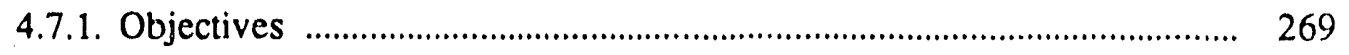

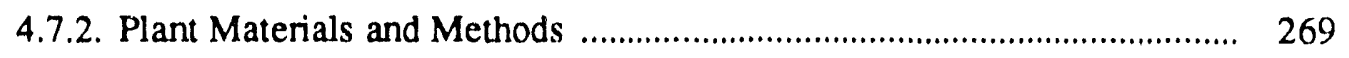

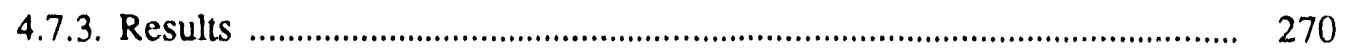

4.8. Spatial Distribution of Trace Elements in Relation to

Salinity of Kesterson Reservoir Sediments ...................................................... 275

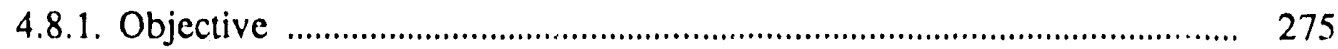

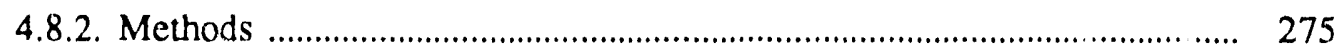

4.8.3. Results ........................................................................................ 276

4.9. Diffusive and Convective Transport of Volatile Selenium through Kesterson Reservoir Soils .............................................................. 291

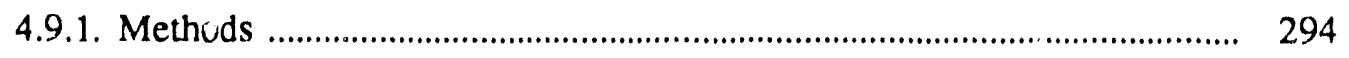

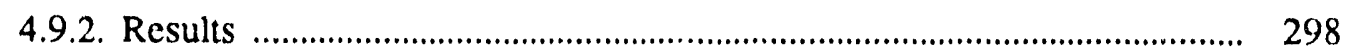

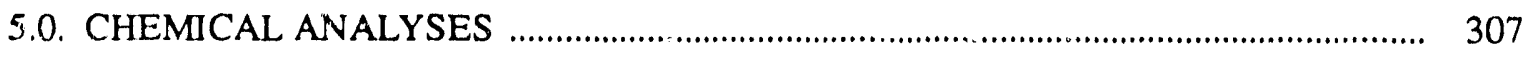

5.1. Fractionation of Selenium in Kesterson Soil ...................................................... 309

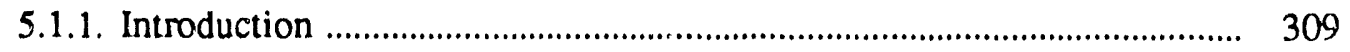

5.1.2. Experimental Procedure ............................................................................ 309

5.1.2.1. Preparation of Soil ................................................................... 309

5.1.2.2. Sequential Extraction of Selenium .......................................... 310

5.1.3. Results and Discussion ..................................................................... $\quad 310$

5.2. Phosphate-Extractable Selenite and Arsenate .................................................... 315

5.2.1. Method …........................................................................................... 315

5.2.2. Soil Profile Data .......................................................................... 318

5.3. Analysis for Organic Selenium in Water ......................................................... 323

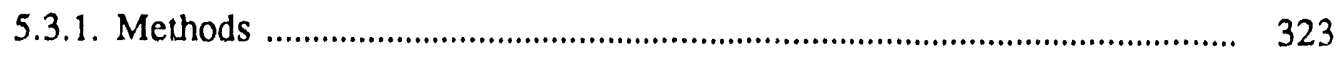

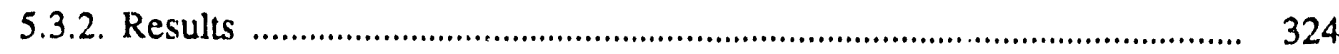

5.4. Synoptic Survey of Water-Extractable and Total Selenium Concentrations in Kesterson Soils ...................................................................... 329

5.5. Quality Control and Quality Assurance for Chemical Analysis in the Kesterson Frogram .................................................................................... 337

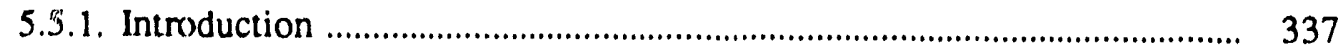

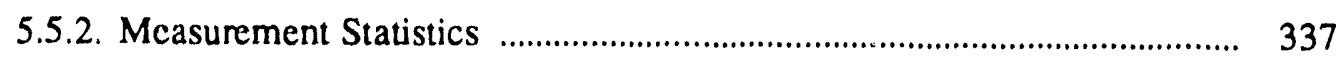

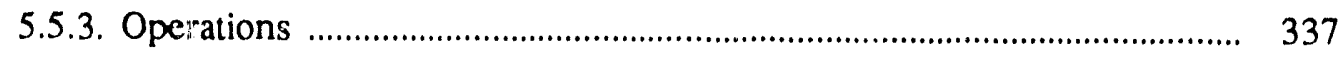

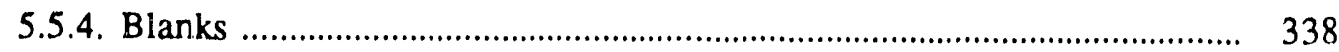

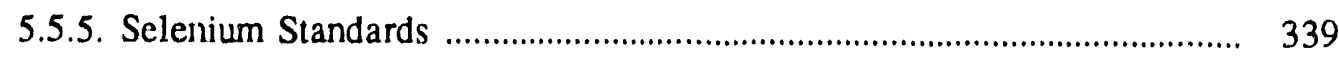


5.5.6. Boron Standards

5.5.7. Spike Recoveries

5.5.8. Duplicates

6.0. REFERENCES

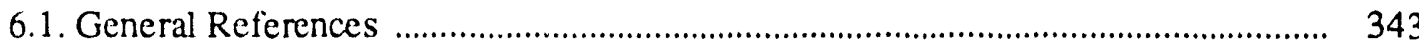

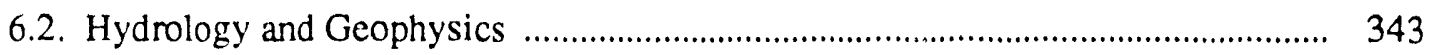

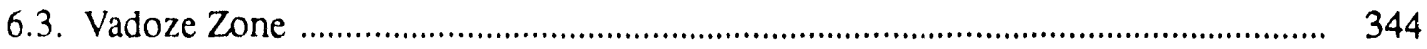

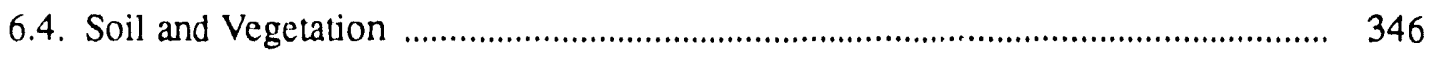

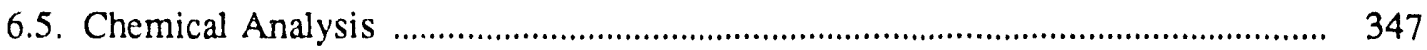




\section{List of Figures}

Page

Figure 2.1. Water table elevation data measured from Pond 1 (UZ-1 and UZ-5), Pond 8 (P8EP-W1 and KR-103), Pond 9 (P9-15' and P9B3-W1) and Pond 11 (F11-15').

Figure 2.2. Estimated annual precipitation at Kesterson Reservoir between 1890 and 1980.

Figure 2.3a. Histogram of the frequency distribution of the estimated annual rainfall at Kesterson Reservoir.

Figure 2.3b. Cumulative frequency distribution for the estimated annual precipitation at Kesterson Reservoir.

Figure 2.4. Comparison between detailed inydrographs from Pond 1 and rainfall data from the 1988-89 wet season.

Figure 2.5a. One-dimensional system used for detailed water table fluctuation studies.

Figure 2.5b. Recharge and discharge rates during a one-year cycle for detailed simulations.

Figure 2.6a. Unsaturated hydraulic conductivity curves of the fine grained surface layer used for the numerical simulations. Three different curves are shown here including the particle size derived curves (part-based), the saturation derived curves (sat-based) (i.e. the $s_{w}^{3}$ described by Scheidegger, 1957) and the curve derived by "fitting" the water table fluctuation data.

Figure 2.6b. Moisture retention curve for the fine-grained surface layer as determined from field measured saturation versus fluid potential values.

Figure 2.7. Simulated and observed water table fluctuation over a one-year period. 
Figure 2.8. Simulated seasonal variations in soil moisture content.

Figure 2.9. Simulated seasonal fluctuations in soil moisture potential.

Figure 2.10. Location map of the Kesterson Reservoir showing the ponds, ground conductivity survey lines, and observation wells.

Figure 2.11. Pixel diagrams showing the comparison between the 1987 and 1988 apparent conductivities for the EM31. Each rectangle represents an areas of 100 by $60 \mathrm{~m}$.

Figure 2.12. Pixel diagrams showing the comparison between the 1987 and 1988 apparent conductivities for the EM34/20. Each rectangle represents an areas of 100 by $60 \mathrm{~m}$.

Figure 2.13. Pixel diagrams showing the comparison between the 1987 and 1988 apparent conductivities for the EM34/40. Each rectangle represents an areas of 100 by $60 \mathrm{~m}$.

Figure 2.14. Graphs illustrating the results of the statistical analysis of the apparent conductivity data. The solid line shows the mean values for each survey line and the envelopes show the $95 \%$ confidence limits of the means. Starred points refer to averages which are significantly different at the $95 \%$ confidence level between the two years. Note that only the first $860 \mathrm{~m}$ of each line is used to calculate the average apparent conductivities.

Figure 2.15. Comparison of 1-D two-layer inversions of the 1987 and 1988 meter readings along Line $X-X^{\prime}$ (Figure 2.10). First layer depths are indicated by the horizontal bars, layer conductivities are given in $\mathrm{mS} / \mathrm{m}$, and the residual errors in the least-square fit are shown in percent within the brackets. F signifies a fixed parameter.

Figure 2.16. Local hydrology and corresponding ground conductivity base models used for forward modeling, where $S=\%$ saturation, $\sigma=$ bulk rock conductivity. The models are not drawn to scaie.

Figure 2.17. Effect of variable water table depth and first-layer saturation on the apparent conductivities measured by each instrument.

Figure 3.1a. Site P9C hydraulic head piofiles during 1988-1989 wet seas on.

Figure 3.1b. Site P9C volumetric water content profiles during 1988-1989 wet season. 
Figure 3.2a. Site P11D depth profiles of soil solution selenium concentrations.

Figure 3.2b. Site P11D depth profiles of soil solution electrical conductivity.

Figure 3.3a. Site P11S1/2 depth profiles of soil solution selenium concentrations.

Figure 3.3b. Site P11S1/2 depth profiles of soil solution electrical conductivity.

Figure 3.4a. Comparison between selenium concentrations at the UZ-8 site in 1986 and 1989.

Figure 3.4b. Comparison between selenium concentrations at the UZ-6 site in 50 1986 and 1989.

Figure 3.5a. Seasonal trends in selenium concentrations in soil water samples at site UZ-6F.

Figure 3.5b. Seasonal trends in selenium concentrations in soil water samples at site UZ-5.

Figure 3.6a Seasonal trends in chloride concentrations in soil water samples at site $\mathrm{UZ}-6 \mathrm{~F}$.

Figure 3.6b. Seasonal trends in chloride concentrations in soil water samples at the site UZ-5.

Figure 3.7a. Maximum and minimum daily air temperature at Los Banos. 66

Figure 3.7b. Average daily relative humidity at Los Banos. 66

Figure 3.8a. Daily pan evaporation at Los Banos and Kesterson Reservoir. 67

Figure 3.8b. Daily precipitation at Kesterson Reservoir. 67

Figure 3.9a. Sand, silt and cliy depth profiles in the vadose zone of plot 8EP. 69 Close-up view shown in inset graph.

Figure 3.9b. Sand, silt and clay depth profiles in the vadose zone of plot 9BE. Close-up view shown in inset graph.

Figure 3.10. Saturated hydraulic conductivity in plot 8EP profile, as measured using a Guelph Permeameter. 
Figure 3.11. Depth to water table in two wells: P8EP W1 and P9BE W1. See text for locations of wells.

Figure 3.12. Diumal fluctuations in soil water flux at two depths in a soil, 3, 7,16 , and 37 days after irrigation (from Jackson and others, 1973).

Figure 3.13. Dependence of bare soil evaporation rate on external conditions and the depth to the water table. The soil used in this example is a fine sandy loam (from Hillel, 1980b).

Figure 3.14. Measured and calculated cumulative evaporation based on field data and numerical modeling, respectively. Surface element properties were adjusted to fit the result of modeling to the first two data points (from Passerate de Silans and others, 1989).

Figure 3.15. Depencience of water evaporation rate on water salinity (here, in terms of water density) (frmm Salhotra and others, 1985).

Figure 3.16. Design and procedure for the use of a microlysimeter in Boast and Robertson (1982): (a) cylinder design, (b) cylinder pushed into soil, (c) cylinder removed and capped on the bottom prior to weighting, and (d) microlysimeter after being placed back into soil.

Figure 3.17. Dependence of cumulative evaporation from a microlysimeter on time after soil isolation and cylinder length. $t_{d}$ is the time when the cumulative evaporation deviates by $0.5 \mathrm{~mm}$ from aciual evaporation (from Boast and Robertson, 1982).

Figure 3.18a. Mean field measured bare soil evaporation rates at plot 8EP; error bars represent one standard deviation on each side of the mean. Number of samples in parentheses.

Figure 3.18b. Mean field measured bare soil evaporation rates at plot 9BE; error bars represent one standard deviation on each side of the mean. Number of samples in parentheses.

Figure 3.19a. Hydraulic potential distribution changes in soil profile of plot 8 EP during the summer and fall of 1988.

Figure 3.19b. Hydraulic potential distribution changes in soil profile of plot 9BE during the summer and fall of 1988 .

Figure 3.20a. Hydraulic potential distribution changes in soil profile of plot 8EP during the sprirg and summer of 1989. 
Figure 3.20b. Hydraulic potential distribution changes in soil profile of plot

Figure 3.21. Dependence of bare soil evaporation rate on the thickness of a surface sand mulch ori a $100 \mathrm{~cm}$ column of Pachappa sandy loam (from Gardner and Fireman, 1958).

Figure 3.22a. Measured and calculated bare soil evaporation rates for plot 8EP; error bars represent one standard deviation on each side of the measured mean.

Figure 3.22b Measured and calculated bare soil evaporation rates for plot $9 \mathrm{BE}$; error bars represent one standard deviation on each side of the measured mean.

Figure 3.23a. Calculated vs. measured bare soil evaporation rates at plot 8EP.

Figure 3.23b. Calculated vs. measured bare soil evaporation rates at plot 9BE.

Figure 3.24a. Seasonal trends in bare soil evaporation as calculated based on pan evaporation data; summer and fall, 1988.

Figure 3.24b. Seasonal trends in bare soil evaporation as calculated based on pan evaporation data; spring and summer, 1989.

Figure 3.25a. Numerically simulated bare soil evaporation rates at plot 8EP compared with actual measured rates; vapor diffusion not taken into account.

Figure 3.25b. Numerically simulated bare soil evaporation rates at plot 8EP compared with actual measured rates; vapor diffusion taken into account.

Figure 3.26. Approximate layouts of piots 8EP and 9BE.

Figure 3.27a. Changes in sodium concentration in the top $9 \mathrm{~cm}$ of soil ir plot 8EP: July 1988 - June 1989. Precipitation in $\mathrm{cm}$ shown in boxes on time axis.

Figure 3.27b. Changes in sodium concentration in the top $9 \mathrm{~cm}$ of soil in plot 9BE: July 1988 - June 1989. Hecipitation in $\mathrm{cm}$ shown in boxps on time axis.

Figure 3.28a. Changes in calcium concentration in the top $9 \mathrm{~cm}$ of soil in plot 8EP; Mly 1988 - June 1989. Precipitation in $\mathrm{cm}$ shown in boxes on time axis. 
Figure 3.28b. Changes in calcium concentration in the top $9 \mathrm{crn}$ of soil in plot 9BE; Jily 1988 - June 1989. Precipitation in $\mathrm{cm}$ shown in boxes on time axis.

Figure 3.29a. Changes in sulfate concentration in the top $9 \mathrm{~cm}$ of soil in plot 108 8EP; July 1988 - June 1989. Precipitation in $\mathrm{cm}$ shown in boxes on time axis.

Figure 3.29b. Changes in sulfate concentration in the top $9 \mathrm{~cm}$ of suil in plot 9BE; July 1988 - June 1989. Precipitation in $\mathrm{cm}$ shown in boxes on time axis.

Figure 3.30a. Changes in chloride concentration in the top $9 \mathrm{~cm}$ of soil in plot 8EP; July 1988 - June 1989. Precipitation in $\mathrm{cm}$ shown in boxes on time axis.

Figure 3.30b. Changes in chloride concentration in the top $9 \mathrm{~cm}$ of soil in plot 9BE; July 1988 - June 1989. Precipitation in $\mathrm{cm}$ shown in boxes on time axis.

Figure 3.31a. Changes in water-extractable selenium concentration in the top $9 \mathrm{~cm}$ of soil in plot 8EP; July 1988 - June 1989. Precipitation in cm shown :.. xes on time axis.

Figure 3.31b. Changes in water-extractable selenium concentration in the top $9 \mathrm{~cm}$ of soil in plot 9BE; July 1988 - June 1989. Precipitation in $\mathrm{cm}$ shown in boxes on time axis.

Figure 3.32a. Changes in selenate concentration in the top $9 \mathrm{~cm}$ of soil in plot 8EP; July 1988 - June 1989. Precipitation in $\mathrm{cm}$ shown in boxes on time axis.

Figure 3.32b. Changes in selenate concentration in the top $9 \mathrm{~cm}$ of soil in plot 9BE; July 1988 - June 1989. Precipitation in $\mathrm{cm}$ shown in boxes on time axis.

Figure 3.33a. Changes in "total" salt concentration in the top $9 \mathrm{~cm}$ of soil in piot 8EP; July 1988 - June 1989. Precipitation in $\mathrm{cm}$ shown in boxes on time axis.

Figure 3.33b. Changes in "total" salt concentration in the top $9 \mathrm{~cm}$ of soil in plot 9BE; July 1988 - June 1989. Precipitation in $\mathrm{cm}$ shown in boxes on time axis.

Figure 3.34a. Changes in chloride concentrations in soil-water at six depths in plot 9BE (10/20/88 -5/25/89). 
Figure 3.3\% b. Changes in selenate concentrations in soil-water at six depths in: plot 9BE (10/20/88 -5/25/89).

Figure 3.35. Water and chloride fluxes into and out of the top $9 \mathrm{~cm}$ of soil.

Figure 3.36a. Impedance factor, $\mathrm{f}_{1}$, as a function of voiumetric water content in five different soils, each soil at a constant bulk density (from Barraclough and Tinker, 1981).

Figure 3.36b. Impedance factor, $f_{1}$ as a function of bulk density at a constant voluinetric water content.

Figure 3.37a. Changes in chloride distribution in soil profile of plot 8EF.

Figure 3.37b. Changes in chloride distribution in soil profile of plot 9BE.

125

Figure 3.38. Scluble selenium proiles resulting fiom water table rise and evaporative flow in a Kesterson soil colımn overlain by fill dirt.

Figure 3.39. Soluble selenium and arsenic profiles in Kesterson soil/fill column experiment.

Figure 3.40. Comparizons of soluble selenium profiles in two Kesterson soil/fill columns (days 162 and 168).

Figure 3.41. Kesterson soil/fill colum' comparisons beiveen soluble selenium soncentrations $\mathrm{n}$. ured with soil core extracts and with solution extracts.

Figure 4.1. Experiment layout in main nlot (Pond 7), 1989.

Figure 4.2. Experimental layout in satellite plot (Pond 5), 1989.

Figure 4.3. Experimental setup for volatilization chambers.

Figure 4.4. Volatilization chamber for selenium.

Figure 4.5. Average CEC in a soil profile (main plot).

Figure 4.6. Changes in $\mathrm{EC}_{(\text {saturation extracs) }}$ due to irrigation under two water regirnes (main ploi).

Figure 4.7. Changes in various chemical species in the soil profile due to 
Figure 4.8. Changes in various chemical species in the soil profile due to irrigation (main plohlow water region).

Figure 4.9. Present $\mathrm{EC}_{\text {(saturation extrac) }}$ status in $0-30 \mathrm{~cm}$ depth in the satellite plot (Aug. 3, 1989).

Figure 4.10. Present distribution of various chemical species in the soil profile (satellite plothigh water region - Aug. 3, 1989).

Figure 4.11. Present distribution of various chemical species in the soil profile (satellite plot/low water region. Aug. 3, 1989).

Figure 4.12a. Field layout of the main soil, water, and vegetation management test plot Kesterson Reservoir.

Figure 4.12b. Experimental layout of the main soil, water, and vegetation management test plot in Pond 7.

Figure 4.13a. Field layout of satellite plot Kesterson Reservoir.

Figure 4.13b. Experimental lajout satellite plot Kesterson Reservoir.

Figure 4.14. Mean (solid line) and standard deviation (bars) ground water level and ground water EC at the main experimental plot.

Figure 4.15. Mean (solid line) and standard deviation (bars) eround water level and EC ground water at the satellite plot.

Figure 4.16. Hydraulic gradient along center line for satell'te plot.

Figure 4.17a. Water table depth and hydraulic gradient along center line as a function of time.

Figure 4.17b. Water table depth and hydraulic gradient at $9 \mathrm{~m}$ from center line in plot 4 as a function of time.

Figure 4.18a. Depth of water applied along center line.

Figure 4.18b. Applied water distribution, perpendicular to center line.

Figure 4.19a. Total ET as a function of distance perpendicular to center line.

Figure 4.19b. Total ET minus applied water as a function of distance, perpendicular to center line. 
Figure 4.20. Fircent of total ET removed from depth intervals $0-15 \mathrm{~cm}, 15-30$ $\mathrm{cm}$ and $30-120 \mathrm{~cm}$.

Figure 4.21. Field-measured water retention curve at $60 \mathrm{~cm}$ depth.

Figure 4.22. Saturated hydraulic conductivity value for Kesterson soil samples (main plot) when treated with distilled and Ca-solution.

Figur 4.2.3. Laboratory measured water retention curves for Kesterson soil samples (main plot), when treated with distilled water and $\mathrm{Ca}$ solution.

Figure 4.24. Example of hysteresis; main drying and wetting curves with scanning curves.

Figure 4.25. The correlation and joint distribution of plant tissue selenium concentration and soil selenium concentration in the fill dirt (0$15 \mathrm{~cm}$ ) of Pond 2 and Pond 6.

Figure 4.26. The correlation and ioint distribution of plant tissue selenium concentration and soil selenium concentration of the sub-surface soil $(25-35 \mathrm{~cm})$ of Pond No. 2 and Pond No. 6.

Figure 4.27a. Soil ion concentrations of center profile.

Figure 4.27b. Soil ion concentrations of eastem profile.

Figure 4.28. Centur profile predicted calcite from soil extracts at four depths (predicted to form from $1 \mathrm{~L}$ of solution).

Figure 4.29. Center profile predicted gypsum from soil extracts at four depths (predicted to form from $1 \mathrm{~L} \mathrm{o}$ ? solution).

Figure 4.30. Center profile predicted glauberite from soil extracts at four depths (predicted to form from $1 \mathrm{~L}$ of solution).

Figure 4.31. Eastern profile predicted calcite from soil extracts at five depths (predicted to form from $1 \mathrm{~L}$ of solution).

Figure 4.32. Eastern profile predicted gypsum from soil extracts at five depths (predicted to form fron: $1 \mathrm{~L}$ of solution).

Figure 4.33. Eastern profile predicted glauberite from soil extracts at five depths (predicted to form from $1 \mathrm{~L}$ of solutinn). 
Figure 4.34. Typical diffractogram of field evaporite.

Figure 4.35. Leaching studies - EC vs. time

Figure 4.36. Leaching studies - pH vs. time.

Figure 4.37a. Leaching study - center column ion concentrations vs. time.

Figure 4.37b. Leaching study - eastem column ion concentrations vs. time.

Figure 4.38a. Leaching studies - center column concentrations of $\mathrm{Ca}$ and $\mathrm{Na}$ in $\mathrm{mmol}_{(\mathfrak{c})} \Lambda, \mathrm{il}$ in $\mathrm{mg} /$ and $\mathrm{Se}$ in $\mu \mathrm{g} /$.

Figure 4.38b. Leaching studies - eastern column concentrations of $\mathrm{Ca}$ and $\mathrm{Na}$ in $\mathrm{mmol}_{(\mathrm{c})} \Lambda, \mathrm{B}$ in $\mathrm{mg} /$ and $\mathrm{Se}$ in $\mu \mathrm{g} /$.

Figure 4.39 Schematic diagram of filles and non-filled sediment columns and instruments.

Figure 4.40. Schematic diagram of monitoring equipment for selenium volatilization from the soil surface and within the soil profile.

Figure 4.41. Total water extractable (TWE) and acid-extractable (TAE) selenium in the sediments after air-drying.

Figure 4.42. Original water-extractable selenium (TWE), selenium after wetting (AW) and following $3.8 \mathrm{~cm}(3-9-89)$ and $26.5 \mathrm{~cm}(4-27)$ water application in non-filled (Exp. IX) and filled (Exp. XII) sediments.

Figure 4.43. Rate of selenium volatilization (niicrogram $\mathrm{m}^{-2} \mathrm{~d}^{-1}$ ) on $4 / 27 / 89$.

Figure 4.44. Selenium volatilization from soil surface before (BI) and after (AI) irrigation for filled and non-filled sediments irrigated weekly (W), biweekly (BW) and triweekly (TW).

Figure 4.45. Selenium volatilization from the soil surface for filled and nonfilled sediments.

Figure 4.46. Volatilized selenium in the filled sediments irrigated biweekly $(\mathrm{BW})$ or triweekly (TW), before (BI) and after (AI) irrigation.

Figure 4.47. Average rate of selenium volatilization within the soil profile for filled sediments. 
Figure 4.48. Average rate of selenium volatilization within the profile for non-filled sediments.

Figure 4.49. Representative germination responses to salinity for three tall wheatgrass cultivars. Symbols indicate experimental observations and lines represent best-fit regression models from Table 4.33 .

Figure 4.50. Typical significant germination response to B concentration. Symbols indicate experimental observations and line represents best-fit regression model using model 4.

Figure 4.51. Typical nonsignificant germination response to B concentration. Symbols indicate experimental observations and line represents best-fit regression model using model 3.

Figure 4.52. The rates of selenium vulatilization for 7 different plant species including selenium accumuiators (Astragalus bisulcatus, Astragalus hamosus, Astragalus cymbicarpos), range plants (Atriplex numularia, Brassica juncea) and crop species (cotton, barley). Plants were grown in growth chambers in $1 / 2$ Hoagland solution with $20 \mu \mathrm{M}$ sodium selenate. Values are mean \pm S.D. for 3 replications.

Figure 4.53. Tissue selenium levels in leaves (A), stem (B) and roots (C) for 7 different plant species. Plants were grown in growth chambers in $1 / 2$ Hoagland solution with $20 \mu \mathrm{M}$ sodium selenate. Values are mear \pm S.D. for 3 replications.

Figure 4.54. Configuration of Kesterson Reservoir.

Figure 4.55. Distribution of total dissolved solids in surface sediments of Kesterson.

Figure 4.56. Distribution of sodium in surface sediments of Kesterson.

Figure 4.57. Distribution of calcium in surface sediments of Kesterson.

Figure 4.58. Distribution of magnesium in surface sediments of Kesterson.

Figure 4.59. Distribution of potassium in surface sediments of Kesterson.

Figure 4.60. Distribution of lithium in surface sediments of Kesterson.

Figure 4.61. Distribution of strontium in surface sediments of Kesterson. 
Figure 4.62. Distribution of silica in surface sediments of Kesterson. 281

Figure 4.63. Distribution of phosphorus in surface sediments of Kesterson. 282

Figure 4.64. Distribution of boron in surface sediments of Kesterson. 282

Figure 4.65. Distribution of selenium in surface sediments of Kesterson. 283

Figure 4.66. Distribution of molybdenum in surface sediments of Kesterson. $\quad 2.83$

Figure 4.67. Distribution of arsenic in surface sediments of Kəsterson. 284

Figure 4.68. Distribution of nickel in surface sediments of Kesterson. 284

Figure 4.69. Distribution of uranium in surface sediments of Kesterson. 285

Figure 4.70. Distribution of molybdenum in a profile in cell 9, Kesterson. 286

Figure 4.71. Distribution of selenium in a profile in cell 9, Kesterson. 286

Figure 4.72. Distribution of vanadium in a profile in cell 9, Kesterson. 287

Figure 4.73. Distribution of arsenic in a profile in cell 9, Kesterson. 287

Figure 4.74. System for measuring volatile selenium emissions from soils 296 under diffusive and convective conditions.

Figure 4.75. Laboratory volatile selenium emission rates from a Pond 4 soil, 299 $(\mathrm{P} 4 \mathrm{X})$ at $25 \mathrm{C}$. Soil gas flow rates randomly varied from 0 to 720 $\mathrm{mm} / \mathrm{h}$.

Figure 4.76. Hysteresis in volatile selenium emission rates under systemati- 299 cally varied soil gas flow rates. Soil P4X, 25.2 C.

Figure 4.77. Volatile selenium emission rates under diffusion-limited condi- $\quad 362$ tions. Soil P4X, 25.2 C.

Figure 4.78. Volatile selenium emission rates under $250 \mathrm{~mm} / \mathrm{h}$ steady soil air 302 flow rate. Soil P4X, 25.2 C.

Figure 4.79. Volatile selenium emission rates under $500 \mathrm{~mm} / \mathrm{h}$ steady soil air flow rate. Soil P4X, 25.2 C. 
Figure 5.2. Comparisons of cations extracted by $0.1 \mathrm{~m} \mathrm{H}_{3} \mathrm{PO}_{4}, 0.1 \mathrm{~m}$ potas-

Figure 5.3. Dependence of extractable selenite, arsenate, and silica on phosphate concentration.

Figure 5.4. Site P11C, water-extractable and phosphate-extractable selenium.

Figure 5.5. Site P9C, soluble arsenic, phosphate-extractable arsenic, and total arsenic.

Figure 5.6. Off-site soil profiles of water-extractable and phosphateextractable arsenic.

Figure 5.7. Comparison of the distribution of total st lenium concentrations for each habitat type: open; grassland; and filled.

Figure 5.8. Comparison of the distribution of water extractable selenium concentrations for each habitat type: open, grassland; and filled.

Figure 5.9. Water extractable fraction of total selenium vs. habitat type. Error bars show the upper half of the range in which there is 95\% confidence.

Figure 5.10. Total selenium vs. habitat type. Error bars show the upper half 332 of the range in which there is $95 \%$ confidence.

Figure 5.11. Water extractable selenium vs. habitat type. Error bars show the upper half of the range in which there is $95 \%$ confidence.

Figure 5.12. Water extractable selenium and selenite for each habitat type.

Figure 5.13. Water extractable selenium vs. total selenium for each habitat type. 


\section{List of Tables}

Page

Table 2.1. Comparison between the water table elevation in February 1989 and the target fill surface elevation. The last column lists the distance between the fill surface and the elevation of the water table.

Table 3.1. Profile-averaged soil water quality, sites P9R and P11.

Table 3.2. Time trend in the distribution of chloride in vadose zone pore waters at the Pond 11 test plot.

Table 3.3. Profile-averaged selenium concentration in pore water samples collected from pore water samples in Pond 1.

Table 3.4. Water quality in ephemeral pools at Kesterson during the winter of 1988-1989.

7able 3.5a. Bare soil and pan evaporation data and calculated rates: Plot $8 \mathrm{EP}$.

Table 3.5b. Bare soil and pan evaporation data and calculated rates: Plot 9BE.

Table 3.6. Calculated average seasonal rates of bare soil evaporation for plots $8 \mathrm{EP}$ and $9 \mathrm{BE}$, compared with average seasonal pan evaporation rates.

Table 3.7. Solubility product constants and solubilities of minerals present or likely to be present at Kesterson Reservoir.

Table 3.8. Concentrations of water-extractable selenium vs. total selenium by XRF analysis.

Table 3.9a. Calculation of bare soil evaporation based on chloride fluxes and changes in moisture content: Plot 8EP. 
Table 3.9b. Calculation of bare suil evaporation based on chloride fluxes and changes in moisture content: Plot 9BE.

Table 3.10. Results of t-test performed to evaluate the significance of monthly and seasonal chloride concentration changes.

Table 3.11. Uncertainties involved in the estimation of water fluxes based on chan, es in chloride concentrations and moisture content.

Table 4.1. Air temperature inside and nutside the volatilization chamber.

Table 4.2. Dry weight of various plant-species inside the volatilization chambers.

Table 4.3. Analysis of soils inside the chambers.

Table 4.4. Syringe and shaker extraction of the same filter for volatile 154 selenium.

Table 4.5. $\quad \mathrm{H}_{2} \mathrm{O}_{2}$ as an extractant compared $\mathrm{H}_{2} \mathrm{O}$ in the shaker method.

Table 4.6. Comparison of drip and shaker method.

Table 4.7. Irrigation schemes research plots Kesterson 1989.

Table 4.8. Laboratory measured saturated hydraulic conductivity values for surface (fill) and subsurface $(60 \mathrm{~cm}$ depth) samples from satellite plot.

Table 4.9. Analysis of inorganic soil selenium in the top $0.15 \mathrm{~m}$ of fill dirt.

Table 4.10. Plant tissue selenium concentration of plant species from two fill sites at Kesterson (Ponds 2 and 6).

Table 4.11. Selenium analysis of soil and plant tissue from the native-soil 193 site in Pond 6.

Table 4.12. Sc!enium analysis of soil and plant tissue from the native-soil slis in Pond 7.

Table 4.13. Tissue selenium concentrations in leaves and biomass of plant 195 species growing at the fill-site in Pond 2 (collected 5/27/89).

Table 4.14. Selenium. concentrations in leaves and biomass of plant species growing at the fill-site in Pond 6 (collected 5/27/89). 
Table 4.15. Ion concentrations from soil extracts 1:5 soil - water extract.

Table 4.16. Center profile $0-5$ inches 1:5 soil water extract data.

Table 4.17. Center profile $5-12$ inches $1: 5$ soil water extract data. 208

Table 4.18. Center profile $12-18$ inches 1:5 soil water extract data. 209

Table 4.19. Center profile $18-24$ inches 1:5 soil water extract data.

Table 4.20. Eastem profile 0 - 5 inches 1:5 soil water extract data. 216

Table 4.21. Eastern profile 5 - 10 inches 1:5 soil water extract data.

Table 4.22. Eastern profile 10 - 15 inches 1:5 soil water extract data.

Tab!e 4.23. Eastern profila $15-2 C$ inches 1:5 soil water extract data.

Table 4.24. Eastern proille 20 - 24 inches 1:5 soil water extract data.

Table 4.25. Analyses of effuents from soil columns packed with 0 to 5 inch 228 depths from Pond 7 soils.

Table 4.26a. Ion concentrations from leaching studies, center column.

Table 4.26b. Ion concentrations from leaching studies, east column.

Table 4.27. Concentration of selenium in soil solution $(\mu \mathrm{g} / \mathrm{l})$ for filled $(\mathrm{F})$ 242 and non-filled (NF) sediments. Biweekly irrigation.

Table 4.28. Concentration of selenium in soil solution $(\mu \mathrm{g} / 1)$ for filled sediments irrigation biweekly (BW) and triweekly (TW).

Table 4.29. Average rate of selenium volatilization from soil surface $\left(\mu \mathrm{g} / \mathrm{m}^{2}\right.$-day).

Table 4.30. Summary of germination conditions.

Table 4.31. Screening solutions used for evaluating the germination of $0.5 \mathrm{mM}$.

Table 4.32. Regression analyses for the germination response of the legumes to salinity in the range 0.14 to $30.6 \mathrm{dS} / \mathrm{m}$. All coefficients are significant at $\mathrm{p} \leq 0.001$. 
Table 4.3. Regression analy ses for the germination response of the grasses to salinity in the range 0.14 to $30.6 \mathrm{dS} / \mathrm{m}$. All coefficients are significant at $\mathrm{p} \leq 0.01$ or $\mathrm{p} \leq 0.001$.

Table 4.34. Regression analyses for the germination response of the legumes to boron in the range of $4.0 \mathrm{mM}$

Table 4.35. Regression analyses for the germination response of the grasses to boron in the range 0 to $4.0 \mathrm{mM}$.

Table 4.36. Regression analyses for the seedling growth response to salinity in the range 0.4 to $30 \mathrm{dS} / \mathrm{m}$. All coefficients are significant at $\mathrm{p}$ $<=0.05$ or less.

Table 4.37. Regression analyses for the seedling growth response to boron in the range 0 to $4.0 \mathrm{mM}$.

Table 4.38. Properties of the topsoil samples collected from Kesterson Reservoir.

Table 4.39. Plant growth and Se uptake for 7 different plant species. Plants were grown in growth chambers in $1 / 2$ Hoagland solution with $20 \mu \mathrm{M}$ sodium selenate. Values are mean \pm S.D. for 3 replications.

Table 4.40. Trace elements in 36 Kesterson sediment samples compared to San Luis Drain sediment (mg 1).

Table 4.41. Correlation coefficients between selected trace elements and salinity indices in Kesterson surface sediment aqueous $(1: 1 \mathrm{~m} / \mathrm{v})$ extracts.

Table 5.1. Sequential extraction of selenium using K-EDTA, phosphate buffer, and $\mathrm{H}_{3} \mathrm{PO}_{4}, \mathrm{KCl}$ and $\mathrm{NaOH}$.

Table 5.2. Adsorption of selenite by activated charcoal (AC) and XAD-8 resin columns. A $10 \mu \mathrm{g} / \mathrm{l}$ standard was used for these trials.

Table 5.3. Adsorption of selenite by activated charcoal and XAD-8 columns. A $20 \mu \mathrm{g} / \mathrm{h}$ standard was used for these trials.

Table 5.4. Adsorption of selenoamino acids by XAD-8 and cation exchange resins. 
- xxvii -

Table 5.6. Analysis of phosphate extracted soil samples for organoselenium compounds.

$\begin{array}{lll}\text { Table 5.7. Selenium standard statistics }(5 / 11 / 88-3 / 22 / 89) . & 340\end{array}$

Table 5.8. Selenium standard statistics (1/24/89-9/21/89). 340

$\begin{array}{lll}\text { Table 5.9. } & \text { Boron standard statistics. } & 341\end{array}$ 


\section{EXECUTIVE SUMMARY}

Scientists and engineers from the Earth Sciences Division at Lawrence Berkeley Laboraiory havi been studying the Kesterson environment and participating in developing cost effective remediation techniques since 1985 . The combined efforts of the USBR and investigators from the USGS, CH2M Hill and more recently, the University of Califomia have resulted in two major remediation actions, stopping drainwater deli ze ses to the Reservoir and filling the low-lying areas to eliminate the formation of ephemeral puols. These two measures have significantly reduced the presence of conditions that are hazardous to wildife at the site. Nevertheless, a large inventory of selenium remains in the soils, and questiuns remain as to both the current and furure consequences of this.

This report describes Kesterson Reservoir related research activities carried out under a cooperative program between Lawrence Berkeley Laboratory and the Division of Agriculture and Natural Resources at the the University of California during FY89. The primary objectives of these investigations are:

- predict the extent, probability for the occurrence, and selenium concentrations in surface vater of temporary wetland habitat at Kesterson;

- assess rates and direction of migration of the Jrainage water plume that seeped into the aquifer under Kesterson;

- monitor and predict changes in quantity and speciation of selenium in surface soils and vadose zone pore-waters; and

- develop a comprehensive strategy through soil, water, and vegetation management to safely dissipate the high concentrations of selenium accumulated in Kesterson soils. 
This report provides an up-date on progress made in each of these areas.

Groundwater monitoring and numerical simulation studies have been carried out to assess the likelihood of forming ephemeral pools from rising groundwater at Kesterson Reservoir. The primary conclusion from these activities is that formation of ephemeral pools due to rising groundwater is unlikely in years of below-normal to slightly above-normal precipitation. In years of heavy rainfall ( $50 \%$ greater than a normal water-year), the majority of unvegetated areas of the Reservoir may be covered with standing water during the late winter. Salt and selenium concentrations in these pools are expected to be considerably lower than in the ephemeral pools that occurred during the $1986-1987$ period but nevertheless, may well exceed the $2-5 \mu \mathrm{g} / 1$ levels judged harmful to wildlife. In years of exceptionally heavy rainfall (100\% greater than a normal year) ponding over much of the Reservoir is anticipated. Contingency plans for surface drainage of the Reservoir into local waterways may be desirable to minimize wildlife exposure to these temporary wetlands.

Migration of the plume of saline but low selenium $(<2 \mathrm{mg} /)$ water that seeped from the Reservoir into the underlying aquifer was monitored using a non-intrusive electromagnetic technique. Data from two sequential surveys, conducted in October 1987 and 1988, indicate that the plume is confined to a band extending about $300 \mathrm{~m}$ from the San I uis Drain. No detectable migration of the leading edge of the plume was observed over the one-year period. However, this is not unexpected because $100-\mathrm{m}$ spatial resolution of the electromagnetic survey was too large to detect migration at the estimated rates of $50 \mathrm{~m} /$ year when the Reservoir was in operation and 5 $\mathrm{m} /$ year following this period.

Vadose zone selenium and salt concentrations have been monitored at several locations in the Reservoir for a period of three years. In addition, over the past year, a detailed study of changes in near-surface salt and selenium concentrations as a result of bare soil evaporation has been completed. In general, it is found that concentrations of selenium and other species continue to change in response to a variety of physical, biological, and chemical factors. Some of the observed changes are seasonal, being affected by the rise and fall of the water table and 
meteorological conditions. Others appear to be a part of a long-term process of species redistribution, as controlled by the remobilization (and immobilization) of species due to reduction/oxidation, adsorption/desorption, and dissolution/precipitation. Current understanding of these processes and the rates at which they occur suggests that:

- Changes in the inventory of soluble selenium residing in the vadose zone take place relatively slowly ( $<10 \%$ of the total inventory per year) after the pond bottom soils are initially dried out.

- Annual cycles of precipitation and evaporation transport selenium and soluble salts both upwards and downwards within the vadose zone. The long term trends created by these fluctuating conditions remain uncertain.

- Bare soil evaporation rates are much lower than expected given the shallow depth to the water table and fine-textured nature of the soils. Consequently evaporative accumulation of selenium at the soil surface will be negligible or at least much slower than previously anticipated.

Beginning in 1988, scientists at the Division of Agriculture and Natura! Resources at the University of Califomia and Lawrence Berkeley Laboratory initiated a new effor aimed at developing a soil water and vegetation management plan for Kesterson Reservoir. The goal of the management plan is two-fold. First, the plan is intended to result in a gradual depletion of the inventory of soluble selenium at the Reservoir through a combination of agriculturally oriented practices that enhance dissipation of selenium from near surface soils. Agriculturally oriented processes that wili coniribute to depletion include microbial volatilization from the soils, direct volatilization by living plants, decomposition and volatilization of selenium-bearing vegetation, harvest and removal of seleniferous vegetation, and leaching. The benefits of using this integrated approach are that (1) no single mechanism needs to be relied upon to detoxify the soils, (2) a stable plant community can be established during this period so that impacts to wildife can be more easily evaluated and controlled, and (3) cleanup and management of the site can be carried out in a cost-effective manner. The management plan is also intended to facilitate 
control over wildlife exposure to selenium contaminated biota by creating a well managed environment. By managing the type of vegetation growing at the site, and by using vegetation to assist in soil moisture control, and consequently surface water accumulation during the wet season, biotic exposure to seleniferous food-chain items can be controlled.

The majority of research associated with this new effort is being carried out in two test plots at Kesterson, a $200 \mathrm{~m}$ by $50 \mathrm{~m}$ plot in Pond 7 and a slightly smaller plot in a "filled" area of Pond 5. Each test plot has a two-line irrigation system system, providing brackish local groundwater as an irrigation supply. In addition, during the germination period, better quality water is trucked in to help stimulate establishment of crop plants. Through an intensive program of soil water sampling, soil gas sampling, vegetation sampling, groundwater monitoring, and soil moisture monitoring, the mass balance fur selenium under irrigated conditions is being evaluated. These studies, in conjunction with supplementary laboratory experiments will provide the information needed to develop an optimai management plan for the site.

Early results from these investigations are summarized as follows:

- A new system for measuring volatile selenium emission rates from vegetated and unvegetated soils has been developed. The new sampler has the advantage that the ambient conditions at which the emission rates are measured are nearly identical to conditions outside the measurement chamber. Additional benefits include the capability for making continuous measurements over a several day period, thereby accounting for diumal fluctuations in volatilization rates created by diumal temperature cycles.

- Establishment of crop plants at the test plot located on the fill site was relatively successful. Barley was the most successful in this plot.

- Establishment of crop plants at the test plot in Pond 7, a grassland site, was not successful. The high salinity of the soil surface is most likely the source of failure. Steps to mitigate this problem, including flushing salts from the surface prior to seeding, are being evaluated 
- Emission of volatile selenium from the soil surface is affected by a number of factors including the moisture regime, presence of plants, and fill material. Preliminary results suggest that a tri-weekly irrigation may result in higher cumulative emission rates than weekly or biweekly irrigation.

- Laboratory and greenhouse germination studies have been unsuccessful in identifying candidates species for crop plants in the Kesterson soils. High salinity has been identified as the primary source of this problem, but, the presence of high concentrations of trace elements may also inhibit germination.

- Volatile emission rates from a number of crop and selenium accumulator plants have been measured in the laboratory. In general, emission rates are small compared to soil emission rates, but nevertheless plants can be expected to slowly contribute to depletion of the inventory through er ission of volatile forms of selenium. Amongst those testet, barley and cotton had the highest per plant emission rates.

- Emission of volatile seleniurn from the soil surface has been shown to be sensitive to convective flux of gas through the soil. Hysteretic effects created by increasing or decreasing the convective flux have also been observed. These laboratory investigations have demonstrated the need to have a better understanding of the biogeochemical and transpor processes leading to dissipation of selenium through microbial volatilization.

Development of improved analytical techniques for speciation of selenium in soil and pore water samples has been an integral part of the Kesterson Reservoir investigation since 1985. This year, we continued this effort along two lines, including development and application of soil fractionation techniques, and application of techniques for separation of organically bound selenium in pore water. Major results from these investigations are summarized as follows:

- Approximately $60 \%$ of the selenium contained in the top six inches of soil is in refractory forms that are expected to resist transformation to more soluble or volatile forms. Further speciation and fractionation studies are in progress to fuither identify labile and 
refractory forms of selenium, and to determine rates of volatilization from the various pools of selenium present in the Kesterson soils.

- Phosphate extraction of soils indicates the presence of a significant pool of adsorbed selenite throughout the soil profile. Only a small fraction of the selenite (10\%) appears to be mobile.

- Pore waters collected by vacuum cup samplers do not have a significant fraction of organically bound selenium $(<5 \%)$. Consequently, the selenate concentration in the pore water is accurately determined from the difference between "total selenium" concentration in the pore water and the selenite concentration.

- A Reservoir-wide synoptic sampling of the top $0.15 \mathrm{~m}$ of soil (54 sampling sites) revealed that the average fractions of water extractable selenium in the fill, grassland, and former cattail areas of the Reservoir are $7 \%, 8 \%$ and $5 \%$ respectively. Average total selenium concentrations for each of the habitats are $2.1 \mathrm{mg} / \mathrm{kg}, 6.6 \mathrm{mg} / \mathrm{kg}$, and $17.3 \mathrm{mg} / \mathrm{kg}$, respectively. Within each habitat type there is a wide range of values. Thus, assessment of management actions based on habitat type alone may not provide a reliable guideline for such decisions. As an altemative, an area by area assessment based on a number of factors such as selenium concentrations, depth to the watertable, and dominant vegetation type may be more appropriate. 


\section{INTRODUCTION}

Scientists and engineers from the Earth Sciences Division at Lawrence Berkeley Laboratory have been studying the Kesterson environment and participating in developing cost effective remediation techniques since 1985 . The combined efforts of the U. S. Fish and Wildlife Service (USFWS), the USBR and investigators from the USGS, $\mathrm{CH} 2 \mathrm{M}$ Hill and more recently, the University of Califomia have resulted in two major remediation actions, stopping drainwater deliveries to the Reservoir and filling the low-lying areas to eliminate the formation of ephemeral pools. These two measures have significantly reduced the presence of conditions that are hazardous to aquatic wildlife at the site. Nevertheless, a large inventory of selenium remains in the soils, and questions remain as to both the current and future consequences of this.

This report describes Kesterson Reservoir related research activities carried out under a cooperative program between Lawrence Berkeley Laboratory and the Division of Agriculture and Natural Resources at the the University of Califomia during FY89. The primary objectives of these investigations are:

- predict the extent, probability for the occurrence, and selenium concentrations in surface water of temporary wetland habitat at Kesterson;

- assess rates and direction of migration of the drainage water plume that seeped into the aquifer under Kesterson;

- monitor and predicl changes in quantity and speciation of selenium in surface soils and vadose zone pore-waters; and

- develop a comprehensive strategy through soil, water ${ }_{\nu}$ and vegetation management to safely dissipate the high concentrations of selenium accumulated in Kesterson soils. 
This report provides an up-date on plogress made in each of these areas. Chapter 2 describes results of recent investigations of water table fluctuations and plume migration. Chapter 3 describes results of ongoing monitoring of soil water selenium concentrations and evaporative accumulation of selenium at the soil surface. Chapter 4 describes early results from the soil, water, and vegetation management field trials as well as supporting laboratory and theoretical studies. In Chapter 5, new analytical methods for selenium speciation are described and quality assurance/quality control statistics for selenium and boron are provided. 


\subsection{HYDROLOGY AND GEOPHYSICS}

The following section summarizes recent investigations relevant to two topics, the potential for creation of ephemeral pools at Kesterson and the extent of the plume of saline but seleniumfree water that seeped into the underlying aquifer while Kesterson was in operation. Major conclusions arrived at from these investigations are:

(1) Formation of ephemeral pools due to rising ground water is unlikely in years of below-normal to slightly above-normal precipitation. In years of heavy rainfall unvegetated areas of the Reservoir may be covered with standing watcr. Salt and selenium concentrations are expected to be considerably lower than in the ephemeral pools that occurred during the 1986-1987 period but selenium concentrations may well be in excess of the 2 to $5 \mu \mathrm{g} / \mathrm{l}$ associated with harmful effects to wildlife.

(2) Non-intrusive electro-magnetic methods are effective for detecting and monitoring large-scale migration of the saline drainage water plume in this environment. Data from two sequential surveys indicate that the plume is confined to a band extending about $300 \mathrm{~m}$ from the San Luis Drain. No detectable migration was observed over the one-year period. 


\subsection{WATER TABLE ELEVATIONS AND ANNUAL FLUCTUATIONS}

Sally Benson, Moshen Alavi and Stacey Pillsbury

Earth Sciences Division, Lawrence Berkeley Laboratory

Every year the water table underlying Kesterson Reservoir rises and falls in response to numerous factors, including: intentional flooding of the surrounding seasonal wetlands; regional precipitation; surface water flow in sloughs and canals; and ground water pumping. Previous estimates based on water-level data collected in 1970 and 1971 indicated that in a typical wateryear the water table would rise above the original ground surface of the Reservoir, creating several hundred acres of ephemeral pools (USBR, 1986). Selenium concentrations in these pools were anticipated to range from 10's to 1000's of ppb, based on observations made during 1987 and 1988 (LBL Annual Report, 1987). The primary cbjective for filling the low-lying areas of the Reservoir was to raise the elevation of the ground surface above the maximum height of the water table. By doing so, the occurrence of the most persistent and biologically hazardous ephemeral pools could be eliminated. Water level data are now available for the current wet season and provide a basis for determining if the filling operation was successful for meeting its primary objective.

\subsubsection{Current and Historic Water Table Fluctuations}

Examples of water table elevation data collected at Kesterson over the past 3 years are shown in Figure 2.1. Similar patterns have been observed in the Kesterson area for over 30 years (LBL, 1985). Annual fluctuations are on the order of 1 to $2 \mathrm{~m}$, with the highest elevations occurring in the period between February and March. This figure, which is a compilation of data from Ponds $1,8,9$, and 11 , also illustrates that the fluctuations are of similar magnitude and character throughout the Reservoir.

Water level data were also collected by the USBR from 300 wells in and around Kesterson 


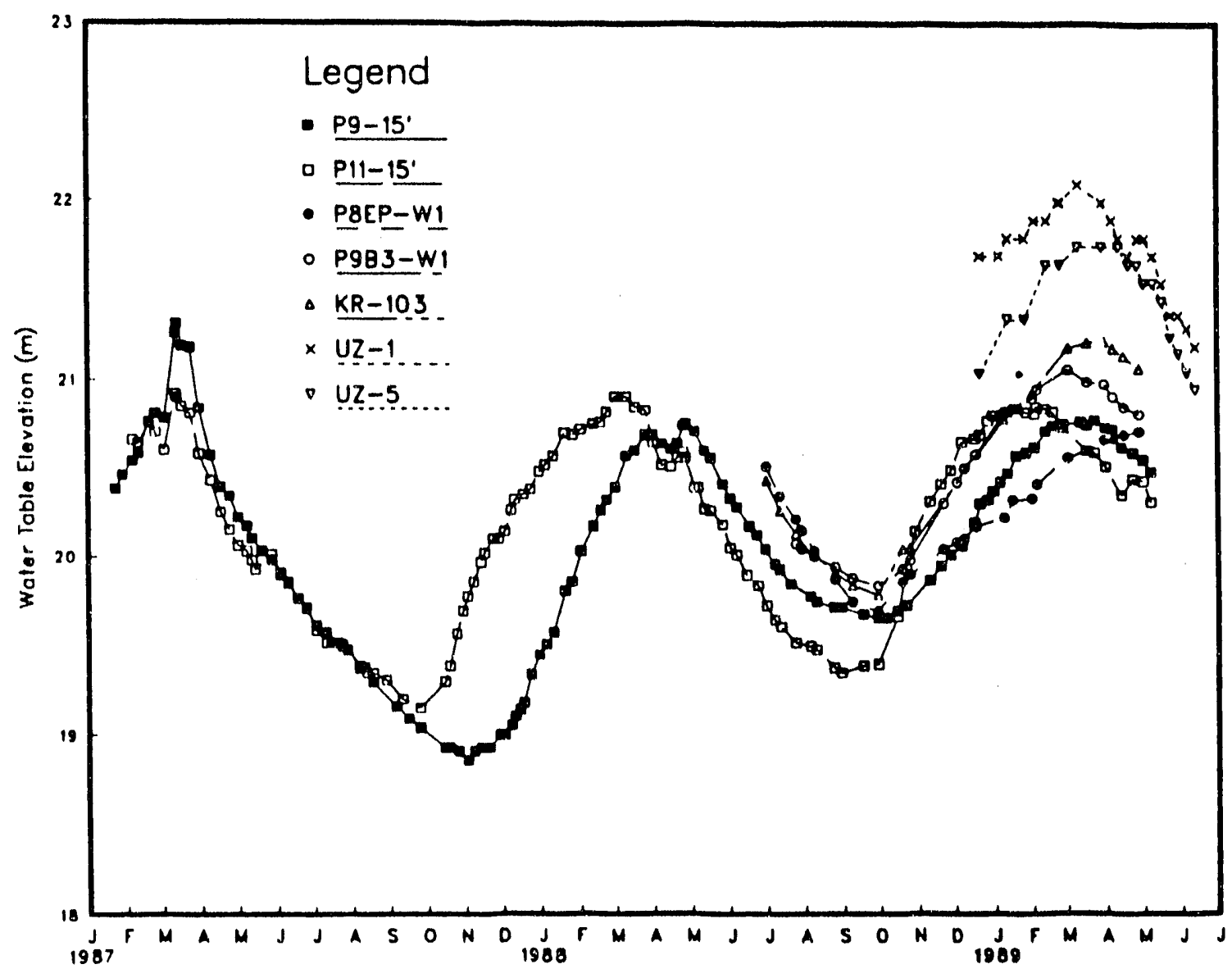

Figure 2.1. Water table elevation data measured from Pond 1 (UZ-1 and UZ-5), Pond 8 (P8EP-W1 and KR-103), Pond 9 (P9-15' and P9B3-W1) and Pond 11 (P11-15'). 
Reservoir during the period between January 31 to February 2, 1989. A comparison between average water table elevation and the engineering specifications for fill elevation is provided on a pond-by-pond basis in Table 2.1. As indicated by the last column in this table, during the 1988/89 wet season, the average distance between the fill surface and the water table ranged from 0.6 to $1.5 \mathrm{~m}$. Water table elevations peaked in March with maximum elevations ranging from zero to 0.3 meters higher than the values listed in Table 2.1 . The filling operation was designed to raise the ground surface to at least 0.15 m.above the maximum height of the water table. Data from the current wet season indicate that this criterion has been satisfied in all of the ponds. In addition, there is a safety margin of nearly a meter or more in the majority of the Reservoir.

Table 2.1. Comparison between the water table elevation in February of 1989 and the target fill surface elevation. The last column lists the distance between the fill surface and the elevation of the water table.

\begin{tabular}{|cccc|}
\hline $\begin{array}{c}\text { Pond } \\
\text { Water Table Elevation } \\
\mathrm{m}\end{array}$ & $\begin{array}{c}\text { Target Fill Surface Elevation } \\
\mathrm{m}\end{array}$ & $\begin{array}{c}\text { Depth to Water Table } \\
\mathrm{m}\end{array}$ \\
\hline 1 & 21.3 & 22.9 & 1.0 \\
2 & 21.3 & 22.6 & 1.3 \\
3 & 21.9 & 22.6 & 0.7 \\
4 & 21.9 & 22.6 & 0.7 \\
5 & 21.3 & 22.4 & 1.1 \\
6 & 21.8 & 22.4 & 0.6 \\
7 & 21.2 & 22.4 & 1.2 \\
8 & 21.3 & 22.4 & 1.1 \\
9 & 20.7 & 22.1 & 1.4 \\
10 & 21.2 & 22.1 & 0.9 \\
11 & 20.7 & 21.8 & 0.9 \\
12 & 20.1 & 21.5 & 1.4 \\
\hline
\end{tabular}




\subsubsection{Anticipated Future Hydrologic Conditions}

As described above, during the 1988-89 wet season, depth to the water table ranged from 0.3 to over $1.5 \mathrm{~m}$ below the ground surface, indicating that ponding due to rising groundwater has not occurred. Field observations and numerical modeling studies, which are described in Section 2.1.3, indicate that in years of below-normal to normal rainfall, the seasonal water-table rise is due primarily to application of surface water to the surrounding duck clubs, which comprise approximately $18 \%$ of the area in a 124 sq. mile $(350 \mathrm{sq} . \mathrm{km}$ ) region centered on Kesterson Reservoir (Mandle and Kontis, 1986). Modeling studies suggest that evapotranspiratio : is the primary cause for the water table decline during the hot summer months. Several other factors may affect the height of the water table, including groundwater pumping, local and regional precipitation, seepage from and discharge into sloughs and canals and long-term trends in valleywide water use patterns. In years with heavy rainfall $(1.5 \times$ normal $)$, water level records suggest a significant incremental contribution to the water table rise during winter months. In the following paragraphs major factors affecting the local water table elevation are described in more detail.

An estimated 0.7 to 1 acre-m/acre of water is applied in September-October to flood the diked enclosures of the duck clubs, which border Kesterson to the south, west, and north. A substantial fraction of this water seeps into the underlying aquifer leaving the remaining water to create ponds with an average depth of about $0.3 \mathrm{~m}$. Over the winter, additional water is applied to maintain pond levels. In early spring the duck clubs are drained over a period of about a month, leading to decreased seepage rates and a corresponding drop of the elevation of the water-table in the surrounding areas. Over the summer, evapotranspiration and internal drainage dry the soils until the next flooding event. As illustrated in Figure 2.1., changes in the elevation of the water table closely follow these events.

Due to the manner in which the duck club and refuge lands are flooded and drained, they create a similar impact on the water table each year. The maximum elevation of the diked enclosures creates an upper limit on the water depth, which in tum determines the upper limit of the 
secpage rate and consequent rise in the water table elevation. For instance, flooding the ponds with more water or large amounts of precipitation will not increase the maximum water level in the duck ponds because it can not be contain 1 within the diked perimeter of the ponds. Therefore, unless the duck club operations are altered significantly, such as by increasing or decreasing the height of the dikes, or by increasing or decreasing the intentionally flooded acreage, future water table elevation increases attributable to flooding the duck clubs will be of a similar magnitude to those observed during the $1988-89$ wet season.

Rainfall is another factor that may contribute to increases in the water table elevation. Although no long term records are available in the immediate vicinity of Kesterson Reservoir, nearly 100 years of rainfall data are available from both Los Banos and Newman. Kesterson is about mid-way between these two monitoring stations. Annual rainfall over this period averages $265 \mathrm{~mm}$ in Newman and $216 \mathrm{~mm}$ in Los Banos. More than $85 \%$ of the annual precipitation typically falls between October and March. Comparison between monthly rainfall data measured at Kesterson from 1986 through 1988 with comparable records at Los Banos and Newman indicates that although monthly rainfall may differ by as much as $50 \%$, annual precipitation at Kesterson was within $15 \%$ of the average of the measurements at Los Banos and Newman. Therefore the average between the two measurements provides a reasonable estimate of annual rainfall at Kesterson and that average annual precipitation is about $240 \mathrm{~mm}$. A plot of the estimated annual precipitation at Kesterson for the period between 1890 and 1980 is provided in Figure 2.2. Frequency and cumulative frequency distributions are provided in Figures $2.3 \mathrm{a}$ and $2.3 \mathrm{~b}$.

Observations over the past three years provide a foundation for assessing the effect of winter rains on the soil-moisture content and water table elevation. Neutron probe measurements, matric potertial measurements, extensive water table elevation measurements, and visual observations all contribute to our assessment. When it rains, some fraction of the water quickly infiltrates through the soil profile. The remainder forms puddles which will either evaporate and/or infiltrate slowly into the soil. Although infiltration rates in the majority of the Kesterson soils are high enough to accommodate even fairly intense rainfall events, their fine texture tends 


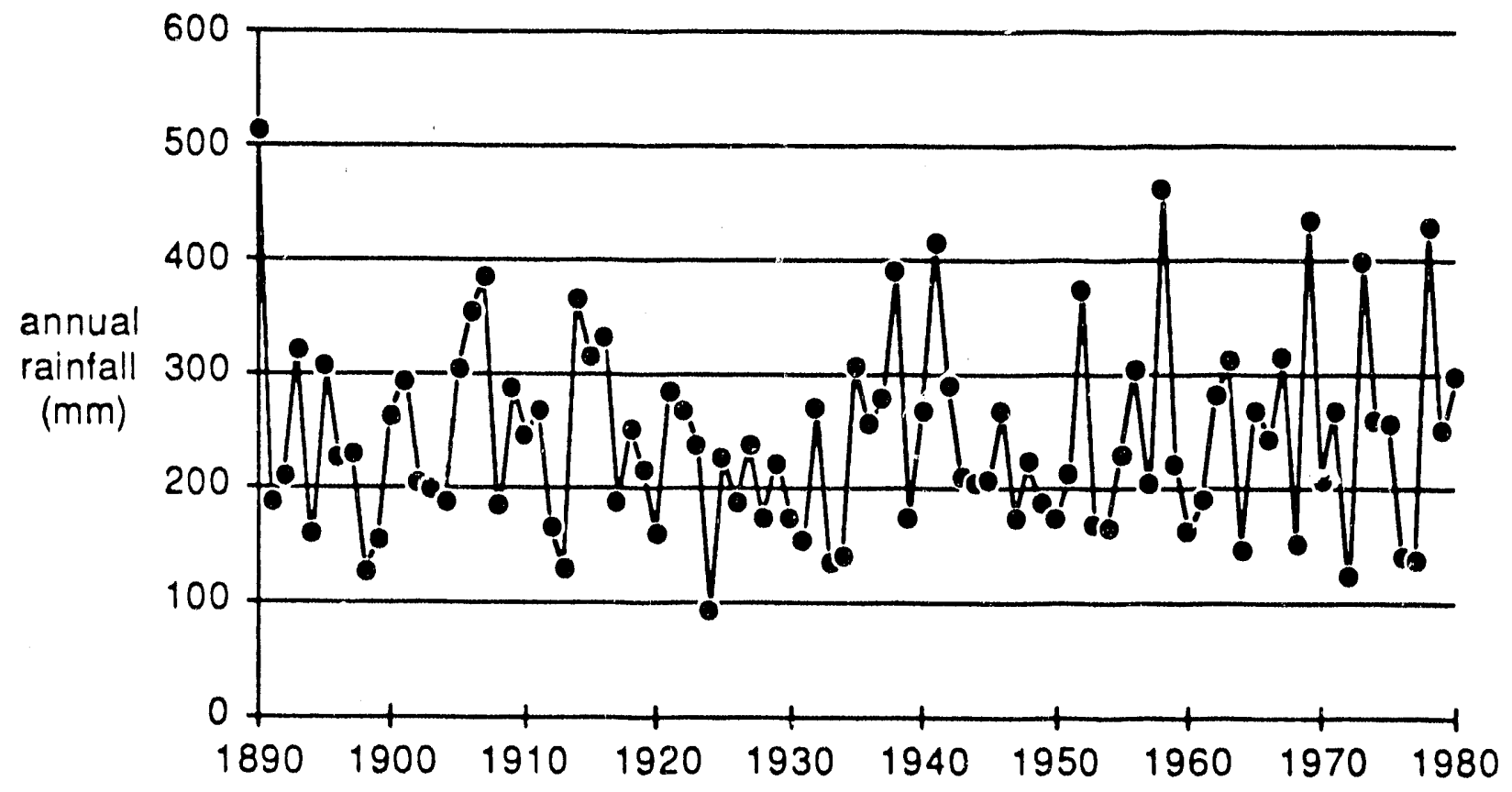

Figure 2.2. Estimated annual precipitation at Kesterson Reservoir between 1890 and 1980. 


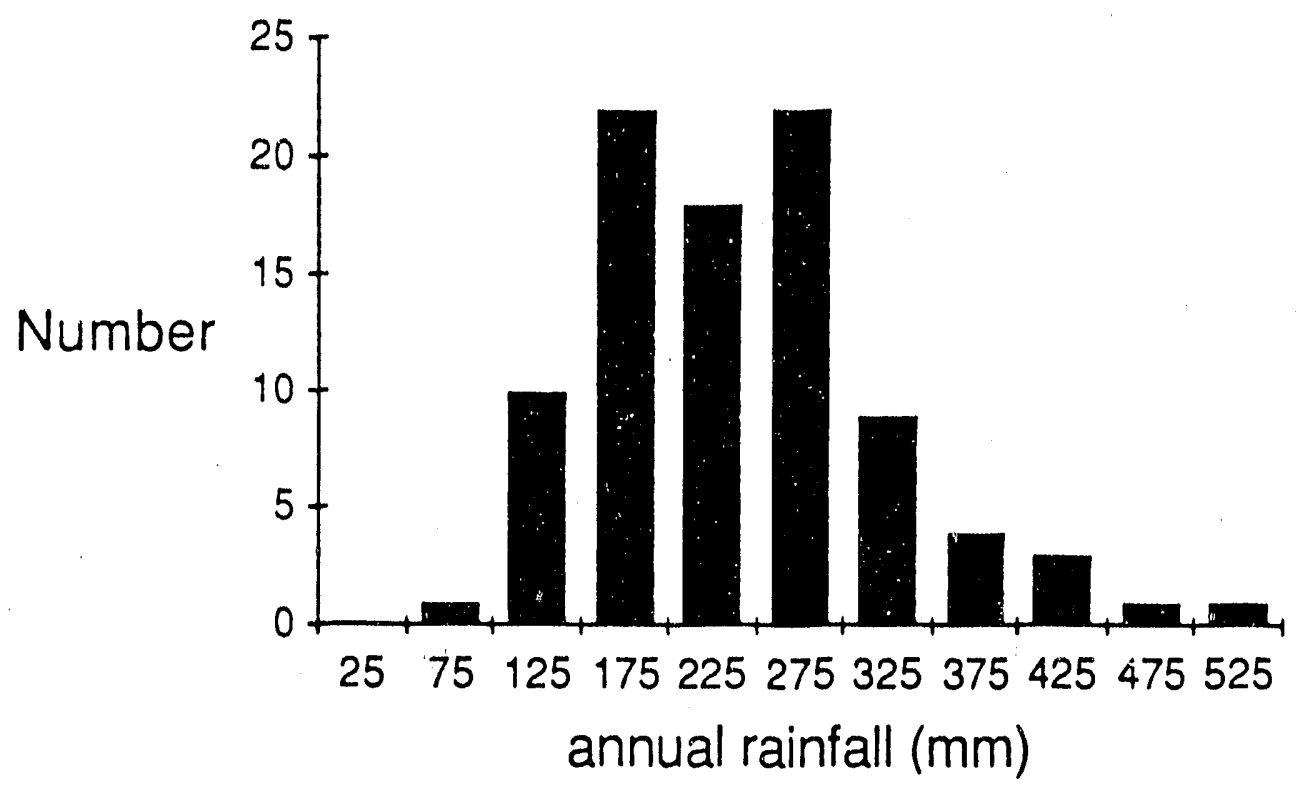

Figure 2.3a. Histogram of the frequency distribution of the estimated annual rainfall at Kesterson Reservoir.

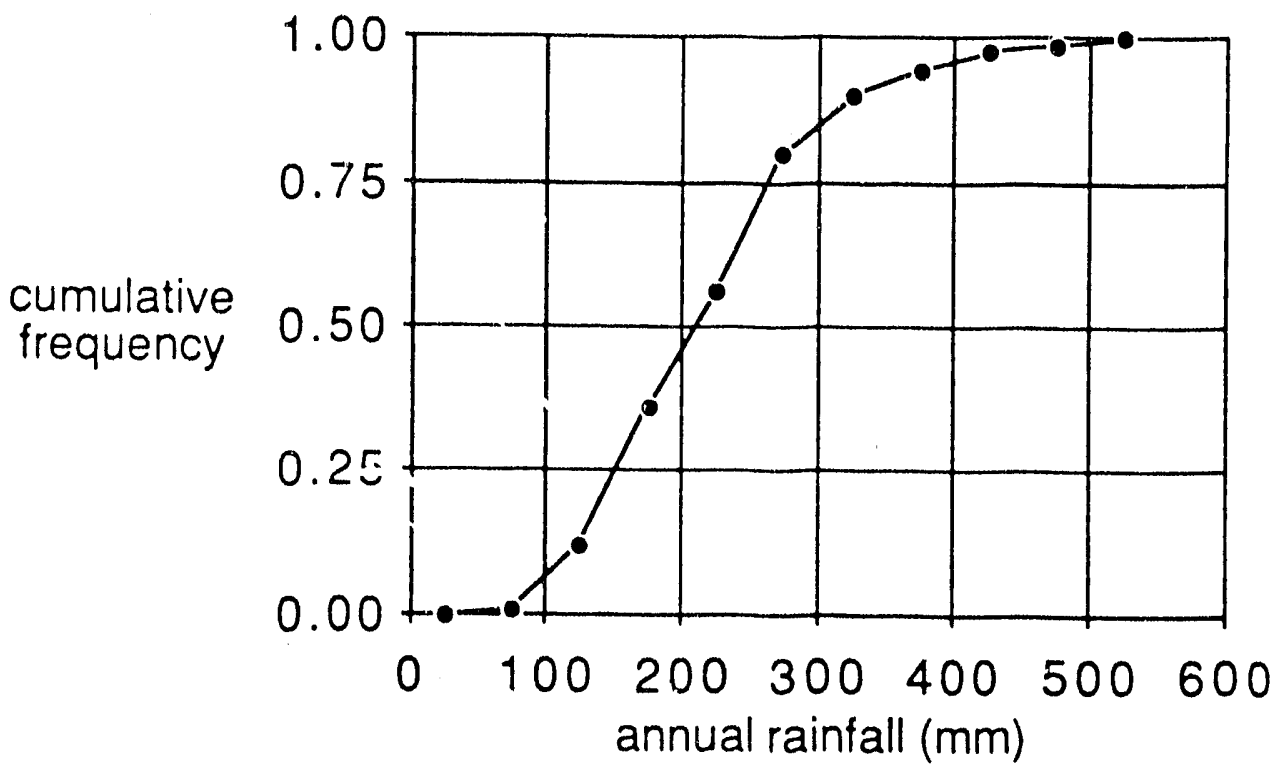

Figure 2.3b. Cumulative frequency distribution for the estimated annual precipitation at Kesterson Reservoir. 
to hold the moisture close to the soil surface, rather than allow it to freely infiltrate to the top of the water table. Support for this proposition is provided in the water level data shown in Figure 2.4. As illustrated, there is no obvious correspondence between increases in water level and timing of rainfall events. The anomalous jump in the water table elevation that occurred during early May was traced to the use of the San Luis Canal for flooding nearby refuge lands.

In the days and weeks following a rainfall event, since the water is held close to the soil surface, evaporation at the soil surface draws some fraction of this water out of the soils. Pan evaporation rates from Kesterson Reservoir average about $4 \mathrm{~cm}$ per month over the period from November to March and are nearly equal to the monthly rainfall averages. Thus during dry to average years, infiltratio : llone is not sufficient to create an increase in the water table elevation following a rainfall event. The above discussion is consistent with the historical water level data showing that in dry and normal water-years, rainfall does not appear to constitute an important contribution to the rise in water table elevation.

In a year with heavy rainfall or following an exceptionally heavy rainfall event the situation may be quite different. Precipitation may exceed evaporation, leaving an excess of water to infiltrate into the soil. In this event rainwater may infiltrate to the water table and contribute to the seasonal rise. If all of the pore space between the water table and the soil surface becomes saturated, the water table will in-effect have risen above the ground surface. To assess the potential for raising the water table above the ground surface during very wet years we made some estimates of the quantity of rain that would be required to fill all of the pore space between the ground surface and the elevation of the water table. These simple calculations indicate that rainfall in excess of $330 \mathrm{~mm}$ may fully saturate the unvegetated soils in a large part of the Reservoir. In comparison, over $400 \mathrm{~mm}$ would required to fully saturate the majority of vegetated soils. In spite of these differences, and the simplistic nature of these estimates, it is clear that during heavy rainfall years, at least some of the Reservoir soils will fully saturate and surface ponding will occur, particularly in Ponds 3, 4, and 6 where the water level came to within $0.3 \mathrm{~m}$ of the ground surface during the 1988-89 wet season. In the event of a $500 \mathrm{mim}$ rainfall year, which is antici- 

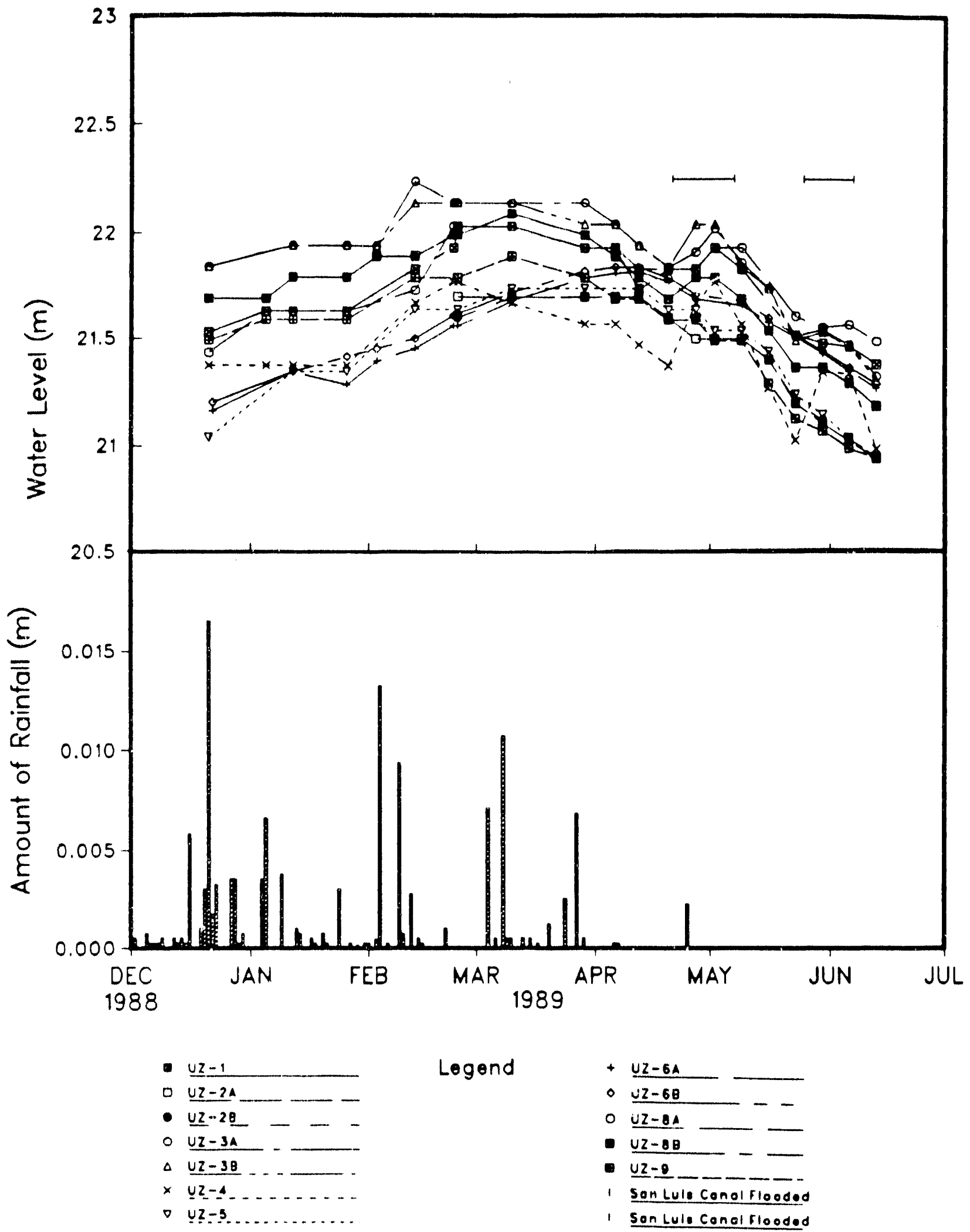

Figure 2.4. Comparison between detailed hydrographs from Pond 1 and rainfall data from the 1988-89 wet season. 
pated to occur about once every 100 years, surface ponding will occur over the majority of the Reservoir. Numerical modeling studies described in Section 2.1.3 substantiate the simplistic calculations used in arriving at these conclusions.

\subsubsection{Numerical Simulation of Water Table Fluctuations}

Detailed one-dimensional modeling has been carried out as a preliminary step in developing a regional model for predicting seasonal fluctuations of water table elevations in an around Kesterson Reservoir. The goal of these simulations was three-fold. First, simulations were carried out to obtain a bettei understanding of the dominant physical processes responsible for the observed seasonal fluctuations in water table elevation, water content, and soil moisture potential. Second, the simulations provide an accurate means of calibrating the model, based not only on the elevation of the water table, but soil moisture content ani soil water potential as well. Finally, these detailed simulations provide information on the appropriate scale required to adequately discretize the system for regional scale simulations. This effort is not yet complete and the following discussions provide a progress report on results to-date.

The degree to which the water table fluctuates in response to recharge/discharge from distant sources such as flooding the duck clubs or local sources such as rainfall infiltration depends critically on several factors, including the unsaturated hydraulic properties of the soil (soil moisture retention characteristics and relative conductivity) and the soil moisture content at initiation of recharge/discharge. This is particularly evident in fine-textured soils with a shallow water table, such as those at Kesterson, where due to the high moisture content of the soils, even a very smail amount of recharge/discharge can raise or lower the water table by several meters. Therefore, to accurately simulate water table fluctuations, it is imperative to develop an accurate correlation between the change in water content of the vadose zone soils and the corresponding change in water table elevation.

Numerous data sets relevant to this undertaking have been collected from Ponds $6,8,9$, and 11 and provide the necessary information on seasonal fluctuations in the hydraulic head, soil moisture content, and water table elevation (LBL Annual Report, 1987; 1988). Information on 
bare soil evaporation rates and indirect information on rates of evapotranspiration are also available from test plots in these ponds (see Sections 3.1, 3.2, and 3.3). Saturated hydraulic conductivity data ard particle size analyses of the fine-grained surface layer as well as hydraulic conductivity data from the shallow aquifer are also available (LBL Annual Report, 1987). These data provide the foundation for developing a calibrated model for assessing water table fluctuations.

For these studies, the one-dimensional system shown in Figure 2.5a. was simulated. The hydrogeology was simplified to include only a fine-grained surface layer in the top $3 \mathrm{~m}$ of the system and the sandy aquifer that extends down to the top of the Corcorran Clay. This representation incorporates the primary features of the local hydrogeologic system (Benson, 1988). A total of 93 elemental volumes were used to discretize the region, with the vast majority being used to finely discretize the surface-most $2 \mathrm{~m}(2 \mathrm{~cm}$ to a depth of $0.5 \mathrm{~m}$ and $4 \mathrm{~cm}$ to a depth of 2 m). The numerical simulator TRUST, which uses the integral finite-difference method for solving a fully transient mass balance equation for saturated/unsaturated flow of water in a compressible porous medium, was used for these calculations (Narasimhan and Witherspoon, 1976). Sources of recharge/discharge considered in this model included bare soil evaporation, rainfall infiltration, and subsurface recharge due to flooding the duck clubs. Rates of recharge and discharge, based on both measured and inferred values, are provided in Figure $2.5 \mathrm{~b}$ for the example described here. In each case simulations were run for a total of three years, repeating the one-year recharge/discharge cycle shown in Figure $2.5 \mathrm{~b}$.

Unsaturated characteristic curves for soil moisture retention and relative conductivity curves were initially based on particle size analyses (Zawiskanski, 1989). These however i.ad to be modified in order to achieve a reasonable match between measured and calculated changes in soil moisture content, hydraulic head, and water table clevation. Newly available moisture retention curves based on correlations between field-measured saturation and hydraulic head profiles were used to replace the particle-size derived curves. Modification of the relative permeability curves, using a trial an error fitting procedure to the water table fluctuation data, was rationalized 


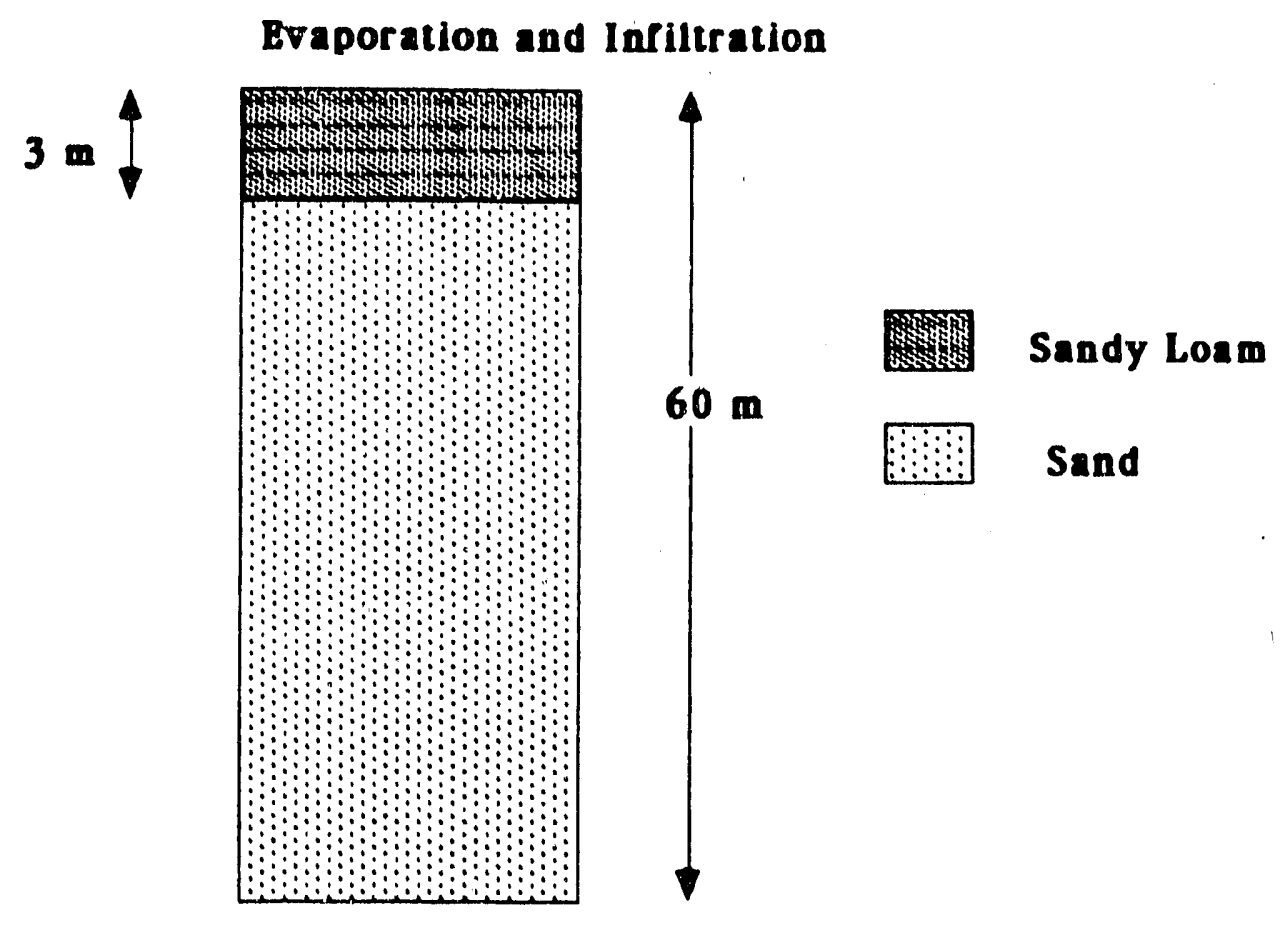

\section{Recharge from Flooding Duck Clubs}

Figure 2.5a. One-dimensional system used for detailed water table fluctuation studies.

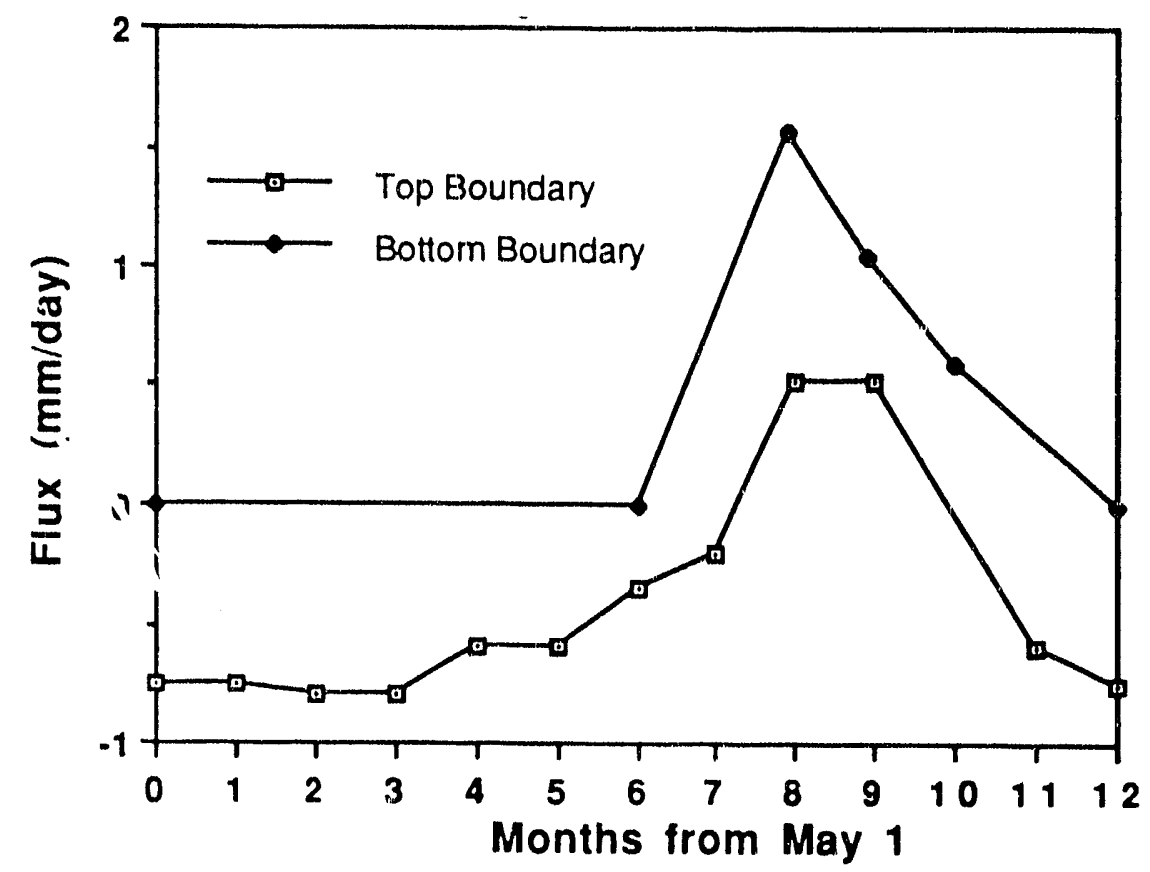

Figure $2.5 \mathrm{~b}$. Recharge and discharge rates during a one-year cycle for detailed simulations. 


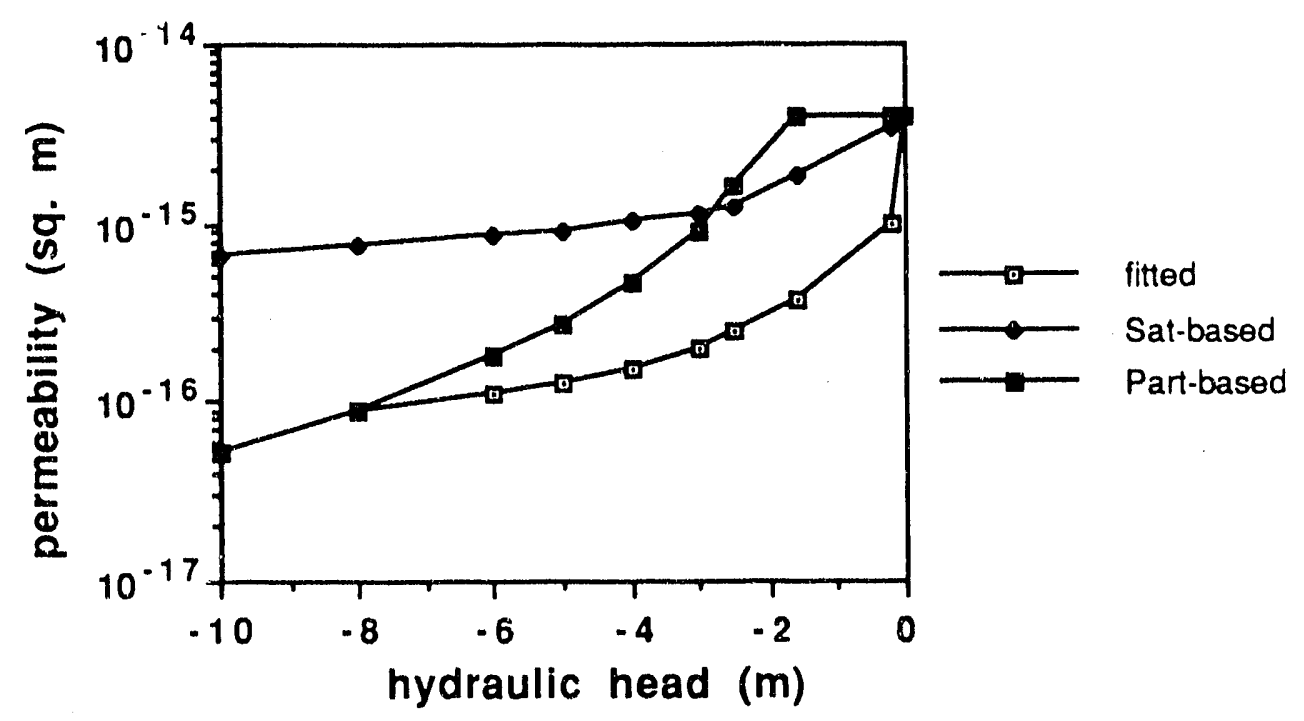

Figure 2.6a. Unsaturated hydraulic conductivity curves of the fine grained surface layer used for the numerical simulations. Three different curves are shown here including the particle size derived curves (part-based), the saturation derived curves (sat-based) (i.e. the $s_{w}^{3}$ described by Scheidegger, 1957) and the curve derived by "fitting" the water table fluctuation data.

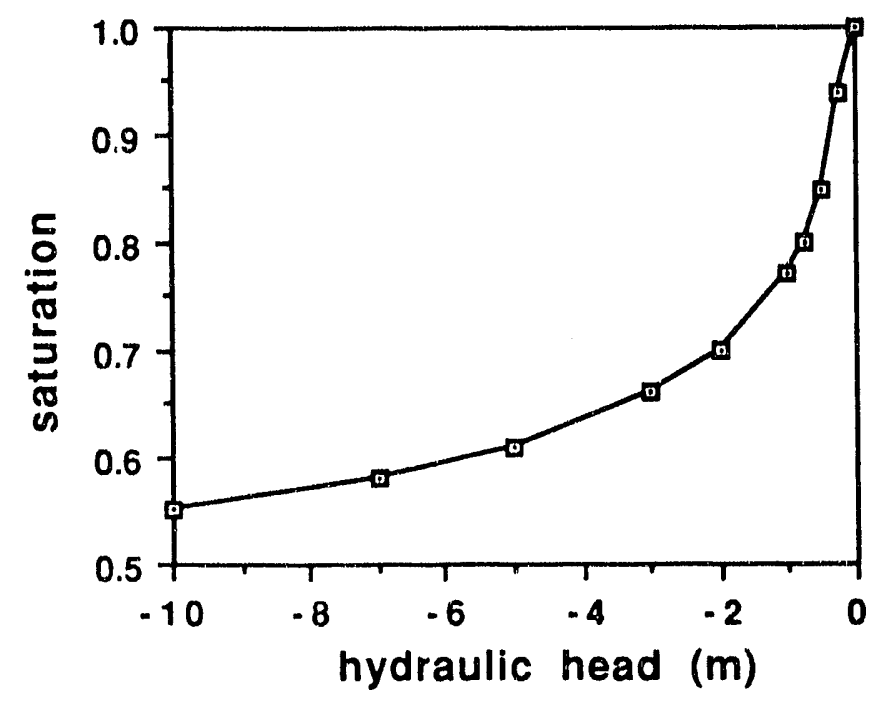

Figure 2.6b. Moisture retention curve for the fine-grained surface layer as determined from field measured saturation versus fluid potential values. 
based on the fact that particle-size generated characteristic curves do not include the effects of macro-pore flow, which have been shown to be important in the Kesterson soils (Long, 1988). The characteristic curves used the example presented here are shown in Figures 2.6a and 2.6b.

Initial and boundary conditions for the example described here were as follows. Initially, the fluid potential was hydrostatic, with a value equivalent to a water table $0.4 \mathrm{~m}$ below the ground surface. This is a good representation of spring-time conditions in areas with a shallow water table, as illustrated in Section 3.3 (Figure 3.20a,b). Fluxes corresponding to evaporation and infiltration of rainwater were imposed at the upper boundary of the system (see Figure $2.5 \mathrm{~b}$ for recharge and discharge rates). Recharge created by flooding the duck clubs was imposed at the bottom boundary of the system (see Figure $2.6 \mathrm{~b}$. for recharge rates). Due to the high conductivity of the shallow aquifer $\left(10^{-4} \mathrm{~m} / \mathrm{s}\right)$, even during the period of maximum recharge, the hydraulic head is essentially constant over the shallow aquifer. Therefore, imposing the flux at the bottom of the system adequately mimics lateral recharge from flooding the duck clubs.

Results from these simulations are shown in Figures 2.7, 2.8, and 2.9. In Figure 2.7, the simulated water table elevation is compared to a typical measured water table elevation fluctuation over a seasonal cycle. Figures 2.8 and 2.9 show simulated soil moisture content and fluid potential variations over the year. These simulated results capture the major features observed from field test plots, as illustrated by Figures $3.19 \mathrm{a}, \mathrm{b}$ and $3.20 \mathrm{a}, \mathrm{b}$ in Sections 3.1 and 3.3. As a result of these detailed simulations the primary factors and the magnitude of fluid fluxes leading to the observed changes in water table elevation, soil moisture contents, and soil moisture potential have been identified. Simulations covering a range of infiltration rates support the conclusion that rainfall in excess of $280 \mathrm{~mm} / \mathrm{year}$ will fully saturate unvegetated soils in the areas of the Reservoir where the water table rises to within $0.4 \mathrm{~m}$ during a normal water-year. Simulations have also been carried out for regions of the Reservoir with a deeper water table ( $1 \mathrm{~m}$ below the ground surface in a normal water-year). Similar pattems to those described above are observed and as discussed in Section 2.1.2, higher infiltration rates are required to fully saturate the Reservoir soils. 


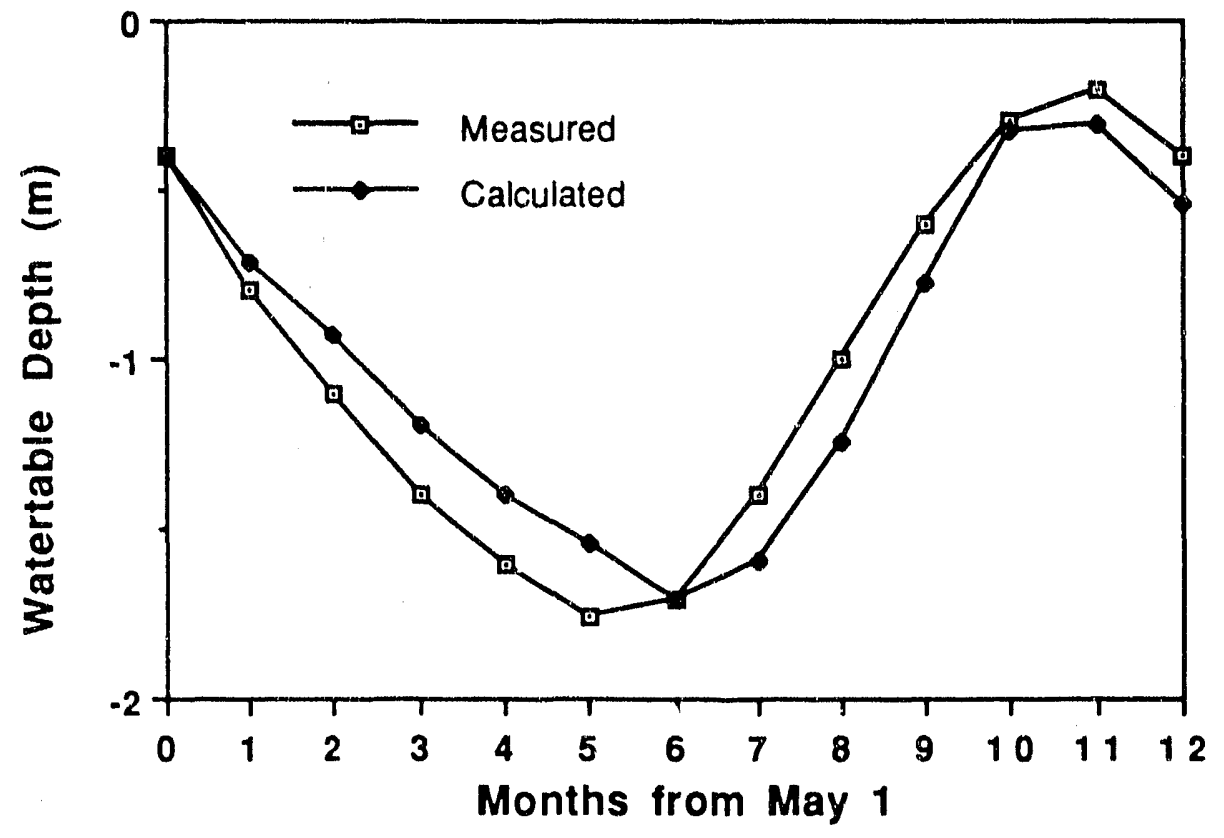

Figure 2.7. Simulated and observed water table fluctuation over a one-year period. 


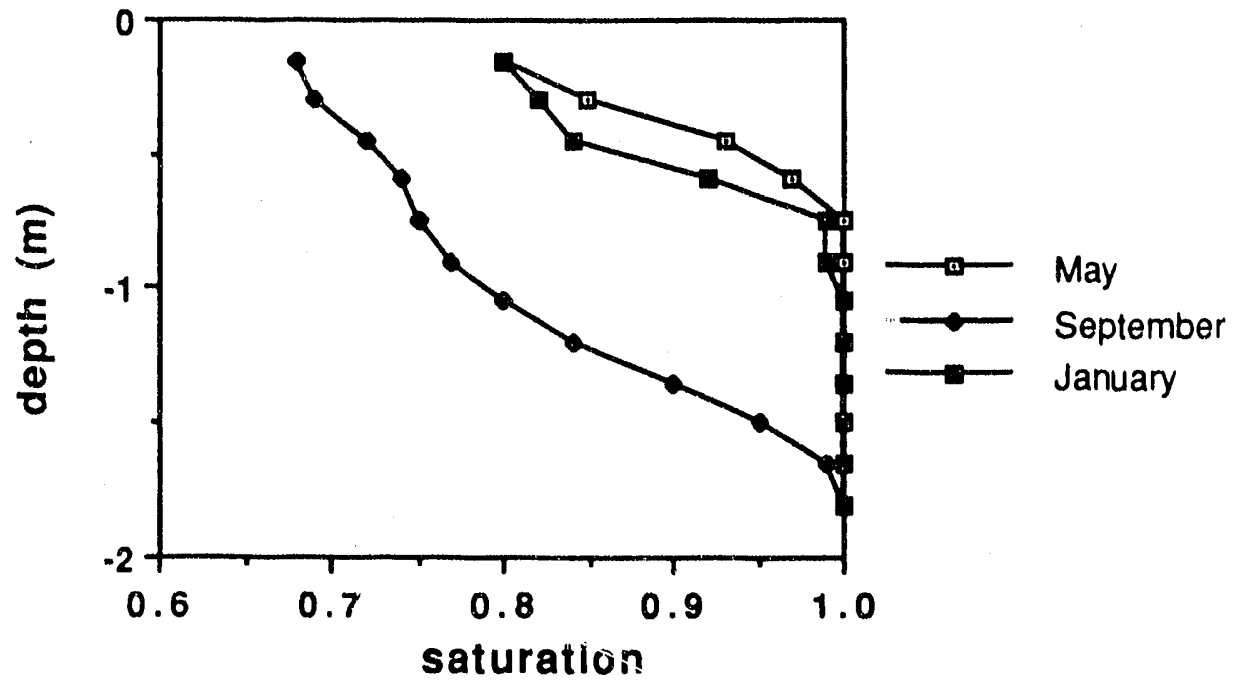

Figure 2.8. Simulated seasonal variations in soil moisture content.

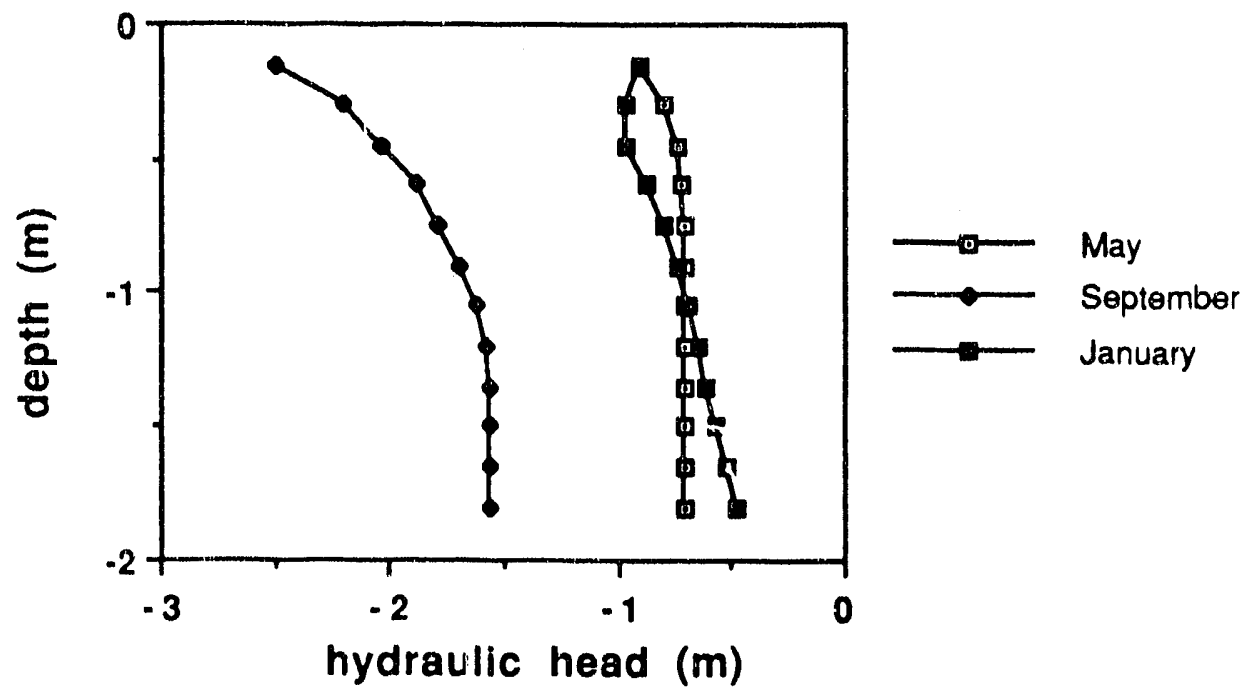

Figure 2.9. Simulated seasonal fluctuations in soil moisture potential. 


\subsection{ELECTRO-MAGNETIC MONITORING OF PLUME MIGRATION}

Norman Goldstein, Stacey Pillsbuty, John Daggett and Sally Benson

Earth Sciences Division, Lawrence Berkeley Laboratory

Reconnaissance ground conductivity surveys were made in October of 1987 and repeated in October 1988 over part of the Fremont Ranch adjacent to Kesterson Ponds 1, 2, and 5. The primary objective of these surveys was to locate and monitor migration of a plume of saline drainage water which had seeped from the Reservoir into the underlying shallow aquifer. The survey results have been described in detail by Goldstein et al (1989); only a summary will be provided here. A location map showing the survey area is provided in Figure 2.10. Measurements were made on a regular grid, consisting of 11 lines spaced $100 \mathrm{~m}$ apart, trending roughly $\mathrm{N} 60^{\circ} \mathrm{W}$. (These lines are approximately parallel to the San Luis Drain where it borders Pond 1).

The measuremeit of ground conductivity by electromagnetic techniques is a result of the laks of electromagnetic induction. While the mathematics are complicated, the basic principles are simple. A transmitter coil is energized with alternating current, which produces a timevarying magnetic field. This primary field induces weak eddy-currents in the ground, which in turn produce a secondary magnetic field. The receiver coil detects this secondary magnetic field, whose strength is a function of the coil spacing, current frequency, and average ground conductivity. Since the first two variables are known for the surveys, the apparent ground conductivity can be calculated.

Two instruments were used to conduct the survey: the Geonics EM31 and EM34-3. The spacing between the transmitter and receiver and the frequency of the instrument control the depth of investigation for these measurements. The FM31 had a depth of investigation of $2 \mathrm{~m}$ for these surveys. The EM34-3 was used with both a 20-m and 40-m coil spacing, resulting in 5 and $10 \mathrm{~m}$ depths of investigation, respectively. The two different EM34-3 surveys will henceforth be ieferred to as the EM $34 / 20$ and EM34/40, corresponding to the intercoil separation. 


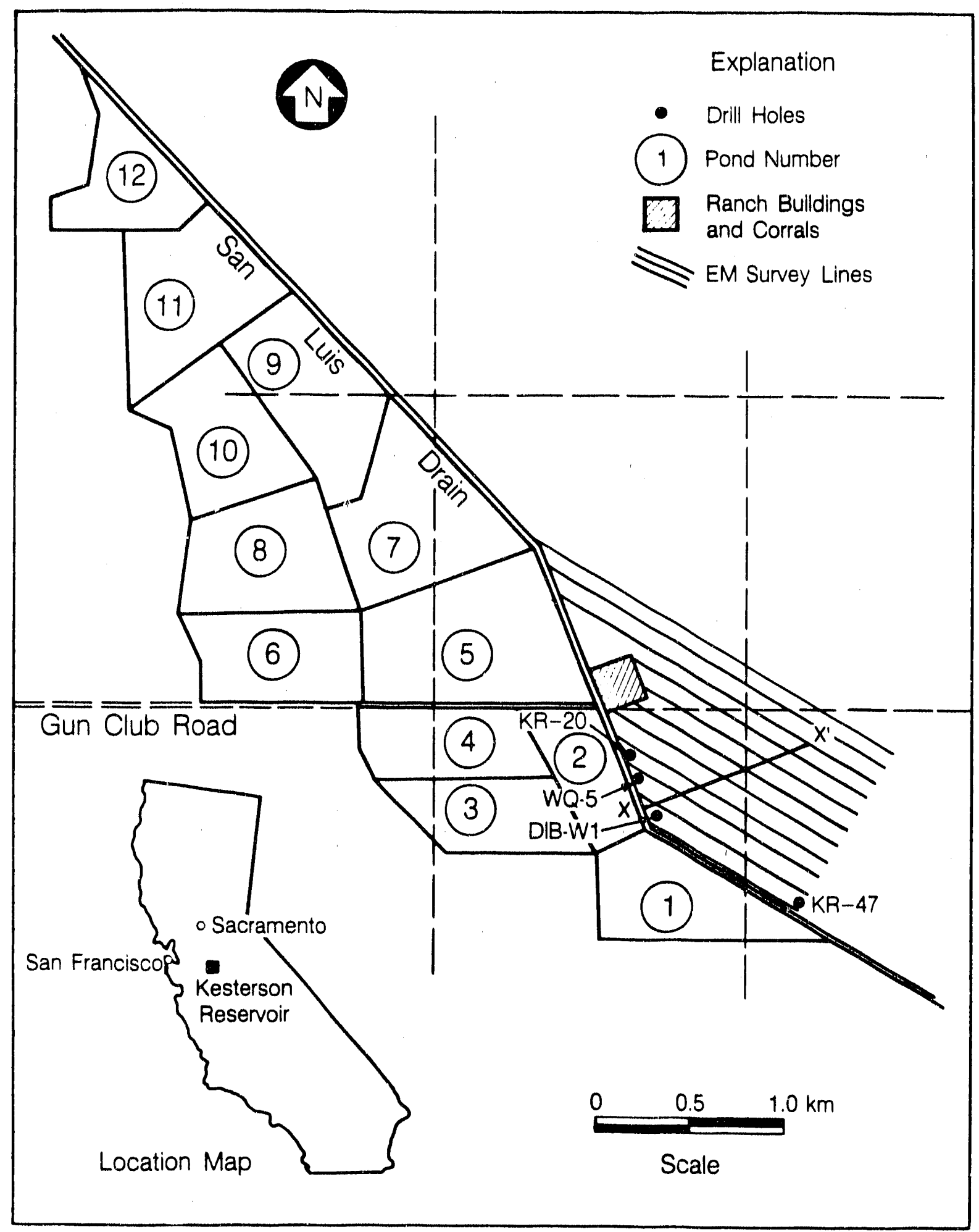

XBL $8711 \cdot 10473$

Figure 2.10. Location map of the Kesterson Reservoir showing the ponds, ground conductivity survey lines, and observation wells. 


\subsubsection{Results}

Data from the EM31 surveys, are shown as pixel plots in Figure 2.11. In both ycars apparent soil conductivities exceed $150 \mathrm{mS} / \mathrm{m}$ throughout the survey area. Similar EM31 readings were reported by Hanson and Grismer (1987) for the Mendota area, approximately 30 miles south of Kesterson, suggesting that the conductive conditions observed on the majority of the Fremont ranch are typical for soils on the west side of the San Joaquin Valley. The apparently high values can be directly attributed to the saline nature of these soils. The pore water of saline soils is also saline, and so has a high conductivity. By the relationship expressed in Arcinic's Law, this results in a high ground conductivity.

There are many areas with higher-than-average conductivities. Although there is some correlation between high conductivity values and proximity to Kesterson Reservoir, numerous discrete highs also exist in what appears to be random locations. Several of these correlate with natural drainage features, such as a slough and an oxbow lake. Comparison of other locations with color aerial photographs, taken at monthly intervals from November 1987 to March 1988, show that they occur on areas that do not acquire normal vegetation during the rainy season. It can be inferred that the soils at both of these type of locations contain higher concentrations of salt, and so have a higher ground conductivity due to the mechanism described above. Consequently, we believe that the anomalies more distant from Kesterson Reservoir are produced naturally and are unrelated to operation of Kesterson Reservoir.

In general, surface conductivities measured in the EM31 survey are lower in 1988 than in 1987. In particular, conductivity anomalies adjacent to Kesterson nearly disappear in 1988. This is attributed to drier soil conditions and a drop in the water table elevation. Additional discussion of these points is provided in Section 2.2.2.

Data from the EM34-3 survey at a 20-m coil separation are shown in Figure 2.12. Positive conductive anomalies are seen adjacent to the reservoir both years. On the basis of their location, shape, and magnitude the anomalies appear to be the result of infiltration and migration of the saline drainage water. The apparent maximum lateral extent of migration is approximately $300 \mathrm{~m}$ 


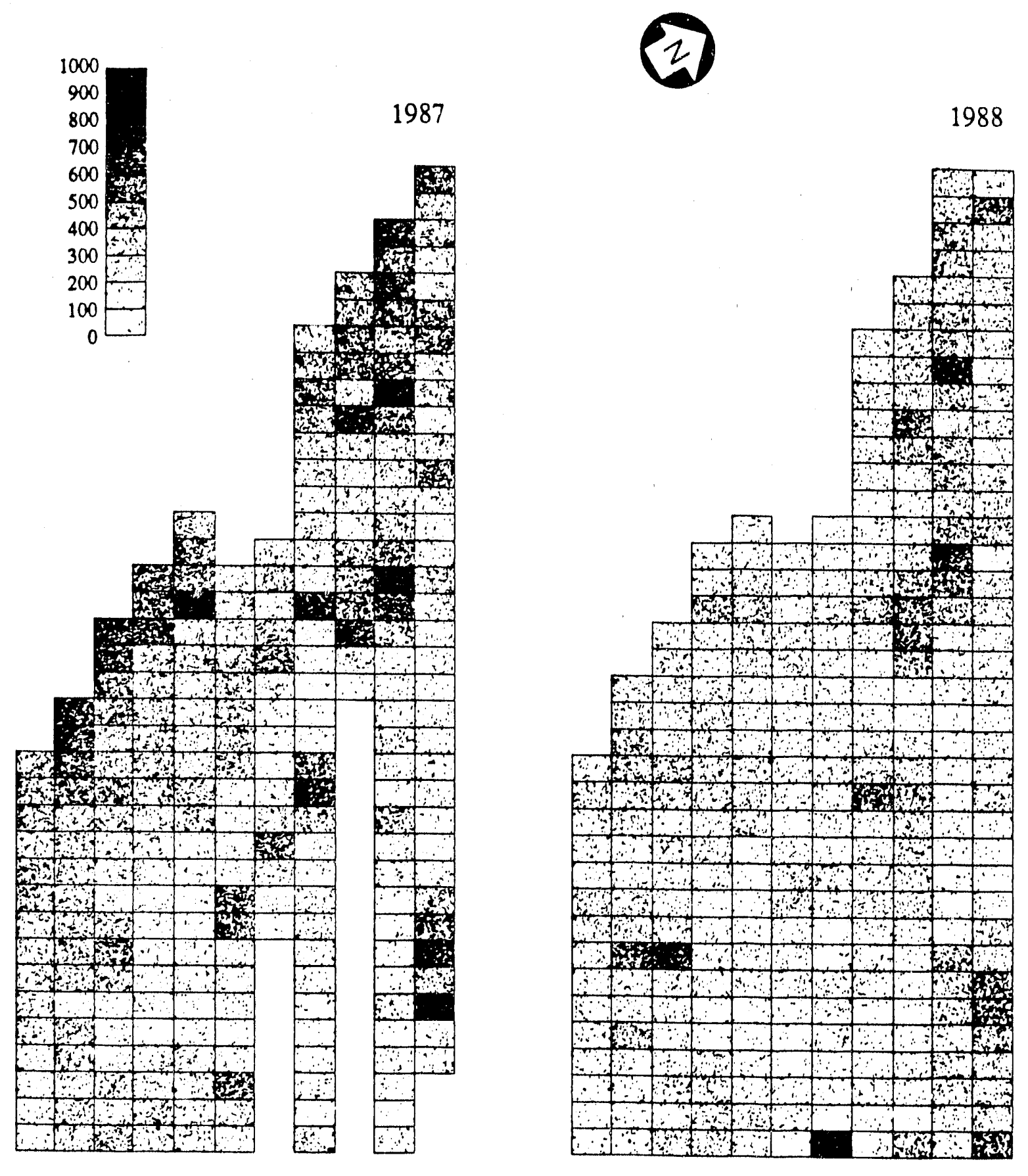

Figure 2.11. Pixel diagrams showing the comparison between the 1987 and 1988 apparent conductivities for the EM31. Each rectangle represents an areas of 100 by $60 \mathrm{~m}$. 

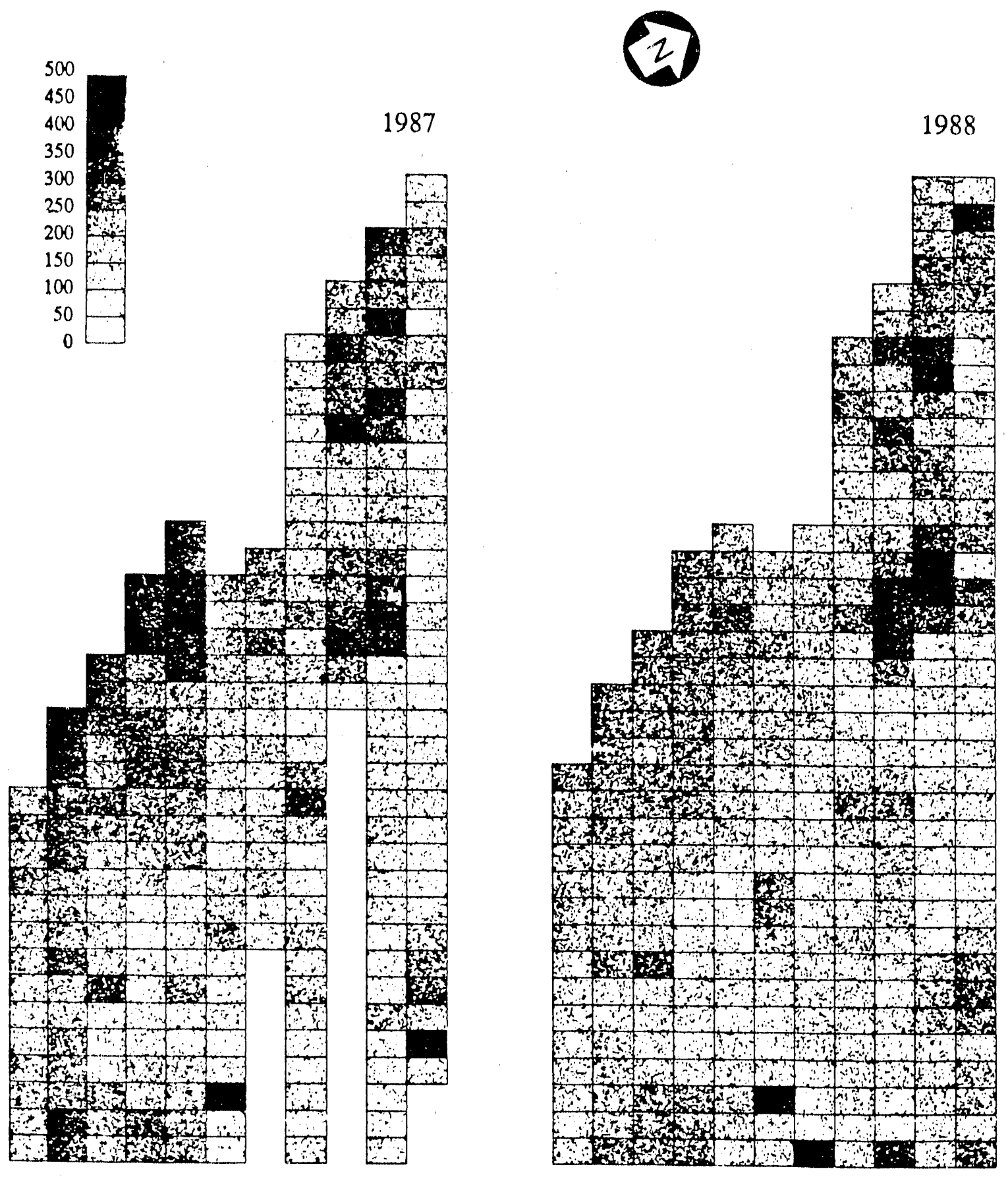

Figure 2.12. Pixel diagrams showing the comparison between the 1987 and 1988 apparent conductivities for the EM34/20. Each rectangle represents an areas of 100 by $60 \mathrm{~m}$. 
adjacent to Pond 2 , the principle inlet point for the agricultural drainage waters into the Reservoir. Less migration appears to have taken place adjacent to Ponds 1 and 5, about $200 \mathrm{~m}$ at Pnnd 1 and less than $100 \mathrm{~m}$ at Pond 5. This interpretation has not been confirmed by ground water quality monitoring. Once again, a comparison between the 1987-1988 data shows a general decrease in conductivity.

Data from the EM34-3 survey at 40-m coil separation (corresponding to a $10 \mathrm{~m}$ depth of investigation) are shown in Figure 2.13. As indicated by the missing data in Figure 2.13, some of the 1987 survey data was inaccurate, due to low battery strength in the instrument, and was discarded. Nevertheless in both years conductive highs occur adjacent to the ponds. Few isolated conductivity anomalies are present at this depth of investigation, due largely to greater volume averaging of these deeper measurenents. The apparent extent of plume migration appears to be the same as for the EM34/20 survey.

A general comparison of all the 1987 and 1988 data suggests that the plume of saline drainwater has, to some degree, mixed with the less saline water used to flood some of the ponds during 1986 and 1987. This is seen best afjacent to Pond 1, where even in 1987 it appears that the fresher water may have mig:ated as much as $100 \mathrm{~m}$ away from the edge of the Reservoir. However, no significant migration of the leading edge of the plume was seen between the two years. This is probably due to the spacing of the survey lines, which at $100 \mathrm{~m}$ was not sufficient to detect migration at an estimated rate of $50 \mathrm{~m} /$ year while Kesterson was flooded and about 5 m/year post-flooding (Benson, 1988).

\subsubsection{Data Analysis}

To provide a more quantit ative interpretation of the differences between the two surveys, data averaging, inverse modeling, and forw wd modeling were performed. Each of these is briefly described in the following paragraphs.

The soil properties in the Kesterson Reservoir area exhibit extreme spatial variability. It was thus realized that not taking measurements at the exact same sites may have masked any 


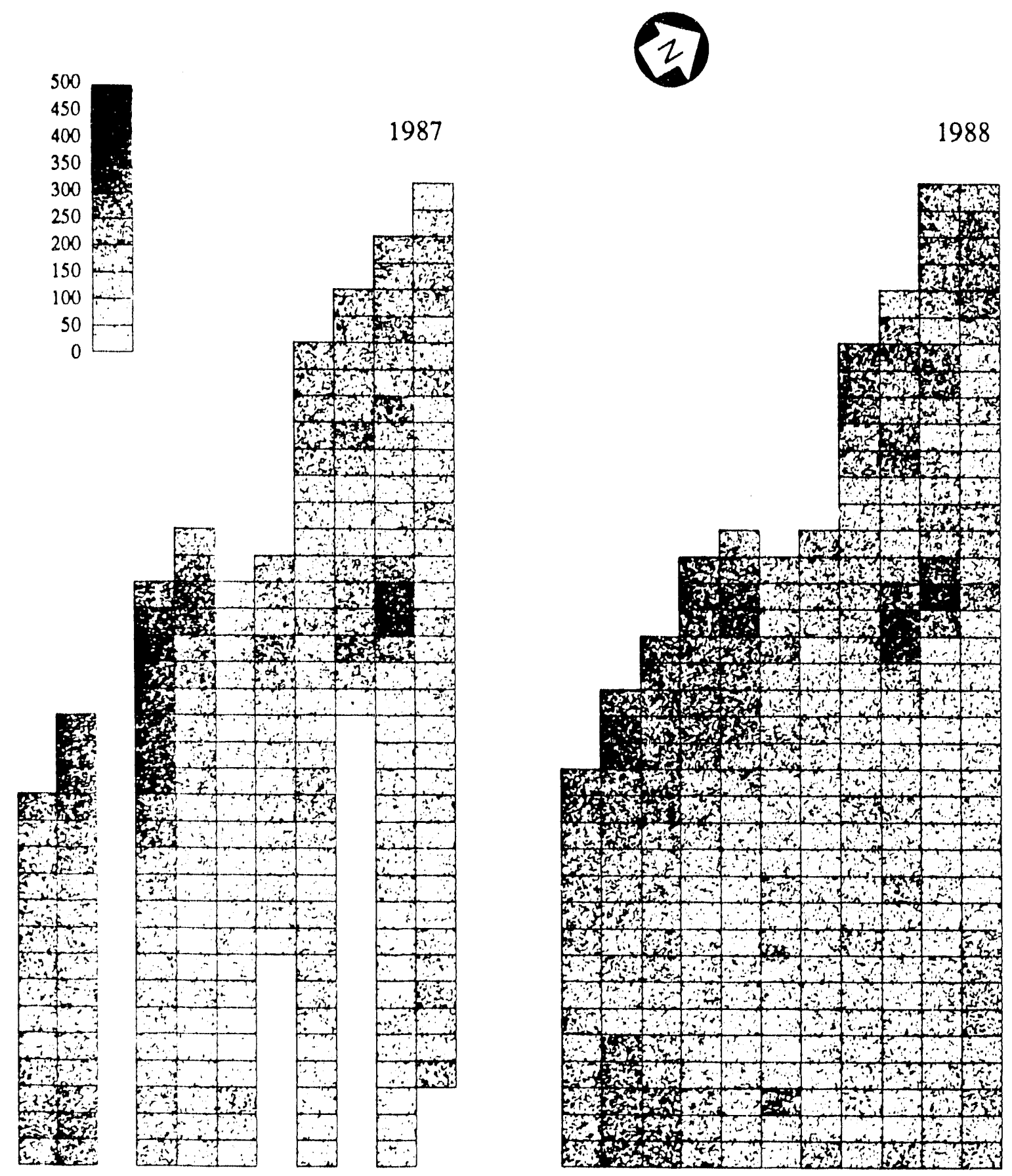

Figure 2.13. Pixel diagrams showing the comparison between the 1987 and 1988 apparent conductivities for the EM34/40. Each rectangle represents an areas of 100 by $60 \mathrm{~m}$. 
significant changes. Thus, data averaging was used to look for systematic differences in the 1987 and 1988 data sets. The data from only the southem-most $860 \mathrm{~m}$ of each survey line was used because these points are all equidistant from the boundary of the reservoir (parallel to Pond 1). Figure 2.14 shows the ean values with $95 \%$ confidence intervals for each of the data sets. Average values that are significantly different between the two years are indicated by an asterisk. In both years all three instruments gave higher average readings out to $300 \mathrm{~m}$, further suggesting that this marks the average migration of the leading edge of the drainage water plume.

For lines closest to the San Luis Drain significant differences between the 1987 and 1988 data sets occur in both the EM31 and EM34/20 values. Farther away both instruments show similar readings for both years. As will be discussed later in this section, the lower averages near the ponds in 1988 can be accounted for by a combination of lower water table and lower average saturation in the near surface soils. The EM34/40 averages have small $(<5 \%)$ but statistically significant differences on all lines except the one closest to the ponds. However, these confidence levels were calculated on the basis of the spatial variability of the conductivities alone, and did not take into account systematic or operator errors. For example, the small and systematic differences between the data for the two years are within the accuracy of the readings, as specified by the instrument manufacturer.

Another means of quantitatively comparing the 1987 and 1988 results involved inverse modeling. For this procedure, readings from the EM31, EM34/20 and EM 34/40 were entered into a numerical program which calculated the closest two-layer ground conductivity model which would produce the given readings at a given survey point. This method is most appropriate for areas where the ground is uniformly layered over large areas. Although our survey results indicate that the layering on the Fremont Ranch is extremely variable over short distances, the inversions still provide a basis for informative comparisons.

The cross-section $X-X^{\prime}$, beginning at the Pond 2 buundary and extending perpendicular to the San Luis Drain was chosen for inversion analysis (see Figure 2.10). The calculated two-layer conductivity models for 1987 and 1988 are shown in Figure 2.15. Conductivities are expressed in 
EM 31

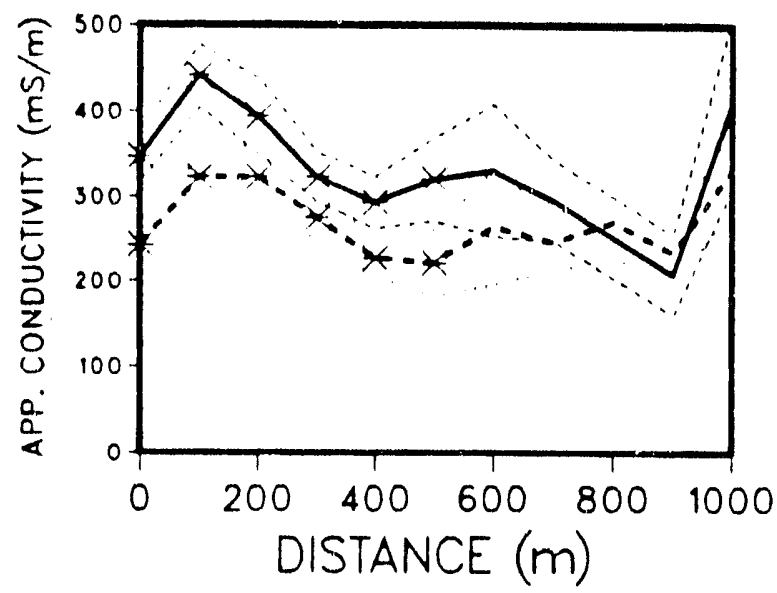

EM $34 / 40$

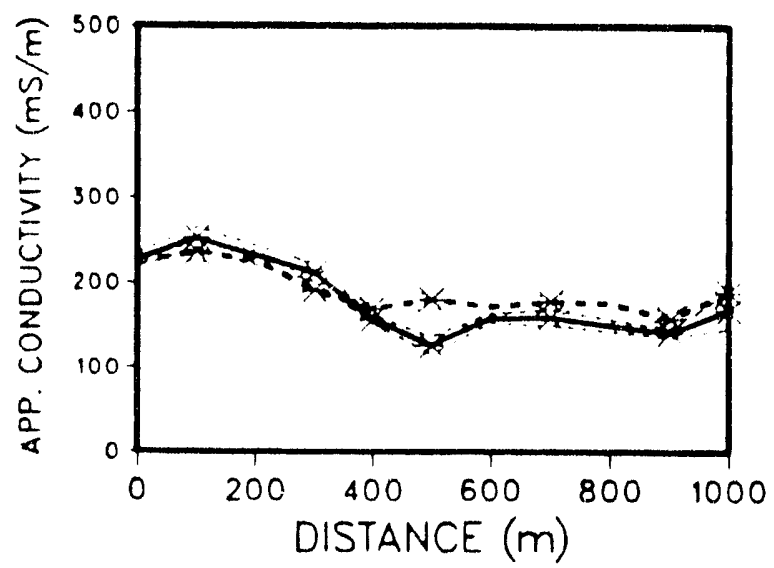

EM $34 / 20$

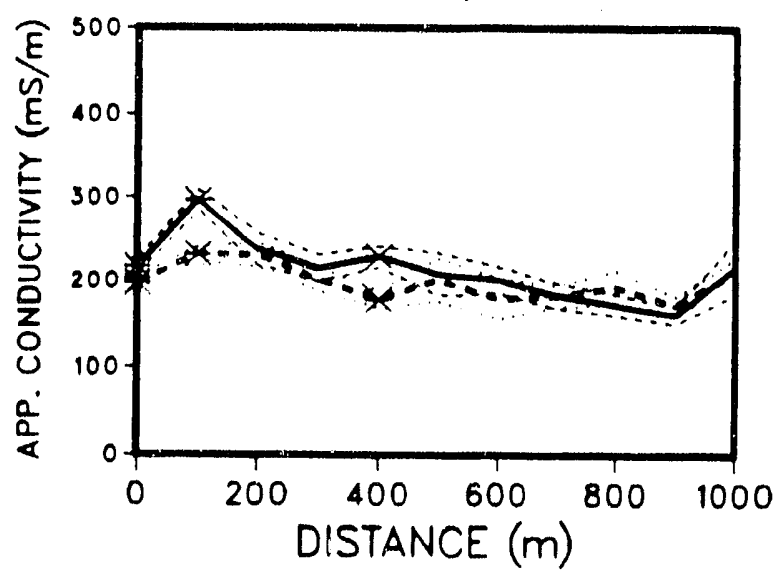

Legend

1987

1988

1987 lower-bound

1987 upper-bound

1988 lower-bound

1988 upper-bound

* SIGNIFICANTLY DIFFERENT

Figure 2.14. Graphs illustrating the results of the statistical analysis of the apparent conductivity data. The solid line shows the mean values for each survey line and the envelopes show the $95 \%$ confidence limits of the means. Starred points refer to averages which are significantly different at the $95 \%$ confidence level between the two years. Note that only the southem-most $860 \mathrm{~m}$ of each line is used to calculate the average apparent conductivities. 


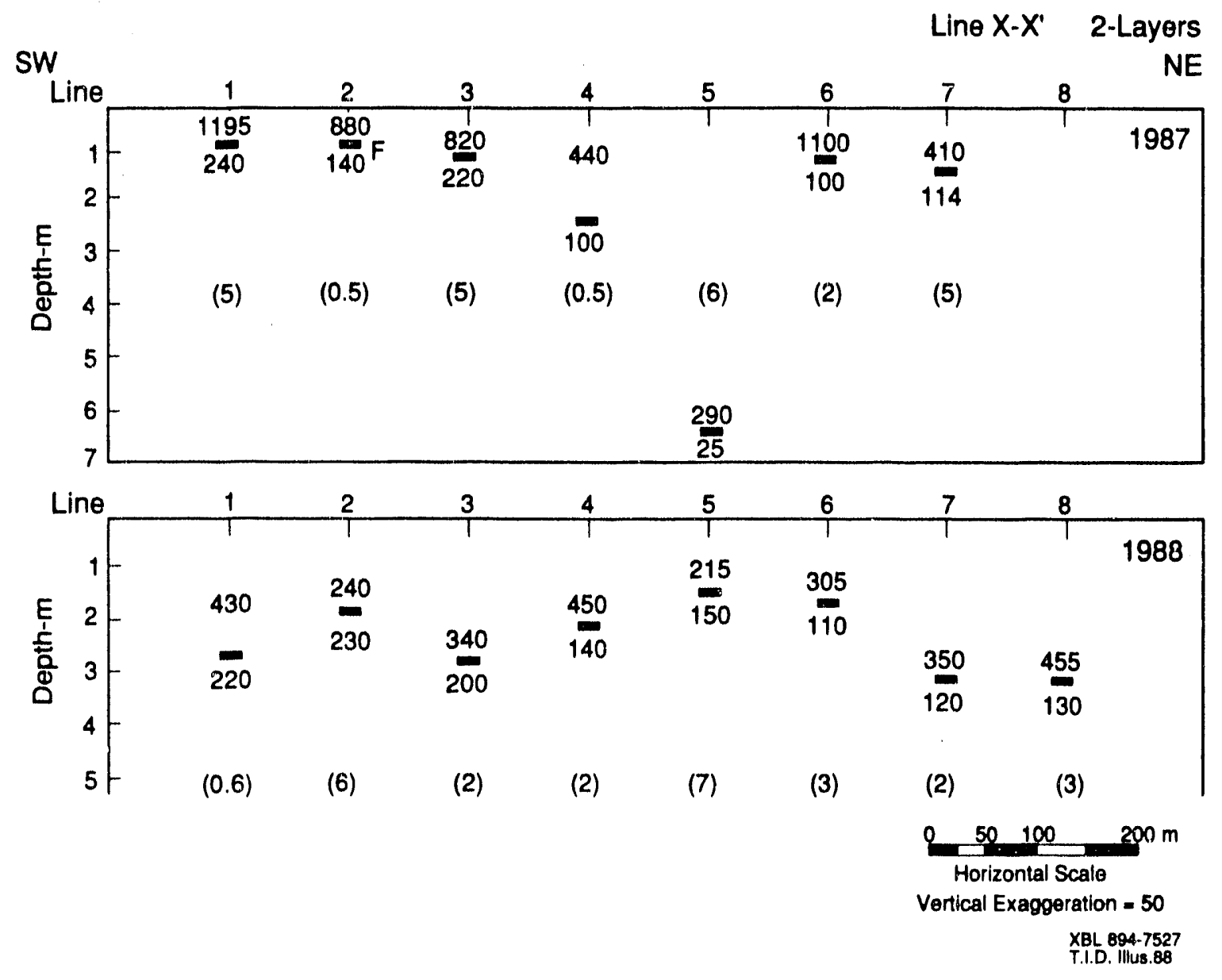

Figure 2.15. Comparison of 1-D two-layer inversions of the 1987 and 1988 meter readings along Line X-X' (Figure 2.10). First layer depths are indicated by the horizontal bars, layer conductivities are given in $\mathrm{mS} / \mathrm{m}$, and the residual errors in the least-square fit are shown in percent within the brackets. F signifies a fixed parameter. 
$\mathrm{mS} / \mathrm{m}$ and the thickness of the first layer is indicated by a horizontal bar. The models obtained from both years are similar in their major features. Both indicate the presence of a high conductivity layer, underlain by a lower conductivity layer. The lower conductivity layer is more conductive near the Reservoir, indicating the presence of the saline drainage water plume.

However, two distinct differences between the 1987 and 1988 data are apparent. First, the thickness of the surface layer increase and its conductivity decreases. This corroborates our interpretation that major differences between the two surveys can be attributed to a lower soil moisture content and deeper water table. Second, a slight reduction in second layer conductivity near Pond 2 is observed in 1988. This suggests that the saline drainage water may have been displaced by fresher ground water. However, given the nature and accuracy of this inversion analysis we can not definitively conclude that this has occurred.

Forward modeling was undertaken to estimate the magnitude of ground conductivity changes that could interfere with detection of the saline plume. These changes were the result of various events encountered in the field: water table fluctuations, rainfall, variable instrument height, and gradational salt distribution in the soil. In this tcchnique, a model of the ground conductivity is input into the computer program, which then calculates the resulting instrument readings. The general local hydrogeology and resulting ground conductivity base models used in these calculations are shown in Figure 2.16. The first model has three layers: (1) an unsaturated saline surface layer, (2) a highly conductive saturated saline layer, and (3) a less conductive Sindy aquifer. In the second mode the presence of the plume is included by superposing on the Saridy aquifer another conductive layer from a depth of 3 to $20 \mathrm{~m}$.

As discussed previously, the water table fell by about $1 \mathrm{~m}$ between 1987 and 1983. 'To quantify the effect of this drop in both water table elevation and vadose zone saturation, trials were run with varying first-layer depths and saturations. The results are given in Figure 2.17. The most important trend is the significant lowering in each of the instrument readings caused by a decrease in saturation. A drop in the water table also lowered the instrument readings, but to a much smaller extent. Further review shows that a combination of first-layer desaturation from 80 


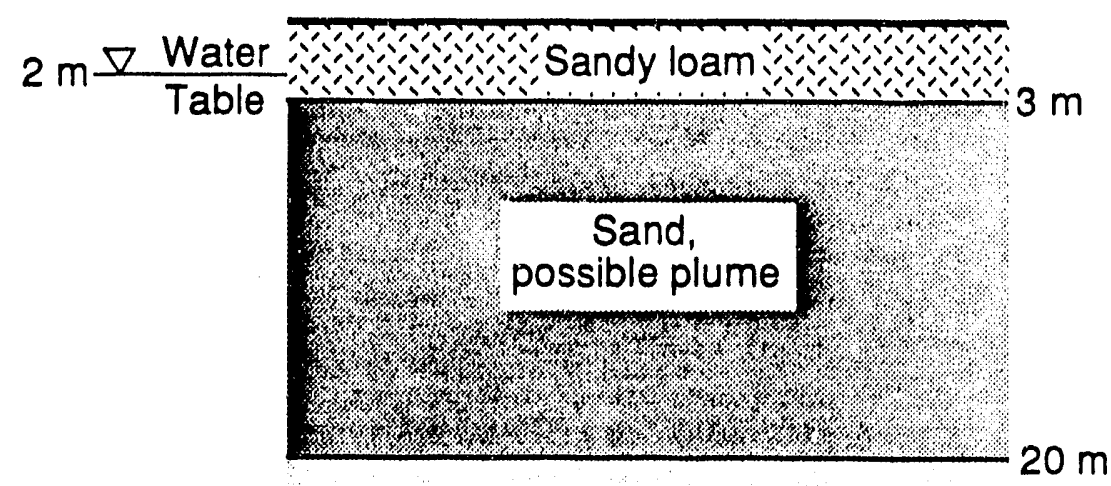

Sand

XBL 894.7542

Claris CAD
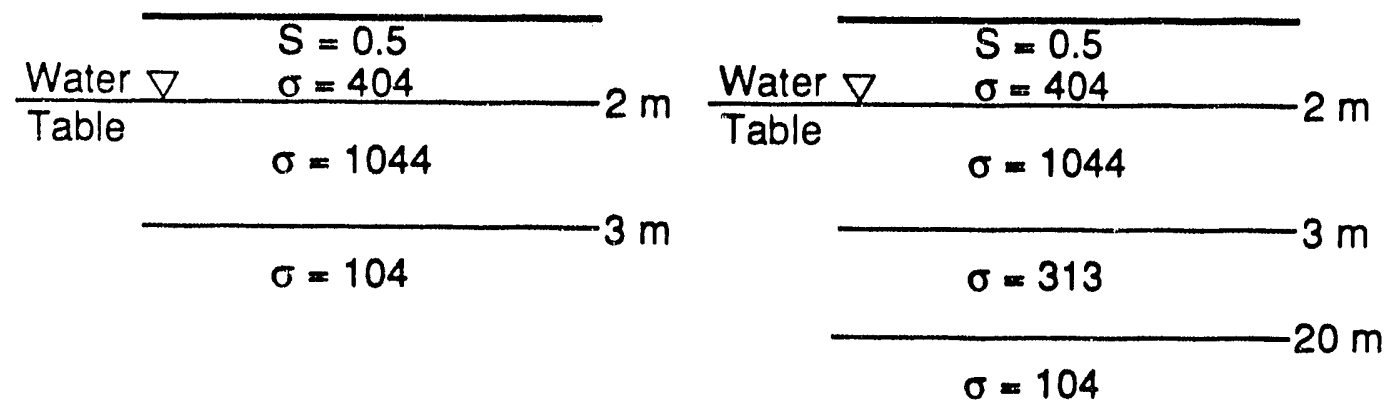

(20a)

(20b)

XBL $894-7543$

Claris CAD

Figure 2.16. Local hydrology and corresponding ground conductivity base models used in forward modeling, where $S=\%$ saturation and $\sigma=$ bulk rock conductivity. The models are not drawn to scale. 
EM 31

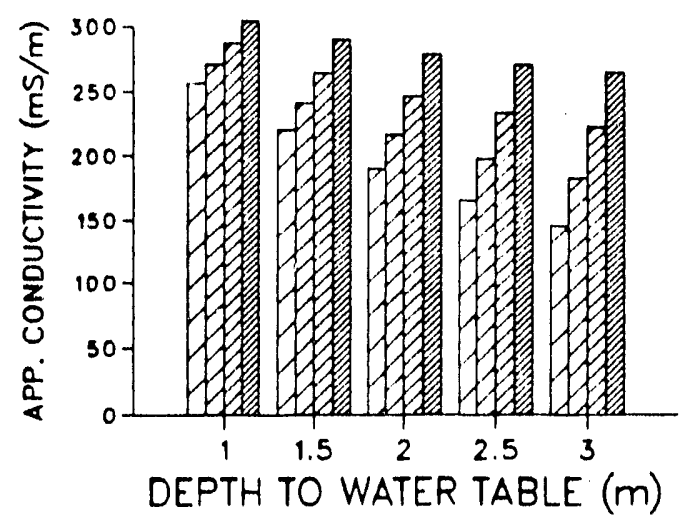

EM 34/40

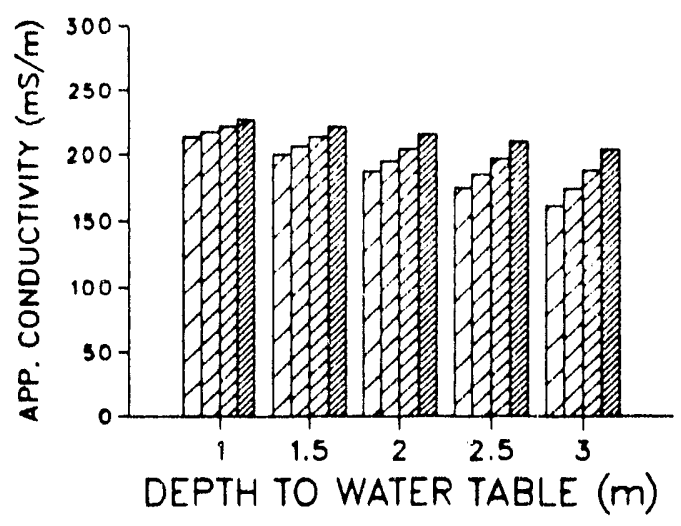

EM 34/20

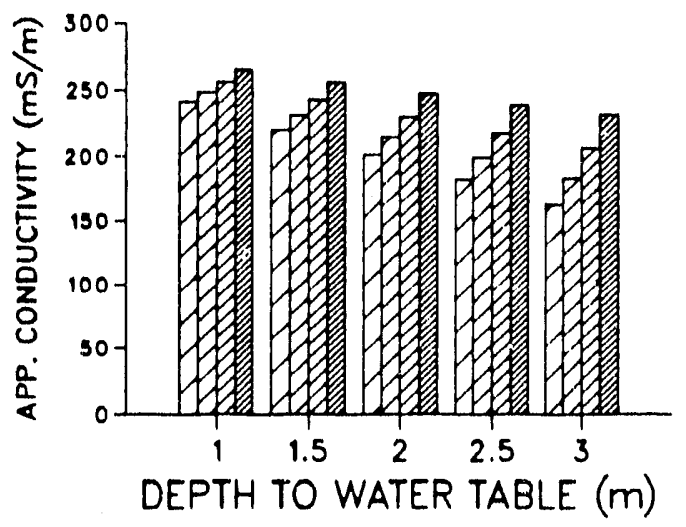

Figure 2.17. Effect of variable water table depth and first-layer saturation on the apparent conductivities measured by each instrument. 
to $60 \%$ and a water table drop from about 1.5 to $2.5 \mathrm{~m}$ below the ground surface produces changes very close to the decreases seen between the 1987 and 1938 averages. For example, the instrument reading decreases produced by the combination of factors areas follows: $92 \mathrm{mS} / \mathrm{m}$ for the EM31, $57 \mathrm{mS} / \mathrm{m}$ for the EM34/20, and $15 \mathrm{mS} / \mathrm{m}$ for the EM34/40. In comparison the observed decreases in average values are about 100,40 , and $10 \mathrm{mS} / \mathrm{m}$ respectively (see Figure 2.14)

Measurable amounts of rain (0.01") were recorded at Kesterson Reservoir for two days during the 1988 survey. If these same amounts fell in the survey area, infiltration would have formed a saturated surface layer approximately two to six mm thick. This layer would contain salts dissolved from the surface, leading to a dramatic increase in its electrical conductivity. Because the instruments are very sensitive to the near-surface conductivity, the ground conductivity measurements taken after these rainfall events may have been significantly effected. To investigate this possibility, we considered several relevant cases. Each case was modelled both without the rainfall layer and with the rainfall layer for thicknesses of 1.0 and $10.0 \mathrm{~mm}$. For the most extreme case the addition of a $10 \mathrm{~mm}$-thick surface conductor increased the EM31, EM $34 / 20$ and EM34/40 readings by $3.8,1.0$, and $0.5 \%$ respectively. Compared to other sources of variability these changes are small. Thus we conclude that the rainfall events did not bias our survey measurements.

The EM31 instrument was carried by a shoulder strap and readings were taken with the instrument at hip height. Changes in the heights of the various operators could thus have resulted in different instrument readings for the same ground conductivity, because of the volume averaging of varying amounts of air. To see how this affected the meter readings, numerical tests were run using instrument heights from 0.7 to $1.3 \mathrm{~m}$ in $0.1 \mathrm{~m}$ steps. (For the survey interpretation the height was assumed to be $1.0 \mathrm{~m}$.) To include the possible effects of saturation, cases were considered for first-layer saturations of 40,50 , and $60 \%$. The results, not shown, did not vary by more than $3 \%$. It was therefore concluded that this change in instrument height had negligible effect on the survey. 


\section{$-35-136$}

The first layer of the soil may have had a gradational variation in conductivity due to vertical variations in the distributions of clays and soluble salts. To determine what effect this would have on the instrument readings, the first layer was subdivided into ceven thin layers. The conductivity of the pore water within each of the sub-layers was varied in non-uniform increasing and also decreasing steps. Only the EM31 readings were altered by these machinations, but as the changes were at greatest only $2.4 \%$, we conclude that the instrument readings are insensitive to the vertical heterogeneity of the first layer.

In summary, the study was successful at locating the plume of saline drainage water. The two consecutive surveys provide similar information regarding the extent of the saline drainage water plume, inspite of several potentially complicating facters such as the decrease in surface conductivity created by drying out the Reservoir. The maximum lateral extract of the plume appears to extend about $300 \mathrm{~m}$ from the San Luis Drain. When access to these lands for the purpose of drilling and ground water sampling is possible, this interpretation can be confirmed. 


\subsection{VADOSE ZONE MONITORING AND EVALUATION}

Data presented in this section is the result of continued monitoring of the vadose zone for changes in soil water quality. These changes were closely monitored, among others, in Ponds 1 , 8,9 , and 11. Ephemeral pool water quality, which may be an important link in the biological cycling of selenium, was monitored throughout the reservoir and the results are presented in Section 3.2. Changes in near-surface salt and selenium concentrations as a result of bare soil evaporation and infiltration as well as the redistribution of species within the soil profile at selected sites within Kesterson Reservoir are discussed. In addition, a laboratory experiment is described in which the effects of capillary rise of Kesterson Reservoir soil solutes into fill dirt are investigated. In general, it is found that concentrations of selenium and other species continue to change in response to a variety of both physical and chemical factors. Some of the observed changes are seasonal, being affected by the rise and fall of the water table and meteorological conditions. Others appear to be a part of a long-term process of species redistribution, as controlled by the remobilization (and immobiiization) of species due to reduction/oxidation, adsorption/desorption, and dissolution/precipitation. Primary conclusions resulting from 3 years of vadose zone monitoring are:

(1) Changes in the inventory of soluble selenium residing in the vadose zone take place relatively slowly ( $<10 \%$ of the total inventory per year) after the pond bottom soils are initially dried out.

(2) Annual cycles of precipitation and evaporation transport selenium and soluble salts both upwards and downwards within the vadose zone. The long term trends created by these fluctuating conditions, remain uncertain; 
(3) Bare soil evaporation rates are much lower than expected given the shallow depth to the water table and fine-textured nature of the soils. Consequently evaporative accumulation of selenium at the soil surface will be negligible or at least much slower than previously anticipated. 


\subsection{VADOSE ZONE MONITORING IN PONDS 1, 9 AND 11 \\ Tetsu Tokunaga, Stacey Pillsbury and Sally Benson \\ Earth Sciences Division \\ Lawrence Berkeley Laboratory}

Vadose zone monitoring of concentrations of selenium and soluble salts has taken place for three years now. The primary objective of these monitoring activities is to develop a data set that provides a foundation for making long term predictions of selenium concentrations available for aqueous transport and biological uptake. Concentrations of salts are also important insofar as they influence the geochemical environment within the soils, and which may affect transport and uptake of selenium, as well as, the stability of the plant community at the Reservoir, which provides the foundation for creating an ecologically stable environment. Monitoring sites are located at numerous locations throughout the Reservoir. Data from selected Ponds are described in tum below.

\subsubsection{Pond 9}

Of the five monitoring sites in the northem portion of Pond 9, four sites were heavily vegetated by the invading shrub Kochia scoparia (burning bush) during the spring and summer of 1988. The effects of soil water removal by these plants, and the limited rainfall during the $1988-89$ wet season $(163 \mathrm{~mm}, 6.4$ inches) are still observable. Even at the end of the recent wet season, both tensiometer data and neutron-probe data indicate that wetting fronts from rainfall infiltration and the seasonal water table rise failed to significantly resaturate a zone of soil nominally spanning the depths of 0.5 to $1.0 \mathrm{~m}$ (Figure 3.1.a,b). The combination of extensive soil water extraction by these plants and limited rainfall during the past winter and spring restricted the ability to obtain soil solution samples at these sites this spring. In these four vegetated test plots, soil solution sampling (with evacuated ceramic cups) was generally limited to occasional samples from near the soil surface $(0.15 \mathrm{~m}$, and $0.30 \mathrm{~m}$ depths $)$ and at the $1.2 \mathrm{~m}$ depth. Thus, complete profiles of soil solution composition were not available for comparisons with data from previous years. 


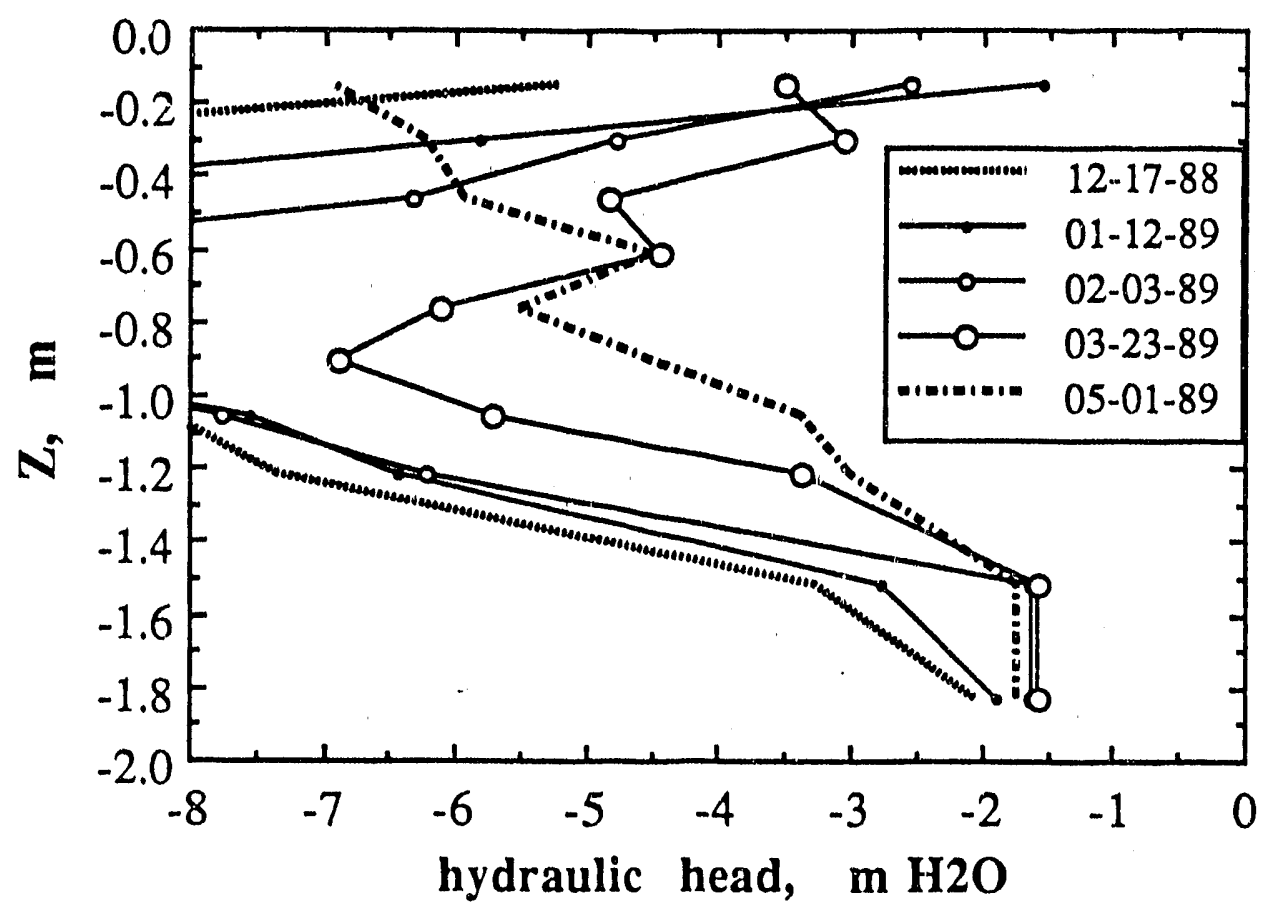

Figure 3.1a. Site P9C hydraulic head profiles during 1988-1989 wet season.

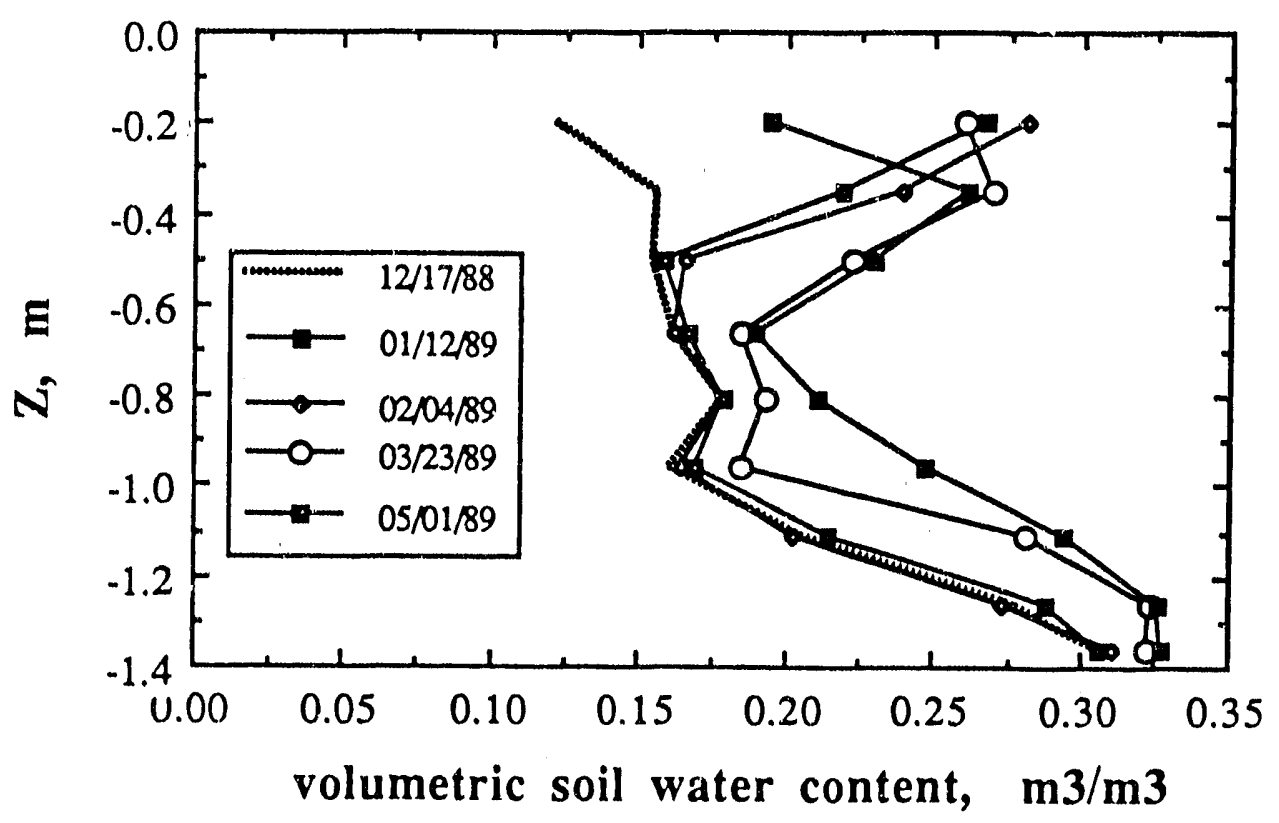

Figure 3.1b. Site P9C volumetric water content profiles during 1988-1989 wet season. 
Of the test plots in the northem region of Pond 9, only site P9R was sufficiently rewetted to permit soil solution sampling. This plot has been maintained in a devegetated condition, thus effectively preventing transpirative soil water losses exhibited at the other sites. Data from this test plot are summarized in the first set of columns in Table 3.1. The tabulated values of soil water selenium content and soil water EC are expressed in terms of arithmetic averages of soil water samples from the $0.15,0.30,0.46,0.61,0.91$, and $1.2 \mathrm{~m}$ depths. From a larger set of soil water samples collected at site $\mathrm{P} 9 \mathrm{R}$, the most representative and complete sets were selected for this table.

All profile-averaged soil solution EC values fall in the relatively narrow range of 22.2 to $27.5 \mathrm{dS} / \mathrm{m}$, with no apparent long-term trends. Sinall declines in profile-averaged ECs during individual sampling seasons are probably due to dilution effects of increased water-saturation of the soi' profile during these shorter intervals. While no significant long-term changes appear to have occurred in the profile-averaged soil water EC, it should be noted that the salinity profiles in this plot reach their maxima in the surface soil, above the $0.15 \mathrm{~m}$ sampler. In the absence of vegetation, the primary zone of salinity change is in this surface region. In this test plot, profileaveraging of EC data over the aforementioned depths is not generally sensitive to the changes occurring in this surface zone.

The soil solution selenium concentidtion data vary considerably both during a given sampling season, and from year to year. The trends of declining average selenium concentration within a given season may be due to moderate amounts of selenate reduction to selenite, and to dilution with ratinwater in less saturated profiles. The long-term apparent trend of increasing selenium concentration in the soil solution may be due to both oxidation of reduced forms of selenium, and some diwnward leaching of selenate from the soil surface. While the latter process is not apparent from the averaged EC data, the soluble selenium profile is more concentrated at the soil surface than the profiles for readily soluble salts. Such differences in soluble selenium and soluble salt $\mathrm{f}$ rofiles could result in more readily detectable increases in selenium relative to other salts in leaching profiles. An apparent overall increase in the profile-average soil water Se 
concentration from approximately $1000 \mu \mathrm{g} / \mathrm{kg}(\mathrm{ppb})$ up to approximately $1500 \mu \mathrm{g} / \mathrm{kg}$ has occurred over a three year monitoring period. This apparent increase may not be significant since variations within a given sampling season are comparably large.

\subsubsection{Pond 11 Soil Water Selenium and Salinity Changes}

Three years of data on soil water composition from monitored soil profiles in an upland region of Pond 11 are now available. This data set was collezted on three vegetated test plots, and two excavated test plots. Soil water samples were collected during periods when soil water conten profiles were nominally comparable. In previous reports (LBL Progress Report 7, LBL Annual Report, 1988), increases in both soil water selenium concentrations and salinity have been noted during the period of spring 1987 to spring 1988. Sampling of these sites during February and March of 1989 provided data which is useful in testing the persistence of these apparent trends. Example profiles of time trends in depth distributions of soluble selenium and soil water EC are shown in Figures 3.2a,b and 3.3a,b. The data shown in Figure 3.2a,b are from a saltgrass site which was disked in late 1986 . This site was rapidly revegetated by both Cressa truxillensis (alkali weed) and Distichlis spicata (salt grass). The data shown in Figure 3.3a,b are from the Pond $11,1 / 2 \mathrm{ft}$ excavation test plot. This plot was prepared by excavating $1 / 2 \mathrm{ft}$ of the original soil surface, as anticipated in the event that the Onsite Disposal Plan were to be implemented. The original soil surface was dominated by Distichlis. The residual soil surface (after excavation) was quickly revegetated by a dense growth of Cressa. Profile-averaged soil water selenium and EC time trends for all Pond 11 monitoring sites are summarized in Table 3.1.

Significant increases in both soil water salinity and soil water selenium content have been observed in the majority of these Pond 11 test plots. The relatively infrequent flooding of Pond 11 with seleniferous drain waters has had several consequences. The total inventory of soluble selenium in these soils is below the Reservoir average. Strongly reducing conditions were probably not as prominent in these soils as they were in many other areas of the Reservoir. During most of the operation of the Reservoir, terrestrial vegetation probably persisted in these Pond 11 soils. Transpirative removal of soil water in the root zone is the cause of salt accumulation 


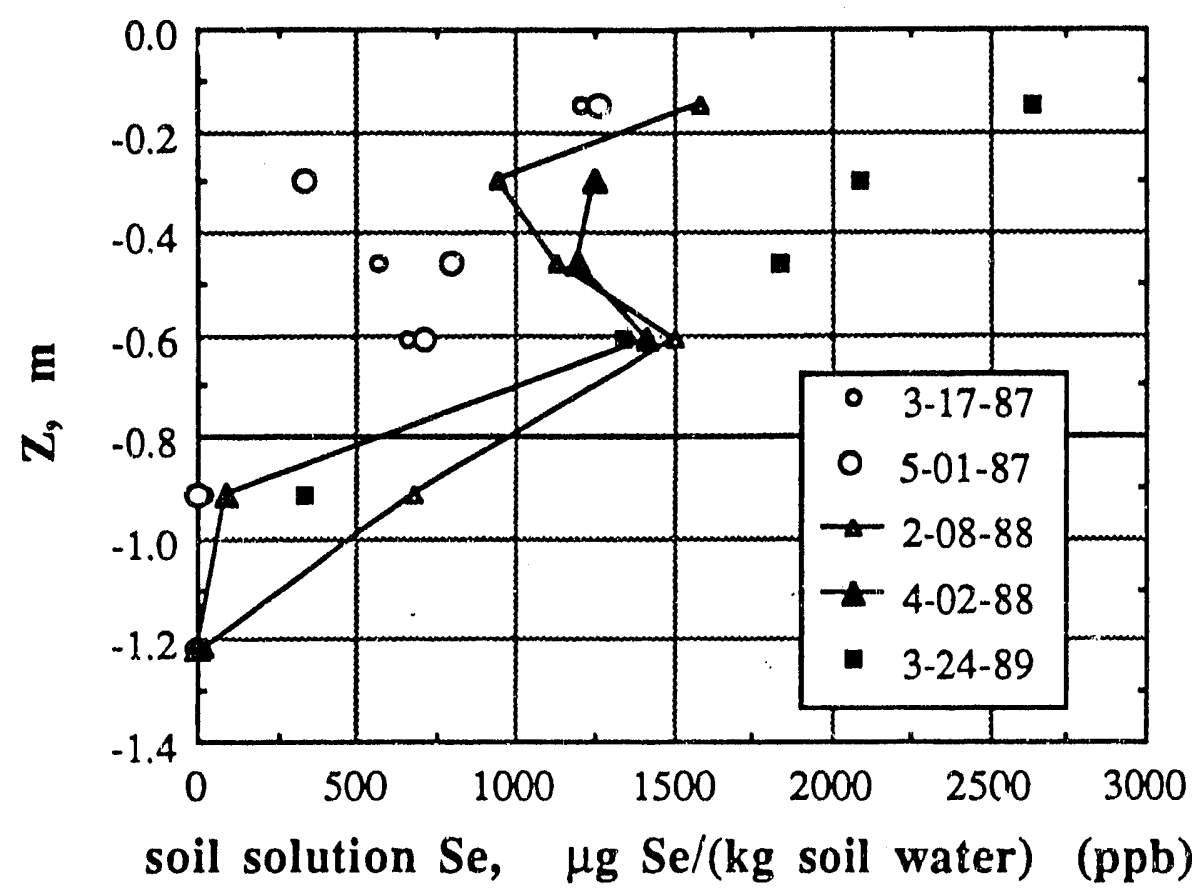

Figure 3.2a. Site P11D depth profiles of soil solution selenium concentrations.

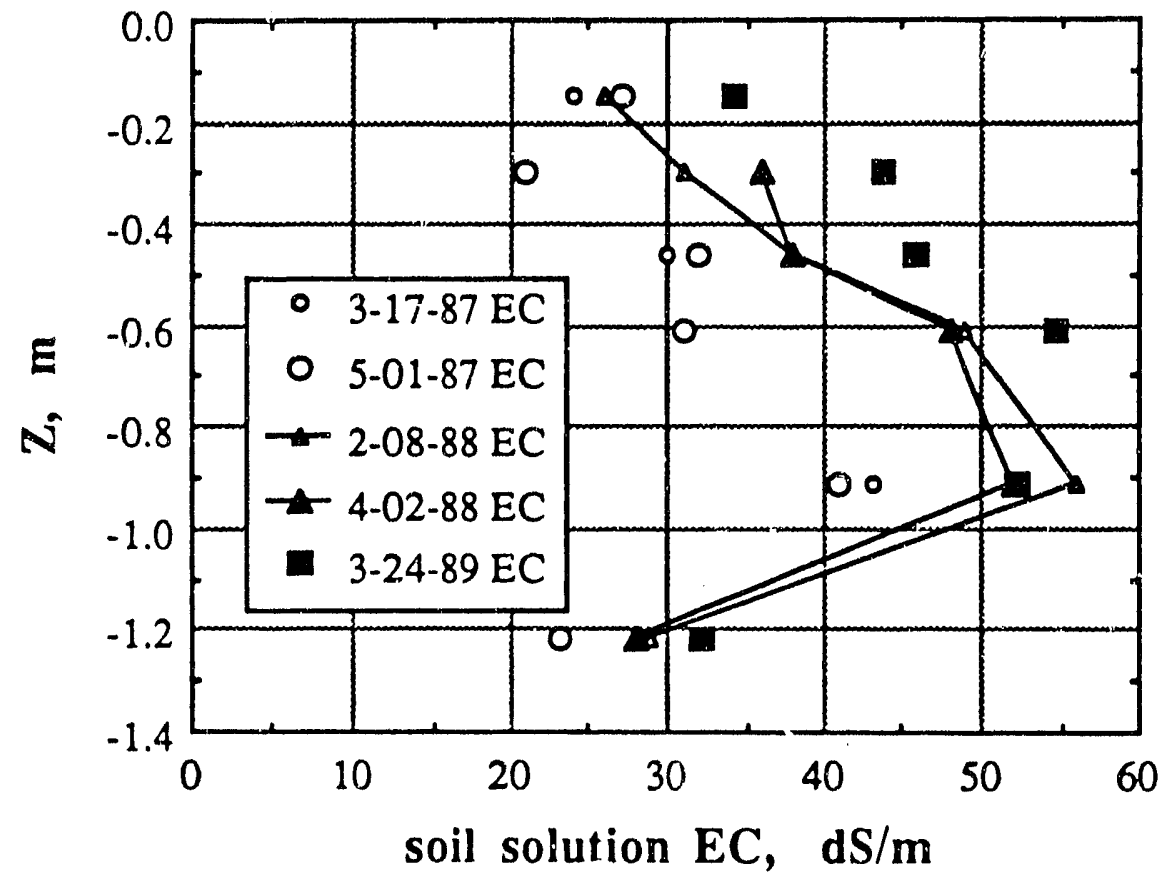

Figure 3.2b. Site P11D depth profiles of soil solution electrical conductivity. 


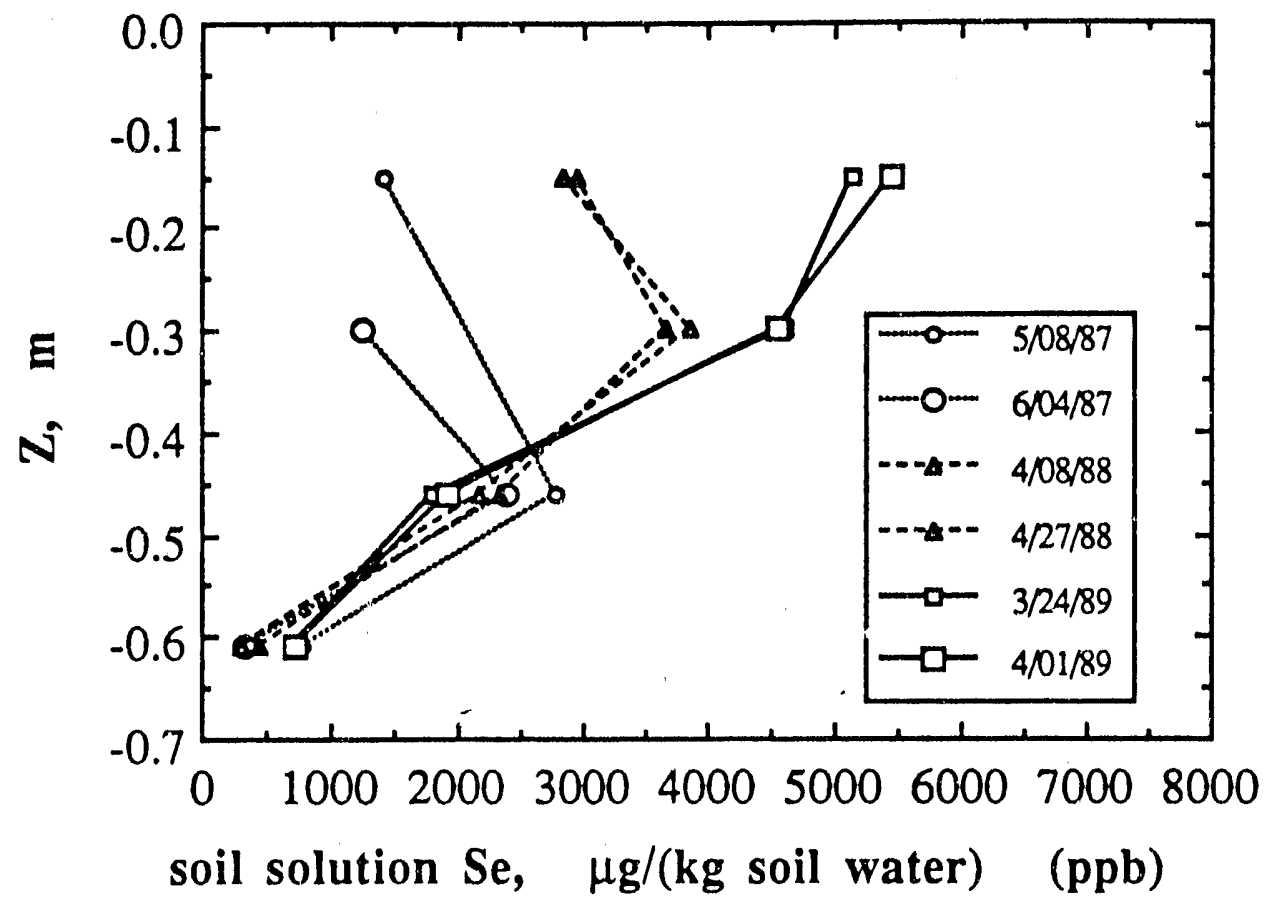

Figure 3.3a. Site P11S1/2 depth profiles of soil solution selenium concentrations.

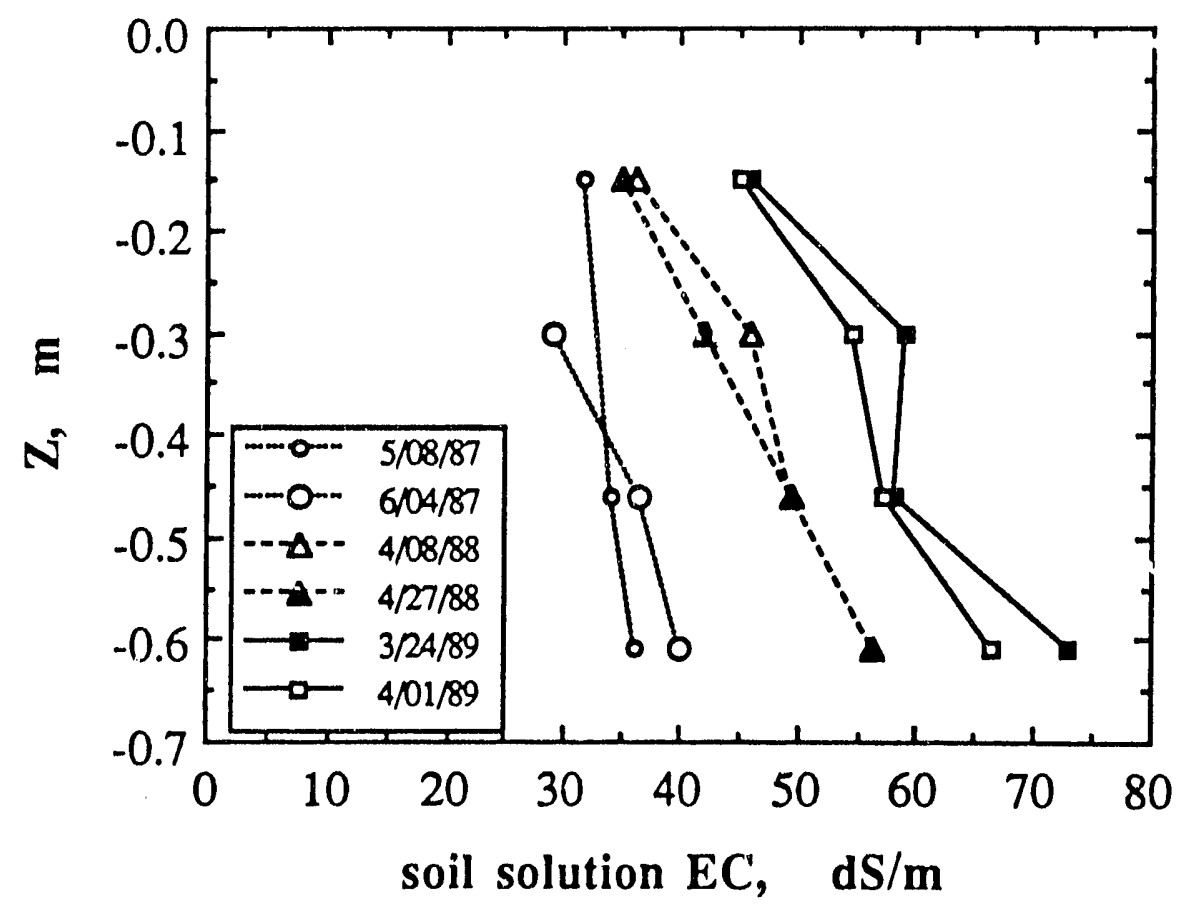

Figure 3.3b. Site P11S1/2 depth profiles of soil solution electrical conductivity. 


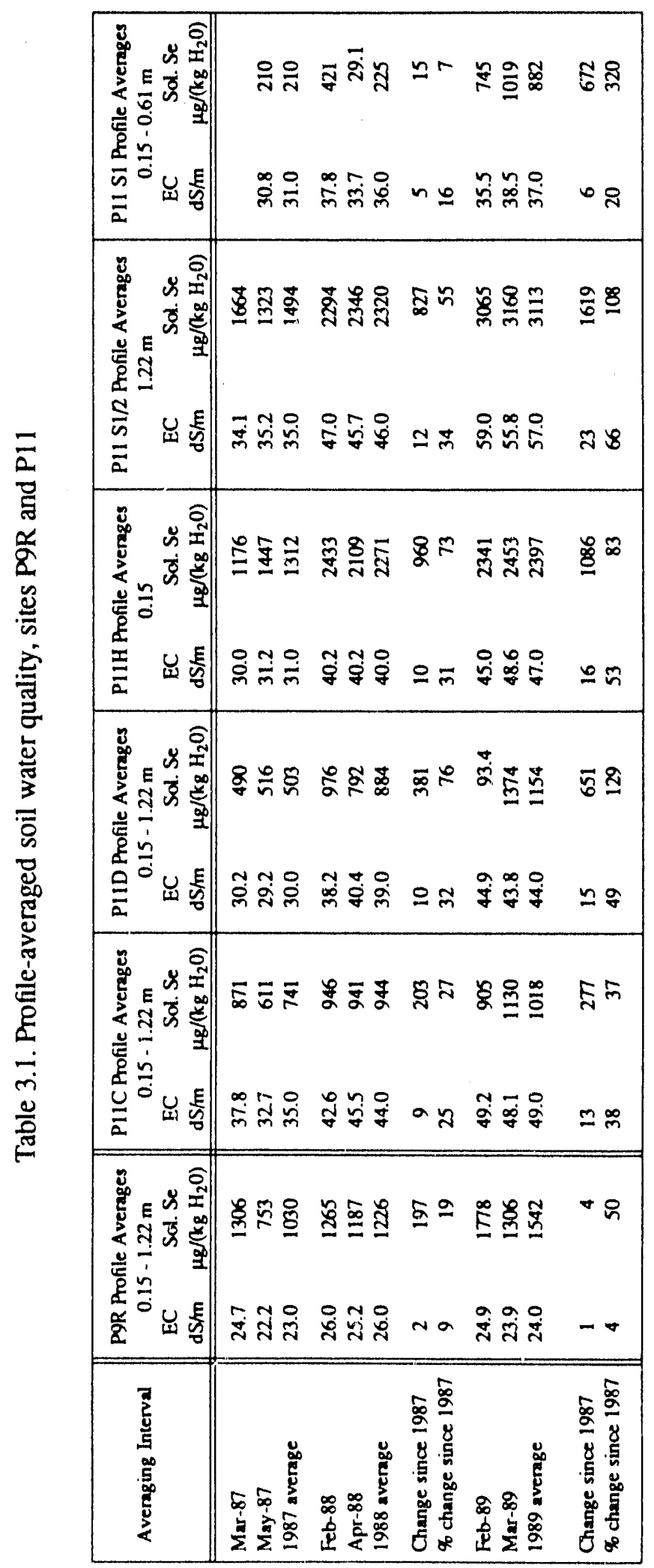


throughout the surface 1 meter of soil, both while the Reservoir was in use and currently. As mentioned in previous reports, soluble selenium increases are due to oxidation of reduced forms of selenium within the soil profiles.

Increases in soil water EC due to upwards flow from the shallow water table are enhanced by the high salinity of this source water $(E C=18 \mathrm{dS} / \mathrm{m})$. Rates of soil water EC increase were generally higher during the first year (1987-1988) when profile-averaged increases of 5 to 12 $\mathrm{dS} / \mathrm{m}$ were observed. These increases corresponded to relative increases of $16 \%$ to $35 \%$. During the 1988-1989 year, rates of profile-averaged EC were more moderate. The net increases in profile-averaged EC in these test plots over the past 2 years ranged from $20 \%$ up to $66 \%$, relative to the initial 1987 average data. During years of higher rainfall inputs, these increases can be expected to be moderated. It should be noted that three factors associated with the observed EC increases must be accounted for before actual rates of salinization of the soil profiles can be obtained. First, the soil water content profiles must be essentially identical at the sampling times under consideration (or further calculations to normalize EC data to common water contents must be included). Under the most extreme conditions, as much as a $20 \%$ relative difference in soil water contents at particular soil water samplers could have occurred at different sampling times. Nearly all of the measured changes in EC were well in excess of what could be attributed to reference water content differences. Second, in the range of interest, the soil solution EC increases nonlinearly with salt content (for a given composition of salts in solution) due to ionpair formation rendering electrolytes less conductive at higher concentrations. Third, salts which move into the soil profile and subsequently precipitate clearly do not contribute to the EC of soil solution samples. When either of these latter two effects are significant, actual changes in soil profile salinity are greater than that inferred from EC data. Since the chloride ion concentration is not affected by the latter two processes (over the range in which vacuum extractions of soil solutions are possible), better estimates of soil profile salinization rates can be obtained through data on soil solution chloride contents. Chloride analyses for the majority of the soil solution samples listed in Table 3.1 have been completed and are presented in Table 3.2. The average 
concentrations and relative changes of averages referenced to 1987 are summarized in the righthand column. The $51 \%$ increase in average chloride content from 1987 to 1988 corresponds to a $29 \%$ increase in average ECs for the same profiles. The $73 \%$ increase in average chloride concentration from 1987 to 1989 corresponds to a 47\% increase in average ECs. From the mass balance of chloride in these Pond 11 soil profiles, net upwards movement of ground water amounted to $0.6 \mathrm{~m}$ in $1987-1988$, and $0.2 \mathrm{~m}$ in $1988-1989$. By including the annual rainfall inputs, annual evapotranspiration at these sites amounted to $0.9 \mathrm{~m}$ and $0.4 \mathrm{~m}$ in 1987-1988 and 1988-1989 respectively.

Apparent increases in profile-averaged soil solution selenium concentrations ranged from $37 \%$ up to $320 \%$ over the past 2 years. The high value of $320 \%$ from the site P11S1 may be unreliable due to inadequate sampling of the site during the first year. Nevertheless, increases in the range of $100 \%$ are characteristic of these sites. Oxidation of various inorganic and organic forms of selenium are the principle sources for the observed increases in the soil solution selenium contents since selenium concentrations in the shallow ground water are low. While the soil profiles in the Pond 11 test sites have probably been infrequently subjected to anaerobic conditions associated with reducing the drain water selenate to adsorbed or insoluble species, extensive reduction has nevertheless taken place. This is evident from the fact that the soil solution sclenium inventories at these sites account for only approximately $20 \%$ of the estimated total selenium inventory. Consequently, although the increase in soluble selenium concentration is large, this only represents remobilization of on the order of $6 \%$ of the total inventory per year. Due to potentially direct exposure to an oxidizing environment, the adsorbed selenite fraction of these soils appears to be among the reasonable precursors to later oxidization and consequent increases in the soil solution selenium content (Weres et al., 1989b).

\subsubsection{Pond 1 Soil Water Selenium and Salinity Changes}

Profiles of pore-water samples from sampling sites in Pond 1 have been analyzed in order to investigate changes in the distribution and inventory of soluble selenium over a three-year period. Six sites were evaluated including UZ-1, 4, 5, 6, 8, and 9. Each of these sites is 


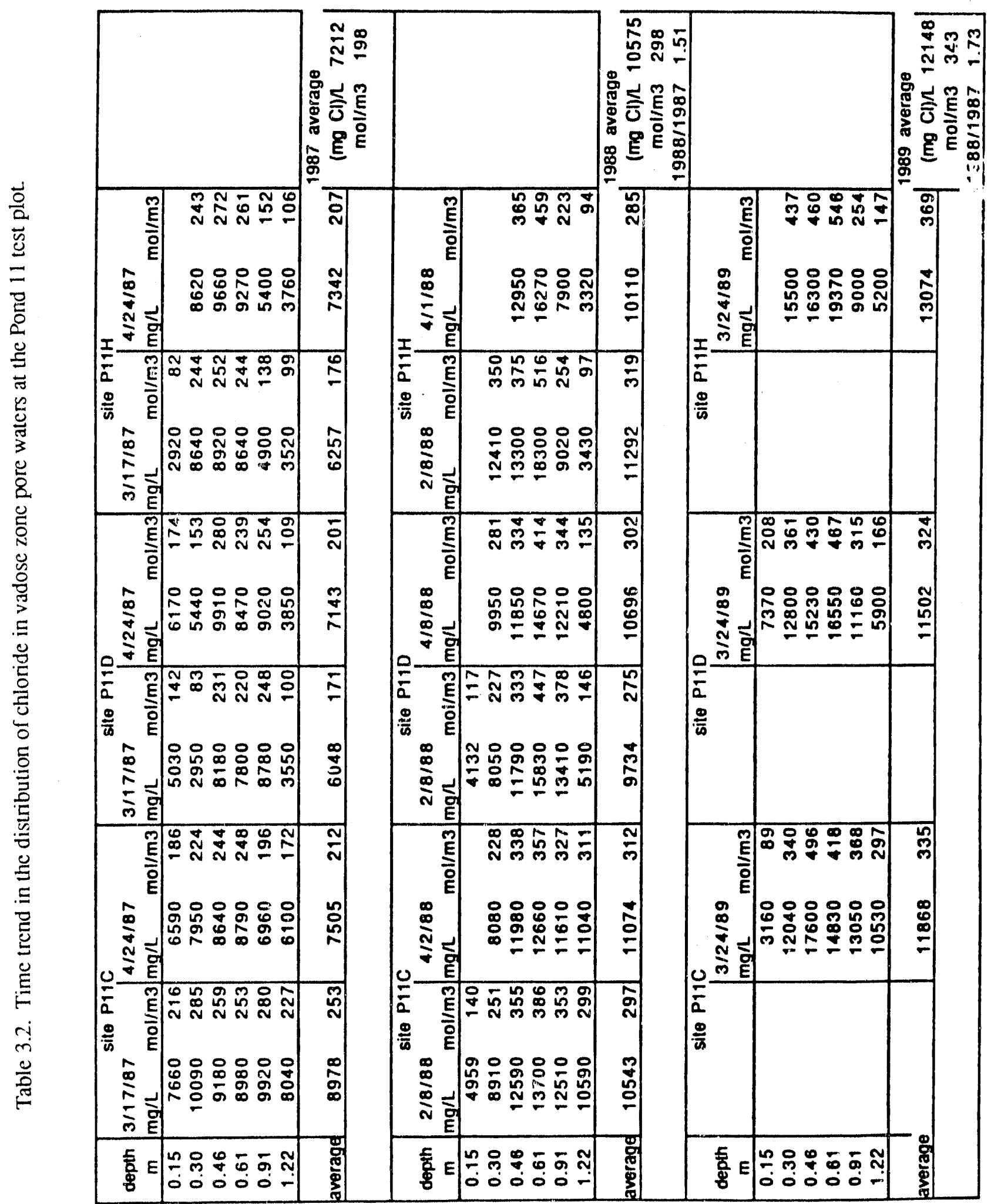


instrumented with an array of soil water samplers and tensiometers, to a depth of $1.2 \mathrm{~m}$. Detailed descriptions of these sites have been provided in the 1987 LBL Annual Report. Unlike the other study sites, the majority of sites in Pond 1 were flooded with less saline and selenium-free water (as part of interim operations) beginning in the autumn of 1986 and during most of 1987.

To determine long term changes in the distribution and inventory of soluble selenium in the soil profile, profiles from 1989 were compared to profiles from 1986. For this comparison two different profiles from 1986 were used, a pre-flooding profile and a post-flooding profile. The two different profiles were used because the post-flooding inventory of soluble selenium was significantly higher than the pre-flooding inventory. These increases were attributed largely to dissolution and downward transport of the seleniferous salt crust at the soil surface. The preflooding profiles of soluble selenium are representative of the undisturbed areas typical of most of the ponds that were flooded while Kesterson Reservoir was used as a disposal facility for agricultural drainwater. The post-flooding profiles, obtained from samples collected severai days after reflooding the pond in October 1986, are representative of the maximum inventory of soluble selenium in the soil profile shortly after drainage water deliveries ceased in 1986 (Long, 1988).

Examination of the shapes of the profiles shows that the time trends at the sites fall into two categories: sites where the selenium distribution is similar to the post-flooding inventory in 1986 , and sites where the top of the profile is similar to the post-flooding values but current seienium concentrations deeper in the profile are higher than post-flooding values. Typical profiles illustrating these two time-trends are provided in Figures 3.4a and 3.4b. The data in Figure 3.4a, from site UZ-8, indicate little change between posi fooding concentrations in 1986 and now. Data from sites UZ-1 and UZ-4 show a similar trend. Figure 3.4b, illustrating data from site UZ-6, shows that selenium concentrations in the top $0.6 \mathrm{~m}$ remain similar to post-flooding concentrations, but below this depth they have increased by a factor of 5 to 10 . Sites UZ-5 and UZ-9 both exhibited a similar trend.

Profile-averaged concentrations were compared in each of the profiles as a simple means of 


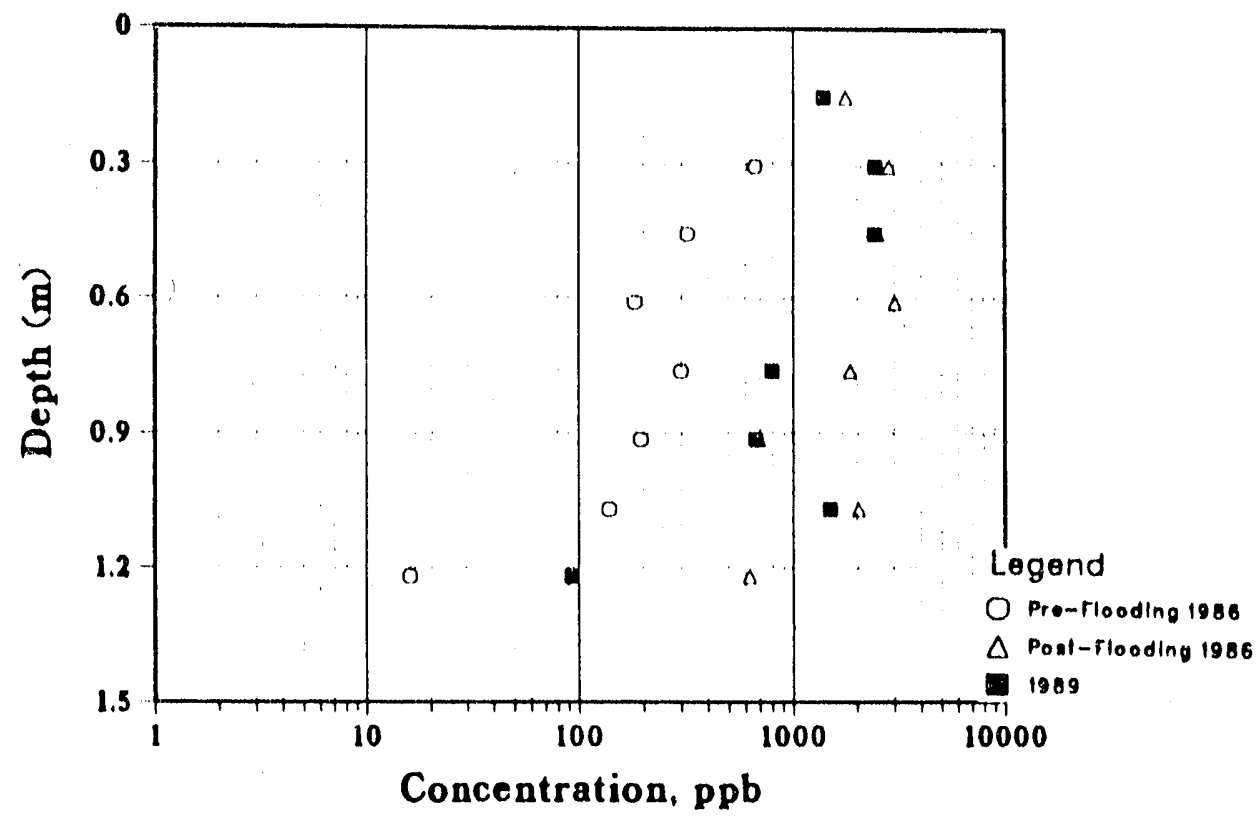

Figure 3.4a. Comparison between selenium concentrations at the UZ-8 site in 1986 and 1989.

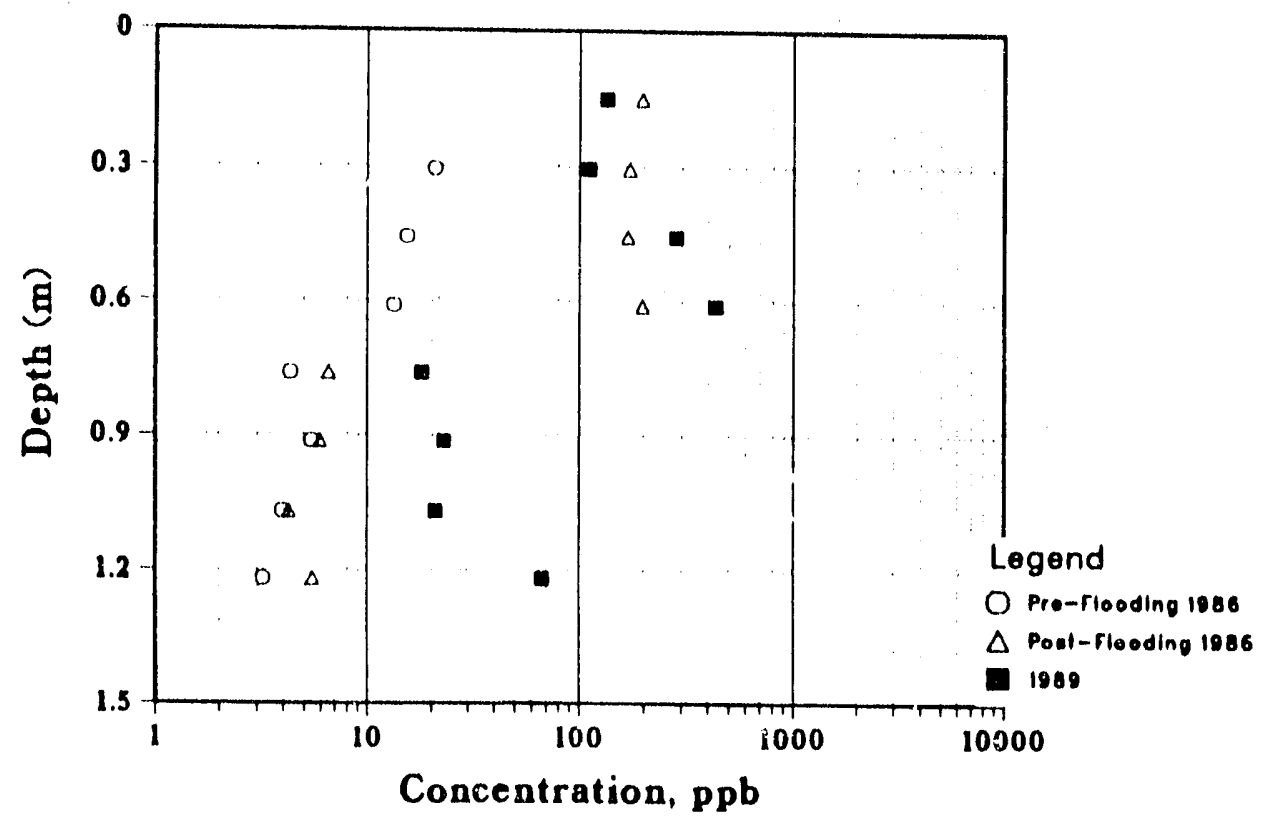

Figure 3.4b. Comparison between selenium concentrations at the UZ-6 site in 1986 and 1989. 
assessing changes in the inventory of soluble selenium. The average concentrations at each of the sites are provided in Table 3.3. As mentioned above, in all cases the post-flooding averages are always higher than the pre-flooding averages in 1986, by factors ranging from 2 to 8 . At sites UZ-1 and 8, 1989 averages are from 30\% to 50\% less than the 1986 post-flooding values, but are still higher than the pre-flooding values. The current values at sites UZ-5 and 6 have increased by $60 \%$ to $70 \%$ above the 1986 post-flooding values. The current average at site UZ-4 is nearly the same as the post-flooding value.

Table 3.3. Profile-averaged selenium concentration in pore water samples collected from pore water samples in Pond 1.

\begin{tabular}{|l|r|r|r|r|r|}
\hline \multirow{2}{*}{ Site No. } & \multicolumn{4}{|c|}{ Average Selenium Concentration $(\mu \mathrm{g} / 1)$} \\
\cline { 2 - 6 } & UZ-1 & UZ-4 & UX-5 & UX-6 & UZ-8 \\
\hline \hline Pre-flooding 1986 & 358 & 812 & 133 & 10 & 272 \\
Post-flooding 1986 & 1060 & 1277 & 344 & 80 & 1759 \\
Maximum 1989 & 700 & 1193 & 554 & 137 & 1320 \\
\hline
\end{tabular}

The above mentioned changes in the distribution and inventory of selenium can be attributed to a limited set of physical and biochemical processes that have occurred over the past three years in Pond 1. Specifically, decreases in the inventory (observed at UZ-1 and UZ-8) and increases in the concentration at deeper depths (observed at UZ-5 and UZ-6) can be ascribed primarily to downward transport of soluble selenium resulting from flooding the ponds during the winters of $1986-87$ and $1987-88$. The significant decreases in the inventories oisserved at UZ-1 and UZ-8 are consistent with previous estimates that from $35 \%$ to $45 \%$ of the soluble inventory was transported out of the top $1.2 \mathrm{~m}$ of soil at these two sites as a result of reflooding Pond 1 in 1986 (Long, 1988). Similarly, the increases in selenium concentrations in the lower part of the profiles at UZ-5 and UZ-6, without a substantial decline in the inventory, are consistent with previous analyses indicating that leaching from the top $0.5 \mathrm{~m}$ occurred but very little selenium was 
transported out of th. - top $1.2 \mathrm{~m}$ at these two sites (Long, 1988). The overall increases in the soluble inventory observed at UZ-5 and UZ-6 can be explained by transformation and remobilization of the reduced forms of selenium, similar to the observations in Ponds 9 and 11 described previously. The rates of remobilization observed at the two sites, resulting in increases of $60 \%$ to $70 \%$ of the initial inventory of soluble selenium over a 2 year period, are within the range of values observed in Ponds 9 and 11 . Note that although this appears to be a fairly rapid rate of increase, the presently soluble inventory at these sites is on the order of about $5 \%$ to $10 \%$ of the total inventory. Consequently, when these rates are normalized to the total inventory, they are less than $10 \%$ per year.

Over the past year we have become more aware that in addition to long-term trends, selenium and salt concentrations may vary significantly on a seasonal basis. These seasonal trends have a potentially important impact on long term changes in the distribution of selenium within the soil profile. Therefore, the Pond 1 sites were also closely monitored over this past wet-season in an attempt to assess the important physical and chemical processes taking place as a result of rainfall infiltration and the rising water table. Monitoring included the abovementioned sites and two new sites in the filled areas which are located approximately 10 meters from sites UZ-1 and 6 and called UZ-1F and $6 \mathrm{~F}$, respectively. A wide variation of trends was observed. As illustrated in Figure 3.5a, remarkable consistency was seen in the overall profile at site UZ-6F. A similar lack of seasonal changes in soil water selenium concentrations in response to changes in soil water conditions was observed in the lower part ( 0.6 to $1.2 \mathrm{~m})$ of the profiles at sites UZ-1, 1F, and 4. However, at the other sites, most notably UZ-5 (see Figure 3.5b), large changes in selenium concentrations took place over the winter. Both large increases and decreases were observed at various depths in the profiles.

The changing soil water conditions, caused hy the fluctuating water table and rainfall infiltration, allow many processes to occur which influence the mobility and redistribution of 


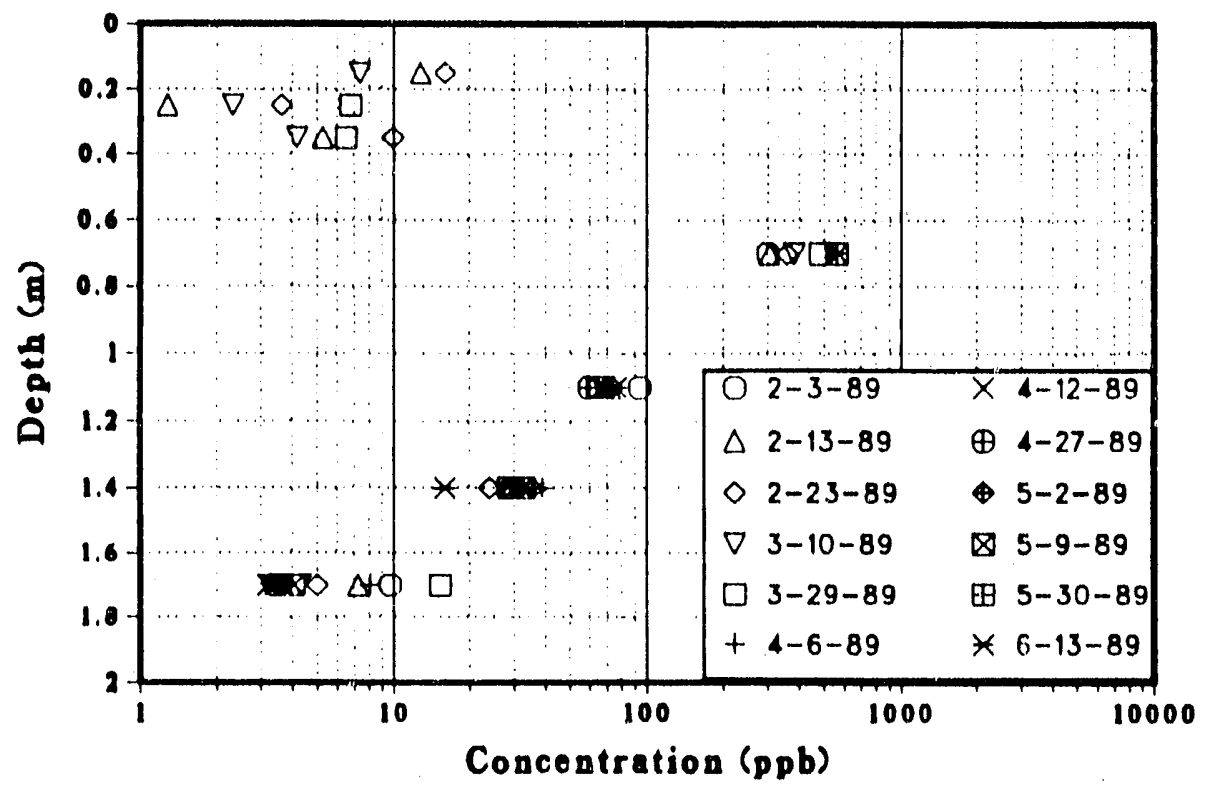

Figure 3.5a. Seasonal trends in selenium concentrations in soil water samples at site UZ-6F.

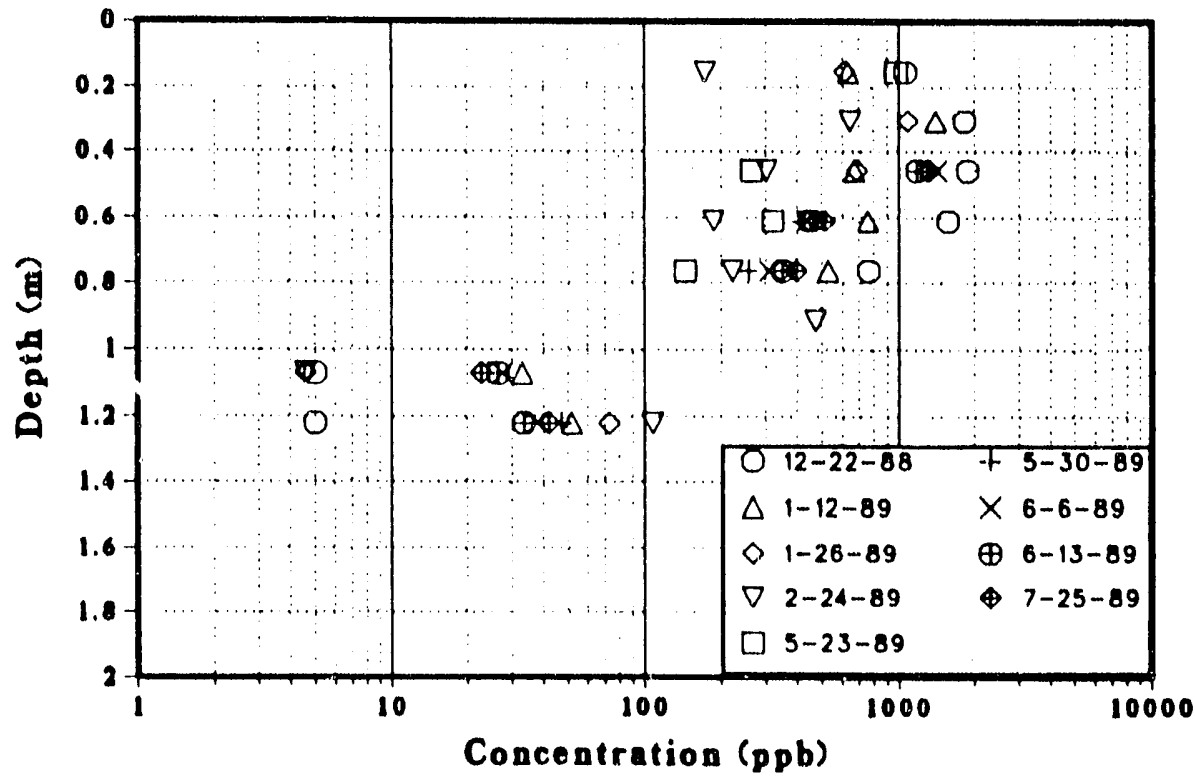

Figure 3.5b. Seasonal trends in selenium concentrations in soil water samples at site UZ-5. 
soluble selenium in the soil profile. Specifically, (1) rainfall infiltration can dissolve selenium associated with salts on the soil surface and transport them deeper into the profile, (2) seleniferous pore-waters occupying the upper portion of the profile may be displaced deeper into the profile by infiltrating rainwater, (3) the rising water table may transport either selenium-bearing or selenium-deficient pore-waters towards the soil surface, (4) hydrodynamic dispersion (created largely by macropore flow) and diffusion accompanying transport can dilute the concentration of soluble selenium, and (5) a higher water content can decrease the anount of oxygen in the soils, thereby promoting reducing conditions which transform soluble selenium to less soluble and mobile forms.

To understand better how these processes caused the observed seasonal changes in selenium concentrations, chloride analyses were performed on the soil waters from two represer1tative sites, namely UZ-6F and UZ-5. The variation in the concentration of chloride, a nonreactive tracer, should allow us to follow the movement of water through the profiles.

The soil waters from site UZ-6F were analyzed as representative of those sites with nearly temporally constant selenium profiles. Profiles of chloride concentrations over the monitoring period are shown in Figure 3.6a. As expected, he chloride concentrations remain nearly constant over the winter. Only samples from $0.7 \mathrm{~m}$ exhibited any type of seasonal change. At this depth, which is directly above the fill-native soil interface, chloride and selenium concentrations in. reased to their highest values during May and June. This trend is best explained by evapotranspirative fluxes of solutes from deeper in the profile into the fill material.

In contrast to UZ-6F, where chloride and selenium concentrations remained fairly constant over the winter season, selenium and chloride concentrations at UZ-5 varied greatly. Chloride concentrations from this site are shown in Figure 3.6b. Variations in chloride concentrations closely paralleled the selenium concentrations, indicating that observed pattems can be explained largely by non-reactive transport within the profile. 


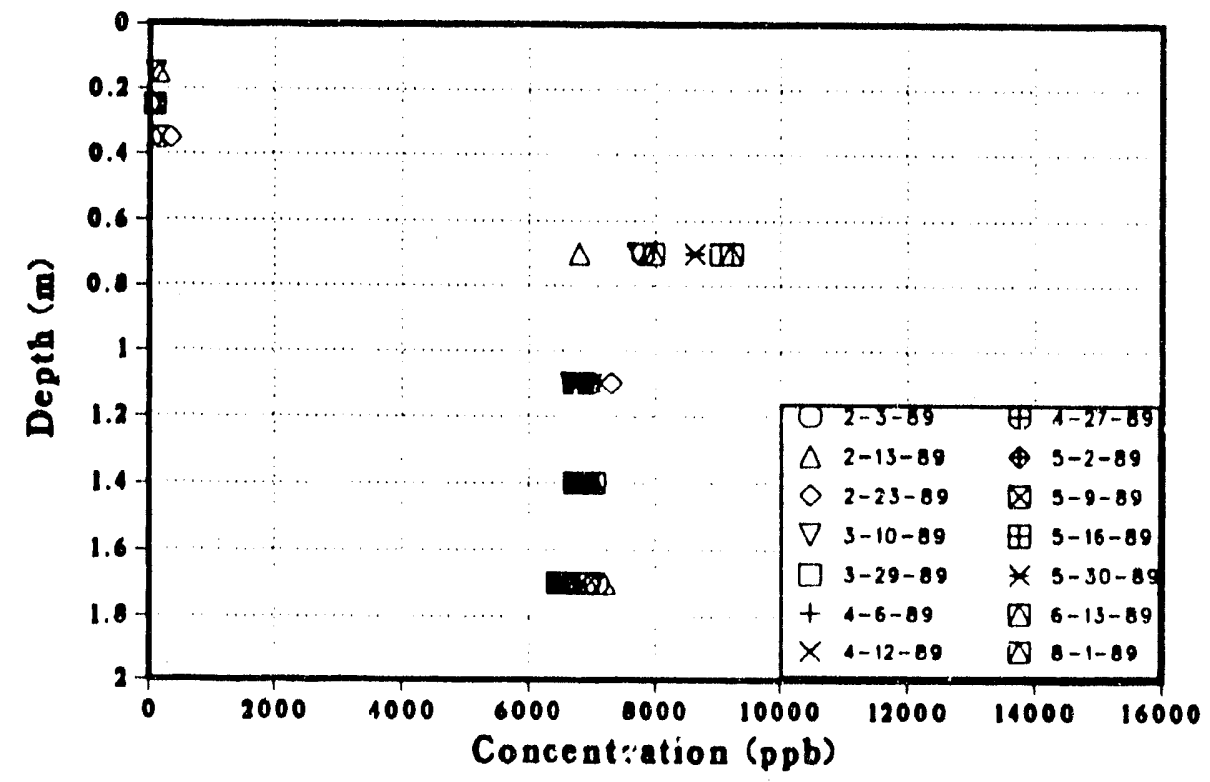

Figure 3.6a. Seasonal trends in chloride concentrations in soil water samples at site UZ-6F.

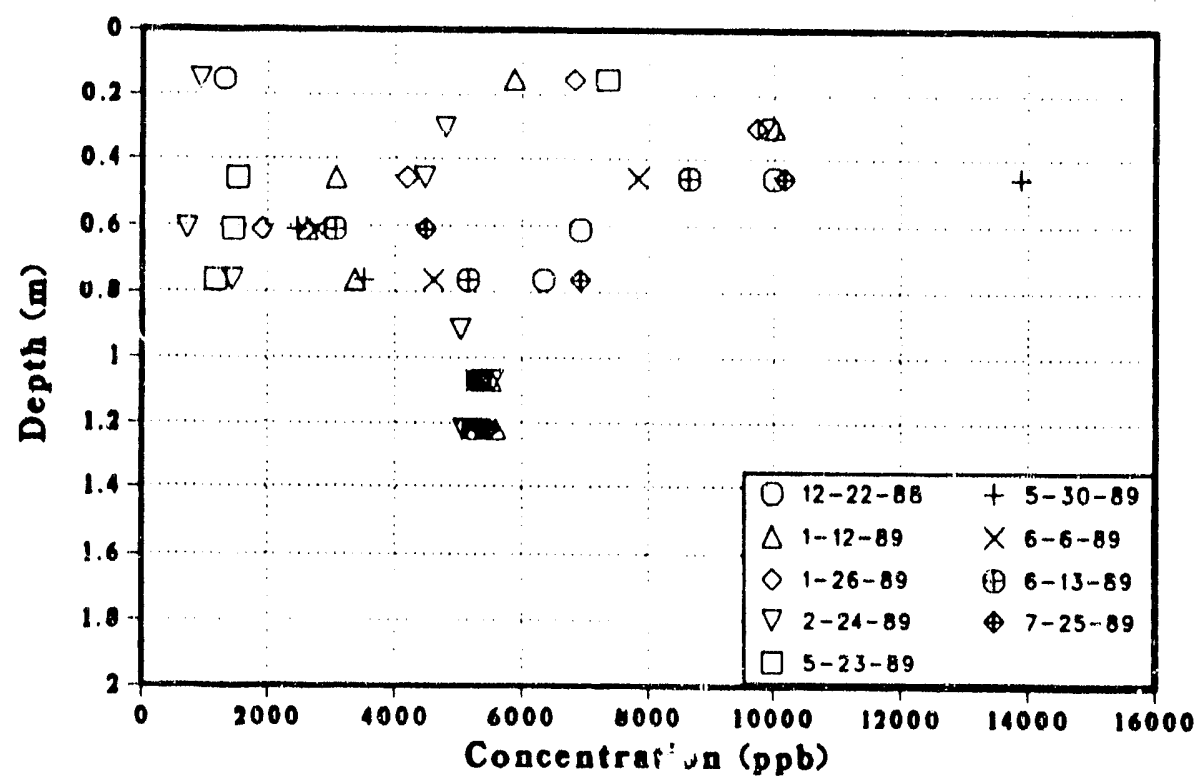

Figure 3.6b. Seasonal trends in chloride concentrations in soil water sarnples at site UZ-5. 
In general, chloride concentrations within the top $0.75 \mathrm{~m}$ decreased over the rainy season, but increasc $d$ once again beginning in May. This pattem is explained best by infiltration and dilution of pore waters with rainwater, followed by evapotranspirative fluxes in the hot season.

An interesting trend is also apparent at depths of 0.30 and $0.4 \mathrm{~J} \mathrm{~m}$. Over the winter, selenium to chloride ratios decrease in excess of rates that cin be explained by purely nonreactive transport. Up to a three-fold decrease in $\mathrm{Se} / \mathrm{Cl}$ suggests that immobilization of selenium is occurring, presumably in response to creation of anaerobic conditions as the water table rises above the sampling interval.

No significant seasonal trends in chloride concentrations were observed for the greatest depths, 1.05 and $1.22 \mathrm{~m}$. Selenium concentrations, however, changed significantly. At $1.05 \mathrm{~m}$ the selenium levels remained extremely low until May, when they rose to about $25 \mu \mathrm{g} /$; at $1.22 \mathrm{~m}$ sclenium level rose to their highest value $(108 \mu \mathrm{g} /)$ in late February, then decreased to about 40 $\mu \mathrm{g} /$. These two disparate trends are difficult to reconcile with simfle one-dimensional transport. Perhaps selenium concentrations increased at $1.05 \mathrm{~m}$ in May in response to the falling water and subsequent re-oxidation of the soils. The increase in selenium concentration at depth of $1.22 \mathrm{~m}$ during the wet season may reflect downward transport through macropores.

These results have provided a preliminary assessment of the processes responsible for seasonal changes in selenum concentrations. More work is necessary before specific conclusions can be drawn. Over this next winter more intensive sampling will be conducted, with the effort focused on providing quantitative assessment of these processes goveming the redistribution of salts and selenium. Additional discussion $f$ seasonal changes in salt and selenium concentrations is provided in Section 3.3. 


\subsection{EPHEMERAL POOL WATER QUALITY}

\section{Tetsu Tokunaga}

Earth Sciences Division

Lawrence Berkeley Laboratory

Concem over selenium uptake into the food chain through ephemeral pool waters motivated sampling of these waters during the 1988-1989 wet season. This wet season at the Reservoir differs from previous ones in two important ways. First, there has been no intentional application of surface water (either the seleniferous agricultural drainage waters, or the more recent application of local, nonseleniferous shallow ground water) during, or prior to the present wet season. Secund, a large portion of the original Reservoir soil surface has been covered by as much as $1.5 \mathrm{~m}$ of fill material, in compliance with the State Water Resources Control Board directive. The implications of these two factors on ephemeral pool formation and water quality will be briefly discussed, and followed with a review of field data from ephemeral pools sampled during the 1988-1989 wet season.

Cessation of intentional applications of surface water in select ponds at the Reservoir have had iwo immediate effects on formation of ephemeral pools outside the areas of intended ponding. The most obvious effect is the lack of pooling due to leakage through check gates separating wet ponds from dry ponds. This effect is significant in light of the observed predominance of ephemeral pool formation from surface overflow during the 1987-1988 wet season. A second important effect of the termination of intentional ponding at the Reservoir is that of diminishing the extent of water table rise in dry ponds in the vicinity of flooded ponds. This results in significant delaring of the onset of ephemeral pool formation in areas which previously were near flooded ponds. An example of this effect can be seen in comparisons between water table levels in previous and current wet seasons at the Pond $6,1 \mathrm{ft}$ excavation test plot which is adja- 
cent to the previously flooded Pond 5. In the previous wet season, the rising water table reached the excavated soil surface in November 1987, and rose to as much as $0.20 \mathrm{~m}$ above the excavated surface during January and February of 1988. During the more recent wet season, the water table had only risen to within $0.51 \mathrm{~m}$ of the excavated surface (peak water level recorded at this site in mid-February 1989). (This latter condition does not preclude the formation of ephemeral pools due to ponding of rainfall).

Ephemeral pool formation during the 1988-1989 season occurred primarily in filled areas of the Reservoir, therefore much of the following discussion will center on processes of surface water accumulation in these areas. The placement of fill dirt over areas in the Reservoir of relatively lower elevation has had several effects conceming ephemeral pool formation and selenium redistribution. The variety of effects may be broadly grouped into factors which prevent or delay surface water accumulation, and factors which contribute to surface water quality pmblems. These factors will be considered in turn.

One direct effect of filling in lower regions is that of elevating the surface further from the seasonally fluctuating water table. This prevents the upward displacement of seleniferous, saline soil water by the rising water table from reaching the surface. The commonly coarse texture of the fill material may lessen the effect of capillary rise of soil water and solutes (including selenium). The initially low salinity of the majority of the fill material has allowed a rapid proliferation of vegetation, dominated by Kochia scoparia and a variety of grasses. The presence of the vegetation will assist in prevention of ephemeral pool sormation through both dewatering the soil profile, and through minimizing puddling by reducing raindrop impact at the soil surface.

Other features of the fill have the potential to coniribute to future ephemeral pool water quality problems. Two of these factors have had immediately observable effects. These are the occurrences of low permeability fill surfaces, and areas where the fill material is comprised of Kesterson Reservoir soils. The latter factor appears to be relevant in only a small fraction of the Reservoir area, and will be discussed in a following paragraph where ephemeral pool water quality data are reviewed. One effect of the filling operation has been the creation of some fill sur- 
faces which have low permeability (probably due to unintentional compaction of the fill dirt during placement, along with the destruction of the original soil structure). Low hydraulic conductivity in these fill surfaces leaves them susceptible to ponding due to restricted rainfall infiltration. This effect is observed at the reservoir through the formation of ephemeral pools on fill surfaces, beginning with the late November 1988 rains. The maximum extent of these pools on fill surfaces in late December 1988 was estimated at about $1 \%$ of the Reservoir area. The previously noted potential beneficial effects of the vegetation cover in fill areas may assist in prevention of rainfall ponding. On the other hand, the increased evapotranspiration due to the presence of plants will increase the rate at which seleniferous, saline soil water from the underlying Reservoir soils will move up into the fill material.

Before reviewing the ephemeral pool water quality data of the 1988-1989 season, it should be noted that none of these pools were formed by rising ground water. The depth to the water table has been as great as $2 \mathrm{~m}$ below the ponded fill surface during the wet season. All of the observed surface waters were a result of rainfall ponding. A total of $73 \mathrm{~mm}$ ( 2.87 inches) of rainfall had been measured at the Reservoir by the time in the 1988-1989 wet season when the majority of pools were observed. This amount represents about $68 \%$ of the average rainfall totaled from September 1 to December 31 at the Reservoir (1982 to 1988 USBR data, with 1984 data missing). The total precipitation of $163 \mathrm{~mm}$ (6.4 inches) during the 1988.1989 season amounts to only 55\% of the mean annual rainfall of $295 \mathrm{~mm}$ (11.6 inches) for the years 1982 through 1988 . The potential for more extensive pool formation during normal and wetter years is clear.

A subset of the observed pools has been selected for periodic water sampling. Most of this subset is listed in Table 3.4, along with estimates of pool size, and measirements of pool water electrical conductivities (ECs) and selenium concentrations. It should be noted that in significant ponding was observed on undisturbed (unfilled) soil surfaces ai the Reservoir Juring the $1988-1989$ season.

Since the pools sampled in filled areas of the Reservoir are due to ponding of rainfall, pool water quality will reflect fill surface solutes mixing with rain water. The fill material was 
Table 3.4. Water quality in ephemeral pools at Kesterson during the winter of 1988-1989.

\begin{tabular}{|c|c|c|c|c|c|c|c|}
\hline $\begin{array}{c}\text { Pond } \\
\quad\end{array}$ & pool site & sample date & $\begin{array}{c}\text { pool area } \\
\text { me }\end{array}$ & $\begin{array}{c}\text { pool depth } \\
\mathrm{mm}\end{array}$ & $\begin{array}{c}E C(25) \\
d S / m\end{array}$ & $\begin{array}{l}\text { selenite conc. } \\
\mu g / \mathrm{kg}, \quad(\mathrm{ppb})\end{array}$ & $\begin{array}{l}\text { total solenium } \\
\mu \mathrm{g} / \mathrm{kg}, \quad(\mathrm{ppb})\end{array}$ \\
\hline 1 & 1-NE-fp & $1 / 12 / 89$ & 100 & 20 & 0.76 & 2.7 & 12.0 \\
\hline 1 & $1 \cdot \cup Z 4 \cdot W \cdot f p$ & $1 / 13 / 89$ & 30 & 20 & 0.34 & 1.6 & 4.8 \\
\hline 1 & $1-U Z 6 \cdot E \cdot f p$ & $1 / 13 / 89$ & 34 & 20 & 0.22 & 0.5 & 1.0 \\
\hline 2 & & $11 / 28 / 88$ & & & 2.61 & 19.0 & 26.1 \\
\hline 2 & 2-NE-fP & $11 / 28 / 88$ & & & 1.21 & 11.8 & 15.8 \\
\hline 2 & $2 \cdot E \cdot 1 p$ & $1 / 12 / 89$ & 1200 & 40 & 5.34 & 16.1 & $2 i .2$ \\
\hline 2 & $2 \cdot W C \cdot f p$ & $1 / 13 / 89$ & 25 & 10 & 0.63 & 3.6 & 5.7 \\
\hline 3 & 3-NNE-fP & $1 / 13 / 89$ & 130 & 40 & 5.34 & 26.1 & 44.3 \\
\hline 3 & 3-NE.fp & $1 / 13 / 89$ & 200 & 30 & 4.57 & 29.1 & 50.4 \\
\hline 4 & $4 \cdot W \cdot 1 p \quad(c t)$ & $1 / 13 / 89$ & 100 & 30 & 1.61 & 5.0 & 11.6 \\
\hline 5 & 5.SE. fp & $11 / 28 / 88$ & & & 0.66 & 5.0 & 17.2 \\
\hline 5 & $5 \cdot S E C \cdot f p$ & $1 / 13 / 89$ & 300 & 30 & 0.93 & 4.3 & 6.5 \\
\hline 6 & $6 P B-f p$ & $12 / 20 / 88$ & & & 3.24 & 10.2 & 30.9 \\
\hline 6 & $6 P B \cdot 1 p$ & $1 / 7 / 89$ & 70 & 40 & 0.88 & 1.5 & 4.2 \\
\hline 6 & $6 P B \cdot 1 p$ & $1 / 12 / 89$ & 15 & 10 & 1.35 & 2.4 & 5.4 \\
\hline 7 & 7.SE-Ip & $12 / 20 / 88$ & 100 & 50 & 2.54 & 16.4 & 31.5 \\
\hline 9 & $9 B E \cdot E \cdot f p$ & $1 / 7 / 89$ & 50 & 30 & 0.23 & & \\
\hline 9 & $9 B E-E \cdot f P$ & $1 / \quad 9 / 89$ & & & 0.77 & 0.6 & 2.4 \\
\hline 9 & $9 P C \cdot t p$ & $12 / 21 / 88$ & 300 & 30 & 0.69 & 2.6 & 4.1 \\
\hline 9 & $9 F C \cdot 1 p$ & $12 / 31 / 88$ & 300 & 30 & 1.13 & 4.8 & 6.8 \\
\hline 9 & $9 P C \cdot 1 p$ & $1 / 7 / 89$ & 1000 & 20 & 0.96 & & \\
\hline 9 & $9 P C \cdot 1 p$ & $1 / 12 / 89$ & 50 & 15 & 1.57 & & \\
\hline 9 & 9.N-fp1(PgX) & $12 / 21 / 88$ & 30 & 20 & 0.18 & 0.3 & 0.4 \\
\hline 9 & $9 \cdot N \cdot \mid p 1$ & $1 / 12 / 89$ & 70 & 30 & 0.18 & & \\
\hline 9 & $9 \cdot N \cdot\{p 2$ & $12 / 21 / 88$ & 50 & 50 & 0.26 & 1.0 & 1.5 \\
\hline 9 & $9 \cdot N \cdot 1 p 2$ & $1 / 12 / 89$ & 15 & 10 & 0.32 & & \\
\hline 9 & 9.NW-fp1 & $12 / 21 / 88$ & 50 & 20 & 0.92 & 5.0 & 7.1 \\
\hline 9 & 9.NW.fp2 & $12 / 21 / 88$ & 300 & 60 & 0.38 & 2.6 & 3.9 \\
\hline 10 & $10 G \cdot N \cdot f p$ & $11 / 28 / 88$ & & & 0.21 & 0.5 & .9 \\
\hline 10 & $10 G \cdot N \cdot f p$ & $12 / 20 / 88$ & 1000 & 30 & 0.18 & 0.1 & .3 \\
\hline 10 & $10 G \cdot N \cdot 1 p 2$ & $12 / 20 / 88$ & & & 0.07 & 0.0 & .0 \\
\hline 10 & $10 \mathrm{G} \cdot \mathrm{N}-\mathrm{f} p$ & $12 / 31 / 88$ & 800 & 20 & 0.10 & 0.0 & .2 \\
\hline 10 & $10 G \cdot S \cdot 1 p$ & $12 / 20 / 88$ & 300 & 50 & 0.07 & 0.0 & .0 \\
\hline 11 & $11 \cdot N W-i p$ & $12 / 20 / 88$ & 500 & 40 & 0.32 & 0.0 & .2 \\
\hline 12 & $12 \cdot N \cdot 1 p$ & $11 / 28 / 88$ & & & 0.95 & 9.3 & 12.3 \\
\hline 12 & $12 \cdot N \cdot f p$ & $12 / 20 / 88$ & 30 & & 0.37 & 2.5 & 4.0 \\
\hline 12 & $12 \cdot E \cdot f p$ & $12 / 20 / 88$ & 30 & 50 & 0.14 & 0.0 & .6 \\
\hline 12 & $12 \cdot E C-f p$ & $12 / 20 / 88$ & 100 & 30 & 0.45 & 1.6 & 2.8 \\
\hline 12 & $12 . S C \cdot f p$ & $12 / 20 / 88$ & 200 & 40 & 0.43 & 0.0 & .9 \\
\hline
\end{tabular}


obtained from several different sources. These include spoil bank material from the DeltaMendota Canal, nearby soils, and interior Reservoir levee material. The variety of sources for fill dirt, variable mixing of fill dirt with Kesterson Reservoir surface soils, and variable fill depths imply that a range of water qualities is to be expected in ephemeral pools which form over filled areas. In the limited sampling to date, selenium concentrations in these pools ranged from 0 to $50 \mu \mathrm{g} / \mathrm{kg}(\mathrm{ppb})$. Visual inspection of the sampling sites which yielded selenium concentrations in excess of $20 \mu \mathrm{g} / \mathrm{kg}$ supported the belief that these higher concentrations are due to the use of original Kesterson materials in filling at these locations. It is unlikely that capillary rise of the underlying Kesterson soil solution contributed to the selenium loading during the 1988-1989 season. The observed concentrations are about one order of magnitude less than those observed in previous years. Nevertheless, over half of the pool sites recently sampled in fill areas have had sclenium concentrations in excess of the surface water quality standard of $5 \mathrm{ppb}$.

The fill has been in place for about one year. The long-term process of "capillary" rise and evaporatively driven movement of seleniferous and saline Kesterson Reservoir soil water upwards into the overlying fill dir has the potential ' $\because$ reintroducing these sclutes into the food chain through both mixing in pool waters and through plant uptake. On the other hand, annual rainfall leaching of surface salt accumulations may be effective in keeping surface water concentrations of selenium and other elements at acceptably low levels. Due to the numerous changes imposed on hydrologic conditions at the Reservoir over the past several years, the extremely variable rainfall patterns, and the rel: tively slow rates of both soil water movement and some selenium transformations, long-term projections of ephemeral pool water quality are presently uliiertain. 


\subsection{BARE SOIL EVAPORATION RATES AT KESTERSON RESERVOIR}

Peter Zawislanski

Earth Sciences Division

Lawrence Berkeley Laboratory

\subsubsection{Impetus for Research}

Soils at Kesterson Reservoir and surrounding fields were salt-rich long before they were cultivited by humans. Early soil surveys performed from 1939 on by the U.S. Department of Agriculture and the University of California classified soils of the area as slightly to strongly salt-affected (USDA Soil Conservation Service, 1952). The salinization of soils is a feature typical of regions characterized by high pan evaporation rates, low rainfall, and shallow groundwater tables, all of which are common to the San Joaquin Valley. Soil salinity is a valley-wide problem (Harradine, 1950); the proximity to shallow, highly saline ground water has long been recognized. Soils become salinized due to the evaporation of water at and near the soil surface and the transpiration of water by plants. The former results in the accumulation of salts at the surface while the latter process concentrates salts in the root zotfe (Hillel, 1980). Both processes lead to the degradation of soil from an agric ultural standpoint. Evaporation of water from the soil surface creates an upward soil water potential gradient; in response to this gradient, water is transported from deeper in the profile towards the soil surface where it evaporates and the species dissolved in it precipitate. Along with the major ions $\left(\mathrm{Na}, \mathrm{Ca}, \mathrm{Mg}, \mathrm{SO}_{4}\right.$ and $\mathrm{Cl}$ ) any dissolved element, including trace elements will be subject to such redistribution. Evaporative concentration of naturally occurring selenium has been documented to occur in the Western San Joaquin Valley (Deverel and Fujii, 1989; Fujii and others, 1988; Fio and Fujii, 1988). Researchers from the U.S. Geological Survey found a close correlatiun between salinity and selenium $\left(r^{2}=0.68\right)$ which suggested that the soluble selenium fraction (mostly selenate, $\mathrm{SeO}_{4}^{2-}$ ) is fairly mobile in the soil/sediment system and may behave similarly to sulfate $\left(\mathrm{SO}_{4}^{2-}\right)$ and other major ions. These 
studies were performed in agricultural fields in the Panoche Creek alluvial fan area, an area assumed to be the source of much of the selenium which found its way into agricultural drains and eventually into Kesterson Reservoir.

Due to the continuous evaporation of pond water during the years of Reservoir operation, salts precipitated at the bottom of the ponds and were incorporated into what is now a salt crust. The entire soil water profile is either saturated or nearly saturated with respect to gypsum $\left(\mathrm{CaSC}_{4}\right.$ - $\left.2 \mathrm{H}_{2} \mathrm{O}\right)$ and calcite $\left(\mathrm{CaCO}_{3}\right)$. Selenium is incorporated into the salt crust; in the soil-water system, selenium concentrations range from background in the ground water $(\approx 5 \mathrm{ppb})$ to thousands of ppb of dissolved selenium near the soil surface and several ppm of total selenium in the top few centimeters of soil. Field experiments performed by LBL personnel in March of 1988 involved the scraping off of 15 and $30 \mathrm{~cm}$ of top soil in Pond 6. This resulted in the reconcentration of selenium and salts near the soil surface. Excavation of a layer of soil accelerated the reconcentration process by decreasing the depth to the water table and altering the physical structure of the surface soil (LBL Annual Report, 1988). The rapidity of this process drew attention to the importance of bare soil evaporation in redistributing species near the soil surface. The understanding of the nature and magnitude of this process will be helpful in the management of Kesterson Reservoir. It is the goal of this research to estimate bare soil evaporation rates and the resultant salt and selenium accumulation rates over an annual cycle. While selenium will not, on the whole, behave in the soil-water-air environment in the same fashion as major ions, its watersoluble fraction $\left(\mathrm{SeO}_{4}^{2-}\right)$ will be strongly affected by moisture fluxes near the soil surface. Due to the uncertainties involved in selenium extraction from soils, interference in selenium analysis, selenium's complex redox chemistry, and the great spatial variability of selenium as compared with major ions, it is far more feasible to estimate evaporation rates and track temporal changes in concentration based on these changes amongst the major ions. This approach was the one taken and is described in the following sections. In addition, the nature of the evapuration process was studied with the hope of gaining an understanding of the conditions which control its magnitude. To this end, numerical simulations have been performed. The results of these simula- 
tions have shed some light on the factors and processes which are dominant in bare soil evaporation.

\subsubsection{Local and Site-Spe cific Hydrology and Hydrogeology}

Potential evaporation far exceeds rainfall on an annual basis in the San Joaquin Valley. Average rates vary depending on the distance from the valley axis; annual evaporation ranges from 1500 to $2200 \mathrm{~mm} / \mathrm{year}$ while annual rainfall averages around 150 to $360 \mathrm{~mm} / \mathrm{year}$. (Davis and others, 1959; LBL Annual Report 1988). Most of the rainfall occurs during the months of November through April. Local hydrologic conditions in the vicinity of Kesterson Reservoir are typical of the valley-wide conditions described above, with a few site-specific deviations. Daily climatological conditions over the twelve month period from July 1988 through June 1989 at Kesterson Reservoir are depicted in Figures 3.7 and 3.8. The air temperature and humidity were measured by an electronic weather station in Los Banos. Precipitation was measured at a weather station at Kesterson Reservoir, evaporation rates presented in Figure 3.8a were measured at the Los Banos Reservoir (from day 0 until day 180 and again from day 216 until day 366) and at Kesterson Reservoir (from day 181 through day 215). (Pan evaporation rates were not recorded at Kesterson Reservoir from July 1988 through November 1988; therefore, evaporation rates at Kesterson were estimated from rates measured at Los Banos Reservoir, based on historical records of evaporation at the two sites. Pan evaporation was not measured at the Los Banos Reservoir during the 34 day period and rates measured at Kesterson were used.) The combination of reduced temperatures and elevated hum cies during the late fall and winter lead to a reduction in measured pan evaporation. Figure 3.8 highlights the disparity between pan evaporation and precipitation; over the twelve month period, total precipitation was measured at $162 \mathrm{~mm}$, while the cumuli ive annual pan evaporation was $2234 \mathrm{~mm}$.

This study concentrates on the soil-sediment system of the top $2.5 \mathrm{~m}$ of soil and seciment. It is the interval which encompasses the vadose (unsaturated) zone, the extent of which varies with the seasonal rise and fall of the water table. In particular, this study focuses on the vadose zone in sites 8EP (Pond 8) and 9BE (Pond 9). In order to characterize the soil/sediment profile, soil was 


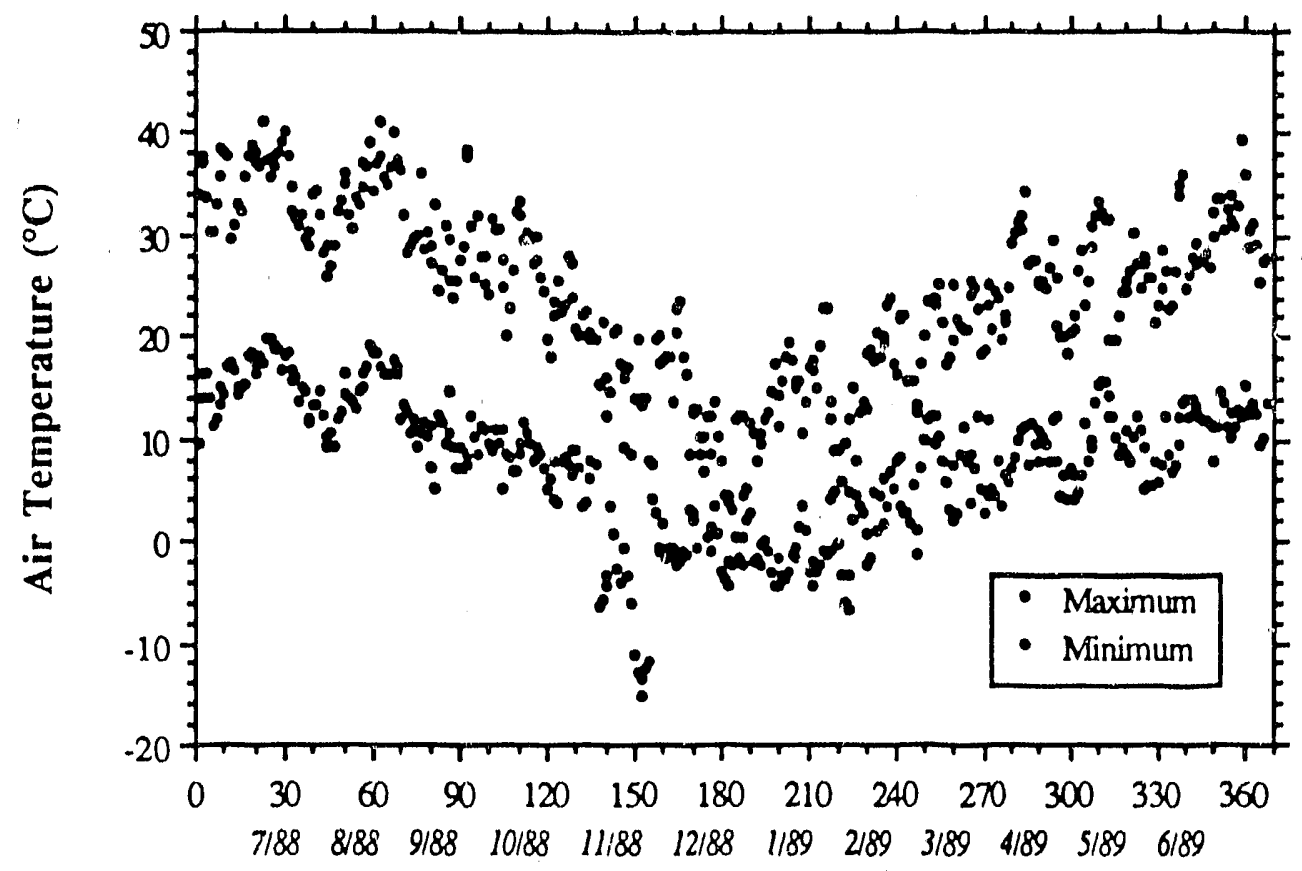

Days since $6 / 30 / 88$

Figure 3.7a. Maximum and minimum daily air temperature at Los Banos.

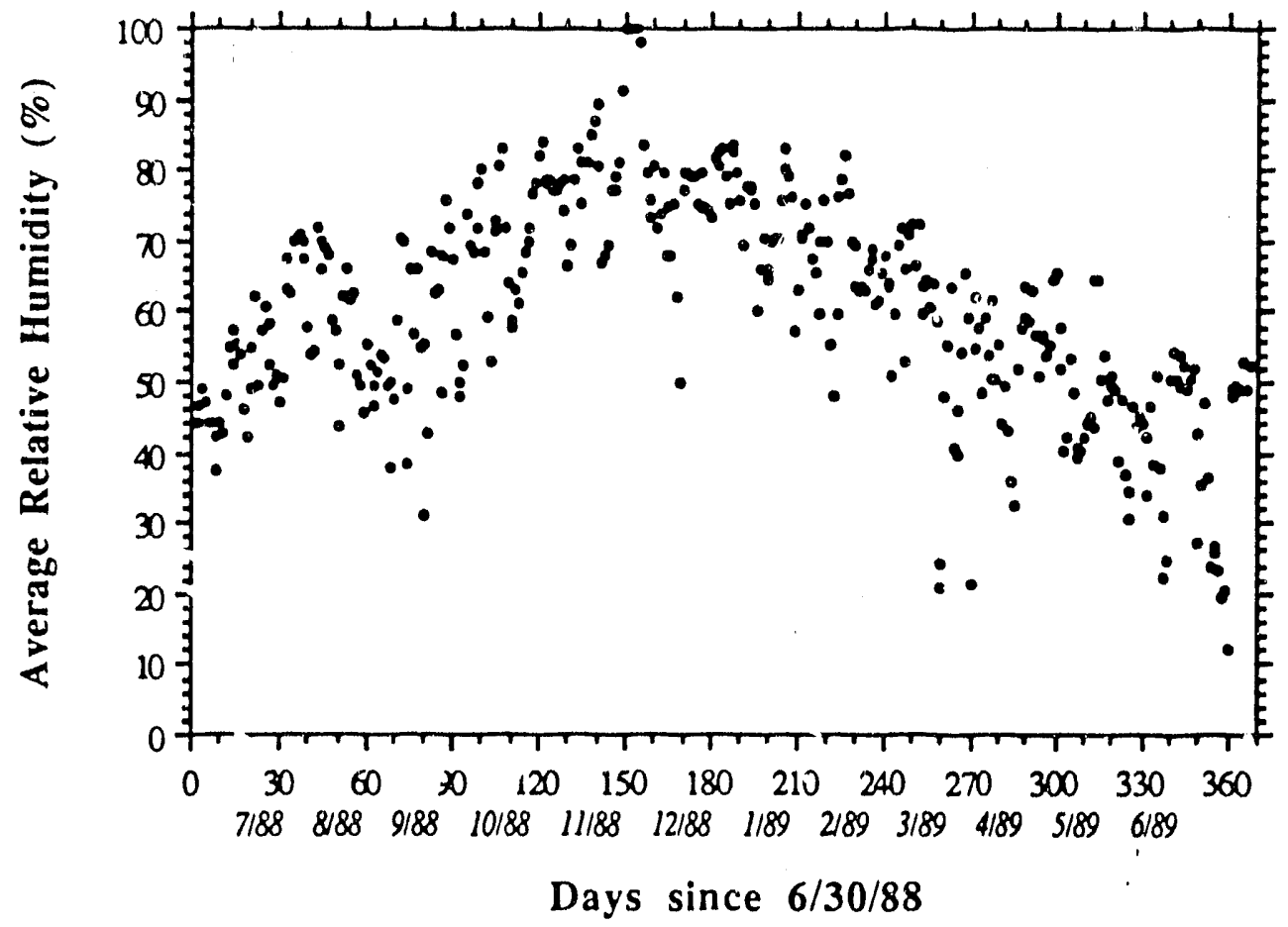

Figure $3.7 \mathrm{~b}$. Average daily relative humidity at Los Banos. 


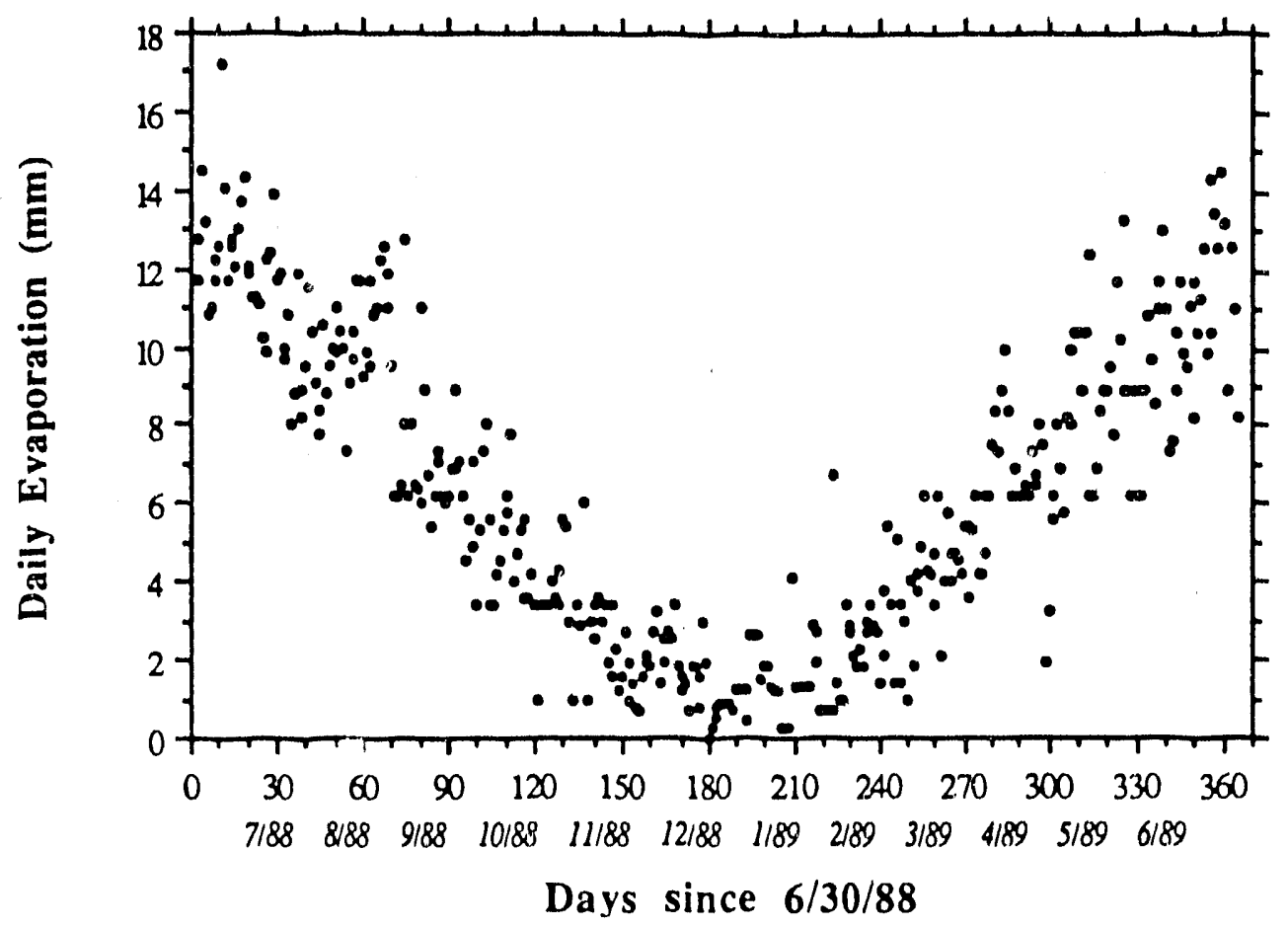

Figure 3.8a. Daily pan evaporation at Los Bano: Reservoir and Kesterson Reservoir (see text for details).

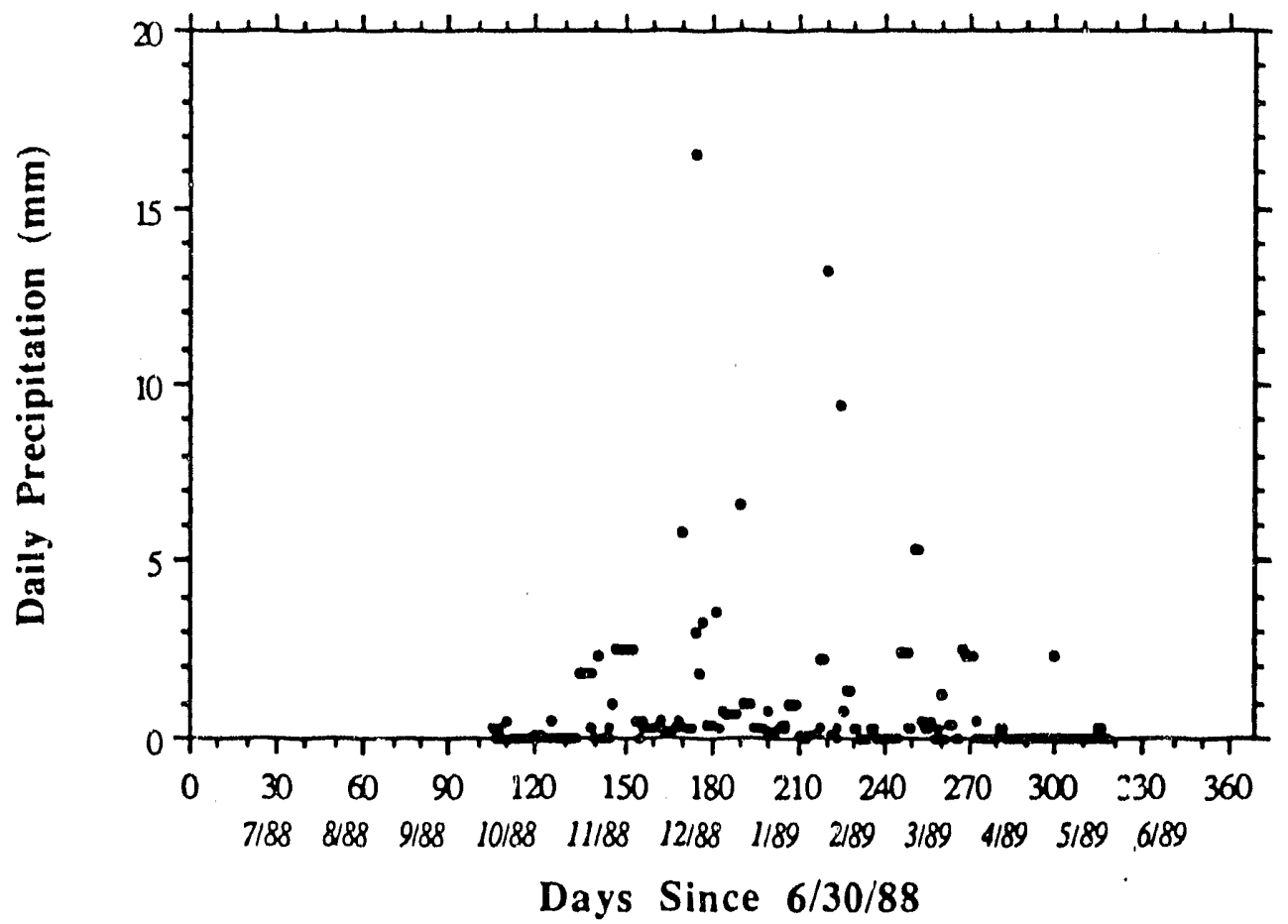

Figure 3.8b. Daily precipitation at Kesterson Reservoir. 
augered in 5 and $10 \mathrm{~cm}$ intervals and particle size analyses were performed; also, a Guelph Permeameter was used to determine saturated conductivities in the field. The particle-size distribution at those two sites is presented in Figure 3.9. Saturated conductivities in plot 8EP are shown in Figure 3.10. The lateral and vertical variabilities are apparent from these data. In addition to the near surface low permeability layer, the soil surface in most ponds is covered by a thin veneer of organic matter which is a remnant of shallow ponds. This organic matter, together with a salt crust sometimes up to $2 \mathrm{~cm}$ thick, is difficult to describe hydrogeologically and may have a unique effect on near surface moisture fluxes. High permeabilities measured near the soil surface of pond $8 \mathrm{EP}(0-20 \mathrm{~cm})$ correspond most likely to macropore and fracture flow. Fluctuations in the elevation of the ground water table at the two plots are presented in Figure 3.11.

\subsubsection{Measurement of Bare Soil Evaporation Rates}

\subsubsection{Important Aspects of Bare Soil Evaporation}

The physical process of water evaporation from soil has been studied for many decades; its effects on water and soil management practices have driven most of the research in this field, especially since the second quarter of this century. In 1939, Moore published a paper which described one of the first laboratory experiments designed to study the evaporation of water from a shallow water table. In 1948, Penman derived an expression for calculating potential evaporation rate $\left(E_{p}\right)$ based on a combination of an aerodynamic approach and an energy balance:

$$
E_{P}=\frac{\Delta}{\Delta+\gamma} R_{A}+\frac{\gamma}{\Delta+\gamma} f(u)\left(e_{A}-e_{D}\right)
$$

where $\Delta$ is the rate of saturation vapor pressure change with respect to air temperature $\left[\mathrm{ML}^{-1} \mathrm{~T}^{-2 \circ}{ }^{\circ}\right.$ eelsius $\left.{ }^{-1}\right], \gamma$ is the psychrometric constant $\left[\mathrm{ML}^{-1} \mathrm{~T}^{-2}{ }^{\circ} \mathrm{Celsius}^{-1}\right], \mathrm{RA}$ is the areal net radiation $\left[\mathrm{LT}^{-1}\right], \mathrm{f}(\mathrm{u})$ is a function of wind velocity $\mathrm{u}\left[\mathrm{L}^{2} \mathrm{TM}^{-1}\right]$, and $\mathrm{e}_{\mathrm{A}}$ and $\mathrm{e}_{\mathrm{D}}$ are saturation vapor pressures at air and dewpoint temperatures respectively $\left[\mathrm{ML}^{-1} \mathrm{~T}^{-2}\right]$. Since Penman, many researchers have derived various expressions describing potential evaporation; most of these expressions are able to predict potential cvaporation quite well. However, the evaporation of water from soils is more complex in that it depends not only on meteorological conditions but 


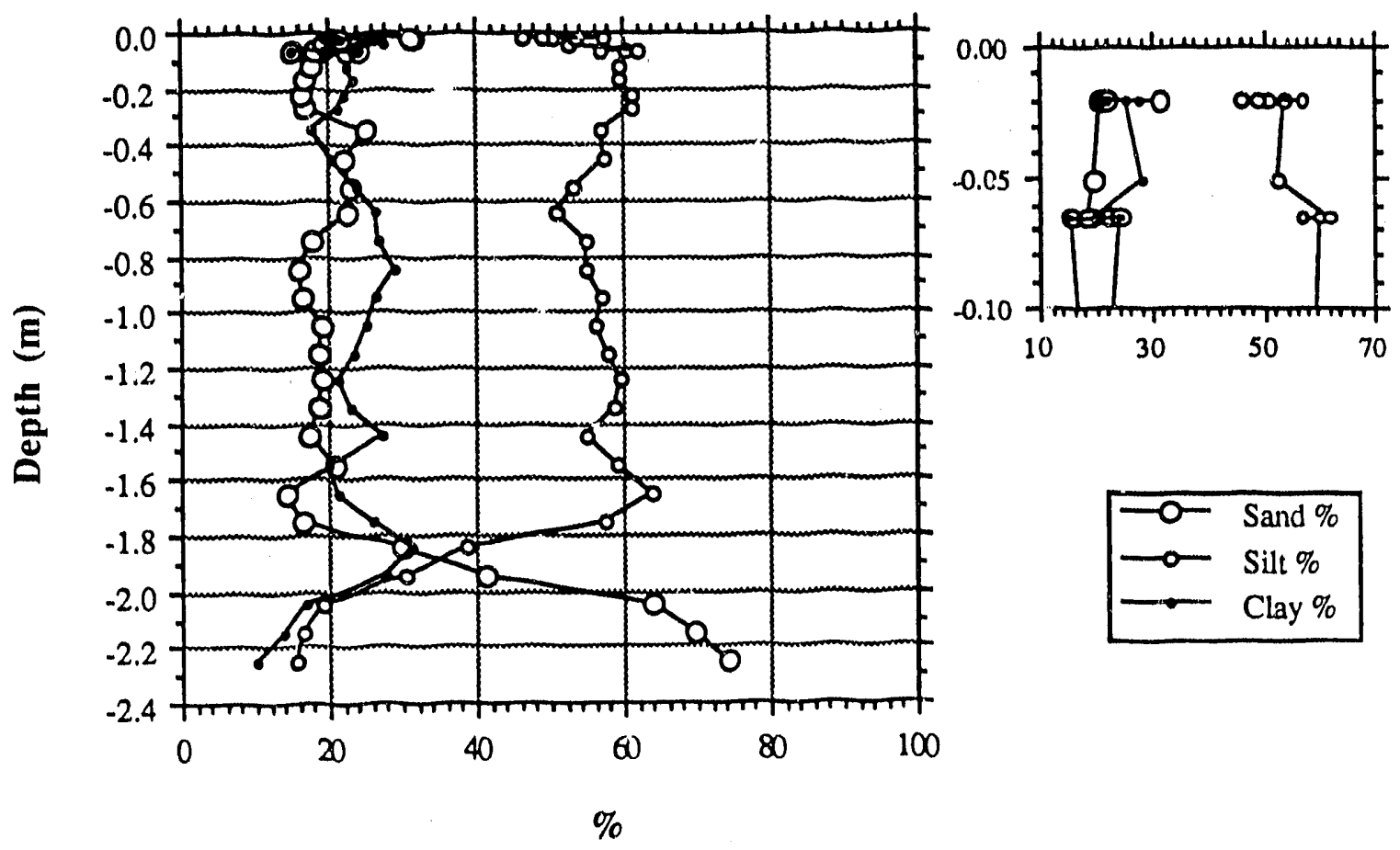

Figure 3.9a. Sand, silt and clay depth profiles in the vadose zone of plot 8EP. Close-up view shown in inset graph.

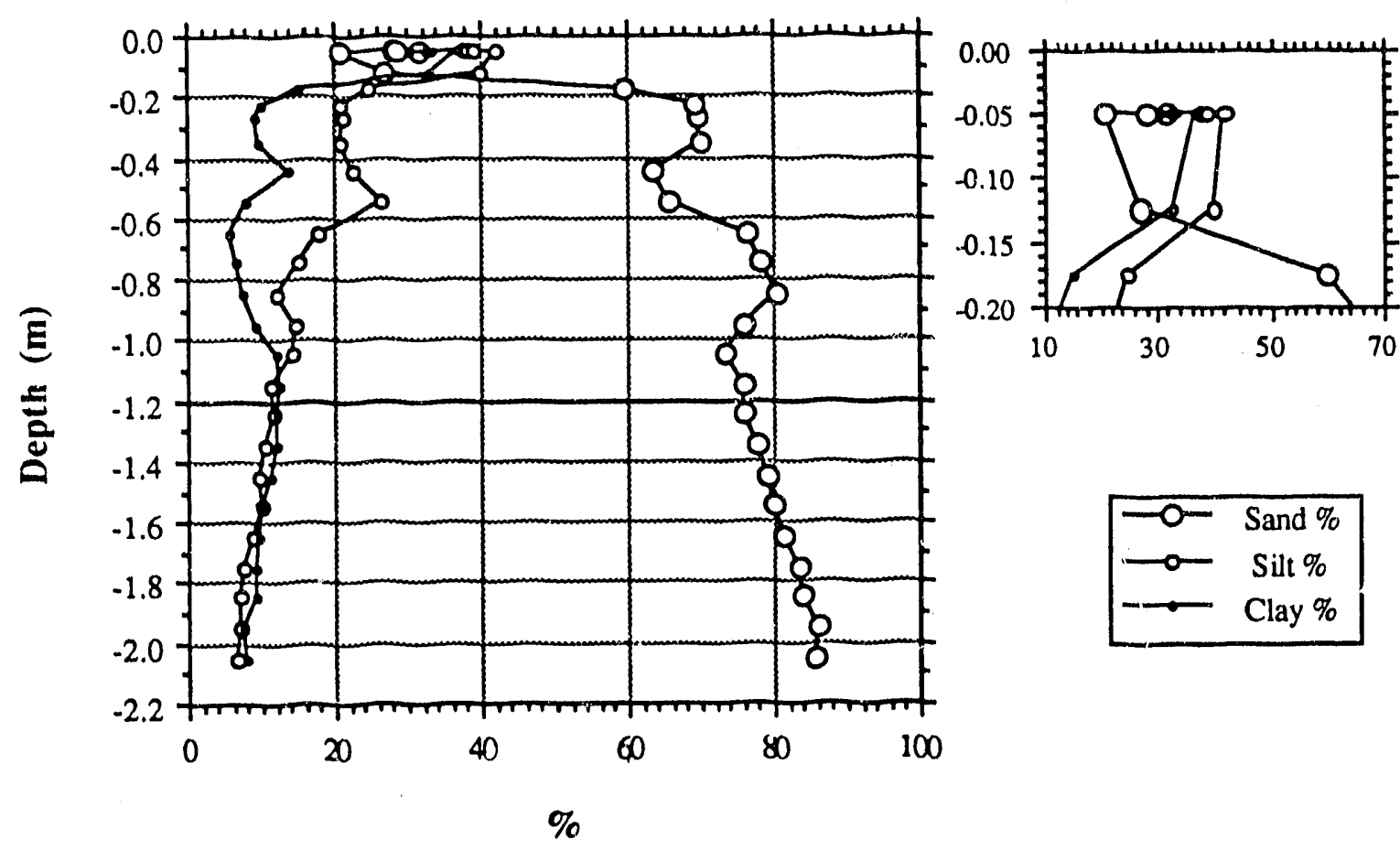

Figure 3.9b. Sand, silt, and clay depth profiles in the vadose zone of plot 9BE. Clcse-up view shown in inset graph. 


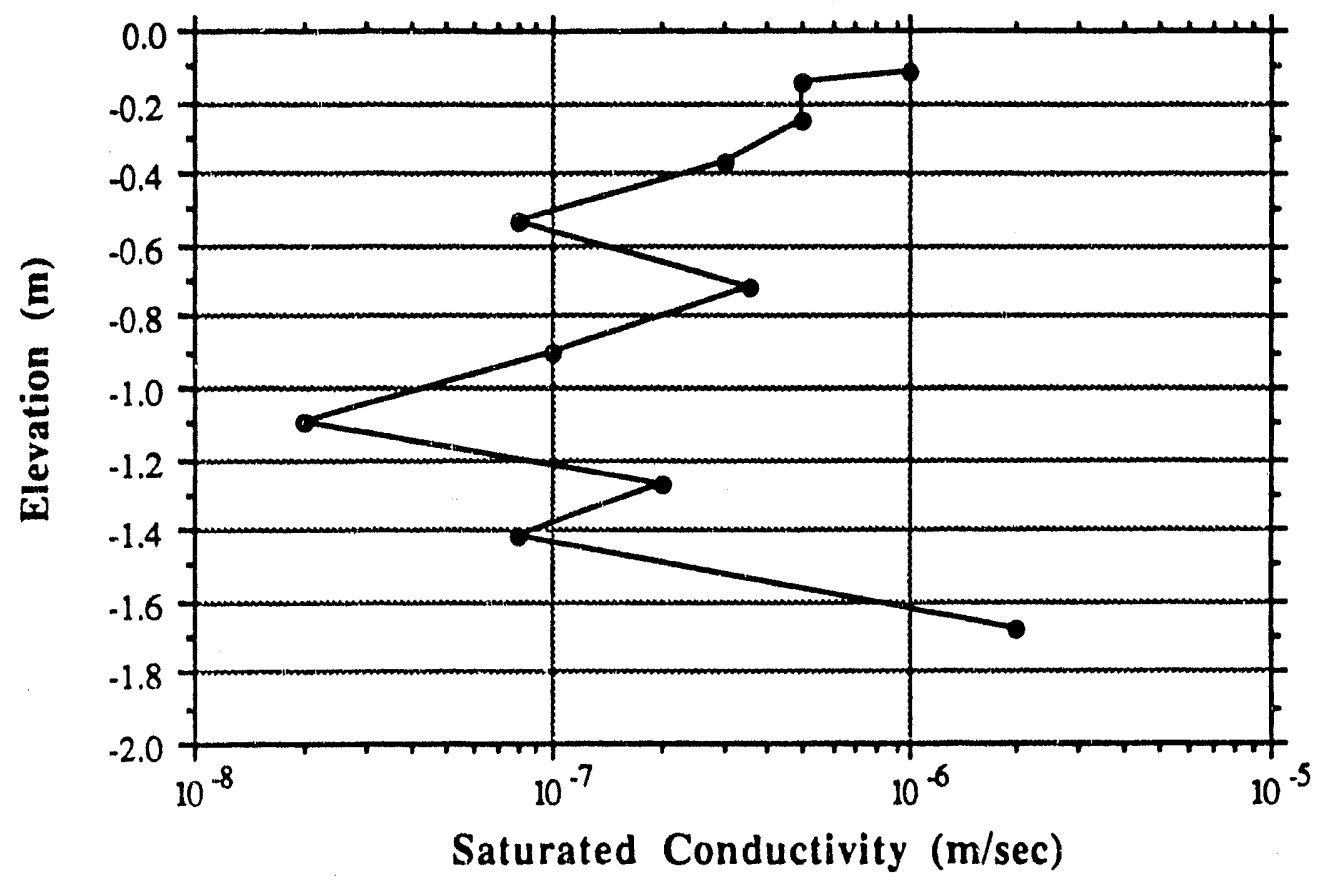

Figure 3.10. Saturated hydraulic conductivity in plot 8EP profile, as measured using a Guelph Permeameter.

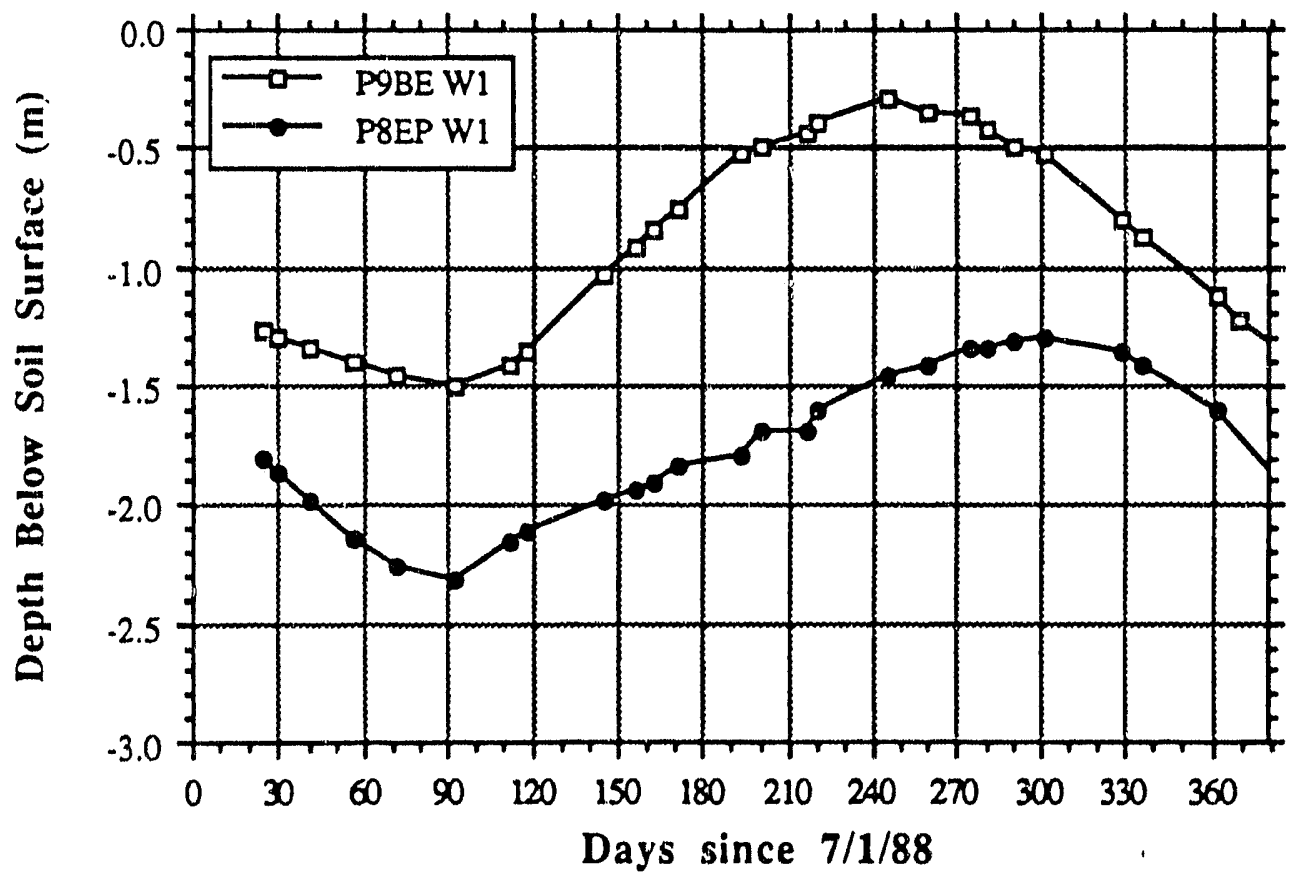

Figure 3.11. Depth to water table in two wells: P8EP W1 and P9BE W1. See text for locations of wells. 
also on soil properties and moisture content. The force which drives evaporation at the soil surface is the net solar radiation (Koorevar and others, 1983); drying of the soil surface creates an upward potential gradient. There are several factors which limit the magnitude of bare soil evaporation. In general, the bare soil evaporation rate will be equal to or less than the potential evaporation rate; the moisture content of soil at the surface as well as physical soil properties are limiting factors in this process. In addition, vapor flow close to the soil surface may become an important flow mechanism under extremely dry conditions (Bresler and others, 1982). While most experimental results have been successfully modelled without accounting for vapor flow, vapor diffusion is a process which should not be neglected. For example, Gardner and Fireman (1958) found that the evaporation rate from a sandy loam soil decreased from nearly $10 \mathrm{~mm} / \mathrm{day}$ to less than $0.5 \mathrm{~mm} / \mathrm{day}$ as a result of $a 6 \mathrm{~mm}$ thick sand mulch on the soil surface. It was concluded, based on modeling, that water moved through the mulch in the vapor phase. Vapor flow in the vaciose zone, under isothermal conditions, may be described by Fick's Law, modified in the following way:

$$
\mathrm{J}_{\mathrm{S}, \mathrm{v}}=-(1-\mathrm{S}) \mathrm{n} \tau_{\mathrm{a}} \mathrm{D}_{\mathrm{A}, \mathrm{v}} \frac{\partial \mathrm{C}_{\mathrm{s}, \mathrm{v}}}{\partial \mathrm{z}}
$$

where $J_{S, v}$ is a vapor mass flux per unit bulk area $\left[M T^{-1} L^{-2}\right], D_{A, v}$ is the diffusivity of water vapor in air $\left[\mathrm{L}^{2} \mathrm{~T}^{-1}\right]$, and $\frac{\partial \mathrm{C}_{S, v}}{\partial \mathrm{z}}$ is the soil gas phase vapor concentration gradient in direction $\mathrm{z}$ $\left[\mathrm{ML}^{-4}\right]$; in addition, the flux of Fick's Law is corrected for the limited gas-phase cross-sectional area due to the presence of solid grains ( $n$, porosity) and water $(0<S$, saturation, -1$)$, and for the gas-phase tortuosity of the path of diffusion ( $\tau_{\mathrm{a}}$, air-filled tortuosity factor, which decreases with increasing tortuosity).

While under field conditions there is no clear division, bare soil evaporation may be divided into two classes: drying of wetted soils and evaporation from a water table. The former process has been described by a great number of researchers. Even though a water table may be present relatively close to the soil surface, evaporation immediately following infiltration will not be very strongly affected by its presence and will depend mostly on external conditions and 
near-surface soil properties. This process has been studied mostly on short cores in the laboratory (e.g. Staple, 1969; Reynolds \& Walker, 1984). Under constant external conditions, three stages of soil drying have been observed (Hillel, 1980b). The initial stage is a constant rate stage during which the soil is still wet enough to transmit water at the same rate as potential evaporation. Therefore, during this stage, bare soil evaporation is weather-controlled. The length of this stage will depend on climatic conditions, i.e. on potential evaporation rate itself, and is usually in the range of a few hours to a few days after infiltration. The second, intermediate, stage is one in which the soil evaporation rate slowly declines; the rate is dependent on how fast the soil can transmit water to the soil surface. This stage has been called the soil-controlled stage. Depending on the amount of infiltration and soil properties, this stage may last for several days to weeks. The third stage is reached when the soil is too dry for any substantial liquid conduction and subsurface vapor diffusion dominates the evaporative flux. Hillel (1975) noted that in a real system, in which external conditions vary diumally and seasonally, these three stages may be difficult to distinguish. In addition, in field conditions with a shallow water table, the third stage will rarely be reached since there will be a certain upward flux of water. Figure 3.12 shows the soil water fluxes on a very small scale, as observed by Jackson and others (1973), after infiltration of $10 \mathrm{~cm}$ of water into a loam soil. It is apparent that the flux varies not only in magnitude but also in direction. Therefore, the establishment of distinct stages of drying is unilikcly. Since the process of soil drying is transient and highly dependent on several variables which are in turn functions of water potential, analytical solutions can be derived for only the simplest of systems and have usually depended on the separate treatment of drying stages. Numerical simulations of this transient system have been performed by, among others, Staple $(1970,1971)$, Hillel $(1975,1976)$, and Reynolds \& Walker (1984).

Evaporation of water from shallow water tables has also been studied extensively (Veihmeyer and Brooks, 1954; Gardner, 1958; Gardner and Fireman, 1958; Hadas and Hillel, 1968, 1972; Ripple and others, 1972; Gardner, 1973; Hillel, 1975). Most of these and other such research has been focused on laboratory measurements of steady-state evaporation under gen- 
erally non-saline conditions. The expected conclusion of such research is that bare soil evaporation decreases with the depth to water table as well as with the increasing coarseness of the sediment. The process of water evaporation from a shallow water table, in a homogeneous system, is more easily described analytically, especially when the systom is brought to steady state in a controlled laboratory environment. An expression was derived by Gardner (1958) for a homogeneous column of soil with a shallow water table:

$$
E_{\max }=\frac{A a}{d^{n}}
$$

where $E_{\max }$ is the maximum evaporation rate from the soil, $d$ is the depth to the water table, $A$ is a constant dependent on $\mathrm{n}$, and $\mathrm{n}$ and a are constants from the following equation:

$$
K(\Psi)=a\left(\Psi^{n}+b\right)^{-1}
$$

where $a, b$, and $n$ are empirically derived constants for a given material. The solution of this equation gives results presented in Figure 3.13. Solutions match results from laboratory experiments with fairly good success, but they are dependent on the homogeneity of the system. The solution of flow through a heterogeneous system lends itself more to a numerical approach. Such an approach has been taken by a number of researchers (Hillel, 1975; Feddes and others, 1975; Passerat de Sillans and others, 1989). Passerat de Sillans and others used a coupled heat and water transport numerical code which took into account heat and moisture fluxes estimated from meterological data. The hydraulic and thermal properties of the surface layer of the soil were free parameters used to fit the results of simulation to the first two data points (two days). The model was then run to simulate the evaporation rate on the following four days. As seen in Figure 3.14, despite the very short run of this experiment, the results are only fair and it appears that the model would substantially overestimate true rates in the future.

More detailed studies of heterogeneous systems have shown the relative impact of soil properties on evaporation rates to increase toward the surface (e.g. Hadas and Hillel, 1972). That is, a change in soil properties near the soil surface will have a greater effect on soil evaporation rates than a similar change at depth. Hysteresis has been shown to affect evaporation rates during early stages after infiltuation (Bresler and others, 1969); however, in field situations, the spatial 


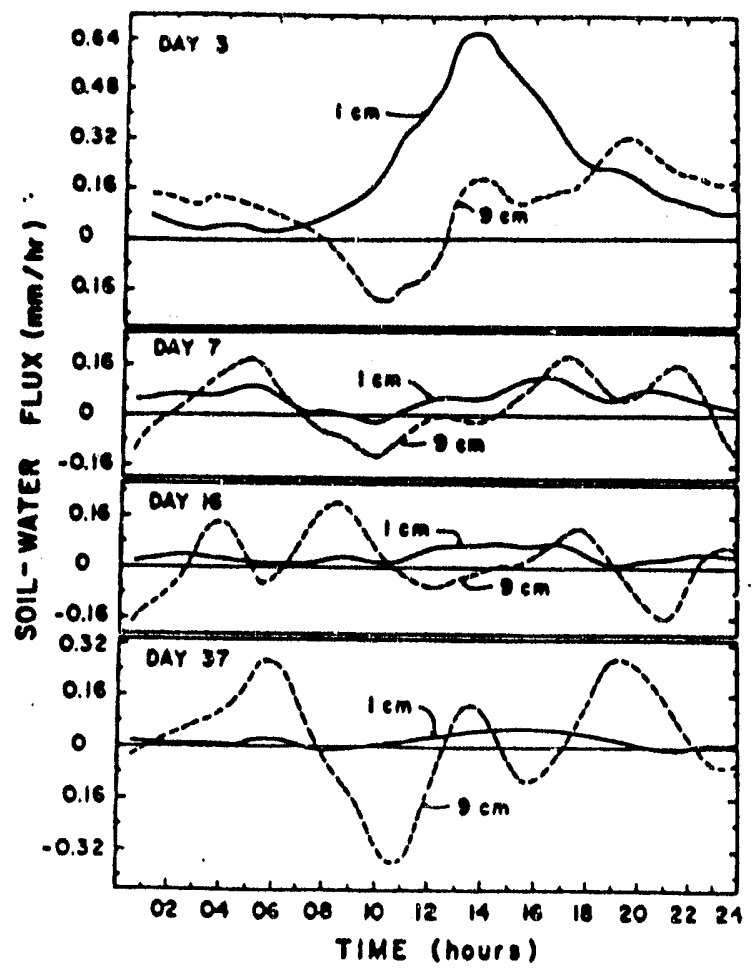

Figure 3.12. Diurnal fluctuations in soil water flux at two depths in a soil, $3,7,16$, and 37 days after irrigation (from Jackson and others, 1973).

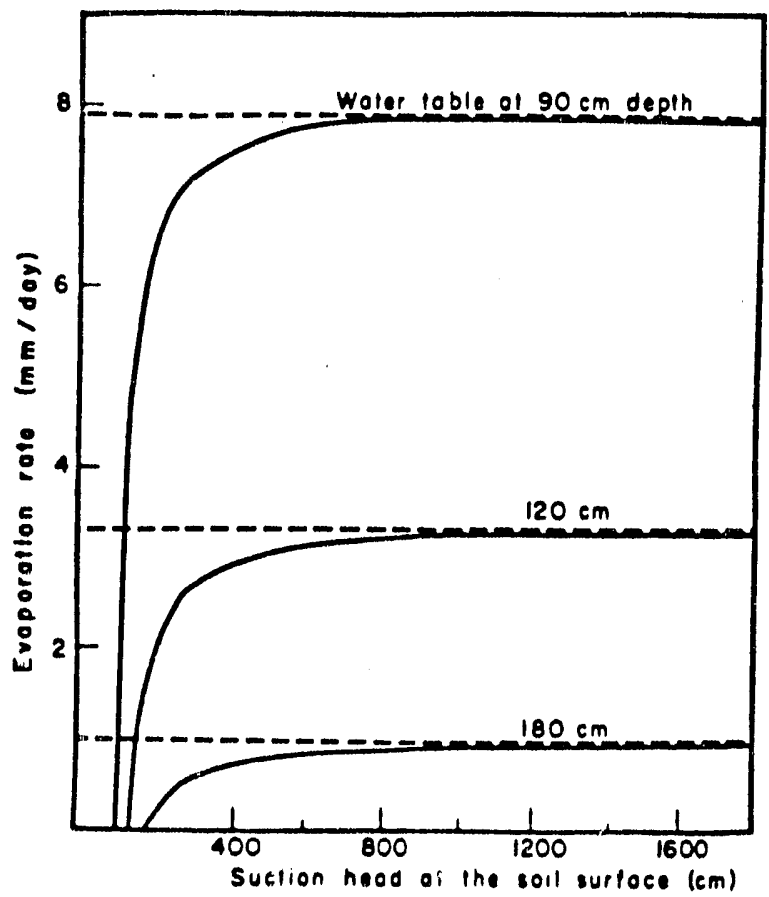

Figure 3.13. Dependence of bare soil evaporation rate on external conditions and the depth to the water table. The soil used in this example is a fine sandy loam (from Hillel, 1980b). 
variability of soil properties will usually be greater than the variation due to hysteresis effects. An experiment involving infiltration and evaporation has been modelled using the numerical model TRUST, taking into account only the wetting curve; the results of these simulations show that, at least in the given system, hysteresis effects are minor.

While it is known that the presence of dissolved species in water tends to decrease the evaporation rate due to lowering of the saturation vapor pressure above the water surface, there are limited studies of this effect on saline water bodies and even fewer studies of this effect on barc suil evaporation. Salhotra and others (1985) summarized three sets of data (Figure 3.15) which suggest that salinity (here presented as water density) has a significant effect on evaporation rate. Qayyum and Kemper (1961) studied the effect of mixing $\mathrm{NaCl}$ and $\mathrm{CaCl}_{2}$ into the top $10 \mathrm{~cm}$ of a $29 \mathrm{~cm}$ column on bare soil evaporation rates. They found that a mass concentration of $1.0 \%$ or more of $\mathrm{NaCl}$ tended to lower moisture loss from the columns, but the salt distribution in this experiment does not reflect natural conditions since the soil was free of salt in the rest of the profile and thus these results do not apply in general. Finally, the gradient of salt concentrations near the soil surface is usually very steep (see Section 3.3.4.5) and may itself drive vapor flow. This aspect of vapor flow is not within the scope of this study and will not be further considered.

\subsubsection{Methods for Measuring Bare Soil 'Evaporation}

In laboratory experiments, the measurement of a bare soil evaporation rate is straightforward; based on the known rate of water inflow into the system and on changes in the mass of the soil column, such a rate may be continuously and quite accurately monitored. In the field, however, such a measurement is more difficult and subject to greater error than the laboratory measurement. In general, four schemes are available: (1) micrometeorological methods, which involve the calculation of a rate based on measurements of several parameters and using one of a number of available equations (Hillel, 1980b); (2) remote sensing, where evaporation rates are estimated based on radiative and reflective properties of the soil; (3) water balance methods, which require the measurement of soil water flux at a given depth and the changes in water content between that depth and the soil surface; and (4) lysimetric methods (van Bavel, 1961; Black 


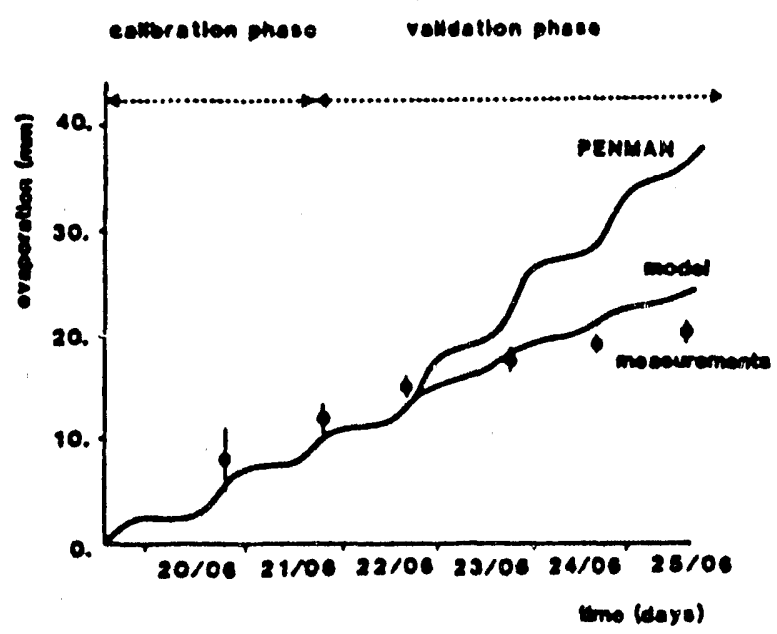

Figure 3.14. Measured and calculated cumulative evaporaticn based on field data and numerical modeling, respectively. Surface element properties were adjusted to fit the result of modeling to the first two data points (from Passerat de Sillans and others, 1989).

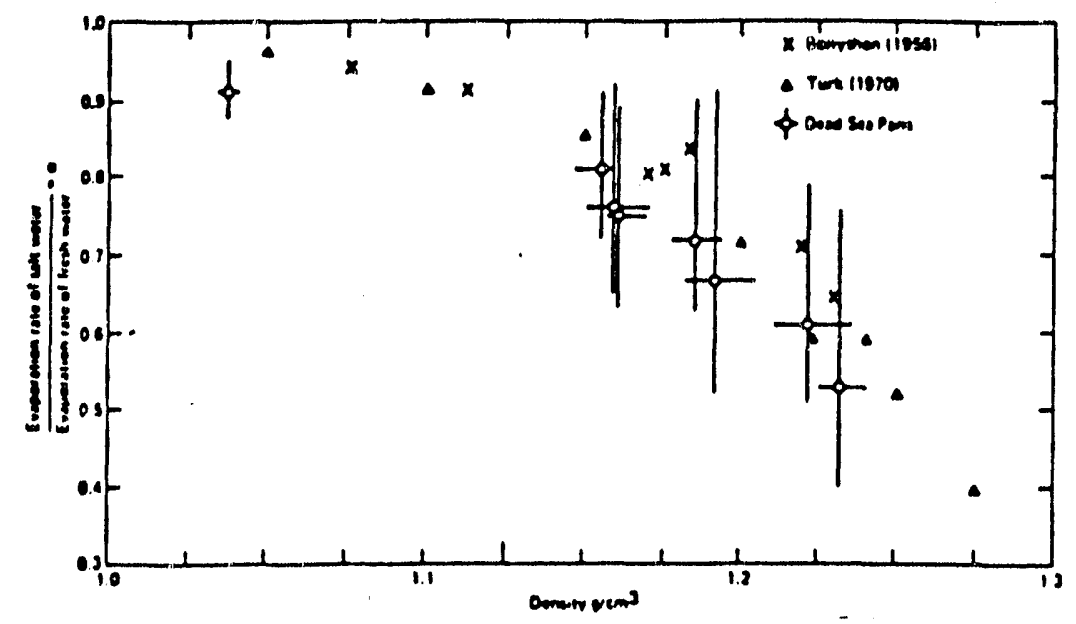

Figure 3.15. Dependence of water evaporation rate on water salinity (here, in terms of water density) (from Salhotra and others, 1985). 
and others, 1969; Boast, 1986). Lysimetric methods involve the direct gravimetric measurement of water loss from hydrologically, but not thermally, isolated bodies of soil or sediment. Since such isolation causes changes in boundary conditions, most significantly lower boundary conditions, there is always concem as to whether the rate measured is the same as it would be from a non-isolated body. Additional error may come from disturbance of the soil during construction. To combat these obstacles, large lysimeters have been built; these structures are expensive to build, essentially fixed in space, and must be weighed by a high capacity balance, dedicated to this purpose (Boast, 1986). Recently, Boast and Robertson (1982) suggested a more convenient approach through the use of "micro-lysimeters." The concept is to use small, easily installed, removed, and weighed lysimeters for only a short period of time, during which the boundary conditions are not significantly altered due to the isolation of the soil, that is, only as long as the measured evaporation rate does not deviate from the true evaporation rate. This approach was the one used in the field at Kesterson Reservoir from July 1988 through June 1989. The microlysimeters, which Boast and Robertson tested against large lysimeters, were brass cylinders with an inside diameter of $76 \mathrm{~mm}, 3 \mathrm{~mm}$ thick walls, and a length of $76 \mathrm{~mm}$. The walls were bevelled at the bottom to $0.5 \mathrm{~mm}$ in order to facilitate insertion into soil (Figure 3.16). The bottom of the device was sealed off with a rubber stopper and the entire lysimeter was put into a plastic bag. The lysimeters were placed in a constant evaporativity chamber. Based on several runs, Boast and Robertson concluded that under a variety of external conditions the rates measured by the 76 $\mathrm{mm}$ lysimeters did not vary from longer $(146 \mathrm{~mm})$ lysimeters until after two days and were less by no more than $10 \%$ after $3 .:$ days (Figure 3.17 ).

In this study, microlysimeters v'ere made out of white PVC, in order to minimize thermal differences between the soil and the insicic of the tube. Each cylinder has an inside diameter of approximately $5.1 \mathrm{~cm}(2 \mathrm{in})$, a $4 \mathrm{~mm}$ (1/6 in) thick wall, and is $10 \mathrm{~cm}$ long. The bottom 1.5 to 2.0 $\mathrm{cm}$ on the outside of the tube was bevelled to make the edge sharp. Two:" 's of eight cylinders were used, each set dedicated to one of the two plots. Except for the first two measurements $(7 / 1 / 88,7 / 29 / 88)$ when three to five microlysimeters were used per plot, all other measurements 

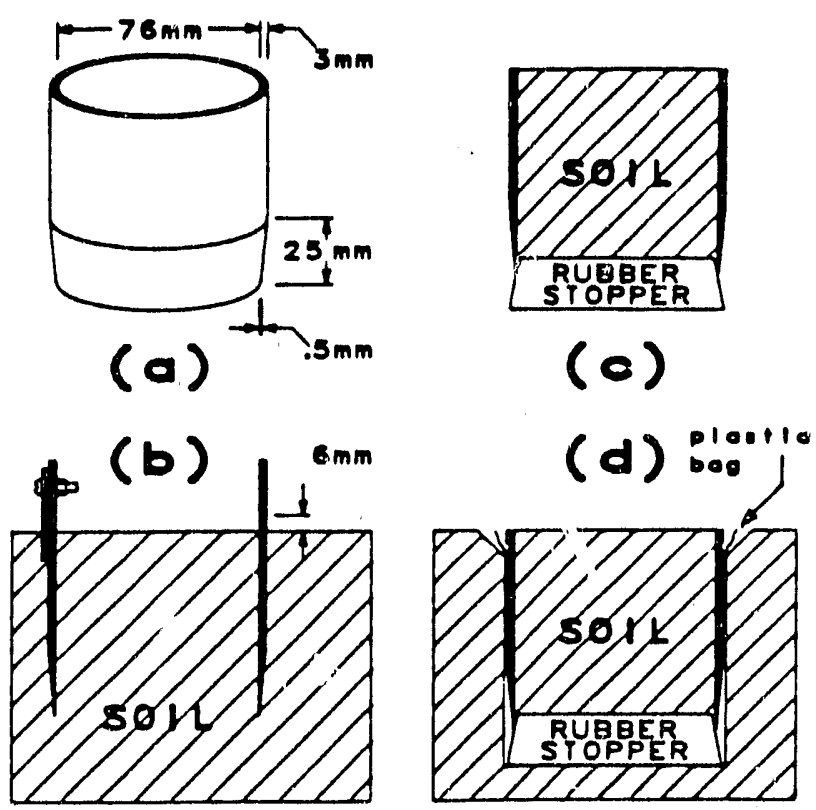

Figure 3.16. Design and procedure for the use of a microlysimeter in Boast and Robertson (1982): (a) cylinder design, (b) cylinder pushed into soil, (c) cylinder removed and capped on the bottom prior to weighing, and (d) microlysimeter after being placed back into soil.

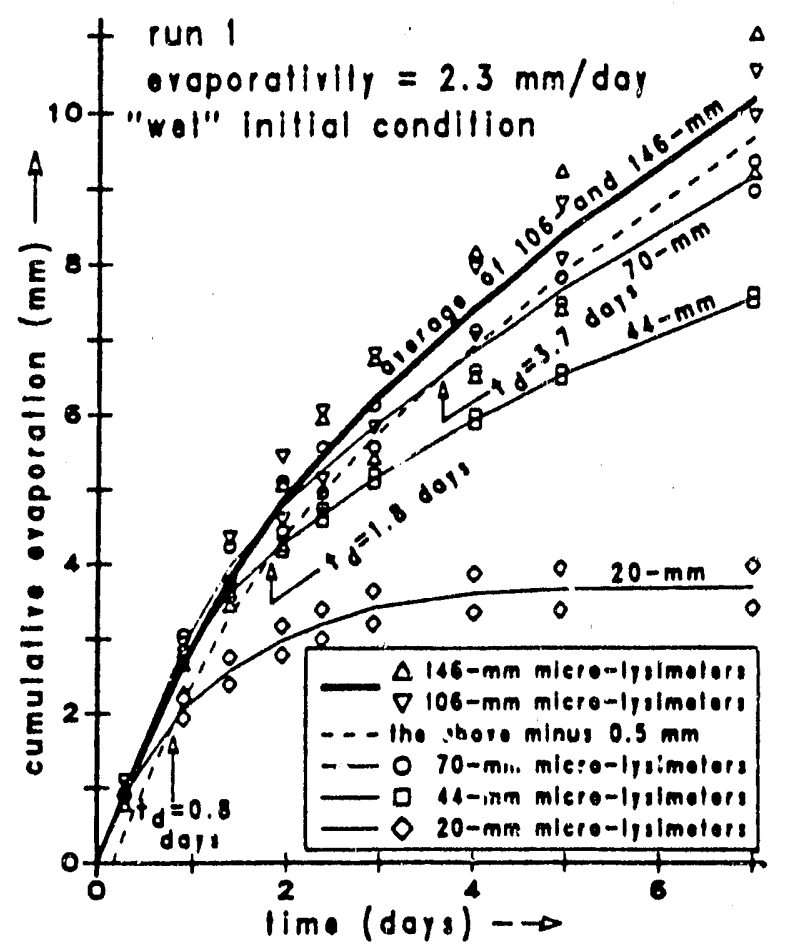

Figure 3.17. Dependence of cumulative evaporation from a microlysimeter on time after soil isolation and cylinder length. $\mathfrak{t}_{d}$ is the time when the cumulative evaporation. deviates by $0.5 \mathrm{~mm}$ from actual evaporation (from Boast and Robertson, 1982). 
were made using the complete sets. The cylinders were inserted into the soil either by hand (if the soil was moist enough) or by hammering. They were then removed with a set of pliers in such a way as to break off the soil at the bottom of the cylinder from the soil immediately below it. Any soil which was hanging out beyond the bottom of the cylinder was shaved off and the bottom of the cylinder was sealed with a plastic end cap. The end cap was secured to the tube using PVC tape, which also prevented moisture loss through the bottorn end. Any soil on the side of the tube was cleaned off. The tubes, with the end cap, PVC tape, and soil were then weighed using a triple beam, 2610 gram capacity Ohaus balance, with a wind shield constructed of wood and plexiglass. After being weighed, the cylinders were placed in unsealed plastic bags and inserted back in the soil so that the tops of the tubes were level with the surrounding soil. After 24 hours, the tubes were removed from the bags, their outside cleaned off, and they were weighed again. Since all boundaries of the tubes were sealed off, except for the top, the change in mass could be due only to loss of water through evaporation or gain of water due to precipitation. However, since this study focused on evaporation losses, evaporation rates were measured only during the dry months, and no rain fell during any of the measurements. The mass of water lost was converted to a volume (assuming density of evaporating water equal to $1.0 \mathrm{~g} \mathrm{~cm}^{-3}$ ) and divided by the crosssectional area of the microlysimeter $\left(\approx 20.26 \mathrm{~cm}^{2}\right)$. The result is equivalent to a loss of water column; similarly, the flux may be expressed as mass per unit area.

These measurements were made approximately every four weeks, from July 1st until October 25th, 1988, and again from March 17th to June 26th, 1989, witi varying frequency. Rates were not measured during the rainy months for three reasons: (1) since during a rainfall event, water would be entering the microlysimeter, it would be necessiar' to know the exact mass of water infiltrating into each cylinder, (2) evaporation of u'ater from a soil is quite rapid immediately following a rainfall event and drops within the next day or so; therefore, a rate measured over a 24 hour period would be a mean value for a range of rates; (3) during a rainfall event of more than a few millimeters, the hydrologic conditions in the tube may become deviant from the surrounding soil due to the presence of a lower boundary at $10 \mathrm{~cm}$. Results of the measurements 
are described in the following section.

\subsubsection{Bare Soil Evaporation Rates in Plots 8EP and 9BE: Field Data and Analysis}

Bare soil evaporation rates measured in the two plots are presented in Figure 3.18a and $3.18 \mathrm{~b}$, for plot $8 \mathrm{EP}$ and $9 \mathrm{BE}$, respectively. The error bars in these two diagrams denote one standard deviation on each side of the mean value. The digits in parentheses indicate the number of data points included in the given mean value. With a few exceptions, eight individual microlysimeters were used throughout the study period in each plot. The measurement on $3 / 17 / 89$ (day 263 ) in plot $9 \mathrm{BE}$ was limited to six cores due to the inadvertent spillage of the other two cores. Overall, values measured in both plots ranged between $0.1 \mathrm{~mm} / \mathrm{day}$ and $1.5 \mathrm{~m} / \mathrm{m} / \mathrm{day}$. This range is substantially lower than expected as based on other studies; however, this was not perceived during the fall season, since the water table in both plots was at a depth of more than 1.5 meters. It was at that time believed that bare soil evaporation rates were being controlled by the soil profile. This conclusion was supported by the apparent correlation between bare soil evaporation rates and the depth to the water table (see Figure 3.11). In general, this trend is observed when the soil profile controls the evaporation rate (cf. Eqn. (3.3)). Between July 1 st and October 25 th, $1 \cap 88$, as the water table dropped, measured bare soil evaporation rates dropped from a mean of $0.80 \mathrm{~mm} /$ day to a mean of $0.13 \mathrm{~mm} / \mathrm{day}$ in plot $8 \mathrm{EP}$ and from a mean of $0.92 \mathrm{~mm} / \mathrm{day}$ to 0.32 $\mathrm{mm} / \mathrm{day}$ in plot 9BE. As the water table dropped, the moisture conterit of the soil profile declined, which is apparent from potential distributions, as measured using tensiometers (Figure 3.19). At that time, it was believed that since the evaporation rate was mostly a function of the depth to the water table, intermediate rates would decline smoothly between measured points and the measured values could be interpreted as mean rates for the two weeks immediately preceding and two weeks immediately following the date of measurement. The variability of masured values was believed to be most likely related to the spatial variability of soil properties in the profilc. A more detail description of the data is presented in Table 3.5, and includes the calculated coefficients of variation for each set of measurements. These range from $7.7 \%$ to $30.1 \%$ for plot $8 \mathrm{EP}$ and from $7.0 \%$ to $31.3 \%$ for plot $9 \mathrm{BE}$ for all sets of measurements. 


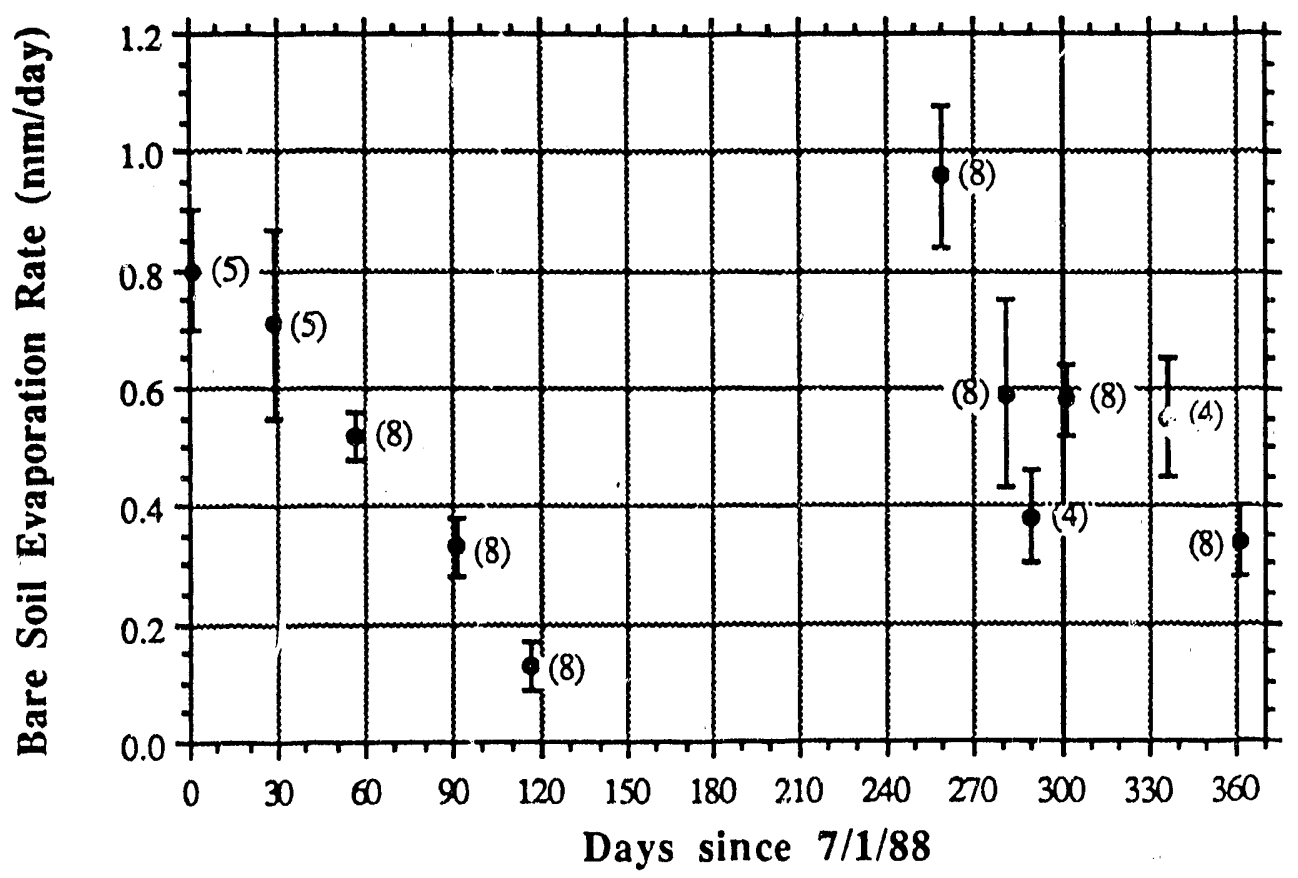

Figure 3.18a. Mean field measured bare soil evaporation rates at plot 8EP; error bars represent one standard deviation on each side of the mean. Number of samples in parentheses.

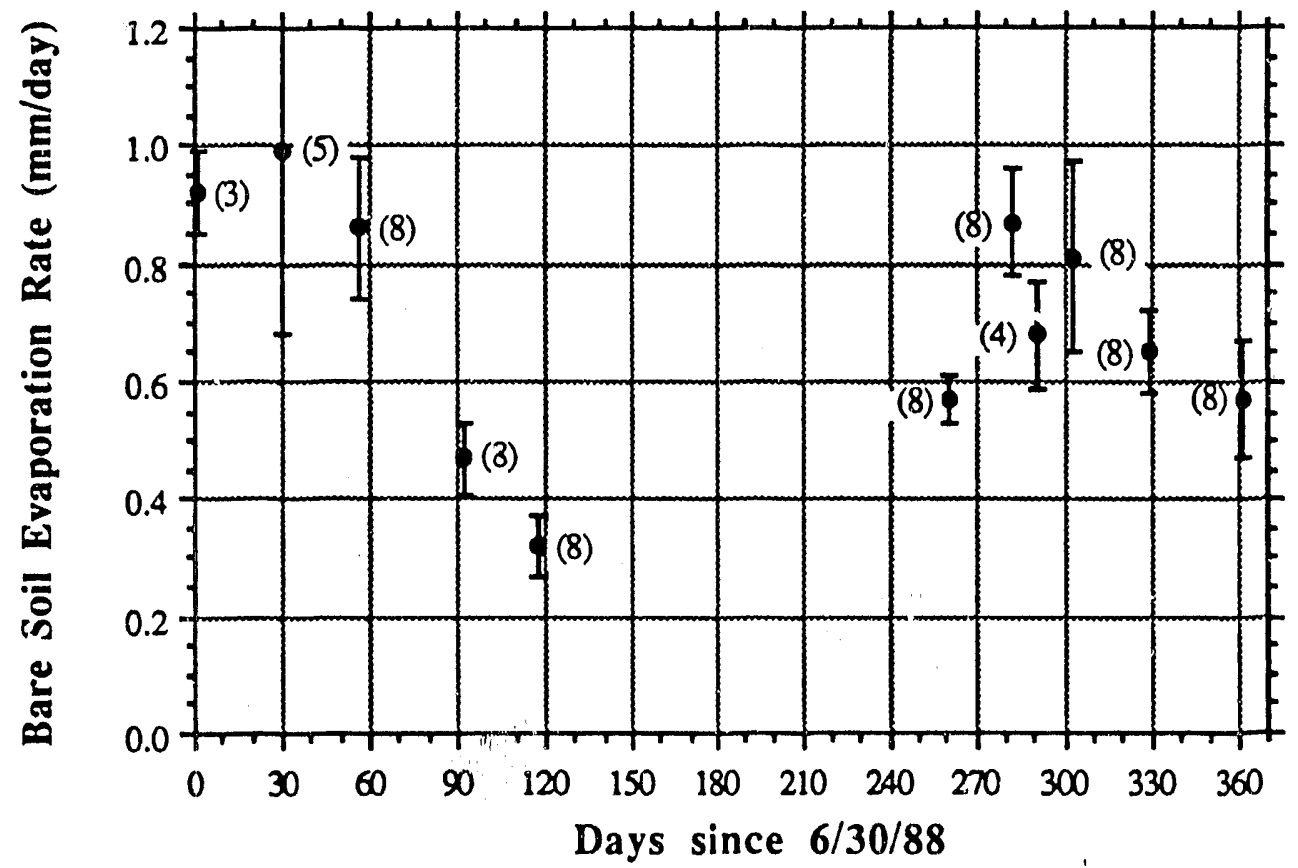

Figure 3.18b. Mean field measured bare soil evapnration rates at plot 9BE; error bars represent one standard deviation on each side of the mean. Number of samples in parentheses. 


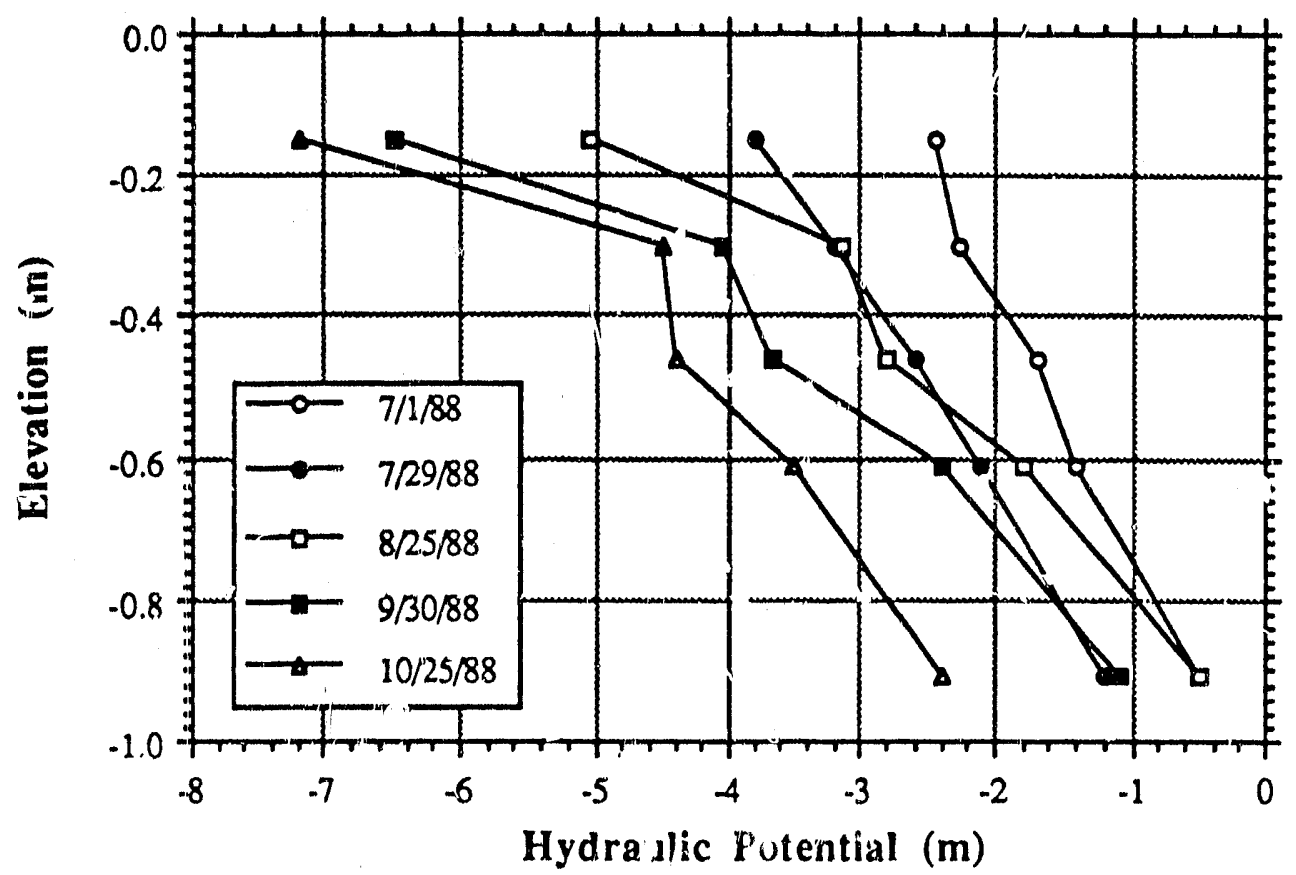

Figure 3.19a. Hydraulic potertial distribution changes in soil profile of plot 8EP during the summer an' 'Il of 1988.

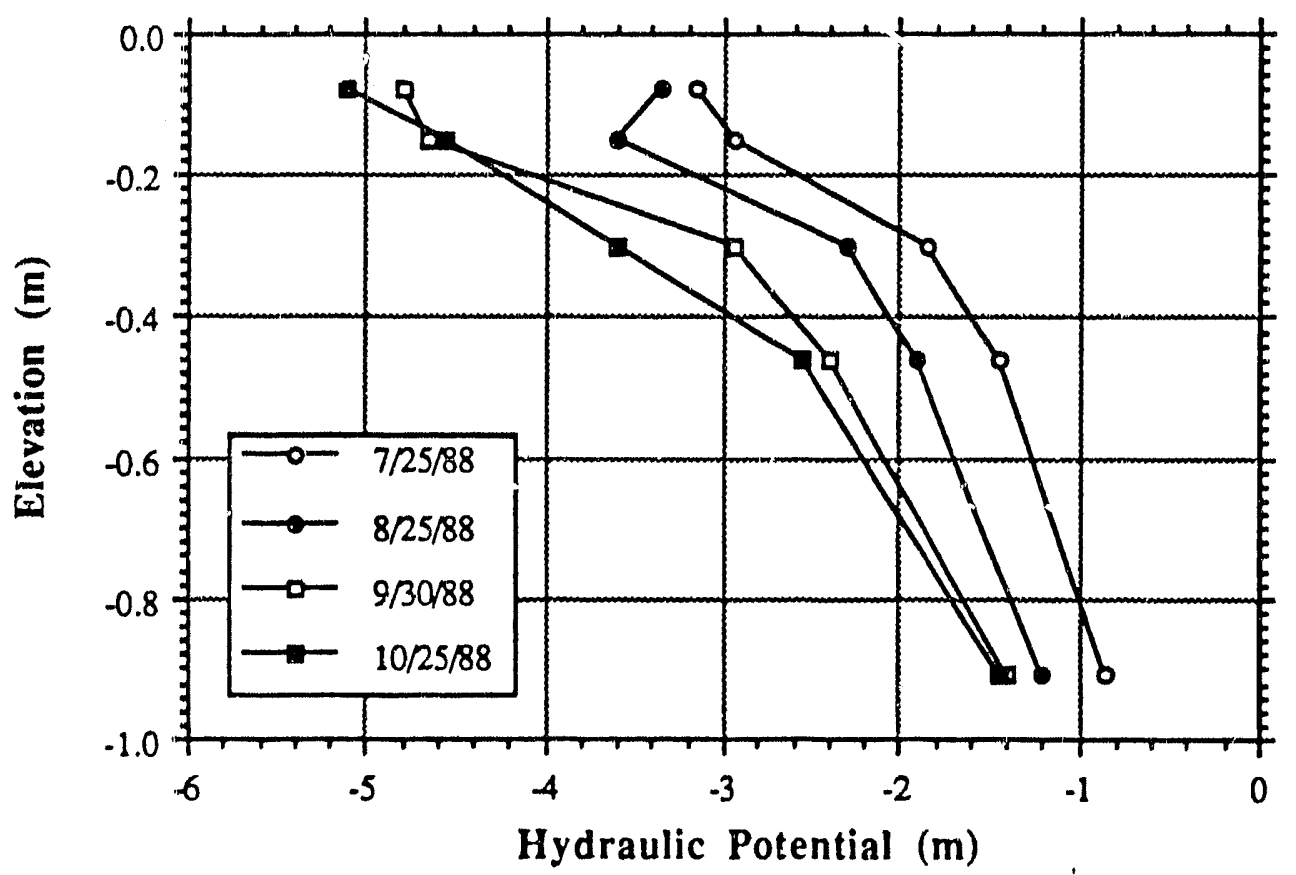

Figure 3.19b. Hydraulic potential distribution changes in soil profile of plot 9BE during the fall and summer of 1988 . 


\begin{tabular}{|c|c|c|c|c|}
\hline 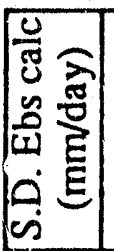 & $\frac{0}{0}$ & $\stackrel{ষ}{8}$ & $\frac{c 7}{0}$ & $\stackrel{n}{0}$ \\
\hline 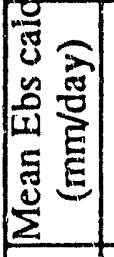 & ஊั & $\overline{0}$ & $\tilde{\pi}$ & $\stackrel{n}{0}$ \\
\hline 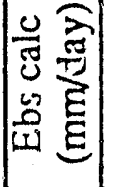 & 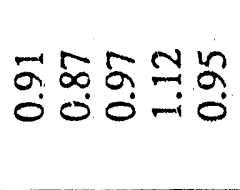 & 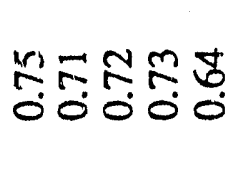 & 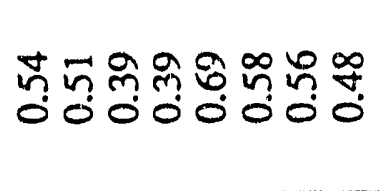 & 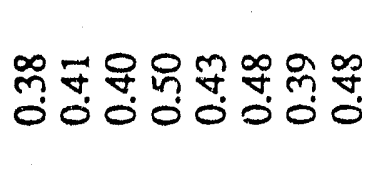 \\
\hline 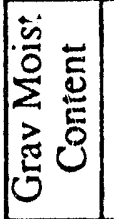 & 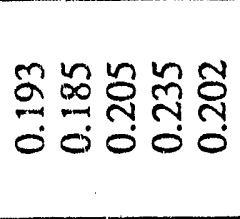 & $\begin{array}{l}\infty \\
0 \\
0 \\
0 \\
0\end{array}$ & 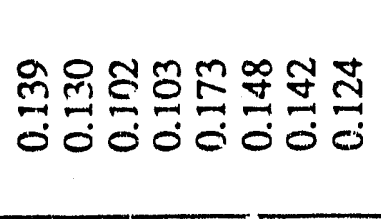 & 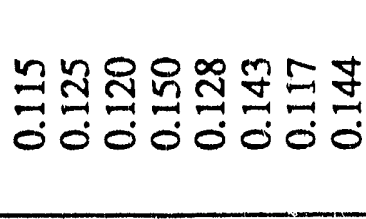 \\
\hline 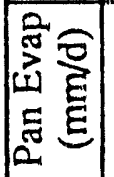 & $\stackrel{N}{N}$ & $\Xi$ & $\ddot{\dot{O}}$ & a) \\
\hline$\sum_{0}^{0}$ & $\stackrel{n}{n}$ & กู่ & $\stackrel{5}{2}$ & $\stackrel{\sim}{n}$ \\
\hline 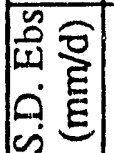 & $\frac{0}{0}$ & $\frac{1}{0}$ & 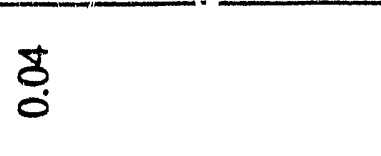 & @o \\
\hline 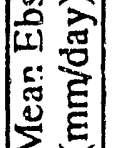 & $\stackrel{\infty}{\circ}$ & $\ddot{0}$ & $\tilde{n}$ & $\tilde{m}_{0}^{m}$ \\
\hline 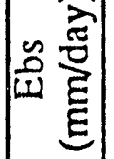 & 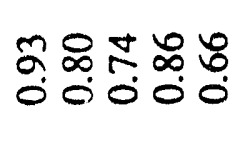 & $\begin{array}{l}m \\
\infty \\
0 \\
0\end{array}$ & 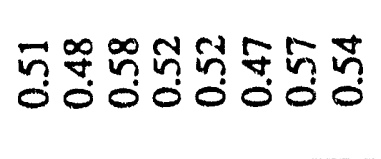 & ñ ตై \\
\hline$\overbrace{\tilde{n}}^{\infty}$ & - & શิ & in & $\vec{a}$ \\
\hline 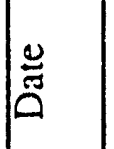 & $\stackrel{\infty}{\stackrel{\infty}{\rightleftharpoons}}$ & 究 & $\frac{\infty}{\infty}$ & 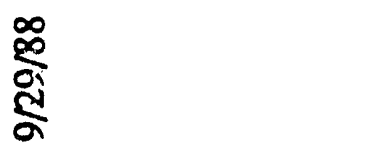 \\
\hline
\end{tabular}




\begin{tabular}{|c|c|c|c|}
\hline 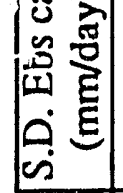 & $\ddot{\circ}$ & 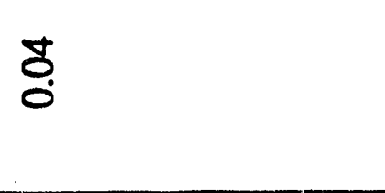 & $\stackrel{2}{0}$ \\
\hline 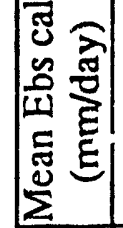 & $\frac{n}{0}$ & ஜุ & ț \\
\hline 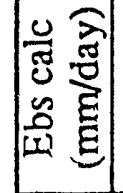 & 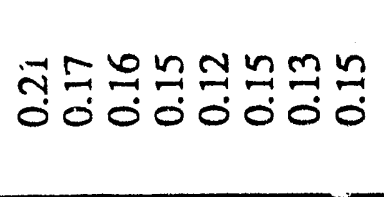 & 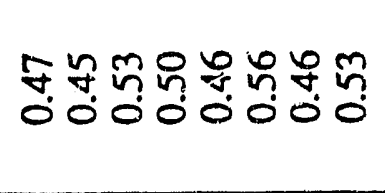 & 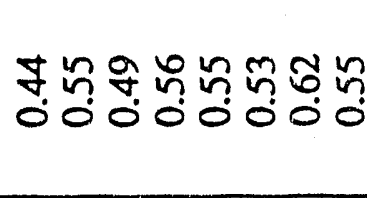 \\
\hline 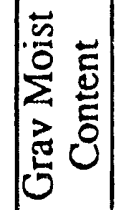 & 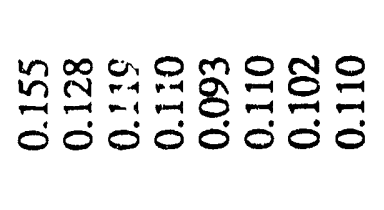 & 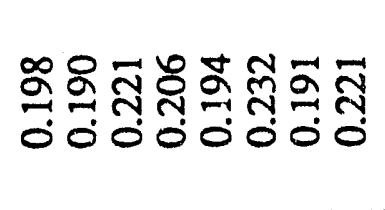 & 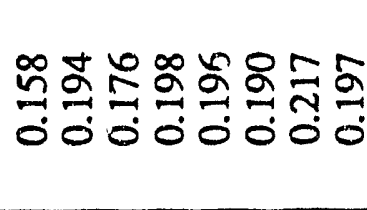 \\
\hline 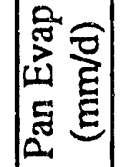 & $\stackrel{\circ}{\dot{m}}$ & ণู & $\stackrel{?}{\sim}$ \\
\hline 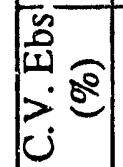 & $\stackrel{\infty}{\stackrel{\rho}{~}}$ & $\stackrel{\sim}{\beth}$. & $\overrightarrow{\mathbf{N}}$ \\
\hline 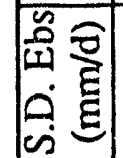 & Ė & $\frac{1}{0}$ & $\stackrel{0}{\circ}$ \\
\hline $\mid$ & $\frac{9}{0}$ & ஜ̊ & ถิ \\
\hline 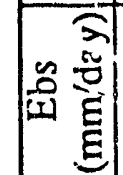 & 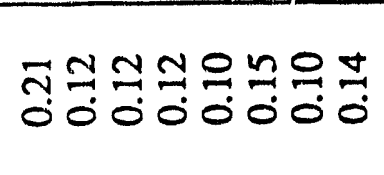 & 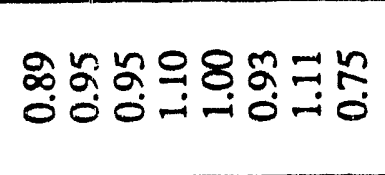 & 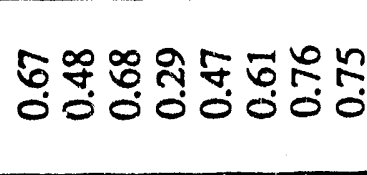 \\
\hline \begin{tabular}{|l|} 
\\
\\
\end{tabular} & $\Xi$ & 8 & $\overrightarrow{\text { s }}$ \\
\hline صٌّ & 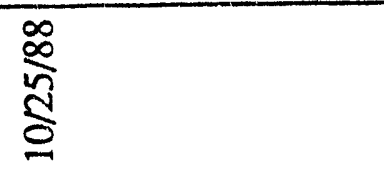 & 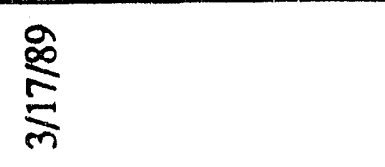 & $\frac{8}{5}$ \\
\hline
\end{tabular}




\begin{tabular}{|c|c|c|c|c|}
\hline 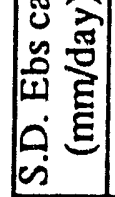 & $\stackrel{n}{0}$ & $\stackrel{5}{0}$ & శ్ & $\stackrel{\infty}{\circ}$ \\
\hline 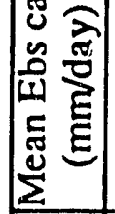 & ت্ & ถุ & চ̋ & $\ddot{b}$ \\
\hline 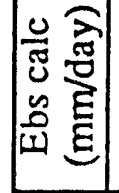 & 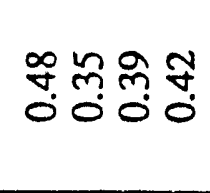 & 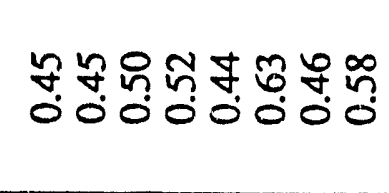 & $\begin{array}{l}\text { No } \\
0 \% 0 \\
000 \\
000\end{array}$ & 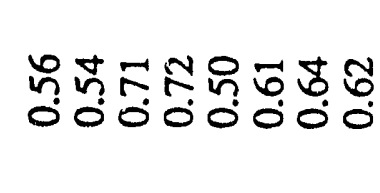 \\
\hline 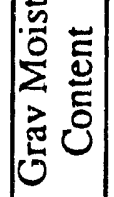 & 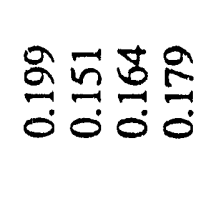 & 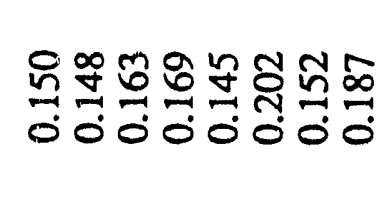 & 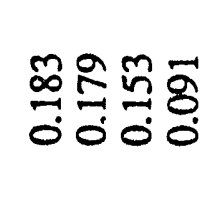 & 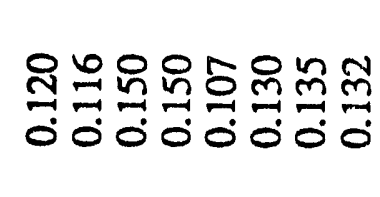 \\
\hline 旅司 & ஸึ & $\stackrel{0}{\infty}$ & $\Xi$ & $\stackrel{b}{\sim}$ \\
\hline 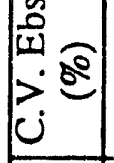 & $\overline{\vec{N}}$ & $\stackrel{m}{\varrho}$ & $\cong$ & $\stackrel{b}{\check{I}}$ \\
\hline 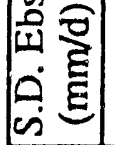 & $\stackrel{\infty}{0}$ & ஜ̊ & $\stackrel{0}{0}$ & 8 \\
\hline | & $\stackrel{\infty}{\grave{0}}$ & 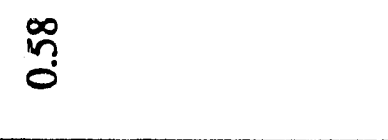 & กั & 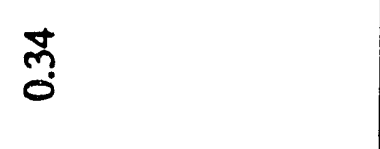 \\
\hline 至 & 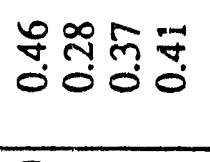 & 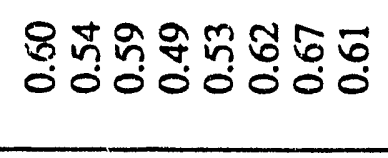 & 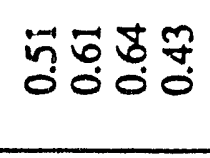 & 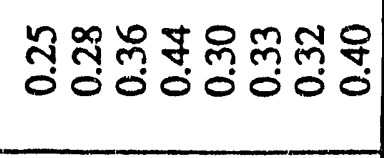 \\
\hline فํ. & 요 & '્ల & ల్ల & $\overline{\mathrm{D}}$ \\
\hline مَّ & 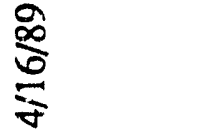 & 灾 & $\frac{2}{8}$ & कू \\
\hline
\end{tabular}




\begin{tabular}{|c|c|c|c|c|}
\hline 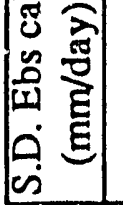 & $\frac{}{0}$ & छั & $\stackrel{5}{0}$ & ర్ \\
\hline 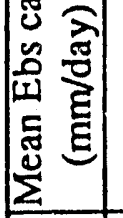 & $\stackrel{\infty}{\Xi}$ & gू & 常 & $\underset{0}{\tilde{O}}$ \\
\hline 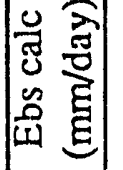 & స్తిర్తి & 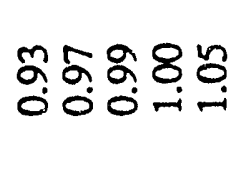 & 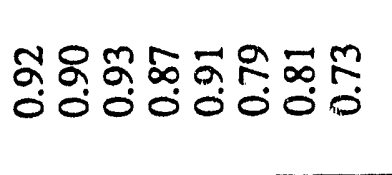 & 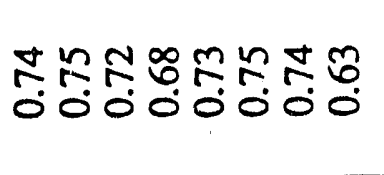 \\
\hline 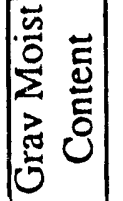 & 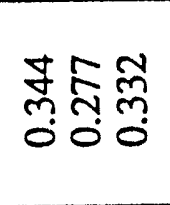 & 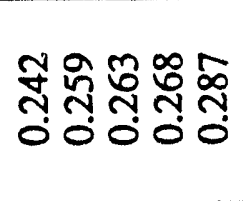 & 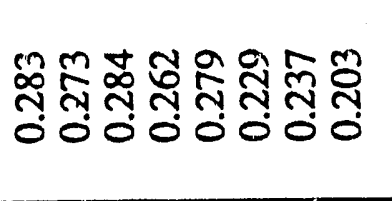 & 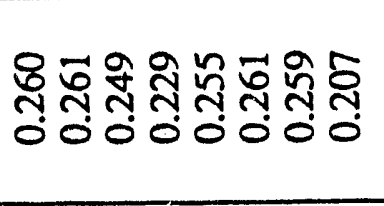 \\
\hline 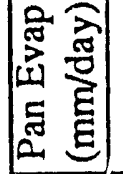 & $\widetilde{I}$ & $\Xi$ & 苍 & $\stackrel{a}{\infty}$ \\
\hline 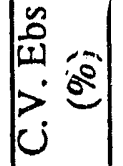 & $\underset{\sim}{\sim}$ & $\bar{m}$ & 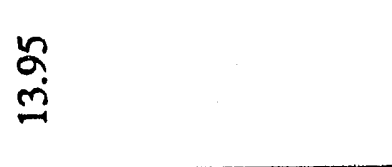 & $\underset{\mathfrak{N}}{\stackrel{F}{\pi}}$ \\
\hline 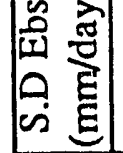 & ర్ & $\overrightarrow{0}$ & $\stackrel{\pi}{0}$ & ¿̊ \\
\hline 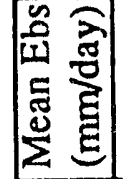 & న్ & 영 & 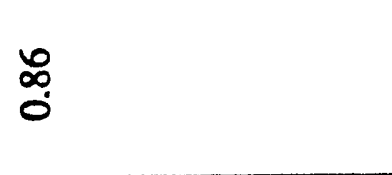 & f \\
\hline 领 & ڤू. & 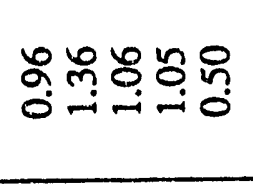 & 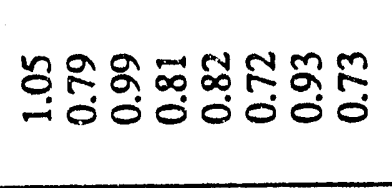 & 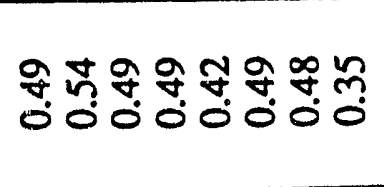 \\
\hline 第 & - & ్లి & $\sqrt[n]{ }$ & 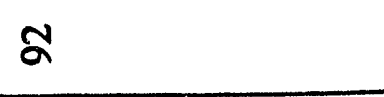 \\
\hline 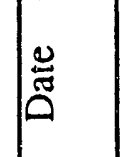 & $\underset{\substack{\delta \\
ٍ}}{\infty}$ & 怘 & 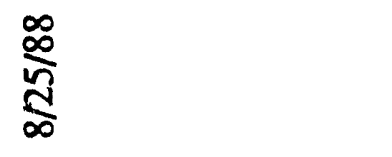 & 怘 \\
\hline
\end{tabular}




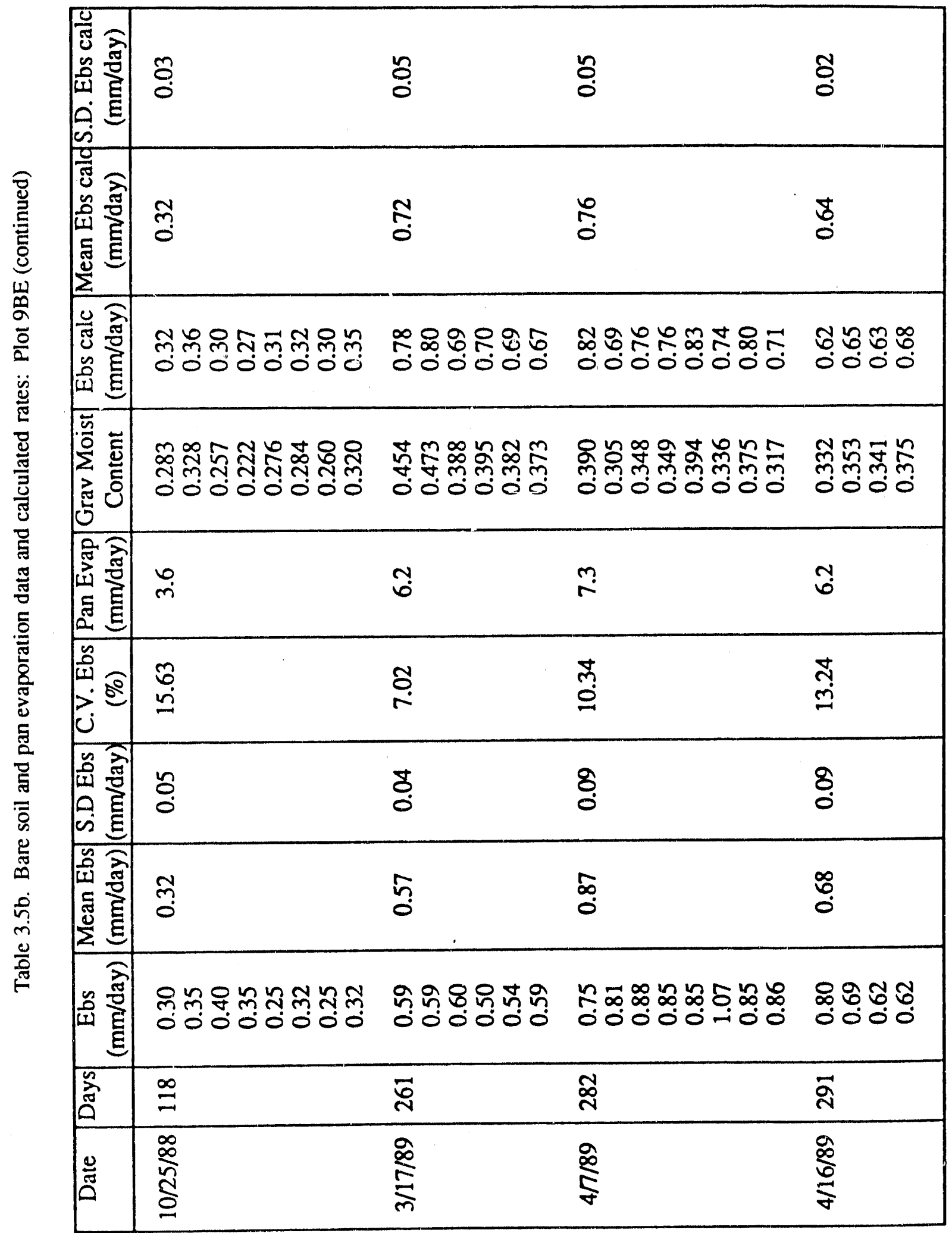




\begin{tabular}{|c|c|c|c|}
\hline 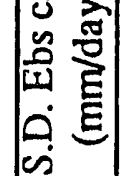 & 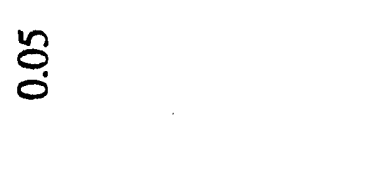 & O̊ & $\stackrel{ \pm}{0}$ \\
\hline 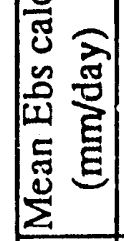 & 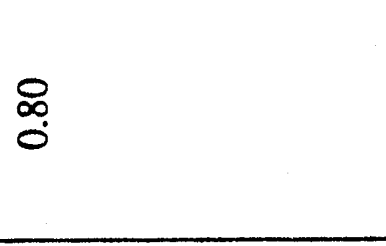 & 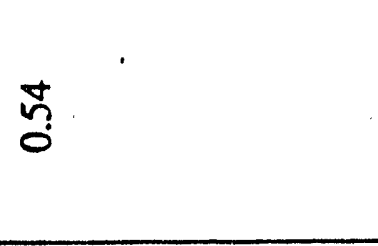 & $\stackrel{n}{\infty}$ \\
\hline 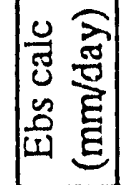 & 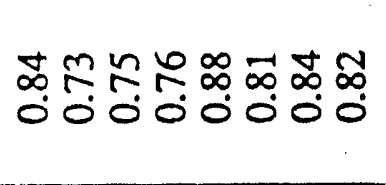 & 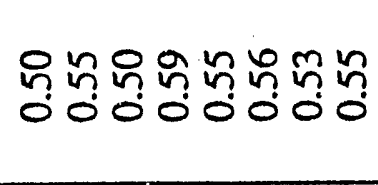 & 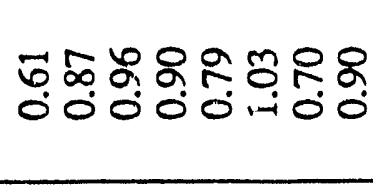 \\
\hline 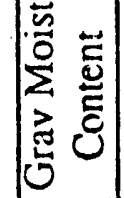 & 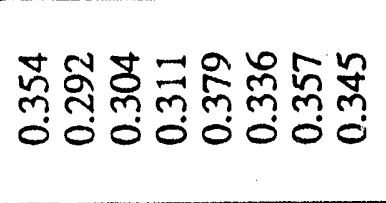 & 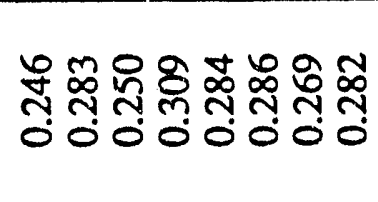 & 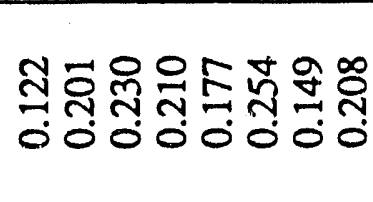 \\
\hline $\mid$ & $\stackrel{\infty}{\infty}_{\infty}$ & ช్ర & $\stackrel{0}{\mathfrak{z}}$ \\
\hline 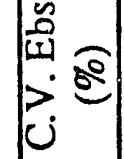 & $\frac{n}{a}$ & $\stackrel{F}{0}$ & $\stackrel{4}{5}$ \\
\hline 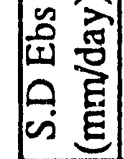 & $\stackrel{0}{0}$ & $\stackrel{5}{0}$ & $\stackrel{0}{0}$ \\
\hline | & $\ddot{\infty}$ & $\ddot{0}$ & $\tilde{n}$ \\
\hline 兘 & 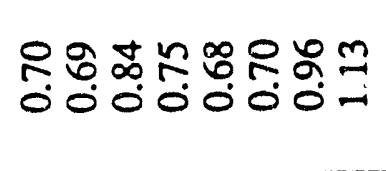 & 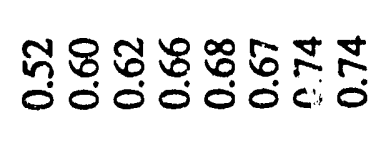 & 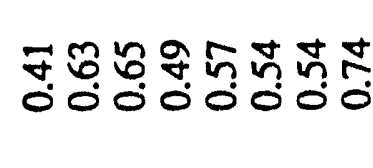 \\
\hline 简 & 官 & શ્లి & ర్ల్ల \\
\hline صَّ & 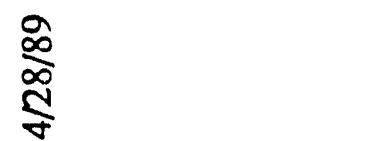 & 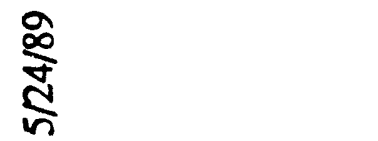 & 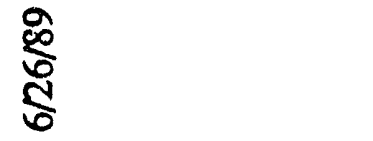 \\
\hline
\end{tabular}


During the spring and early summer of 1989 , rates were expected to rise substantially due to the rise of the water table at both plots (see Figure 3.11). At plot 9BE, the water table was at a depth of $28 \mathrm{~cm}$ at its shallowest (3/2/89), a depth at which almost any soil is expected to be able to transmit water at a rate nearly equivalent to potential evaporation. The increased moisture content throughout the soil profile can be seen through tensiometer data (Figure 3.20). The fact that bare soil evaporation rates measured at that time were still in the sub-millimeter-per-day range, while pan evaporation was measured in the 2 to $5 \mathrm{~mm} /$ day range, indicated that other factors were controlling bare soil evaporation besides the depth to the water table. Further measurements during the season reinforced this suspicion; while the water table was declining at both plots, bare soil evaporation rates measured were erratic, although they did not vary substantially from approximate $y 0.5 \mathrm{~mm} /$ day in plot $8 \mathrm{EP}$ and $0.6-0.8 \mathrm{~mm} /$ day in plct $9 \mathrm{BE}$. This range of rates is similar to that observed from a soil with a surface mulch (Gardner and Fireman, 1958), in which case water vapor diffusion through the high porosity, low bulk density surface layer was found to be the dominant mode of water transport (Figure 3.21). This suggested that the salt crust present on the soil surface has an effect similar to a surface mulch. The process of vapor diffusion is driven by gradients in vapor concentrations near the soil surface (see Equation (3.2)), which means that the lower the external humidity and the higher the temperature, the higher the rate of diffusion. If diffusion is the dominant transport process at these plots, then external (atmospheric) conditions may be controlling soil evaporation. The same atmospheric conditions which control vapor diffusion also control potential evaporation rates. Therefore, there should be a correlation between measured pan evaporation rates and measured bare soil evaporation rates. In addition to the vapor concentration gradient, $\mathbf{J}_{\mathbf{S}, \mathbf{v}}$ of Equation (3.2) is also directly proportional to soil gasphase porosity, tortuosity, and inversely proportional to soil liquid-phase saturation, or moisture content. However, in the given case, a reduction in soil moisture content will lead to an increase in $\Delta z$, or the one-dimensional travel distance of water vapor. Also, while vapor diffuition may be dominant near the soil surface, water movement below the top $2-3 \mathrm{~cm}$ is certain to be dominated by liquid flow; therefore, a lower moisture content will cause a decrease in unsaturated soil con- 


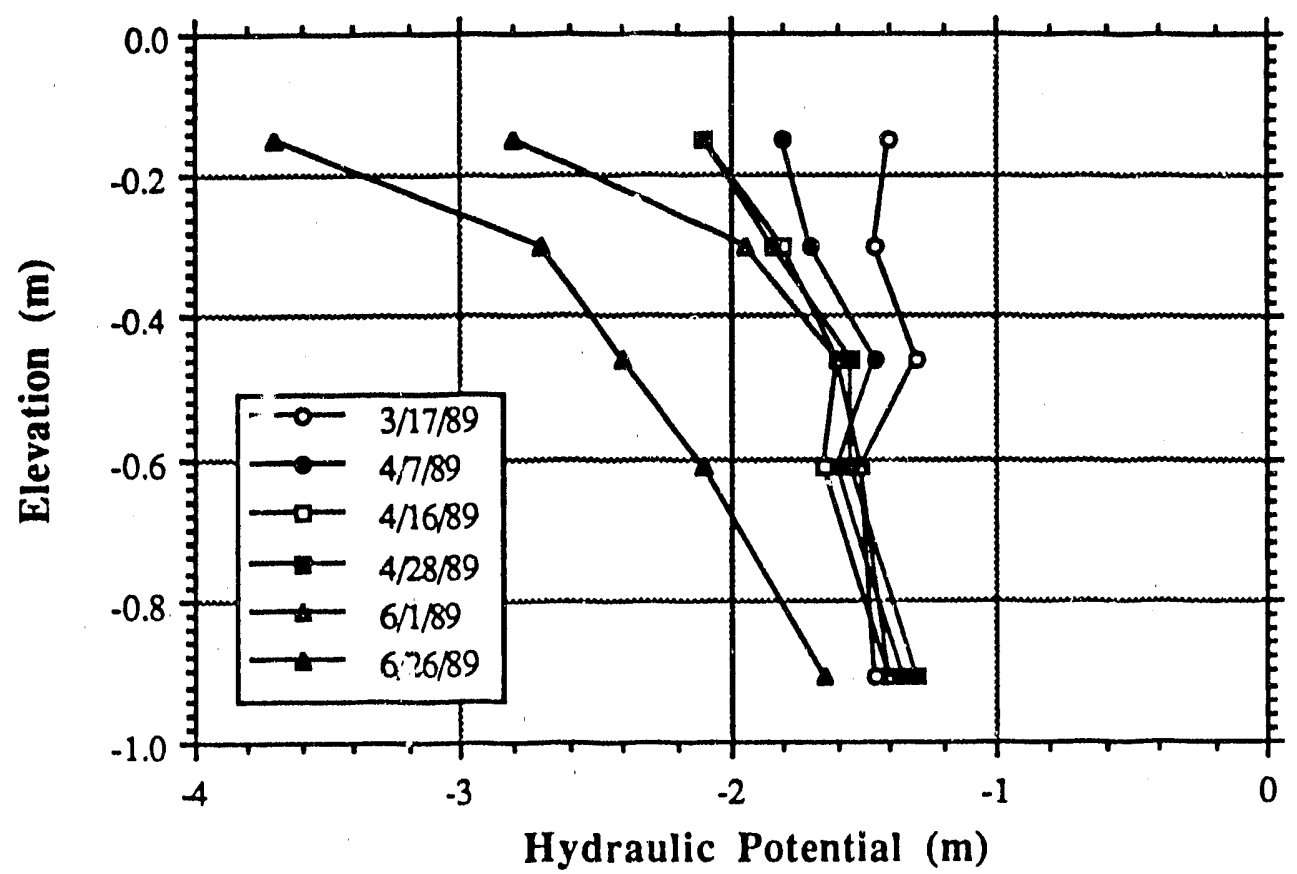

Figure 3.20a. Hydraulic potential distribution changes in soil profile of plot 8EP during the spring and summer of 1989.

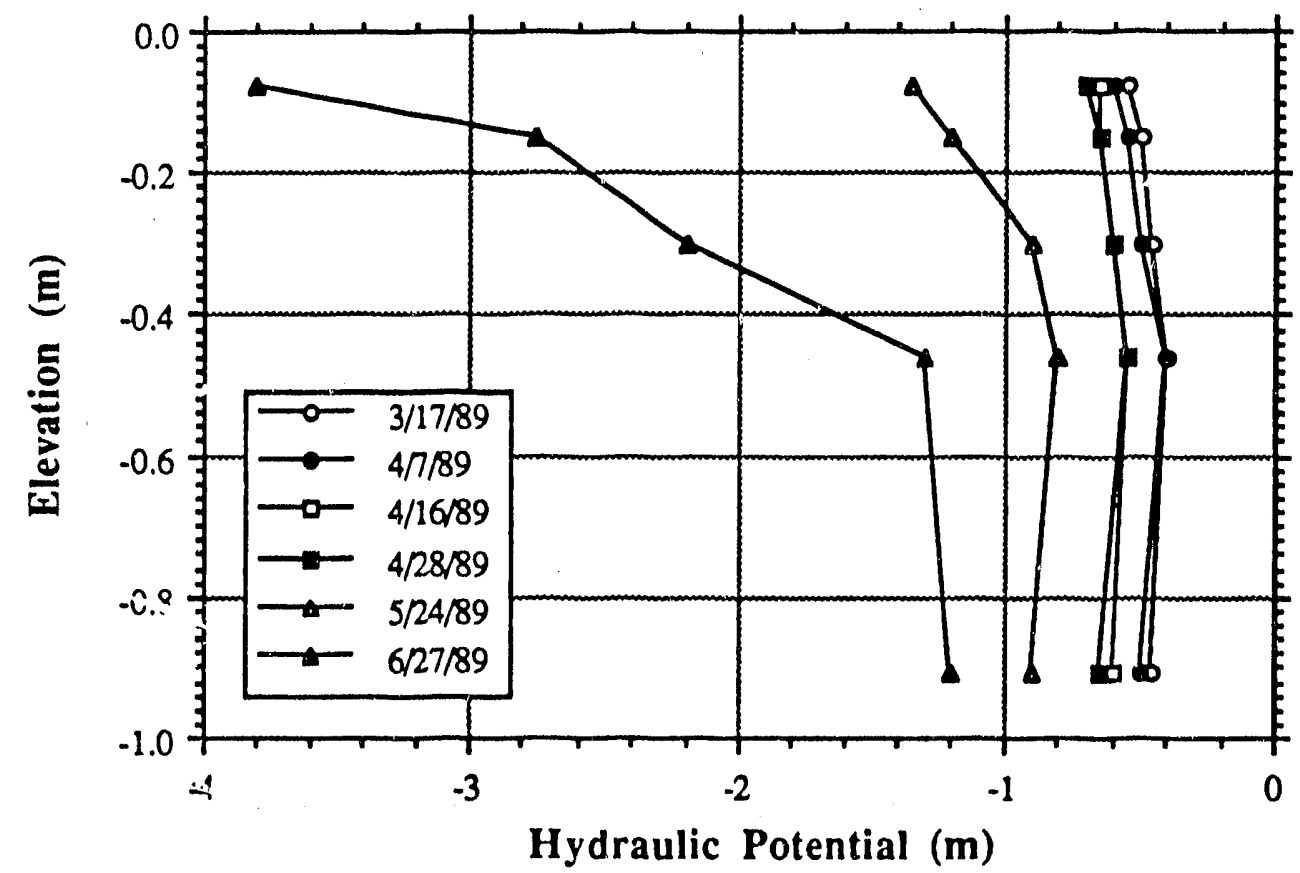

Figure 3.20b. Hydraulic potential distribution changes in soil profile of plot 9BE during the spring and summer of 1989. 


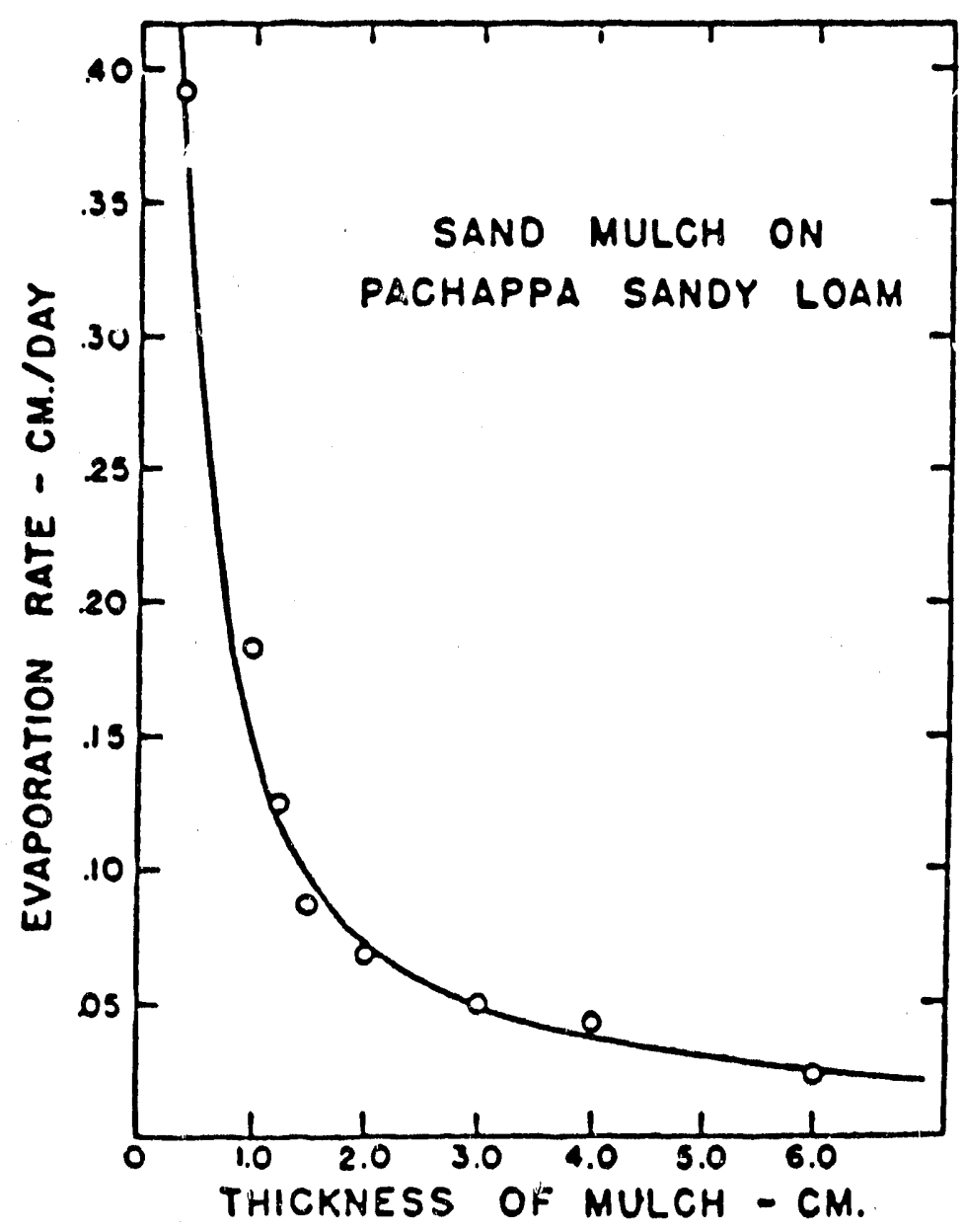

Figure 3.21. Dependence of bare soil evaporation rate on the thickness of a surface sand mulch on a $100 \mathrm{cin}$ column of Pachappa sandy loam (from Gardner and Fireman, 1958). 
ductivity which will hinder the transport of water towards the soil surface. The vapor concentrathun (or humidity) in a suil is directly related to matric and osmotic potentials (Koorevar and others, 1983). At a matric head of $-3,200 \mathrm{~m}$ soil humidity is $78.9 \%$, where $s$ at a matric head of $-10,000 \mathrm{~m}$, soil humidity drops to $47.2 \%$. This drop reduces the vapor concentration difference between the soil and the atmosphere which, in the given case, would lead to a reduction in vapor flow. On the other hand, the change in saturation associated with such a decline in matric potential would be fairly minor (5 to $15 \%$ for most soils). Therefore, it is likely that a decrease in moisture content of near-surface soils will result in a decrease in bare soil evaporation rates.

In order to test the above dependences, bare soil evaporation rate (Ebs) data was fit to the following equation:

$$
E_{b s}=C E_{\text {pais }}\left(\theta_{\text {grav, }, 9}\right)^{b}
$$

where $E_{p a n}$ is the measured pan evaporation rate $\left[L T^{-1}\right], \theta_{g r a v, 9}$ is gravimetric moisture content of the top $9 \mathrm{~cm}$ of soil $\left[\mathrm{MM}^{-1}\right]$, and $\mathrm{C}$ and $\mathrm{b}$ are dimensionless constants, essentially dependent on soil characteristics, but without any particular significance attached to either one. For each plot, two data points were chosen for which $E_{b s}, E_{p o x}$, and $\theta_{g r a v, 9}$ differed; for both plots, the data from $7 / 29 / 88$ and 8/25/88 were chosen. Equation (3.5) was then solved for $\mathrm{C}$ and $\mathrm{b}$ for each plot. For plot $8 \mathrm{EP}, \mathrm{C}$ was found to be equal to 0.44 and $\mathrm{b}$ to be equal to 1.08 ; the same values for plot $9 \mathrm{BE}$ were found to be 0.224 and 0.732 , respectively. $E_{\mathrm{por}}$ and $\theta_{\mathrm{grav}, 9}$ data for each sample date was used to calculate a bare soil evaporation rate $\left(E_{b s, c a l c}\right)$. The results of this calculation are compared with the actual measurements in Fig. 3.22. (The lines which join points in this graph are only for the purpose of differentiation between the two data sets and do not indicate the expected trends between data points.) With a few exceptions, the fit is satisfactory; the point on day 263 was not expected to be fitted well due to the fact that the measurement may have been affected by a rainfall event of $1.3 \mathrm{~mm}$ on the previous day. Therefore, the rate measured on that day would be expected to be somewhat elevated. This effect, however, was not observed in plot 9BE, possibly due to more rapid infiltration of water into the higher porosity surface soil there, although this explar.ation is probably not satisfactory. The last two data points from each plot are not fit very 


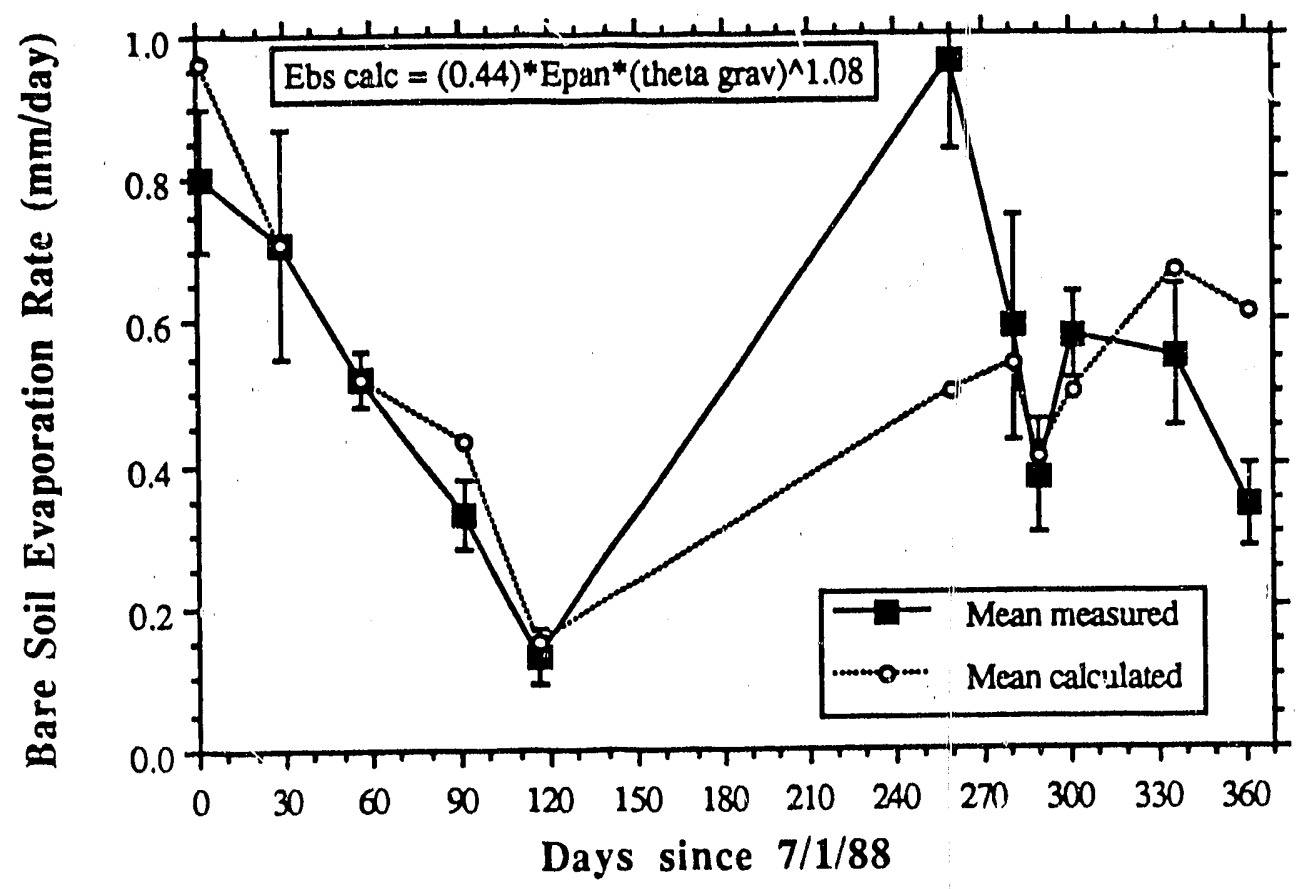

Figure 3.22a. Measured and calculated bare soil evaporation rates for plot 8EP; error bars represent one standard deviation on eacin side of the measured mean.

疍

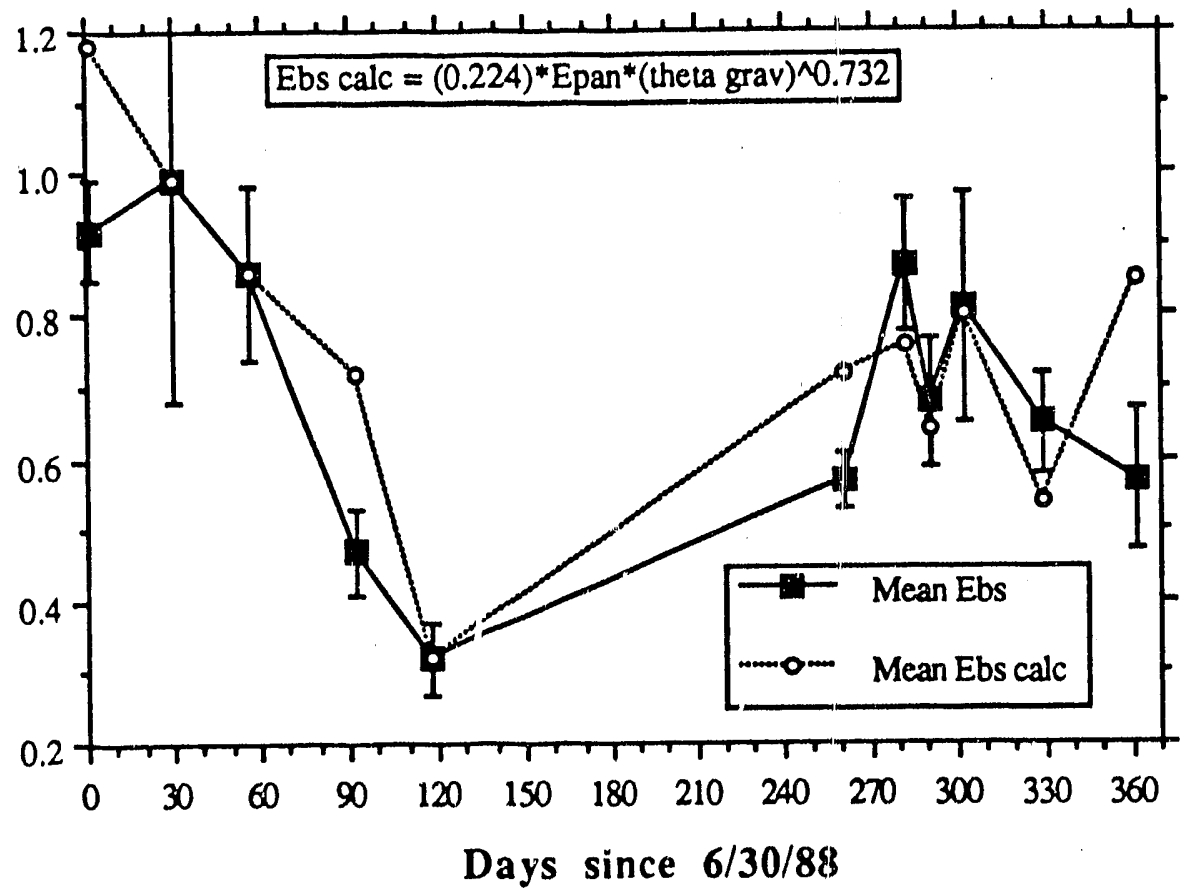

Figure 3.22b. Measured and calculated bare soil evaporation rates at plot 9BE; error bars represent one standard deviation on each side of the measured mean. 
well either; this may be due to a fairly rapid drying of surface soil during this period. A comparison of gravimetric moisture content of soil from both plots between $7 / 1 / 88$ and $6 / 26 / 89$ (Table 3.5), shows a substantial net drying of the suil over an annual cycle, clearly demonstrating the transient state of the soil profile in both plots, as a result of the presence of excess water, a remnant from when the ponds were flooded. This should result in lower soil evaporation rates over the next annual cycle; indeed, this trend is seen in data from both plots. However, the calculated values are higher than the measured values in May and June of 1989, suggesting, perhaps, that soil properties of the top $9 \mathrm{~cm}$ interval have changed somewhat since the beginning of the twelve month cycle and are no longer described by the above calculated constants, $C$ and $b$. The correlation between Ebs,calc and Ebs is presented in Figure 3.23. The line in these plots designates a slope of 1 .

A few points need to be made abcut this analysis. (1) It is not intended to serve as a predictive tool, but rather as a test of the supposition that soil moisture content and extemal conditions are the chief factors controlling bare soil evaporation; as such, this has been shown, although the system is clearly more complicated than this analysis allows for. (2) Bare soil evaporation is affected not only by bulk moisture content, but also by the distribution of moisture within the 9 $\mathrm{cm}$ interval; this is not taken into account in the above analysis. (3) Pan evaporation rates were estimated based on rates measured in Los Banos (see Section 3.3.2) and slight variations may be expected to occur, even within Kesterson Reservoir, unfortunately, due to an initial ignorance about the processes involved, pan evaporation rates were not measured within the test plots themselves, as it was assumed that bare scil evaporation was controlled by the soil profile and not external conditions. Therefore, the dat 2 may have been fit more successfully if pan rates were measured within the test plots.

While the above approach should not be used for quantitative prediction of evaporation rates in the future, it may be used to estimate an average seasonal rate for the two drying seasons in question. This may be done by linearly interpolating $\theta_{\text {grav }, 9}$ between measured values and using pan evaporation rates measured on each day of the two periods. When this is done, the pat- 


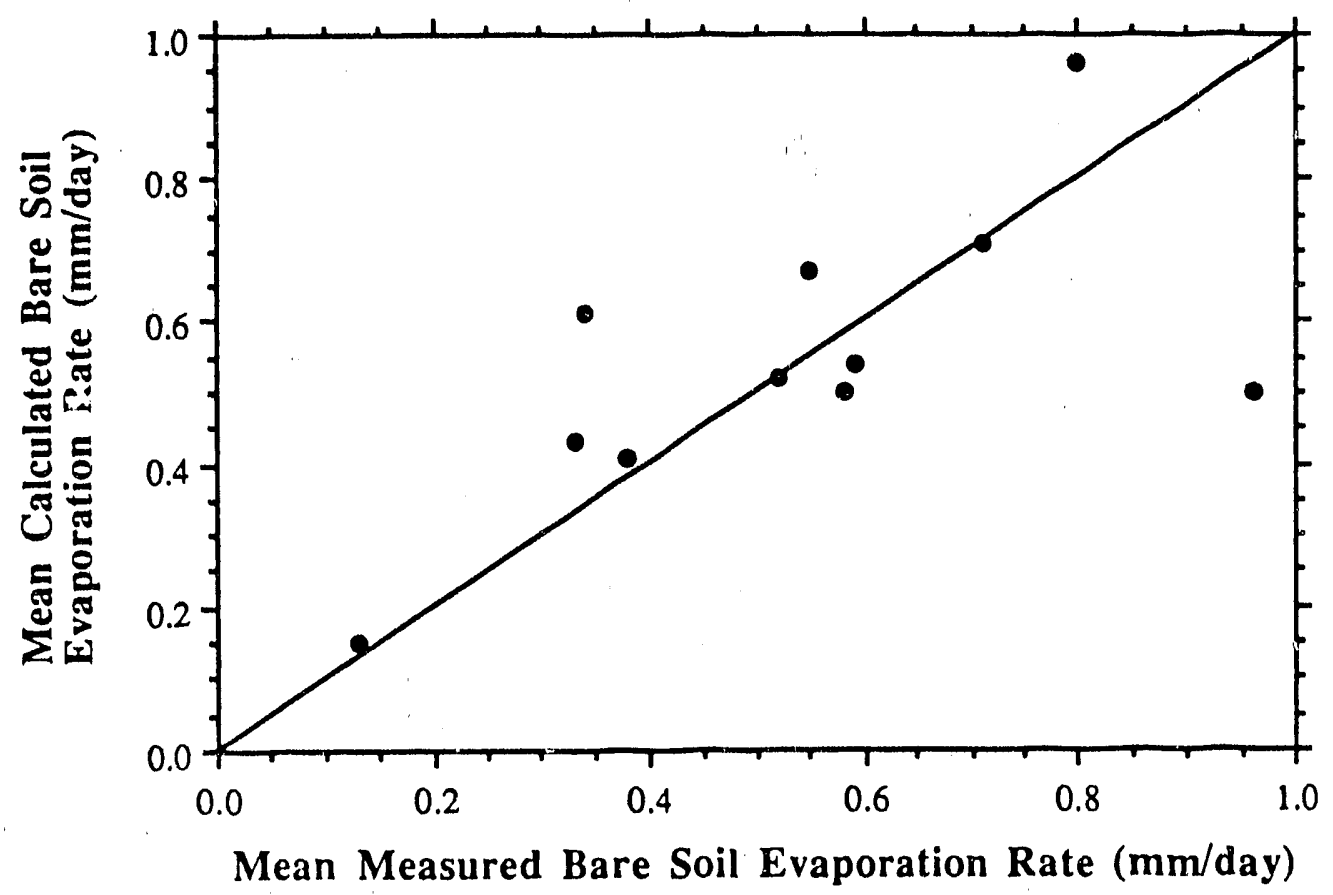

Figure 3.23a. Calculated vs. measured bare soil evaporation rates at plot 8EP.

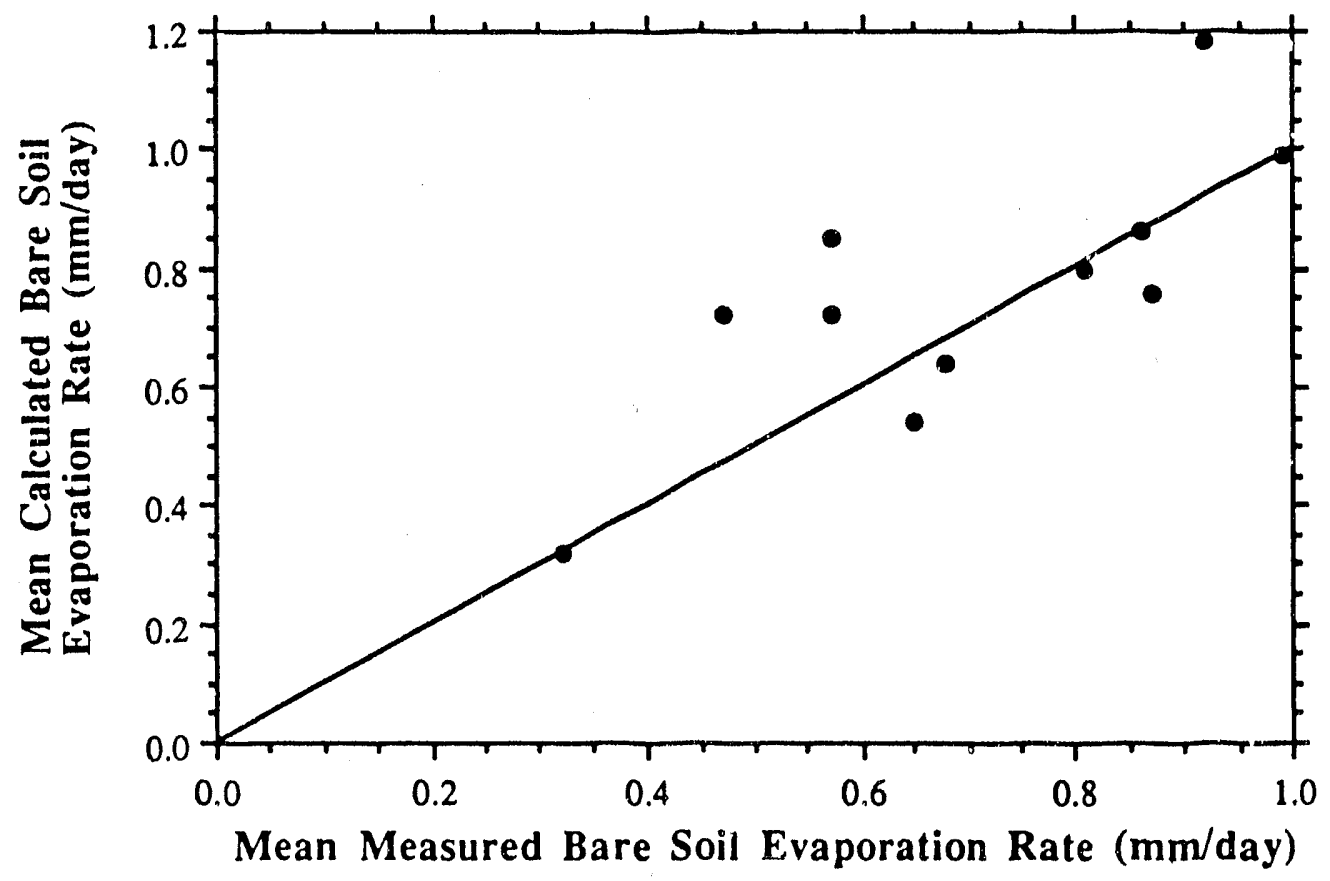

Figure 3.23b. Calculated vs. measured bare soil evaporation rates at plot 9BE. 


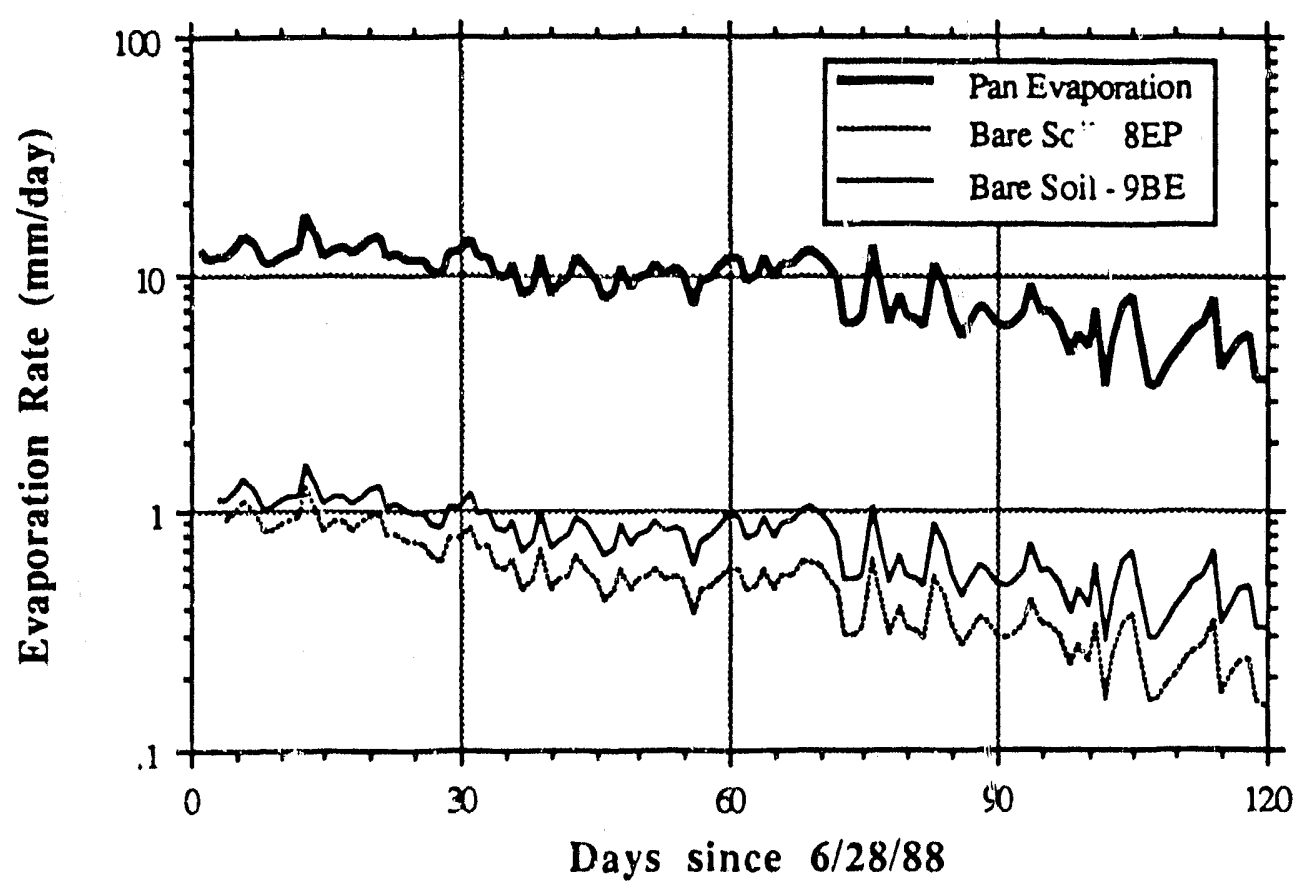

Figure $3.24 \mathrm{x}$. Seasonal trends in bare soil evaporation as calculated based on pan evaporation data; summer and fall, 1988.

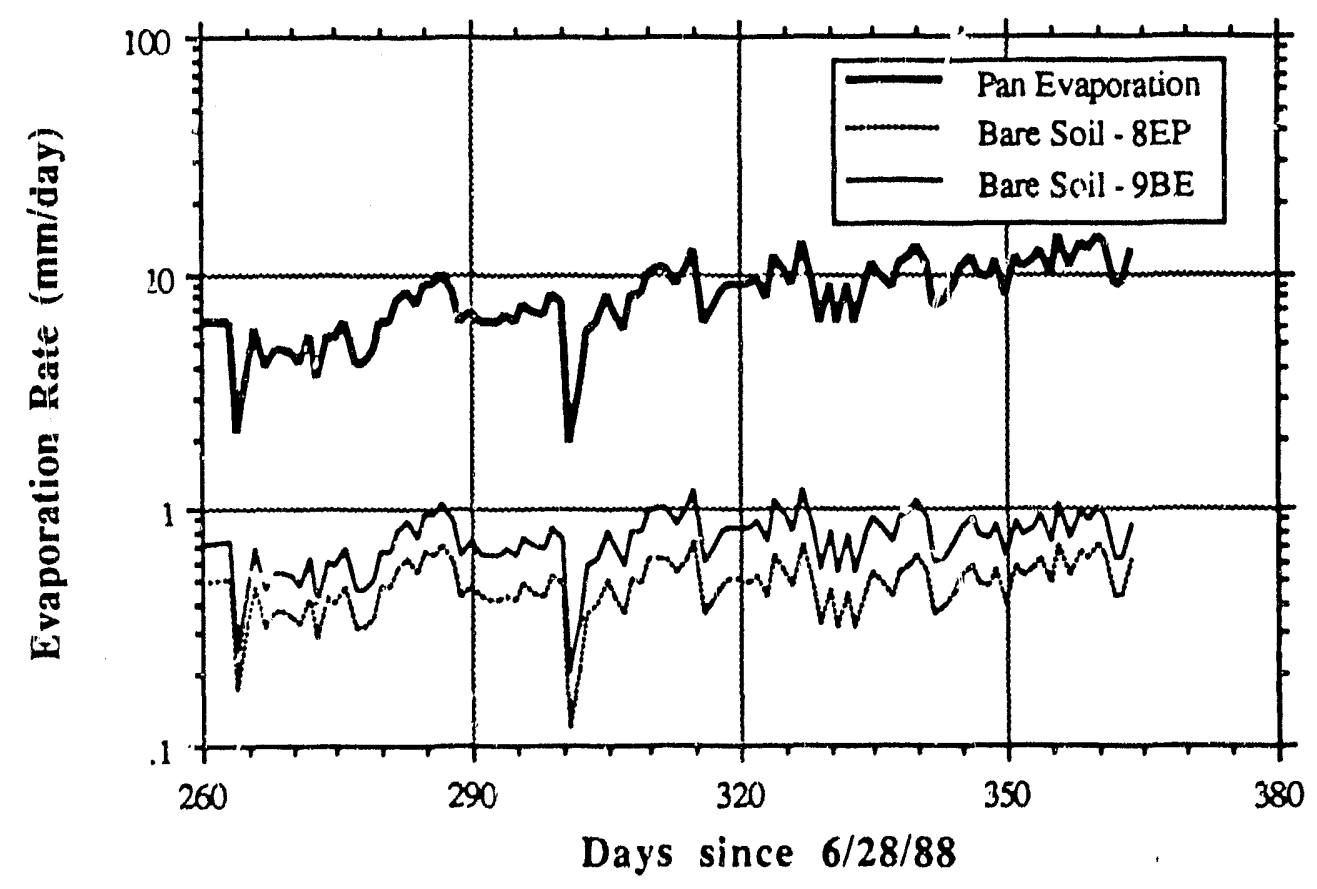

Figure 3.24b. Seasonal trends in bare soil evaporation as calculated based on pan evaporation data; spring and summer, 1989. 
terns of evaporation shown in Figure 3.24 are calculated. The average rates are presented in Table 3.6 below. Since it is known that this approach overestimates bare soil evaporation during the second season, the average bare soil evaporation rates calculated for that season should be considered to be upper limits on the actual rates. Rates calcuiated for the first season should be fairly accurate.

Table 3.6. Calculated average seasonal rates of bare soil evaporation for plots 8EP and $9 \mathrm{BE}$, compared with average seasonal pan evaporation rates.

\begin{tabular}{|lcccccc|}
\hline Season & $\begin{array}{c}\text { Total Pan } \\
\text { Evaporation } \\
(\mathrm{mm})\end{array}$ & $\begin{array}{c}\text { Total Bare } \\
\text { Soil } \\
\text { Evap, P8EP } \\
(\mathrm{mm})\end{array}$ & $\begin{array}{c}\text { Total Bare } \\
\text { Soil } \\
\text { Evap. P9BE } \\
(\mathrm{mm})\end{array}$ & $\begin{array}{c}\text { Avg E } \\
\text { (mm/day })\end{array}$ & $\begin{array}{c}\text { Avg E } \\
\text { at 8EP } \\
(\mathrm{mm} / \text { day })\end{array}$ & $\begin{array}{c}\text { Avg E } \\
\text { at 9BE } \\
(\mathrm{mm} / \text { day })\end{array}$ \\
\hline \hline $\begin{array}{l}\text { Summer and } \\
\text { Fall 1988 }\end{array}$ & 1071.4 & 60.8 & 92.0 & 9.08 & 0.52 & 0.78 \\
\hline $\begin{array}{l}\text { Spring and } \\
\text { Summer 1989 }\end{array}$ & 836.4 & 47.9 & 75.5 & 8.20 & 0.47 & 0.74 \\
\hline
\end{tabular}

The significance of vapor diffusion in this process may be more quantitatively demonstrated using a numerical model. Numerical modeling of the system in plot 8EP was performed using the code TRUST. To test the importance of vapor diffusion, the program was modified in such a way as to be able to account for vapor ciffusion near the soil surface. Simulations were performed of the system with and without vapor diffusion. Results of simulatiuns using both approaches are shown in Figure 3.2.5a. Lines joining both the data points and the simulation results are only for the purpose of differentiation and do not indicate between-point trends. Neither approach was able to satisfactorily simulate field-measured rates. However, the simulations which took into account vapor diffusion (Figure 3.25b), gave results which, while not always correct in magnitude, followed trends in rates somewhat more closely. In general, in the non-diffusive case, the answer was almost not at all sensitive to variations in surface potential, but instead was highly dependent on the depth to the water table. This was to be expected and is in accord with the concept of a profile-controlled evaporation rate. It needs to be pointed out that the data point on day 261 was collected within 24 hours of a rainfall event and cannot be expected to be well simulated 


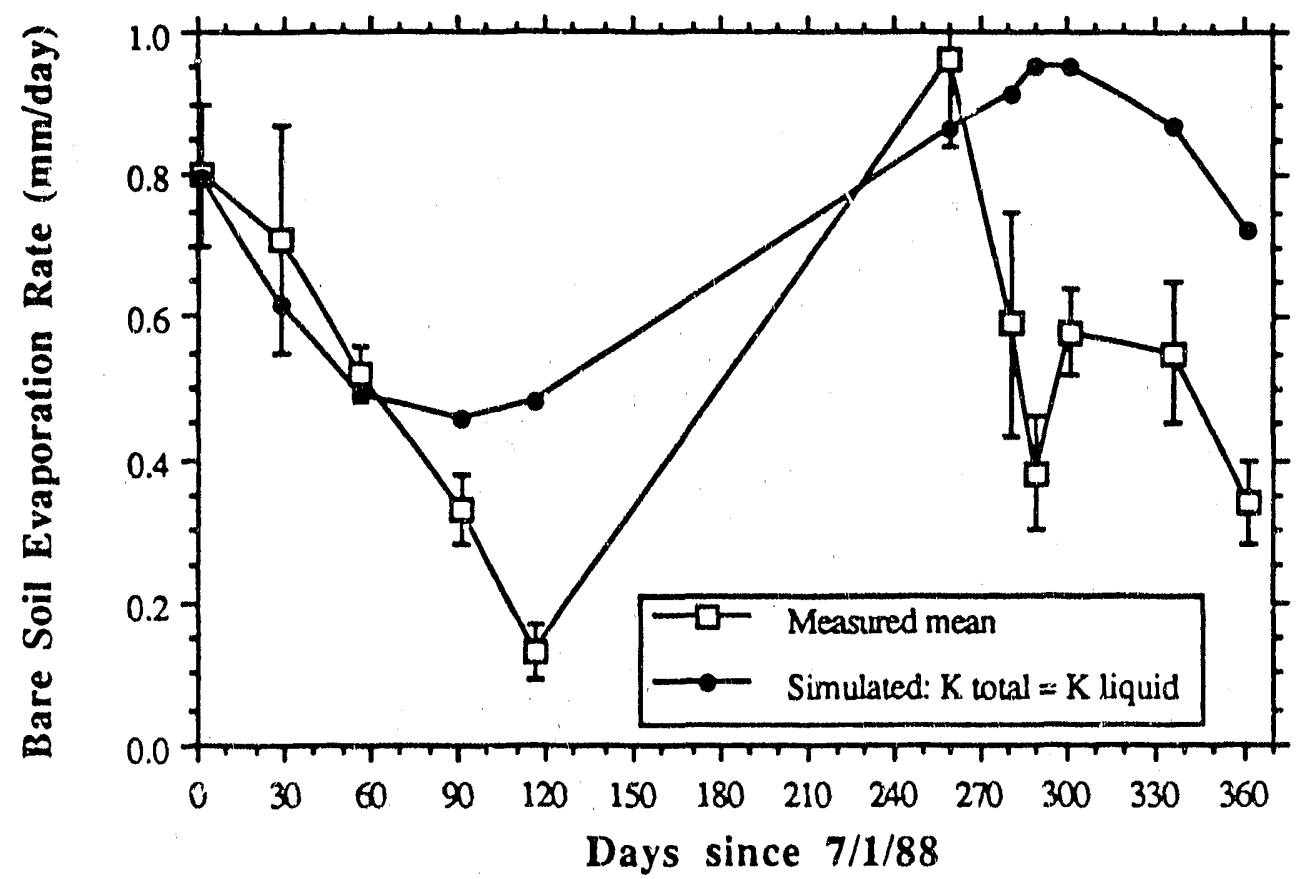

Figure 3.25a. Numerically simulated bare soil evaporation rates at plot 8EP compared with actual measured rates; vapor diffusion not taken into account.

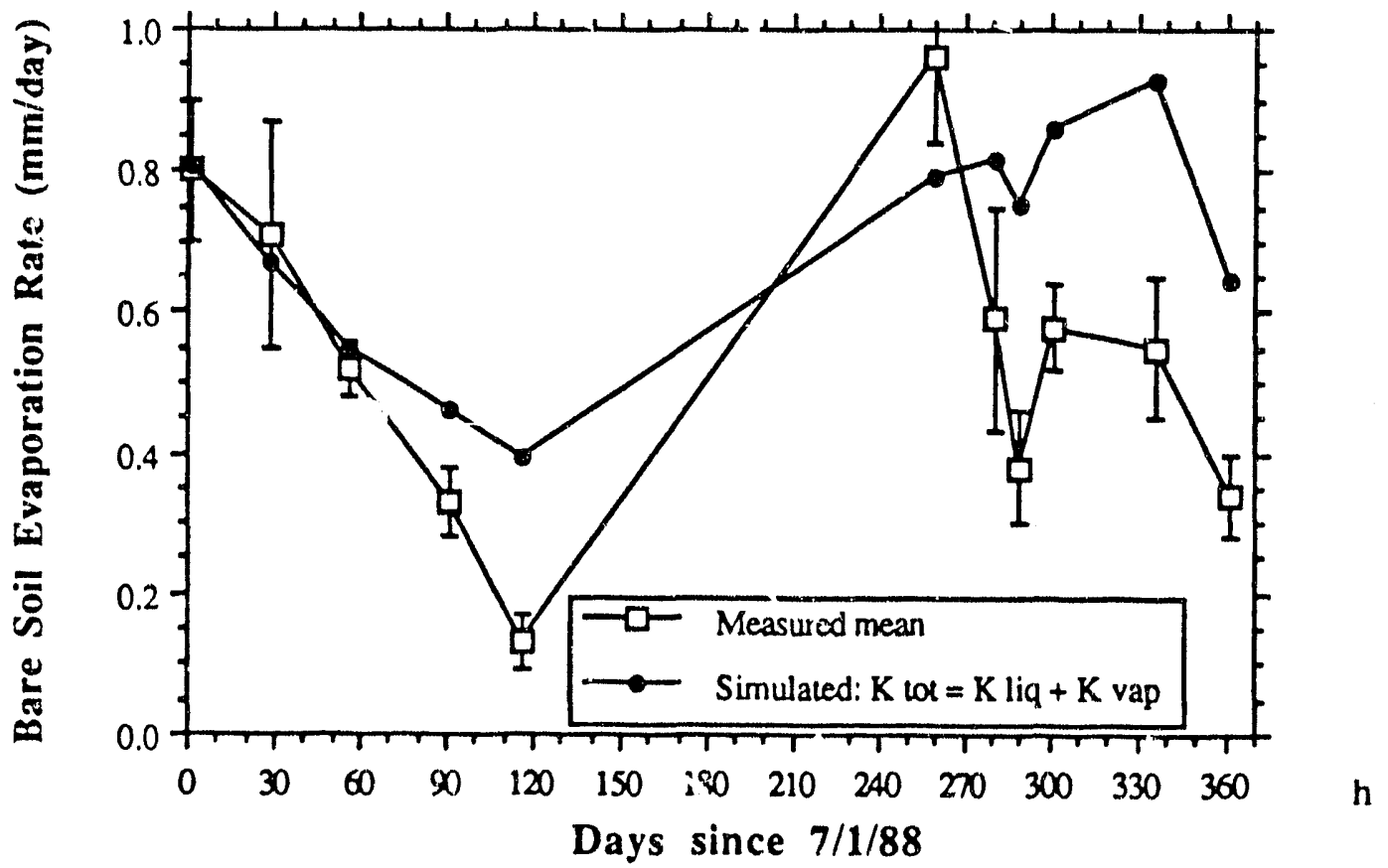

Figure 3.25b. Numerically simulated bare soil evaporation rates at plot 8EP compared with actlual measured rates; vapor diffusion taken into account. 
without the application of an appropriate amount of water in the simulation, which was not done (see Section 3.3.3.3). A detailed description of the input parameters, boundary conditions, external conditions, program structure, and associated uncertainties may be found in Zawislanski (1989).

\subsubsection{Errors Involved in Bare Soil Evaporation Rate Measurement}

There are several potential sources of error involved. (1) Evaporation rates are based on mass differences of soil cores, which are measured in the field using a 2610 gram capacity balance. This balance nominally has a precision of $0.1 \mathrm{~g}$; however, it is possible to interpolate between $0.1 \mathrm{~g}$ marks. In the field, masses were recorded down to $0.01 \mathrm{~g}$, although it is more reasonable to assume a precision of $0.02 \mathrm{~g}$, based on the reproducibility of individual measurements. On particularly windy days, the precision of the balance may go to as much as $0.05 \mathrm{~g}$. For the purpose of this analysis, $0.05 \mathrm{~g}$ will be assumed to be the precision of the balance. Since rates are based on differences in mass, the error, due to the random nature of the uncertainty, is equal to the scirlare root of the sums of the squares of the uncertainty for each measurement (Taylor, 1982). Therefore, the total error in the difference of these masses is equal to: $\left((0.05)^{2}+(0.05)^{2}\right)^{0.5}$ $=0.07 \mathrm{~g}$. (2) The mass difference is then converted to volume through division by water density $\left(1.00 \mathrm{gcm}^{-3}\right)$ and the error becomes equal to $0.07 \mathrm{~cm}^{3}$. The mass difference is then divided by the cross-sectional area of the misrolysimeter. This introduces somewhat more error, in that the radius of the microlysimeter is equal to $2.54 \pm 0.05 \mathrm{~cm}$, which gives an area of $20.26 \pm 0.79 \mathrm{~cm}^{2}$. After dividing water volume by cross-sectional area, the total error becomes equal to the square root of the sum of the original fractional uncertainties; therefore, the fractional crror becomes: $\left((0.07 / 1) 2+(0.79 / 20.26)^{2}\right) 0.5=0.08$ or $8 \%$ for a sample which lost $1 \mathrm{~g}$ of water during the measurement period. This is approximately an average value; for the lowest mass difference observed $(0.20 \mathrm{~g}, 0.10 \mathrm{~mm} /$ day $)$ the fractional error is $35 \%$ and for the greatest mass difference observed $(2.73 \mathrm{~g}, 1.36 \mathrm{~mm} / \mathrm{day})$, the fractional error is $4.7 \%$. This gives an average precision of 0.04 $\mathrm{mm} / \mathrm{day}$ to the bare soil evaporation rate measurement. 
There are also small errors associated with the measurement of $\theta_{\text {grav, } 9}$. The method for measuring gravimetric $m$ isture content is described in Section 3.3.4.3. The precision of the method is dependent on the precision of the laboratory balance, which is $0.01 \mathrm{~g}$. Therefore, for a soil sample of $50.00 \mathrm{~g}$ which contains $10.00 \mathrm{~g}$ of water $\left(\theta_{\text {grav }}=0.250\right)$, the fractional error would be equal to $0.1 \%$, which, in general, is insignificant. There are errors associated with the selection of a subsample for $\theta_{\text {grav }}$ determination; if a soil sample is not thoroughly homogenized, the given subsample may not be representative of the larger sample. There will always be intrasample variability, but it may be considered insignificant, especially if the subsample is sufficiently large (e.g. $10-20 \%$ of the total sample). The results of measurement of both $E_{b s}$ and $\theta_{g r a v}$ are dependent on the spatial variability of soil within each plot. This is unavoidable, and is one of the two main reasons why as large a number of samples needs to be taken as possible. The other reason for a large sample set is the possibility of core disturbance by wind and animals. Wind tends to displace dry soil and salt crust; it may be assumed that, on average, approximately the same mass of soil will blow into as out of a given microlysimeter. However, it is possible that the net mass change will not be zero. Installing a number of microlysimeters greatly increases the chances of the average rate measured not being affected by saltation. The presence of jackrabbits and coyotes at Kesterson Reservoir raises the possibility of core disturbance by animals. On one occasion, a microlysimeter which was not part of this study was urinated on by a coyote and thereby became worthless for that particular measurement. Physical disturbances by jackrabbits would most likely have an effect similar to saltation. Neither the wind nor animal disturbances can be quantified.

\subsubsection{Measurement of Chemical Changes in Near-Surface Soils}

\subsubsection{Species Mobility and Reactivity}

Soil water in both plots is dominated by the presence of sodium, calcium, magnesium, sulfate, and chioride. Potassium and bicarbonate are present in substantially lower concentrations. In general, $\mathrm{Na}^{+}>\mathrm{Ca}^{2+} \geq \mathrm{Mg}^{2+}>\mathrm{K}^{+}$, and $\mathrm{SO}_{4}^{2-} \geq \mathrm{Cl}^{-}>\mathrm{HCO}_{3}^{-}$. Mobility of these ions is limited to a certain extent by their solubilities. Table 3.7 presents information about equilibrium 
solubility products and solubilities of minerals which have either been found or are likely to precipitate at Kesterson Reservoir. As is apparent from this table, the solubilities of calcium,

Table 3.7. Solubility product constants and solubilities of minerals present or likely to be present at Kesterson Reservoir.

\begin{tabular}{|c|c|c|c|}
\hline Mineral Name & Mineral Formula & pK at $25^{\circ} \mathrm{C}$ & $\begin{array}{c}\text { Solubility at } 25^{\circ} \mathrm{C} \\
\mathrm{pH} 7(\mathrm{mg} / \mathrm{L})\end{array}$ \\
\hline Calcite & $\mathrm{CaCO}_{3}$ & 8.41 & $100 \dagger$ \\
\hline Epsomite & $\mathrm{MgSO}_{4} \cdot 7 \mathrm{H}_{2} \mathrm{O}$ & 1.88 & 267,000 \\
\hline Gypsum & $\mathrm{CaSO}_{4} \cdot 2 \mathrm{H}_{2} \mathrm{O}$ & 4.58 & 2100 \\
\hline Halite & $\mathrm{NaCl}$ & -1.57 & 360,000 \\
\hline Magnesite & $\mathrm{MgCO}_{3}$ & 7.83 & $10^{*}$ \\
\hline Mirabillite & $\mathrm{Na}_{2} \mathrm{SO}_{4} \cdot 10 \mathrm{H}_{2} \mathrm{O}$ & 1.23 & 280,000 \\
\hline Sylvite & $\mathrm{KCl}$ & -0.90 & 210,000 \\
\hline
\end{tabular}

pK data from Lindsay, 1979; solubility data from Seidell, 1958, except as noted by * . †Partial pressure of $\mathrm{CO}^{2}=10^{-3}$ bar.

* Magnesite solubility calculated from pK value.

sulfate, and magnesium are strongly limited by their low solubilities relative to gypsum, calcite, and magnesite. In most near-surface soils at Kesterson Reservoir, concentrations of these ions exceed the listed solubility values; calcite and gypsum have been found to be present throughout most profiles investigated (Flexser, 1988). On the other hand, the very high solubilities of mirabillite and halite, allow for equally high concentrations of sodium and chloride; under most field conditions, the concentrations of these two species do not exceed their solubilities, except at the soil surface, or within millimeters of the surface, where water evaporation is taking place. It is important to note that solubilities of minerals are dependent on the ionic strengin and temperature of the solution. In general, the solubilities of the above minerals will increase with ionic strength, although their relative mobilities will not change significantly. Of the two most soluble species, sodium mobility is potentially further limited by its sorption through cation exchange. Chloride mobility may be altered in the other direction, i.e. increased through negative adsorption, or anion exclusion, when, due to the negative charge on the surface of clay particles, it is repelled away from the solid surface, with the resultant apparent increase in concentration in the 
bulk solution (Sposito, 1984). This may lead to an overestimate of water flow; since this effect is very minor in solutions with a chloride concentration of approximately $1000 \mathrm{mg} / \mathrm{L}$ or more (Van De Pol and others, 1977), anion exclusion is most likely not significant in view of the substantially higher chloride concentrations in the field. Due to its high solubility and mobility, chloride has been used reliably as a tracer for fluid flow (e.g. MacFarlane and others, 1983) and in other experiments at Kesterson Reservoir (Long, 1988). While all major ions were analyzed for as part of this study, only chloride was used to quantitatively analyze water flow.

Part of the rationale for measuring and estimating evaporation rates is to be able to understand selenium fluxes near the soil surface. The difficulty of making estimates based on changes in selenium concentration is in part a result of the complex, reduction/oxidation-controlled chemistry of selenium. The many transformations which selenium undergoes in the soil system lead to a greatly decreased mobility; furthermore, the fact that selenium speciation is strongly kinetically controlled makes the quantitative analysis of selenium concentration changes so much more difficult. The solubility and mobility of selenium in a soil system will depend strongly on the redox state of the element. In general, the oxidized forms of selenium are more mobile than the reduced forms. In an aqueous environment, the tetravalent selenite ion, $\mathrm{SeO}_{3}^{2-}$, the hexavalent selenate ion, $\mathrm{SeO}_{4}^{2-}$, and elemental selenium, $\mathrm{Se}^{0}$, are the most common inorganic selenium species. Elemental selenium is highly insoluble in water and its dissolution kinetics are extremely slow (McNeal \& Balistrieri, 1989). Selenite is usually found in mildly oxidizing environments; its salts are moderately soluble, but its mobility is most hindered by its strong affmity for sorption onto iron oxides (Balistrieri and Chao, 1987) and clay particles (Bar-Yosef and Meek, 1987). Selenate is found in oxidizing environments; its salts are highly soluble and it adsorbs only weakly. In general, the solubility of selenium salts will be comparable to the equivalent sulfate salts (e.g. $\mathrm{Na}_{2} \mathrm{SeO}_{4}\left(\mathrm{Na}_{2} \mathrm{SO}_{4}\right)$ - high solubility; $\mathrm{CaSeO}_{4}\left(\mathrm{CaSO}_{4}\right)$ - low solubility). Water which was brought into Kesterson Reservoir contained mostly selenate and some selenite (Weres and others, 1985). As water percolated through pond bottoms, much of the selenate and s'lenite became reduced to elemental selenium, which currently may comprise a large 
percentage of the total selenium inventory in Kesterson soils. Besides changing redox states, selenium has been found to be volatile; losses of selenium thmugh volatilization have been observed at Kesterson Reservoir, but have not yet been adequately quantified (Frankenberger and Karlson, 1988). In addition, a yet undetermined fraction of the selenium inventory exists in organic forms, the mobility of which is extremely limited. In the top $9 \mathrm{~cm}$ of soil at the two plots of interest, water soluble selenium comprises between $4 \%$ and $20 \%$ of the total selenium (see Section 3.3.4.4). In consideration of these factors and the spatial variability of selenium near the soil surface, apparent changes in selenium concentrations cannot be used to estimate nearsurface water fluxes.

\subsubsection{Procedures for Sample Collection}

Four types of samples were collected as part of this study: (1) surface $(9 \mathrm{~cm})$ soil cores, (2) soil profiles, (3) soil water, and (4) ground water. The first type of samples was collected using the same technique as described in Section 3.3.3.3; in fact, the same soil cores which were used to measure bare soil evaporation rates were used as soil samples. Through the use of the same set of coring devices in each sampling period, a uniformity of sampli size was maintained. Soil variability is known to interfere with comparisons of temporal changes in soil salinity (Rhoades, 1978, 1984). Therefore, all samples were collected from small areas within each plot; this reduced the spatial variability which obscures trends (see Figure 3.26 for plot diagrams). After the microlysimeters were weighed for the second time, the top of each cylinder was covered with 2.7 mil-thick plastic and secured with PVC tape to avoid spillage of soil and loss of moisture. The cores were then transported in a vertical position back to the laboratory. Procedures for the collection of soil water, ground water, and soil profile samples have been described in past LBL Progress Reports.

\subsubsection{Methods for Sample Preparation and Analysis}

Once in the laboratory, the cores containing the surface soil samples were weighed and measured. The soil was then carefully extracted from the tube and homogenized, i.e. chopped up 

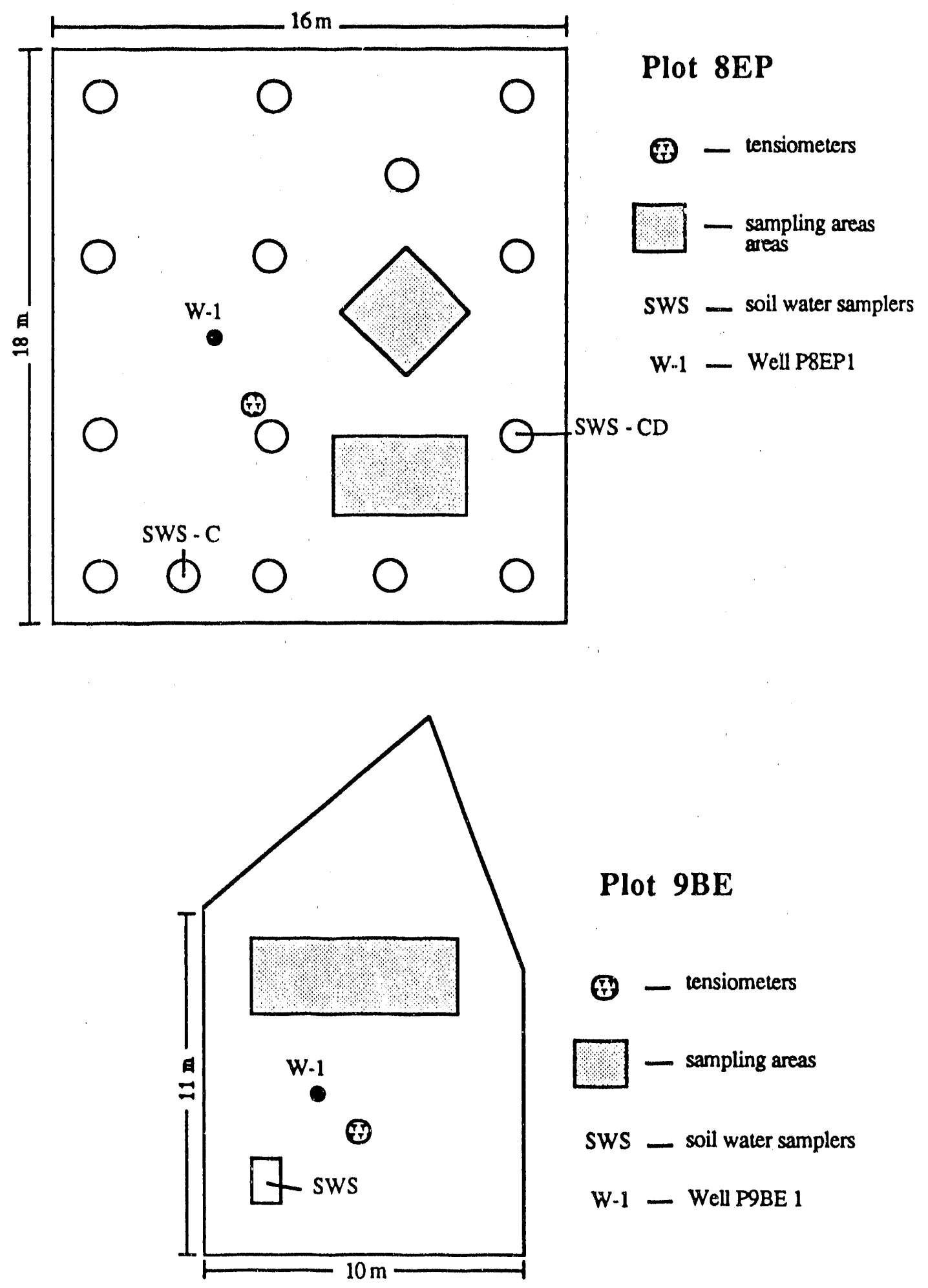

Figure 3.26. Approximate layouts of plots 8EP and 9BE. 
and thoroughly mixed. Homogenization was carried out in a metal bowl; soil was chopped until it passed a $4.75 \mathrm{~mm}$-mesh sieve. In order to prevent significant drying of the sample, this procedure was performed as rapidly as possible. After the soil was homogenized, a subsample of known mass (usually between 10 and $50 \mathrm{~g}$ ) was placed into an open stainless steel container and put into a $105^{\circ} \mathrm{C}$ oven. The subsample was allowed to dry for approximately 24 hours. The remainder of the sample was placed into a plastic bag and stored in a humidified chamber. After subsequent weighing, the gravimetric moisture content of the soil (mass of water per mass of solid) was calculated. Anothe: subsample of known mass (on the order of 10 to $20 \mathrm{~g}$ ) was then used to prepare a 10:1 water to soil extract. The stirring process went on for 2 hours. Subsequently, the suspension was centrifuged at between 3000 and 6000 revolutions per minute for 5 to 20 minutes, depending on the texture of the soii. The supematant liquid was then poured off and filtered through a $0.45 \mu \mathrm{m}$ filter in preparation for chemical analysis. The final liquid was placed in $60 \mathrm{ml}$ or $120 \mathrm{ml}$ plastic bottles with screw-caps. The remainder of each soil sample was stored in a plastic bag in a humidified chamber. The samples from soil profiles were treated in a similar manner, except that their volume was not measured; otherwise, the extract procedure was identical.

Three analytical methods were used for the analysis of water samplcs. Sodium, calcium, magnesium, sulfate, and boron were analyzed for using an Inductively Coupled Plasma Spectrophotometer (ICP) produced by Applied Research Laboratories. Potassium, selenite, and selenium were analyzed for using atomic absorption spectroscopy (AAS) coupled with a hydride generator. The difference between the selenium concentration and the selenite concentration is nearly equal to the selenate concentration (LBL Progress Report 10,1989). Chloride was analyzed for using Mohr titration, as described by Flaschka and others (1969).

\subsubsection{Qualitative Analysis of Changes in Species Concentrations in the Upper $9 \mathrm{~cm}$ of the Soil Profile}

Samples of the top $9 \mathrm{~cm}$ of soil were collected from both plots on a monthly basis. The relative changes in salt concentrations are indicative of near-surface water fluxes. Each point in Figures 3.27 to 3.33 is the analysis of an extract from one $9 \mathrm{~cm}$ core of soil. The spread of data points on any given day reflects the spatial variability within each plot; as mentioned before, 


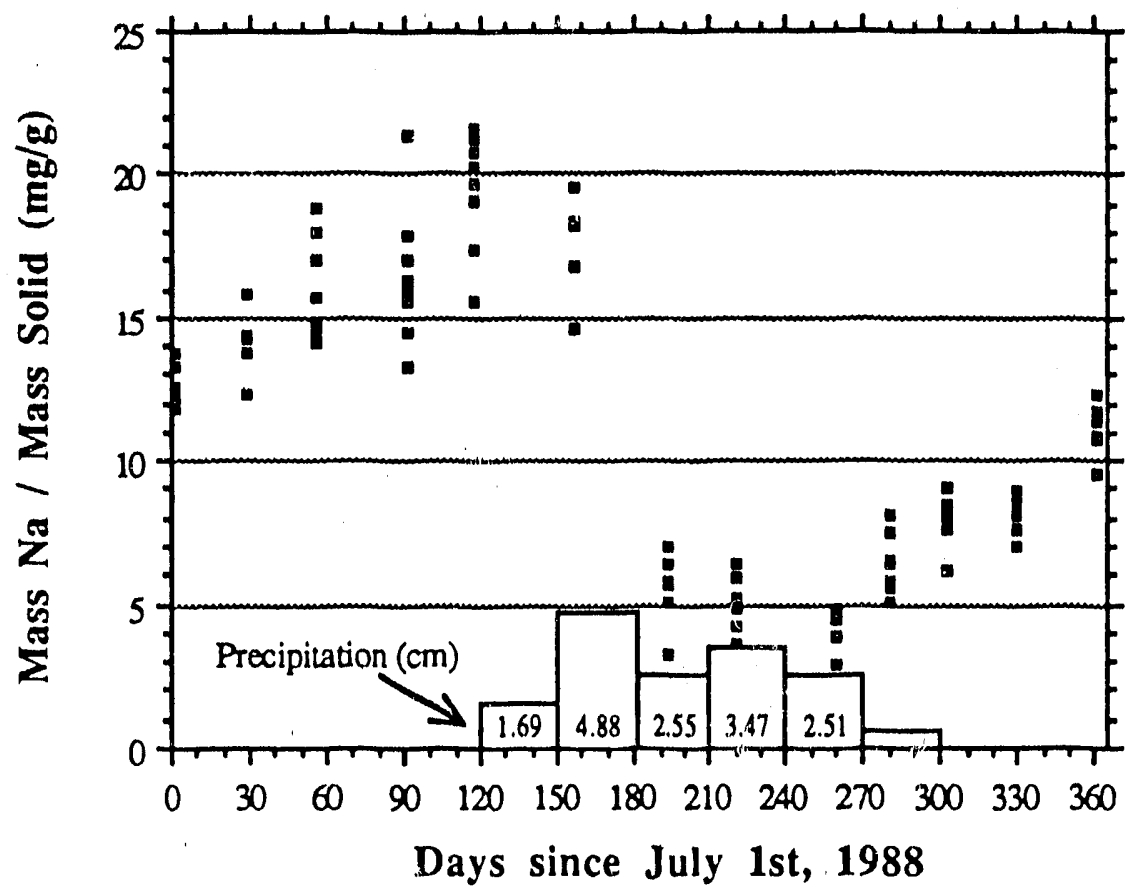

Figure 3.27a. Changes in sodium concentration in the top $9 \mathrm{~cm}$ of soil in plot 8EP: July 1988 - June 1989. Precipitation in $\mathrm{cm}$ shown in boxes on time axis.

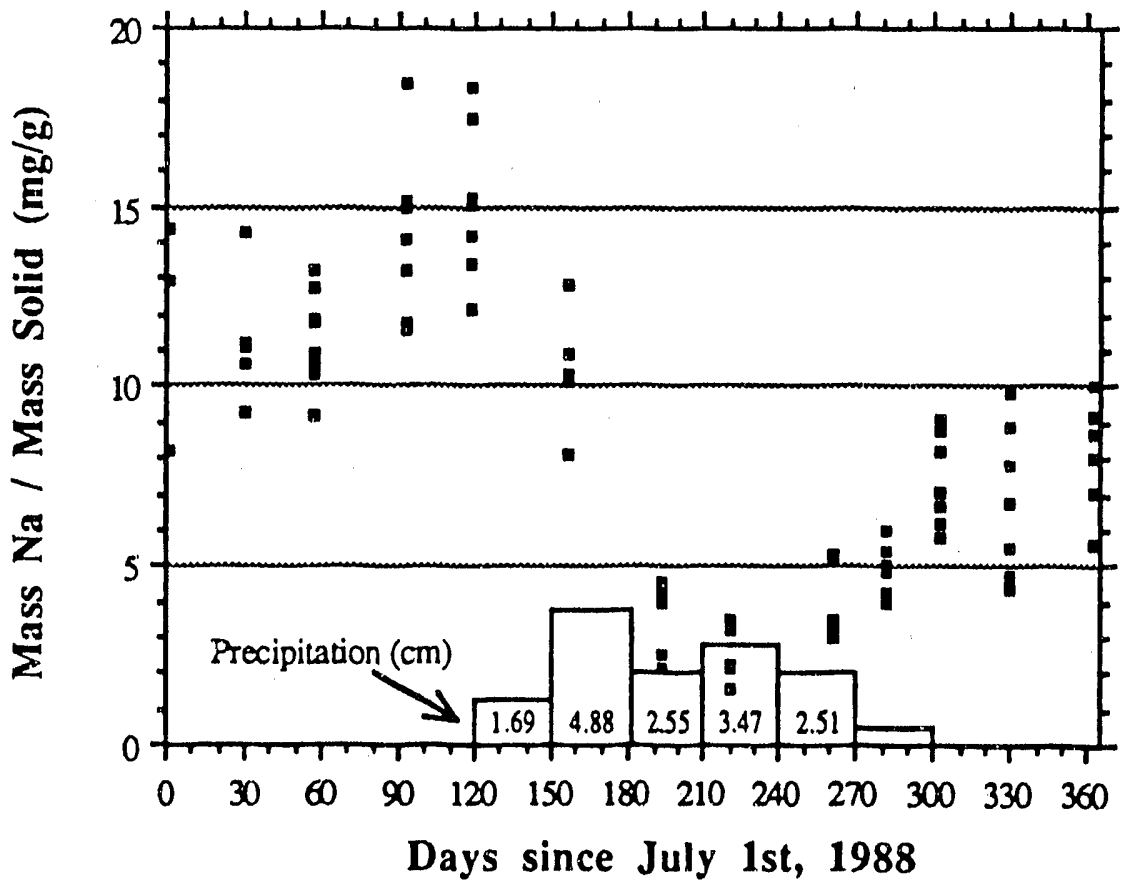

Figure $3.27 \mathrm{~b}$. Changes in sodium concentration in the top $9 \mathrm{~cm}$ of soil in plot 9BE: July 1988 - June 1989. Precipitation in $\mathrm{cm}$ shown in boxes on time axis. 


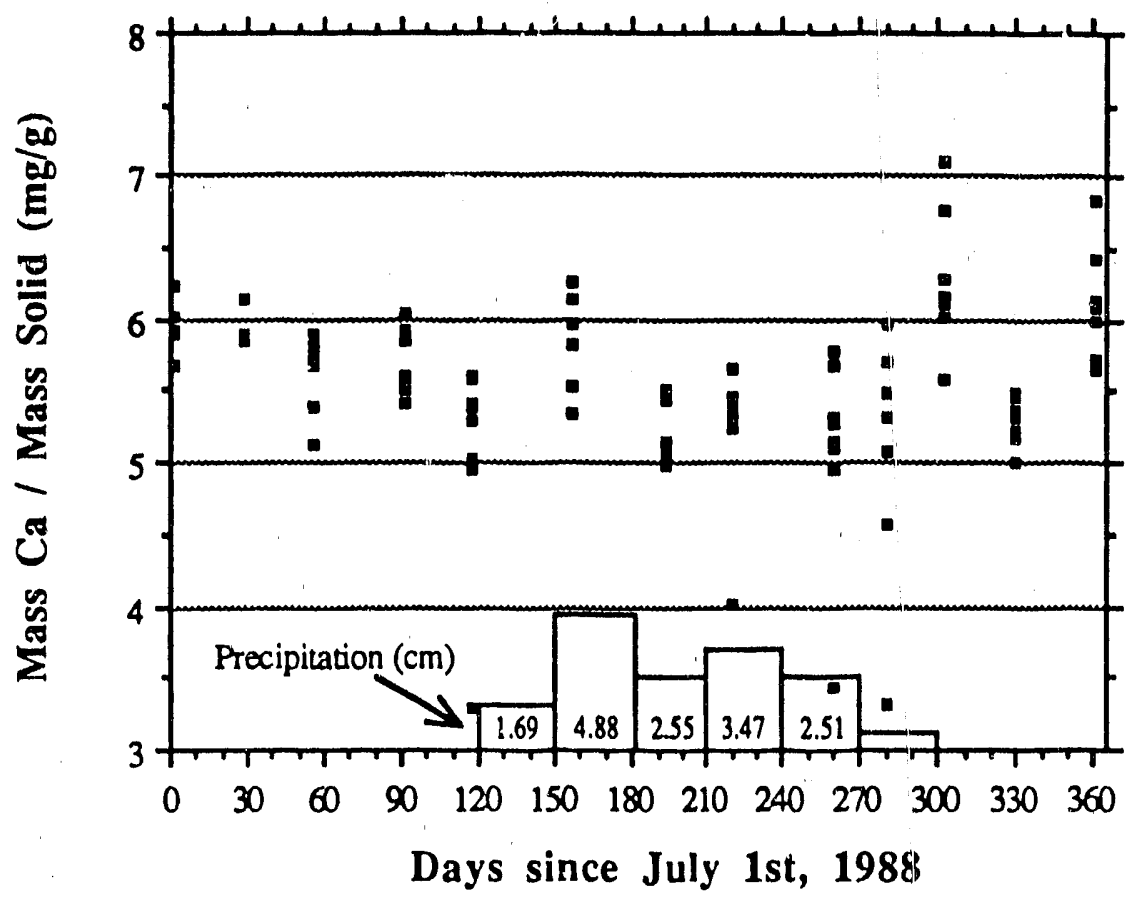

Figure 3.28a. Changes in calcium concentration in the top $9 \mathrm{~cm}$ of soil in plot $8 E P$ : July 1988 - June 1989. Precipitation in cm shown in boxes on time axis.

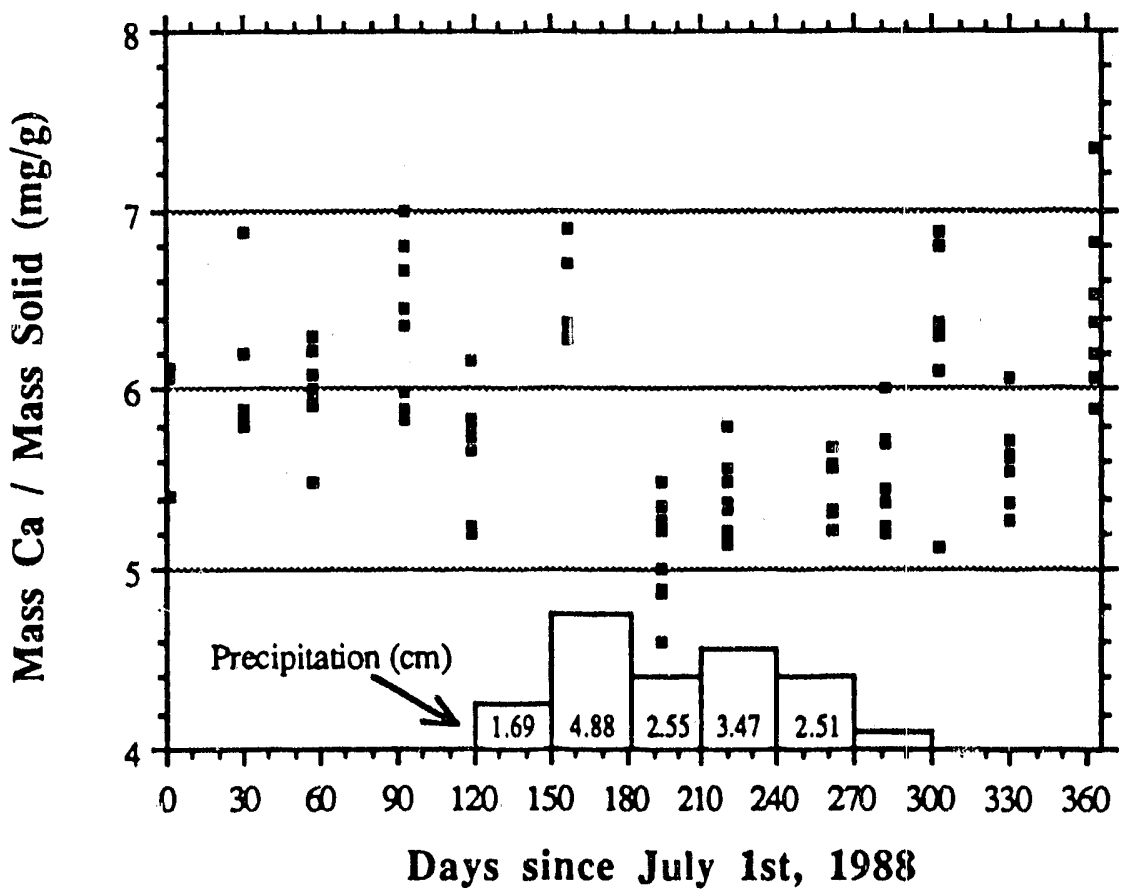

Figure 3.28b. Changes in calcium concentration in the top $9 \mathrm{~cm}$ of soil in plot $9 \mathrm{BE}$ : July 1988 - June 1989. Precipitation in $\mathrm{cm}$ shown in boxes on time axis. 


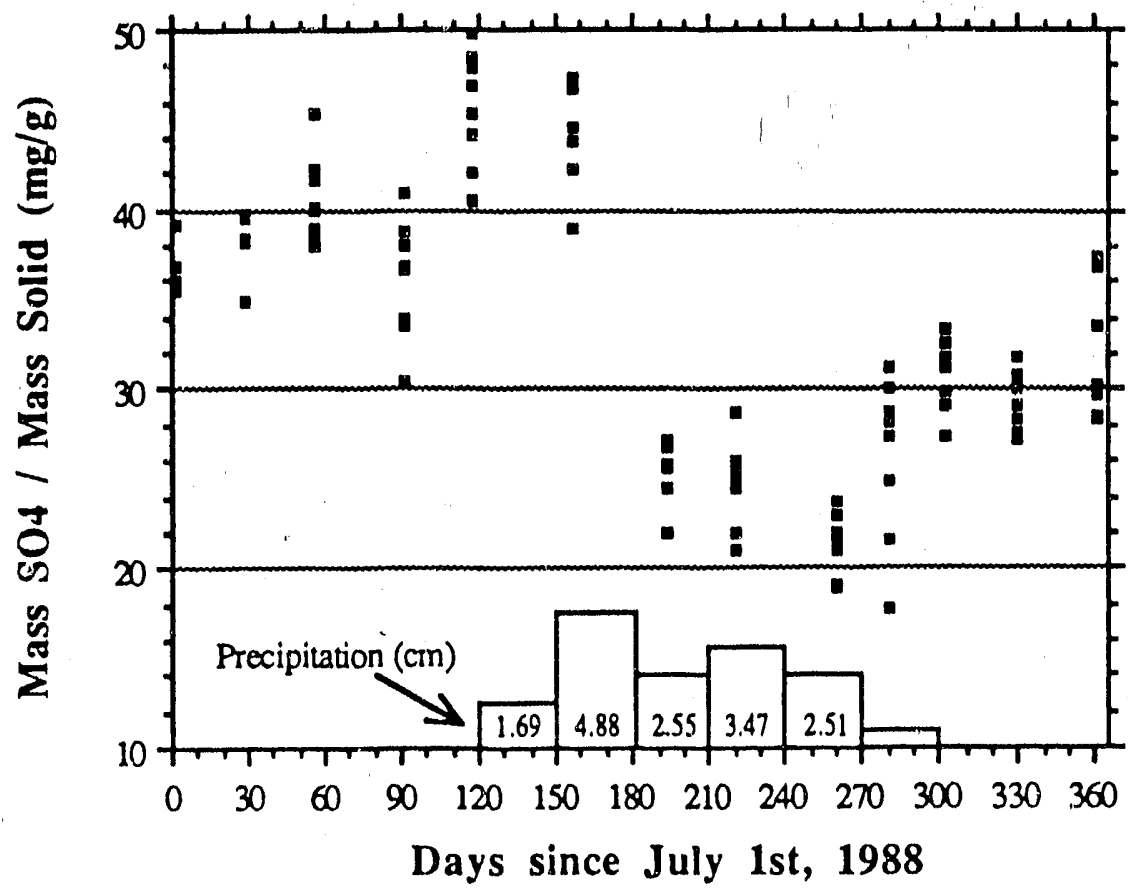

Figure 3.29a. Changes in sulfate concentration in the top $9 \mathrm{~cm}$ of soil in plot 8EP: July 1988 - June 1989. Precipitation in $\mathrm{cm}$ shown in boxes on time axis.

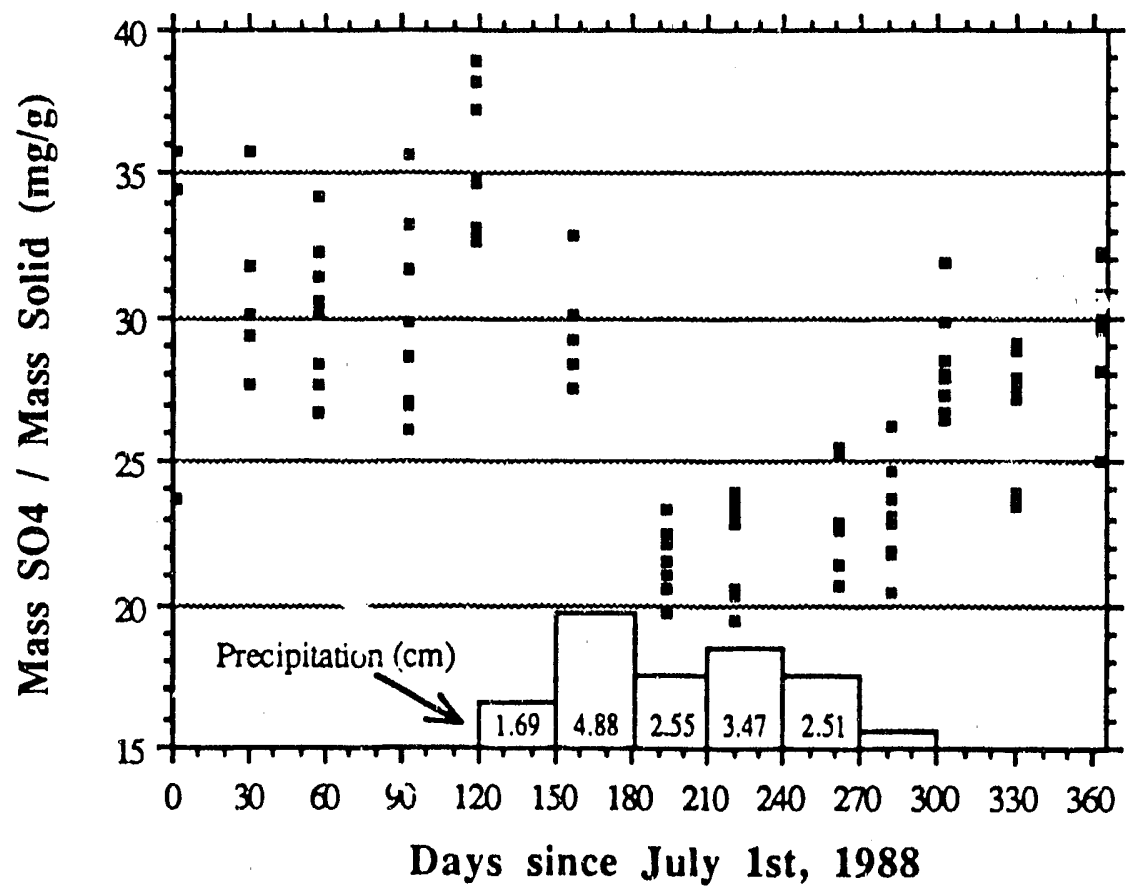

Figure 3.29b. Changes in sulfate concentration in the top $9 \mathrm{~cm}$ of soil in plot 9BE: July 1988 - June 1989. Precipitation in $\mathrm{cm}$ shown in boxes on time axis. 


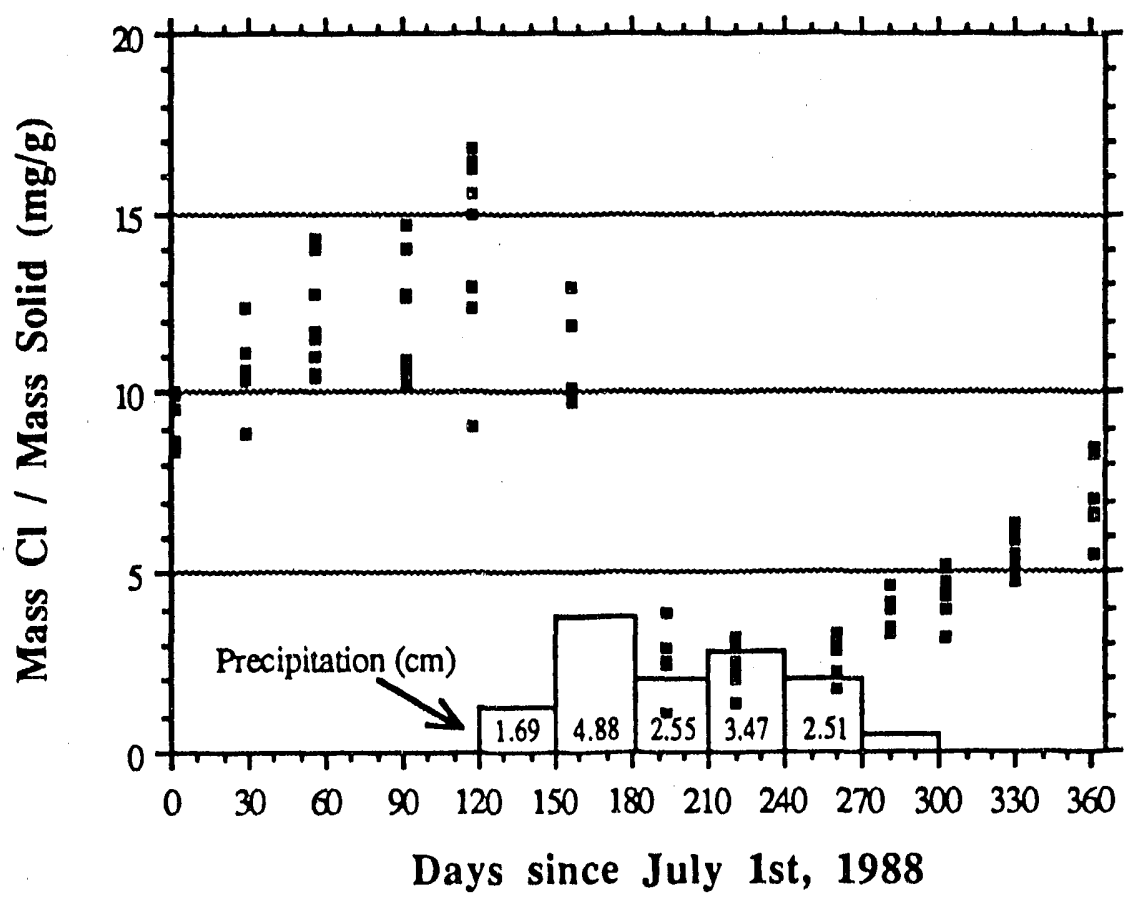

Figure 3.30a. Changes in chloride concentration in the top $9 \mathrm{~cm}$ of soil in plot 8EP: July 1988 - June 1989. Precipitation in $\mathrm{cm}$ shown in boxes on time axis.

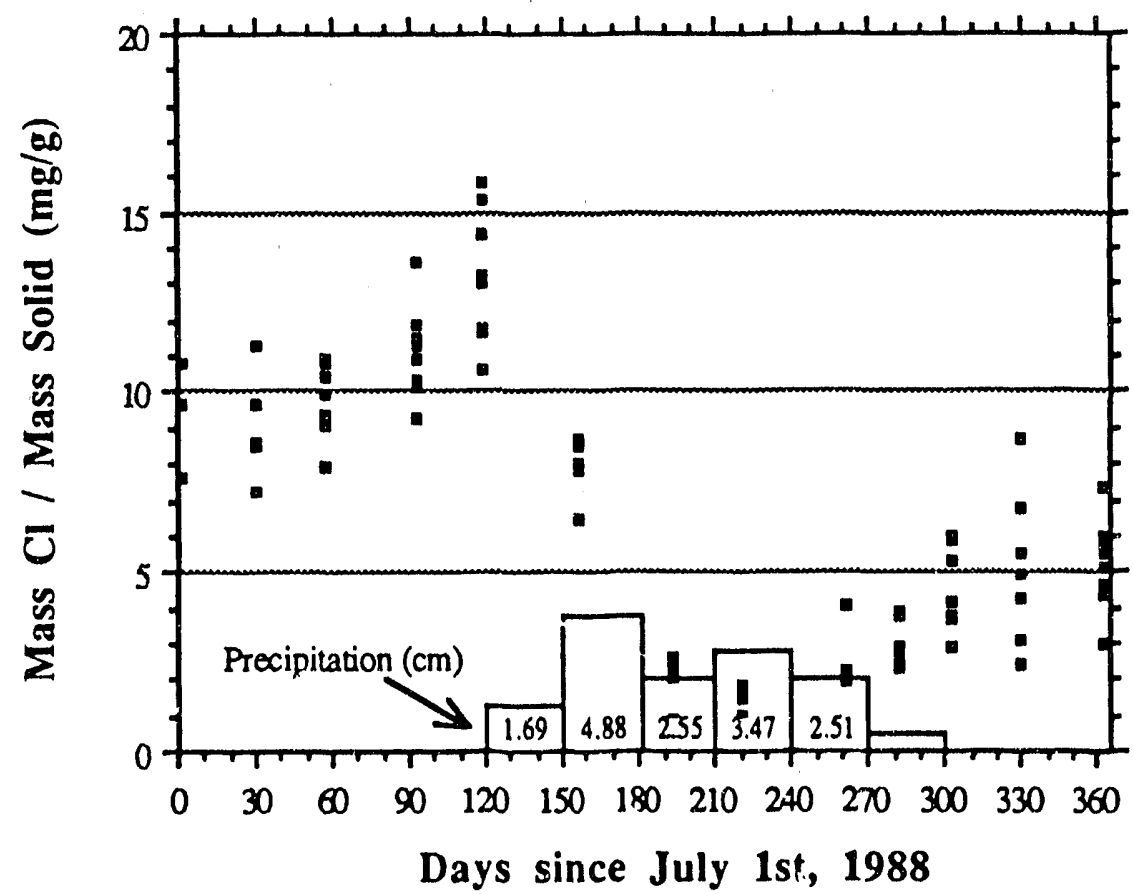

Figure $3.30 \mathrm{~b}$. Changes in chloride concentration in the top $9 \mathrm{~cm}$ of soil in plot $9 \mathrm{BE}$ : July 1988 - June 1989. Precipitation in $\mathrm{cm}$ shown in boxes on time axis. 


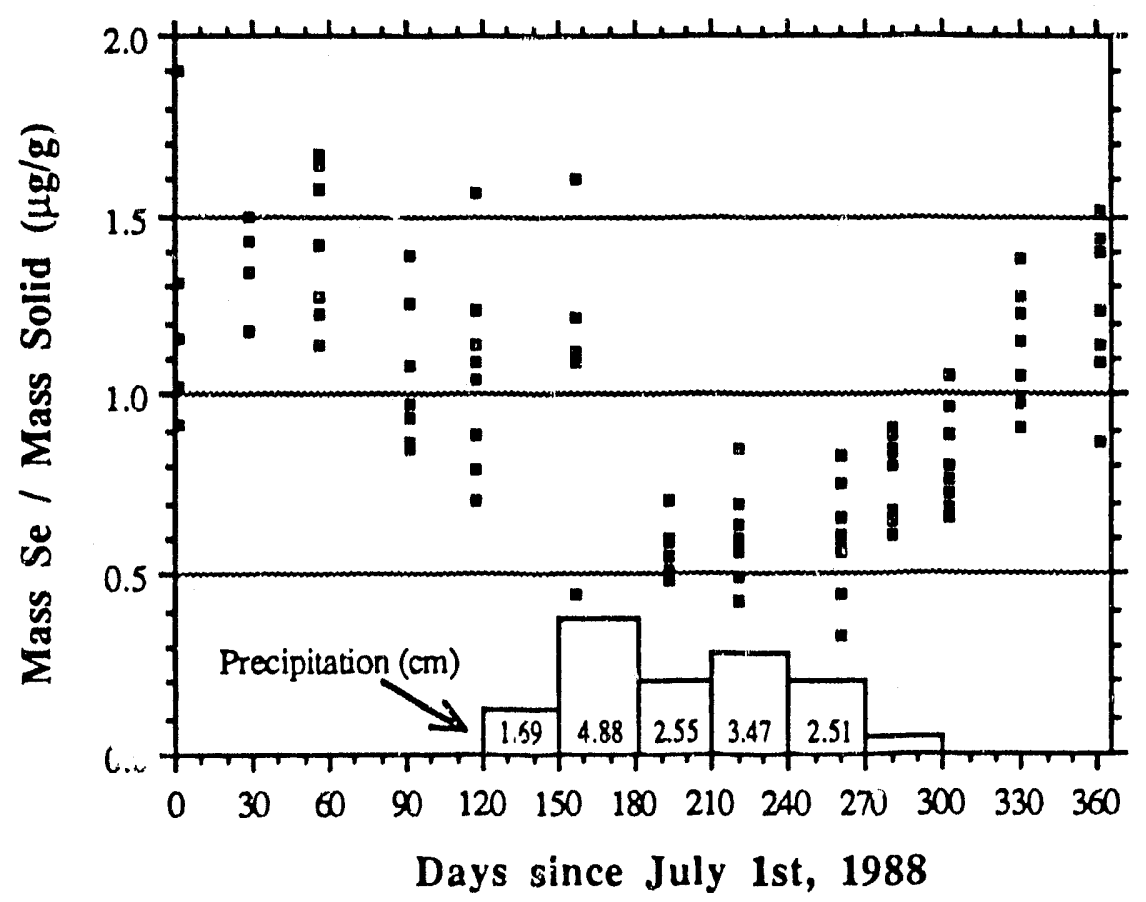

Figure 3.31a. Changes in water-extractable selenium concentration in the top $9 \mathrm{~cm}$ of soil in plot 8EP: July 1988 - June 1989. Precipitation in $\mathrm{cm}$ shown in boxes on time axis.

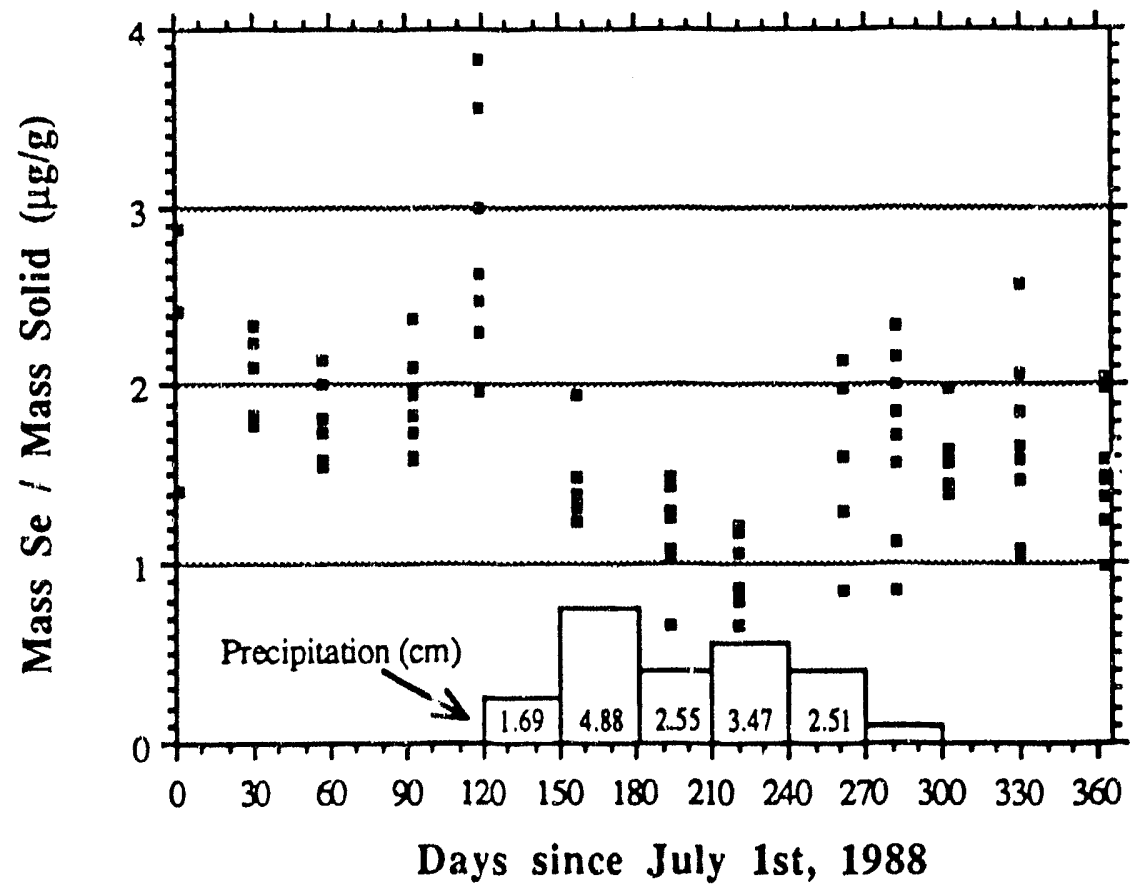

Figure $3.31 \mathrm{~b}$. Changes in water-extractable selenium concentration in the top $9 \mathrm{~cm}$ of soil in plot. 9BE: July 1988 - June 1989. Precipitation in $\mathrm{cm}$ shown in boxes on time axis. 


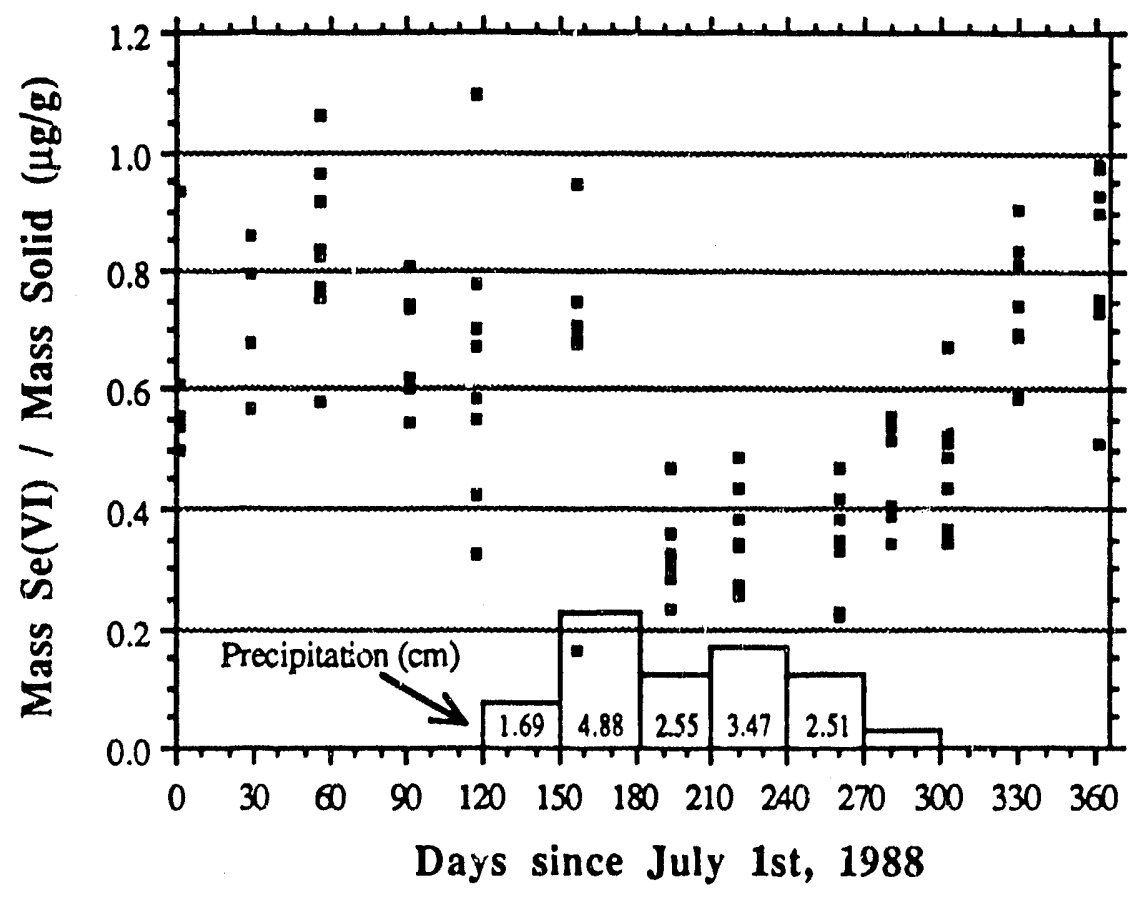

Figure 3.32a. Changes in selenate concentration in the top $9 \mathrm{~cm}$ of soil in plot $8 \mathrm{EP}$ : July 1988 - June 1989. Precipitation in $\mathrm{cm}$ shown in boxes on time axis.

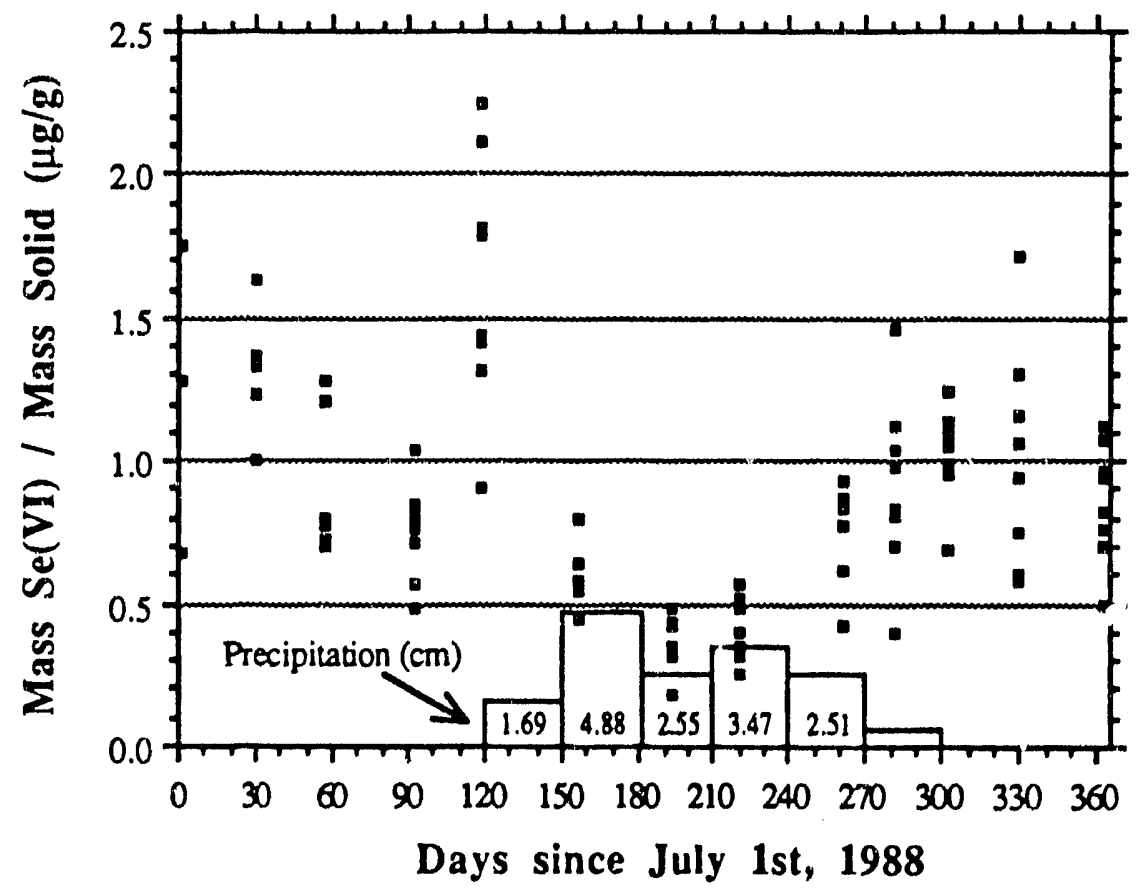

Figure 3.32b. Changes in selenate concentration in the top $9 \mathrm{~cm}$ of soil in plot 9BE: July 1988 - June 1989. Precipitation in $\mathrm{cm}$ shown in boxes on time axis. 


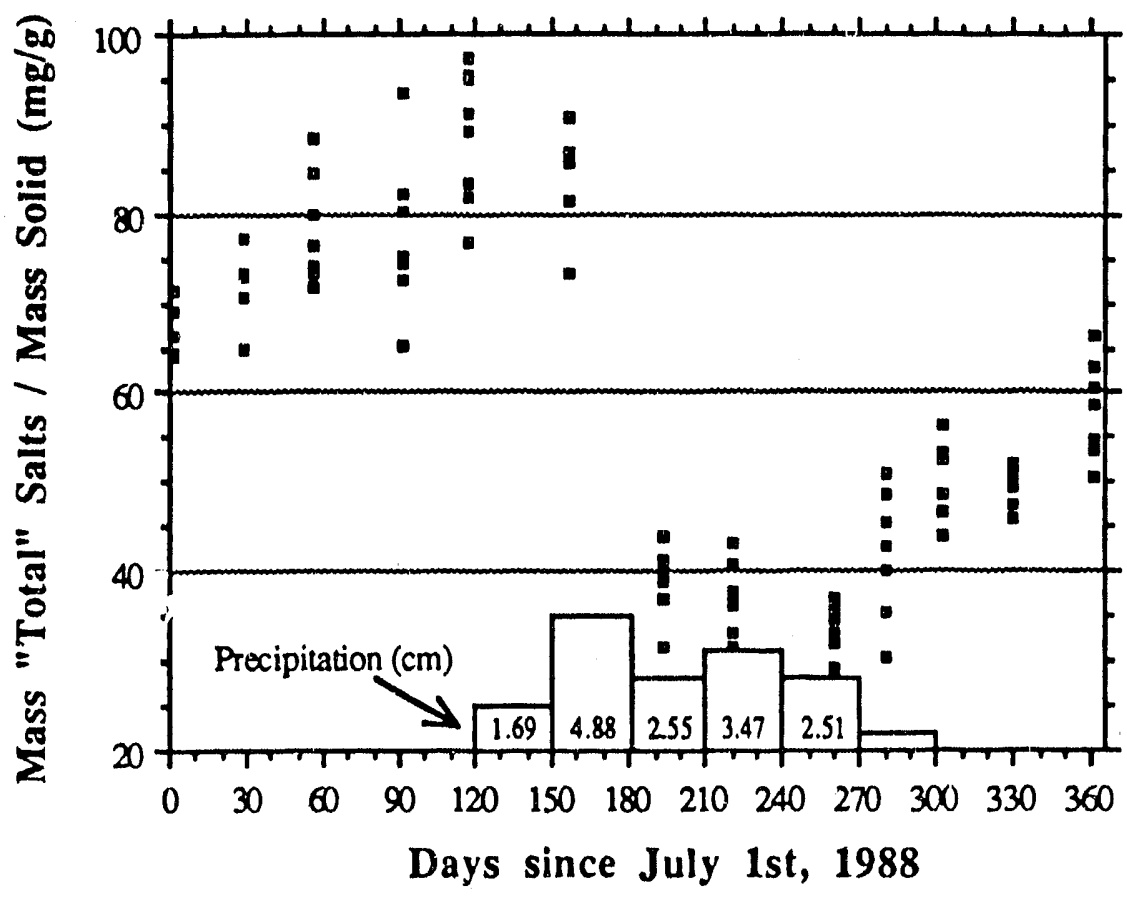

Figure 3.33a. Changes in "total" salt concentration in the top $9 \mathrm{~cm}$ of soil in plot $8 \mathrm{EP}$ : July 1988 - June 1989. Precipitation in $\mathrm{cm}$ shown in boxes on time axis.

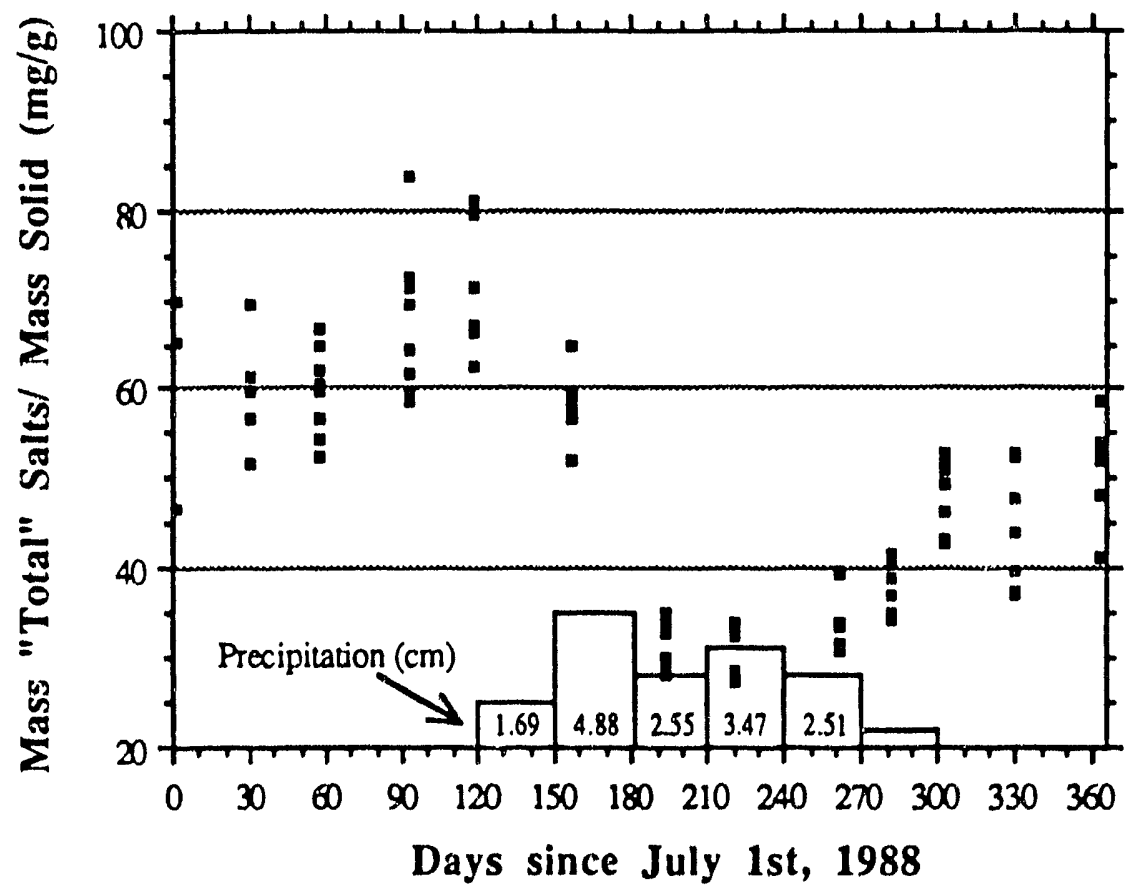

Figure 3.33b. Changes in "total" salt concentration in the top $9 \mathrm{~cm}$ of soil in plot 9BE: July 1988 - June 1989. Precipitation in $\mathrm{cm}$ shown in boxes on time axis. 
despite sampling within a relatively small area $\left(4\right.$ to $5 \mathrm{~m}^{2}$ ), the spatial variability was rather large, especially in plot 9BE (see following paragraphs). In general, changes in species concentrations are more difficult to discern from data from plot 9BE. Nevertheless, three cycles of drying, wetting, and drying, resulting in corresponding increases, decreases, and increases in salt concentrations are observed at both plots. In reality, there are only two periods: one of drying and salinization during the late spring, summer, and early fall, and another of wetting and desalinization during late fall, winter, and early spring months. In Figures 3.27 to 3.33 the summer and early fall months are represented by data from day 1 through approximately day 120 ; the wet period took place from approximately day 120 until day 240 . Following day 240 , increases in salt concentrations were due to evaporation during late spring and early summer months (see Figures 3.7 and 3.8 for weather patterns during the study term).

Concentrations of the most mobile species $\left(\mathrm{Na}^{+}, \mathrm{Cl}^{-}\right)$changed most dramatically with time. For example, during the first drying period (July - October, 1988), the mean sodium concentration in the top $9 \mathrm{~cm}$ increased from $12.73 \mathrm{mg} / \mathrm{g}\left(\mathrm{C} . \mathrm{V}^{1}=6.3 \%\right)$ to $19.47 \mathrm{mg} / \mathrm{g}(\mathrm{C} . \mathrm{V} .=10.7 \%)$ in plot $8 \mathrm{EP}$ and from $11.85 \mathrm{mg} / \mathrm{g}(\mathrm{C} . \mathrm{V} .=27.3 \%)$ to $15.54 \mathrm{mg} / \mathrm{g}(\mathrm{C} . \mathrm{V} .=14.9 \%)$ in plot $9 \mathrm{BE}$ (Figure 3.27). The mean chloride concentration rose from $9.33 \mathrm{mg} / \mathrm{g}(\mathrm{C} . \mathrm{V} .=7.8 \%)$ to $14.30 \mathrm{mg} / \mathrm{g}$ (C.V. $=$ $18.5 \%)$ in plot $8 \mathrm{EP}$ and from $9.38 \mathrm{mg} / \mathrm{g}(\mathrm{C} . \mathrm{V} .=17.3 \%)$ to $13.23 \mathrm{mg} / \mathrm{g}(\mathrm{C} . \mathrm{V} .=14.0 \%)$ in plot $9 \mathrm{BE}$ (Figure 3.30). No clear trends emerge from the distribution of selenium data during the summer and fall of 1988 (Figures $3.31,3.32$ ). This is probably in large part due to the much greater spatial variability of selenium than major ions. Since selenite is mostly found adsorbed onto solid matter in the soil, changes in selenate concentrations are more indicative of soluble selenium behavior (Figure 3.32). In neither plot, however, did selenate concentrations change along any discemible trend.

With the onset of the rainy season in late October, salts which had been accumulating near the soil surface were beginning to get flushed down deeper into the soil profile by infiltrating rainwater. This effect is quite apparent in the rather sudden decrease in concentrations of all 1 Coefficient of Variation (C.V.) $=$ Standard Deviation (S.D.) divided by Mean of data set times 100 . 
species, except calcium, after day 150. A greater decrease in concentrations in plot 9BE between days 120 and 150 is consistent with the higher flow rates exper,ied in the coarser-textured sediments of that plot. During the rainy season, the mean concentration of sodium in plot $8 \mathrm{EP}$ declined from a high of $19.47 \mathrm{mg} / \mathrm{g}$ at the end of the summer to $5.05 \mathrm{mg} / \mathrm{g}(\mathrm{C} . \mathrm{V} .=17.2 \%)$ on day 220. The corresponding decrease in plot $9 \mathrm{BE}$ was from $15.54 \mathrm{mg} / \mathrm{g}$ to $2.84 \mathrm{mg} / \mathrm{g}(\mathrm{C} . \mathrm{V} .=25.7 \%)$. Similar decreases were observed in chloride concentrations (Figure 3.30). Coincident with these declines, were decreases in selenate concentrations at both plots (Figure 3.32). While still obscured by spatial variability, the range of selenate concentrations during this period was between 0.0 and $0.55 \mu \mathrm{g} / \mathrm{g}$ which was lower than at any time before; even though it is certain that some selenate was being flushed out of the surface $9 \mathrm{~cm}$ of soil during this period, these data do not positively confirm this. However, data from soil-water samplers and extracts from soil profiles in both plots also support this notion. Changes in EC and concentrations of chloride and selenate in in-situ soil-water of plot 9BE are shown in Figure 3.31. Following rainfall events of early winter, significant pulses of salts and selenium were observed moving through the soil profile. Concentrations of both salts and selenate rose most sharply at a depth of $15 \mathrm{~cm}$ and progressively less with depth. Such a pattern of increase is due to the flushing out of species from the top few centimeters of soil. This pattern is confirmed by data from extracts made of soil in profile at both plots. While detection of a selenate decrease in surface samples is impeded by spatial variability of selenium concentrations, data from soil-water samplers and soil extracts in profile leave little doubt that selenate was being flushed out along with chloride and other salts.

In the months following most of the season's rainfall events, concentrations of species in the top $9 \mathrm{cn}$ of the soil profile slowly increased in response to evaporatively induced water flow toward the surface. Between day 220 and day 361 , the mean concentration of sodium in plot 8EP ascended from a low of $5.05 \mathrm{mg} / \mathrm{g}$ to $11.10 \mathrm{mg} / \mathrm{g}(\mathrm{C} . \mathrm{V} .=7.6 \%)$; the corresponding increase in plot 9BE was from $2.84 \mathrm{mg} / \mathrm{g}$ to $8.24 \mathrm{mg} / \mathrm{g}(\mathrm{C} . \mathrm{V} .=16.6 \%$ ) (Figure 3.27 ). The mean chloride concentration rose from $2.35 \mathrm{mg} / \mathrm{g}$ to $7.09 \mathrm{mg} / \mathrm{g}(\mathrm{C} . \mathrm{V} .=13.3 \%)$ in plot $8 \mathrm{EP}$ and from $1.12 \mathrm{mg} / \mathrm{g}$ to $5.21 \mathrm{mg} / \mathrm{g}(\mathrm{C} . \mathrm{V} .=24.6 \%)$ in plot 9BE (Figure 3.30). Similar increases were observed in total 
salts concentrations (Figure 3.33). Unlike during the summer and fall of 1988, increases in selenate concentrations were easily discemible during the late spring and summer of 1989 and resulted in selenate concentrations ranging from 0.5 to $1.0 \mu \mathrm{g} / \mathrm{g}$ at plot $8 \mathrm{EP}$ and 0.5 to $1.5 \mu \mathrm{g} / \mathrm{g}$ in plot 9BE. Redistribution of salts and selenate in the soil profile of plot 9BE was observed through soil-water samplers (Figure 3.34). Due to the limited cata from plot 8EP during this period (sampler failure), this redistribution is not very evident.

The year encompassed by this study was a particularly dry one (total precipitation $=162$ $\mathrm{mm}$, compared with an average precipitation from 1982 to 1988 of $279 \mathrm{~mm}$ ). Nevertheless, a net decrease in the near surface concentrations of both salts and selenate was observed. This decrease, while slight, is indicative of a system in transition. Due to the unnatural accumulation of salts and selenium at and near the soil surface as a result of ponding and subsequent evaporation, the redistribution of species in the next few years will most likely result in a net decrease, albeit small, of salt concentrations at the soil surface. This may or may not be true for soluble selenium, depending on the rate of oxidation of the insoluble fraction, although an increase of soluble selenium due to evaporative concentration seems unlikely. According to the results of XRF analyses of four soil samples from each plot (Table 3.8), water-extractable selenium comprises between $3.8 \%$ and $20.1 \%$ of total selenium in the top $9 \mathrm{~cm}$ of soil. The inventory of potentially oxidizable selenium is substantial, especially in plot 9BE and may be even greater in certain other parts of Kesterson Reservoir. The rate of selenium oxidation will play an important role in determining soluble selenium concentrations. Trends of soluble selenium redistribution will depend very strongly on weather pattems in the years to come.

\subsubsection{Quantitative Analysis of Chloride Accumulation: Calculation of Seasonal Evaporation Rates}

The qualitative analysis of data presented in the previous section helped delineate two fairly distinct stages in the annual cycle of wetting and drying of the surface soils at Kesterson Reservoir. In order to quantitatively describe the evaporative concentration of species near the soil surface and thereby estimate seasonal evaporation rates, a non-reactive, high solubility, high 


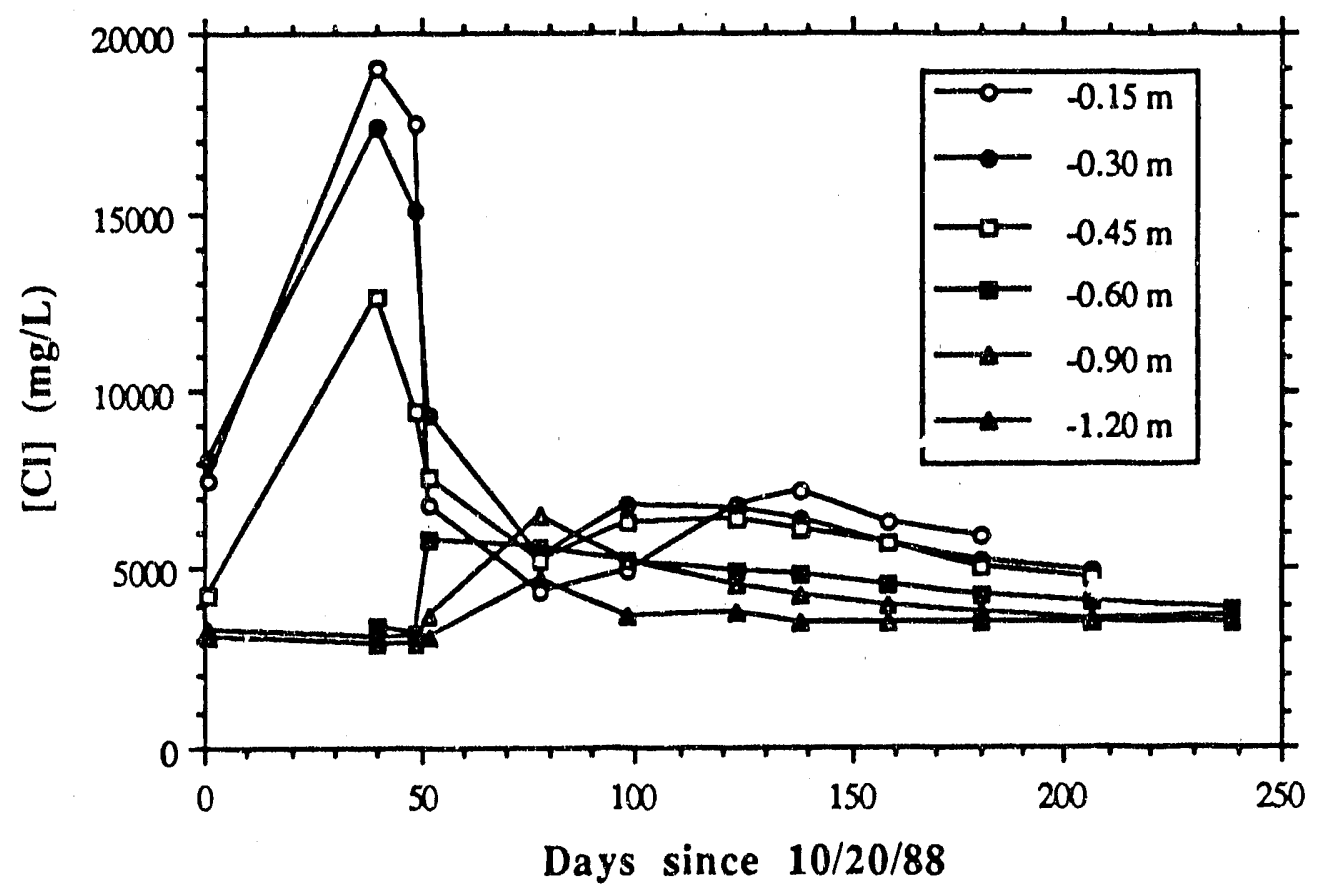

Figure 3.34a. Changes in chloride concentrations in soil-water at six depths in plot 9BE $(10 / 20 / 88-5 / 25 / 89)$.

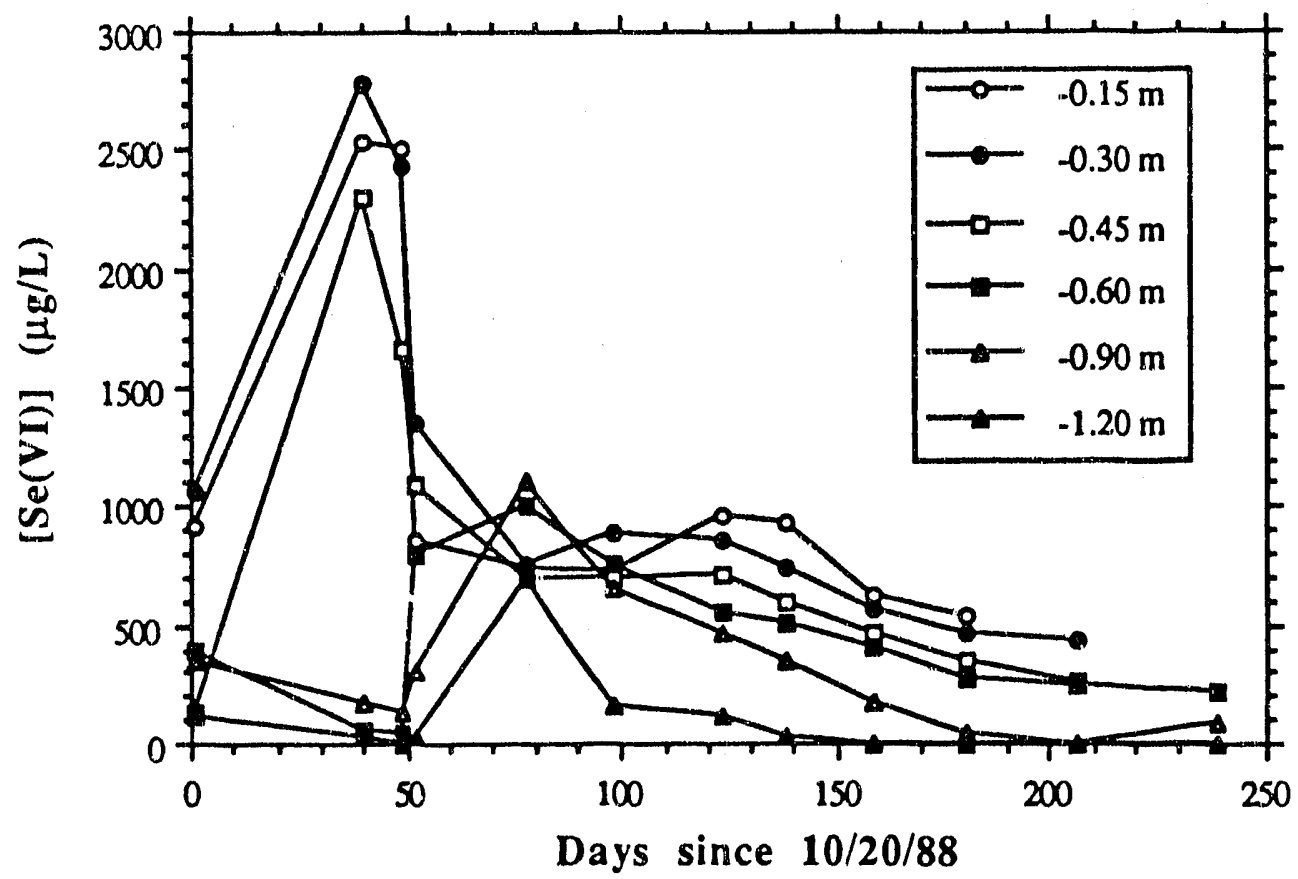

Figure $3.34 \mathrm{~b}$. Changes in selenate concentrations in soil-water at six depths in plot $9 \mathrm{BE}$ $(10 / 20 / 88-5 / 25 / 89)$. 
concentration species must be used. Satisfying these criteria, chloride will serve as a tracer in this analysis.

Table 3.8. Concentrations of water-extractable selenium vs. total selenium by XRF analysis

\begin{tabular}{|ccccc|}
\hline $\begin{array}{c}\text { Plot and } \\
\text { Sample Name }\end{array}$ & $\begin{array}{c}\text { Date } \\
\text { Collected }\end{array}$ & $\begin{array}{c}\text { Total Se as } \\
\text { analyzed by } \\
\text { XRF }(\mu \mathrm{g} / \mathrm{g})\end{array}$ & $\begin{array}{c}\text { Water- } \\
\text { extractable } \\
\text { Se }(\mu \mathrm{g} / \mathrm{g})\end{array}$ & $\begin{array}{c}\text { Percent of } \\
\text { water-extractable } \\
\text { Se }\end{array}$ \\
\hline \hline Plot 8EP ML1E & $10 / 25 / 88$ & 7.8 & 1.6 & 20.1 \\
Plot 8EP ML8E & $10 / 25 / 88$ & 4.6 & 0.7 & 15.3 \\
Plot 8EP Surf1D & $2 / 5 / 89$ & 5.9 & 0.4 & 7.1 \\
Plot 8EP Surf4D & $2 / 5 / 89$ & 8.0 & 0.9 & 10.7 \\
& & & & \\
Plot 9BE ML3E & $10 / 25 / 88$ & 26.5 & 3.8 & 14.4 \\
Plot 9BE ML6E & $10 / 25 / 88$ & 16.5 & 2.0 & 12.0 \\
Plot 9BE Surf4D & $2 / 5 / 89$ & 17.2 & 0.7 & 3.8 \\
Plot 9BE Surf6D & $2 / 5 / 89$ & 22.9 & 1.2 & 5.3 \\
\hline
\end{tabular}

\subsection{Approach}

Bare soil evaporation rates may be estimated based on increases in chloride concentrations in the top $9 \mathrm{~cm}$ of soil (or any top interval for that matter), changes in the moisture content of that interval, and the chloride concentration gradient along which chloride diffusion takes place. The first two variables can and have been measured in the field over the period of this study and have been presented in previous sections. Unfortunately, the magnitude of chloride diffusion in the soil must be estimated and involves substantial error due to the unknown relationship between tortuosity and saturation in Kesterson sediments, especially in surface soils. Figure 3.35 displays the water and chloride fluxes ( $\mathrm{q}_{w}$ and $\mathrm{J}_{\mathrm{Cl}}$ respectively) into and out of the surface $9 \mathrm{~cm}$ of soil. Water mass balance requires that the mass of waier entering the element be equal to the mass of water leaving the element plus any mass of water accumulated within the element:

$$
q_{w, a d v} \rho_{w} A \Delta t=q_{w, e b s} \rho_{w} A \Delta t+\Delta M_{w}
$$

where $q_{w, a d v}$ is the advective flux of water from below the element $\left[\mathrm{LT}^{-1}\right], \mathrm{q}_{w, e b s}$ is the evaporative flux of water out of the top of the element $\left[\mathrm{LT}^{-1}\right], \rho_{w}$ is the density of water $\left[\mathrm{ML}^{-3}\right], A$ is the 


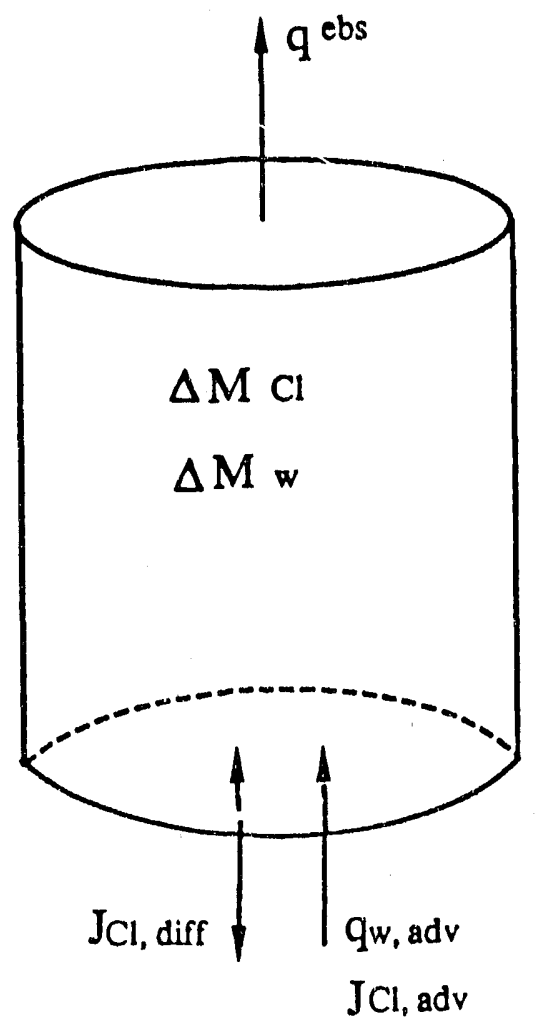

Figure 3.35. Water and chloride fluxes into and out of the top $9 \mathrm{~cm}$ of soil. 
cross-sectional area of the element, $\Delta t$ is the time increment, and $\Delta \mathrm{M}_{\mathrm{w}}$ is the change in the mass of water within the element. $\mathrm{M}_{\mathrm{w}}$ may be expressed as the product of gravimetric moisture content and the mass of solid within the element:

$$
\Delta M_{w}=\Delta \theta_{\text {grav }} M_{\text {solid }}
$$

Equation (3.6) can then be rewritten as:

$$
q_{w, a d v}=q_{w, e b s}+\Delta \theta_{\text {grav }} \frac{M_{\text {solid }}}{\rho_{w} A \Delta t}
$$

A similar mass balance expression may be set up for chloride:

$$
\mathrm{J}_{\mathrm{Cl}, \text { adv }} \mathrm{A} \Delta \mathrm{t}+\mathrm{J}_{\mathrm{Cl}, \text { diff }} \mathrm{A} \Delta \mathrm{t}=\Delta \mathrm{M}_{\mathrm{Cl}}
$$

where $\mathrm{J}_{\mathrm{Cl} \text {,adv }}$ is the advective flux of chloride into the element $\left[\mathrm{ML}^{-2} \mathrm{~T}^{-1}\right], \mathrm{J}_{\mathrm{Cl} \text {,diff }}$ is the diffusive flux of chloride into or out of the element $\left[\mathrm{ML}^{-2} \mathrm{~T}^{-1}\right]$, and $\Delta \mathrm{M}_{\mathrm{Cl}}$ is the net change in chloride mass within the clement. The advective flux of chloride may be expressed as follows:

$$
\mathrm{J}_{\mathrm{Cl}, \mathrm{adv}}=\mathrm{q}_{\mathrm{w}, \mathrm{adv}} \mathrm{C}_{\mathrm{Cl}, \mathrm{lb}}
$$

where $\mathrm{C}_{\mathrm{Cl}, \mathrm{lb}}$ is the concentration of chloride per volume of soil solution at the lower boundary of the element. The diffusive flux of chloride may be described in the following way:

$$
\mathrm{J}_{\mathrm{Cl}, \mathrm{diff}}=-\left[\mathrm{D}_{0} \mathrm{nS} \tau\right] \frac{\Delta \mathrm{C}_{\mathrm{Cl}}}{\Delta \mathrm{z}}
$$

where $D_{0}$ is the diffusivity of the chloride ion in water $\left[\mathrm{L}^{2} \mathrm{~T}^{-1}\right], \mathrm{n}$ is porosity, $\mathrm{S}$ is relative saturation, $\tau$ is a tortuosity factor, and $\Delta \mathrm{C}_{\mathrm{Cl}} / \Delta \mathrm{z}$ is the chloride soil solution concentration gradient $\left[\mathrm{ML}^{-4}\right]$. Combining equations (3.9) through (3.11):

$$
\mathrm{q}_{\mathrm{w}, \mathrm{\Delta dv}} \mathrm{C}_{\mathrm{Cl}, \mathrm{lb}}-\left[\mathrm{D}_{0} \mathrm{nS \tau}\right] \frac{\Delta \mathrm{C}_{\mathrm{Cl}}}{\Delta \mathrm{z}}=\frac{\mathrm{M}_{\mathrm{Cl}}}{\mathrm{A} \Delta \mathrm{t}}
$$

Solving for $q_{w, u d v}$, one obtains:

$$
q_{w, \Omega d v}=\left(\frac{\Delta M_{C l}}{A \Delta t}+\left[D_{0} n S \tau\right] \frac{\Delta C_{C l}}{\Delta z}\right) \frac{1}{C_{C l, l b}}
$$

substituting the above expression for $q_{w, a d v}$ in equation (3.3.4.3) and rearranging to solve for $q_{w, e b s}:$

$$
q_{w, e b s}=\frac{\Delta M_{C l}}{C_{C l, l b} A \Delta t}+\frac{1}{C_{C l, l b}}\left[D_{0} n S \tau\right] \frac{\Delta C_{C l}}{\Delta z}-\Delta \theta_{\text {grav }} \frac{M_{\text {solid }}}{\rho_{w} A \Delta t}
$$


The first term on the right hand side of equation (3.14a) reflects the evaporation rate which would be calculated if there were no net change in moisture content and no chloride diffusion. The second term is the correction for diffusion of chloride; the third term is the additional evaporation which causes net drying of the soil interval. As mentioned before, terms 1 and 3 can be calculated with greater accuracy than term 2 ; this is due to the fact that the tortuosity factor, $\tau$, is not a constant under desaturating conditions. Research conducted over the last two to three decades has shown that the tortuosity of flow path increases significantly with decreasing moisture content, as a result of water film thinning in the porous medium. The proportion of water-filled pores which are connected to a continuous pore network gradually declines along with moisture content (Pinner and Nye, 1982). This results in the lowering of the diffusivity of species in porous media and a reduction in diffusive flux under a given concentration gradient. This effect has been characterized by using "impedance factors" in place of tortuosity factors (Porter and others, 1960; Barraclough and Tinker, 1981, 1982). In general, it has been found that the impedance factor is an approximately linear function of volumetric moisture content $\left(\theta_{\mathrm{vol}}\right)$; the slope of this function varies from soil to soil and has also been found to be dependent on the compaction of a given soil (Figure 3.36). It appears that the linear nature of this function breaks down as $\theta_{\text {vol }}$ falls below 0.1 or so. Unfortunately, the slope of this function for soil in plots 8EP and 9BE is not known. However, certain assumptions may be made based on the bulk density of these nearsurface soils and their textural compositions. For example, the surface $9 \mathrm{~cm}$ of soil at plot 8EP is texturally characterized as a clay loam to loam with a bulk density of $1.31 \mathrm{~g} \mathrm{~cm}^{-3}$ (C.V. $=4.3 \%$ ). Therefore, it is texturally similar to the sandy clay loam and the loam of Figure 3.36a. On the other hand, the surface $9 \mathrm{~cm}$ of the soil at plot $9 \mathrm{BE}$ is a clay loam to silty clay loam w:th a bulk density of $0.96 \mathrm{~g} \mathrm{~cm}^{-3}$ (C.V. $=7.1 \%$ ), which makes it most similar to the clay and silty clay loam of Figure 3.3.4.11a. Quite obviously, such comparisons must be made with extreme caution: the impedance factor of any given soil depends on other properties, such as structure and organic matter content. Thus, diffusivities calculated using these functions must be interpreted as highly approximate. In this fashion, the diffusivity in term 2 of equation (3.14) was calculated. 


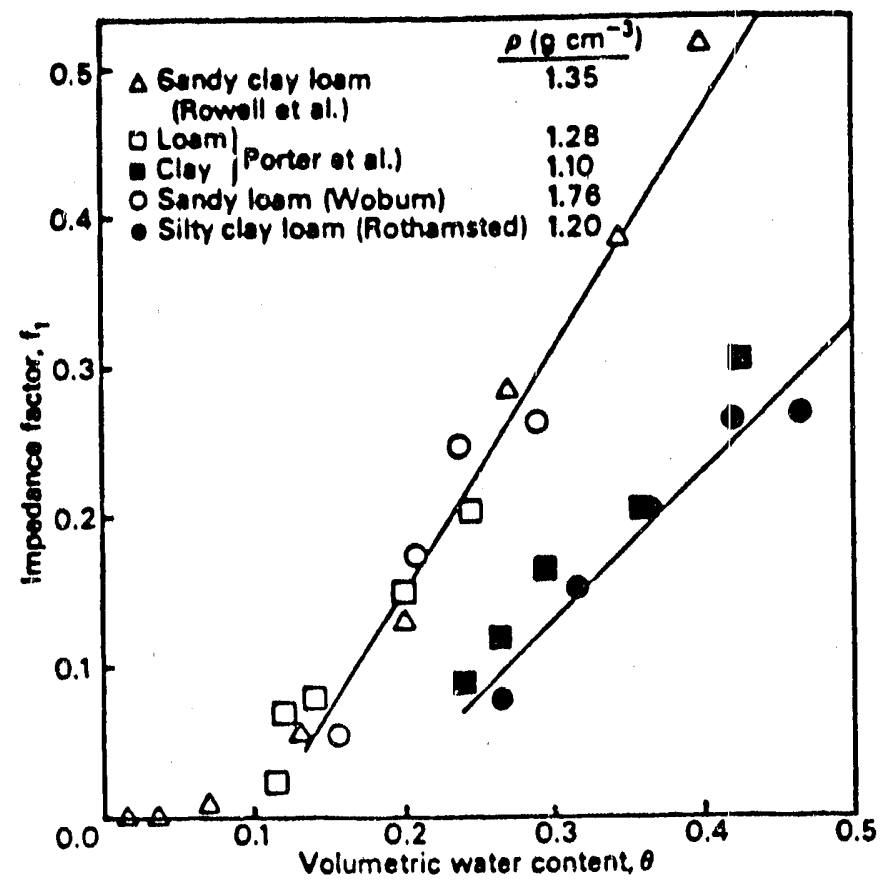

Figure 3.36a. Impedance factor, $\mathrm{f}_{1}$, as a function of volumetric water content in five different soils, each soil at a constant bulk density (from Barraclough and Tinker, 1981).

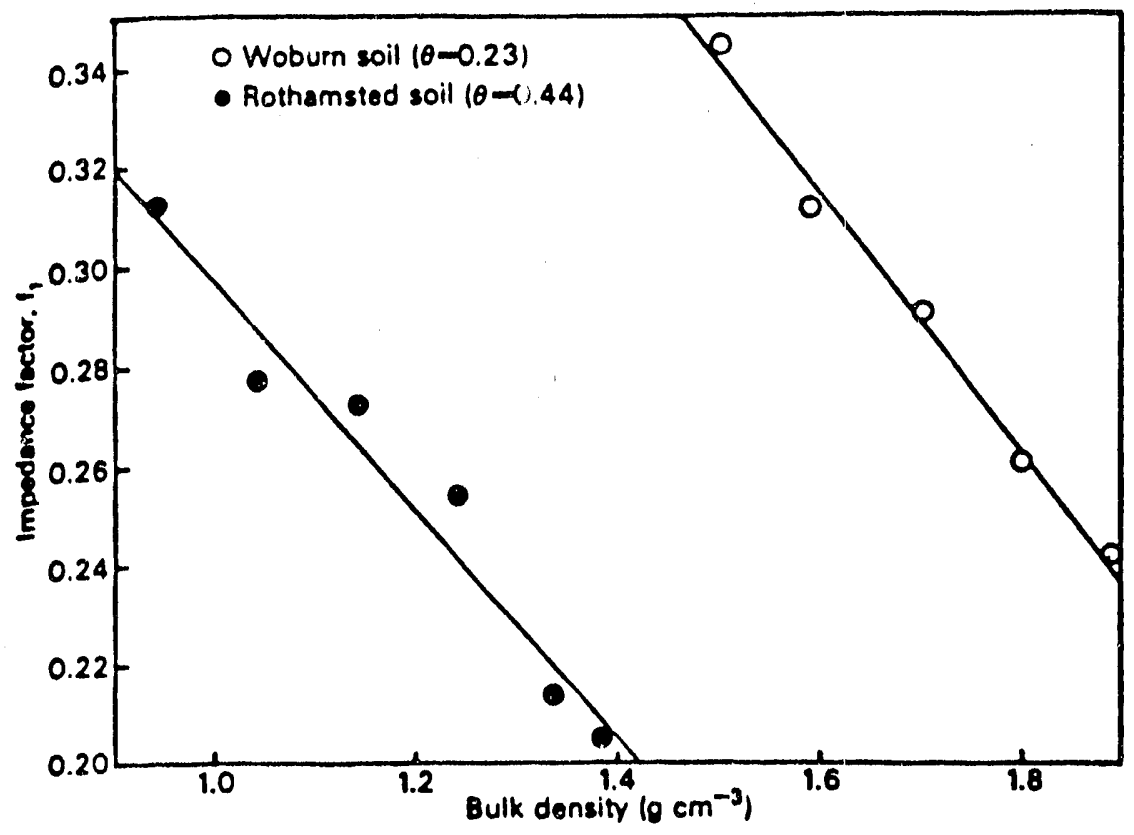

Figure 3.36b. Impedance factor, $f_{1}$ as a function of bulk density at a constant volumetric water content. 


\subsection{Results}

Table 3.9 summarizes the calculations involved in solving equation (3.14) for both plots and for two seasons for each plot. In general, the concentration of chloride at the lower boundary of the surface soil element is not known exactly; however, based on profile samples, the concentration at a $15 \mathrm{~cm}$ depth will be only slightly lower than at a $10 \mathrm{~cm}$ depth (see Figure 3.37). Therefore, chloride concentrations as measured in the $15 \mathrm{~cm}$ soil water samplers are used for this calculation. During the summer and fall of 1988 , it was possible to collect only one sample in each plot from the $15 \mathrm{~cm}$ sampler. The concentration of chloride in this sample is used for the entire season. In the spring and early summer of 1989, it was possible to collect samples in plot $9 \mathrm{BE}$ until late May, and in plot 8EP until late April. For the remainder of this season, concentrations were extrapolated from previous trends. $\Delta z$ for the calculation of term 2 was taken as $10 \mathrm{~cm}$ - approximately the distance from the middle of the near-surface interval to the $15 \mathrm{~cm}$ sampler. $\mathrm{q}_{\mathrm{w}, \text { evap }}$, as calculated with or without term 2 , is within the range of bare soil evaporation rates measured in the field using microlysimeters. This is an encouraging result, considering the spatial variability of parameters involved. All measured val tes used in the calculation of Table 3.9 are mean values of samples collected on the given day in each plot, with the exception of the mass of solid which is an average of all measurements within each season; this was done to avoid error due to small differences in solid mass, although this averaging did not make a significant difference in seasonal averages. The effect of spatial variability is apparent in the monthly values of $\mathrm{q}_{w, \text { evap }}$ calculated using this approach. For example, in plot 8EP, during the fall season, $\mathrm{q}_{w, e v a p}$ between $8 / 25 / 88$ and $9 / 29 / 88$ was calculated to be $0.19 \mathrm{~mm} /$ day $(0.01 \mathrm{~mm} /$ day if diffusion is neglected). However, direct measurements during this period found the rates to average at 0.46 $\mathrm{mm} / \mathrm{day}(\mathrm{S} . \mathrm{D} .=0.17$ ). On the other hand, the rate calculated over the following month, 9/29/88 to $10 / 25 / 88$ was $0.98 \mathrm{~mm} /$ day $(0.78 \mathrm{~mm} /$ day if diffusion neglected), while rates measured directly fell to $0.23 \mathrm{~mm} / \mathrm{day}(\mathrm{S} . \mathrm{D} .=0.11$ ). Over the entire season though, the average calculated rates are

quite close to directly measured rates. Average seasonal bare soil evaporation rates during the summer and fall of 1988 were calculated as $0.66 \mathrm{~mm} / \mathrm{day}(0.45 \mathrm{~mm} / \mathrm{day}$ without diffusion) and 


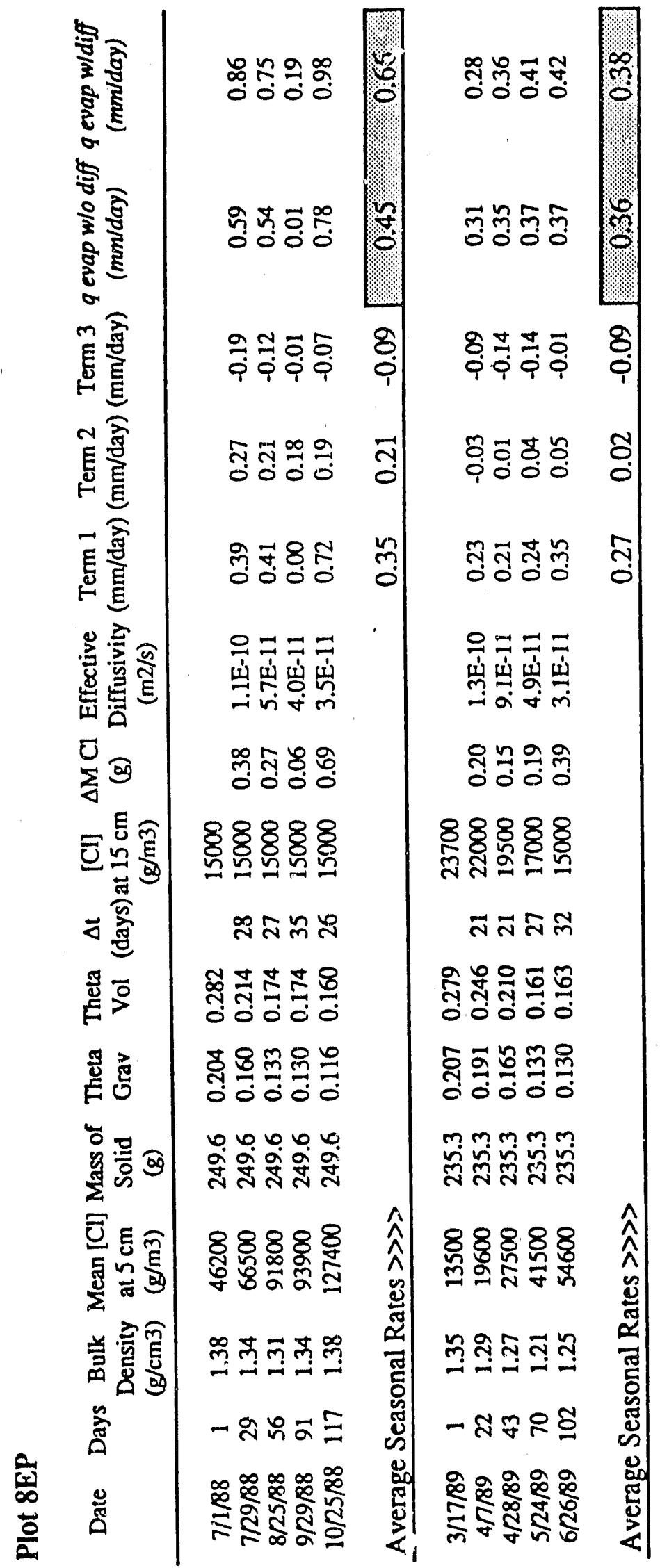




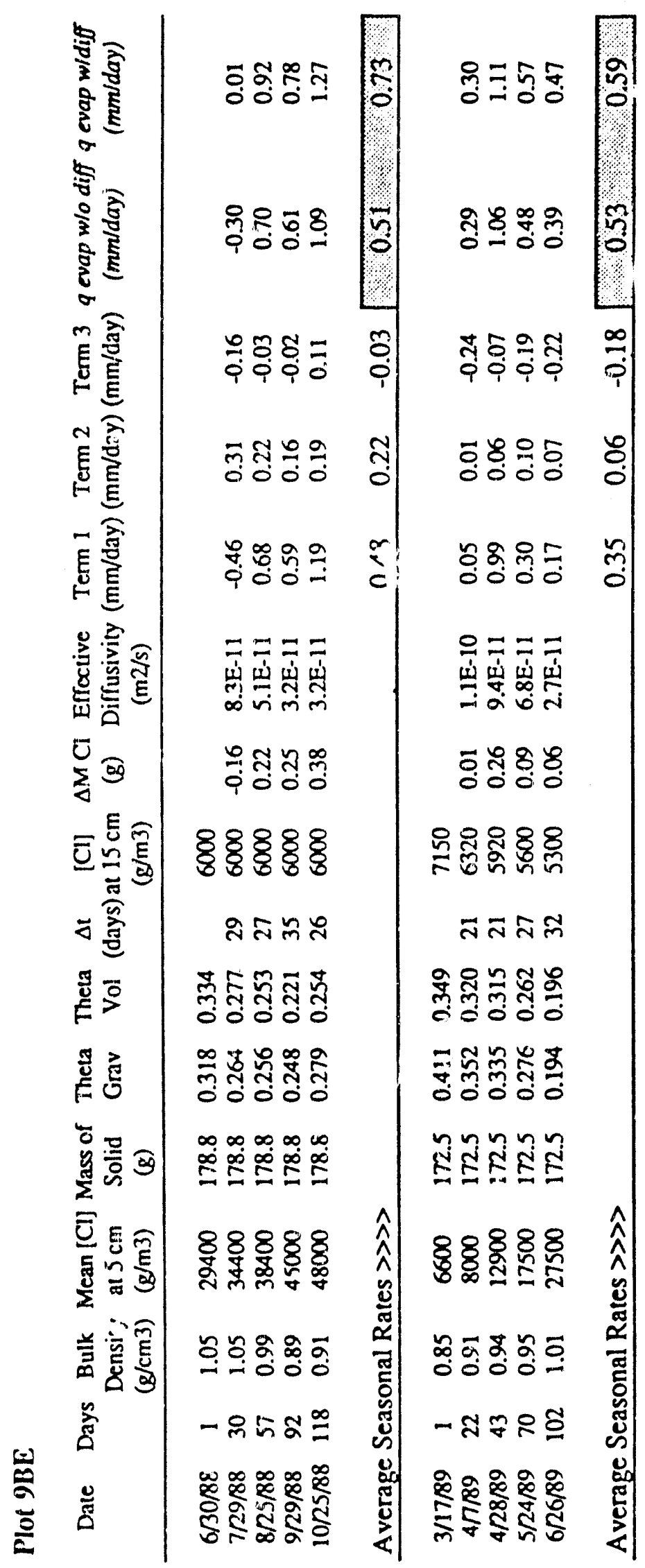




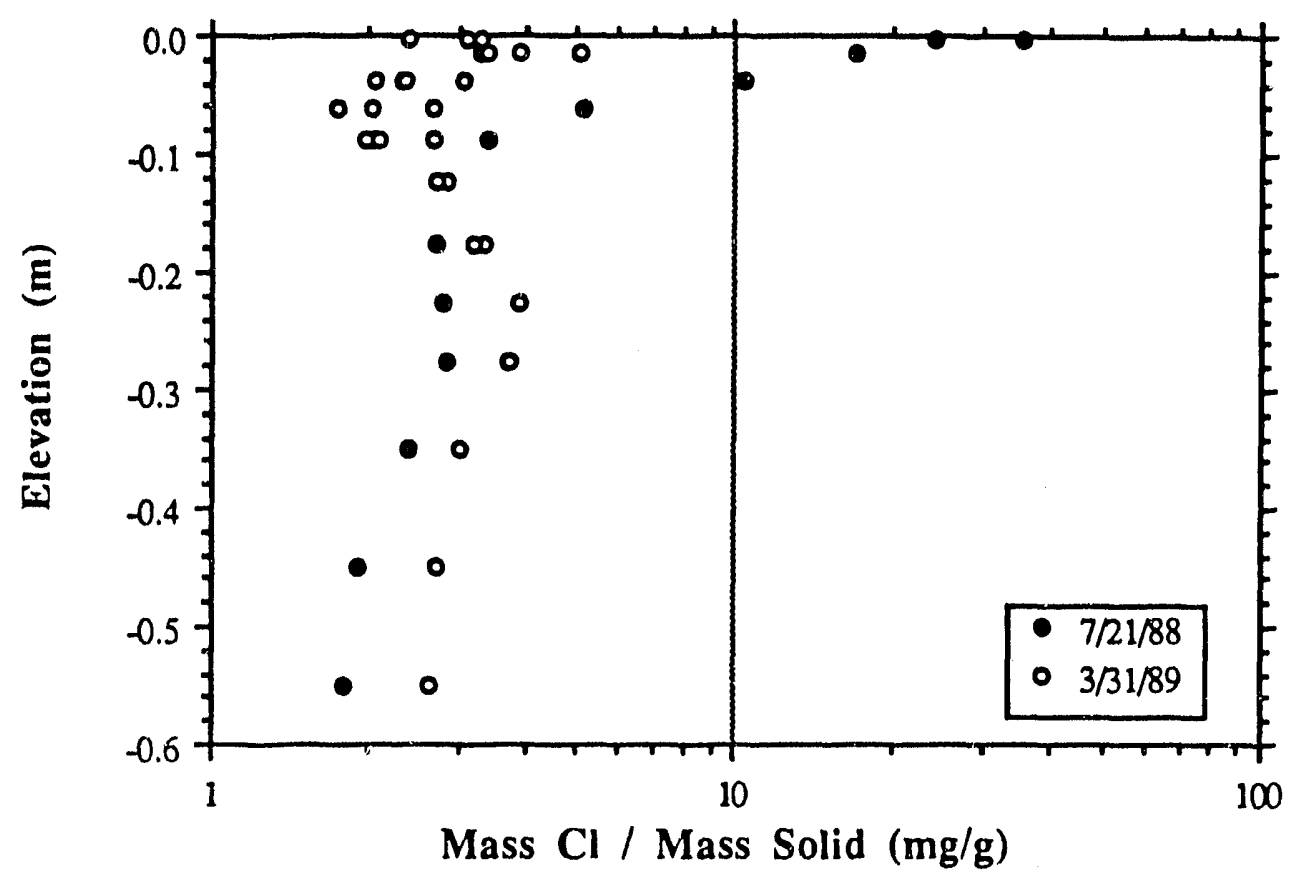

Figure 3.37a. Changes in chloride distribution in the soil profile of plot 8EP.

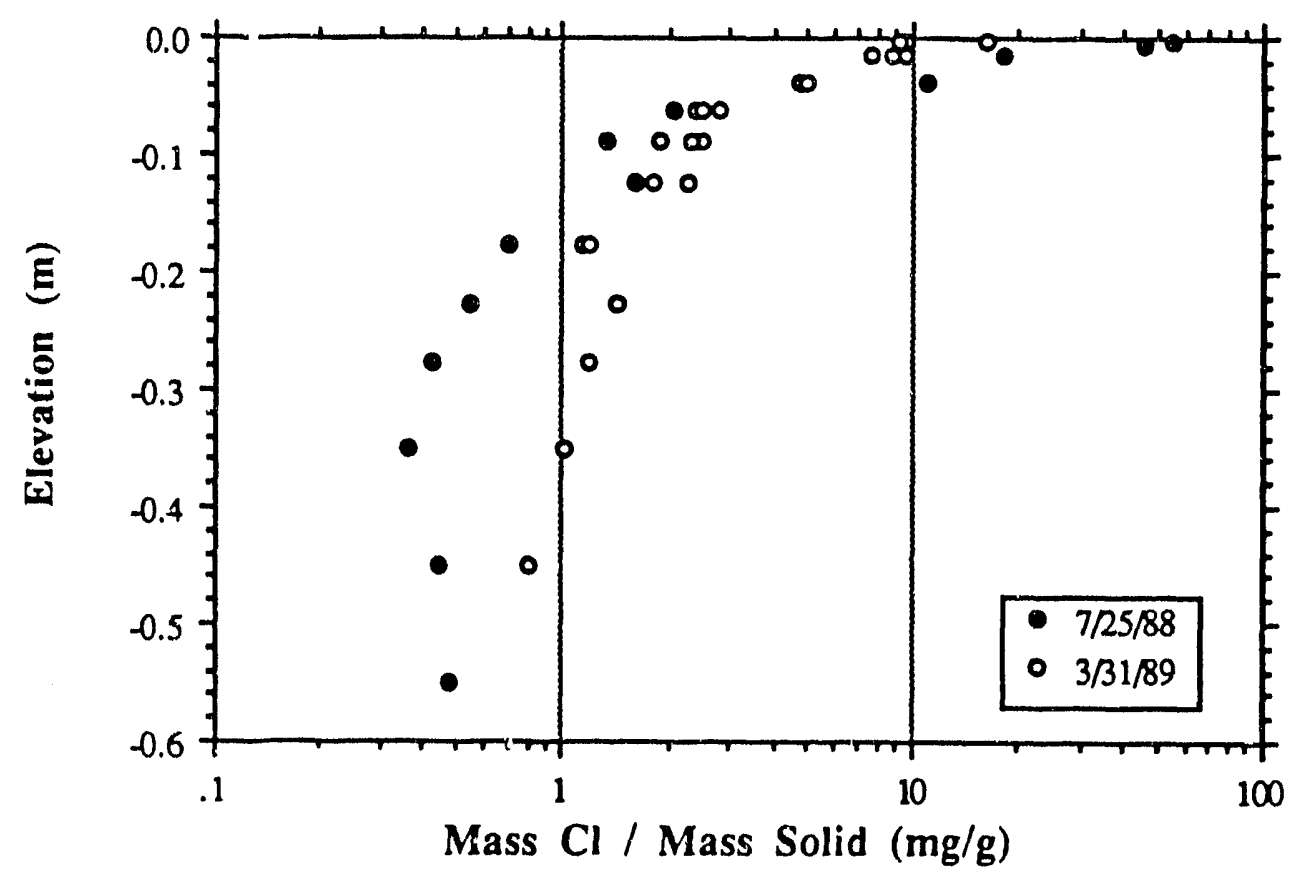

Figure 3.37b. Changes in chloride distribution in the soil profile of plot 9BE. 
$0.73 \mathrm{~mm} /$ day $(0.51 \mathrm{~mm} /$ day without diffusion) for plots $8 \mathrm{EP}$ and $9 \mathrm{BE}$ respectively. During the spring and summer of 1989 , the rates were computed to be $0.38 \mathrm{~mm} / \mathrm{day}(0.36 \mathrm{~mm} /$ day without diffusion) and $0.59 \mathrm{~mm} /$ day $(0.53 \mathrm{~mm} /$ day without diffusion) for plots $8 \mathrm{EP}$ and $9 \mathrm{BE}$ respectively (compare with $\mathrm{T}^{\prime}$ le 3.6 ).

\subsection{Analysis of Trend Significance and Errors Involved}

Due to the relatively high frequency of sampling and spatial variability, it may be expected that changes in the mean concentrations of chloride observed from month to month may not be significant. A t-test was used to determine whether differences between mean chloride concentrations were significant. Table 3.10 summarizes the results. Differences over each season as a whole are significant at the $1 \%$ confidence level. The results of the above test suggest that evaporation rates calculated in Table 3.9 should not be trusted at the monthly interval, especially during the summer and fall (1988) season; instead, only seasonal averages should be considered dependable.

It is important to know the cumulative error involved in the flux calculation. This problem will be treated separately for each of the three main terms of Equation (3.14), since they have different amounts of unresolved uncertainty (Table 3.11). It is quite clear from the above error analysis that Term 2 needs to be treated separately since the uncertainty associated with that term is one order of magnitude greater than for the other two terms. The combined error for terms 1 and 3 results in an uncertainty of approximately $0.02 \mathrm{~mm} /$ day for both plots, for both seasons. The uncertainty in Term 2 is approximately $0.11 \mathrm{~mm} / \mathrm{day}$ for both plots during the first season and $0.01 \mathrm{~mm} / \mathrm{day}$ and $0.03 \mathrm{~mm} /$ day during the second season for plot $8 \mathrm{EP}$ and $9 \mathrm{BE}$, respectively.

\subsubsection{Conclusions}

Results of direch physical measurements of bare soil evaporation rates as well as calculations of average rates based on chemical changes in near-surface soil, indicate that the process of bare soil evaporation is very slow at both plots $8 \mathrm{EP}$ and $9 \mathrm{BE}$. Directly measured rates in plot $8 \mathrm{EP}$ ranged from $0.13 \mathrm{~mm} / \mathrm{day}(\mathrm{S} . \mathrm{D} .=0.04)$ to $0.96 \mathrm{~mm} / \mathrm{day}(\mathrm{S} . \mathrm{D} .=0.12)$; in plot $9 \mathrm{BE}$ these rates 
Table 3.10. Results of t-test performed to evaluate the significance of monthly and seasonal chloride concentration changes

\begin{tabular}{|c|c|c|c|c|c|}
\hline Date & $\begin{array}{c}\text { Mean } \\
{[\mathrm{Cl}]}\end{array}$ & $\begin{array}{c}\text { Standard } \\
\text { Deviation }[\mathrm{Cl}]\end{array}$ & $\begin{array}{l}\text { Number of } \\
\text { Samples }\end{array}$ & $\begin{array}{l}\text { Significant at } \\
1 \% \text { error? }\end{array}$ & $\begin{array}{c}\text { Significant at } \\
5 \% \text { error? }\end{array}$ \\
\hline \multicolumn{6}{|l|}{ Plot 8EP } \\
\hline $7 / 1 / 88$ & 9.33 & 0.73 & 5 & & \\
\hline $7 / 29 / 88$ & 10.67 & 1.25 & 5 & No & Yes \\
\hline $8 / 25 / 88$ & 12.03 & 1.50 & 8 & No & No \\
\hline $9 / 29 / 88$ & 12.03 & 1.73 & 8 & No & No \\
\hline $10 / 25 / 88$ & 14.30 & 2.64 & 8 & No & Yes \\
\hline $3 / 17 / 89$ & 2.80 & 0.53 & 8 & Yes & Yes \\
\hline $4 / 7 / 89$ & 3.73 & 0.49 & 8 & Yes & Yes \\
\hline $4 / 28 / 89$ & 4.51 & 0.65 & 8 & Yes & Yes \\
\hline $5 / 24 / 89$ & 5.51 & 0.58 & 8 & Yes & Yes \\
\hline $6 / 26 / 89$ & 7.09 & 0.94 & 8 & Yes & Yes \\
\hline \multicolumn{6}{|l|}{ Plot 9BE } \\
\hline $6 / 30 / 88$ & 9.38 & 1.62 & 3 & & \\
\hline $7 / 29 / 88$ & 8.47 & 1.12 & 5 & No & No \\
\hline $8 / 25 / 88$ & 9.71 & 1.02 & 8 & No & Yes \\
\hline $9 / 29 / 88$ & 11.12 & 1.33 & 8 & No & Yes \\
\hline $10 / 25 / 88$ & 13.23 & 1.85 & 8 & Yes & Yes \\
\hline $3 / 17 / 89$ & 2.75 & 1.00 & 6 & Yes & Yes \\
\hline $4 / 7 / 89$ & 2.83 & 0.63 & 8 & No & No \\
\hline $4 / 28 / 89$ & 4.32 & 1.25 & 8 & Yes & Yes \\
\hline $5 / 24 / 89$ & 4.85 & 2.11 & 8 & No & No \\
\hline $6 / 26 / 89$ & 5.21 & 1.28 & 8 & No & No \\
\hline
\end{tabular}


Table 3.11. Uncertainties involved in the estimation of water fluxes based on changes in chloride concentrations and moisture content

\begin{tabular}{|clcc|}
\hline Term & \multicolumn{1}{c}{ Variable } & Error & Cumulative Error \\
\hline \hline 1 & $\Delta$ Mass of $\mathrm{Cl}$ & $2.8 \%$ & \\
1,2 & {$[\mathrm{Cl}]$ at $15 \mathrm{~cm}$} & $(2 \%)$ & \\
1,3 & Cross-Sectional Area & $3.9 \%$ & \\
1,3 & $\Delta \mathrm{t}$ & 0 & \\
2 & Diffusivity in water & $?^{*}$ & \\
2 & Average Porosity & $1.8 \%$ & \\
2 & Average Saturation & $2.1 \%$ & \\
2 & Impedance(Tortuosity) & $\approx 50 \% * *$ & \\
2 & $\Delta[$ Cl] & $(2.8 \%)$ & \\
2 & $\Delta z$ & $0.1 \%$ & \\
3 & $\Delta \theta_{\text {grav }}$ & $0.05 \%$ & \\
3 & Mass of Solid & 0 & \\
3 & Density of Water & $\gg \gg$ & \\
& & $\gg>$ & $3.9 \%$ \\
1 & $\gg>$ & $\gg>$ & \\
2 & $\gg>$ & & \\
3 & $\gg>$ & & \\
\hline
\end{tabular}

*The error associated with chloride diffusivity in water is difficult to estimate, due to its temperature dependence; however, it will be no greater than the error associated with the impedance (tortuosity) term.

**This "error" is roughly estimated based on the data in Barraclough and Tinker (1981) and Pinner and Nye (1982) and is due to the fact that the relationship between impedance factor and volumetric water content for Kesterson soils is not known.

Note: all other error values are based only on errors involved in the measurement of a variable for an average soil or water sample and do not take into account spatial variability. For values in parentheses, the calculated error is probably negligible compared with uncertainties in the way these variables are defined. 
ranged from $0.32 \mathrm{~mm} / \mathrm{day}(\mathrm{S} . \mathrm{D} .=0.05)$ to $0.99 \mathrm{~mm} /$ day $(\mathrm{S} . \mathrm{D} .=0.31)$. Based on two data points from each plot, an equation of the following form:

$$
E_{b s}=C E_{p o r} \theta_{\text {grav }, 9}^{b}
$$

was fit to solve for a bare soil evaporation rate dependent only on potential evaporation $\left(E_{p o l}\right)$ and the moisture content of the top $9 \mathrm{~cm}$ of soil $\left(\theta_{\text {grav }, 9}^{\mathrm{b}}\right)$. Overall, the fit was satisfactory and Equation (3.3.3.5) was used to predict bare soil evaporation rates for both plots over the two seasons when rates were measured. This calculation gave average rates for the summer/fall 1988 season of 0.52 and $0.78 \mathrm{~mm} / \mathrm{day}$ for plots $8 \mathrm{EP}$ and $9 \mathrm{BE}$, respectively, and 0.47 and $0.74 \mathrm{~mm} / \mathrm{day}$ for the two plots during the spring/summer 1989 season (see Table 3.6). Changes in chemistry were used in the quantitative analysis of soil evaporation rates. By taking into account changes in chloride concentration in the top $9 \mathrm{~cm}$ of soil, concentration gradients in soil water, and the net drying out of the $9 \mathrm{~cm}$ interval, average seasonal bare soil evaporation rates were estimated for both plots (see Table 3.9). The rates for the first season, for plots 8EP and 9BE, respectively, were between 0.45 and $0.66 \mathrm{~mm} /$ day and between 0.51 and $0.73 \mathrm{~mm} /$ day, depending on whether chloride diffusion in soil water was taken into account or not. For the second season, the rates were between 0.36 and $0.38 \mathrm{~mm} / \mathrm{day}$ and between 0.53 and $0.59 \mathrm{~mm} / \mathrm{day}$, for plots $8 \mathrm{EP}$ and $9 \mathrm{BE}$ respectively. These values agree well with those obtained through an extrapolation of directly measured data, although they are somewhat lower during the spring/summer 1989 season. This is probably due to the fact that Equation (3.5) overestimates bare soil evaporation rates during the last two months of that season. The reasons for this overestimation are discussed in Section 3.3.3.3.

The above data support several conclusions. Firstly, either approach was satisfactory in estimating bare soil evaporation rates. While the direct approach is very useful in determining actual rates and their field variability, the indirect approach is probably more effective in calculating average seasonal rates. Used in tandem, these two methods not only provide more information but may also be used to test one anothers accuracy. Since rates measured by both methods agree, one may put more faith in the results. 
Secondly, in agreement with the qualitative changes in chloride and selenium concentrations near the soil surface, the low rates of bare soil evaporation are not likely to cause a substantial increase in either salt or selenium concentrations over the next few years. This conclusion is strongly dependent on site-specific properties of the soil surface and soil profile and may not be arbitrarily applicable at other locations at Kesterson Reservoir. It is also dependent on future weather and revegetation patterns. Considering the redistribution of salts and selenium during the twelve months of this study, it is possible that there may be a net decrease of salt concentrations during wetter years. The fate of selenium is controlled by the kinetics of its oxidation reactions and volatilization. However, it may be said with some certainty that over an annual cycle, selenium concentrations are not likely to increase due to an evaporative flux.

Thirdly, as supported by the results of the quantitative analysis of Section 3.3.3.3 and numerical modeling, water vapor diffusion may be a major process in controlling evaporation from these soils. It is likely that the presence of salt and a salt crust near and at the soil surface, has an effect similar to a mulch in limiting bare soil evaporation. This suggests that salt-laden soils under certain conditions may come to a pseudo-steady-state condition (over an annual cycle) under which the further accumulation of salts near the soil surface is limited by the presence of the salts themselves. The results of numerical simulations suggest that a better understanding of hydraulic properties of near-surface soils may shed light on the evaporation process from a playa-like environment.

In applying these results to Kesterson Reservoir as a whole, the following conclusions may be made:

- In areas of the Reservoir which are in a similar setting to plots 8EP or 9BE, i.e., highly saline, highly seleniferous, covered by a salt crust, unvegetated or only sparsely vegetated, and not fllled with non-native soil, similarly low bare soil evaporation rates may be expected. Those areas which have higher salt concentrations are not likely to become more vegetated very rapidly, thus salt and selenium distributions in the soil profile are not likely to change significantly over the next few years. Areas with lower 
salt concentrations are likely to become revegetated, which will cause the redistribution of salts and soluble selenium towards the root zone.

- In vegetated areas of the Reservoir, which have not been filled with non-native soil, whereas further increases in salt and selenium concentrations in the root zone are likely, significant evaporative concentration of species near the soil surface is not expected.

- In areas of the Reservoir which have been filled by non-native soil from the DeltaMendota Canal, movement of salts and selenium into the non-native material is to be expected. Due to the enormous variability in physical properties of this material, it is difficult to estimate the length of time necessary for a reconcentration of species near the surface of the fill sediment. However, due to the relatively non-saline character of this material, bare soil evaporation rates are likely to be limited mostly by profile properties and the distance to the ground water table.

Finally, all of the above findings may be useful in choosing an appropriate management strategy for Kesterson Reservoir. These data demonstrate the seasonal accumulation of salt and soluble selenium concentration near the soil surface under unvegetated conditions. They also provide estimates of salt and selenium response to rainfall which may be extended to the likely response to irrigation. The fact that surface concentrations of soluble selenium and salts decrease during the winter due to very sparse precipitation, may suggest that even infrequent irrigation may be sufficient to keep soluble and potentially more biologically available selenium below the soil surface. Furthermore, the physical management of the soil surface may also be designed to minimize salt and selenium accumulation, for example by periodic mulching, which would tend to reduce bare soil evaporation rates in areas not covered by a surface salt crust. 


\title{
3.4. CAPILLARY RISE OF KESTERSON RESERVOIR SOIL SOLUTES INTO FILL DIRT
}

\author{
Tetsu Tokunaga \\ Earth Sciences Division \\ Lawrence Berkeley Laboratory
}

The importance of capillary rise and evaporative concentration of soluble salts (including selenium) in the Kesterson Reservoir environment has been noted in numerous previous reports (LBL, 4th Progress Report (1987), through LBL, 2nd Arunual Report (1989)). The recent work of Fio and Fujii (1988) provided evidence for evaporative accumulation of selenium in soil surfaces of the Panoche Fan. The conditions of low rainfall, high potential evaporation, and a shallow water table drive the upward flow of soil water. Of these factors, only the effect of proximity to the water table has been moderated by the introduction of fill material. The rate at which capillary rise and evapotranspiratively driven soil water flow will move selenium and other solutes from Reservoir soils up into the fill material remains to be determined. Resolution of this question will be possible through periodic field core sampling of the fill material. Such sampling has been initiated during the past year for the purpose of establishing baseline fill dirt selenium contents at several sites.

In order to demonstrate the potential importance of upward movement of Reservoir soil solutes into the overlying fill, a simple column experiment is being conducted. A brief description of this experiment, and an overview of some of the results to date will be provided here. While reference will be made to a single column, the experiment is essentially being performed in duplicate through a second column under very similar conditions.

A. $0.0762 \mathrm{~m}$ inside diameter, $0.62 \mathrm{~m}$ tall PVC pipe section was packed with $0.35 \mathrm{~m}$ of Kesterson soil, and capped with $0.27 \mathrm{~m}$ of fill dirt. The Kesterson soil was sampled in $0.10 \mathrm{~m}$ layers from the northem region of Pond 9. This soil was coarsely sieved $(50 \% / 50 \%$ by weight through 
$5 \mathrm{~mm} / 10 \mathrm{~mm}$ sieves) at approximately $0.17 \mathrm{~g} / \mathrm{g}$ moisture content. The sieved soil was packed into the column while preserving the $0.10 \mathrm{~m}$ sampling sequence. Each $0.10 \mathrm{~m}$ layer was packed in 4 stages to minimize particlc sorting and allow for control of bulk density. The fill material (originally from the Delta-Mendota Canal) was packed over Kesterson soil in a similar manner. Subsamples of each layer of Kesterson soil and fill dirt were taken to determine the initial distribution of the soluble selenium. The initial soluble selenium inventory was estimated through $5: 1$ (water:soil mass ratio) extracts as described in previous reports. Phosphate extracts of the individual soil layers were also performed. A saline soil solution was prepared in a composition which was similar to Pond 9 soil water, but without selenium.

At the beginning of the experiment, this solution was allowed to rise into the column through a bottom end port. The inflow water level was regulated with a constant-head Mariotte bo:de, modified to compensate for temperature fluctuations which occurred in the laboratory. The water table was maintained at $\mathrm{Z}=-0.325 \mathrm{~m}$ (elevations referenced to the Kesterson soil/fill interface). This depth corresponds to a distance of $0.595 \mathrm{~m}(1.95 \mathrm{ft})$ below the fill surface. During this initial wetting period, evaporation from the surface of the fill was minimized with a loose cover. After 55 days of capillary rise of the saline, selenium free solution into the column, small (approximately $1 \mathrm{~g}$ ) core samples were taken along the length of the column. Extracts of these core samples were taken at water:soil ratios of approximately 50:1. Soluble selenium concentrations in these extracts were normalized back to the soil soiution contents of the individual cores. On day 55 , the water table was permitted to rise at a rate of $0.02 \mathrm{~m} / \mathrm{day}$, until day 71 when the water table exceeded the Kesterson soil/fill interface by $0.02 \mathrm{~m}(0.25 \mathrm{~m}$ below the fill surface). During the period when the water table was permitted to rise, the cover over the fill surface was removed to permit bare soil evaporation as well. Pan evaporation rates of 1 to $3 \mathrm{~mm} / \mathrm{day}$ were measured independently over the fill surface. (These pan evaporation rates are comparable to Kesterson field pan evaporation rates during the winter months.) The water table was maintained at $Z=+0.02 \mathrm{~m}$ ( $0.25 \mathrm{~m}$ below the fill surface) for 42 days, during which evaporatively driven flow was allowed to continue. A nearly steady-state inflow rate of $1.7 \pm 0.1 \mathrm{~mm} / \mathrm{day}$ was meas- 
ured during this period. During this time, a sample of the soil solution profile was obtained along the length of the column through small ceramic, vacuum water extractors. On day 113 , the water table was lowered at an average rate of $0.014 \mathrm{~m} /$ day. From day 139 through day 298, the water table was maintained at the base of the column while evaporation was permitted to continue at the surface of the fill. Soil solution and soil core samples were taken at various times during this last stage. One of the columns was then disconnected from the water supply and sectioned for soil analyses. Operation of the replicate column is continuing.

An important feature of the experimental design is the absence of selenium in the inflow solution. While the solution selenium concentration in much of the Reservoir soils is of the order of $1000 \mu \mathrm{g} / \mathrm{kg}$, the exclusion of selenium from the laboratory column inflow solution served to assure that concentration profile changes are essentially due to redistribution of the original soluble selenium profile. In particular, any increases in the selenium content of the fill could be solely attributed to upwards displacement of selenium from the underlying Kesterson soil, and could not be due to preferential flow of selenium originating from the inflow source solution.

The soluble selenium profiles from several samplings are shown in Figure 3.38. Several intermediate sampling times have not been included for the sake of clarity. The initial condition (0.0 days) reflects an essentially 'clean' fill overlying a typical distribution of soluble selenium in Kesterson surface soils (aside from the rectilinear shape due to homogenizing samples over 0.10 $m$ intervals). The initial concentration profile was developed from 5:1 water extracts of subsamples of the individual soil layers prior to packing of the column. The initial 5:1 water extractable selenium inventory was equivalent to $0.28 \pm 0.02 \mathrm{~g} / \mathrm{m}^{2}$.

The soluble selenium profile at time $=55$ days demonstrates that selenium has been transported into the initially clean fill during the course of capillary uptake of water. Through integration of the concentration profile, a day 55 soluble selenium inventory of $0.40 \mathrm{~g} / \mathrm{m}^{2}$ is obtained (a $44 \%$ increase over the initial inventory). However, soluble selenium mass balance comparisons of the day 0 and day 55 profiles are tenuous due to uncertainty in the day 55 profile distribution in the vicinity of the apparent concentration maximum at $\mathrm{Z}=+0.05 \mathrm{~m}$, and uncer- 


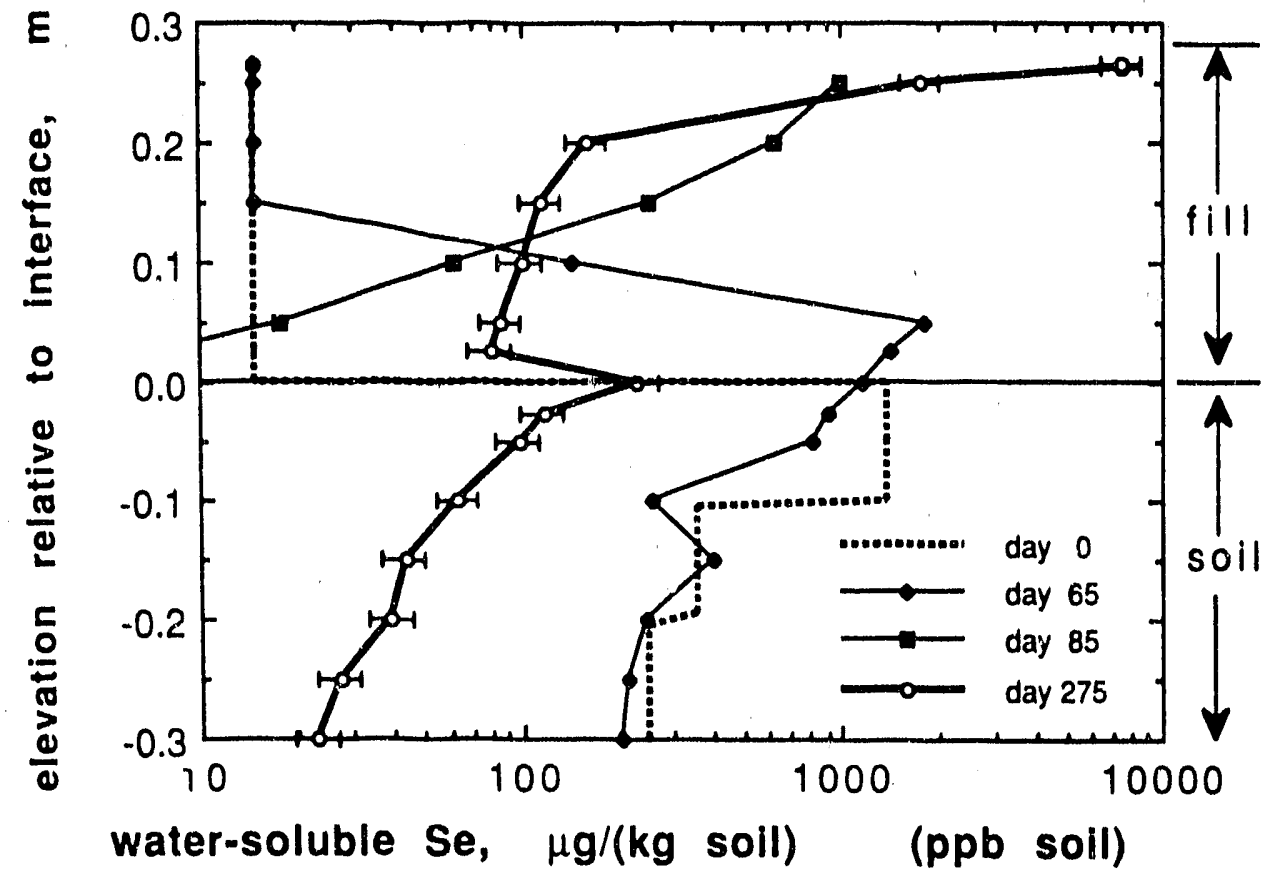

Figure 3.38. Soluble selenium profiles resulting from water table rise and evaporative flow in a Kesterson soil column overlain by fill dirt. 
tainties associated with the small-scale core samples from which the profile was generated. It should be noted that at this stage (day 55), the water table was still at $Z=-0.325 \mathrm{~m}$, and that the wetting front had advanced only as far as about $\mathrm{Z}=+0.12 \mathrm{~m}$.

The day 85 profile, taken directly from vacuum extracts of the soil solution, show that soluble selenium has reached the surface of the fill. At this stage, the water table was at $Z=+0.02 \mathrm{~m}$. The soluble selenium concentration in the surface of the fill is now in the range of concentrations in the original Kesterson surface soil. The lack of water-soluble selenium in the Kesterson soil at this sampling time is due to the combined effects of upward displacement of soluble selenium into the fill material, and to the development of reducing conditions below the water table. The soluble selenium inventory obtained from the day 85 data is equivalent to $0.16 \pm 0.02 \mathrm{~g} / \mathrm{m}^{2}$ ( $57 \pm 9 \%$ of the initial inventory). The apparently low selenium inventory at this stage is likely to be due to a combination of (1) accumulation of soluble selenium at the fill surface (in both dissolved and precipitated evaporite forms, beyond the sampling zone of the uppermost vacuum sampler), (2) reduction of selenate to selenite, and subsequent adsorption of the later throughout much of the profile, and (3) reduction to zero valent selenium. None of these three components are extractable through the ceramic vacuum solution sampling.

During the interval between days 113 and 139 while the water table was being lowered, outflow from the bottom of the column was continuously collected and analyzed for selenium. Effluent selenium concentrations ranged from 2 to $6 \mu \mathrm{g} /(\mathrm{kg}$ solution) (ppb solution). The cumulative loss of selenium due to drainage amounted to the equivalent of $0.11 \mathrm{mg} / \mathrm{m}^{2}$, or only $0.04 \%$ of the initial soluble selenium inventory. The very low ground water oufflow component to the selenium inventory is consistent with the soluble selenium concentraticn profile under high water table conditions (the day 85 profile for example). More generally, the measured low selenium outflow is consistent with the well documented lack of selenium movement into ground water when traversing reducing sediments.

The day 275 profile was obtained through water-extractions of core samples. The uppermost sample was taken directly at the surface $(0.02 \mathrm{~m}$ increment). The water table had been 
maintained at the bottom of the column for 136 days prior to this sampling. Consequently, most of the soil column, including the deeper Kesterson soil was under oxidizing conditions. This is evident from the reappearance of soluble selenium (primarily as selenate) in the lower portions of the column. The day 275 soluble selenium inventory amounted to $0.37 \pm 0.06 \mathrm{~g} / \mathrm{m}^{2}(133 \% \pm 20 \%$ of the initial inventcry). Intermediate sampling times between days 85 and 275 all exhibit maximum selenium concentrations at the fill surface. An increase in the water-soluble selenium inventory is also suggested from other profiles taken after day 150. A more conclusive analysis of possible increases in the soluble selenium inventory will soon be available through analyses of sections from the dismantled core.

The column solution and water samples are at various stages of analyses with respect to other constituents. Major cations and anions, arsenic, boron, and molybdenum are being included in the analyses. While most of these other analyses have yet to be completed, some data for arsenic in the soil solution has been compiled. Figure 3.39 shows both selenium and arsenic concentrations obtained from vacuum extracted soil solution samples on day 82 . It is interesting to note that arsenic movement into the fill lags considerably behind the selenium front. While arsenic has entered into the fill, its affinity to adsorb on particle surfaces strongly retards its advance.

The issue of representativeness of results of these data has at least two facets. These are (1) reproducibilty of the specific experiment, and (2) applicability to actual field conditions. Each of these concerns will be addressed. Due to the limitations of working with a small solumn scale, only small solution and soil samples were collected during the bulk of the experiment. Dilutions of these samples for analyses were kept to a minimum when low concentritions were expected. On the other hand, the principle zone of interest is generally the region of the selenium concentration maxima. In this region, even dilute samples were concentrated enough with respect to selenium to keep analytical uncertainties to within 5\%. Replicability of results was checked in two ways. Profiles from the duplicate columns were compared at nearly identical sampling times. An example of such a comparison is provided in Figure 3.40 for columns sample on days 


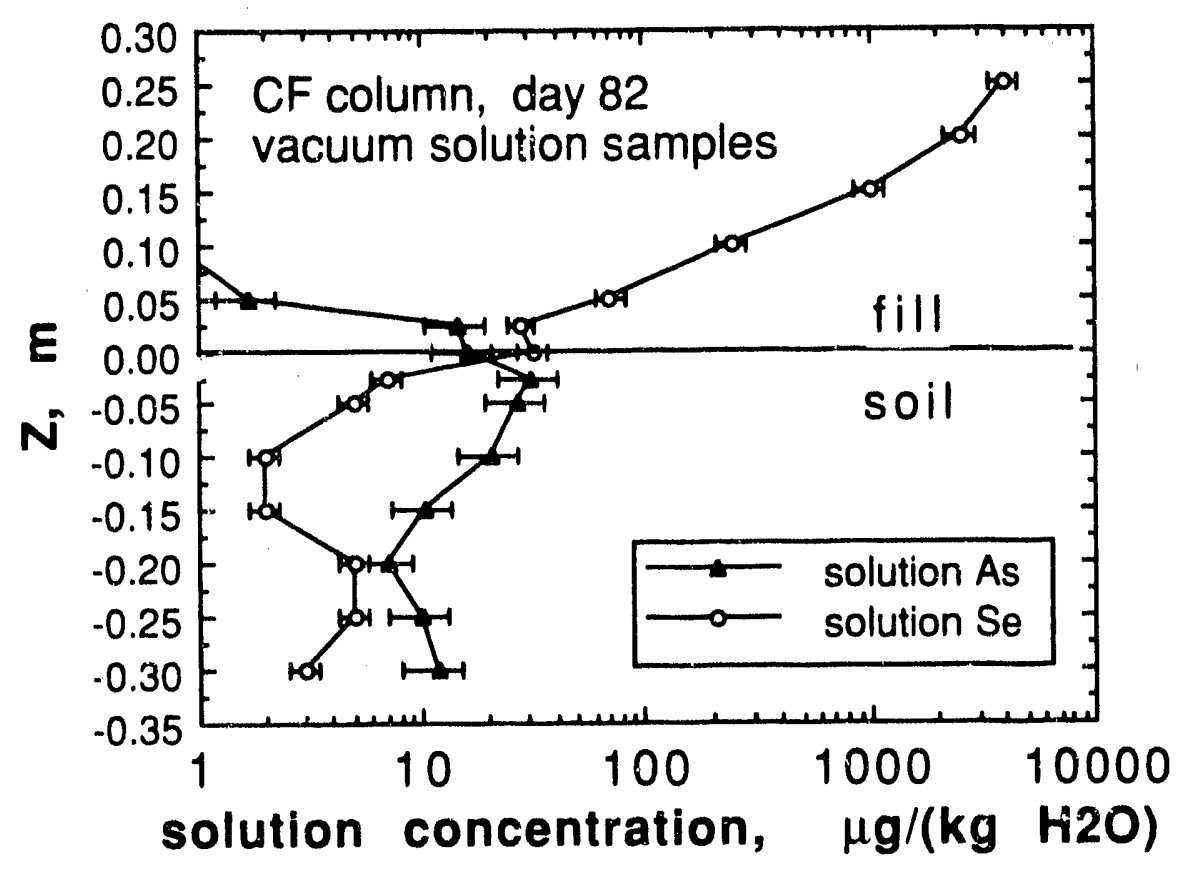

Figure 3.39. Soluble selenium and arsenic profiles in Kestersun soil/fill column experiment.

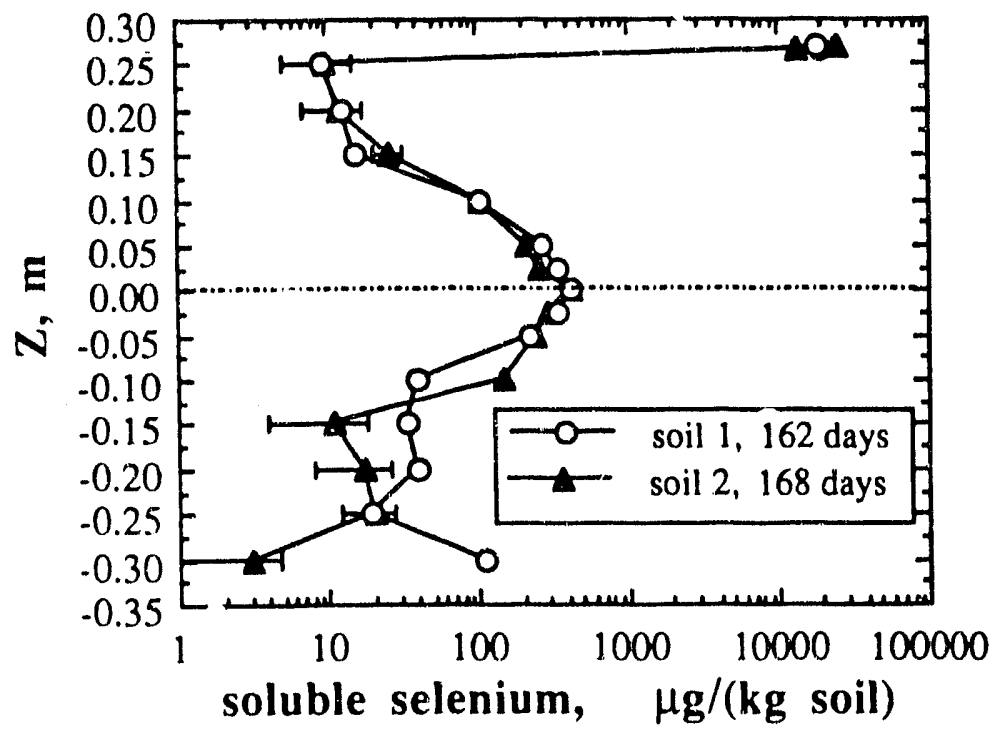

Figure 3.46. Comparisons of soluble selenium profiles in two Kesterson soil/fill columns (days 162 and 168). 
162 and 168. The major features of the profiles are well replicated. However, it should be noted that the logarithmic concentration scale needed to display the full range of interest obscures significant differences in portions of the profiles. Another approach to checking selenium concentration profiles involves comparing profiles obtained from vacuum extractions of column solutions with extracts obtained from core sampling at the same locations. An example of this type of comparison is shown in Figure 3.41. Again, the major features of the profiles are in agreement, although regions with significant differences exist. It is generally expected that the extracts obtained from core samples will yield somewhat higher concentrations of selenium through the contribution of desorbed/dissolved selenite. It should be noted that in Figure 3.41 the surface maximum in selenium was obtainable only through core sampling, thus comparison with a vacuum solution sampler was not possible in this region.

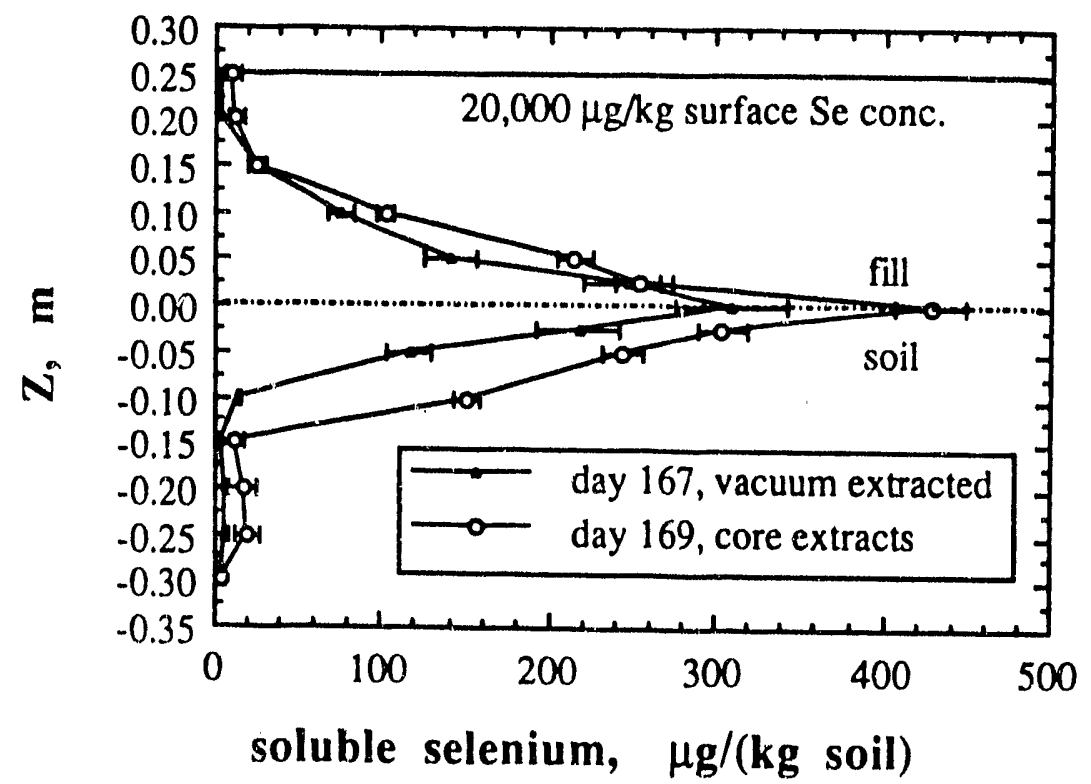

Fig :re 3.41. Kesterson soil/fill column, comparisons between soluble selenium concentrations measured with soil core extracts and with solution extracts.

Conceming implications of this experiment on field conditions, relevant features of transport of Kesterson soil solutes have been demonstrated. However, it is important to keep in mind differences in spatial and temporal scales between this laboratory experiment and the field. The total column length of $0.63 \mathrm{~m}$ is about one third that of the appropriate field dimension. This difference allowed for more rapid responses to be obtained. While the effects of capillary rise, 
displacement by ground water fluctuations, and evaporation on selenium and salt transport are clearly demonstrated, it should be noted that these factors commonly effect less rapid changes on the field scale. The counterbalancing effect of rainfall infiltration and redistribution of solutes deeper into the soil profile is not considered in this experiment. The field is expected to respond both slower and with wider fluctuations which are practical to observe only on the field scale.

Results of this experiment demonstrate the potential for further wildlife exposures to selenium and other solutes as these constituents are transported into the fill dirt from the Reservoir soils. Perhaps the most critical pathway for this exposure is through a two step process of solute accumulation in fill surfaces during the dry season, and dissolution of these solutes in surface waters during rainfall ponding. However, recent measurements of bare soil evaporation indicate that salt accumulation at the soil surface is not likely to occur. On the ocher hand, the observed high selenium concentrations in rainfall pools in some areas filled with Kesterson soil demonstrates that a distinct evaporite crust is not needed for the occurrence of surface water with selenium concentrations in excess of recent recommended levels $(2 \mu \mathrm{g} / \mathrm{l})$. Introduction of even a small percentage of the selenium inventory into shallow surface waters would result in concentrations in excess of presently accepted standards. Permeability of the soil surface, and timing of rainfall events relative to the seasonal rise of the water table will generally be important variables in this process. A less direct pathway for wildlife exposure to selenium and other solutes in the absence of ponding is through the intermediate step of plant uptake of selenium. 


\subsection{SOIL AND VEGETATION MANAGEMENT FOR KESTERSON RESER VOIR}

Beginning in 1988, scientists at the Division of Agriculture and Natural Resources at the University of Califomia and Lawrence Berkeley Laboratory initiated a new effort aimed at developing a soil water and vegetation management plan for Kesterson Reservoir. The goal of the management plan is two-fold. First, the plan is intended to result in a gradual depletion of the inventory of soluble selenium at the Reservoir through a combination agriculturally oriented practices that enhance dissipation of selenium from near surface soils. Agriculturally oriented processes that will contribute to depletion include microbial volatilization from the soils, direct volatilization by living plants, decomposition and volatilization of selenium-bearing vegetation, harvest and removal of seleniferous vegetation, and leaching. The benefits of using this integrated approach are that (1) no single mechanism needs to be relied upon to detoxify the soils, (2) a stable plant community can be established during this period so that impacts to wildlife can be more easily evaluated and controlled, and (3) cleanup and management of the site can be carried out in a cost-effective manner. The management plan is also intended to facilitate control over wildlife exposure to selenium contaminated biota by creating a well managed environment. By managing the type of vegetation growing at the site, and by using vegetation to assist in soil moisture control, and consequently surface water accumulation during the wet season, biotic exposure to seleniferous food-chain items can be controlled.

The majority of research associated with this new effort is being carried out in two test plots at Kesterson, a $200 \mathrm{~m}$ by $50 \mathrm{~m}$ plot in Pond 7 and a slightly smaller plot in a "filled" area of Pond 5. Each test plot has a two-line irrigation system, providing brackish local ground water for irrigation. In addition, during the germination period, better quality water is trucked in to help stimulate establishment of crop plants. Through an intensive program of soil water sampling, 
soil gas sampling, vegetation sampling, ground water monitoring, and soil moisture monitoring, the mass balance for selenium under irrigated conditions is being evaluated. These studies, in conjunction with supplementary laboratory experiments, will provide the information needed to develop an optimal management plan for the site. This progress report provides information on the current status of the individual components of the integrated research program. 


\title{
4.1. SOIL, PLANT AND VOLATILIZATION STUDIES
}

\author{
J. W. Biggar, G. R. Jayaweera and D. E. Rolston \\ Department of Land, Air and Water Resources, \\ University of California, Davis
}

Soil-water-vegetation management can be used as an alternative to other methods to deplete the inventory of soluble selenium in Kesterson soils. A principal objective of the management system is to optimize selenium volatilization utilizing plant and soil mechanisms. Manipulation of the system through water management, tillage, and selection of $\mathrm{p}$ ant species requires study in order to determine management practices that achieve the desired results in environmentally acceptable ways. It is worth noting that this is not simply a monitoring activity but rather an attempt to manage the system. Monitoring changes in the system is an important aspect of the investigation, and monitoring methodology itself requires attention as there are no "standard" methods universally accepted by everyone. In this report we include a brief description of the locations as these have been described elsewhere.

\subsubsection{Studies at Kesterson}

Established replicated trials at (a) Main plot (Pond 7) which represents the unfilled area, and (b) Satcllite plot (Pond 5) which represents the filled area.

\subsubsection{Main Plot}

The objective of this study was to identify a cooler scason crop which is suited for Kesterson unfilled soils which can produce high biomass and is able to provide plant volatilization. Tolerance to salinity and boron is also an important consideration. Three crop species, barley (UC 337), alfalfa (Maopa 69), which were selected out of five varieties tested in Phase I studies, and tall fescue (Mustang) are compared with native vegetation in this experiment. The treatments include fertilized and unfertilized plots in each variety (Figure 4.1). 


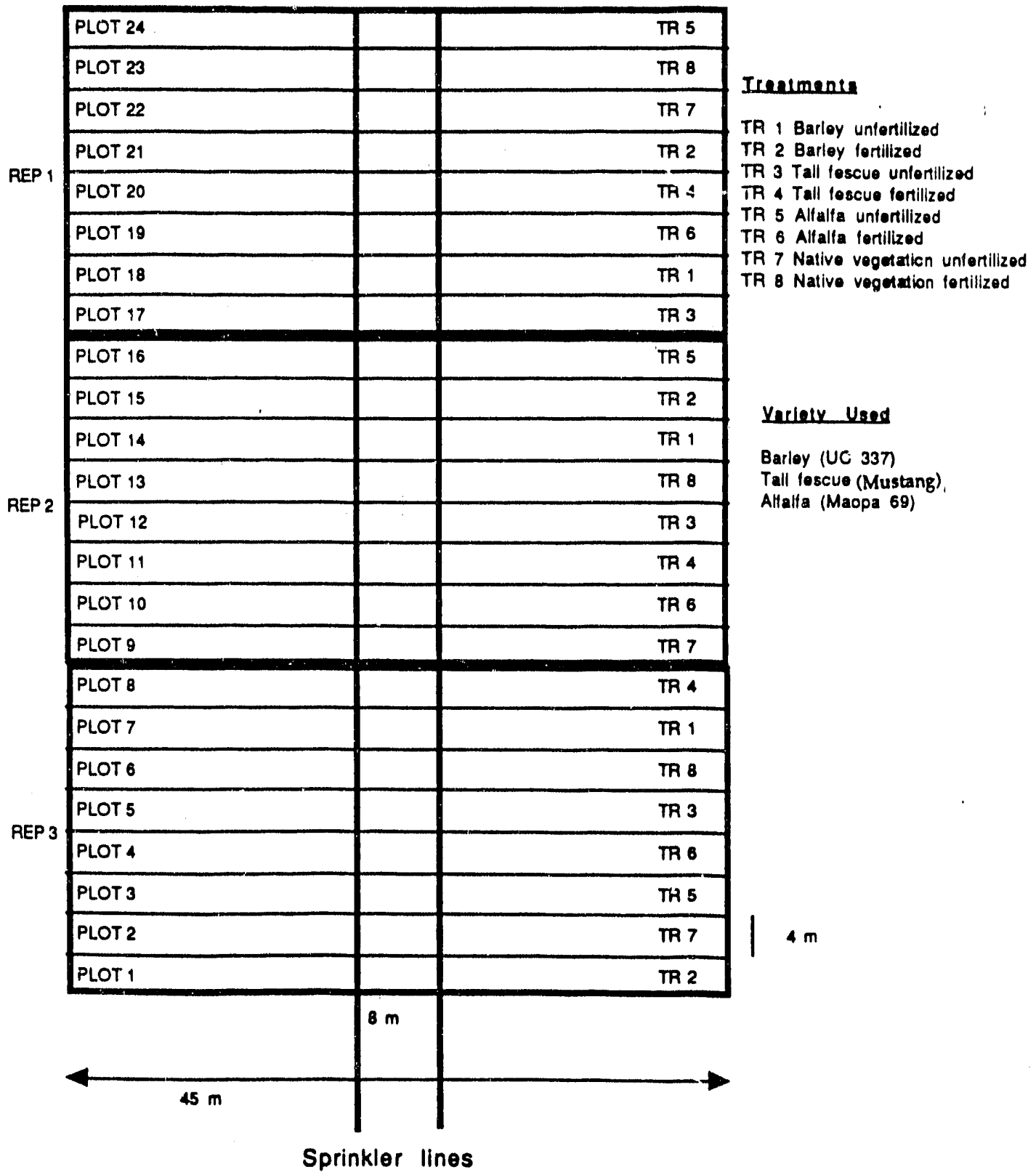

Figure 4.1. Experiment layout in main plot (Pond 7), 1989. 


\subsubsection{Satellite Plot}

The objective of this study is to establish a cropping pattem to the newly filled soil and to study the selenium status. Barley (UC 337), alfalfa (Maopa 69) and tall fescue (Mustang) were tested in Pond 5. All plots were fertilized in this experiment (Figure 4.2).

\subsubsection{Volatilization Studies}

\subsubsection{Sampling Procedure}

Sampling of volatile selenium in the field was performed with the newly developed experimental setup. This setup includes chambers to collect volatile selenium, an evaporative cooler, and a water distribution system (Figure 4.3). The volatilization chamber $(30 * 30 * 45 \mathrm{~cm})$ is made up of plexiglass (Figure 4.4), and is equipped with a radiator which receives water from the evaporative cooler, a fan and a selenium trap (charcoal filters). The water from the evaporative cooler is distributed with the use of a water pump and the level of water in the evaporative cooler was maintained by a supply tank. The power for the experimental setup was supplied with a generator. The chamber is exposed to the outside through a hole at the upper end of the wall directly opposite the fan. The chambers are placed $10 \mathrm{~cm}$ deep in the soil to avoid any volatile selenium moving from the surrounding area. Identical chambers with a solid base are used as a control.

\subsubsection{Data Collected}

Volatile selenium samples were collected from the main plot and a nearby barren plot.

Bare plot: Three sampling chambers and two control chambers were installed in the bare plot to obtain the base selenium levels before rototilling and irrigation. Moisture content measurements in the surface soil were made. Air temperature was continuously recorded inside and outside in one of the chambers by using a Rustrak Ranger data logger. Volatilization measurements were made continuously for $42 \mathrm{~h}$. Volatile selenium levels which were obtained for one chamber show a release of $17.44 \mu \mathrm{g} / \mathrm{m}^{2} /$ day and the sample extraction and analysis for the other 


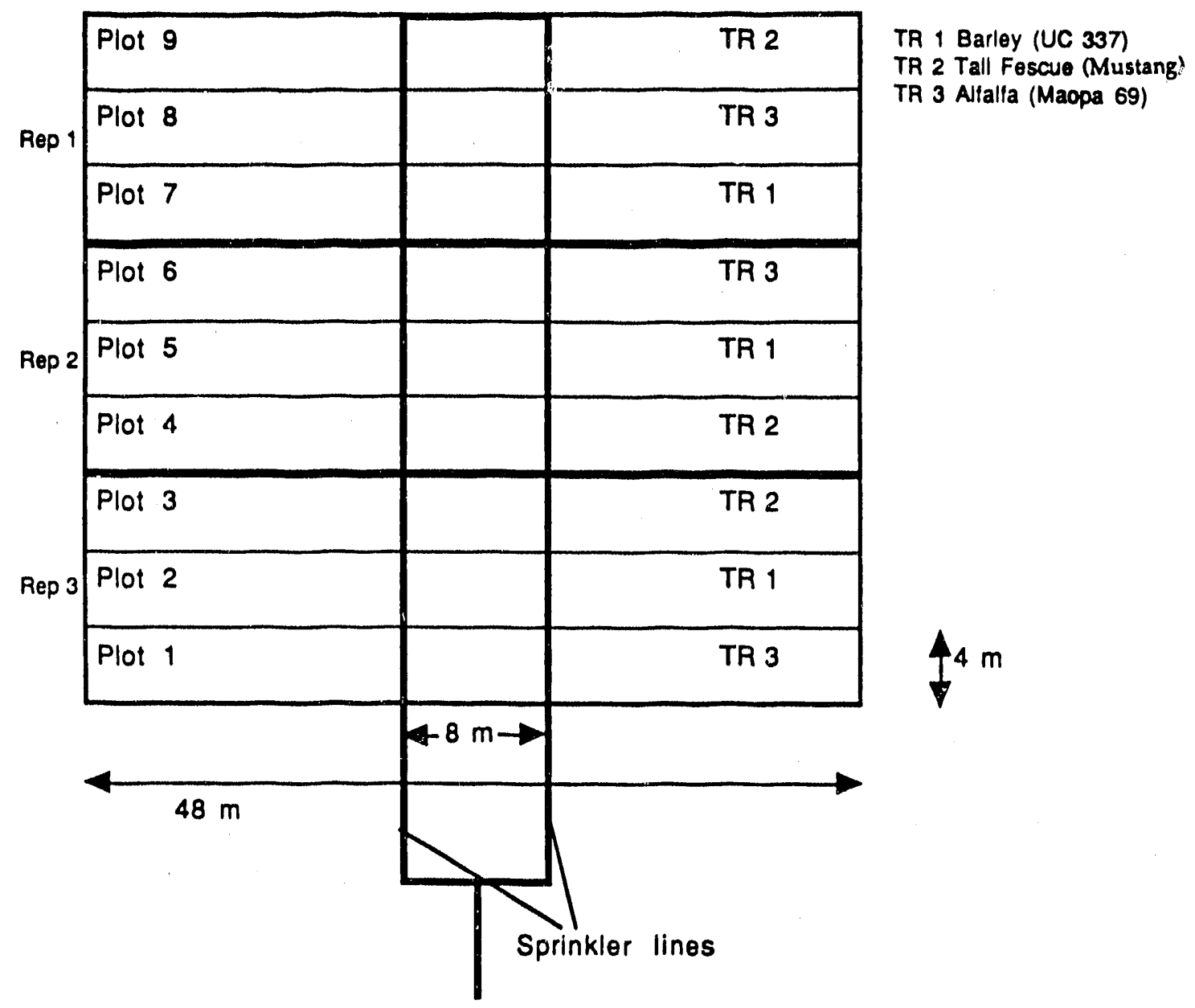

Figure 4.2. Experimental layout in satellite plot (Pond 5), 1989. 


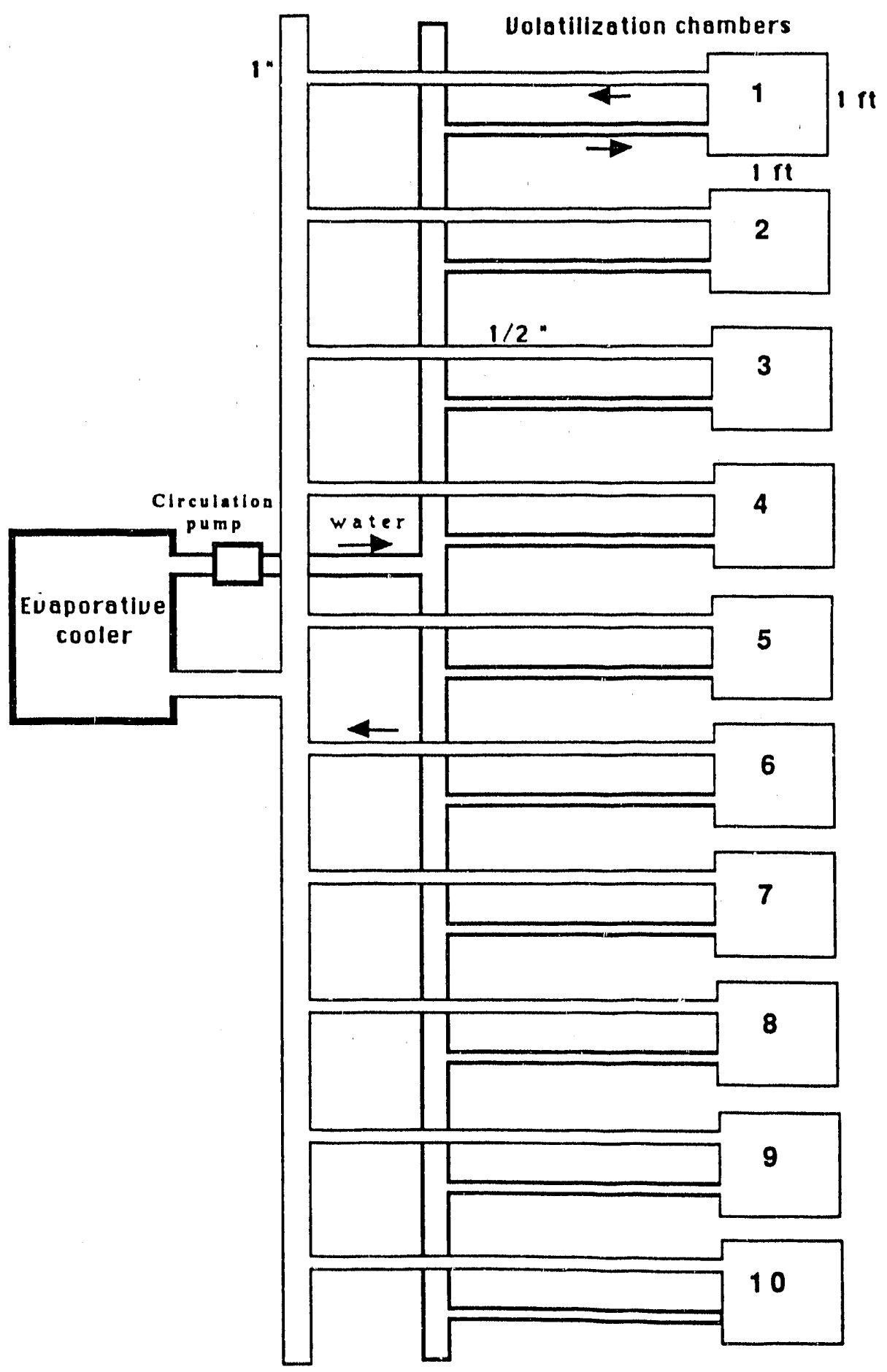

Figure 4.3. Experimental setup for volatilization chambers. 


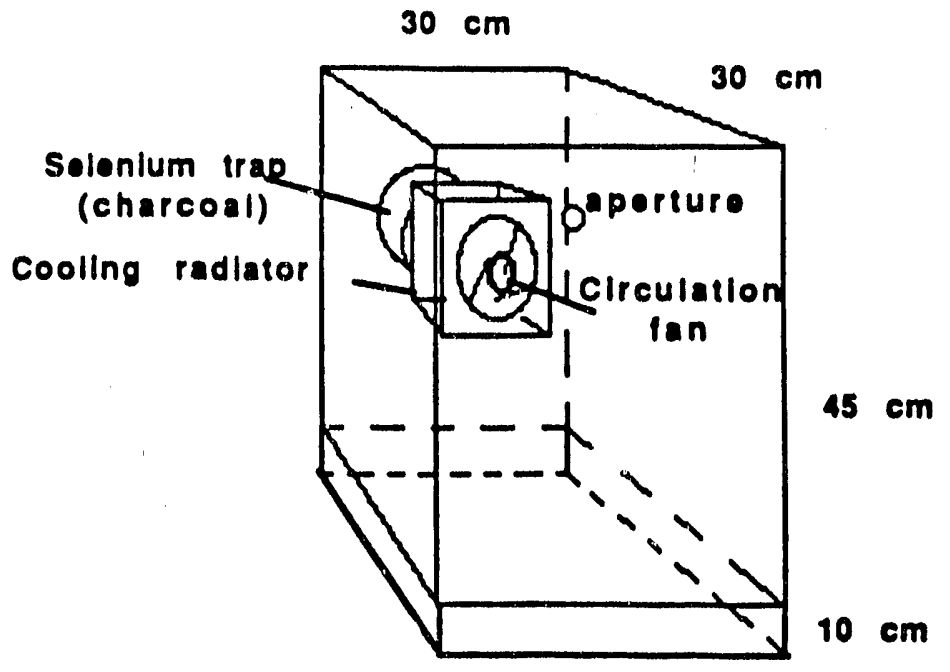

Volatilization chamber for Selenium

Figure 4.4. Volatilization chamber for selenium. 
replicates is yet in progress. These low volatilization rates are comparable to similar measurements made elsewhere at the Reservoir in unirrigated soils during the hot summer months.

Main Plot: Volatilization measurements in the main plot were made before and after rototilling and irrigation.

Measurements done before rototilling and irrigation are as follows:
a. Soil with tall fescue plants
b. Soil with barley plants
c. Soil without barley plants
d. Soil with native vegetation
e. Soil without native vegetation

Two control chambers were installed. All these measurements were made in duplicate. Moisture measurements were made in surface soils. Inside and outside air temperatures of the chambers were recorded continuously in one of the chambers with a "Rustrak Ranger" data logger. Temperature ineasurements were made in all chambers at various times (Table 4.1).

Volatile selenium samples were collected for $48 \mathrm{~h}$. The plants were harvested for biomass (Table 4.2) and selenium analysis. The soils inside the chambers were sampled at 0-5 and 5-15 $\mathrm{cm}$ deptiss (Table 4.3). Some volatilization traps were analyzed and other analysis are in progress. The chamber with tall fescue showed a volatilization rate of $4.89 \mu \mathrm{g} / \mathrm{m}^{2} / \mathrm{day}$.

The following volatilization measurements were made after rototillage and irrigation.
a. Plowed - high water
b. Unplowed - high water
c. Plowed - low water
d. Unplowed - low wate,

All of these measurements were made in duplicate. Air temperatures inside and outside the chambers and soil moisture measurements were made. Volatile selenium was collected for $24 \mathrm{~h}$. Sample extraction and analysis are in progress. 
Table 4.1. Air temperature inside and outside the volatilization chamber

\begin{tabular}{|c|c|c|c|c|c|c|c|c|c|c|c|}
\hline \multirow[t]{2}{*}{ Day } & \multirow[t]{2}{*}{ Time } & \multicolumn{8}{|c|}{$\begin{array}{l}\text { Inside Air Temperature }\left({ }^{\circ}\right) \\
\ldots \ldots \text { Chamber No.*...... }\end{array}$} & \multirow{2}{*}{$\begin{array}{l}\text { Outside } \\
\text { Air }\left({ }^{\circ} \mathrm{C}\right)\end{array}$} & \multirow{2}{*}{$\begin{array}{l}\text { Inside/ } \\
\text { Outside }\end{array}$} \\
\hline & & 1 & 2 & 4 & 5 & 6 & 7 & 9 & 10 & & \\
\hline 1 & $2: 24 \mathrm{pm}$ & 31.5 & 31.5 & 33.0 & 32.5 & 33.0 & 32.5 & 32.0 & 32.5 & 32.0 & 1.01 \\
\hline 1 & $4: 30 \mathrm{pm}$ & 30.2 & 30.5 & 32.5 & 31.5 & 32.0 & 31.5 & 30.5 & 31.0 & 31.5 & 0.99 \\
\hline 2 & $12.58 \mathrm{pm}$ & 14.0 & 13.5 & 13.0 & 13.0 & 13.0 & 13.0 & 13.0 & 13.0 & 14.0 & 0.94 \\
\hline 2 & $7: 31$ am & 15.0 & 15.3 & 15.5 & 15.8 & 16.0 & 16.1 & 17.0 & 16.0 & 16.5 & 0.96 \\
\hline 2 & $10: 12$ am & 29.5 & 29.5 & 29.6 & 29.8 & 30.0 & 30.0 & 29.5 & 29.5 & 29.5 & 1.01 \\
\hline
\end{tabular}

*Chambers 3 and 8 are controls.

Table 4.2. Dry weight of various plant-species inside the volatilization chambers

\begin{tabular}{|ccc|}
\hline Chamber & Plant Species & Dry Weight $(\mathrm{g})$ \\
\hline \hline 1 & Tall fescue & 5.8 \\
2 & Tall fescue & 12.2 \\
5 & Barley & 13.2 \\
6 & Barley & 16.0 \\
9 & Native (salt grass) & 27.0 \\
10 & Native (salt grass) & 36.6 \\
\hline
\end{tabular}

Table 4.3. Analysis of soils inside the chambers

\begin{tabular}{|c|c|c|c|c|}
\hline \multirow[b]{2}{*}{ Chamber } & \multicolumn{2}{|c|}{$\begin{array}{r}\text { Depth }(0-5 \mathrm{~cm}) \\
\text { Water }\end{array}$} & \multicolumn{2}{|c|}{$\begin{array}{r}\text { Depth }(5-15 \mathrm{~cm}) \\
\text { Water }\end{array}$} \\
\hline & Selenite & $\begin{array}{l}\text { ractable Se } \\
1 \ldots \ldots\end{array}$ & $\begin{array}{r}\text { Selenite } \\
\ldots . . .\end{array}$ & ractable $\mathrm{Se}$ \\
\hline 1 & 0.19 & 0.54 & 5.19 & 33.58 \\
\hline 2 & 3.15 & 3.30 & 4.70 & 30.78 \\
\hline 4 & 6.15 & 11.48 & 9.10 & 34.98 \\
\hline 5 & 3.58 & 14.82 & 9.35 & 45.32 \\
\hline 6 & 2.90 & 15.58 & 13.90 & 44.96 \\
\hline 7 & 17.56 & 65.54 & 13.43 & 98.80 \\
\hline 9 & 11.16 & 40.06 & 8.27 & 73.34 \\
\hline 10 & 15.61 & 35.88 & 7.79 & 60.70 \\
\hline
\end{tabular}




\subsubsection{Extraction Procedure}

Charcoal filters are used to trap volatile selenium in the field. An efficient and time saving extraction procedure was developed to obtain volatile selenium and is described as follows.

Comparison of syringe/shaker extractions using $\mathrm{H}_{2} \mathrm{O}$. The same filter is extracted with the use of syringe and shaker methods using $\mathrm{H}_{2} \mathrm{O}$ as the extractant. The data (Table 4.4) shows that syringe and shaker method extracted nearly the same amount of volatile selenium.

Therefore it is concluded that shaker method can be used in the extraction of volatile selenium due to the convenience over the syringe method.

Use of $\mathrm{H}_{2} \mathrm{O}_{2}$ as the extractant in the shaker method. Volatile selenium is mostly in the form of dimethyl selenide. Therefore extraction with $\mathrm{H}_{2} \mathrm{O}$ may not remove all organic selenium from the filter material. There were two alternative approaches in the extraction.

a. To select an organic solvent to wash out organic selenium from the trap. However, this may interfere with the present analytical procedure for selenium.

b. To convert organic selenium to inorganic form and wash out with water. This conversion can be carried out by oxidation with $\mathrm{H}_{2} \mathrm{O}_{2}$. The present extraction procedure was developed on this principle.

Numcrous filters were extracted by three / lifferent methods. In all three consecutive extractions were performed for each filter using a filter:solution ratio of 1:50.

Method 1: $\mathrm{H}_{2} \mathrm{O}_{2} / \mathrm{H}_{2} \mathrm{O}_{2} / \mathrm{H}_{2} \mathrm{O}_{2}$

Method 2: $\mathrm{H}_{2} \mathrm{O}_{2} / \mathrm{H}_{2} \mathrm{O} / \mathrm{H}_{2} \mathrm{O}$

Method 3: $\mathrm{H}_{1} \mathrm{O} / \mathrm{H}_{2} \mathrm{O} / \mathrm{H}_{2} \mathrm{O}$

Hydrogen peroxide solution was prepared by $1 \mathrm{ml} 1 \mathrm{NaOH}, 2 \mathrm{ml} 30 \% \mathrm{H}_{2} \mathrm{O}_{2}$ in $25 \mathrm{ml}$ deionized distilled water.

The data (Table 4.5) show that alkaline $\mathrm{H}_{2} \mathrm{O}_{2}$ is a superior extractant than $\mathrm{H}_{2} \mathrm{O}$ in removing organic selenium from charcoal filters. The numbers within parentheses (Table 4.5) show the amount of selenium extracted by $\mathrm{H}_{2} \mathrm{O}_{2}$ relative to $\mathrm{H}_{2} \mathrm{O}$. 
Table 4.4. Syringe and shaker extraction of the same filter for volatile selenium

\begin{tabular}{|c|cc|}
\hline & Syringe Extraction Shaker Extraction \\
\hline \hline 1 & 4.64 & 4.36 \\
2 & 96.18 & 87.60 \\
3 & 10.22 & 10.98 \\
4 & 9.38 & 9.43 \\
5 & 2.99 & 2.90 \\
\hline
\end{tabular}

Table 4.5. $\mathrm{H}_{2} \mathrm{O}_{2}$ as an extractant compared $\mathrm{H}_{2} \mathrm{O}$ in the shaker method

\begin{tabular}{|c|ccc|}
\hline Sample & $\mathrm{H}_{2} \mathrm{O}_{2} / \mathrm{H}_{2} \mathrm{O}_{2} / \mathrm{H}_{2} \mathrm{O}_{2}$ & $\begin{array}{c}\mathrm{H}_{2} \mathrm{O}_{2} / \mathrm{H}_{2} \mathrm{O} / \mathrm{H}_{2} \mathrm{O} \\
\text {-... ng of Se (ratio) -... }\end{array}$ & $\mathrm{H}_{2} \mathrm{O} / \mathrm{H}_{2} \mathrm{O} / \mathrm{H}_{2} \mathrm{O}$ \\
\hline \hline 1 & $2121(6.5)$ & $2283(7.0)$ & $328(1)$ \\
2 & $706(6.8)$ & $711(6.9)$ & $103(1)$ \\
3 & $275(5.7)$ & $289(6.0)$ & $49(1)$ \\
\hline
\end{tabular}

Table 4.6. Comparison of drip and shaker method

\begin{tabular}{|c|c|cc|cc|}
\hline \multirow{2}{*}{ Sample } & Extraction & Shaker & Total & Drip & Total \\
\hline \hline 1 & 1 & 1630.62 & & 2988.5 \\
& 2 & 466.12 & & 0 & \\
& 3 & 225.29 & & $\cdots$ & \\
& 4 & 138.76 & & $\cdots$ & 2988.5 \\
& sum & & 2760.79 & & 2323.05 \\
\hline 2 & iul & & 1815.70 & & $23 .-\cdots$ \\
\hline
\end{tabular}


Therefore it was concluded that extraction of volatile selenium from charcoal filters can be performed by using $\mathrm{H}_{2} \mathrm{O}_{2}$ for the first wash and $\mathrm{H}_{2} \mathrm{O}$ for the successive washings.

\subsubsection{Drip Method}

Even with four successive washings, in the shaker method of extraction, it is difficuif to remove all selenium from the filter material. This may be $d$ te to equilibrium of selenium between the filter material and the solution. The drip method was used to attempt higher extraction efficiency.

In the drip system, the $\mathrm{H}_{2} \mathrm{O}_{2}$ solution is placed in a top fill external feeding canister with pre-attached external delivery gravity set (Sandoz nutrition-clinical products division). At the end of the delivery system a column (syringe) packed with the filter material is attached. The solution dripping through the filter material is collected in a container placed below the column. To ensure complete extraction the same procedure is repeated. The comparison of drip and shaker method is shown in Table 4.6. In a single extraction, the drip method was more efficient than even four extractions with the shaker method. In addition, several rates were tested and it was found that over the range of rates tested, the flow rate does not have a significant effect on thr extraction of organic selcnium from the filter. Therefore, faster rates, even up to $60 \mathrm{ml} / \mathrm{h}$, can be used in the extlaution of volatile selenium. Confirmation of this is in progress.

\subsubsection{Soil and Plant Studies}

\subsubsection{Main Plot}

Cation exchange capacity (CEC) was measured in six soil profiles in the experimental site. The average CEC in the soil ranges from 1,7 to $12.51 \mathrm{me} / 100 \mathrm{~g}$ (Figur: 4.5).

Saturation extracts were prepared from the initial (04/21/89) and final $(08 / 04 / 89)$ soil samples collected from various treatments. Electrical conductivity of the initial soil extracts is indicative of the salinity of the surface soil $(0-15 \mathrm{c}, \mathrm{n}$ ) at the time of seed establishment (Figure 4.6). As shown in Figure 4.6, irrization has not contributed to the surface salinity. This may be due to 


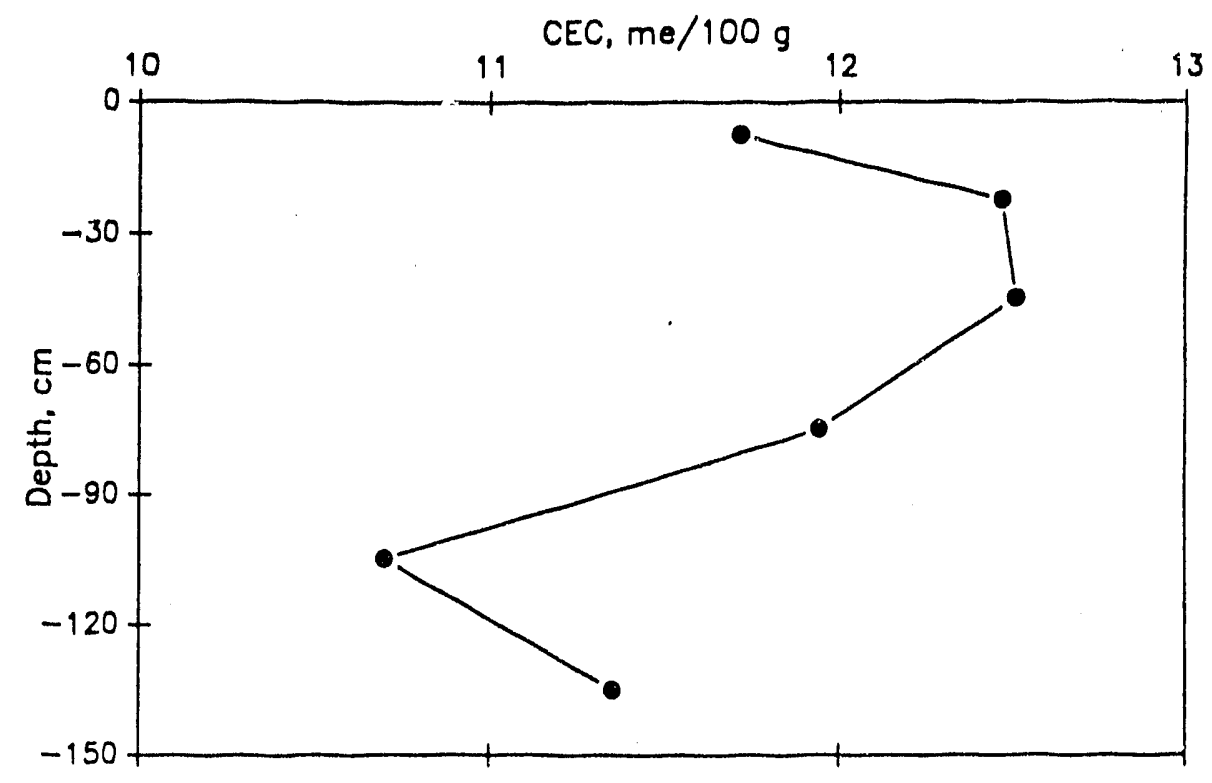

Figure 4.5. Average CEC in a soil profile (main plot).

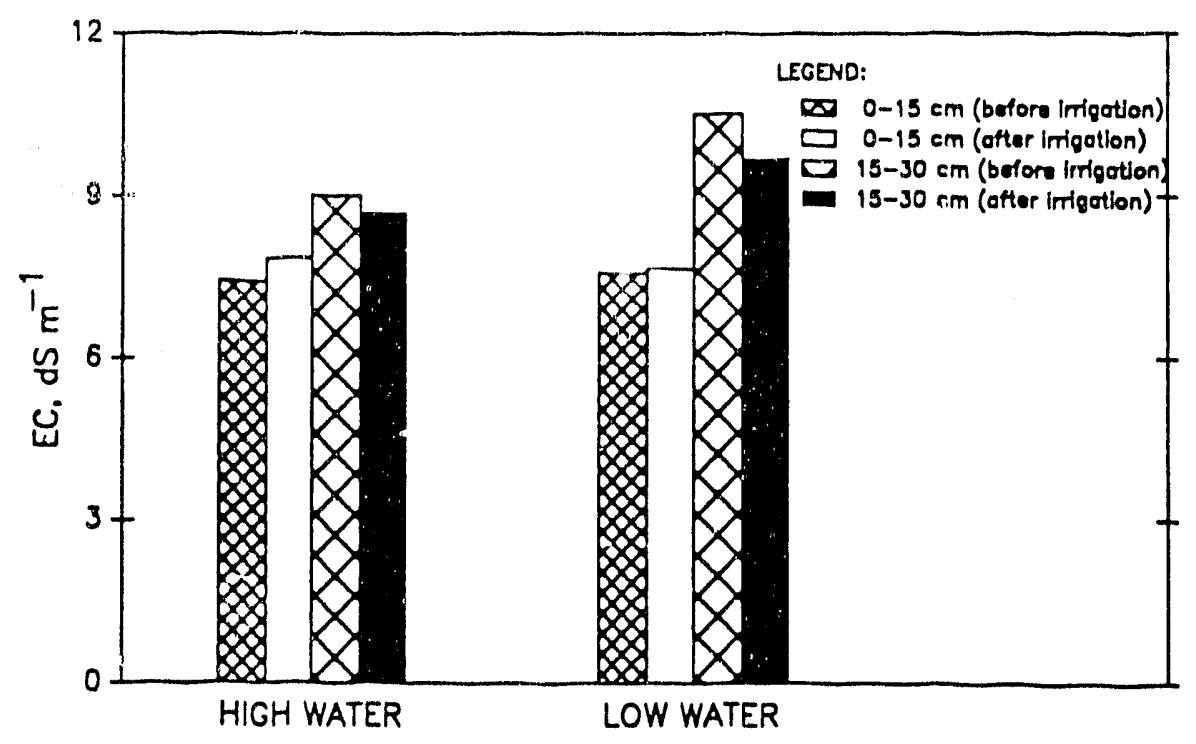

Figure 4.6. Changes in $\mathrm{EC}_{\text {(saturation extracts) }}$ due to irrigation under two water regimes (main plot). 
fresh irrigation water trucked in during part of the experiment. The changes in various chemical species in the soil profile $(0-30 \mathrm{~cm}$ depth) is shown in Figures 4.7 and 4.8 . Sodium and sulfate are the most dominant ions in the soil profile.

\subsubsection{Satellite Plot}

Saturation extracts were obtained from the initial (4/21/89) and final $(8 / 3 / 89)$ soil samples. Initial EC values of the surface soils ranges from 0.64 to $2.74 \mathrm{dS} / \mathrm{m}$. With irrigation, however, the salinity of the whole soil profile increased to fairly high values under both water regimes (Figure 4.9). Initial concentrations of all chemical species were fairly low. Final concentrations of all dominant species are shown in Figures 4.10 and 4.11. As shown in Figures 4.10 and 4.11 $\mathrm{Na}^{+}$and $\mathrm{Cl}^{-}$are the dominant ions in the satellite site.

Selenite and total soluble selenium concentrations (1:5 soil:water extract) were measured in initial and final soil samples, and data indicate that soluble selenium levels in these soils are extremely low. Plant samples were collected from each treatment and selenium and dry matter content were determined. Plant selenium concentrations in barley, tall fescue and alfalfa were $0.41,0.37$ and $0.37 \mathrm{ppm}$ respectively. Barley produced the highest dry matter content $\left(449 \mathrm{~g} / \mathrm{m}^{2}\right)$ relative to alfalfa $\left(48 \mathrm{~g} / \mathrm{m}^{2}\right)$ and tall fescue $\left(35 \mathrm{~g} / \mathrm{m}^{2}\right)$.

\subsubsection{Discussion}

Reliable methods are now available for collecting and meas'ring selenium volatilization from field soils. The design of the new volatilization c.sdmber shows good potential for improving the quality of data collected in various environments. Even for a broad range of temperature and sunlight conditions the environment in the chamber can be better matched with that outside than by other methods. Extraction methods for volatile selenium have become more thorough and efficient, improving data collection and processing of samples. Salinization of surface soils in the fill area was demonstrated to occur in response to irrigation with saline ground water. 


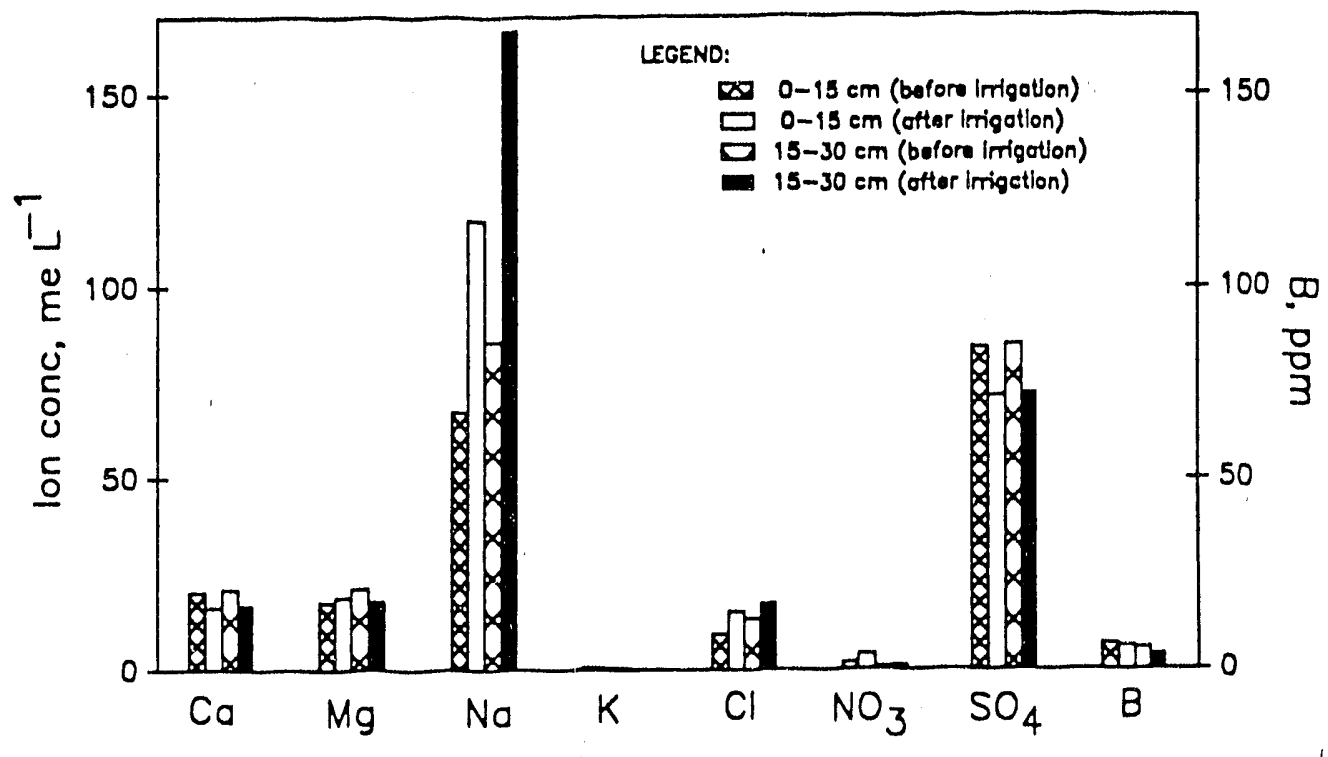

Figure 4.7. Changes in various chemical species in the soil profile due to irrigation (main plot high water region).

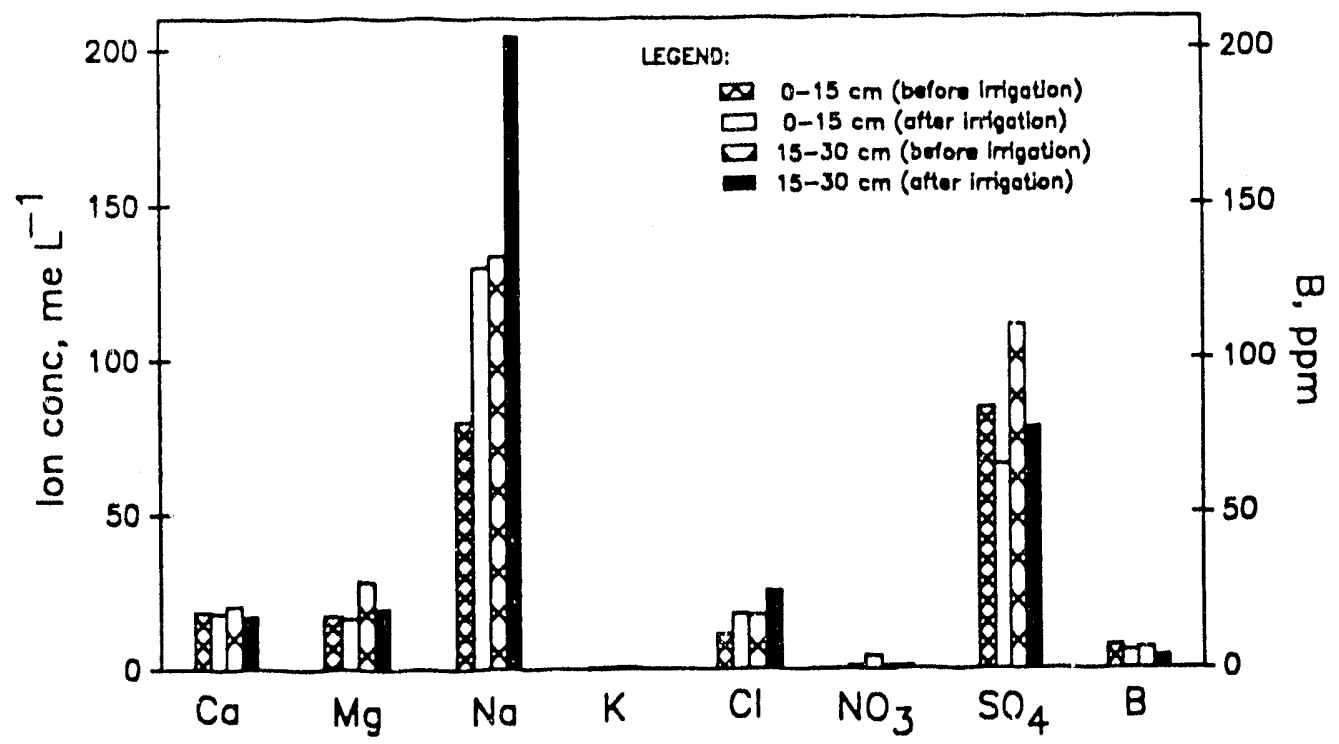

Figure 4.8. Changes in various chemical species in the soil profile due to irrigation (main plot low water region). 


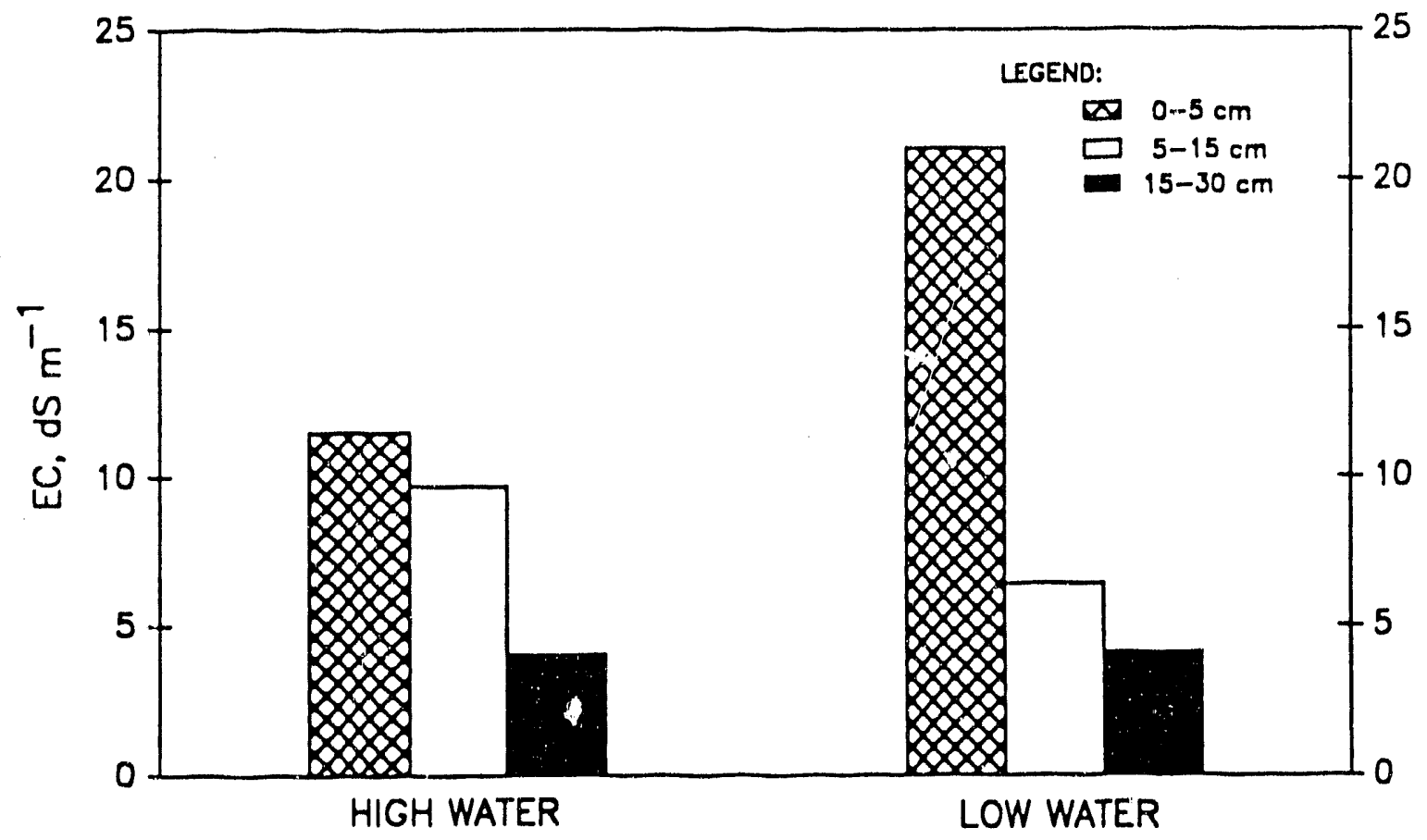

Figure 4.9. Preserit $\mathrm{EC}_{\text {(saturation extrats) }}$ status in 0-30 cm depth in the satellite plot (Aug. 3, 1989). 


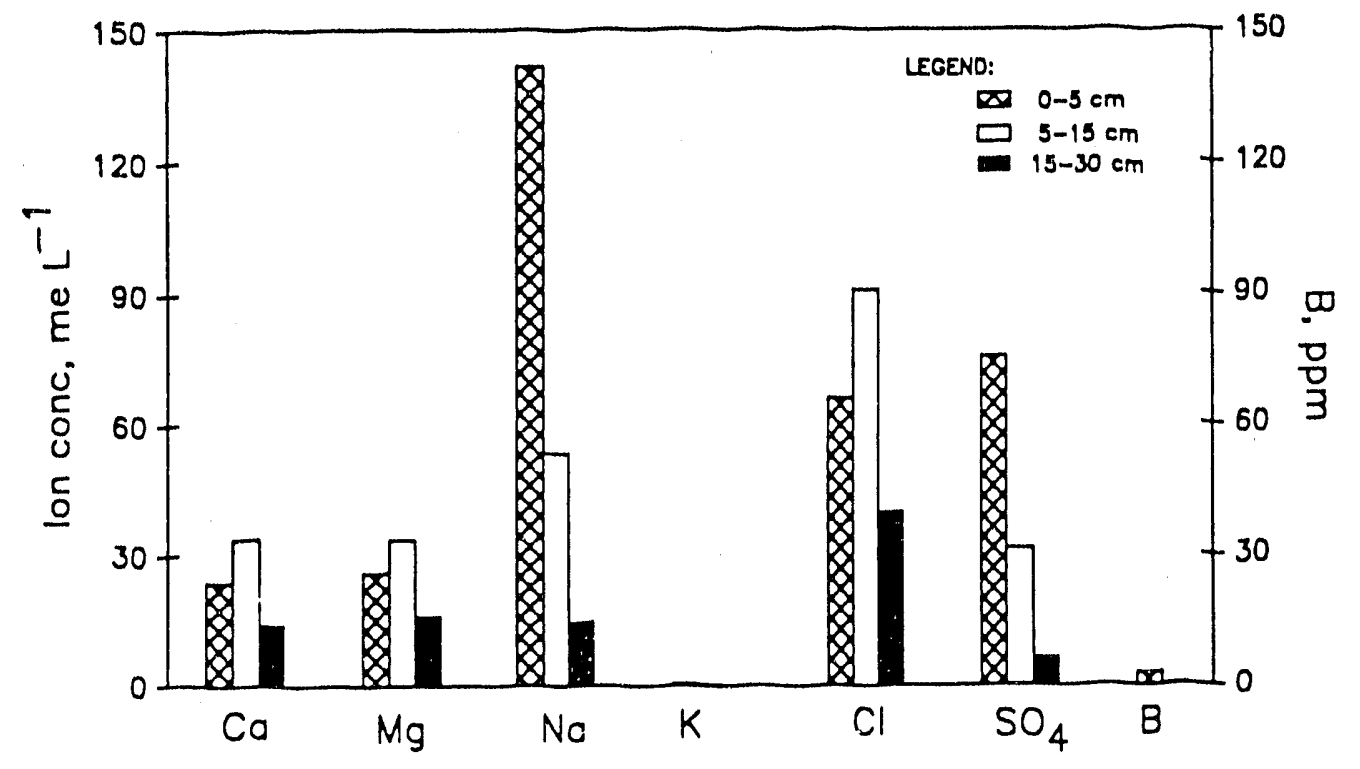

Figure 4.10. Present distribution of various chemical species in the soil profile (satellite plot high water region - Aug. 3, 1989).

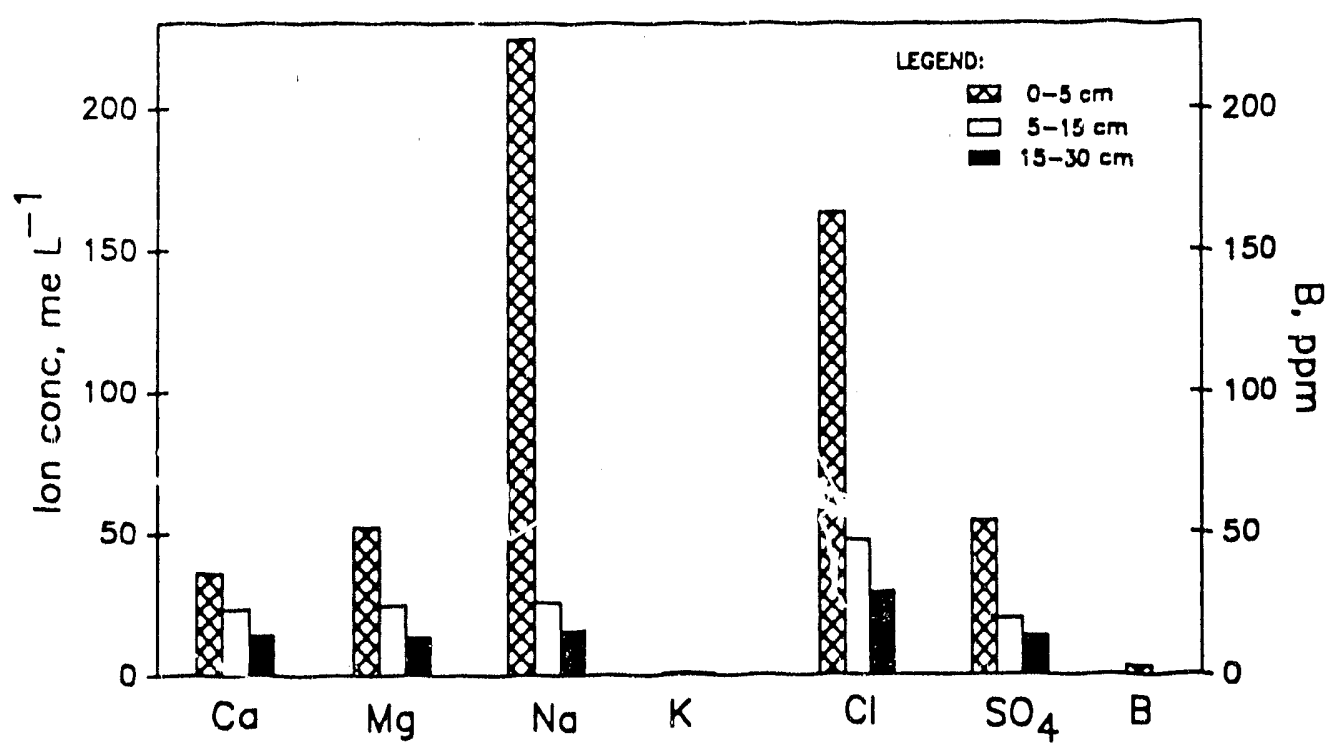

Figure 4.11. Fresent distribution of various chemical species in the soil profile (satellite plot low water region - Aug. 3, 1989). 


\section{$-161-/ 162$}

This in turm inhibits plant growth and has unknown effects on soil microbial processes and selenium volatilization. 


\title{
4.2. GROUND WATER AND VADOSE ZONE MOISTURE RELATED TO SELENIUM REMOVAL BY IRRIGATED VEGETATION
}

\author{
Wesley W. Wallender, Jan W. Hopmans, James W. Biggar and Dennis E. Rolston \\ Department of Land, Air and Water Resources \\ University of Califomia, Davis
}

The soil moisture regime is an important component of the hydrologic cycle since it influences the movement and chemical transformation of selenium in the vadose zone. Moisture-dependent processes of selenium depletion include microbial volatilization from soil, volatilization form plants and leaching. Plants are especially important because they play a dual rcle of direct selenium removal as well as influencing the soil's water content and organic matter which affect other selenium removal pathways.

Selenium is redistributed in the unsaturated zone by water transport driven by rainfall and irrigation, transpiration, evaporation, drainage and seasonal water table fluctuation. Rainfall and irrigation move water and solutes such as selenium downward while transpiration and evaporation drive solutes to the surface. Applied water which passes the root zone as well as water moving laterally from adjacent duck clubs may raise the water table. Depending on solubility, some solutes will be driven upward in the soil profile as the saturated zone invades the root zone. Others such as selenium are chemically reduced under aneaobic conditions and immobilized. Under aerobic conditions and downward water flow, oxydized forms of selenium will leach toward the ground water.

Soil moisture can be manipulated by irrigation timing and amount. Excess irrigation raises the water content beyond the soil's water holding capacity and water bypasses the root zone and contributes to the water table. In a ntrast, by applying only the amount which can be stored, deep percolation and downward transport of selenium is controlled. The plant adds further flexibility to soil water management. In addition to smoothing in the vertical direction, horizontal variation should also be smoothed by the lateral expansion of each plant's root system. With 
smoothing, water which is applied nonuniformly, is stored more uniformly as it redistributes after infiltration and the potential for leaching in high application areas is reduced. In summary, it is hypothesized that the plant integrates spatial variation in soil properties and thus leaching of selenilum to the ground water is reduced.

Large variation in measured soil selenium is a prime motivation for both intensive and extensive soil moisture measurements. As will be shown later, the field experiment and computer simulation studies are designed to investigate small scale as well as field-wide soil moisture properties and movement.

The objective of the research is to measure, monitor, simulate and analyze the possible benefits of irrigation in relation to selenium reduction. Field, laboratory and simulation studies are conducted to characterize the role of soil moisture in selenium disposition over time.

\subsubsection{Procedures}

\subsubsection{Description of Experimental Sites}

Two sites were chosen to monitor soil water regime and its influence on selenium inventory. These are the main plot (in Pond 7), already in operation during the first phase of the project, and the satellite plot (in Pond 5). The satellite plot was covered with 1 to 2 feet of fill material during the landfilling operation in 1988.

To facilitate land preparation and seeding, field instrumentation used in the main plot for the 1988 experiment was rmoved. In the spring of 1989 , twenty-four experimental plots were established in the main $\Gamma$ i. Eight treatments were chosin, each replicated three times. The field layout of the main plot is shown in Figure 4.12a. In this figure, the large numbered dots I:present ground water observation wells. These $3.05 \mathrm{~m}$ long PVC pipes are used to monitor ground water level and ground water salinity and their variation in the main plot. Also shown in Figure $4.12 \mathrm{a}$ is a dual sprinkler irrigation system in the center of the main plot. Impact sprinklers (Rannbird 20-14 H) with 3/32-inch nozzles were installed on 18-inch high risers every 15 feet 
KESTERSON MAIN SITE (POND 7) FIELD LAYOUT, 1989.

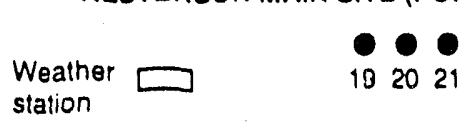

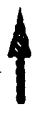

$\mathrm{N}$

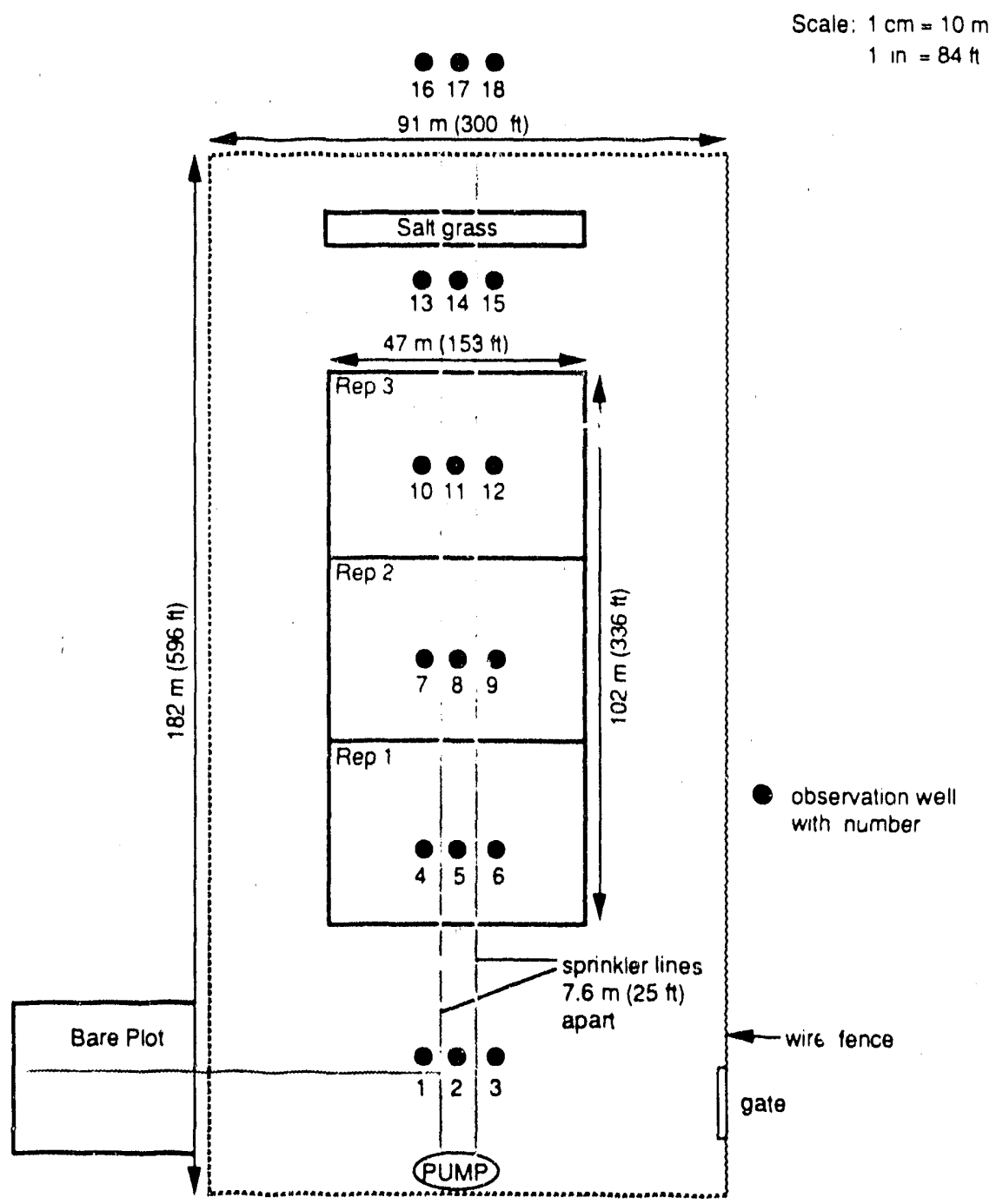

Figure 4.12a. Field layout of the main soil, water, and vegetation management test plot Kesterson Reservoir. 
along the sprinkler lines. The sprinkler lines are 25 feet apart and allow for uniform water application between the two lines. Water application decreases in the direction of the main plot boundary. The area for additional measurements, west of the main plot, has no vegetation but is irrigated and tilled periodically (bare plot). The undisturbed saltgrass at the northern end of the main pl"t within the fenced area is used to monitor irrigation treatment effects on selenium inventory in natural vegetation. Weather station data will be used to estimate plant transpiration and soil evaporation.

Throughout most of the surnmer, four sprinkler lines were used to promote germination and emergence of the planted seeds. To reduce anticipated salinity problems, the main plot was irrigated with good quality water trucked from the Delta-Mendota Canal during that period. Starting September 6, the main plot was irrigated using the two sprinkler lines with pumped ground water from a nearby well (EC is $13 \mathrm{dS} / \mathrm{m}$ ).

Figure $4.12 \mathrm{~b}$ shows the individual treatments in the main plot, as well as the instrumentation. Each of the following vegetation treatments were replicated three times: barley fertilized and unfertilized, tall fescue fertilized and unfertilized, alfalfa fertilized and unfertilized, and salt grass fertilized and unfertilized. Due to poor germination of the barley and tall fescue treatments, these plots were tilled in early September.

Aluminum access pipes were installed in the center of each treatment (*-symbol). These pipes are used to measure soil water content down to a depth of $150 \mathrm{~cm}$ : with a neutron probe. In addition, access pipes were installed at $3,6,9,12,15$ and $18 \mathrm{~m}$ from the center in plots $1,9,14$ and 19. In these same 4 plots, 10 additional pipes were installed at a $0.3 \mathrm{~m}$ spacing starting at the center of the plot and perpendicular to the sprinkler lines. Tensiometers were inserted at 60,150 and $210 \mathrm{~cm}$ depth in the same four plots near the access pipes at 6,12 , and $18 \mathrm{~m}$ distance away from the center line, as well as near five access pipes with the $0.3 \mathrm{~m}$ spacing. These tensiomewrs serve a dual purpose. First, they measure the root zone water potential and indicate depth to ground water. Second, differences in water potential with changing soil depth indicate whether soil water is moving down toward the ground water or up toward the soil surface. 
KESTERSON MAIN SITE (POND 7) EXPERIMENTAL LAYOUT, 1989.

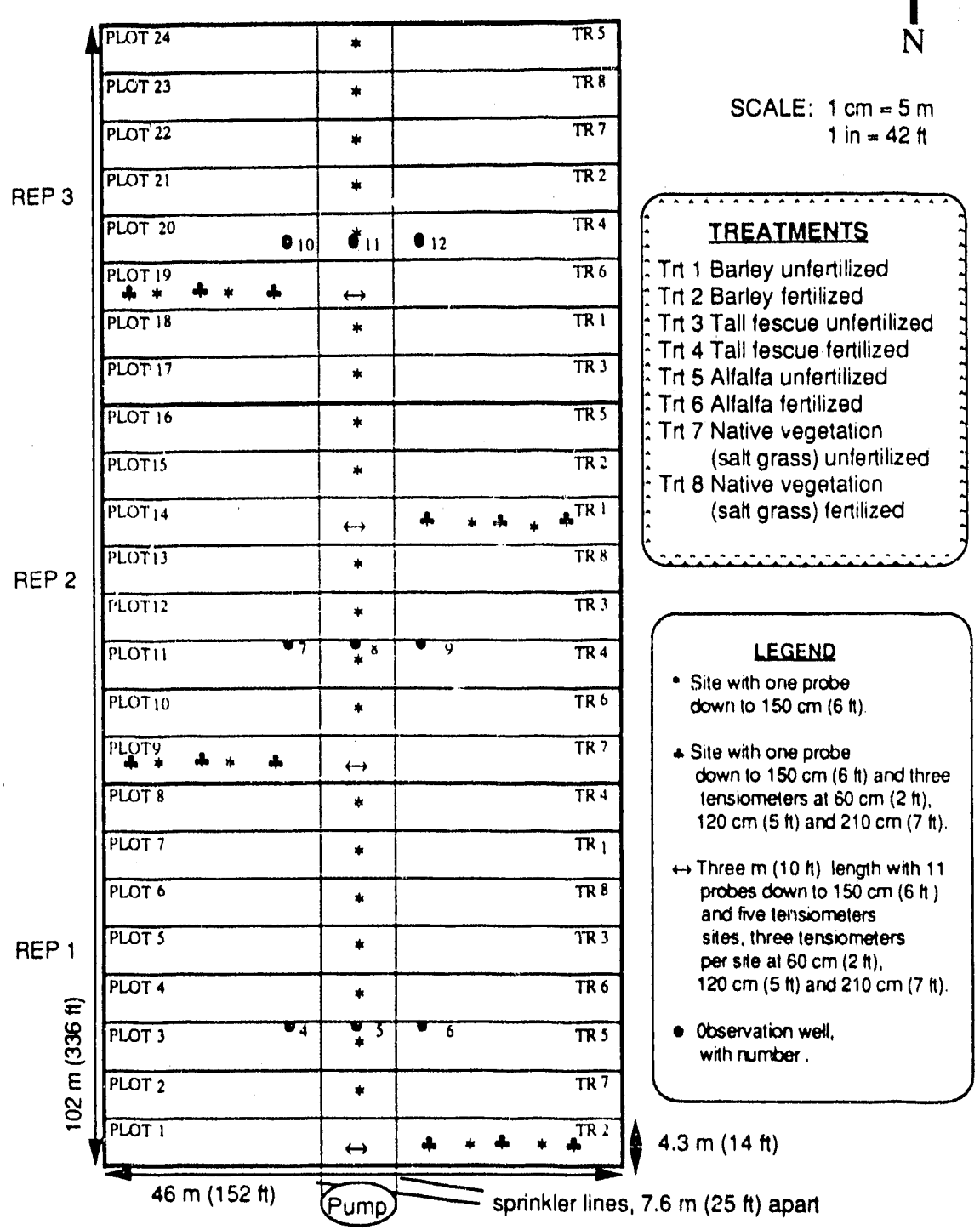

Figure 4.12b. Experimental .ayout of the main soil, water, and vegetation management test plot in Pond 7. 
A similar group of instruments was installed in the bare plot and in the undisturbed salt.. grass area. The field layout of the satellite plot is shown in Figure 4.13a. Again, a dual sprinkler line system was in stalled with similar riser spacing and nozzle characteristics as in the main plot. In contrast to the main plot, only three r egetation treatments (barley, tall fescue and alfalfa, cach replicated three times) were monitored. After seeding, four sprinkler lines and Delta Mendota Canal water were used 10 facilitate germination. Later, gmund water from a nearby well was used for the irrigation water (EC of $7 \mathrm{dS} / \mathrm{m}$ ). Figure $4.13 \mathrm{~b}$ illustrates locations of access pipes, tensiometers and ground water observation wells.

\subsubsection{Field Measurements}

The first set of measurements in Phase II was made June 13, 1989. These measurements include water content at depths of $15,30,60,90,120$ and $150 \mathrm{~cm}$ and tensiometer readings at 60 , 150 and $210 \mathrm{~cm}$ depth. In addition, ground water level depth and ground water salinity were measured. Soil samples were taken at various depths for neutron probe calibration and soil salinity in both the main and satellite plot. Catch can measurements were taken in both plots to verify the anticipated water application distribution of the irrigation systems Water application rates were chosen to minimize water movement and associated leaching to the ground water, while simultaneously creating a favorable soil environment for plant growth and soil selenium depletion.

In both plots, soil samples were collected in $8 \mathrm{~cm}$ diameter and $6 \mathrm{~cm}$ tall soil cores at depths of 30 and $60 \mathrm{~cm}$. In total, 80 samples were taken, part of which originate from the fill material in the satellite plot. The samples are used to characterize the soil hydraulic properties, soil texture and their variation within and between the two research plots.

\subsubsection{Laboratory Experiments}

Water retention and unsaturated hydraulic conductivity relationships for the 80 samples are determined in the laboratory. The one-step outflow technique allows measurement of both the moisture retention and relative conductivity for 40 samples simultaneousiy. A preliminary study 
KESTERSON SATELLITE SITE (POND 5) FIELD LAYOUT, 1989.

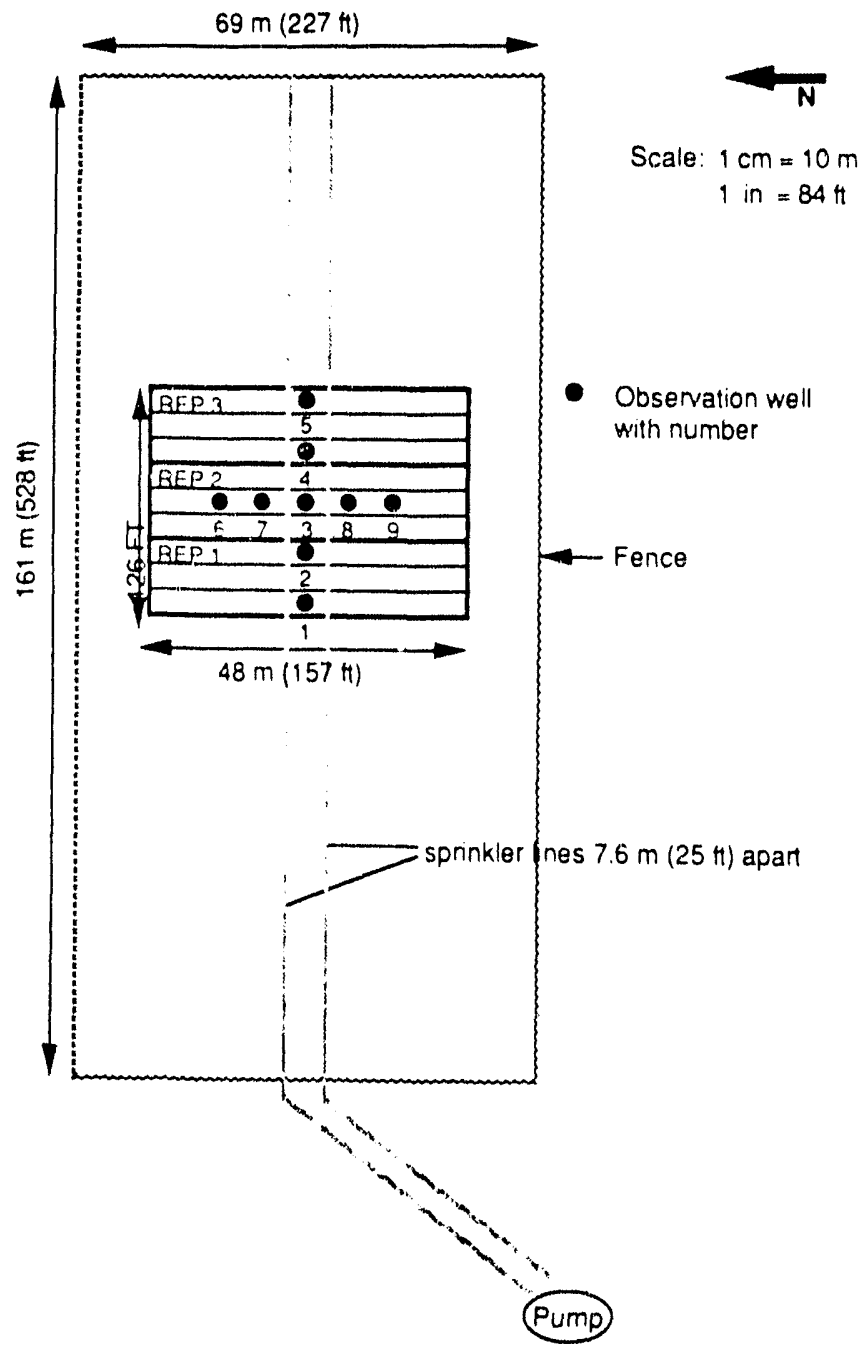

Figure 4.13a. Field layout of satellite plot Kesterson knservoir. 


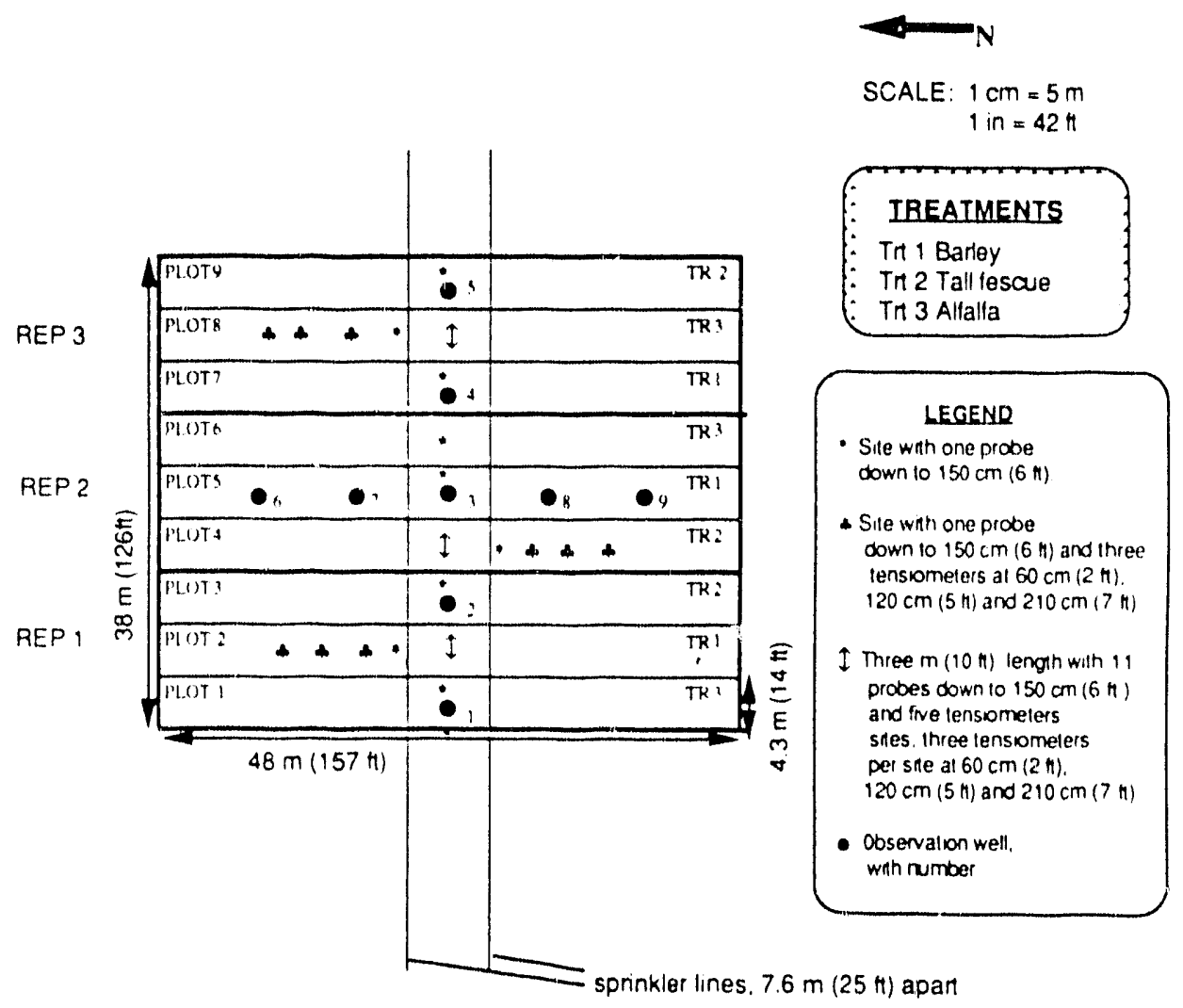

Figure 4.13b. Experimental layout satellite plot Kesterson Reservoir. 
was done to assess the influence of suil solution salts on the retention and conductivity functions.

\subsubsection{Computer Simulations}

The moisture regime for various water management scenarios is simulated with the numerical model SWATRE which uses the laboratory measured soil physical data and the field measured boundary conditions. Hysteresis in the water retention curves has been implemented into this model to more closely resemble the actual field situation with its wetting and drying cycles during and after each irrigation. Field measurements of water content, soil water pressure head and ground water level are used to validate the model. Monte-Carlo simulations will account for the spatial variability of the soil properties govening soil water transport.

\subsection{2, Results and Discussions}

The quantities of water applied to the research plots are shown in Table 4.7. For most of the summer, high quality Delta Mendota Canal water was applied to the main plot. Despite this effort, germination was poor. Possible causes are (1) the delayed planting of the seeds, and (2) the high soil salinity. Delta Mendota Canal water was used only until the middle of June in the satellite plot. Since all treatments germinated well, pumped ground water was applied thereafter.

\subsubsection{Field Me'asurements}

Fluctuations in ground water level below the soil surface and ground water salinity for the main plot are depicted in Figure 4.14. This figure shows the mean (solid line) and standard deviation (bars) from the 21 cbservations wells (Figure 4.12a) for both attributes starting at August 1, 1988. Following the rise in ground water table in the winter of 1988-1989 the ground water level decreases in 1989 , to a tepth lower than it was the same time last year. The variation in ground water level is relatively small. Ground water salinity seems to follow the trend in ground water level. However, its variation is much larger. Within the main plot area, ground water salinity varies from 10 to $35 \mathrm{dS} / \mathrm{m}$. Furthermore, the main ground water salinity appears to increase with time within the one year monitoring period. Ground water depth and salinity for the satellite plot is shown in Figure 4.15. Since the satellite plot was established this year, data are not available 
Table 4.7. Irrigation schemes research plots Kesterson 1989.

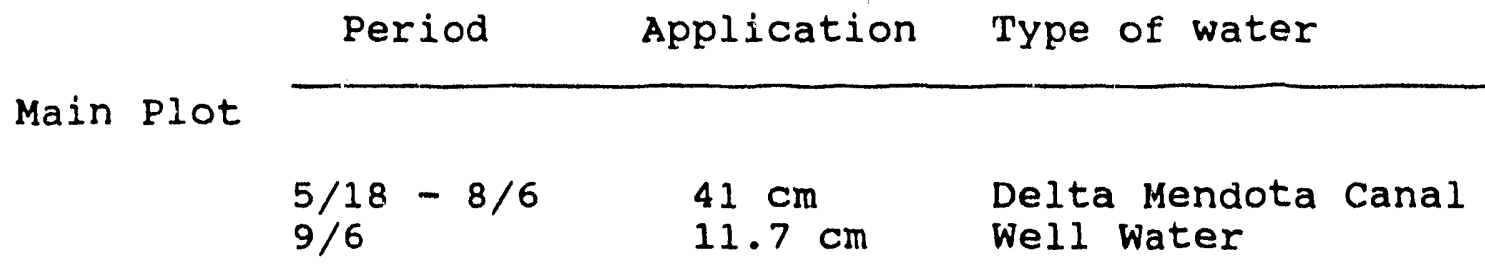

Bare Plot
$9 / 6$
$4.4 \mathrm{~cm}$
Well water

Satelite plot

$\begin{array}{lll}5 / 20-6 / 11 & 0.6 \mathrm{~cm} / \text { day } & \text { Delta Mendota Canal } \\ 6 / 14-7 / 30 & 0.5 \mathrm{~cm} / \text { day } & \text { Well Water } \\ 8 / 4 & 6.5 \mathrm{~cm} & \text { Well Water } \\ 8 / 16 & 2.5 \mathrm{~cm} & \text { Well Water } \\ 8 / 26 & 2.5 \mathrm{~cm} & \text { Well Water } \\ 9 / 6 & 2.5 \mathrm{~cm} & \text { Well Water }\end{array}$




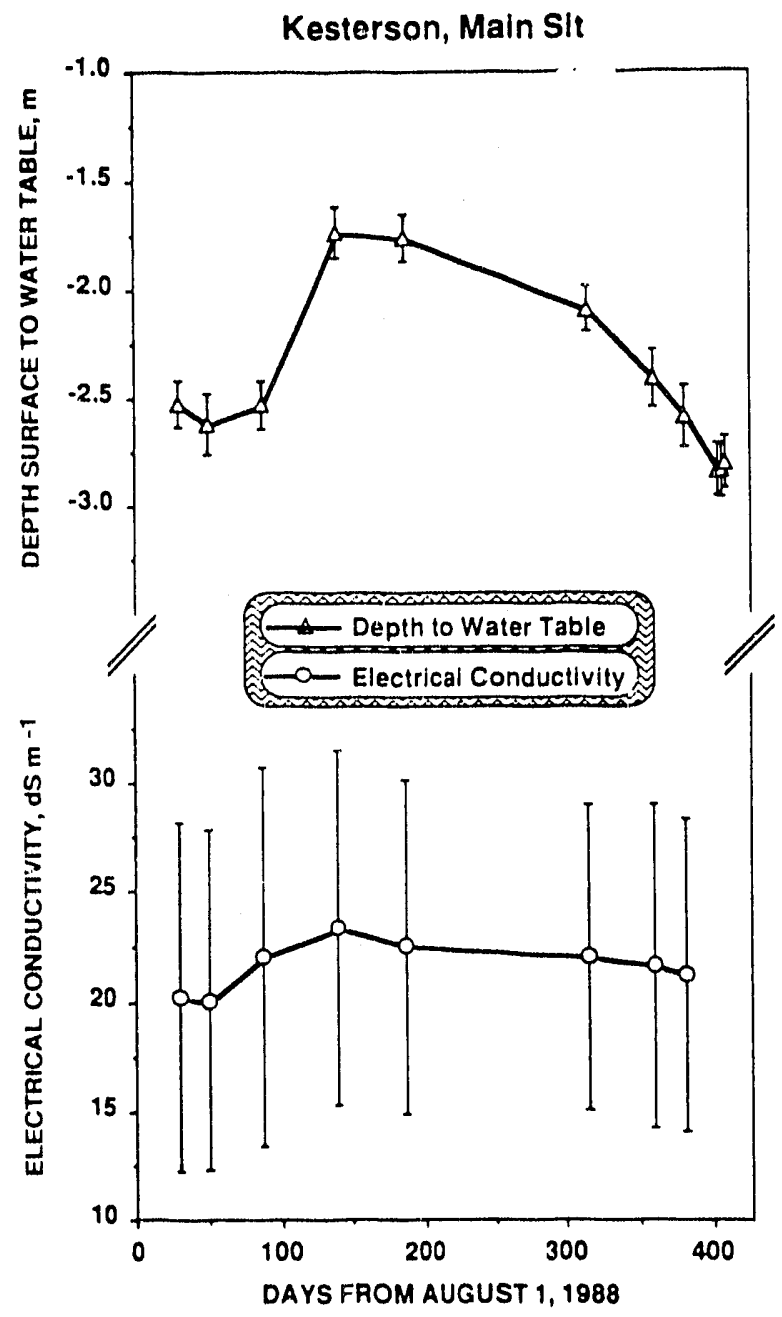

Figure 4.14. Mean (solid line) and standard deviation (bars) ground water level and ground water EC. at the main experimental plot. 
for 1988. As in the main plot, also here the ground water level continues to decrease through the summer. The average ground water level is, however, approximately $60 \mathrm{~cm}$ closer to the soil surface than in the main plot. Ground water salinity appears to increase during the monitoring period, but is significantly lower in magnitude than in the main plot.

Application of irrigation water was limited to minimize downward water flow to the water table. Tensiometers were installed to measure hydraulic gradients and, therefore, to determine whether flow toward the ground water occurred. An example of hydraulic gradient calculations is demonstrated in Figure 4.16. Hydraulic gradients are shown between 150 and $210 \mathrm{crn}$ depth for the center transect of the satellite plot, one day before and one day after a $2.5 \mathrm{~cm}$ irrigation. Positive values indicate upward flow and negative values downward flow toward the ground water. The three groups of data at approximately 1,10 and $26 \mathrm{~m}$ are from the 5 sets of tensiometers along the sprinkler lines at treatment plots 2, 4, and 8. Obviously, some downward flow appears to occur. However, hydraulic gradient calculations can become erratic when tensiometers are placed close to the ground water table. A closer look at the tensiometer readings revealed that hydraulic gradient values smaller than -0.5 are caused by errors in the tensiometer measurements. Nevertheless, the results in Figure 4.16 show that downward flow occurs in most cases, indicating that more water was applied than removed by plant root uptake and soil evaporation. Ground water levels, however, are consistently decreasing with time during the summer (Figure 4.15).

The relation between hydraulic gradient and ground water table as a function of time is shown in Figures $4.17 \mathrm{a}$ and $4.17 \mathrm{~b}$ for the tensiometers in research plot 4 (Figure $4.13 \mathrm{~b}$ ). In both figures ground water level is going down with time in response to the regional trends described in Section 2.1, while hydraulic gradients indicate downward flow due to local application of irrigation water.

Water application distributions for the satellite plot are shown in Figures 4.18a and 4.18b for catch cans along and normal to the sprinkler laterals, respectively. In Figure 4.18a, the three clusters of data originate from catch can readings in research plots 2, 4, and 8 . From the distribu- 


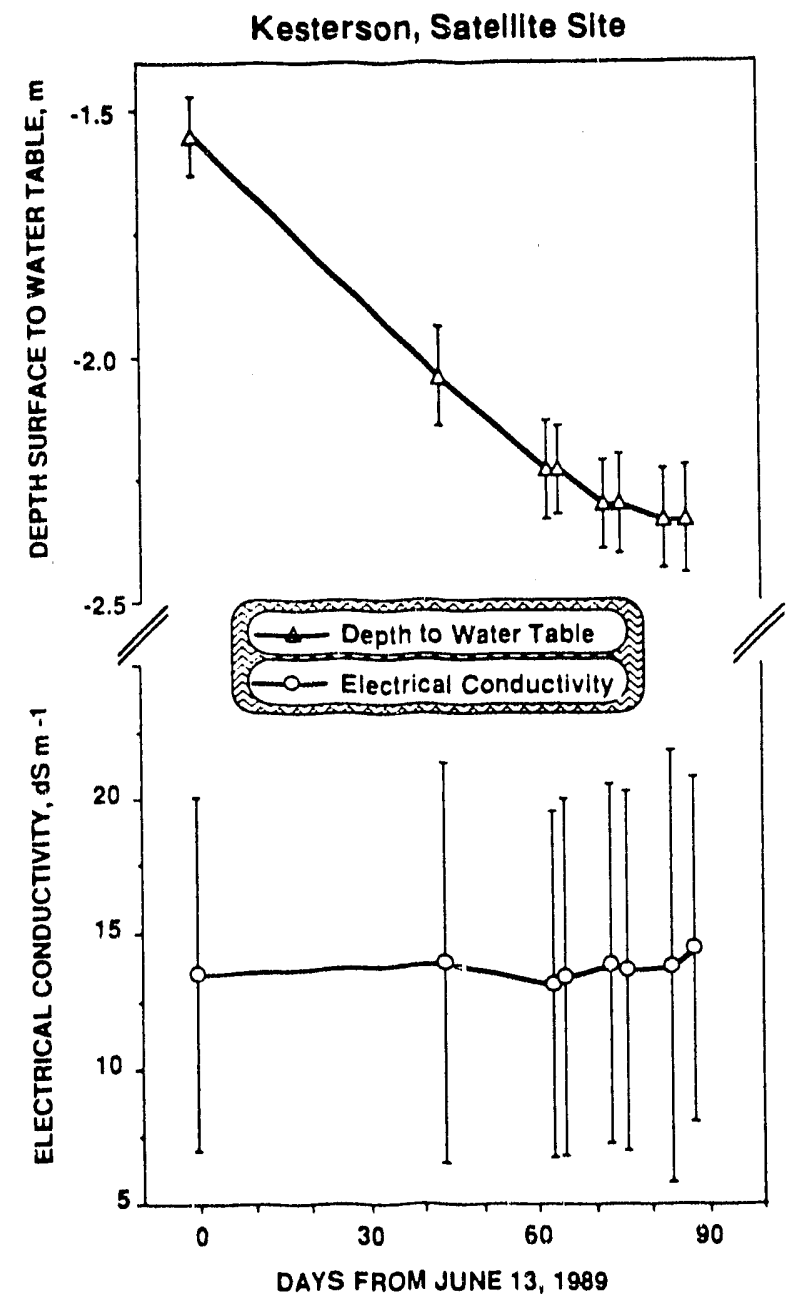

Figure 4.15. Mean (solid line) and standard deviation (bars) ground water level and EC ground water at the satellite plot. 


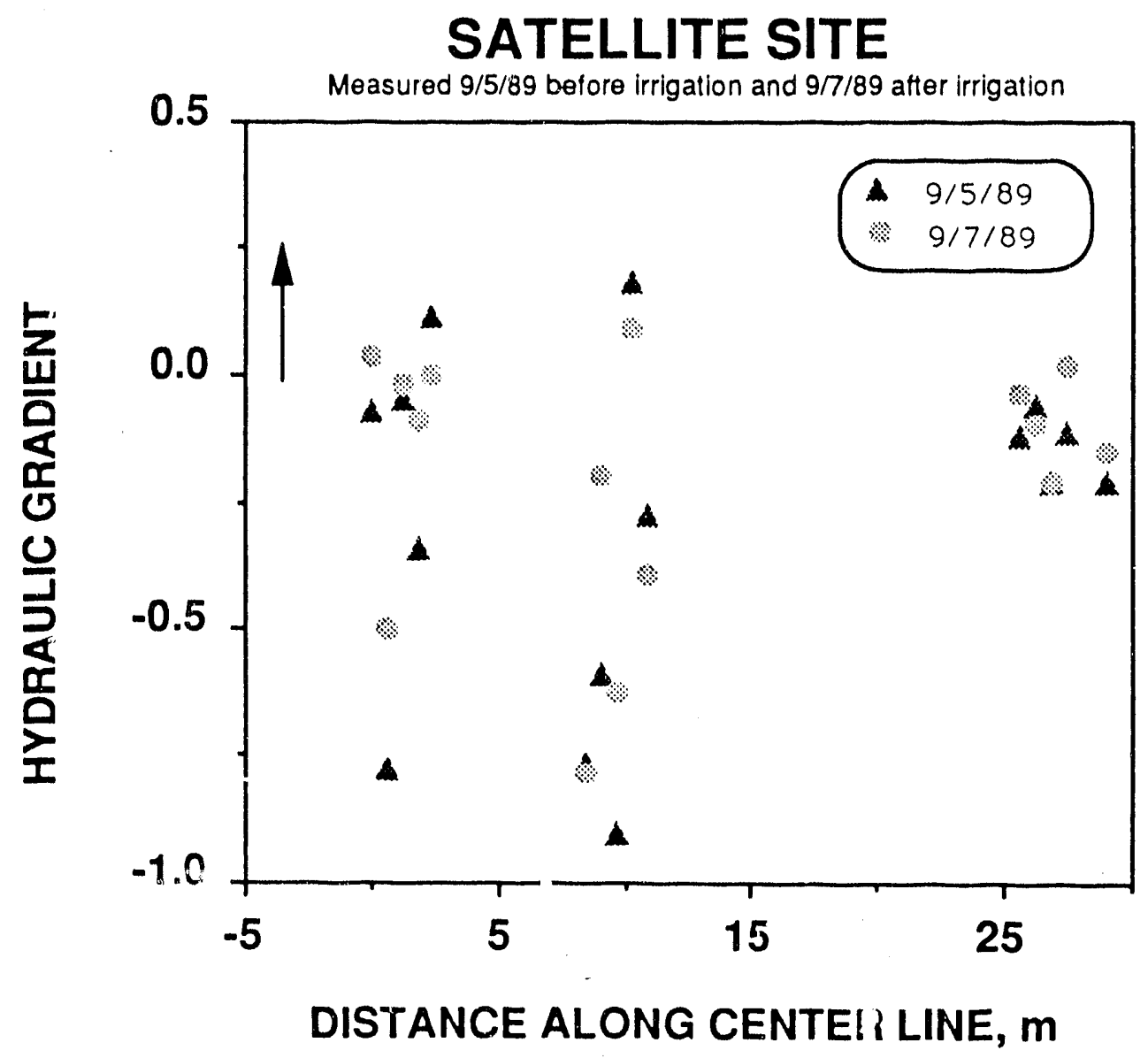

Figure 4.16. Hydraulic gradient along center line for satellite plot. 


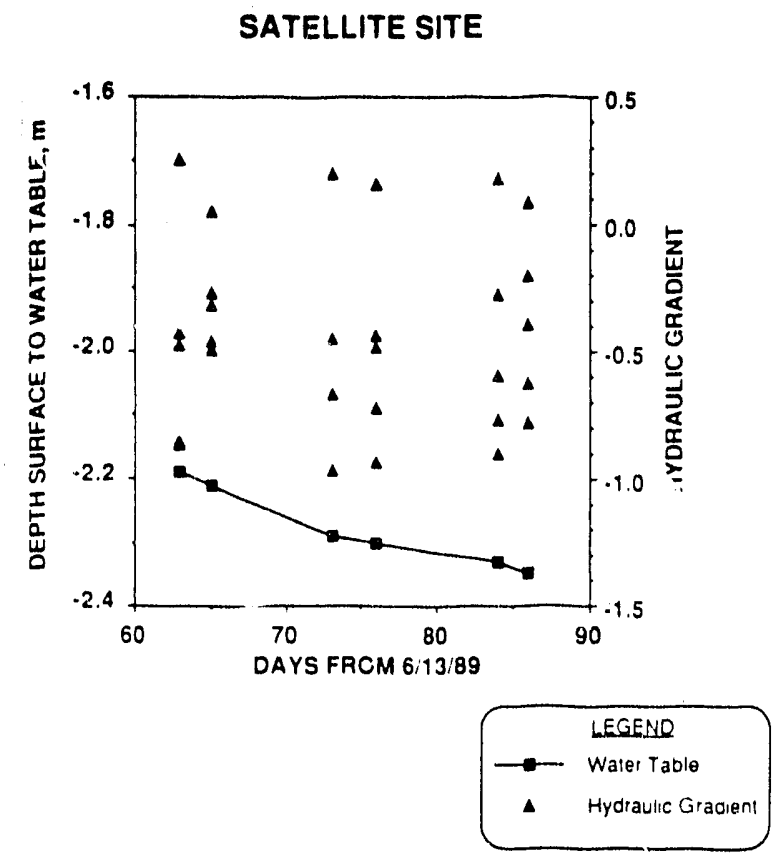

Hydraulic gradient between 210 and $150 \mathrm{~cm}$ calculated lrom cluster of 5 tensiometers along center line in plot 4; depin 10 waler tabie at well *3

Figure 4.17a. Water table depth and hydraulic gradient along center line as a function of time.

\section{SATELLITE SITE}

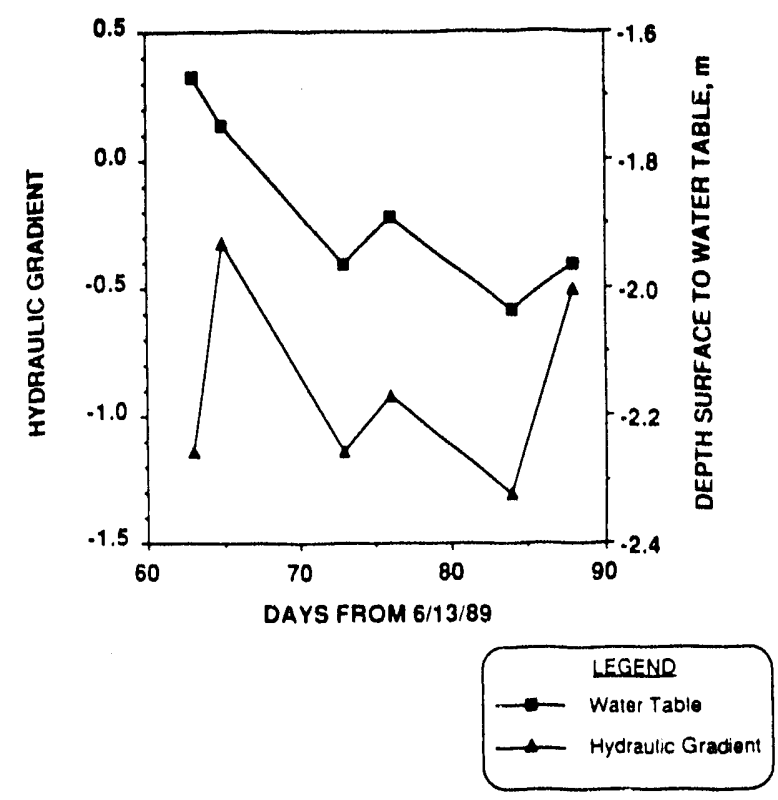

Hydraulic gradient between 210 and $150 \mathrm{~cm}$ calculated from lensiometers at subplot $9 \mathrm{~m}$ from comter line in plot 4; depth to water table tor wall 48.

Figure 4.17b. Water table depth and hydraulic gradient at $9 \mathrm{~m}$ from center line in plot 4 as a function of time. 


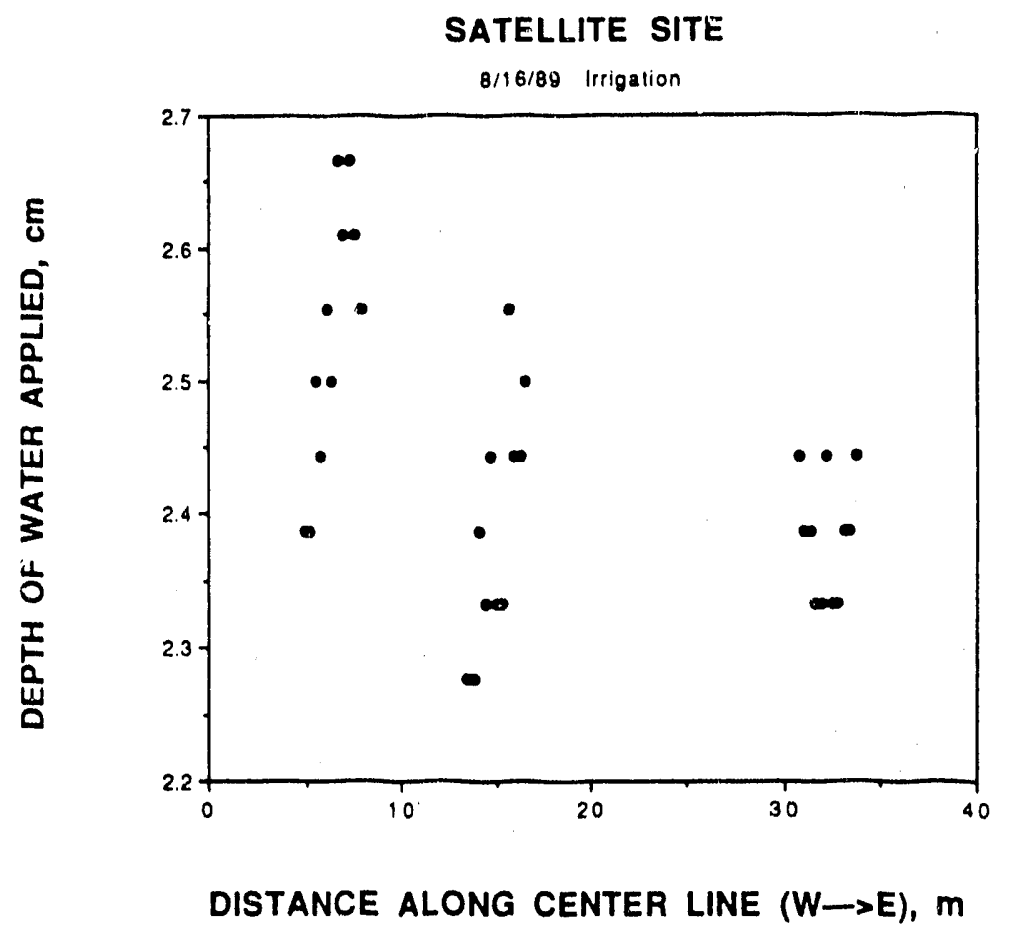

Figure 4.18a. Depth of water applied along center line.

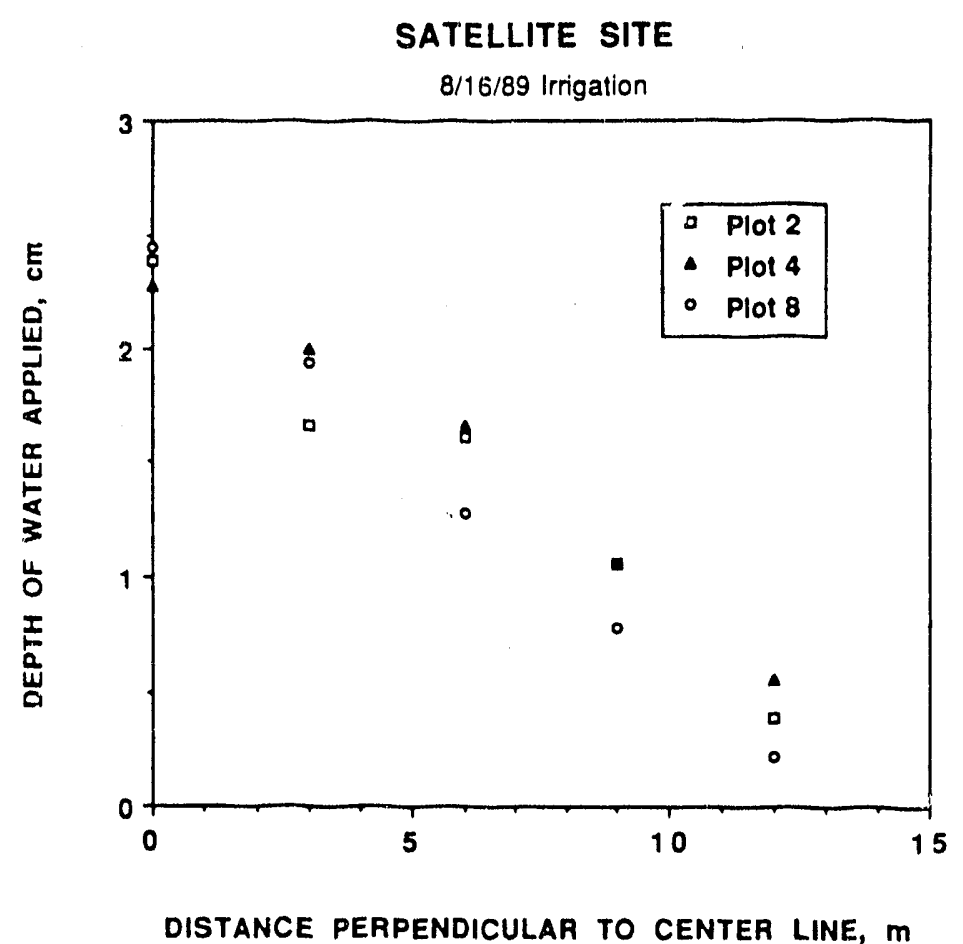

Figurc 4.18b. Applied water distribution, perpendicular to center line. 
water application between two sprinkler nozzles is fairly large (coefficient of variation is $10 \%$ ). Second, average water application decreases in an easterly direction, going from plot 1 to plot 9 (Figure 4.13b). This occurs despite the relatively short sprinkler pipe length. The lower water application in plot 8 at the eastem side of the satellite plot is also apparent in Figure $4.18 \mathrm{~b}$. Moreover, the placement of the two sprinkler lines in the center of the satellite plot did not result in an uniform water application between the two lines. Water application decreases toward the edges of the plots.

To estimate total evapotranspiration (ET) between two irrigation dates, changes in soil water storage $(\mathrm{cm})$ between two successive irrigation dates (10 day period) are plotted versus distance (m), perpendicular to the center line for all three instrumented plots of the satellite site in Figure 4.19a. Since the water applied decreases from the center to the edge of the plots (Figure 4.18b) one would expect a decrease in ET in the same direction. The results in Figure 4.19a confirm this expectation. Surprising is the low value of total ET for this ten day period. The range in total ET in the center of the plots is from 0.8 to $1.8 \mathrm{~cm}$, corresponding to a daily ET of 0.8 to $1.8 \mathrm{~mm}$. Since the total applied water there was approximately $2.5 \mathrm{~cm}$, we must have overirrigated the satellite plot. The difference between total ET and water applied for the period $8 / 17$ to $8 / 26 / 89$ shows clearly that excess water was applied in the center region of the satellite plot. However, going outwards from the plot center, ET and applied water are abont equal. Both the applied water and ET are low at the edge of the plots. The overirrigations are consistent with the downward water flow, observed from the hydraulic head gradients in Figures 4.16 and 4.17.

Figure 4.20 shows the percentage of total ET derived from subsequent soil layers. Such an analysis is necessary to determine num which depths the plant roots extract the water for transpiration. This was done for a transect along the center line of the satellite plot, as woll as for the instrumented plots perpendicular to tie center line. The results for the center line are shown in Figure 4.20. Clearly, most of the soil water removed by ET originates from the upper $15 \mathrm{~cm}$ (50$100 \%$ ). Results for the transect perpendicular to the center line were not so successful, mainly because total ET becomes relatively small for sites near the edges of the plots. Small errors in 


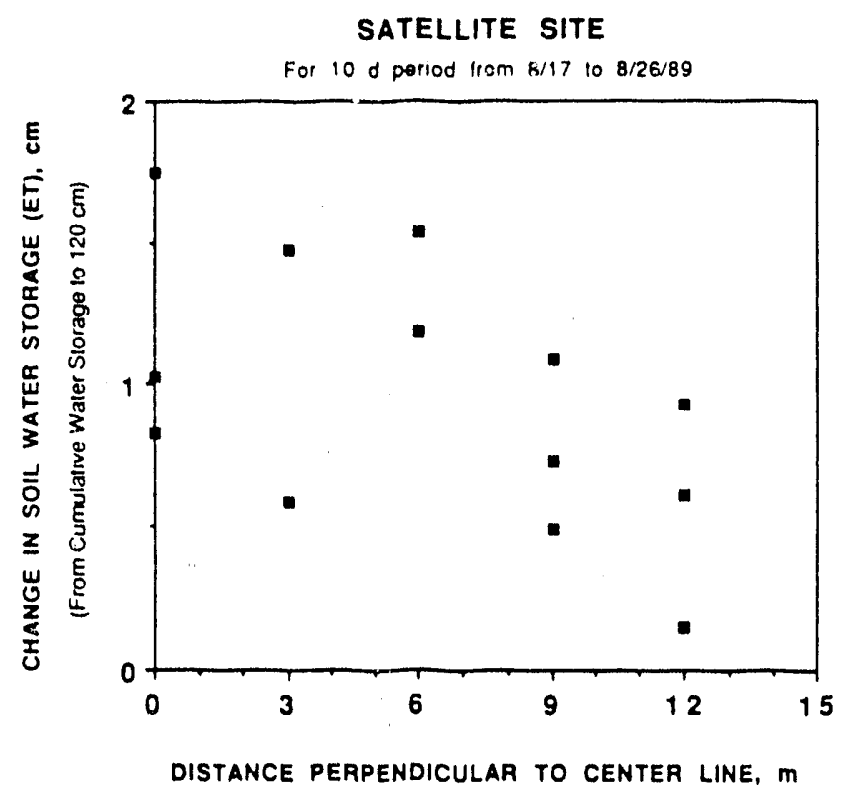

Figure 4.19a. Total ET as a function of distance perpendicular to center line.

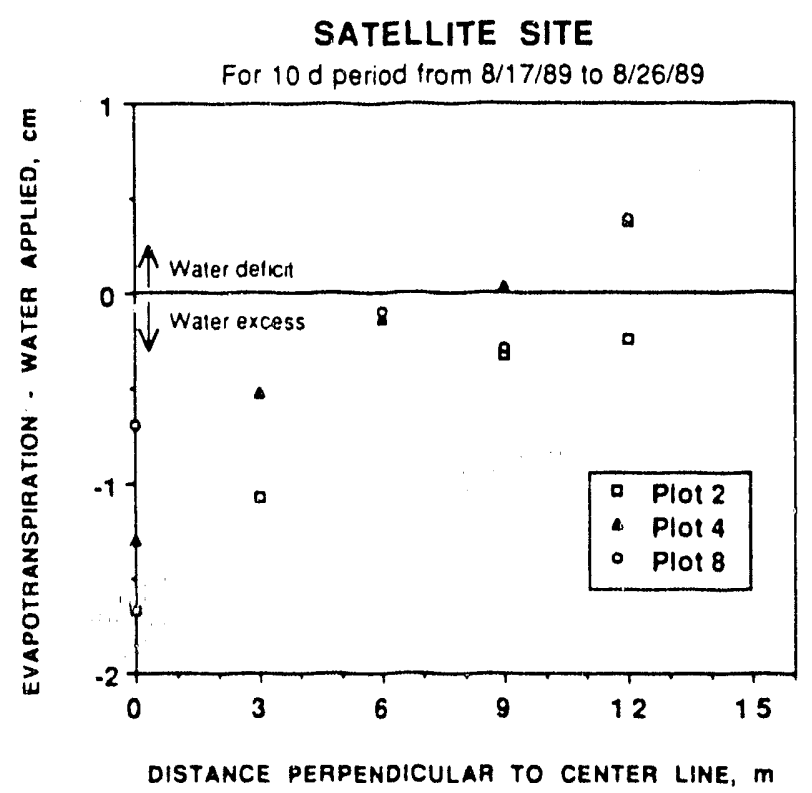

Figure 4.19b. Total ET minus applied water as a function of distance, perpendicular to center line. 
SATELLITE SITE

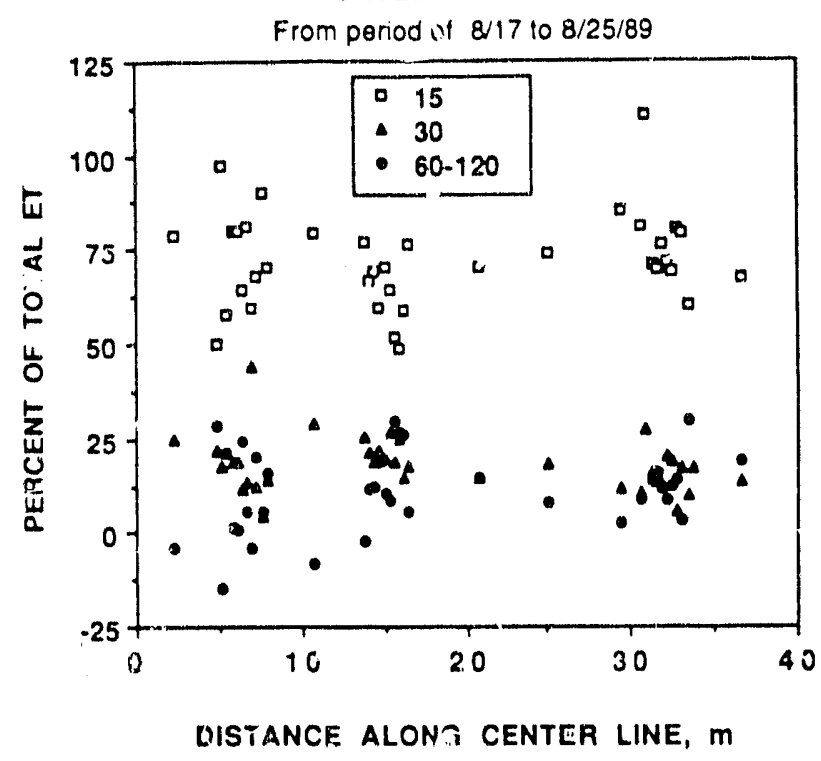

Figure 4.20. Percent of total ET removed from depth intervals $0-15 \mathrm{~cm}, 15-30 \mathrm{~cm}$ and $30-120 \mathrm{~cm}$.

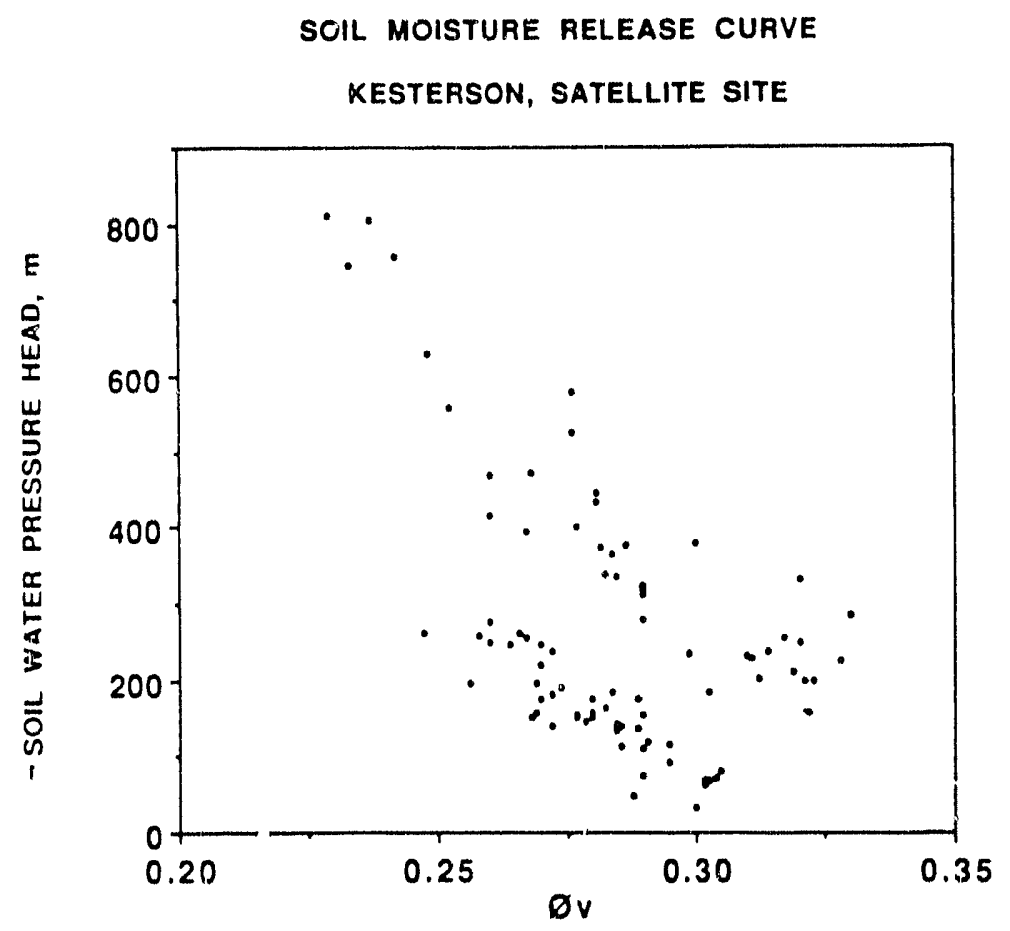

Derived from field values of paired neutron probe anoi tensiometer data

Figure 4.21. Ficld-measured water retention curve at $60 \mathrm{~cm}$ depth. 
the neutron probe readings within the measuring period then ber'ome significant in the water storage calculations.

Since both soil water pressure head and water content are measured simultar. ously at equal depths, it is possible to derive a field-measured water retention curve. This is done in Figure 4.21 for all $60 \mathrm{~cm}$ depth locations in the satellite plot. The data in Figure 4.21 suggest that. two different soils exist at the $60 \mathrm{~cm}$ depth. Most likely, these are the fill material and the original top soil.

\subsubsection{Laboratory Experiments}

In order to determine the saturated hydraulic conductivity and water retention curves of the Kesterson soil samples, we need to saturate the samples with water. The salt concentration of this water is expected to have a pronounced effect on the hydraulic properties to be determined. Since the soil water in the Kesterson ponds is very salty, we initiated a small study to evaluate the influence of salts on the conductivity and retention curves. The samples collected in the main plot are sandy clay loams with an average clay content of $29 \%$. The clay fraction consists of predominantly montmorillonite. The samples contained more than $75 \mathrm{meq} / 1 \mathrm{Na}(\mathrm{S} A \mathrm{R}=14.0)$. To investigate soil solution effects two different salt concen'rations were used; deionized water and synthesized water containing $100 \mathrm{meq} / \mathrm{l} \mathrm{Ca}(\mathrm{EC}=10.1 \mathrm{dS} / \mathrm{m})$.

Each of the samples was first saturated with deionized water. Using the one-step outflow method, outflow was monitored until zero outflow while applying 1 bar of pressure in a Tempe pressure cell containing the sample. Thereafter, the saturated hydraulic conductivity was deter. mined using the constant head method. After resaturating the samples with the synthesized water, again outflow and saturated hydraulic conductivity were measured. After an initial decline of the saturated hydraulic conductivity due to swelling and dispersion in the first rur with the deionized water, the conductivity seems unaffected by the added $\mathrm{Ca}$ in the second run (Figure 4.22 .

Figure 4.23 shows the effect of added salts on the water retention curves for one representa- 


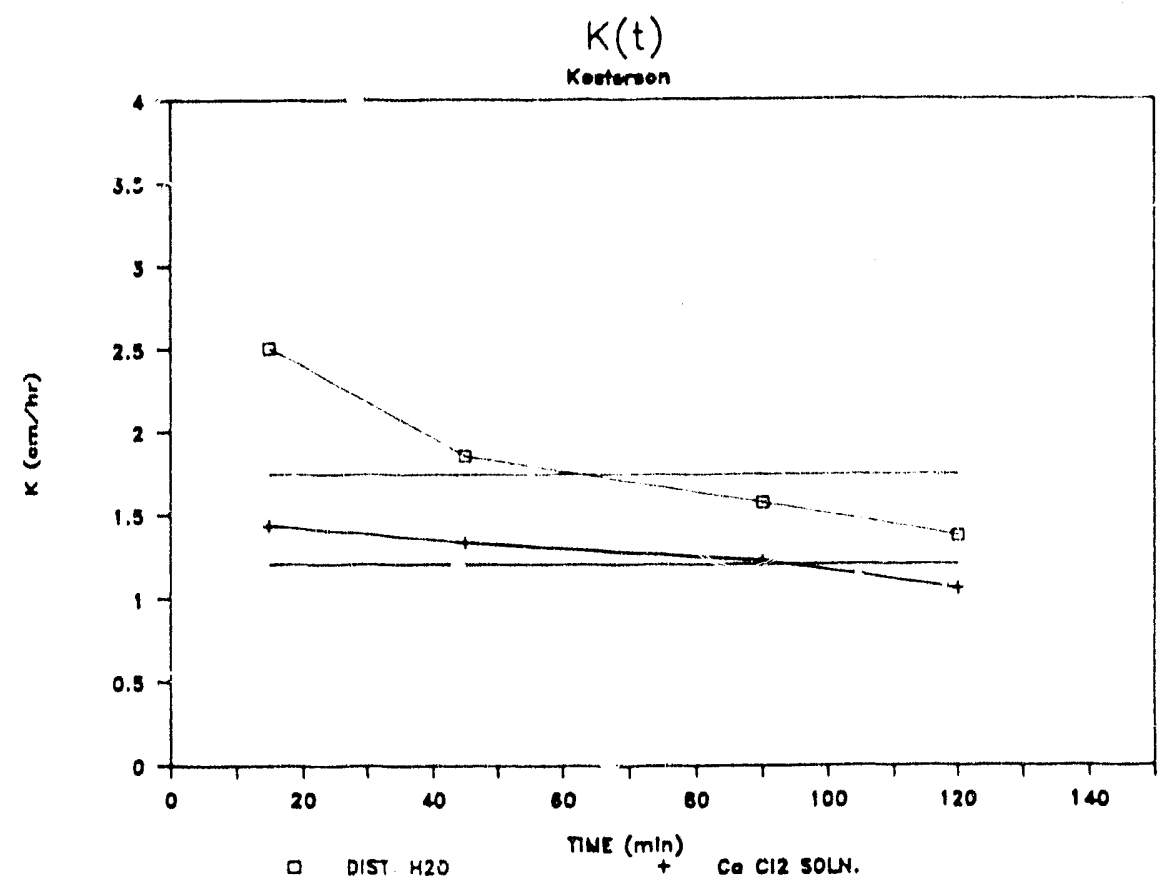

Figure 4.22. Saturated hydraulic conductivity value for Kesterson soil samples main plot) when treated with distilled and Ca-solution.

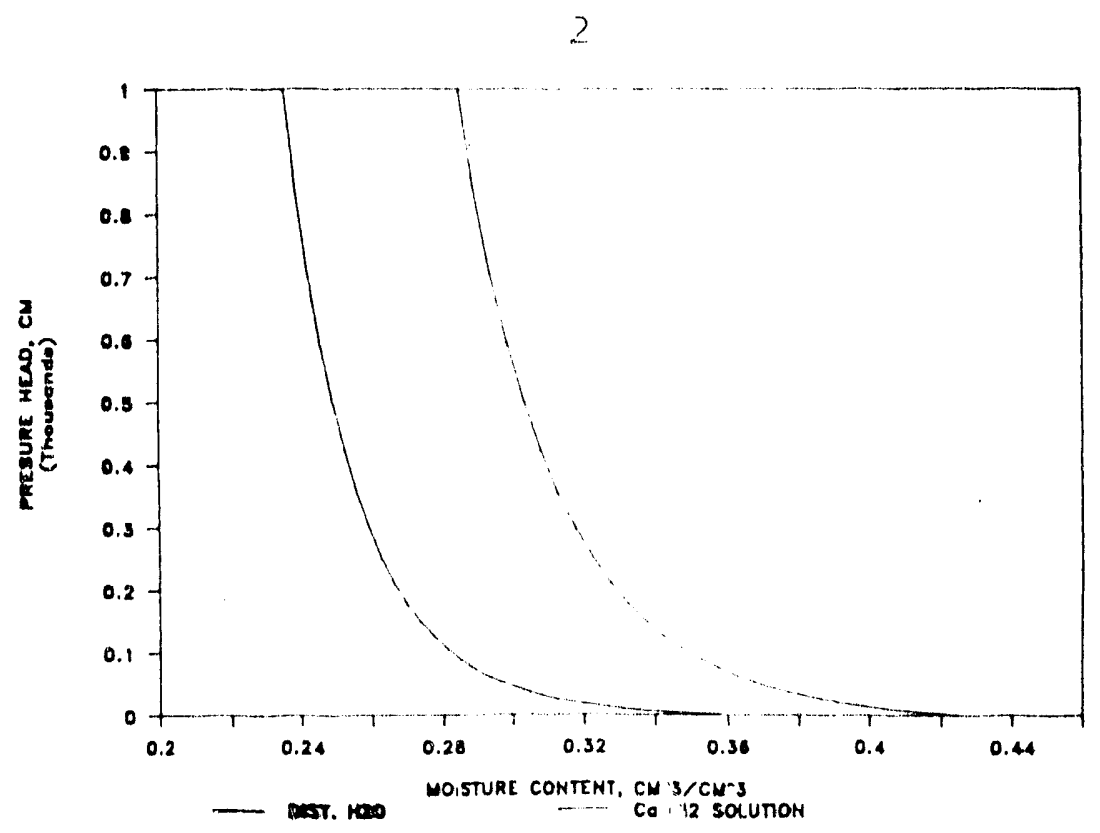

Figure 4.23. Laboratory measured water retention curves for Kesterson soil samples (main plot), when treated with disilled water and $\mathrm{Ca}$-solution. 
Figure 4.23 shows the effect of added salts on the water retention curves for nne representative sample. Saturating the high-Na soil sample with distilled water had a significant effect on the water retention curve due to swelling and chemical dispersion. Using the EC-10.1 synthesized water, we further determined saturated hydraulic conductivity values for the surface and subsurface samples of the satellite plot. Twenty samples were taken from the surface fill material, while another twenty samples came from the original surface soil at $60 \mathrm{~cm}$ depth. Table 4.8 shows the measured conductivity values for these two depths. Apparent is the large variation in conductivity values within each of the two sample populations. Furthermore, it appears that subsurface saturated hydraulic conductivity is slightly higher than for the surface. The large standard deviation values preclude significant difference between the two populations.

\subsubsection{Computer Simulations}

A numerical unsaturated water flow model was adapted to allow simulation of water flow for the irrigated research plots in Pond 7. This also included the incorporation of hysteresis of the water retention curves to the computer code. Figure 4.24 shows the main drying and wetting retention curves for a hypothetical soil and two hysteresis loops as determined with the hysteresis model. Usually, only the main drying curve is measured and used for characterization of the soil's water retention capacity. However, since soils under irrigation are subject to a sequence of wetting and drying cycles, it was anticipated that hysteresis might be important in simulating actual field conditions.

The loop coded as \#1 shows the path of a retention curve describing a soil that is initially drying according to the main drying curve, followed by a wetting-drying cycle. The soil described by the second loop is initially wetting according to the main wetting curve, but then follows a sequence of drying and wetting. Results so far indicated that the incorporation of hysteresis in the computer code of the water simulation model has a significant influence on water table response to irrigation. Following irrigation, the water capacity of the soil increases when a wetting scanning curve rather than the main drying curve is followed. Ther :fore, if hysteresis is considered, more water is stored in the wetted part of the soil profile and less of the applied water 
Table 4.8. Laboratory measured saturated hydraulic conductivity values for surface (fill) and subsurface $(60 \mathrm{~cm}$ depth) samples from satellite plot.

Saturated Hydraulic Conductivity $(\mathrm{cm} / \mathrm{hr}$ )

\section{Surface}

0.032

6.744

0.695

0.929

0.297

6.320

4.524

0.186

1.041

0.452

6.463

4.309

0.012

8.666

6.925

1.501

8.435

0.297

0.247

4.963
Subsurface

$$
\begin{aligned}
& 0.009 \\
& 1.46 \\
& 0.16 \\
& 0.407 \\
& 0.478 \\
& 0.033 \\
& 8.198 \\
& 34.566 \\
& 0.021 \\
& 0.358 \\
& 21.061 \\
& 3.764 \\
& 7.487 \\
& 52.054 \\
& 11.743 \\
& 16.512 \\
& 24.020 \\
& 13.971 \\
& 49.364 \\
& 44.985
\end{aligned}
$$

$\begin{array}{lll}\text { mean } & 3.15 & 14.53 \\ \text { st.dev } & 3.18 & 17.63\end{array}$




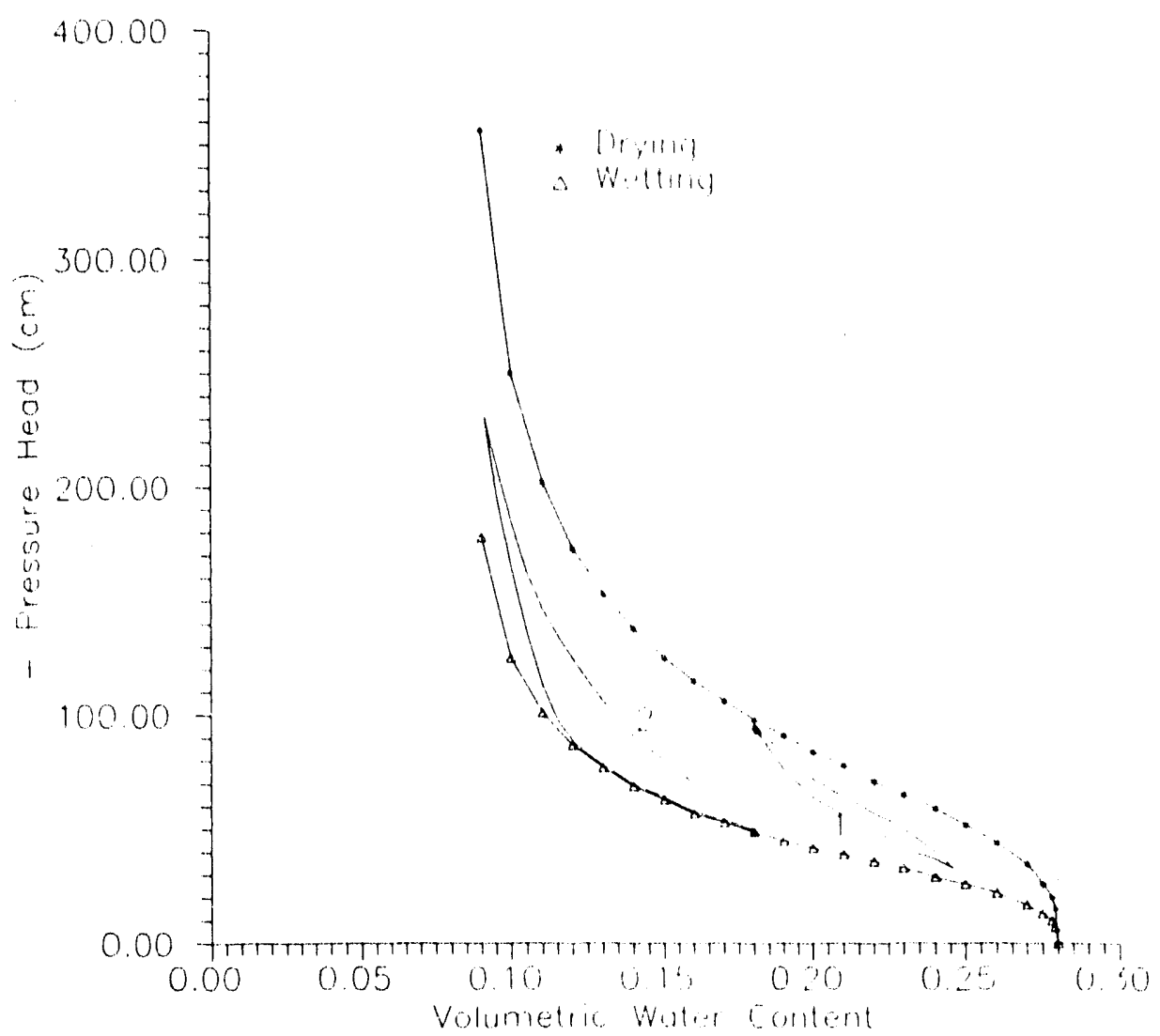

Figure 4.24. Example of hysteresis; main drying and wetting curves with scanning curves. 


\section{$-187-/ 188$}

will flow to the ground water in the computer simulations.

Simulations have also indicated that spatial variation of the soil properties can account for field-measured variation in soil water pressure head as determined from the tensiometers, and ground water levels. The variation in soil water retention and conductivity curves will be incerporated in the model as well, as more data become available from the laboratoiy measurements. 


\subsection{BIOMASS, SPECIES DIVERSITY AND SELENIUM CONCENTRATIONS IN KESTERSON PLANTS}

Lin $W u$, Environmental Horticulture Department;

J.W. Biggar, Land, Air and Water Resources Department; and

Z. Z. Huang, Environmental Horticulture Department, University of California, Davis

\subsubsection{Objectives}

The objective of research described here is to provide information on vegetation and biomass distribution, plant species diversity and selenium accumulation by plant tissue at Kesterson Reservoir.

This section presents the results of the research conducted in 1989. The biomass distribution, species diversity, and selenium accumulation by plants were studied for four sites at Kesterson. Two of the sites were located where the surface soil consists of fill dirt (Pond 2 and Pond 6 sites). The remaining two have natural soil covers (Ponds 6 and 7).

\subsubsection{Materials and Methods}

Two separate plant and soil sample collections were made in four sites at Kesterson Reservoir, on May 13 and May 17, 1989. For each site, a $30 \mathrm{~m} \times 15 \mathrm{~m}$ area (plot) was chosen with the aim of maximizing the number of species sampled, since the objective of these collections was to survey both the selenium uptake by plants and the plant species diversity within each area. The selected plots are thus representatives of most of the vegetation in the area.

For the first set of collections, all above-ground plant materials and one core of the top 15 $\mathrm{cm}$ of soil, were collected from each of $101 \mathrm{~m} \times 1 \mathrm{~m}$ quadrats. Both plant and soil samples were collected randomly within each site (Tables 4.9 through 4.12). For the second sampling, one $1 \mathrm{~m}$ $\times 1 \mathrm{~m}$ quadrat was placed at each corner of the plot and another was placed in the center. The aim of this sample collection was for biomass and tissue selenium measurements, as well as to detect any relationships between plant selenium accumulation and soil selenium concentration. Two 
soil samples were collected from each location, one from the soil surface to $15 \mathrm{~cm}$ depth and a second from 25 to $35 \mathrm{~cm}$ depth.

Plant samples were oven-dried at $65^{\circ} \mathrm{C}$ for 72 hours. Leaves (including stems in some cases) were ground to a powder in a coffee grinder. For selenium accunnulation measurements, 5 $\mathrm{ml}$ of concentrat $2 \mathrm{HNO}_{3}$ and $2.5 \mathrm{ml}$ of $\mathrm{HClO}_{4}$ were added to $50 \mathrm{mg}$ of dry plant material ini a $75-\mathrm{ml}$ volumetric digestion tube and allowed to digest ovemight at room temperature. Further tissue digestion was conducted at $150^{\circ} \mathrm{C}$ raised finally to $210^{\circ} \mathrm{C}$ on a heating block (scientific AD40 block digester). After cooling the digestion extract, selenium reduction was accomplished by adding $3 \mathrm{ml} 6 \mathrm{~N} \mathrm{NCl}$ into the extract and heating to $150^{\circ} \mathrm{C}$ (Ganje and Page, 1974). The final analysis was made by hydride generation flame atomic absorption (Perkin-Elmer) with heated quartz cell, utilizing Argon as the carrier gas.

Soils were air dried for a minimum of two weeks, and sieved through a $1 \mathrm{~mm}$ sieve. Soilwater mixtures (1:2 weight/volume) were shaken slowly ovemight in a $1500 \mathrm{ml}$ flask. Clear soil extract was collected by centrifugation. Two $\mathrm{ml} \mathrm{HClO}_{4}$ and $5 \mathrm{ml} \mathrm{HNO}_{3}$ were added into $5 \mathrm{ml}$ soil extract. Digestion was conducted at $150^{\circ} \mathrm{C}$ to $210^{\circ} \mathrm{C}$ on the heating block. After cooling the digestion extract, $3 \mathrm{ml} 6 \mathrm{~N} \mathrm{HCl}$ were added and the mixture heated to $150^{\circ} \mathrm{C}$. The selenium concentration was measured using hydride generation flame atomic adsorption spectrophotometry.

\subsubsection{Results and Conclusions}

The selenium concentration of the top $15 \mathrm{~cm}$ of fill dirt in Pond 2 ranged from below detection limits to $9 \mathrm{ppb}$. The water-extractable soil selenium concentration at the Pond 6 site was below detection limits (Table 4.9). For the unfilled sites in Pond 6 and Pond 7 the water extractable soil selenium concentration for the top $15 \mathrm{~cm}$ soil ranged from $230 \mathrm{ppb}$ to $550 \mathrm{ppb}$ and from $75 \mathrm{ppb}$ to $300 \mathrm{ppb}$ respectively.

At least 11 different plant species were found at the fill sites (Tables 4.10, 4.13 and 4.14). Only five species were found at the native-soil sites. Distichlis spicata is the most abundant species at these plots. The rest of the species was less than $15 \%$ of the vegetation cover. 
Table 4.9. Analysis of inorganic soil selenium in the top $0.15 \mathrm{~m}$ of fill dirt.

\begin{tabular}{|c|c|c|c|c|c|}
\hline \multicolumn{6}{|c|}{ POND 2} \\
\hline \multirow{2}{*}{\multicolumn{2}{|c|}{ Quadrat pH }} & \multirow{2}{*}{$\mathrm{EC}$ (mmhos) } & \multirow{2}{*}{ Sulfate (ppm) } & \multicolumn{2}{|c|}{ Total Inorganic Se (ppb) } \\
\hline & & & & mean & s.d. \\
\hline 1 & 8.16 & .57 & 340 & 1.29 & 2.23 \\
\hline 2 & 7.88 & .44 & 330 & 0.0 & 0.0 \\
\hline 3 & 8.07 & .65 & 400 & 8.86 & 1.12 \\
\hline 4 & 7.89 & .55 & 353 & 0.0 & 0.0 \\
\hline 5 & 8.26 & .54 & 367 & 6.69 & 5.85 \\
\hline 6 & 8.42 & .20 & 73 & 0.0 & 0.0 \\
\hline 7 & 8.45 & .24 & 143 & 2.96 & 1.12 \\
\hline 8 & 8.13 & .24 & 100 & 0.0 & 0.0 \\
\hline 9 & 8.66 & .19 & 80 & 0.0 & 0.0 \\
\hline 10 & 8.60 & .27 & 137 & 0.0 & 0.0 \\
\hline Average & 8.27 & .39 & 232 & 1.98 & 3.24 \\
\hline \multicolumn{6}{|c|}{ POND 6} \\
\hline \multirow{2}{*}{\multicolumn{2}{|c|}{ Quadrat pH }} & \multirow{2}{*}{$\mathrm{EC}$ (mmhos) } & \multirow{2}{*}{ Sulfate (ppm) } & \multicolumn{2}{|c|}{ Total Inorganic Se (ppb) } \\
\hline & & & & mean & s.d. \\
\hline 1 & 8.50 & .34 & 81.7 & 0.0 & 0.0 \\
\hline 2 & 8.48 & .20 & 66.7 & 0.0 & 0.0 \\
\hline 3 & 8.39 & .22 & 90.0 & 0.0 & 0.0 \\
\hline 4 & 8.42 & .19 & 61.7 & 0.0 & 0.0 \\
\hline 5 & 8.57 & .13 & 46.7 & 0.0 & 0.0 \\
\hline 6 & 8.39 & .23 & 46.7 & 0.0 & 0.0 \\
\hline 7 & 8.43 & .23 & 63.3 & 0.0 & 0.0 \\
\hline 8 & 8.53 & .25 & 103.3 & 0.0 & 0.0 \\
\hline 9 & 8.37 & .22 & 95.0 & .58 & .82 \\
\hline Average & 8.45 & .22 & 72.8 & $\mathrm{n} / \mathrm{a}$ & $\mathrm{n} / \mathrm{a}$ \\
\hline
\end{tabular}

$\mathrm{n} / \mathrm{a}=$ Not applicable, insufficient data all values are the mean of three subsamples per site. 
Table 4.10. Plant ti'ssue selenium concentration of plant species from two fill sites at Kesterson (Ponds 2 and 6)

\begin{tabular}{|c|c|c|c|c|c|}
\hline \multirow{2}{*}{$\begin{array}{l}\text { Pond/ } \\
\text { Site }\end{array}$} & \multirow{2}{*}{ Species } & \multicolumn{2}{|c|}{ Se Concentration (ppm) } & \multicolumn{2}{|c|}{ Species Mean, SD (ppm) } \\
\hline & & mean & SD & mean & SD \\
\hline $\begin{array}{l}2 / 2 \\
2 / 5 \\
2 / 7\end{array}$ & $\begin{array}{c}\text { Avena fatua } \\
\text { " " } \\
" \text { " }\end{array}$ & $\begin{array}{l}.460 \\
2.18 \\
1.36\end{array}$ & $\begin{array}{l}.021 \\
\mathrm{n} / \mathrm{a} \\
.042\end{array}$ & 1.33 & .859 \\
\hline $\begin{array}{l}2 / 3 \\
2 / 7\end{array}$ & $\begin{array}{l}\text { Bassia hyssopifolia } \\
" " ~\end{array}$ & $\begin{array}{l}2.69 \\
5.75\end{array}$ & $\begin{array}{l}.007 \\
\mathrm{n} / \mathrm{a}\end{array}$ & 4.22 & 2.16 \\
\hline $\begin{array}{c}2 / 6 \\
2 / 10\end{array}$ & $\begin{array}{l}\text { Bromus rubens } \\
" \text { " }\end{array}$ & $\begin{array}{l}.541 \\
.273\end{array}$ & $\begin{array}{l}\mathrm{n} / \mathrm{a} \\
\mathrm{n} / \mathrm{a}\end{array}$ & .407 & .190 \\
\hline $\begin{array}{l}2 / 4 \\
2 / 5 \\
2 / 3 \\
2 / 7\end{array}$ & $\begin{array}{c}\text { Melilotus indica* } \\
" \quad " \\
" \quad " \\
" \quad "\end{array}$ & $\begin{array}{l}.091 \\
.189 \\
.154 \\
.472\end{array}$ & $\begin{array}{l}.022 \\
.011 \\
.004 \\
.010\end{array}$ & .226 & .169 \\
\hline $\begin{array}{l}2 / 1 \\
2 / 5\end{array}$ & 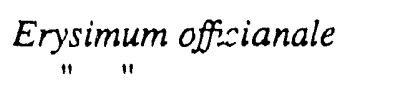 & $\begin{array}{l}11.1 \\
6.33\end{array}$ & $\begin{array}{r}1.30 \\
\mathrm{n} / \mathrm{a}\end{array}$ & 8.71 & 3.37 \\
\hline $\begin{array}{l}2 / 1 \\
2 / 4\end{array}$ & $\begin{array}{l}\text { Atriplex patula } \\
\text { var.hastata } \\
\text { " " }\end{array}$ & $\begin{array}{l}8.31 \\
6.96\end{array}$ & $\begin{array}{l}0.53 \\
.074\end{array}$ & 7.64 & .950 \\
\hline $2 / 1$ & Bromus rigidus & 1.67 & .007 & 1.67 & .007 \\
\hline $2 / 1$ & Polypogon monspeliensis & 19.2 & 1.74 & 19.2 & 1.74 \\
\hline $2 / 10$ & Centaurea solstitalis & 10.9 & $\mathrm{n} / \mathrm{a}$ & 10.9 & $\mathrm{n} / \mathrm{a}$ \\
\hline $2 / 7$ & Franseria acanthicarpa & $>3.0$ & $n / i d$ & $>3.0$ & $\mathrm{n} / \mathrm{a}$ \\
\hline $2 / 5$ & Distichlis spicata & 4.07 & .380 & 4.07 & .380 \\
\hline
\end{tabular}

* For all species except Melilotus indica, in which stems were used, leaves were the plant part analyzed. 
Table 4.11. Selenium analysis of soil and plant tissue from the native-soil site in Pond 6

\begin{tabular}{|c|c|c|c|c|c|c|c|c|}
\hline \multicolumn{6}{|c|}{ SOIL } & \multicolumn{3}{|c|}{ PLANT } \\
\hline \multirow{2}{*}{ Site } & \multirow{2}{*}{$\begin{array}{c}\text { E.C. } \\
\text { (mmhos) }\end{array}$} & \multirow[t]{2}{*}{$\mathrm{pH}$} & \multirow{2}{*}{$\begin{array}{l}\mathrm{SO} 4 \\
(\mathrm{ppm}) \\
\end{array}$} & \multicolumn{2}{|c|}{ Total Se (ppb) } & \multirow{2}{*}{ Plant Species } & \multicolumn{2}{|c|}{ Se Conc. (ppm) } \\
\hline & & & & mean & sd & & mean & sd \\
\hline 1 & 3.17 & 7.45 & 2967 & 454.8 & 5.5 & Distichlis spicata & 2.65 & 0.08 \\
\hline 2 & 4.95 & 7.60 & 3900 & 371.1 & 10.2 & & 1.60 & .20 \\
\hline \multirow[t]{2}{*}{3} & 5.86 & 7.52 & 4000 & 333.3 & 0.8 & " " & .044 & .06 \\
\hline & & & & & & Atriplex patula* & 2.74 & .12 \\
\hline \multirow[t]{2}{*}{4} & 3.52 & 7.25 & 3467 & 348.3 & 0.0 & Distichlis spicata & 2.14 & .05 \\
\hline & & & & & & Atriplex patula & 10.9 & .16 \\
\hline \multirow[t]{2}{*}{5} & 6.14 & 7.93 & 4833 & 554.3 & 12.1 & Distichlis spicata & .459 & .02 \\
\hline & & & & & & Atriplex patula & 10.1 & 1.1 \\
\hline 6 & 4.35 & 7.70 & 4000 & 267.6 & 11.0 & & 2.11 & .04 \\
\hline 7 & 3.69 & 7.68 & 3567 & 311.3 & 13.8 & $"$ & 2.63 & .28 \\
\hline \multirow[t]{2}{*}{8} & 4.77 & 7.52 & 4200 & 263.3 & 2.8 & " " & 5.73 & $\mathrm{n} / \mathrm{a}$ \\
\hline & & & & & & Distichlis spicata & 0.0 & 0.0 \\
\hline 9 & 5.17 & 7.76 & 3933 & 276.8 & 8.13 & & 0.0 & $\mathrm{n} / \mathrm{a}$ \\
\hline 10 & 4.56 & 7.77 & 4000 & 237.7 & 6.51 & $"$ & .744 & .04 \\
\hline mean & 4.62 & 7.62 & 3887 & & & & & \\
\hline s.d. & .974 & .193 & 489.7 & & & & & \\
\hline
\end{tabular}

* Full proper name is Atriplex patula var. hastata.

$\mathrm{n} / \mathrm{a}$ Not applicable because of only one data point.

E.C. Electrical conductivity

Species mean Se levels for all pond 6 sites

\begin{tabular}{lcc}
\hline & mean & s.d. \\
Atriplex patula & 5.70 & 3.94 \\
Distichlis spicata & .955 & 1.04
\end{tabular}


Table 4.12. Selenium analysis of soil and plant tissue from the native-soil site in Pond 7

\begin{tabular}{|c|c|c|c|c|c|c|c|c|}
\hline \multicolumn{6}{|c|}{ SOIL } & \multicolumn{3}{|c|}{ PLANT } \\
\hline \multirow{2}{*}{ Site } & \multirow{2}{*}{$\begin{array}{c}\text { E.C. } \\
\text { (nimhos) }\end{array}$} & \multirow{2}{*}{$\mathrm{pH}$} & \multirow{2}{*}{$\begin{array}{l}\mathrm{SO} 4 \\
(\mathrm{ppm})\end{array}$} & \multicolumn{2}{|c|}{ Total Se (ppb) } & \multirow{2}{*}{ Plant Species } & \multicolumn{2}{|c|}{ Se Conc. (ppm) } \\
\hline & & & & mean & sd & & mean & sd \\
\hline 1 & 2.78 & 7.43 & 2550 & 177.5 & 7.07 & Distichlis spicata & 2.71 & 0.028 \\
\hline 2 & 2.05 & 7.46 & 2000 & 75.05 & 5.73 & $\begin{array}{c}" \\
\text { Melilotus indica }\end{array}$ & $\begin{array}{r}1.90 \\
13.56\end{array}$ & $\begin{array}{l}.093 \\
.104\end{array}$ \\
\hline 3 & 3.29 & 7.48 & 3400 & 198.1 & 25.2 & $\begin{array}{l}\text { Distichlis spicata } \\
\text { Franseria acanth. }\end{array}$ & $\begin{array}{r}3.58 \\
16.20\end{array}$ & $\begin{array}{l}.300 \\
.171\end{array}$ \\
\hline 4 & 2.68 & 7.65 & 2867 & 130.3 & .78 & $\begin{array}{l}\text { Distichlis spicata } \\
\text { Melilotus indica }\end{array}$ & $\begin{array}{l}2.15 \\
8.88\end{array}$ & $\begin{array}{l}0.40 \\
1.79\end{array}$ \\
\hline 5 & 2.79 & 7.84 & 2933 & 145.2 & 12.2 & $\begin{array}{l}\text { Distichlis spicata } \\
\text { Franseria acanth. } \\
\text { Melilotus indica }\end{array}$ & $\begin{array}{r}2.46 \\
17.83 \\
18.55\end{array}$ & $\begin{array}{l}.064 \\
0.86 \\
1.24\end{array}$ \\
\hline 6 & 2.82 & 7.58 & 3367 & 168.7 & 13. $\mathrm{C}$ & $\begin{array}{l}\text { Distichlis spicata } \\
\text { Franseria acanth }\end{array}$ & $\begin{array}{r}2.43 \\
15.26\end{array}$ & $\begin{array}{l}.012 \\
.123\end{array}$ \\
\hline 7 & 3.04 & 7.64 & 3400 & 111.9 & .78 & Distichlis spicata & 2.82 & .024 \\
\hline 8 & 2.91 & 7.34 & 3033 & 319.3 & 17.9 & $\begin{array}{c}" \\
\text { Melilotus indica }\end{array}$ & $\begin{array}{r}2.06 \\
17.25\end{array}$ & $\begin{array}{l}.020 \\
1.18\end{array}$ \\
\hline 9 & 3.01 & 7.45 & 3400 & 132.6 & .78 & Distichlis spicata & 3.03 & .044 \\
\hline 10 & 3.13 & 7.63 & 3200 & 267.6 & 1.63 & $\begin{array}{l}" " \\
\text { Melilotus indica } \\
\text { Heliotropium cur. }\end{array}$ & $\begin{array}{r}5.15 \\
19.70 \\
15.34\end{array}$ & $\begin{array}{l}.043 \\
.102 \\
.179\end{array}$ \\
\hline $\begin{array}{l}\text { mean } \\
\text { s.d. }\end{array}$ & $\begin{array}{l}2.85 \\
.355\end{array}$ & $\begin{array}{l}7.55 \\
.146\end{array}$ & $\begin{array}{l}3015 \\
456.8\end{array}$ & & & & & \\
\hline
\end{tabular}

Full species names: Franseria acanthicarpa

Heliotropium curassavicum

Species mean Se levels for a'll pond 7 sites

\begin{tabular}{lcc}
\hline & mean & s.d. \\
Franseria acanth. & 16.43 & 1.30 \\
Distichlis spicata & 15.59 & 4.40 \\
Atriplex patula & 2.83 & .956 \\
Heliotropium cur. & 15.34 & n/a
\end{tabular}


Table 4.13. Tissue selenium concentrations in leaves and biomass of plant species growing at the fill-site in Pond 2 (collected 5/27/89)

\begin{tabular}{|c|c|c|c|c|}
\hline \multirow{2}{*}{ Site } & \multirow{2}{*}{ Species } & \multicolumn{2}{|c|}{ Selenium Conc. (ppm) } & \multirow{2}{*}{$\begin{array}{l}\text { Dry Weight } \\
(\mathrm{g} / \mathrm{sq} \cdot \mathrm{m})\end{array}$} \\
\hline & & mean & s.d. & \\
\hline \multirow[t]{12}{*}{1} & Atriplex canescens & 11.42 & .466 & 27.45 \\
\hline & Avena barbata & 5.844 & $\mathrm{n} / \mathrm{a}$ & 2.51 \\
\hline & Avana fatua & 5.250 & .215 & 12.75 \\
\hline & Bassia hyssopifolia & -. & .. & 66.76 \\
\hline & Bromus mollis & 8.113 & .802 & 8.13 \\
\hline & Bromus rubens & 1.109 & $n / a$ & 10.97 \\
\hline & Centaurea solstitalis & 15.29 & .272 & 48.65 \\
\hline & Erysimum officianale & 18.47 & .815 & 11.09 \\
\hline & Festuca megalurat & 2.452 & .224 & 1.20 \\
\hline & Matricaria matricar.\# & 3.362 & $\mathrm{n} / \mathrm{a}$ & 2.97 \\
\hline & Melilotus indica" & 1.969 & .180 & 69.78 \\
\hline & Polypogon monspeliensis & 10.61 & .518 & 4.29 \\
\hline \multirow[t]{7}{*}{2} & Atriplex patula & 15.71 & .438 & .38 \\
\hline & Avana fasua & 3.044 & .252 & 24.41 \\
\hline & Bassia hyssopifolia & 9.868 & .080 & 8.08 \\
\hline & Bromus mollis & 1.329 & $n / a$ & .99 \\
\hline & Centaurea solstitalis & -- & -- & 7.82 \\
\hline & Franseria acanthicarpa & 11.95 & .216 & .71 \\
\hline & Melilotus indica & .635 & .060 & 115.74 \\
\hline \multirow[t]{5}{*}{3} & Atriplex patula & 7.65 & .441 & 3.27 \\
\hline & Avana fatua & 13.57 & $\mathrm{n} / \mathrm{a}$ & 2.21 \\
\hline & Bassia hyssopifolia & 8.766 & .677 & 385.38 \\
\hline & Polypogon monspeliensis & 30.82 & 1.35 & 14.51 \\
\hline & Unidentified " $\mathrm{H} "$ & 13.63 & .403 & 58.98 \\
\hline \multirow[t]{12}{*}{4} & Atriplex canescens & -- & -- & 5.12 \\
\hline & Atriplex pasula & 12.10 & .561 & 58.46 \\
\hline & Avena fatua & 1.825 & .082 & 25.21 \\
\hline & Bassia hyssopifolia & - & -- & 13.13 \\
\hline & Bromus mollis & -. & -. & .98 \\
\hline & Bromus rubens & 1.952 & .350 & 4.00 \\
\hline & Censaurea solstitalis & 17.01 & 1.45 & 7.13 \\
\hline & Franseria acanthicarpa & 9.522 & .681 & 10.58 \\
\hline & Melilotus indica & -- & -- & 16.00 \\
\hline & Polypogon monspeliensis & 15.60 & .206 & 3.02 \\
\hline & Unidentified "J" & -- & -- & 4.76 \\
\hline & Unidentified "K" & -. & -. & 1.85 \\
\hline \multirow[t]{9}{*}{5} & Atriplex patula & 15.98 & 1.64 & 8.07 \\
\hline & Avena barbata & .893 & $n / a$ & 4.36 \\
\hline & Avena fatica & 1.333 & $\mathrm{n} / \mathrm{a}$ & 8.62 \\
\hline & Bromus mollis & 1.866 & $\mathrm{n} / \mathrm{a}$ & .60 \\
\hline & Bromus rubens & 1.665 & $\mathrm{n} / \mathrm{a}$ & 7.14 \\
\hline & Festuca megalurat & 1.622 & .114 & .686 \\
\hline & Franseria acanthicarpa & 14.59 & 1.68 & 13.18 \\
\hline & Hordeum lejorinum & 2.787 & .135 & 21.23 \\
\hline & Melilotus indica & .597 & .058 & 56.31 \\
\hline
\end{tabular}

\# Matricaria matricarioides

- Stems only were used for Melilotus indica
+ Whole plant used for Festuca megulara Se measurement. $\mathrm{n} / \mathrm{a}$ Not applicable, insufficient data. 
Table 4.14. Selenium concentrations in the leaves and biomass of various plant species growing at the fill-site in Pond 6 (collected 5/27/89)

\begin{tabular}{|c|c|c|c|c|}
\hline \multirow{2}{*}{ Site } & \multirow{2}{*}{ Species } & \multicolumn{2}{|c|}{ Selenium Conc. (ppm) } & \multirow{2}{*}{$\begin{array}{l}\text { Dry Weight } \\
(\mathrm{g} / \mathrm{sq} \cdot \mathrm{m})\end{array}$} \\
\hline & & mean & s.d. & \\
\hline \multirow[t]{9}{*}{1} & Avena falua & .6828 & .032 & 61.85 \\
\hline & Avana barbata & -. & -. & 20.58 \\
\hline & Bassia hyssopifolia & 8.236 & .447 & 160.25 \\
\hline & Bromus rubens & .541 & $\mathrm{n} / \mathrm{a}$ & 5.35 \\
\hline & Erodium cicusarium & .275 & $\mathrm{n} / \mathrm{a}$ & 2.96 \\
\hline & Festuca megalurat & .4604 & $\mathrm{n} / \mathrm{a}$ & .52 \\
\hline & Franseria acanthicarpa & 3.270 & 0.0 & 70.15 \\
\hline & Melilotus indica* & .4472 & .041 & 48.75 \\
\hline & Unidentified "A" &.- & -. & 2.77 \\
\hline \multirow[t]{9}{*}{2} & Avena barbata & .0421 & $n / a$ & 1.69 \\
\hline & Avana falua & .3253 & .059 & 20.50 \\
\hline & Bussia hyssopifolia & 7.058 & .325 & 344.28 \\
\hline & Bromus rubens & -. & -- & 1.06 \\
\hline & Fesiuca megularat & .2518 & .008 & 3.87 \\
\hline & Franseria acanthicarpa & 1.087 & .051 & 4.63 \\
\hline & Hordeum leporinum & .095 & $\mathrm{n} / \mathrm{a}$ & 1.90 \\
\hline & Melilo:us indica & .1684 & .012 & 85.16 \\
\hline & Unidentified "B" & $-\cdot$ & -- & 5.60 \\
\hline \multirow[t]{9}{*}{3} & Avana barbala & 0.0 & 0.0 & 5.25 \\
\hline & Bromus rubers & .1332 & .044 & 1.12 \\
\hline & Erysinum officianale & .8897 & .049 & 93.85 \\
\hline & Festuca megalurat & .0338 & $n / a$ & .42 \\
\hline & Franseria acanihicarpa & .7144 & .020 & 2.90 \\
\hline & Melilotus indica & .1224 & .045 & 121.75 \\
\hline & Unidentified "D" & -- & m & 4.29 \\
\hline & Unidentified "E" & .. & -- & 2.09 \\
\hline & Unidentified "F" & -- & 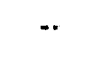 & .45 \\
\hline \multirow[t]{5}{*}{4} & Atriplex patula & 1.172 & .036 & 1.70 \\
\hline & Bassia hyssopifolia & 2.388 & .060 & 76.38 \\
\hline & Franseria acanthicarpa & 1.596 & .005 & 101.02 \\
\hline & Melilotus indica & .0741 & .028 & 108.68 \\
\hline & Polypogon aviculare & .5673 & .017 & 8.58 \\
\hline \multirow[t]{2}{*}{5} & Avena fatua & .3428 & 0.0 & 102.78 \\
\hline & Bromus rubers & .5081 & $\mathrm{n} / \mathrm{a}$ & 6.53 \\
\hline
\end{tabular}

+ For Fostuca megulara the whole plant was used.

- For Melilocus indica, stems only were used.

n/a Not applicable, insufficient data. 
The plant tissue selenium concentration ranged from less than detection to $20 \mathrm{ppm}$ at the native soil sites. Variation in tissue selenium concentrations exists both between sites and plant species. Generally Melilotus indica, Heliotropium cur and Atriplex patula had higher selenium tissue concentration than Distichlis spicata (Table 4.12).

For the fill-sites plant tissue selenium concentrations ranged from an undetectable level to $30 \mathrm{ppm}$. Again tissue selenium concentrations varied depending on the sample location and plant species. The species found to be relatively high in tissue selenium concentration are: Atriplex patula, Polypogon monspeliensis, Centaurea solstitalis and Franseria acanthicarpa. The biomass production of the plant species in the sites of topsoil replacement ranged from $2 \mathrm{~g} / \mathrm{m}^{2}$ to $500 \mathrm{~g} / \mathrm{m}^{2}$. Bassia hyssopifolia, Avena fatua, Melilotus indica and Franseria acanthicarpa contributed over $60 \%$ of the biomass at the two fill s:tes (Tables 4.13 and 4.14 ).

No significant correlation was detected between the plant tissue selenium concentration and the selenium concestration in the fill $\operatorname{din}(\mathrm{R}=0.20, \mathrm{P}>0.05)$ (Figure 4.2.5). However, there is a near significant correlation between the plant tissue selenium concentration and the sub-irr. face soil selenium concentration found in Pond 2 and Pond $6(R=0.30, P=0.05)$ (Figure 4.26). This result suggests that the plant species may accumulate significant amounts of selenium from the sintusurface soil regardless of the replacement of the topsoil.

Several corclusions may be drawn from the above studies:

1. A variety of different plant species have been introduced as buried seed into the Kesterson evaporation ponds with the fill dirt.

2. Plant tissue selenium concentration was found to be very variable within and between plant species in both the fill dirt and natural soil sites.

3. Plant species may accumulate significant amounts of selenium from the subsurface soil regardless of the replacement of top soil. 


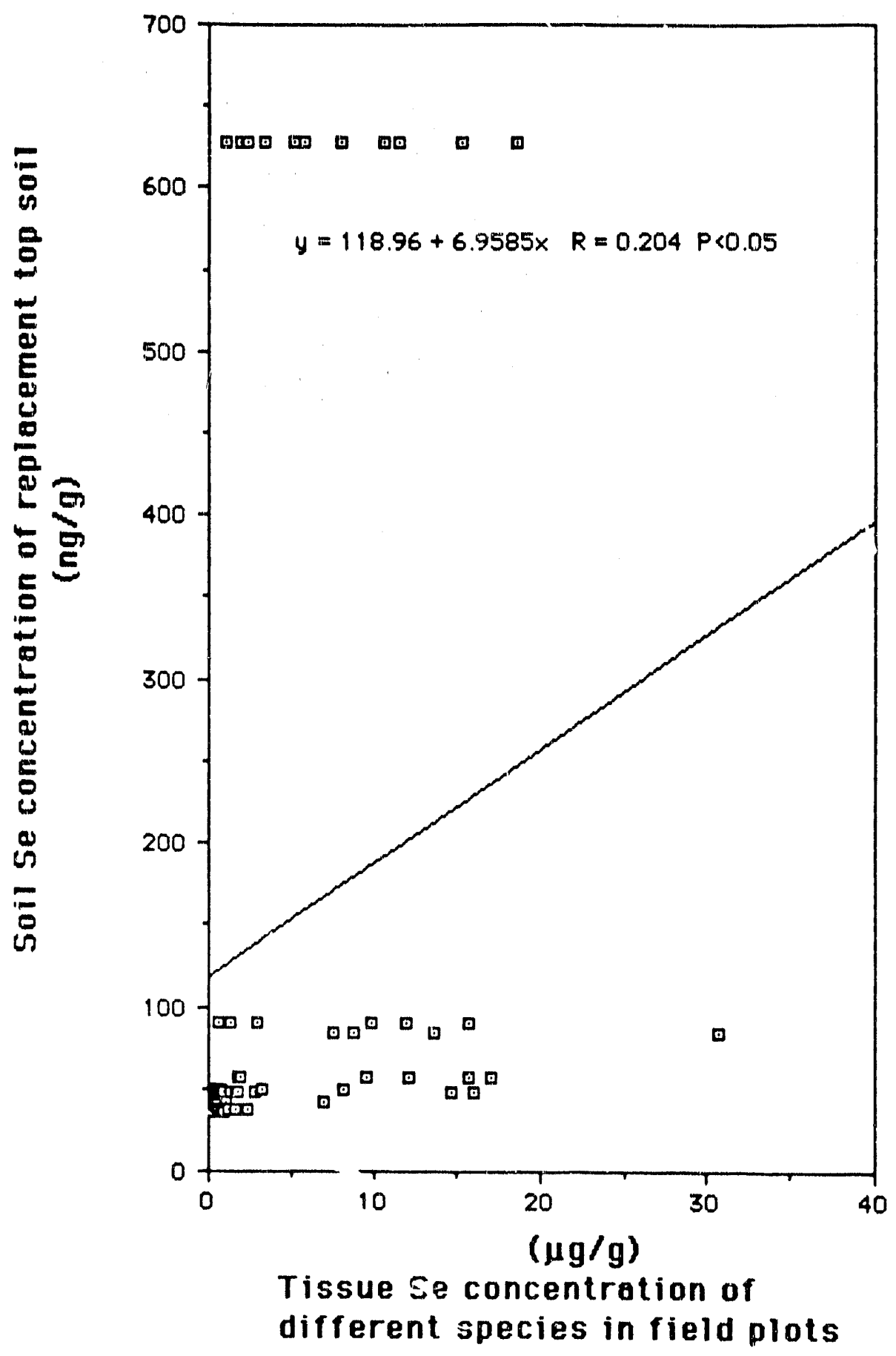

Figure 4.25. The correlation and joint distribution of plant tissue selenium concentration and soil selenium concentration in the fill dirt $(U-15 \mathrm{~cm})$ of ? 


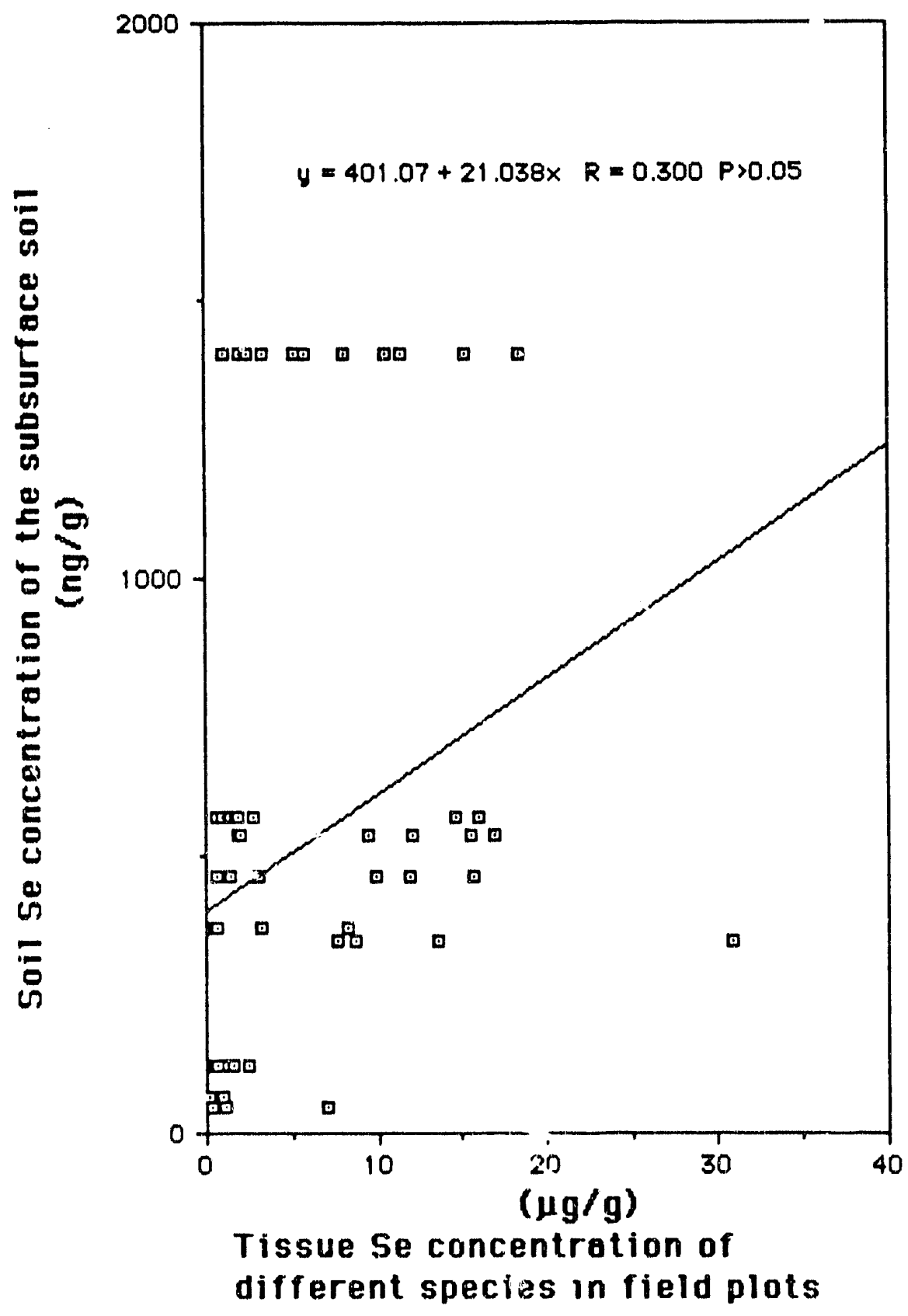

Figure 4.26. The correlation and joint distribution of plant tissue selenium concentration and soil selenium concentration of the subsurface soil $(25-35 \mathrm{~cm})$ of Pond 2 and Pond 6. 


\title{
4.4. THE EFFECT OF EVAPORITE FORMATION AND DISSOLUTION ON SALINITY AND TOXIC ELEMENT MANAGEMENT IN SURFACE SOILS
}

\author{
K. K. Tanji, R. A. Dahlgren and G. R. Smith, \\ Department of Land, Air and Water Resources, \\ University of California, Davis, Califomia
}

\subsubsection{Objectives}

Knowledge of the reactivity and mobility of selenium and other trace elements on or near the soil surface is required to determine methods for containing and dissipating selenium in an environmentally safe manner. Co-precipitation, adsorption and occlusion can incorporate trace elements into evaporites, one of the principle sinks and sources of dissolved mineral salts in Kesterson soils. These evaporites form when evapoconcentration, evapotranspiration, or both, concentrate soil waters and dissolve when rainfall, irrigation water, or a rise in shallow ground water add water to the soil.

The objectives of this study are to:

1. Collect evaporite samples. X-ray analyses of these samples will identify the minerals most likely to form from evapoconcentration of the Kesterson Reservoir's water. Chemical analyses of these samples will confirm the results of the X-ray analyses, as well as correlate the incorporation of Se, B, As, and Mo into different evaporites.

2. Collect soil samples from Kesterson Reservoir. C SALT, an equilibrium brine chemistry model that can speciate a sample up to an ionic strength of $20 \mathrm{miclal}$, will be used to speciate the soil solution based on the chemical analyses of extracts from the soil samples, as well as to predict the mineralogy of evaporites that form near the soil surface.

The results of this study will be of importance for assessing: 
1. Leaching and accumulation of salts and toxic elements at and near the soil surface,

2. Establishment and growth of plants, and

3. Soil microbial volatilization.

\subsubsection{Sampling Procedures}

Soil and evaporite samples were collected on April 20, 1989. Because the Kesterson Reservoir had been filled prior to this date and the ground water was 1.5 meters from the surface, only a limited number of evaporite samples were available.

Two auger holes were dug in Pond 7 (the main field plot) of the Kesterson Reservoir. The first hole was dug in the middle of the transect, between observation wells 8 and 9 (formally 14 and 15). The site, which was recently tilled and unvegetated, had been leached by irrigation during the previous year. Soil samples were collected in six-inch increments to a depth of 24 inches. The second hole was dug at the east edge of the main plot, directly in line with observation wells 8 and 9. This site, which was mowed without incorporating the plants into the soil, had not been leached by irrigation. Soil samples were collected in five-inch increments, to a depth of 25 inches. Samples from both holes were taken to the lab, air-dried, and sieved through a 2-mm screen. In addition, ten soil clods were collected randomly from the north-west section of Plot 7.

Two evaporite samples were collected from undisturbed surfaces; one from an ongoing study area in Pond 8 (see Section 3.4), which had not been filled in and was below the average elevation of the original reservoir, and the other from a vegetated area along the west side of Pond 6 between the pond berm and Mud Slough. Both samples were bagged and brought back to the laboratory for $\mathrm{x}$-ray analysis.

\subsubsection{Projects in Progress}

\subsubsection{Chemical Speciation of Soil Extracts}

Soil-water extracts (1:5) were made with $100 \mathrm{~g}$ of air-dried soil from each soil sample collected from the two auger holes in Pond 7. The samples were filtered through a Whatman \#2 
filter, analyzed for the major anions $\left(\mathrm{Cl}^{-}, \mathrm{SO}_{4}^{2-}\right.$ and alkalinity) by HPLC, and for the major cations $\left(\mathrm{Na}^{+}, \mathrm{K}^{+}, \mathrm{Mg}^{2+}, \mathrm{Ca}^{2+}\right)$, and $\mathrm{B}$ by ICP. Selenium concentration was determined by the hydride generator AA method. Molybdenum and arsenic concentrations are currently being determined by the graphite fumace and hydride generator AA methods, respectively. Table 4.15 presents the concentrations of the major ions obtained from soil extracts in $\mathrm{mg} / \mathrm{l}$ and $\mathrm{mol} / \mathrm{h}$. From these soil water extracts, the cation concentrations are generally ordered:

$$
\left[\mathrm{Na}^{+}\right]>\left[\mathrm{Ca}^{2+}\right]>\left[\mathrm{Mg}^{2+}\right]>\left[\mathrm{K}^{+}\right] \text {. }
$$

while the anion concentrations are generally ordered

$$
\left[\mathrm{SO}_{4}^{2-}\right]>\left[\mathrm{Cl}^{-}\right] \approx\left[\mathrm{HCO}_{3}^{-}\right]>\left[\mathrm{NO}_{3}^{-}\right]
$$

Ion concentrations from the soil extracts at each depth are plotted in Figures $4.27 \mathrm{a}$ and $4.27 \mathrm{~b}$ in $\mathrm{mmol}(\mathrm{c}) / 1$ or meq $/$. The soil extracts are dominated by $\mathrm{Na}^{+}, \mathrm{Ca}^{2+}$, and $\mathrm{SO}_{4}^{2-}$.

With a high water-to-soil ratio, some of the gypsum $\left[\mathrm{CaSO}_{4} \cdot 2 \mathrm{H}_{2} \mathrm{O}\right]$ and thenardite $\left[\mathrm{Na}_{2} \mathrm{SO}_{4}\right]$ may have undergone complete dissolution. Such dissolution would increase the concentrations of the respective ions. Dissolution and dilution would affect the equilibrium between the solution and the adsorbed phases. Both processes tend to bias the chemical analysis, so that Table 4.15 would not reflect solution concentrations in situ. These considerations should be kept in mind when reviewing the 1:5 soil water extracts and the predictions by C SALT that use the data in Table 4.15. Both sites had comparatively low concentrations of $\mathrm{NO}_{3}^{-}$and $\mathrm{B}$. Concentrations of sslenium in the 1:5 soil-water extract ranged from 32 to $58 \mu \mathrm{g} \mathrm{L}^{-1}$.

C SALT used these chemical analyses to determine the minerals that are most likely to form in the soil during evapoconcentration. C SALT assumes that $1 \mathrm{~L}$ of water is initially present. This volume is then theoretically concentrated by a user-specified concentration factor. Predicted results at a concentration factor of 1 give a complete equilibrium chemical speciation of the 1:5 soil water extract. Predicted results at a concentration factor of 5 gives an estimate of the composition of soil water at a 1:1 soil water ratio. Higher concentration factors predict the soil solution chernistry at decreasing water contents. All samples were concentrated up to 500 fold. A fir.ie concentration factor cannot simulate complete dryness, so an arbitrary value has to 


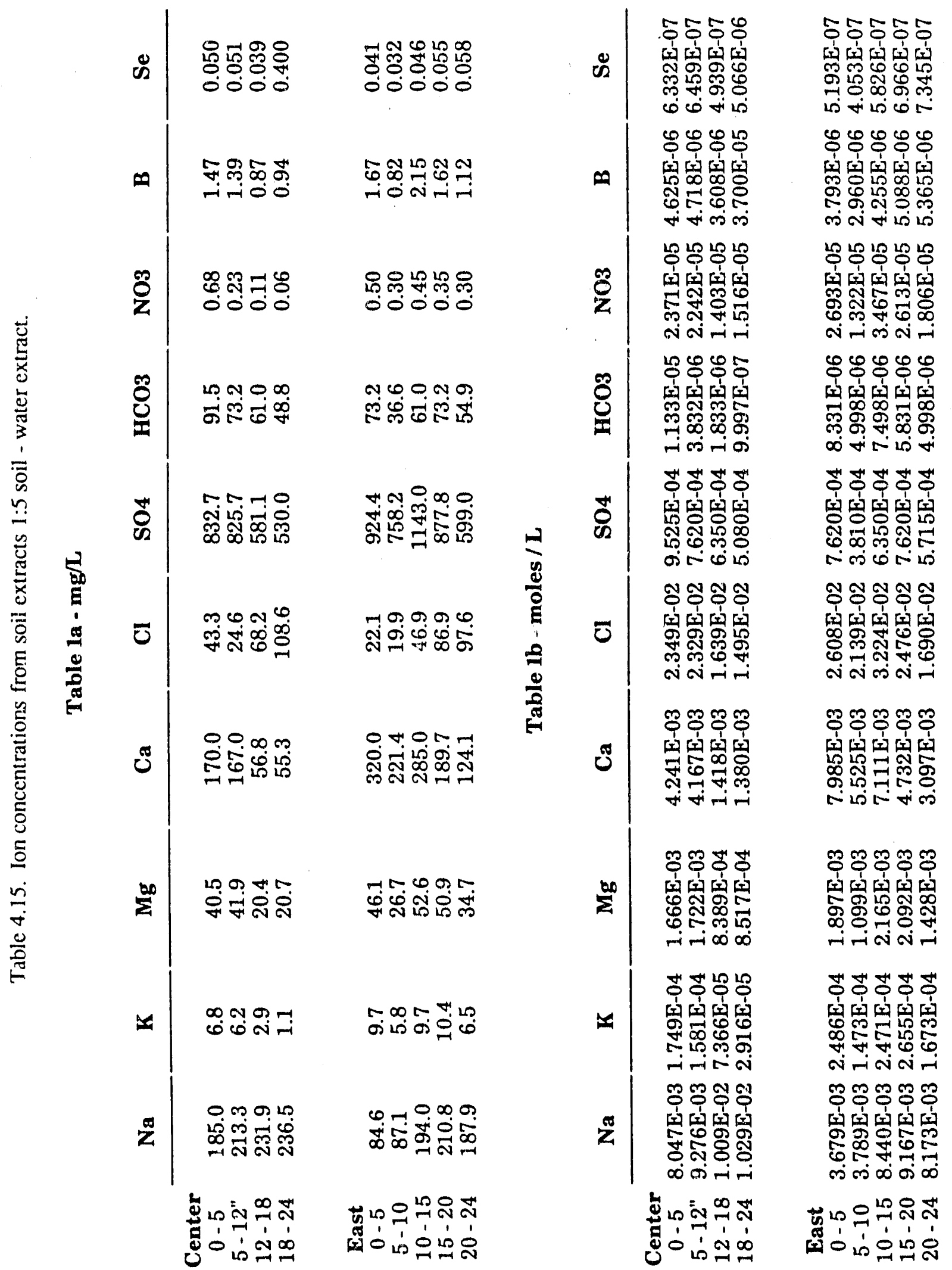




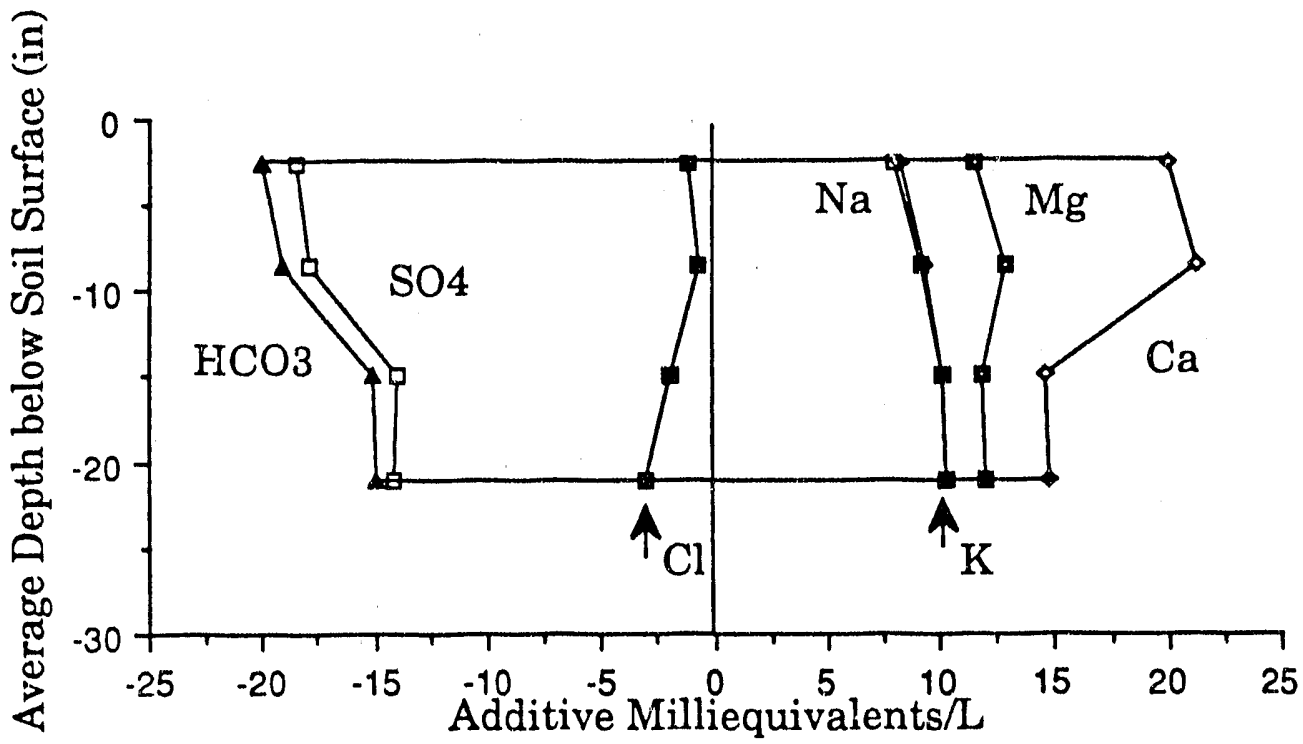

Figure 4.27a. Soil ion concentrations of center profile.

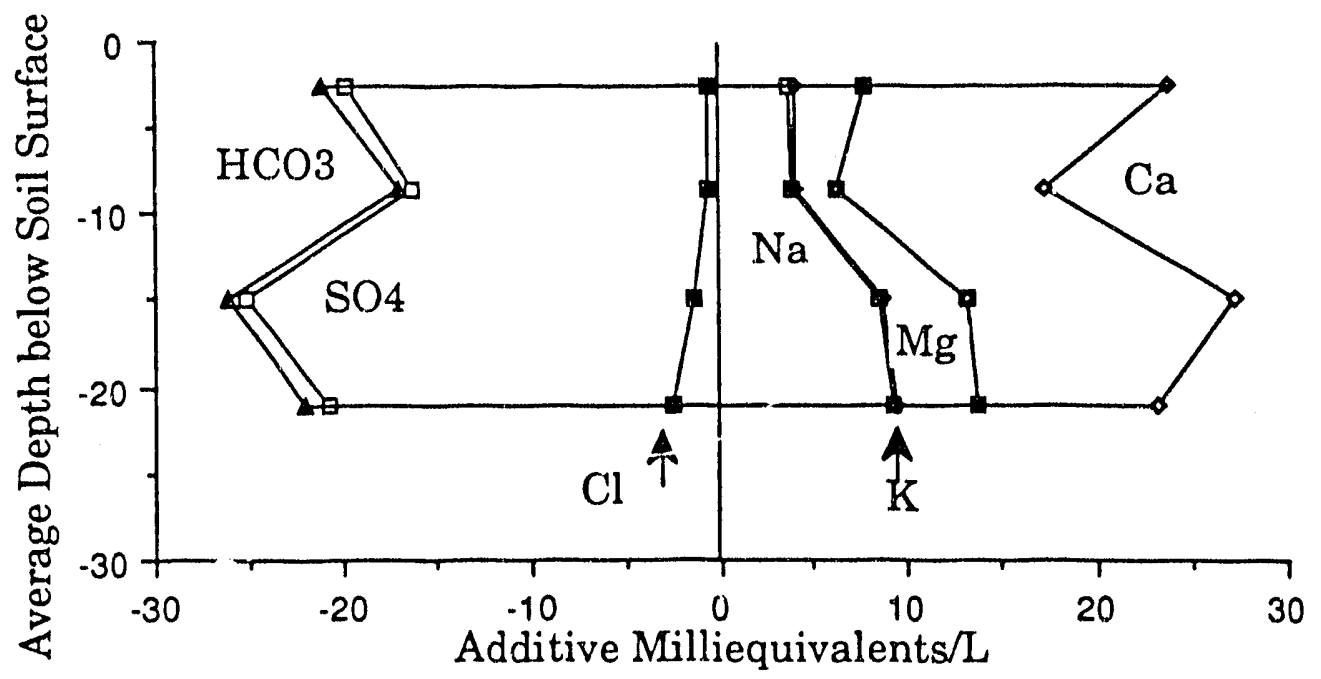

Figure 4.27b. Soil ion concentrations of eastem profile. 
be chosen. A concentration factor of 500 , which is a 100 -fold concentration of a 1:1 soil water sample should provide a good estimate of a "dry" soil (1\% soil moisture). Because the top of the soil profile experiences more intense drying than soil at depth, the top two samples were also concentrated 1000 -fold.

Dolomite $\left[\mathrm{CaMg}\left(\mathrm{CO}_{3}\right)_{2}\right]$, magnesite $\left[\mathrm{MgCO}_{3}\right]$, and nesquehonite $\left[\mathrm{MgCO}_{3} \cdot 3 \mathrm{H}_{2} \mathrm{O}\right]$ were removed from consideration in each of the runs of C SALT. These minerals were rot considered because they are rarely found forming at the pressures and temperatures found at the earth's surface. Therefore, runs eliminating these minerals from consideration are expected to be more representative in predicting both the solution chemistry and the desiccation of the soil water.

Tables 4.16 through 4.19 present selected data derived from C SALT for the center profile, namely, thermodynamic solution data, ion concentrations, and amounts of precipitates formed. Figures 4.28 through 4.30 show graphically the amounts of solid phases in Tables 4.16 through 4.19. Each figure presents the moles of a different solid phase predicted to form in one liter of extract from each soil at a given sampling depth. Only individual points were calculated but lines have been drawn between data points to help make each plot more comprehensible. Plots for each solid phase (within a figure) were made to the same scale, with scales varying between figures.

A speciation of the initial soil extract predicts that calcite $\left[\mathrm{CaCO}_{3}\right]$ will precipitate at a $\mathrm{pH}$ of 8.05. Calcite is generally predicted to form at a concentration factor of 5 , as can be seen in Table 4.16. Above this concentration factor, the pH drops below 7.95, allowing gypsum to form rather than calcite. Approximately ten times more calcite is predicted to form at the 5 to 12 inches than at 0 to 5 inches soil depih. At 12 to 18 inch soil depths and 18 to 24 inch soil depths, the maximum amount of calcite predicted to form decreases to approximately $6 \mathrm{mmol} / \mathrm{l}$. This profile had been leached by irrigatio: during the previous year. Root-water extractions may have enhanced the precipitation of carbonates which is regulated by the partial pressure of carbon dioxide. Root and microbial respiration would increase the partial pressure of carbon dioxide in the soil. The increased partial pressure of carbon dioxide decreases $\mathrm{pH}$, which, in tum, would 
Table 4.16. Center profile 0 - 5 inches 1:5 soil water extract data.

Thermodynamic Data

\begin{tabular}{lcccccc} 
Concentration Factor & 1 & 5 & 10 & 100 & 500 & 1000 \\
\hline lonic Strength (molal) & 0.032312 & 0.13571 & 0.21771 & 1.7513 & 8.6527 & 10.93 \\
PCO2 (atm) & 0.00034 & 0.00034 & 0.00034 & 0.00034 & 0.00034 & 0.00034 \\
PH & 8.05 & 7.85 & 7.85 & 7.85 & 7.85 & 7.85 \\
Density (g/cm^3) & 1.0038 & 1.0094 & 1.0164 & 1.0237 & 1.0643 & 1.127 \\
Osmotic Coefficient & 0.8359 & 0.7747 & 0.7733 & 0.707 & 0.7522 & 0.9384 \\
Activity of Water & 0.9996 & 0.9985 & 0.9975 & 0.9799 & 0.8976 & 0.8507 \\
Temperature $\left({ }^{\circ} \mathrm{C}\right)$ & 25 & 25 & 25 & 25 & 25 & 25
\end{tabular}

\section{Concentrations of lons (molal)}

\begin{tabular}{|c|c|c|c|c|c|c|}
\hline Concentration Factor & 1 & 5 & 10 & 100 & 500 & 1000 \\
\hline $\mathrm{Na}$ & $8.0286 E .03$ & $4.0164 \mathrm{E} .02$ & $8.0380 E-02$ & $8.0527 E .01$ & $4.0850 E+00$ & $3.9020 E+00$ \\
\hline$k$ & $1.7461 \mathrm{E} \cdot 04$ & $8.7350 E .04$ & $1.7482 E-03$ & 1.7514 E. 02 & $8.8844 E-02$ & $1.8199 E-01$ \\
\hline $\mathrm{Mg}$ & $1.6585 \mathrm{E}-03$ & $8.3090 E \cdot 03$ & $1.6629 E-02$ & $1.6653 E-01$ & $8.4350 E-01$ & $1.7258 E+00$ \\
\hline $\mathrm{Ca}$ & $3.3201 \mathrm{E} .03$ & $1.2762 E .02$ & $1.2130 \mathrm{E}-02$ & 1.4765E.02 & 1.7954E.02 & $1.3866 \mathrm{E} .02$ \\
\hline $\mathrm{B}(\mathrm{OH}) 4$ & $8.2460 E-07$ & $2.6750 E \cdot 06$ & 5.3970 E-06 & $6.0840 E-05$ & $5.0439 E-04$ & $1.1544 \mathrm{E} \cdot 03$ \\
\hline $\mathrm{Cl}$ & $1.2173 E .03$ & $6.0896 E .03$ & $1.2187 E .02$ & $1.2209 E-01$ & 6.1937E.01 & $1.2687 E+00$ \\
\hline $\mathrm{SO} 4$ & $8.6492 \mathrm{E} .03$ & $3.4883 E-02$ & 5.6382 E-02 & 4.5794E-01 & $2.2660 E+00$ & $2.3858 E+00$ \\
\hline $\mathrm{H}$ & $1.0640 E-08$ & $1.9470 E \cdot 08$ & $2.0790 E-08$ & $2.9070 E .08$ & $2.5090 E-08$ & $1.8820 E \cdot 08$ \\
\hline $\mathrm{OH}$ & $1.3700 E \cdot 06$ & 1.0060E.OE & 1.0660 E-06 & $1.5010 E-06$ & 1.6790E-06 & $1.9210 E \cdot 06$ \\
\hline $\mathrm{HCO} 3$ & $6.6691 \mathrm{E}-04$ & $4.6735 \mathrm{E}-04$ & $5.0344 E-04$ & $7.3421 E-04$ & $1.0255 E-03$ & $9.9478 E-04$ \\
\hline $\mathrm{CO} 3$ & 5.8810E-06 & 3.9430 E.06 & 5.0010E.06 & $2.1610 \mathrm{E}-05$ & 8.1750 E-0.5 & 1.0997E-04 \\
\hline $\mathrm{H} 2 \mathrm{CO} 3$ & 1.1720 E.05 & $1.1510 \mathrm{E}-05$ & 1.1330 E-05 & $8.4150 E-06$ & $2.1890 E-06$ & $1.5180 E-06$ \\
\hline
\end{tabular}

Amounts of Compounds (mol $/ \mathrm{kg}$ ) or (mol)

\begin{tabular}{|c|c|c|c|c|c|c|}
\hline Concentration Factor & 1 & 5 & 10 & 100 & 500 & 1000 \\
\hline \multicolumn{6}{|l|}{ Glauberite [ $\mathrm{Na} 2 \mathrm{Ca}(\mathrm{SO} 4) 2]$} & $2.2329 E+00$ \\
\hline $\mathrm{MgB}(\mathrm{OH}) 4$ complex & $1.4830 E \cdot 08$ & $1.4090 E-07$ & $4.5450 \mathrm{E} \cdot 07$ & $1.8880 \mathrm{E}-05$ & 4.3414E-04 & $2.0318 E .03$ \\
\hline MgCO3 complex & $3.8870 \mathrm{E} \cdot 06$ & $7.7420 E-06$ & 1.5660 E-05 & $2.1098 E-04$ & $1.9891 \mathrm{E}-03$ & $4.9056 \mathrm{E}-03$ \\
\hline $\mathrm{MgOH}$ complex & $1.5090 E-07$ & 3.2630 E-07 & 5.6180E-07 & $3.6340 E \cdot 06$ & 2.7920 E-05 & $6.8100 \mathrm{E}-05$ \\
\hline $\mathrm{CaB}(\mathrm{OH}) 4$ complex & $4.8090 E-08$ & $3.2910 \mathrm{E} \cdot 07$ & 4.5190E-07 & $2.0630 E-06$ & $8.3320 E-06$ & $1.4840 E-05$ \\
\hline $\begin{array}{l}\mathrm{CaCO} 3 \text { complex } \\
\text { Calcite [ } \mathrm{CaCO} 3 \text { ] }\end{array}$ & $\begin{array}{l}1.2400 E-05 \\
8.9852 E-04\end{array}$ & $1.8350 E-05$ & $1.7420 \mathrm{E}-05$ & $2.5990 E-05$ & 5.0320 E-05 & $4.7050 E-05$ \\
\hline Glauberite [ $\mathrm{Na} 2 \mathrm{Ca}\left(\mathrm{SO}_{4}\right) 2$ ] & & & & & & $2.2329 E+00$ \\
\hline Gypsum [ CaSO4.2H2O ] & & $8.3856 \mathrm{E} .03$ & $3.0212 E-02$ & 4.0959E.01 & $2.1348 E+00$ & $2.1630 E+00$ \\
\hline $\mathrm{B}(\mathrm{OH}) 3$ cornplex & $1.2680 \mathrm{E} \cdot 05$ & $6.4740 E-05$ & $1.2951 E-04$ & $1.2793 E .03$ & 5.9576E-03 & $1.0942 E-02$ \\
\hline HSO4 complex & 3.8960 E.09 & $1.6120 E-08$ & $2.2650 E-08$ & $6.5250 E-08$ & $7.6920 E \cdot 08$ & $5.0940 E-08$ \\
\hline
\end{tabular}


Table 4.17. Center profile $5-12$ inches $1: 5$ soil water extract data.

Thermodynamic Data

\begin{tabular}{lccccc} 
Concentration Factor & 1 & 5 & 10 & 100 & 500 \\
\hline lonic Strength (molal) & 0.031048 & 0.14777 & 0.22339 & 1.8015 & 8.8079 \\
PCO2 (atm) & 0.00034 & 0.00034 & 0.00034 & 0.00034 & 0.00034 \\
PH & 8.11 & 7.97 & 7.9 & 7.9 & 7.9 \\
Density (g/cm^3) & 1.0037 & 1.0093 & $1.01 f 2$ & 1.0237 & 1.0345 \\
Osmotic Coefficlent & 0.8478 & 0.7717 & 0.7782 & 0.7091 & 0.7314 \\
Activity of Water & 0.9996 & 0.9984 & 0.9973 & 0.9785 & 0.8948 \\
Temperature ( $\left.{ }^{\circ} \mathrm{C}\right)$ & 25 & 25 & 25 & 25 & 25
\end{tabular}

Concentrations of lons (molal)

\begin{tabular}{|c|c|c|c|c|c|}
\hline Concentration Factor & 1 & 5 & 10 & 100 & 500 \\
\hline $\mathrm{Na}$ & $9.2555 \mathrm{E} \cdot 03$ & $4.6301 E .02$ & $9.2662 \mathrm{E}-02$ & $9.2829 \mathrm{E}-01$ & $4.6618 \mathrm{E}+00$ \\
\hline$k$ & 1.5765E.04 & $7.8864 E-04$ & 1.5783E-03 & $1.5811 E-02$ & $7.9404 E-02$ \\
\hline$M g$ & $1.7124 \mathrm{E} \cdot 03$ & $8.5789 \mathrm{E} .03$ & $1.7175 \mathrm{E} .02$ & $1.7188 E-01$ & 8.5971E-01 \\
\hline $\mathrm{Ca}$ & $2.5061 \mathrm{E} .03$ & $9.5906 \mathrm{E} .03$ & 1.2403E.02 & 1.59:7E.02 & $2.1892 E .02$ \\
\hline $\mathrm{B}(\mathrm{OH}) 4$ & 8.8960E.06 & $3.2760 \mathrm{E}-05$ & 5.6840E-05 & $6.3642 E-04$ & $5.1565 E-03$ \\
\hline $\mathrm{Cl}$ & $6.9245 \mathrm{E} .04$ & $3.4640 \mathrm{E} \cdot 03$ & $6.9325 \mathrm{E} .03$ & 6.9450E-02 & $3.4877 E-01$ \\
\hline SO4 & 8.5762E.03 & 4.2903E-02 & $5.6662 E .02$ & $4.5910 E-01$ & $2.2473 E+00$ \\
\hline $\mathrm{H}$ & $9.2290 E-9$ & $1.5100 E-08$ & 1.8660 E- 08 & $2.6560 \mathrm{E} \cdot 08$ & $2.3890 \mathrm{E}-08$ \\
\hline $\mathrm{OH}$ & $1.5690 \mathrm{E} \cdot 06$ & $1.3280 E-06$ & $1.1940 E \cdot 06$ & $1.6340 \mathrm{E}-06$ & $1.6490 \mathrm{E}-06$ \\
\hline $\mathrm{HCO}$ & $7.6949 E-04$ & 6.3:75E-04 & 5.6594 E.04 & 8.1993E-04 & $1.0877 E .03$ \\
\hline $\mathrm{CO} 3$ & 7.7080 E.06 & $7.0620 E-06$ & $6.2730 E-06$ & 2.5980 E.05 & $9.8040 E-05$ \\
\hline $\mathrm{H} 2 \mathrm{CO}_{3}$ & $1.1730 E-05$ & $1.1490 E-05$ & $1.1290 \mathrm{~F}-05$ & $8.1730 E-06$ & 1.9320 E-06 \\
\hline
\end{tabular}

Amounts of Compounds $(\mathrm{mol} / \mathrm{kg})$ or $(\mathrm{mol})$

\begin{tabular}{|c|c|c|c|c|c|}
\hline Concentration Factor & 1 & 5 & 10 & 100 & 500 \\
\hline $\mathrm{MgB}(\mathrm{OH}) 4$ complex & $1.6530 \mathrm{E} \cdot 07$ & $1.6630 \mathrm{E} \cdot 06$ & $4.79 .40 E-06$ & 1.8080 E-04 & $3.4290 E-03$ \\
\hline MgCO3 complex & $5.2900 E-06$ & $1.3540 \mathrm{E}-05$ & $2.0010 \mathrm{E}-05$ & 2.5211E.04 & $2.1678 E-03$ \\
\hline MgOH complex & $1.7920 \mathrm{E} \cdot 07$ & $4.2000 E-07$ & $6.3930 \mathrm{E} \cdot 07$ & 3 8620E.06 & 2.4390 E.05 \\
\hline $\mathrm{CaB}(\mathrm{OH}) 4$ complex & $3.9180 E-07$ & $2.7600 E-06$ & 5.1540E.06 & $2.0860 E-05$ & $8.0100 E-05$ \\
\hline $\mathrm{CaCO} 3$ complex & $1.2330 E-05$ & $2.3090 E-05$ & $2.2070 E \cdot 05$ & $3.2630 \mathrm{E}-05$ & $6.6180 E-05$ \\
\hline Calcite [ $\mathrm{CaCO} 3$ ] & $1.6392 E .03$ & $1.1185 E .02$ & & & \\
\hline \multicolumn{6}{|c|}{ Glauberite [ $\mathrm{Na} 2 \mathrm{Ca}(\mathrm{SO} 4) 2$ ] } \\
\hline Gypsum [ $\mathrm{CaSO} 4.2 \mathrm{H} 2 \mathrm{O}$ ] & & & 2.9199E-¿2 & $4.0106 \mathrm{E} \cdot 01$ & $2.0723 E+00$ \\
\hline $\mathrm{B}(\mathrm{OH}) 3$ complex & $1.1886 E-04$ & $6.0471 \mathrm{E} .04$ & $1.2178 \mathrm{E} \cdot 03$ & $1.2031 \mathrm{E} .02$ & 5.5963E.02 \\
\hline HSO4 complex & $3.4510 E \cdot 09$ & $1.5280 E \cdot 08$ & $2.0210 \mathrm{E}-08$ & $5.8260 E .08$ & $6.5670 E \cdot 08$ \\
\hline
\end{tabular}


Table 4.18. Center profile $12-18$ inches 1:5 soil water extract data.

Thermodynamic Data

\begin{tabular}{|c|c|c|c|c|c|}
\hline Concentration Factor & 1 & 5 & 10 & 100 & 500 \\
\hline Ionic Strength (molal) & 0.0229 & 0.10866 & 0.21487 & 1.7747 & 8.1715 \\
\hline $\mathrm{PCO} 2(\mathrm{~atm})$ & 0.00034 & 0.00034 & 0.00034 & 0.00034 & 0.00034 \\
\hline pH & 8 & 8.09 & 8.04 & 7.9 & 7.9 \\
\hline Density $\left(g / \mathrm{cm}^{\wedge} 3\right)$ & 1.0032 & 1.0067 & 1.0111 & 1.0801 & 1.2666 \\
\hline Osmotic Coefficient & 0.8895 & 0.8276 & 0.7982 & 0.7281 & 0.7767 \\
\hline $\begin{array}{l}\text { Activity of Waier } \\
\text { Temperature }\left({ }^{\circ} \mathrm{C}\right)\end{array}$ & $\begin{array}{c}0.9997 \\
25\end{array}$ & $\begin{array}{l}0.9985 \\
25\end{array}$ & $\begin{array}{c}0.9971 \\
25\end{array}$ & 0.9762 & 0.8867 \\
\hline
\end{tabular}

\section{Concentrations of lons (molal)}

\begin{tabular}{|c|c|c|c|c|c|}
\hline Concentration & 1 & $\mathbf{5}$ & 10 & 100 & 500 \\
\hline $\mathrm{Na}$ & $1.0065 \mathrm{E}-02$ & $5.0349 E-02$ & $1.0075 E-01$ & $1.0186 E+00$ & $4.7508 E+00$ \\
\hline K & $7.3530 \mathrm{E} \cdot 05$ & $3.6784 E-04$ & $7.3609 E-04$ & 7.4418E-03 & 3.9191 E-02 \\
\hline $\mathrm{Mg}$ & 8.3532E-04 & 4.1742E-03 & $8.3578 E-03$ & $8.4499 E-02$ & 4.4241E-01 \\
\hline $\mathrm{Ca}$ & $1.4106 E-03$ & 4.6557E.03 & 8.3128E-03 & $1.4844 E-02$ & $1.5966 \mathrm{E}-02$ \\
\hline $\mathrm{B}(\mathrm{OH}) 4$ & $4.4170 \mathrm{E}-06$ & $2.7\{40 E-05$ & 4.8410 E-05 & $4.2274 \mathrm{E}-04$ & $3.9062 E-03$ \\
\hline $\mathrm{Cl}$ & 1.9197E.03 & $9.6027 \mathrm{E} .03$ & $1.9216 E-02$ & 1.9427E-01 & $1.0231 E+00$ \\
\hline SO4 & $6.0360 E-03$ & 3.0193E-02 & $6.0421 E-02$ & 4.8254E-01 & $2.1721 E+00$ \\
\hline $\mathrm{H}$ & $1.1590 E-08$ & $1.0780 E-08$ & $1.3440 E-08$ & $2.4850 E-08$ & $1.9280 E-08$ \\
\hline $\mathrm{OH}$ & $1.1920 E \cdot 06$ & 1.7010 E-06 & $1.6290 E-06$ & $1.6270 E-06$ & $1.6910 \mathrm{E}-06$ \\
\hline $\mathrm{HCO} 3$ & $5.9102 E .04$ & 8.3751E.04 & 7.9856E-04 & 8.8010E-04 & $1.2548 E-03$ \\
\hline $\mathrm{CO} 3$ & $4.3340 E-06$ & $1.1090 E \cdot 05$ & 1.1730 E.05 & 2.5130 E.05 & 6.9610 E.05 \\
\hline $\mathrm{H} 2 \mathrm{CO}_{3}$ & $1.1740 E-05$ & $1.1550 E \cdot 05$ & $1.1320 E-05$ & 8.2530E-06 & 2.2530E-06 \\
\hline
\end{tabular}

$$
\text { Amounts of Compounds (mol/kg) or (mol) }
$$

\begin{tabular}{|c|c|c|c|c|c|}
\hline Concentration Factor & 1 & 5 & 10 & 100 & 500 \\
\hline \multicolumn{5}{|l|}{ Glauberite [ $\mathrm{Na} 2 \mathrm{Ca}(\mathrm{SO} 4) 2$ ] } & $3.0680 E-01$ \\
\hline $\mathrm{MgB}(\mathrm{OH}) 4$ cornplex & $4.4080 E-08$ & $7.5230 E-07$ & $2.0150 \mathrm{E} \cdot 06$ & $7.1010 E \cdot 05$ & 2.3430 E-03 \\
\hline MgCO3 complex & $1.5800 \mathrm{E} \cdot 06$ & $1.1720 E-05$ & $1.8410 \mathrm{E} \cdot 05$ & $1.3562 E-04$ & $1.3193 E-03$ \\
\hline MgOH complex & $7.2980 E-08$ & $2.9090 \mathrm{E}-07$ & $4.2240 E \cdot 07$ & $2.1640 E-06$ & $2.2730 \mathrm{E}-05$ \\
\hline $\mathrm{CaB}(\mathrm{OH}) 4$ complex & 1.2260 E -07 & $1.2740 E-06$ & $2.9290 E-06$ & $1.4990 \mathrm{E}-05$ & 7.4260 E- 05 \\
\hline $\mathrm{CaCO} 3$ complex & $4.2870 E-06$ & $2.0160 E .05$ & $2.7700 \mathrm{E} \cdot 05$ & 3.2690 E-05 & $5.5850 E-05$ \\
\hline Calcite [ $\mathrm{CaCO}$ ] ] & & $2.4011 E-03$ & $5.8211 E-03$ & & \\
\hline Glauberite [ $\mathrm{Na} 2 \mathrm{Ca}(\mathrm{SO} 4) 2$ ] & & & & & $3.0680 \mathrm{E}-01$ \\
\hline Gypsum [ $\mathrm{CaSO} 4.2 \mathrm{H} 2 \mathrm{O}$ ] & & & & $1.2831 E \cdot 01$ & $4.3125 E-01$ \\
\hline $\mathrm{B}(\mathrm{OH}) 3$ complex & $7.5720 E-05$ & $3.7251 \mathrm{E} \cdot 04$ & $7.5045 E-04$ & $7.6168 \mathrm{E}-03$ & $3.6413 E-02$ \\
\hline HSO4 complex & $3.4230 E-09$ & 9.1970 E.09 & $1.6470 E-08$ & $6.0050 \mathrm{E}-08$ & 7.3110E-08 \\
\hline
\end{tabular}


Table 4.19. Center profile $18-24$ inches 1:5 soil water extract data.

Thermodynamic Data

\begin{tabular}{lccccc} 
Concentration Factor & $\mathbf{1}$ & 5 & 10 & 100 & 500 \\
\hline lonic Strength (molal) & 0.022448 & 0.10616 & 0.20989 & 1.9045 & 8.7923 \\
PCO2 (atm) & $0.00034 \mathrm{a} ! \mathrm{m}$. & 0.00034 atm. & $0.00034 \mathrm{~atm}$. & 0.00034 & 0.00034 \\
pH & 8.03 & 8.1 & 8.04 & 7.9 & 7.9 \\
Density (g/cm^3) & 1.0032 & 1.0065 & 1.0107 & 1.0773 & 1.2662 \\
Osmotic Coefficient & 0.8971 & 0.8396 & 0.8126 & 0.7133 & 0.8136 \\
Activity of Water & 0.9996 & 0.9984 & 0.9969 & 0.9756 & 0.875 \\
Temperature ( $\left.{ }^{\circ} \mathrm{C}\right)$ & 25 & 25 & 25 & &
\end{tabular}

\section{Concentrations of lons (molal)}

\begin{tabular}{|c|c|c|c|c|c|}
\hline Concentration Factor & 1 & 5 & 10 & 100 & 500 \\
\hline $\mathrm{Na}$ & $1.0265 E-02$ & $5.1353 E .02$ & $1.0277 \mathrm{E} .01$ & $1.0396 E+00$ & $4.9090 E+00$ \\
\hline K & $2.9130 \mathrm{E}-05$ & $1.4575 E .04$ & 2.9167E-04 & $2.9505 E-03$ & 1.5518E-02 \\
\hline $\mathrm{Mg}$ & $8.4785 E \cdot 04$ & 4.2375E-03 & $8.4850 E-03$ & 8.5831E-02 & 4.4805E-01 \\
\hline $\mathrm{Ca}$ & $1.3721 \mathrm{E} .03$ & $4.3796 \mathrm{E}-03$ & $7.7082 E \cdot 03$ & $1.7086 \mathrm{E}-02$ & 1.5402E-02 \\
\hline $\mathrm{B}(\mathrm{OH}) 4$ & $5.0160 E-06$ & 2.9650E-05 & 5.3160 E- 05 & $4.6907 E-04$ & 4.7218E-03 \\
\hline $\mathrm{Cl}$ & 3.0562E.03 & $1.5288 E \cdot 02$ & $3.0596 \mathrm{E}-02$ & 3.0950E-01 & $1.6278 E+00$ \\
\hline $\mathrm{SO} 4$ & $5.5047 \mathrm{E} \cdot 03$ & $2.7537 \mathrm{E} .02$ & 5.5108E-02 & 4.3516E-01 & $1.9349 E+00$ \\
\hline $\mathrm{H}$ & $1.0970 E \cdot 08$ & $1.0600 E-08$ & $1.3120 E-08$ & $2.3890 E \cdot 08$ & $1.5760 E-08$ \\
\hline $\mathrm{OH}$ & 1.2540 E.06 & $1.7: 10 E-06$ & $1.6420 E-06$ & $1.6440 \mathrm{E}-06$ & $1.7030 \mathrm{E}-06$ \\
\hline $\mathrm{HCO} 3$ & $6.2190 E-04$ & $8.4346 E-04$ & 8.0609E.04 & $8.7159 E-04$ & $1.2386 \mathrm{E}-03$ \\
\hline $\mathrm{CO} 3$ & $4.8020 E-06$ & 1.1260E-05 & 1.1970E-05 & $2.7350 E-05$ & $6.0540 \mathrm{E}-05$ \\
\hline $\mathrm{H} 2 \mathrm{CO} 3$ & $1.1740 E-05$ & $1.1550 E .05$ & $1.1330 E-05$ & 8.2910E-06 & 2.27DOE-06 \\
\hline
\end{tabular}

Amounts of Compounds ( $\mathrm{mol} / \mathrm{kg}$ ) or (mol)

\begin{tabular}{|c|c|c|c|c|c|}
\hline Concentration Factor & 1 & 5 & 10 & 100 & 500 \\
\hline \multicolumn{5}{|l|}{ Glauberite [ $\mathrm{Na2Ca}(\mathrm{SO} 4) 2$ ] } & $2.7940 E-01$ \\
\hline $\mathrm{MgB}(\mathrm{OH}) 4$ comiplex & 5.1690E.08 & $8.6020 \mathrm{E} \cdot 07$ & 2.3300 E-06 & 7.9640 E- 05 & $3.1836 \mathrm{E} \cdot 03$ \\
\hline MgCO3 complex & 1.7940 E.06 & 1.2290 E.05 & $1.9480 E-05$ & $1.4369 E-04$ & $1.3677 \mathrm{E} .03$ \\
\hline $\mathrm{MgOH}$ complex & $7.9070 E \cdot 08$ & $3.0310 E-07$ & $4.4040 E-07$ & $2.1190 E-06$ & $2.7840 E-05$ \\
\hline $\mathrm{CaB}(\mathrm{OH}) 4$ complex & $1.3870 E \cdot 07$ & $1.3650 E .06$ & $3.1310 \mathrm{E} \cdot 06$ & $1.9870 E-05$ & $1.0273 E-04$ \\
\hline $\mathrm{CaCO}$ uimplex & $4.6790 \mathrm{E} \cdot 06$ & $1.9700 E \cdot 05$ & $2.6950 E \cdot 05$ & $4.0080 E-05$ & 5.7180E-05 \\
\hline Calcite [ $\mathrm{CaCO}$ ] & & $2.4873 E .03$ & 6.0463E-03 & & \\
\hline Glauberite [ $\mathrm{Na} 2 \mathrm{Ca}(\mathrm{SO} 4) 2$ ] & & & & & $2.7940 E-01$ \\
\hline Gur um [ $\mathrm{CaSO} 4.2 \mathrm{H} 2 \mathrm{O}]$ & & & & $1.2229 E-01$ & $4.3835 E-01$ \\
\hline $8(\mathrm{OH}) 3$ complex & $8.1560 E-05$ & $4.0216 \mathrm{E} \cdot 04$ & $8.1001 E \cdot 04$ & $8.2170 E-03$ & $3.8132 \mathrm{E}-02$ \\
\hline HSO 4 complex & $2.9650 E-09$ & 8.3210 E.09 & $1.4850 \mathrm{E} \cdot 08$ & $5.0160 E-08$ & $5.9020 E-08$ \\
\hline
\end{tabular}



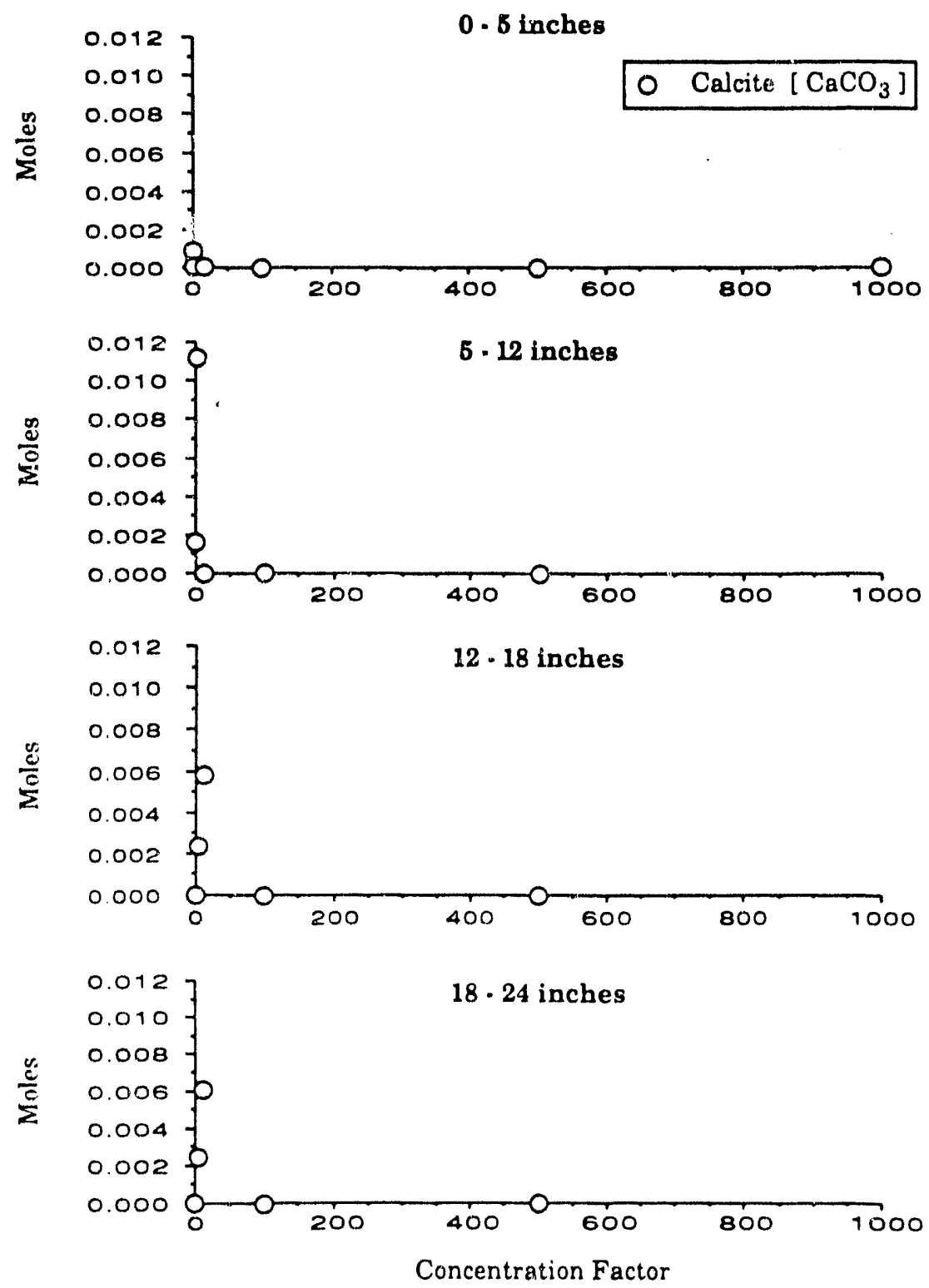

Figure 4.28. Center profile predicted calcite from soil extracts at four depths (predicted to form from 1 L of solution). 

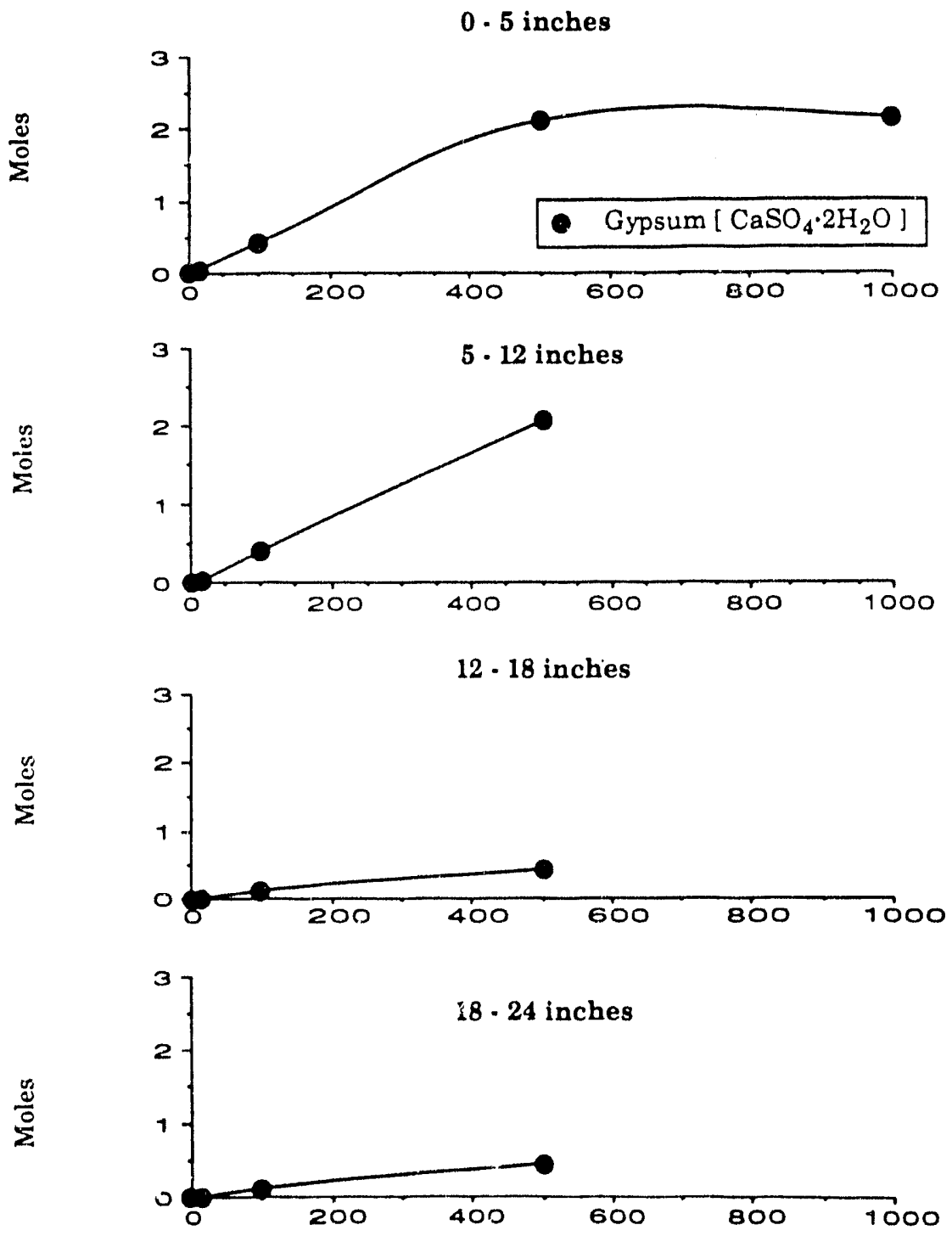

Concentration Factor

Figure 4.29. Center profile predicted gypsum from soil extracts at four depths (predicted to form from $1 \mathrm{~L}$ of solution). 


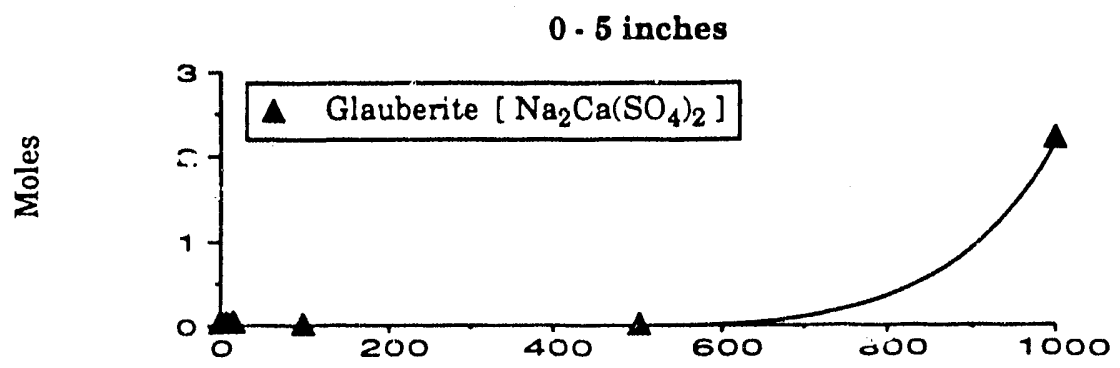

$5 \cdot 12$ inches

None Predicted
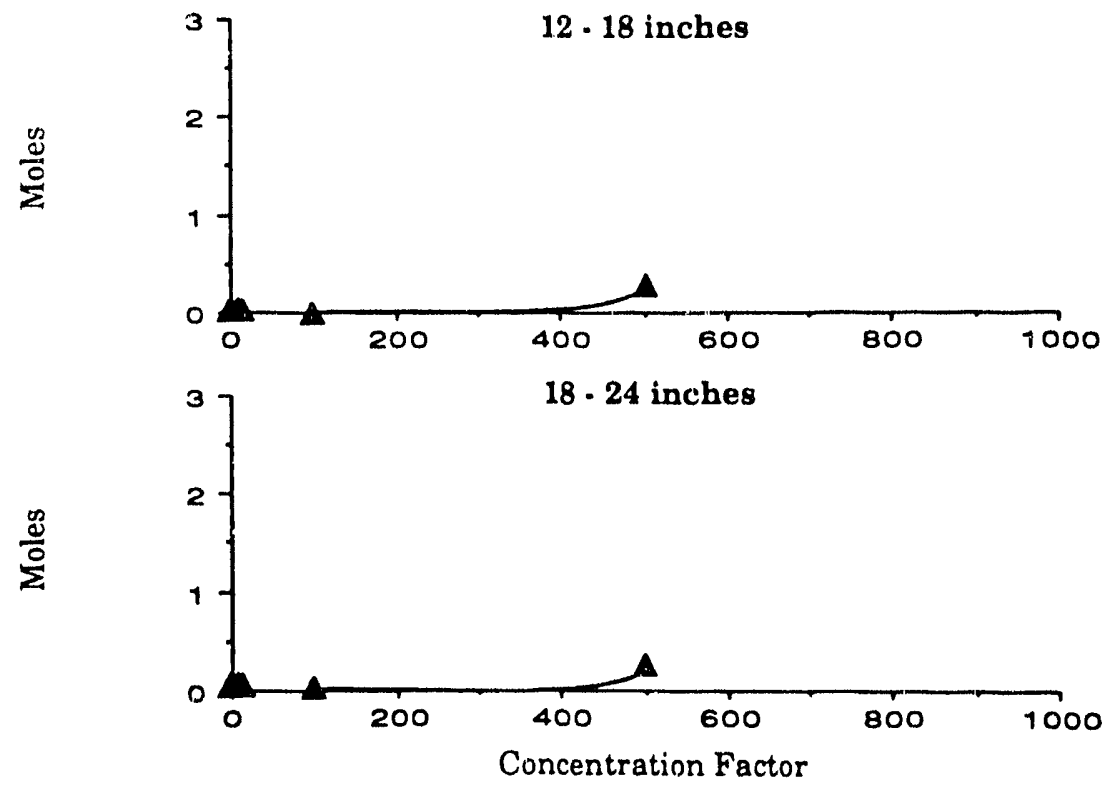

Figure 4.30. Center profile predicted glauberite from soil extracts at four depths (predicted to form from $1 \mathrm{~L}$ of solution). 
dissolve calcite. The dissolved calcite would be available for transport to greater depths. This accounts for the peak concentration of calcite between the 5 and 12 inch depths. However, this may not be the complete explanation, because the distribution of gypsum also has an effect, as will be explained below.

At high concentration factors, the $\mathrm{pH}$ was set to 7.85 . For the most part gypsum is the dominant mineral predicted to form in the eastern profile, as can be seen in Figure 4.29. More than 2 $\mathrm{mol} / \mathrm{l}$ of gypsum is predicted to form when soil extracts at 0 to 5 inch and 5 to 12 inch depths are concentrated 500-fold. At greater deptrss, the amount of gypsum predicted to form at this concentration factor is approximately $0.5 \mathrm{~mol} / \mathrm{h}$. This salt distribution indicates the upward redistribution of salts within the soil profile through the capillary rise of shallow ground water. However, the ground water did not rise to the surface during the winter of 1989 . Also, the profile was leached by irrigation during the previous year, which should dissolve the gypsum and redistribute this salt downward in the profile. There are two possible explanations as to why more gypsum exists at the top of this profile than at the bottom. First, this may be due to the spatial variability of the chemical constituents: only one auger hole was dug in this plot. Had more samples been taken, a more accurate description of the chemical composition would have been obtained. Secondly, the amount of water provided for leaching may not have been sufficient to redistribute all of the gypsum within the profile. A comparison of the center and eastern profiles supports this viewpoint. Over eight moles of gypsum are predicted to form at the top of the eastern profile, while just over 2 moles of gypsum are predicted to precipitate at the top of the center profile. The amounts precipitated reflect the initial calcium and sulfate concentrations in the sample. Assun:ing the two profiles began with the same amount of gypsum in the soil several years ago, the irrigation and leaching of the center profile has been partially successful. Some, but not all, of the gypsum has been redistributed downward in the profile.

Glauberite $\left[\mathrm{Na}_{2} \mathrm{Ca}\left(\mathrm{SO}_{4}\right)_{2}\right]$ is predicted to form only at the highest concentration factors. Glauberite is a very soluble evaporite, and it forms only under very concentrated solute conditions. Figure 4.30 shows the amounts of glauberite predicted to precipitate. Glauberite is 
predicted to form at 1000 -fold concentration in the 0 to 5 inch soil extract. A small amount of glauberite is predicted to form in the 12 to 18 and 18 to 24 inch depths at a concentration factor of 500 . Some leaching of this profile has occurred, because no glauberite is predicted to form at the top two depths of the center profile at a concentration factor of 500 .

As glauberite forms, both calcium and sulfate are incorporated into this solid phase, leaving little or none of these ions to form additional gypsum as the solution is concentrated. Once glauberite forms, it does so at the expense of gypsum formation. The amount of gypsum predicted to precipitate at the top of the center soil profile levels off because glauberite is also predicted to form.

$\mathrm{X}$-ray analysis indicates gypsum and thenardite are ubiquitous in the samples collected from the Kesterson Reservoir. Glauberite was not identified in the evaporite samples. This may be due to kinetic limitations on the formation of glauberite. C SALT, being an equilibrium model, does not account for kinetic constraints in the formation of evaporite minerals. Unlike the magnesium-containing carbonate minerals mentioned earlier, glauberite forms at the pressure and temperatures of the Earth's surface. Harvie et al. (1980), in their study of evapoconcentration of seawater, predicted the formation of glauberite and verified their prediction with the positive identification of a salt deposit in Germany. The limitations of C SALT should be recognized when the model predictions are being evaluated.

Tables 4.20 through 4.24 present selected data derived from C SALT for the eastem profile. Figures 4.31 through 4.33 present graphically the amounts of solid phases in Tables 4.20 through 4.24. Figures 4.31 through 4.33 are formatted similarly to Figures 4.28 through 4.30 . In contrast to the center profile, the eastem profile has not been irrigated and leached.

Speciation of the initial soil extract predicts the formation of calcite, with a pH of 8.05 . Calcite is generally predicted to form at a concentration factor of 5 , as can be seen in Figure 4.31. Above this concentration factor, the $\mathrm{pH}$ drops below 7.95 , allowing gypsum to form rather than calcite. In the eastem profile, the greatest amount of calcite formed is at 0 to 5 inch depth. The amount of calcite precipitated then decreases with depth. This distribution of calcite typifies 
Table 4.20. Eastem profile 0 - 5 inches $1: 5$ soil water extract data.

Thermodynamic Data

\begin{tabular}{lcccccc} 
Concentration Factor & 1 & 5 & 10 & 100 & 500 & 1000 \\
\hline lonic Strenght (molal) & 0.04226 & 0.13595 & 0.18536 & 1.2654 & 6.2816 & 11.705 \\
PCO2 (atm) & 0.00034 & 0.00034 & 0.00034 & 0.00034 & 0.00034 & 0.00034 \\
pH & 7.9 & 7.9 & 7.9 & 7.9 & 7.9 & 7.9 \\
Density (g/cm^3) & 1.0043 & 1.0121 & 1.0218 & 1.0305 & 1.1073 & 1.197 \\
Osmotic Coefflcient & 0.7849 & 0.7489 & 0.7694 & 0.7607 & 0.8985 & 1.2219 \\
Activity of Water & 0.9996 & 0.9987 & 0.998 & 0.9844 & 0.9103 & 0.7891 \\
Temperature ( $\left.{ }^{\circ} \mathrm{C}\right)$ & 25 & 25 & 25 & 25 & 25 & 25
\end{tabular}

Concentrations of lons (molal)

\begin{tabular}{|c|c|c|c|c|c|c|}
\hline Concentration Factor & 1 & 5 & 10 & 100 & 500 & 1000 \\
\hline $\mathrm{Na}$ & $3.6708 \mathrm{E} \cdot 03$ & $1.8370 E \cdot 02$ & $3.6782 \mathrm{E} .02$ & $3.6899 E-01$ & $1.9032 E+00$ & $3.1001 E+00$ \\
\hline$k$ & $2.4847 E .04$ & $1.2435 \mathrm{E} .03$ & $2.4897 E .03$ & $2.4977 \mathrm{E} .02$ & $1.2882 E-01$ & 2.6867E-01 \\
\hline $\mathrm{Mg}$ & $1.8903 E .03$ & $9.4597 \mathrm{E} .03$ & $1.8940 E .02$ & $1.8988 E-01$ & $9.7649 E-01$ & $2.0263 E+00$ \\
\hline $\mathrm{Ca}$ & $7.0251 \mathrm{E} .03$ & $1.1698 \mathrm{E} \cdot 02$ & $1.2837 \mathrm{E} .02$ & 1.3931E.02 & $1.2288 E-02$ & $7.1132 E-03$ \\
\hline $\mathrm{B}(\mathrm{OH}) 4$ & $6.7360 E .07$ & $3.4060 E .06$ & $6.8360 E .06$ & $7.6020 E .05$ & $5.8632 E-04$ & $1.4108 E .03$ \\
\hline $\mathrm{Cl}$ & $2.7956 \mathrm{E} .03$ & $1.3991 E .02$ & $2.8013 E-02$ & $2.8102 E-01$ & $1.4494 E+00$ & $3.0229 E+00$ \\
\hline SO4 & $1.0414 E .02$ & $3.8280 \mathrm{E} \cdot 02$ & $4.3935 E-02$ & $2.5993 \mathrm{E} \cdot 01$ & $1.2809 E+00$ & $2.2183 E+00$ \\
\hline $\mathrm{H}$ & $1.5340 E \cdot 08$ & $1.7250 \mathrm{E}-08$ & $1.7920 E-08$ & $2.2880 E-08$ & $1.8330 \mathrm{E}-08$ & $9.4200 E-09$ \\
\hline $\mathrm{OH}$ & $1.0000 E-06$ & $1.1400 E-06$ & $1.1830 E .06$ & $1.6790 E-06$ & $2.3990 E .06$ & $2.7670 E-06$ \\
\hline $\mathrm{HCO} 3$ & $4.7116 E \cdot 04$ & $5.2744 E-04$ & $5.4339 E-04$ & $7.1719 E-04$ & 8.9970E-04 & $1.4184 E-03$ \\
\hline $\mathrm{CO} 3$ & $3.1860 E \cdot 06$ & $5.1570 E .06$ & $6.0710 \mathrm{E}-06$ & 2.5130 E-05 & $1.1603 E-04$ & $1.5126 \mathrm{E}-04$ \\
\hline $\mathrm{H} 2 \mathrm{CO} 3$ & 1.1710 E.05 & 1.1550 E-O5 & 1.1450 E.05 & $8.5140 \mathrm{E}-06$ & $3.9820 E-06$ & $1.5390 \mathrm{E}-06$ \\
\hline
\end{tabular}

Amounts of Compounds (mol/kg) or (mol)

\begin{tabular}{|c|c|c|c|c|c|c|}
\hline Concentration Factor & 1 & 5 & 10 & 100 & 500 & 1000 \\
\hline Glauberite_Na2Ca(SO4)2 & : & & & & & $4.3457 E-01$ \\
\hline $\mathrm{MgB}(\mathrm{OH}) 4$ complex & $1.3090 E-08$ & $2.1070 E-07$ & $7.6090 E \cdot 07$ & $3.7900 E-05$ & $1.0193 E-03$ & $7.1268 E-03$ \\
\hline MgCO3 complex & $2.2470 E .06$ & $1.1510 E \cdot 05$ & $2.3720 E \cdot 05$ & $3.3814 E-04$ & 3.7439E-03 & $1.2887 \mathrm{E}-02$ \\
\hline MgOH complex & $1.1750 E-07$ & $4.2470 E \cdot 07$ & $7.8760 E \cdot 07$ & $5.1340 E-06$ & 4.5510 E-05 & $2.5313 E .04$ \\
\hline $\mathrm{CaB}(\mathrm{OH}) 4$ complex & $7.8400 E-08$ & $3.8970 E-07$ & $7.8110 E \cdot 07$ & $3.7520 E-06$ & $1.3420 E \cdot 05$ & $2.1420 E-05$ \\
\hline $\begin{array}{l}\mathrm{CaCO} 3 \text { complex } \\
\text { Anhydrite [ } \mathrm{CaSO} 4 \text { ] }\end{array}$ & 1.3270 E.05 & $2.1790 E-05$ & 2.4770 E- 05 & $3.6070 E-05$ & 6.0330 E. 05 & $\begin{array}{l}5.2390 E-05 \\
8.1735 E+00\end{array}$ \\
\hline Calcite [ $\mathrm{CaCO}_{3}$ ] & $9.2901 \mathrm{E} \cdot 04$ & $1.4315 \mathrm{E}-02$ & $6.5546 E \cdot 03$ & & & \\
\hline Glauberite [ $\mathrm{Na} 2 \mathrm{Ca}\left(\mathrm{SO}_{4}\right) 2$ ] & & & & & & 4.3457E-01 \\
\hline Gypsum [ $\mathrm{CaSO} 4.2 \mathrm{H} 2 \mathrm{O}$ ] & & $1.3838 E-02$ & $6.0419 E \cdot 02$ & $7.8694 \mathrm{E}-01$ & $4.1185 E+00$ & \\
\hline$B(\mathrm{OH}) 3$ complex & $1.4650 E \cdot 05$ & $7.3150 E-05$ & $1.4611 \mathrm{E}-04$ & $1.4321 E \cdot 03$ & $6.3742 E-03$ & $8.1117 \mathrm{E} \cdot 03$ \\
\hline HSO4 complex & $5.8050 E-09$ & $1.5590 E-08$ & $1.5760 E \cdot 08$ & $3.7270 E \cdot 08$ & $4.5890 E-08$ & $3.3350 E-08$ \\
\hline
\end{tabular}


Table 4.21. Eastern profile 5 - 10 inches 1:5 soil water extract data.

Thermodynamis Data

\begin{tabular}{lccccc} 
Concentration Factor & 1 & 5 & 10 & 100 & 500 \\
\hline Ionic Strenght (molal) & 0.029669 & 0.11583 & 0.14673 & 0.97156 & 4.6721 \\
PCO2 (atm) & 0.00034 & 0.00034 & 0.00034 & 0.00034 & 0.00034 \\
pH & 7.97 & 7.9 & 7.9 & 7.9 & 7.9 \\
Density (g/cm^3) & 1.0038 & 1.0095 & 1.0166 & 1.0236 & 1.0271 \\
Osmotic Coefficient & 0.8066 & 0.7408 & 0.7642 & 0.7211 & 0.6925 \\
Activity of Water & 0.9997 & 0.999 & 0.9985 & 0.989 & 0.9495 \\
Temperature (을 & 25 & 25 & 25 & 25 & 25
\end{tabular}

Concentrations of lons (molal)

\begin{tabular}{|c|c|c|c|c|c|}
\hline Concentration Factor & 1 & 5 & 10 & 100 & 500 \\
\hline $\mathrm{Na}$ & $3.7812 \mathrm{E} \cdot 03$ & $1.8918 E \cdot 02$ & $3.7865 E-02$ & $3.7921 E-01$ & $1.8997 E+00$ \\
\hline $\mathrm{k}$ & $1.4668 \mathrm{E} \cdot 04$ & $7.3384 E \cdot 04$ & $1.4688 E-03$ & $1.4710 E-02$ & $7.3692 E-02$ \\
\hline $\mathrm{Mg}$ & $1.0946 \mathrm{E}-03$ & $5.4788 E \cdot 03$ & $1.0965 \mathrm{E}-02$ & $1.0972 E-01$ & $5.4820 E-01$ \\
\hline $\mathrm{Ca}$ & $4.6010 \mathrm{E} \cdot 03$ & $1.1432 E \cdot 02$ & $1.2384 \mathrm{E}-02$ & $1.3109 E-02$ & $1.7877 E-02$ \\
\hline$B(O H) 4$ & $3.8520 E-06$ & $1.6670 E-05$ & 3.3330 E- 05 & $3.5320 E \cdot 04$ & $2.2568 \mathrm{E}-03$ \\
\hline $\mathrm{Cl}$ & $.5877 E \cdot 04$ & $2.7956 E-03$ & $5.5956 \mathrm{E}-03$ & 5.603 & $3 E-01$ \\
\hline $\mathrm{SO} 4$ & $7.8756 \mathrm{E} \cdot 03$ & $3.5255 E-02$ & $3.8634 \mathrm{E}-02$ & $2.5014 \mathrm{E}-01$ & $1.2052 E+00$ \\
\hline$H$ & $1.2730 \mathrm{E} \cdot 08$ & $1.7000 E-08$ & $1.7540 E-08$ & $2.3880 E-08$ & $2.7570 E-08$ \\
\hline $\mathrm{OH}$ & 1.1360 E-06 & $1.1160 E-06$ & $1.1410 \mathrm{E}-06$ & $1.5360 E-06$ & $1.9980 E-06$ \\
\hline $\mathrm{HCO} 3$ & $5.4512 E-04$ & $5.1904 \mathrm{E}-04$ & $5.3011 E-04$ & $7.2489 E-04$ & $9.3086 E-04$ \\
\hline $\mathrm{CO} 3$ & $3.9430 E-06$ & $4.6880 E-06$ & 5.1840 E. .06 & $1.7210 E-05$ & $7.2540 E \cdot 05$ \\
\hline $\mathrm{H} 2 \mathrm{CO} 3$ & 1.1730 E. 05 & $1.1580 E-05$ & $1.1500 E-05$ & 9.8330 E-06 & $4.8970 E-06$ \\
\hline
\end{tabular}

Amounts of Compounds ( $\mathrm{mol} / \mathrm{kg}$ ) or (mol)

Concentration Factor 5

10

100

500

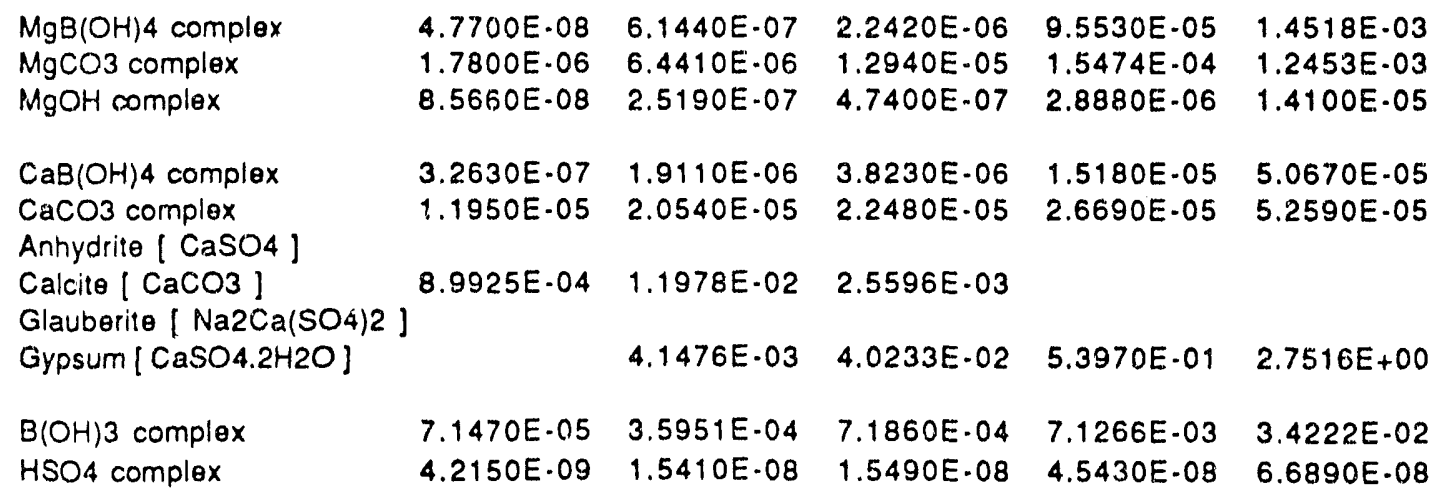


Table 4.22. Eastern profile 10-15 inches 1:5 soil water extract data.

Thermodynamic Data

\begin{tabular}{lccccc} 
Concentration Factor & 1 & 5 & 10 & 100 & 500 \\
\hline lonic Strenght (molal) & 0.043577 & 0.1496 & 0.23726 & 1.9697 & 10.149 \\
PCO2 (atm) & 0.00034 & 0.00034 & 0.00034 & 0.00034 & 0.00034 \\
pH & 7.98 & 7.9 & 7.9 & 7.9 & 7.9 \\
Density (g/cm^3) & 1.0044 & 1.0125 & 1.0226 & 1.0808 & 1.3242 \\
Osmotic Coefflclent & 0.8053 & 0.7711 & 0.7719 & 0.7038 & 0.7943 \\
Activity of Waier & 0.9996 & 0.9984 & 0.9972 & 0.9775 & 0.8746 \\
Temperature $\left({ }^{\circ} \mathrm{C}\right)$ & 25 & 25 & 25 & &
\end{tabular}

Concentrations of lons (molal)

\begin{tabular}{|c|c|c|c|c|c|}
\hline Concentration Factor & 1 & 5 & 10 & 100 & 500 \\
\hline $\mathrm{Na}$ & $8.4221 \mathrm{E} .03$ & $4.2145 E .02$ & $8.4381 \mathrm{E} .02$ & $8.4977 E .01$ & $4.4990 E+00$ \\
\hline K & $2.4647 E-04$ & $1.2334 \mathrm{E}-03$ & $2.4694 \mathrm{E}-03$ & $2.4868 E-02$ & 1.3166E-01 \\
\hline $\mathrm{Mg}$ & $2.1560 E-03$ & $1.0793 E .02$ & $2.1605 E .02$ & $2.1720 E-01$ & $1.1407 E+00$ \\
\hline $\mathrm{Ca}$ & $5.1892 E \cdot 03$ & $1.2487 \mathrm{E} .02$ & $1.2354 E \cdot 02$ & $1.5630 \mathrm{E}-02$ & $1.8033 E-02$ \\
\hline $\mathrm{B}(\mathrm{OH}) 4$ & $1.0280 E \cdot 05$ & $4.3700 E-05$ & $8.8080 E-05$ & $1.0023 E-03$ & $9.0739 \mathrm{E} .03$ \\
\hline $\mathrm{Cl}$ & $1.3202 E-03$ & $6.6063 E-0.3$ & $1.3227 E-02$ & $1.3320 \mathrm{E}-01$ & $7.0522 E-01$ \\
\hline $\mathrm{SO} 4$ & $1.1796 \mathrm{E} \cdot 02$ & $3.8875 E-02$ & 5.9478E-02 & 4.8996E-01 & $2.5291 E+00$ \\
\hline $\mathrm{H}$ & $1.2900 E-08$ & $1.7580 E-08$ & $1.8780 E-08$ & $2.6410 E-08$ & 2.0480E-08 \\
\hline $\mathrm{OH}$ & $1.1910 E-06$ & $1.1430 E \cdot 06$ & 1.2100 E.06 & $1.7260 E-06$ & $1.8790 \mathrm{E} \cdot 06$ \\
\hline $\mathrm{HCO} 3$ & $5.7138 \mathrm{E} \cdot 04$ & $5.3161 E .04$ & $5.6888 E \cdot 04$ & 8.1697 E.04 & $1.1721 E .03$ \\
\hline $\mathrm{co3}$ & $4.5770 E-06$ & 5.2220E-06 & $6.6100 E \cdot 06$ & $3.0870 E-05$ & 1.171BE-04 \\
\hline $\mathrm{H} 2 \mathrm{CO} 3$ & $1.1710 E-05$ & $1.1480 E-05$ & $1.1280 \mathrm{E}-05$ & $8.1070 E-06$ & $1.6610 \mathrm{E}-06$ \\
\hline
\end{tabular}

Amounts of Compounds (mol/kg) or (mol)

\begin{tabular}{|c|c|c|c|c|c|}
\hline Concentration Factor & 1 & 5 & 10 & 100 & 500 \\
\hline $\mathrm{MgB}(\mathrm{OH}) 4$ complex & $2.1840 E-07$ & $2.8660 \mathrm{E} \cdot 06$ & $9.3070 \mathrm{E}-06$ & $3.7250 E \cdot 04$ & $9.5044 E-03$ \\
\hline $\mathrm{MgCO} 3$ complex & $3.5940 E-06$ & $1.2730 E \cdot 05$ & $2.5810 \mathrm{E} \cdot 05$ & $3.5485 E-04$ & $3.5382 E .03$ \\
\hline MgOH complex & $1.5450 E-07$ & $4.6280 E \cdot 07$ & $8.0280 E \cdot 07$ & 5.1100E-06 & 4.2.930E.05 \\
\hline $\mathrm{CaB}(\mathrm{OH}) 4$ complex & $8.3840 E \cdot 07$ & $5.0120 E .06$ & $7.9090 E-06$ & $3.3140 E-05$ & $1.3276 E-04$ \\
\hline $\begin{array}{l}\mathrm{CaCO} 3 \text { complex } \\
\text { Anhydrite [ } \mathrm{CaSO} 4 \text { ] }\end{array}$ & $1.3670 E \cdot 05$ & $2.2660 \mathrm{E} \cdot 05$ & $2.2520 E \cdot 05$ & $3.5540 E-05$ & $6.5810 E \cdot 05$ \\
\hline Calcite [ $\mathrm{CaCO}_{3}$ ] & $1.8916 E-03$ & $2.8391 \mathrm{E} \cdot 03$ & & & \\
\hline \multicolumn{6}{|c|}{ Glauberite [ $\mathrm{Na} 2 \mathrm{Ca}(\mathrm{SO} 4) 2$ ] } \\
\hline Gypsum [ $\mathrm{CaSO} 4.2 \mathrm{H} 2 \mathrm{O}$ ] & & $2.0152 E .02$ & $5.8703 E .02$ & $7.0020 E .01$ & $3.7720 E+00$ \\
\hline $\mathrm{B}(\mathrm{OH}) 3$ complex & $1.8713 \mathrm{E} \cdot 04$ & $9.4161 E .04$ & $1.8832 E-03$ & $1.8607 \mathrm{E} .02$ & $8.6475 E .02$ \\
\hline HSO4 complex & $5.7230 E .09$ & $1.5510 E-08$ & $2.0440 E-08$ & $5.6540 \mathrm{E}-08$ & 5.9690 E. 08 \\
\hline
\end{tabular}


Table 4.23. Eastern profile $15-20$ inches $1: 5$ soil water extract data.

Thermodynamic Data

\begin{tabular}{lccccc} 
Concentration Factor & 1 & 5 & 10 & 100 & 500 \\
\hline Ionic Strenght (molal) & 0.035303 & 0.14814 & 0.24079 & 2.0449 & 14.053 \\
PCO2 (atm) & 0.00034 & 0.00034 & 0.00034 & 0.00034 & 0.00034 \\
pH & 8.06 & 7.8 & 7.8 & 7.9 & 7.9 \\
Density (g/cm^3) & 1.0039 & 1.0099 & 1.0173 & 1.0793 & 1.3206 \\
Osmotic Coefflcient & 0.8416 & 0.786 & 0.7857 & 0.7194 & 0.9528 \\
Activity of Water & 0.9996 & 0.9983 & 0.997 & 0.9752 & 0.826 \\
Temperature ( $\left.{ }^{\circ} \mathrm{C}\right)$ & 25 & 25 & 25 & &
\end{tabular}

Concentrations of lons (molal)

\begin{tabular}{|c|c|c|c|c|c|}
\hline Concentration Factor & 1 & 5 & 10 & 100 & 500 \\
\hline $\mathrm{Na}$ & $9.1468 \mathrm{E} \cdot 03$ & $4.5760 \mathrm{E} \cdot 02$ & $9.1588 \mathrm{E} \cdot 02$ & $9.2448 E-01$ & $4.6190 E+00$ \\
\hline $\mathrm{K}$ & $2.6442 E \cdot 04$ & $1.3228 \mathrm{E} .03$ & $2.6476 \mathrm{E}-03$ & 2.6725E-02 & $1.4202 E-01$ \\
\hline $\mathrm{Mg}$ & $2.0821 \mathrm{E} \cdot 03$ & $1.0434 \mathrm{E}-02$ & $2.088 ; E-02$ & $2.1034 \mathrm{E}-01$ & $1.1070 E+00$ \\
\hline $\mathrm{Ca}$ & $3.3081 \mathrm{E}-03$ & $1.3340 E-02$ & 1.2833 E.02 & $1.6524 \mathrm{E}-02$ & $1.8646 \mathrm{E}-02$ \\
\hline $\mathrm{B}(\mathrm{OH}) 4$ & $9.2120 \mathrm{E} \cdot 06$ & $2.6450 E-05$ & $5.3470 E-05$ & 7.8105E-04 & 8.1075E-03 \\
\hline $\mathrm{Cl}$ & $2.4456 \mathrm{E} \cdot 03$ & $1.2235 E-02$ & 2.4488E-02 & $2.4718 E-01$ & $1.3135 E+00$ \\
\hline $\mathrm{SO} 4$ & $9.1175 \mathrm{E}-03$ & $3.5350 E-02$ & $5.6867 \mathrm{E} .02$ & $4.6086 \mathrm{E}-01$ & $2.2329 E+00$ \\
\hline$H$ & $1.056 \cap E-08$ & $2.2040 E-08$ & $2.3540 E-08$ & $2.5220 E-08$ & $1.5840 E-08$ \\
\hline $\mathrm{OH}$ & $1.3980 \mathrm{E}-06$ & $9.0520 E-07$ & $9.6120 \mathrm{E} \cdot 07$ & $1.7150 E-06$ & 4.1540E-06 \\
\hline $\mathrm{HCO} 3$ & $6.8096 E \cdot 04$ & 4.1938E-04 & $4.5194 E \cdot 04$ & $8.1685 E-04$ & 4.5706E-04 \\
\hline $\mathrm{CO} 3$ & $6.2200 \mathrm{E}-06$ & 3.2800 E-06 & $4.2160 E \cdot 06$ & $3.1630 E-05$ & $1.9045 \mathrm{E}-04$ \\
\hline $\mathrm{H} 2 \mathrm{CO} 3$ & $1.1720 \mathrm{E}-05$ & $1.1480 E-05$ & $1.1270 E \cdot 05$ & $8.0380 E-06$ & $1.0130 \mathrm{E}-06$ \\
\hline
\end{tabular}

Amounts of Compounds (mol/kg) or (mol)

\begin{tabular}{|c|c|c|c|c|c|}
\hline Concentration Factor & 1 & 5 & 10 & 100 & 500 \\
\hline \multicolumn{5}{|l|}{ Glauberite [ $\mathrm{Na2Ca}(\mathrm{SO} 4) 2$ ] } & $1.4688 E \cdot 01$ \\
\hline $\mathrm{MgB}(\mathrm{OH}) 4$ complex & $2.0300 E \cdot 07$ & $1.7120 E-06$ & 5.5240E-06 & $2.8939 E-04$ & $9.3368 E-03$ \\
\hline MgCO3 complex & 5.0290E.06 & $7.8160 E \cdot 06$ & $1.5910 E \cdot 05$ & $3.5498 E-04$ & $4.8563 E-03$ \\
\hline $\mathrm{MgOH}$ complex & $1.8840 E \cdot 07$ & $3.5820 E-07$ & $6.1450 E-07$ & $4.9420 E-06$ & $6.06130 E-05$ \\
\hline $\mathrm{CaB}(\mathrm{OH}) 4$ complex & 5.2230E.07 & $3.3500 E-06$ & $5.0860 \mathrm{E} \cdot 06$ & $2.8640 E-05$ & $1.4340 E \cdot 04$ \\
\hline $\begin{array}{l}\mathrm{CaCO} 3 \text { complex } \\
\text { Anhydrite [ } \mathrm{CaSO} 4 \text { ] }\end{array}$ & $1.2730 \mathrm{E}-05$ & $1.5480 E \cdot 05$ & $1.4980 E \cdot 05$ & $3.9180 E-05$ & $9.7780 \mathrm{E}-05$ \\
\hline Calcite [ $\mathrm{CaCO} 3$ ] & $1.4005 E \cdot 03$ & & & & \\
\hline Glauberite [ $\mathrm{Na} 2 \mathrm{Ca}\left(\mathrm{SO}_{4}\right) 2$ ] & & & & & 1.4688E-01 \\
\hline Gypsum [ $\mathrm{CaSO} 4.2 \mathrm{H} 2 \mathrm{O}$ ] & & $1.0264 E \cdot 02$ & $3.4427 \mathrm{E} \cdot 02$ & $4.6066 E \cdot 01$ & $2.3704 E+00$ \\
\hline $\mathrm{B}(\mathrm{OH}) 3$ complex & $1.3963 E \cdot 04$ & $7.1677 E \cdot 04$ & $1.4336 E .03$ & $1.4013 E .02$ & $6.2496 \mathrm{E} \cdot 02$ \\
\hline HSO4 complex & $3.9610 \mathrm{E} .09$ & $1.7600 E-08$ & $2.4310 E .08$ & 5.0960E.08 & $3.4850 E-08$ \\
\hline
\end{tabular}


Table 4.24. Eastern profile 20-24 inches 1:5 soil water extract data.

Thermodynamic Data

\begin{tabular}{lccccc} 
Concentration Factor & $\mathbf{1}$ & $\mathbf{5}$ & 10 & 100 & 500 \\
\hline Ionic Strenght (molal) & 0.032313 & 0.14062 & 0.21773 & 1.762 & 9.0858 \\
PCO2 (atm) & 0.00034 & 0.00034 & 0.00034 & 0.00034 & 0.00034 \\
pH & 8.05 & 7.9 & 7.9 & 7.9 & 7.9 \\
Density (g/cm^3) & 1.0038 & 1.0093 & 1.0163 & 1.0774 & 1.3046 \\
Osmotic Coefficlent & 0.8359 & 0.7702 & 0.7734 & 0.7067 & 0.7604 \\
Activity of Water & 0.9996 & 0.9985 & 0.9975 & 0.9798 & 0.8917 \\
Temperature ( $\left.{ }^{\circ} \mathrm{C}\right)$ & 25 & 25 & 25 & &
\end{tabular}

\section{Concentrations of lons (molal)}

\begin{tabular}{|c|c|c|c|c|c|}
\hline Concentration & 1 & 5 & 10 & 100 & 500 \\
\hline $\mathrm{Na}$ & $8.0286 E .03$ & $4.0164 \mathrm{E} .02$ & $8.0381 E .02$ & $8.1008 E-01$ & $4.2909 E+00$ \\
\hline K & $1.7461 \mathrm{E} .04$ & $8.7351 E-04$ & $1.7482 \mathrm{E} \cdot 03$ & $1.7618 E-02$ & 9.3321 E.02 \\
\hline $\mathrm{Mg}$ & $1.6585 \mathrm{E}-03$ & $8.3070 E .03$ & $1.6625 E-02$ & $1.6746 E-01$ & 8.8531E.01 \\
\hline $\mathrm{Ca}$ & $3.3201 \mathrm{E}-03$ & 1.2251E.02 & $1.2129 \mathrm{E} \cdot 02$ & $1.4788 E-02$ & $1.7833 \mathrm{E}-02$ \\
\hline $\mathrm{B}(\mathrm{OH}) 4$ & 8.2460E.07 & $2.9890 \mathrm{E}-06$ & $6.0210 \mathrm{E} \cdot 06$ & 6.8220E-05 & $6.0128 E-04$ \\
\hline $\mathrm{Cl}$ & $1.2173 E \cdot 03$ & $6.0896 \mathrm{E}-03$ & $1.2187 \mathrm{E} \cdot 02$ & 1.2282E-01 & $6.5058 E-01$ \\
\hline $\mathrm{SO} 4$ & B.6493E.03 & $3.7827 E-02$ & $5.6385 E .02$ & $4.6061 \mathrm{E}-01$ & $2.3792 E+00$ \\
\hline $\mathrm{H}$ & $1.0640 E-08$ & $1.7430 E-08$ & $1.8530 E-08$ & $2.5930 \mathrm{E}-08$ & $2.1780 E-08$ \\
\hline $\mathrm{OH}$ & 1.3700 E-06 & $1.1350 E-06$ & 1.1960E.06 & 1.6860E-06 & $1.8740 E-06$ \\
\hline $\mathrm{HCO} 3$ & 6.6691E.04 & 5.2941E-04 & $5.6488 E-04$ & $8.2470 E-04$ & $1.1774 \mathrm{E}-03$ \\
\hline $\mathrm{CO} 3$ & $5.8810 \mathrm{E}-06$ & 5.0690E-06 & 6.2970E-06 & $2.7350 E-05$ & $1.0523 E-04$ \\
\hline $\mathrm{H} 2 \mathrm{CO} 3$ & 1.1720 E.05 & 1.1500 E.05 & $1.1330 E \cdot 05$ & 8.3980E-06 & 2.0100E-06 \\
\hline
\end{tabular}

\section{Amounts of Compounds (mol/kg) or (mol)}

\section{Concentration Factor} 1

$$
5
$$

10

100 500

$\mathrm{MgB}(\mathrm{OH}) 4$ complex
$\mathrm{MgCO} 3$ complex
$\mathrm{MgOH}$ complex
$\mathrm{CaB}(\mathrm{OH}) 4$ complex
$\mathrm{CaCO} 3$ complex
Anhydrite [ $\mathrm{CaSO} 4$ ]
Calcite [ $\mathrm{CaCO} 3$ ]
Glauberite [ $\mathrm{Na} 2 \mathrm{Ca}(\mathrm{SO} 4) 2$
Gypsum [ $\mathrm{CaSO} 4.2 \mathrm{H} 2 \mathrm{O}$ ]
B(OH)3 complex
$\mathrm{HSO} 4$ complex

$\begin{array}{ll}1.4830 E-08 & 1.5430 E \cdot 07 \\ 3.8870 E-06 & 9.7560 E-06 \\ 1.5090 E-07 & 3.6090 E \cdot 07 \\ & \\ 4.8100 E-08 & 3.4280 E-07 \\ 1.2400 E-05 & 2.2110 E-05 \\ 8.9854 E-04 & 3.4521 E-03 \\ & \\ & 5.4410 E-03 \\ 1.2680 E \cdot 05 & 6.4400 E-05 \\ 3.8960 E-09 & 1.5530 E-08\end{array}$

5.0700E-07

1.9720 E.05

6.3030E.07

5.4890E-07

$2.1930 E .05$

2.1230E-05

$2.6754 \mathrm{E} \cdot 04$

4.0980E-06

$5.3831 E .04$

$2.6876 \mathrm{E} .03$

3.4130E-05

2.3090E-06

3.2820E.05

9.6140E-06

$6.3810 E \cdot 05$

3.8960E.09

$1.5530 E \cdot 08$
4.1209E-01

$2.2434 E+00$

$1.2878 E .04$

1.2774E-03

5.8240E-08

6.1029E-03

6.8300 E. 08 


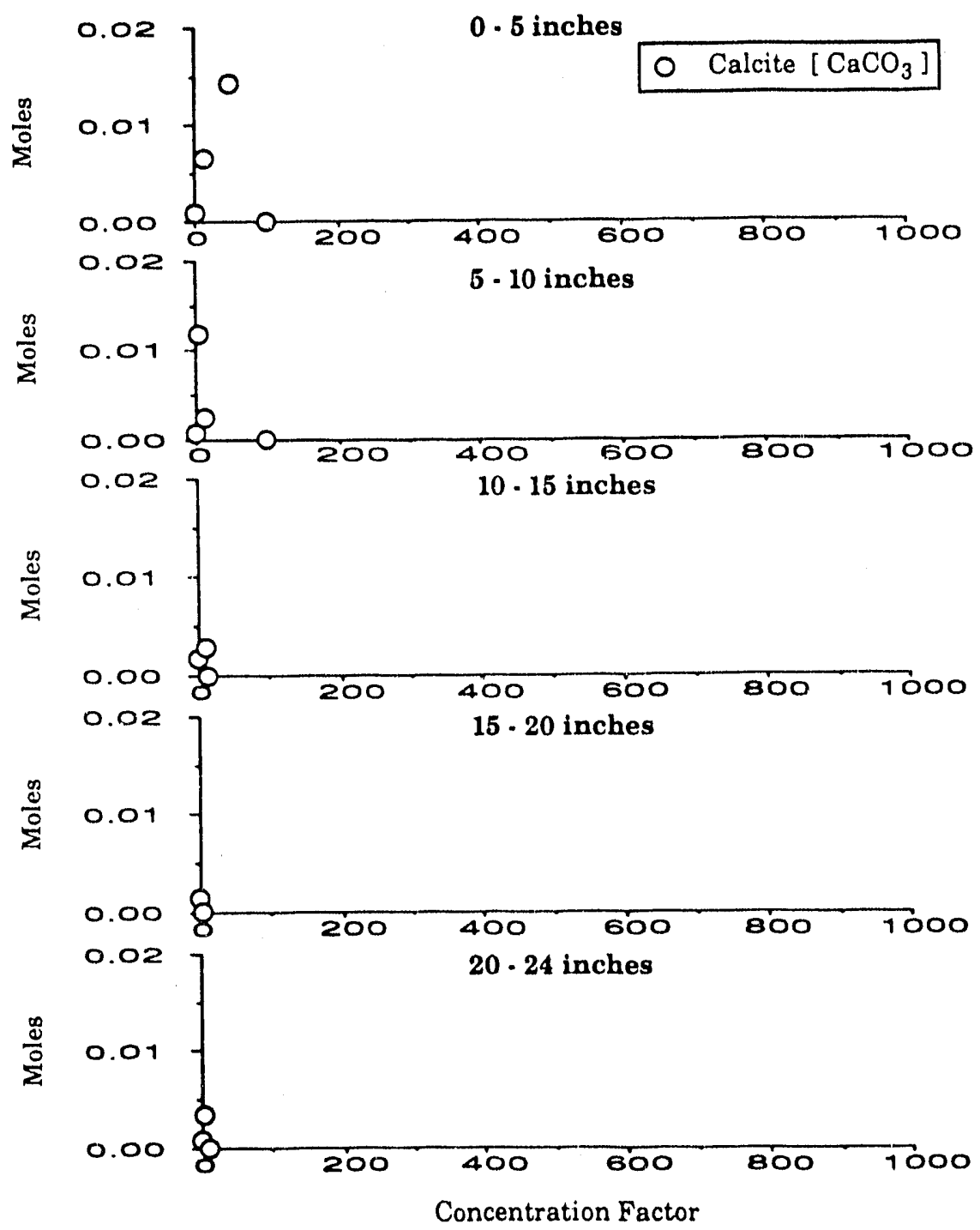

Figure 4.31. Eastern profile predicted calcite from soil extracts at five depths (predicted to form from $1 \mathrm{~L}$ of solution). 

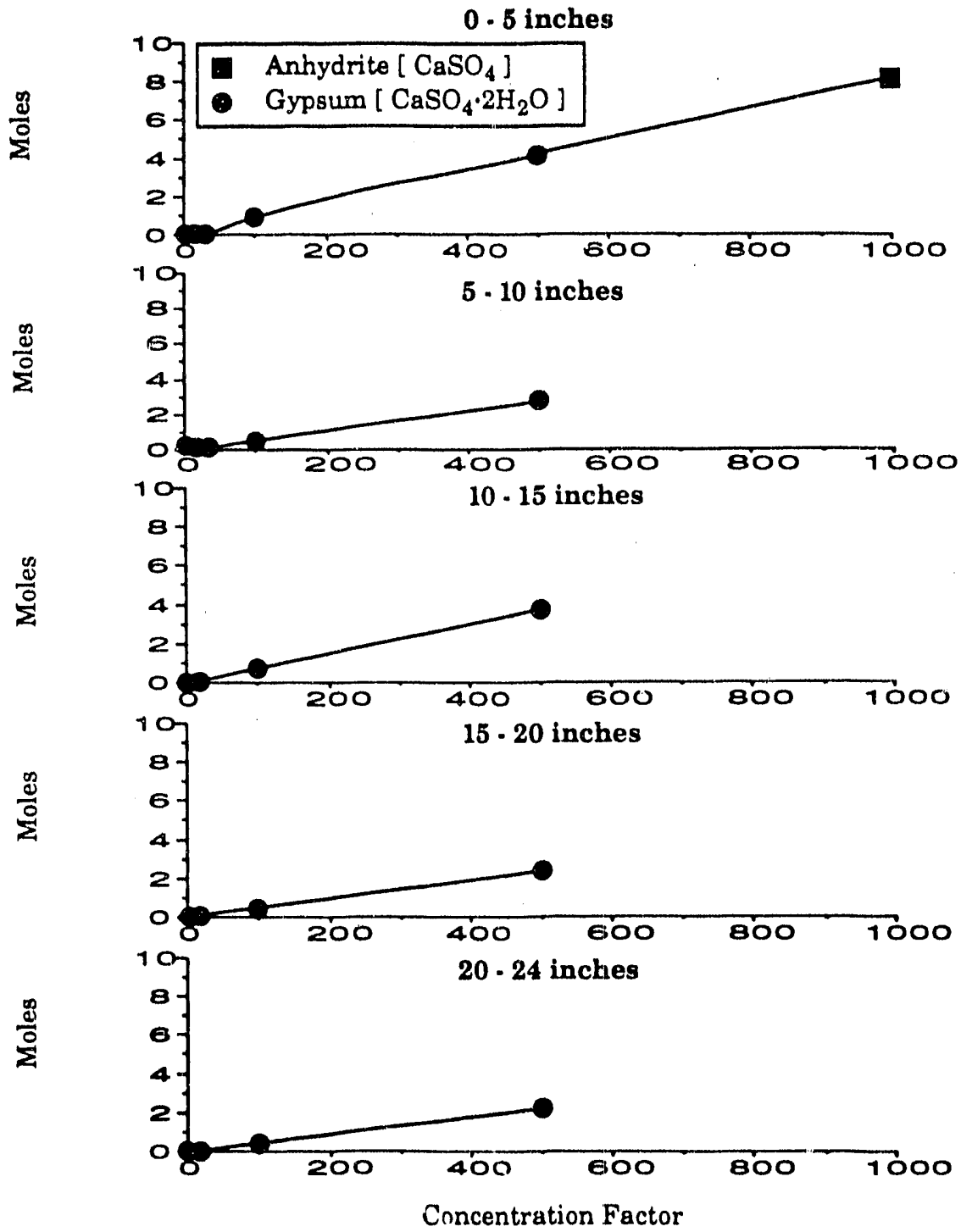

Figure 4.32. Eastern profile predicted gypsum from soil extracts at five depths (predicted to form from $1 \mathrm{~L}$ of solution). 


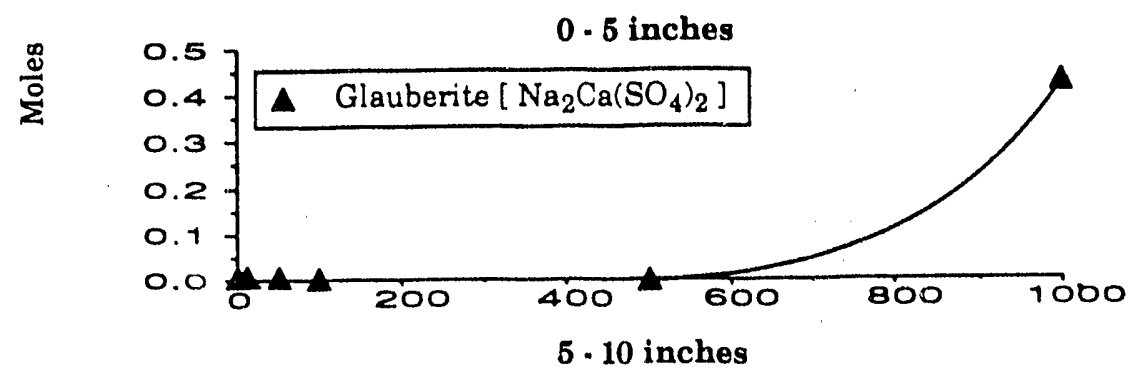

$\frac{0}{2}$

None Predicted

$10 \cdot 15$ inches

None Predicted

$\frac{0}{0}$

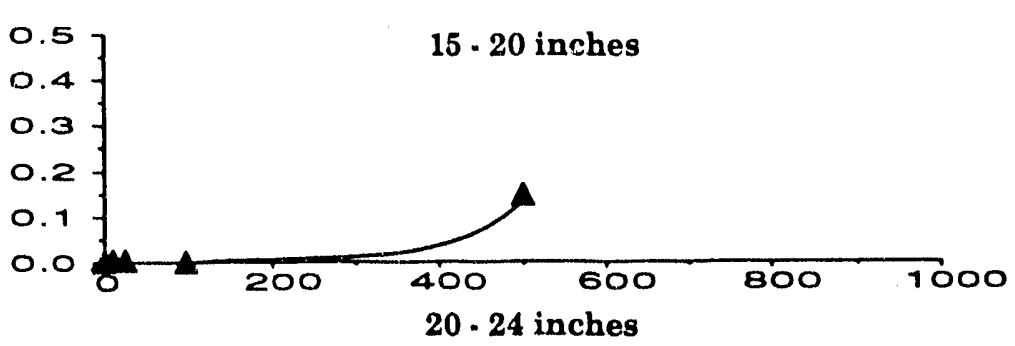

$\frac{0}{2}$

None Predicted

Concentration Factor

Figure 4.33. Eastern profile predicted glauberite from soil extracts at five depths (predicted to form from $1 \mathrm{~L}$ of solution). 
a distribution without leaching, with most of the calcite occurring near the top of the profile.

Gypsum is the dominant mineral predicted to form in the eastern profile, as can be seen in Figure 4.32. At all depths and at a concentration factor of 500, approximately 3 to 4 moles of gypsum are predicted to precipitate. The amount of gypsum predicted slightly decreases with depth. However, the similarity in the amounts of gypsum predicted to form reinforces the fact that this profile has not been leached.

At a concentration factor of 1,000 , a phase change from gypsum to anhydrite occurs in the surface depth because the activity of water drops below 0.78 . The unhydrated form of calcium sulfate is more stable than the hydrated form when the activity of water is lowered.

Glauberite is predicted to form only at the highest concentration factors used. Figure 4.33 presents amounts of glauberite predicted to precipitate. Glauberite forms at 1000 -fold concentration in the 0 to 5 inch soil extract. No glauberite is predicted to form in the 51010,10 to 15 , or 20 to 24 inch depths. A small amount of glauberite is predicted to form in the 15 to 20 inch depth, at a concentration factor of 500. The precipitation of glauberite in the 15 to 20 inch depth and the absence of precipitation in the other depths at a concentration factor of 100 are due to slight differences in the speciation of the initial soil extract. The differences may be due to spatial variability.

At elevated concentration factors the formation of glauberite reduces the further precipitation of gypsum, as was seen in the center profile. However, both the scale in Figure 4.33 and the relatively small amount of glauberite mask the deviation from linearity shown in Figure 4.30.

Neither thenardite nor mirabilite $\left[\mathrm{Na}_{2} \mathrm{SO}_{4} \cdot 10 \mathrm{H}_{2} \mathrm{O}\right]$ is predicted to form, yet thenardite is a major evaporite identified by X-ray diffraction of tield samples. C SALT may predict the formation of these minerals at higher concentration factors. A 500-fold concentration of a solution should provide a good estimation of the extent of soil-water evapoconcentration. On the other hand, the initial concentrations of the soil extract are relatively dilute. Another possible explanation is that there are kinetic limitations to the formation of glauberite. If glauberite is slow in forming, the sodium concentrations would be elevated over those predicted. Sodium-sulfate 
solid phases would then have the opportunity to form at these elevated sodium concentrations.

\subsubsection{Particle Size Analysis and Clay Mineralogy}

A particle size analysis of the top and bottom samples from each auger hole in Pond 7 was conducted, following procedures for mineral analysis given by Jackson (1969). All samples were sandy clay loams with an average clay content of $29.4 \%$ and an average sand content of $58.7 \%$.

Each of the four samples was also treated and X-rayed to identify the major aluminosilicates minirals in the clay fraction, (Jackson, 1969). The major aluminosilicate mineral in all samples was smectite. The samples also contained varying amounts of vermiculite, mica, and kăolinite.

\subsubsection{Formation of Salt Crusts on Clods}

Ten clods, each approximately $5 \times 5 \times 5 \mathrm{~cm}$, were collected from the tilled plot in Pond 7. They showed visible accumulation of sal's within the macropores. The clods were coated with paraffir on all sides, except for the top and bottom, and placed in separate petri dishes. Distilled water was then added to the petri dishes to provide a medium for salt redistribution. Upward movement of water, driven by evaporation from the top surface of the clods, resulted in the redistribution of salts in the clods. Over a period of two to three weeks, salt crusts formed on the top surface of the clods.

An X-ray analysis of the salt crusts identified g.psum, thenardite, and trona $\left[\mathrm{Na}_{2} \mathrm{CO}_{3} \cdot \mathrm{NaHCO}_{3} \cdot 2 \mathrm{H} 2 \mathrm{O}\right]$ as the major evaporite minerals. The presence of these minerals indicates that the dominant solutes within the clod water are $\mathrm{Na}^{+}, \mathrm{Ca}^{2+}, \mathrm{SO}_{4}^{2-}, \mathrm{HCO}_{3}^{-}$, and $\mathrm{CO}_{3}^{2-}$. Given the chemical compositi $n$ of the ground water at Kesterson Reservoir, minerals composed from these solutes are expected.

\subsubsection{Identification of Field Evaporite Samples}

Two evaporite samples were collected from Kesterson Reservoir. An "X-ray analysis of these samples indicates that thenardite is the dominant mineral in bnth samples. Gypsum, anhy- 
drite, nahcolite $\left[\mathrm{NaHCO}_{3}\right]$, nesquehonite and halite $[\mathrm{NaCl}]$ may also be present in trace quantities. Nesquehonite is rarely identified in soil samples. Its identification may be the result of interference from the other minerals present in the sample.

Figure 4.34 shows a typical X-ray diffractogram of a field evaporite sample. This diffractogram identifies two evaporites: thenardite and gypsum. Also, many diffractogram peaks are not identified. These peaks are probably from silicate minerals that are inseparably incorporated in the field samples, or from trace amounts of other evaporites.

The identification of these minerals in natural surface saits is consistent with those identified in artificially formed crusts on clods. In both cases, the dominant ions making up the minerals are $\mathrm{Na}^{+}, \mathrm{Ca}^{2+}, \mathrm{SO}_{4}^{2-}, \mathrm{HCO}_{3}^{-}$, and $\mathrm{CO}_{3}^{2-}$.

\subsubsection{Leaching Studies}

Soil columns were packed with $50 \mathrm{~g}$ of $<2 \mathrm{~mm}$ soil from surface horizons ( 0 to 5 inches) in Pond 7 (center and east auger holes correspond to leached and unleached sites, respectively). The soil columns were leached with distilled water, and $50 \mathrm{~mL}$ of effluent were collected every 24 hours. Table 4.25 contains electrical conductivity (EC), major cations and anions, B, Se and $\mathrm{pH}$ in the effuents.

In Figure 4.35, EC is plotted as a function of time. An initial flushing out of soluble salts is seen, followed by relatively constant EC for about five days. Effluents from the center column (leached site) show that EC dropped rapidly to about $0.16 \mathrm{dS} \mathrm{m}^{-1}$. In contrast, effluents from the eastem column (unleached site) had a constant EC of about $2 \mathrm{dS} \mathrm{m}^{-1}$ between days 3 through 6 . This constant EC is attributed to the dissolution of gypsum during leaching. The EC decreased on day 7 , indicating that gypsum was being depleted in the soil column.

Figure 4.36 presents $\mathrm{pH}$ measurements in the efftuents. The $\mathrm{pH}$ from the center, leached soil was lower than the eastem, unleached soil. The $\mathrm{pH}$ in the effluents from the latter soil column increased from 7.4 to about 7.7 and remained at that $\mathrm{pH}$ level.

Tables $4.26 \mathrm{a}$ and $4.26 \mathrm{~b}$ and kFigures $4.37 \mathrm{a}$ and $4.37 \mathrm{~b}$ contain plots of major soiute species 


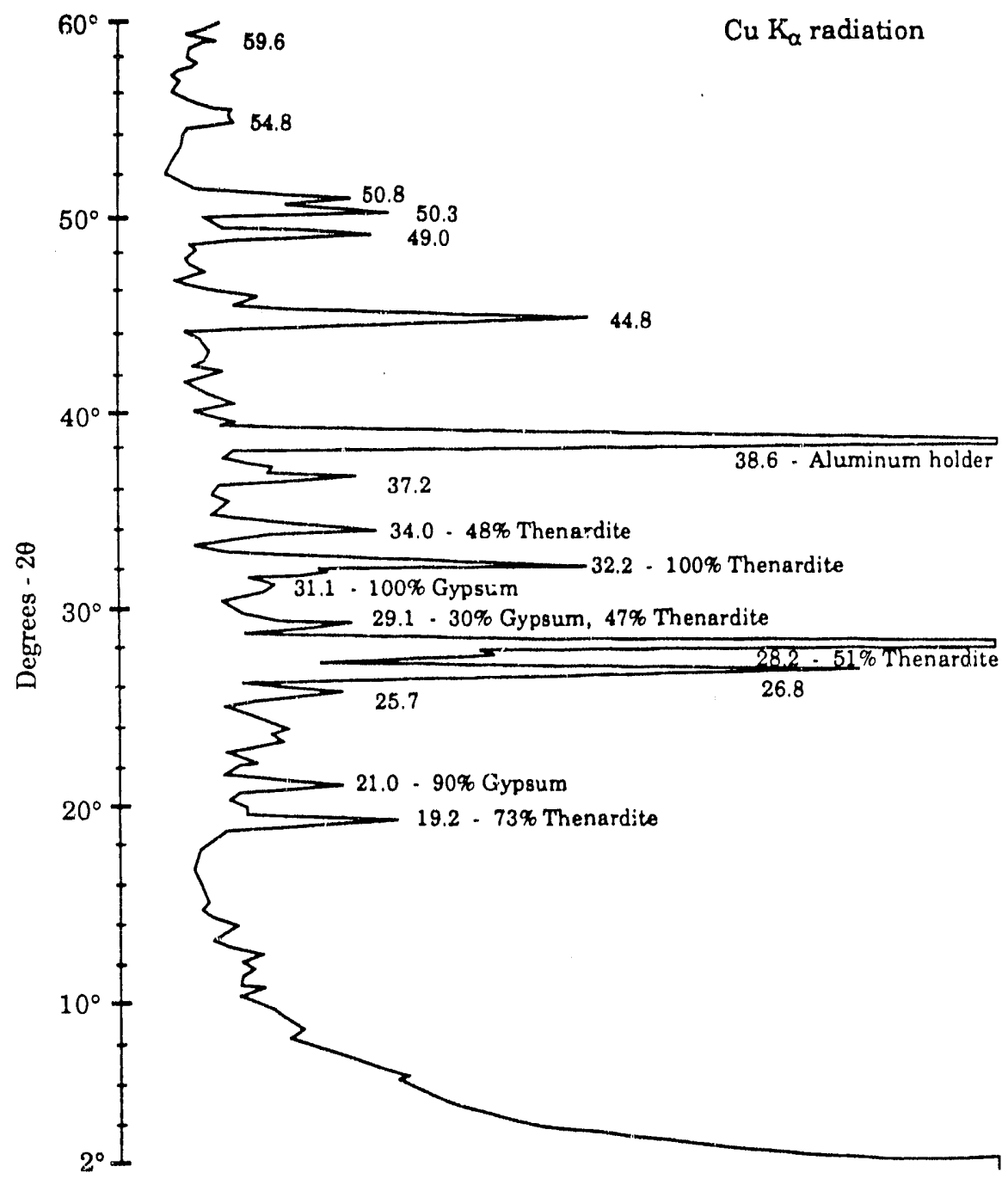

Figure 4.34. Typical diffractogram of field evaporite. 
Table 4.25. Analyses of effuents from soil columns packed with 0 to 5 inch depths from Pond 7 soils

\begin{tabular}{|c|c|c|c|c|c|c|c|c|c|c|}
\hline Day & $\begin{array}{c}\mathrm{EC} \\
\mathrm{dS} \mathrm{m}^{-1}\end{array}$ & $\mathrm{pH}$ & $\mathrm{Cl}$ & $\mathrm{SO}_{4}$ & $\begin{array}{l}\mathrm{Ca} \\
\mathrm{mg} \mathrm{L}\end{array}$ & ${ }_{-1}^{M g}$ & $\mathrm{Na}$ & $\mathrm{K}$ & B & $\begin{array}{c}\mathrm{Se} \\
\mu \mathrm{g} \mathrm{L}^{-1}\end{array}$ \\
\hline \multicolumn{11}{|c|}{ Center, leached site } \\
\hline 1 & 4.39 & 7.0 & 411 & 12926 & 526 & 183 & 459 & 23.6 & 7.23 & 2.19 \\
\hline 2 & 2.67 & 7.1 & 2 & 3317 & 541 & 119 & 28 & 13.5 & 1.42 & 0.76 \\
\hline 3 & 2.34 & 7.1 & 6 & 2838 & 529 & 58 & 19 & 15.4 & 0.82 & 1.03 \\
\hline 4 & 2.15 & 7.0 & 7 & 2519 & 516 & 2 & 14 & 11.7 & 0.57 & 0.58 \\
\hline 5 & 2.09 & 7.1 & 5 & 2838 & 521 & 7 & 5 & 9.6 & 0.43 & 0.68 \\
\hline 6 & 1.75 & 7.2 & 2 & 1835 & 422 & 1 & 3 & 7.4 & 0.50 & 0.54 \\
\hline 7 & 0.96 & 7.2 & 0.1 & 426 & 416 & 1 & 2 & 9.3 & 0.11 & 0.63 \\
\hline \multicolumn{11}{|c|}{ East unleached site } \\
\hline 1 & 6.22 & 7.4 & 100 & 3247 & 435 & 206 & 1070 & 17.8 & 6.47 & 1.37 \\
\hline 2 & 2.40 & 7.5 & 108 & 1511 & 479 & 120 & 28 & 10.8 & 1.20 & 0.65 \\
\hline 3 & 0.72 & 7.6 & 0.5 & 294 & 133 & 14 & 7 & 3.2 & 0.50 & 0.75 \\
\hline 4 & 0.22 & 7.8 & 0.4 & 35 & 35 & 3 & 6 & 2.2 & 0.31 & 0.62 \\
\hline 5 & 0.16 & 7.7 & 0.4 & 10 & 23 & 2 & 4 & 1.9 & 0.22 & 0.65 \\
\hline 6 & 0.14 & 7.7 & 0.5 & 7 & 22 & 2 & 4 & 1.1 & 0.17 & 0.56 \\
\hline 7 & 0.13 & 7.6 & 0.6 & 3 & 18 & 2 & 5 & 0.0 & 0.29 & 0.87 \\
\hline
\end{tabular}




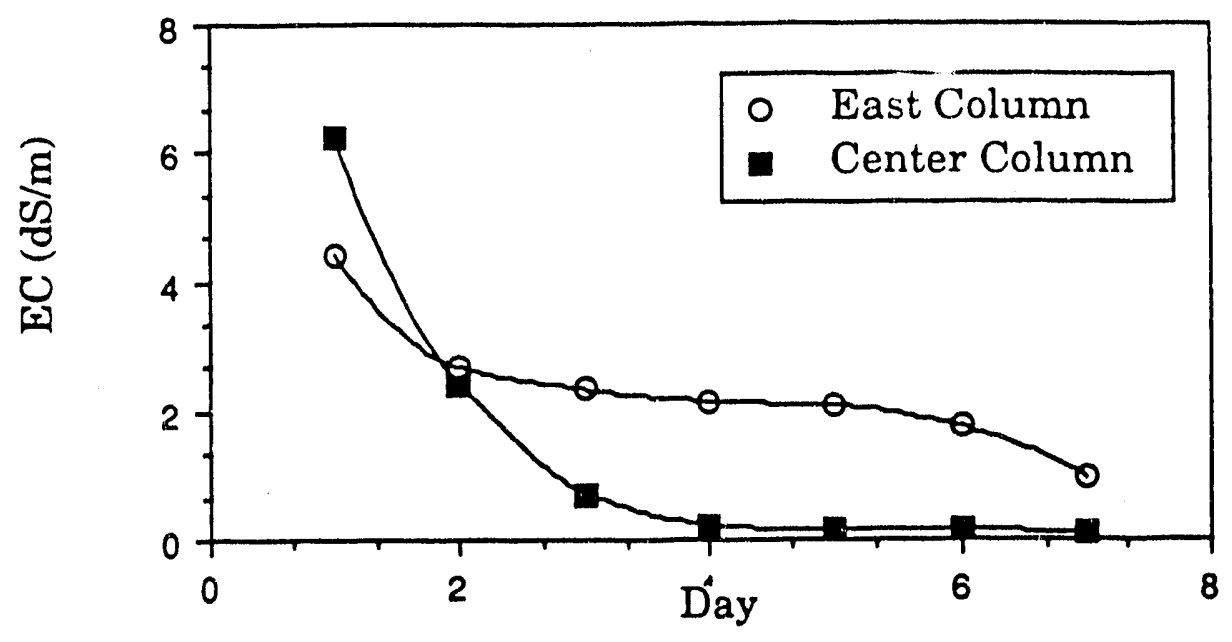

Figure 4.35. Leaching studies - EC vs. time.

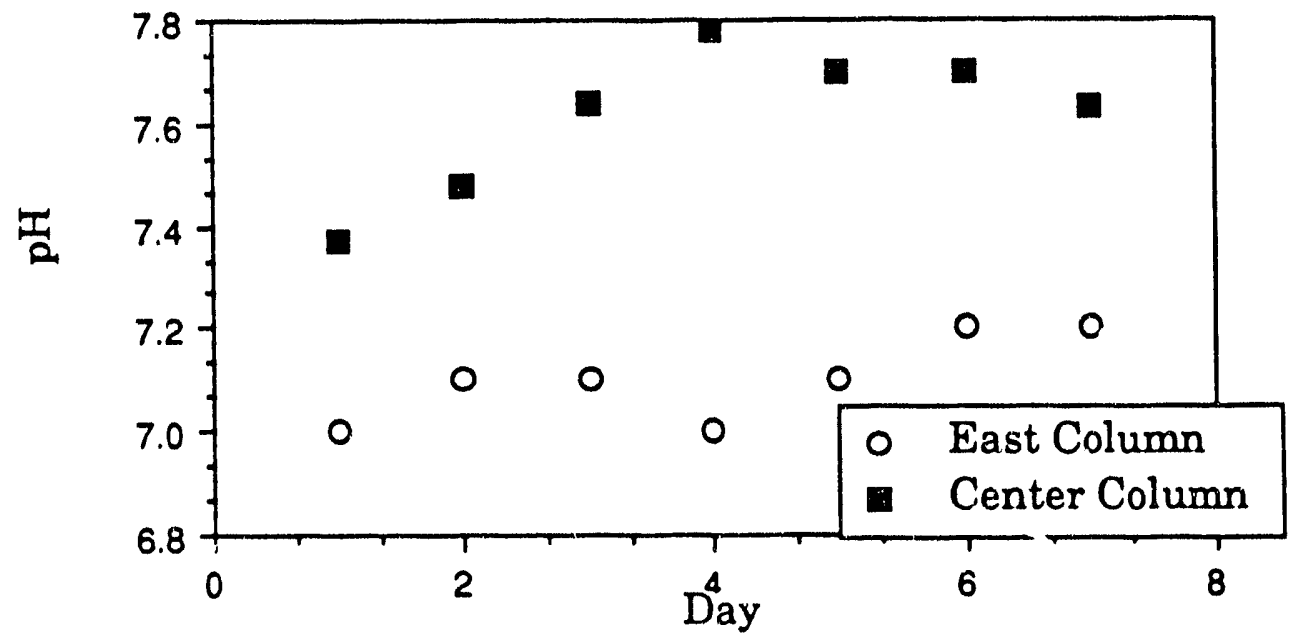

Figure 4.36. Leaching studies - pH vs. time. 
in effluents vs. time with concentrations expressed in $\mathrm{mmol}_{(\mathrm{c}) / 1}$ or $\mathrm{meq}^{-1}$. For the column from the center, leached soil (Figure 4.37a) the concentrations of all constituents decreased after the second day to less than $2 \mathrm{mmol} / \mathrm{l}$. The dominant ions in the leachate were $\mathrm{Na}^{+}$and $\mathrm{SO}_{4}^{2-}$, perhaps reflecting the presence of small quantities of thenardite. After the first leachate, $\mathrm{Na}^{+}$ concentration dropped off rapidly while $\mathrm{SO}_{4}^{2-}$ and $\mathrm{Ca}^{2+}$ remained at elevated concentrations, most probably from the dissolution of gypsum.

In contrast, Figure $4.37 \mathrm{~b}$ shows a different leaching pattern from the column prepared from the eastem, unleached soil. Corresponding to the constant EC in the effluents, $\mathrm{SO}_{4}^{2-}$ and $\mathrm{Ca}^{2+}$ concentrations remained at elevated levels until day 7 when gypsum began to be depleted.

Figures $4.38 \mathrm{a}$ and $4.38 \mathrm{~b}$ show leaching patterns of $\mathrm{B}$ in $\mathrm{mg} /$, Se in $\mu \mathrm{g} /$, and $\mathrm{Na}^{+}$and $\mathrm{Ca}^{2+}$ in $\mathrm{mmol}$ (c) $/ 1$. Boron is plotted in $\mathrm{mg} / \mathrm{l}$ multiplied by 100 and $\mathrm{Se}$ as $\mu \mathrm{g} / \mathrm{l}$ multiplied by 50 . Although definite comparisons among these constituents cannot be made without additional data, some intersting inferences are possible. For instance, the leaching pattern of B follows closely to that of the rapidly decreasing concentrations of $\mathrm{Na}^{+}$in both columns. X-ray analysis revealed that most of the $\mathrm{Na}^{+}$is in the form of thenardite. Boron seems to be related to the dissolution of thenardite. In contrast, Se in the effluents after the initial flush from both columns was relatively constant in concentration. Selenium does not appear to be associated with either thenardite nor gypsum to a great degree. Recall that the unleached soil contained gypsum. The selenium leached apparently is from the adsorbed phase. These apparent relationships require further research. 
Table 4.26a. Ion concentrations from leaching studies, center column.

\begin{tabular}{|c|c|c|c|c|c|c|c|}
\hline Day & Cl & SO4 & $\mathbf{C a}$ & $\mathbf{M g}$ & $\mathbf{N a}$ & $\mathbf{K}$ & $\mathbf{B}$ \\
\hline 1 & 11.59 & 80.69 & 26.21 & 15.09 & 19.95 & 0.6 & 0.68 \\
\hline 2 & 0.05 & 73.02 & 26.97 & 9.82 & 1.23 & 0.34 & 0.13 \\
\hline 3 & 0.17 & 61.62 & 26.39 & 4.8 & 0.83 & 0.39 & 0.08 \\
\hline 4 & 0.2 & 54.7 & 25.74 & 1.84 & 0.6 & 0.3 & 0.05 \\
\hline 5 & 0.13 & 61.64 & 25.97 & 0.55 & 0.22 & 0.25 & 0.04 \\
\hline 6 & 0.05 & 39.86 & 21.04 & 0.12 & 0.13 & 0.19 & 0.05 \\
\hline 7 & 0 & 9.26 & 20.72 & 0.12 & 0.08 & 0.24 & 0.01 \\
\hline
\end{tabular}

Table 4.26b. Ion concentrations from leaching studies, east column.

$\begin{array}{ccccccccc}\text { Day } & \text { Cl } & \text { SO4 } & \text { Ca } & \text { Mg } & \text { Na } & \text { K } & \text { B } \\ & 2.81 & 70.51 & 21.71 & 16.98 & 46.54 & 0.46 & 0.61 \\ 2 & 3.06 & 32.81 & 23.91 & 9.86 & 1.22 & 0.28 & 0.11 \\ 3 & 0.01 & 6.4 & 6.66 & 1.16 & 0.29 & 0.08 & 0.05 \\ 4 & 0.01 & 0.76 & 1.76 & 0.22 & 0.26 & 0.06 & 0.03 \\ 5 & 0.01 & 0.21 & 1.16 & 0.15 & 0.18 & 0.05 & 0.02 \\ 6 & 0.02 & 0.16 & 1.07 & 0.14 & 0.18 & 0.03 & 0.02 \\ 7 & 0.02 & 0.06 & 0.89 & 0.13 & 0.21 & 0 & 0.03\end{array}$




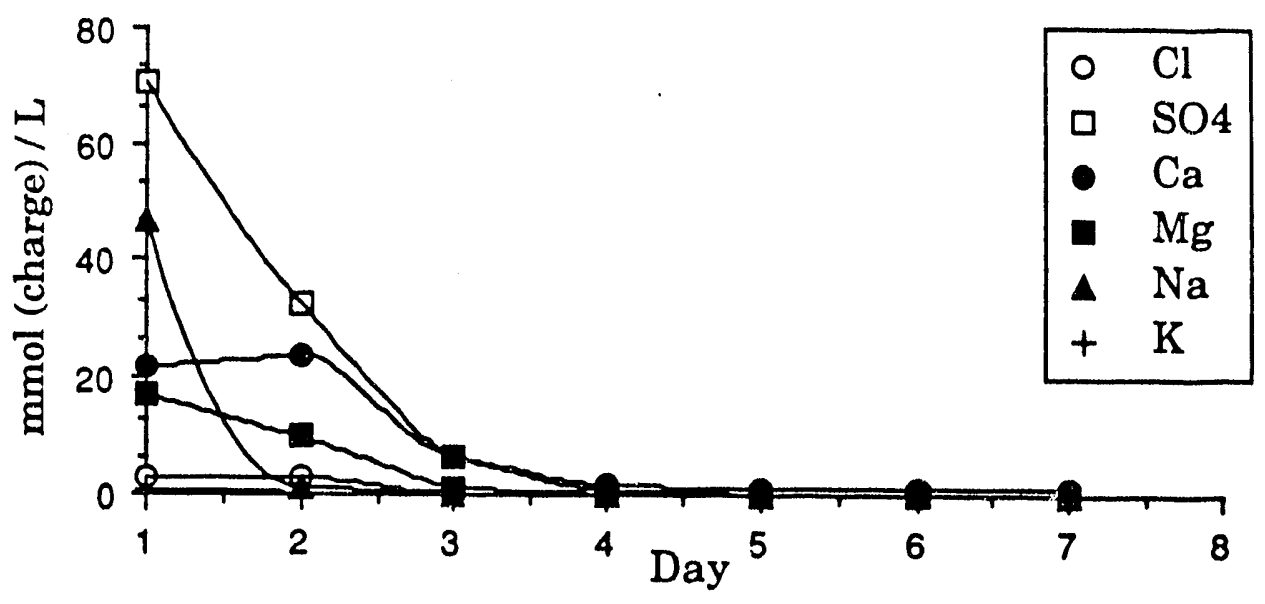

Figure 4.37a. Leaching study - center column ion concentrations vs. time.

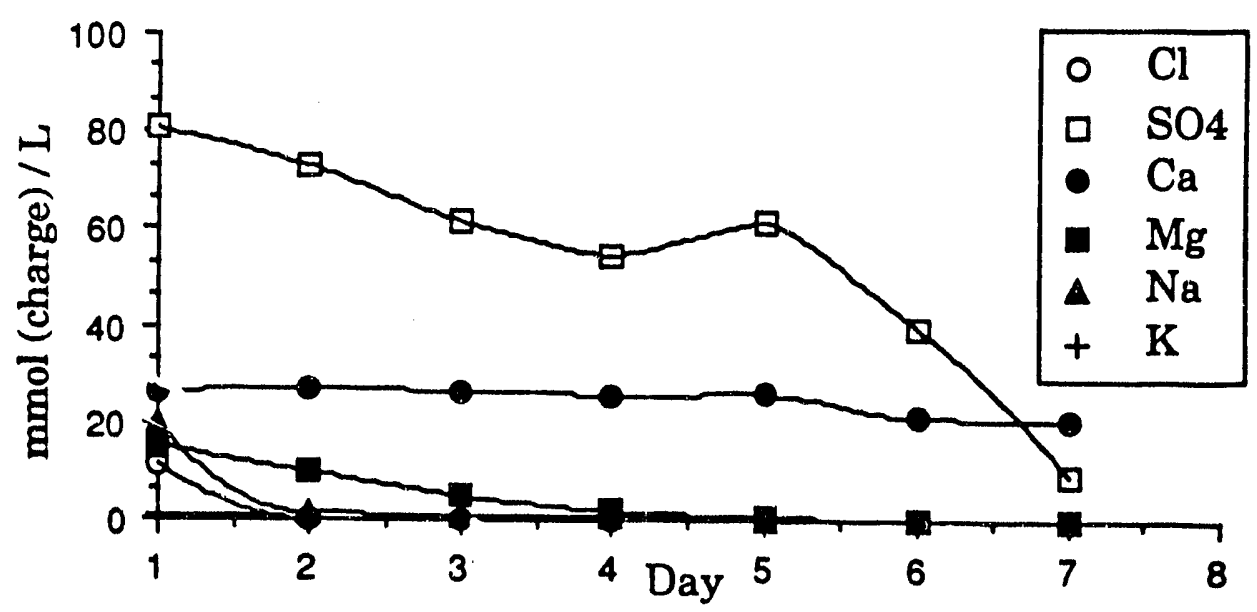

Figure 4.37b. Leaching study - eastem column ion concentrations vs. time. 


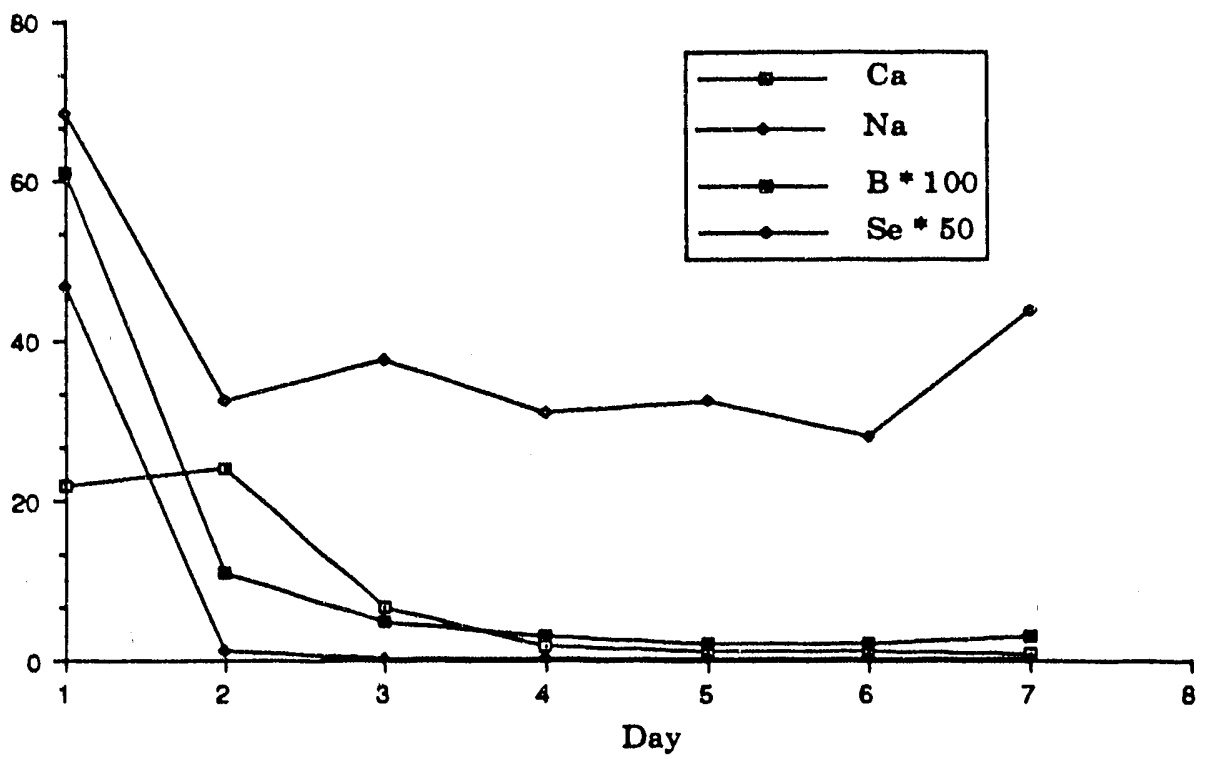

Figure 4.38a. Leaching studies - center column concentrations of $\mathrm{Ca}$ and $\mathrm{Na}$ in $\mathrm{mmol}_{(\mathrm{c})} /$, $\mathrm{B}$ in $\mathrm{mg} / \mathrm{l}$ and $\mathrm{Se}$ in $\mu \mathrm{g} / \mathrm{l}$.

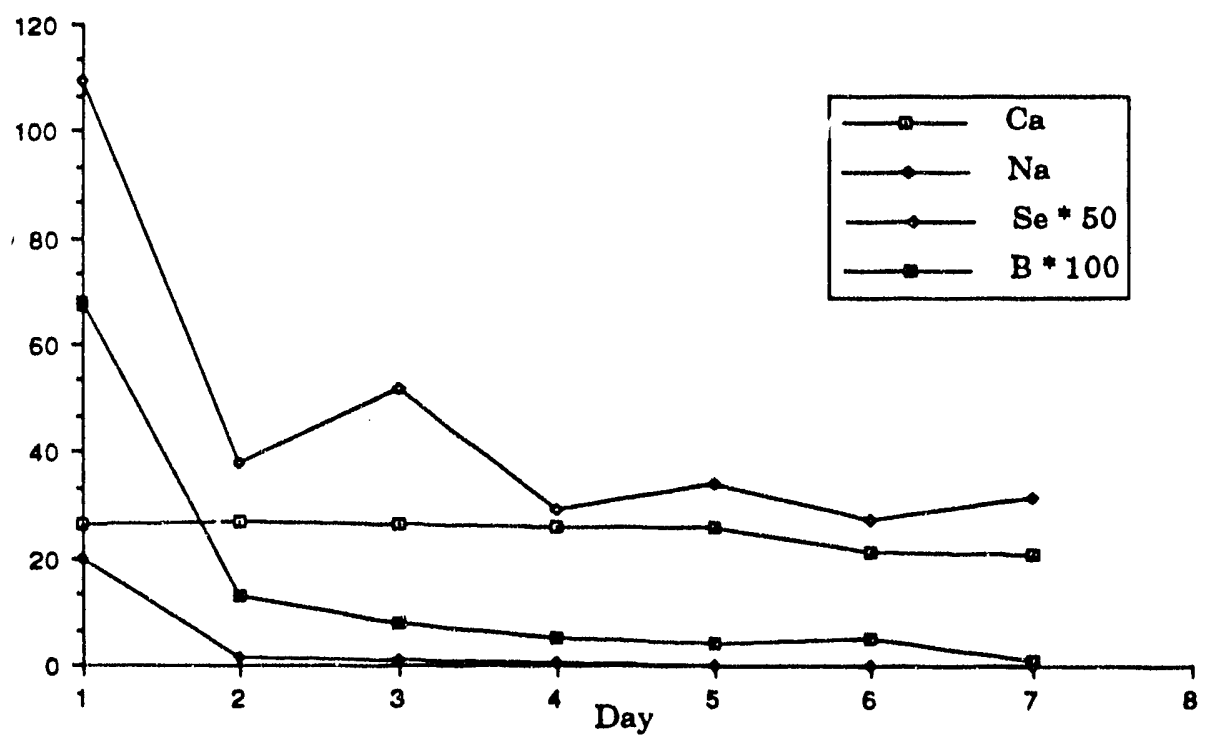

Figure $4.38 \mathrm{~b}$. Leaching studies - eastern column concentrations of $\mathrm{Ca}$ and $\mathrm{Na}$ in $\mathrm{mmol}_{(\mathrm{c})} / 1$, $\mathrm{B}$ in $\mathrm{mg} /$ and $\mathrm{Se}$ in $\mu \mathrm{g} /$. 


\title{
4.5. THE EFFECT OF IRRIGATION STRATEGY ON DISSIPATION OF SELENIUM
}

\author{
D. A. Goldhamer, \\ 9240 South Riverbend Ave. \\ Keamey Agricultural Center \\ Parlier, Califomia 93648 \\ M. H. Alemi, \\ Land and Water Resources Dept. \\ University of Califormia, Davis
}

\section{5.i. Cbjectives}

The effects of surface and subsurface irrigation and irrigation frequency on the vertical movement and volatilization of selenium in Kesterson Reservoir sediments have been evaluated under greenhouse conditions using large columns planted with native vegetation.

\subsubsection{Experimental Plan}

Sediments from Pond 7 of Kesterson Reservoir were collected from 0-15, 15-30, 30-60, and 60-100 cm depth intervals and brought to the greenhouse (UC Davis). Subsequently sediments were air-dried in the greenhouse over a three-week period. Sediments from each depth increment were sieved and thoroughly mixed to get a homogeneous material. Sediment columns approximately $1 \mathrm{~m}$ in length and $15 \mathrm{~cm}$ (in diameter) were packed and placed in a controlled temperature chamber inside greenhouse. The top of the columns are exposed to the greenhouse conditions at temperatures similar to dry season at the Kesterson Reservoir. Two sets of columns were prepared. In one case sediments were packed in the same order as collected from the reservoir. These set of columns are referred to as non-filled sediments. In another case, $30 \mathrm{~cm}$ of fill material which has been used to fill the low areas of Kesterson ponds was placed on the top of the upper $65 \mathrm{~cm}$ pond sediments $(0-15,16-30$, and $5 \mathrm{~cm}$ material from the $61-100 \mathrm{~cm}$ layer $)$. This was done to simulate the filled areas of the ponds and are referred to as filled sediments. A $3 \mathrm{~cm}$ sand layer was placed at the bottom of all surface irrigated columns to facilitate the drainage 
from the bottom of the profile. Figure 4.39 shows the layering of the columns for both filied and non-filled sediments. Initially aqueduct water was applied from the bottom of the columns at zero pressure to wet the columns by capillary-driven infiltration. After wetting was complete monitoring instruments were installed and soil samples were taken for water extracted (1:5) and acid-extractable (perchloric acid) Se analysis. Native plants (saltgrass) were transplanted to these columns. Irrigation started by applying aqueduct water. Three irrigation frequencies (weekly- W, biweekly- BW, and triweekly- TW) were used. To simulate surface irrigation, water is applied at a rate less than or equal to the rate of evapotranspiration. An automatic drip irrigation system was installed to apply irrigation water. The actual evapotranspiration was measured in a separate column by weighing the column weekly. An estimate of actual evapotranspiration was obtained from the average of the evapotranspiration obtained from weighing technique and the amount of water used in subirrigation columns (discussed later). Thermocouples, redox potential electrodes, and tensiometers were installed (see Figure 4.39) for monitoring soil temperature, redox potential, and soil water pressure head, respectively. Porous cups were installed at various depths (Figure 4.39) for soil water sampling.

To determine the soil zone from which selenium volatilization might occur, soil air gaseous selenium was sampled at various depths periodically for volatile selenium analysis. A perforated stainless steel tube ("gas probe") was installed at various depths (Figure 4.39 and 4.40) to collect gaseous selenium samples from soil air. After purging the probe with nitrogen gas, a charcoal cartridge containirg $0.4 \mathrm{~g}$ of charcoal filter was placed into the probe and remained there for a period of 24 hrs or more. A hydrogen peroxide-sodium hydroxide solution was used for extracting selerinm from the charcoal. The solutions were heated at $90^{\circ} \mathrm{C}$ and sent to the $1 a b$ for analysis. Selenium gas sampling was performed prior to and after irrigation. Volatilization of selenium from the soil surface and plant canopy were measured before and after irrigation by covering the plants and circulating the air inside the chamber through a selenium gas washing assembly (Figure 4.40). A hydrogen peroxide-sodium hydroxide solution was used for gas washing. The solution was heated for about one hour at $90^{\circ} \mathrm{C}$ and sent to the laboratory for selenium 

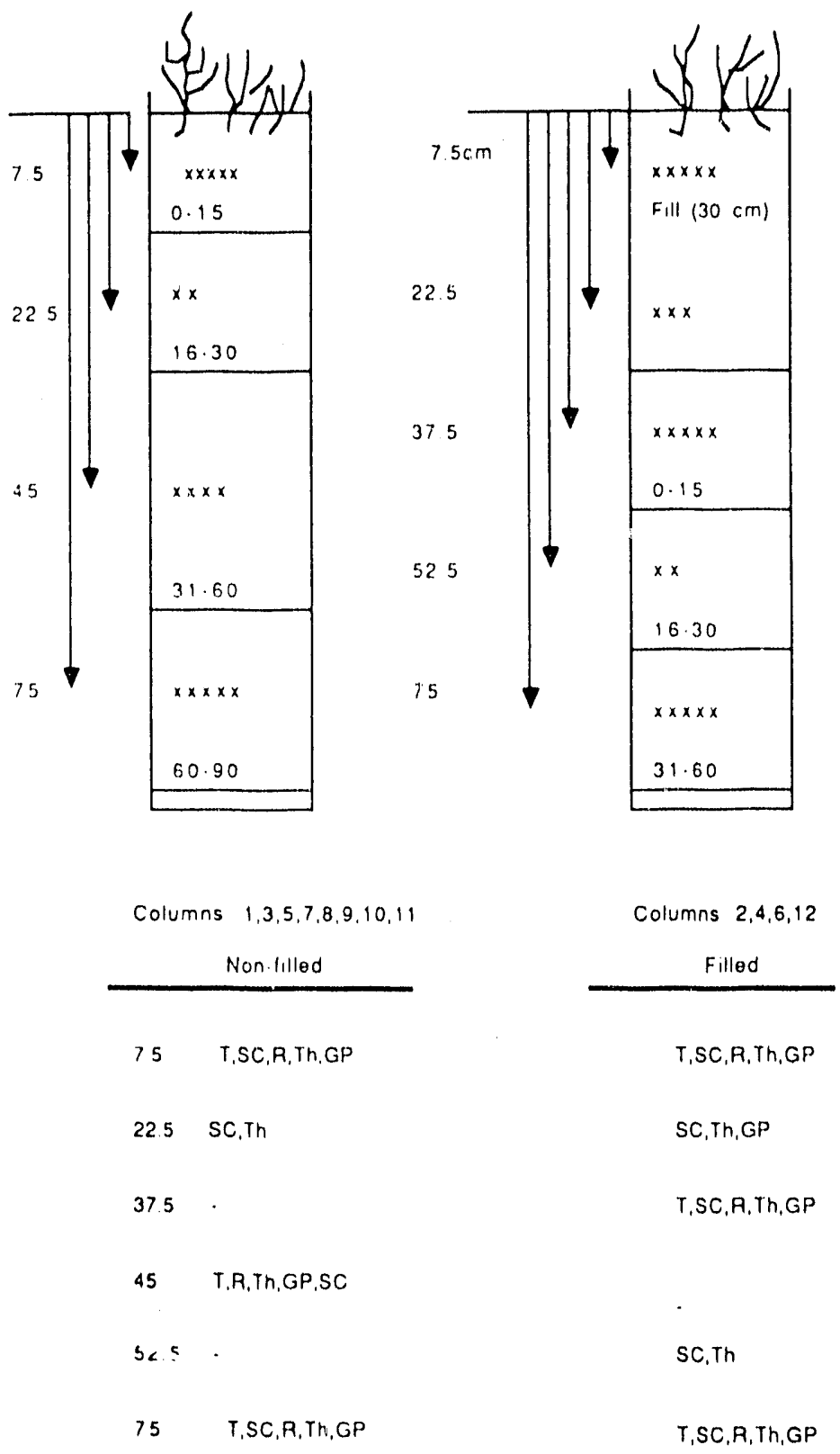

T (Tensiomelei; SC(solution sampler), R( redox electrode). Th(thermocouple), GP(gas probo)

Figure 4.39. Schematic diagram of filled and non-filled sediment columns and instruments. 


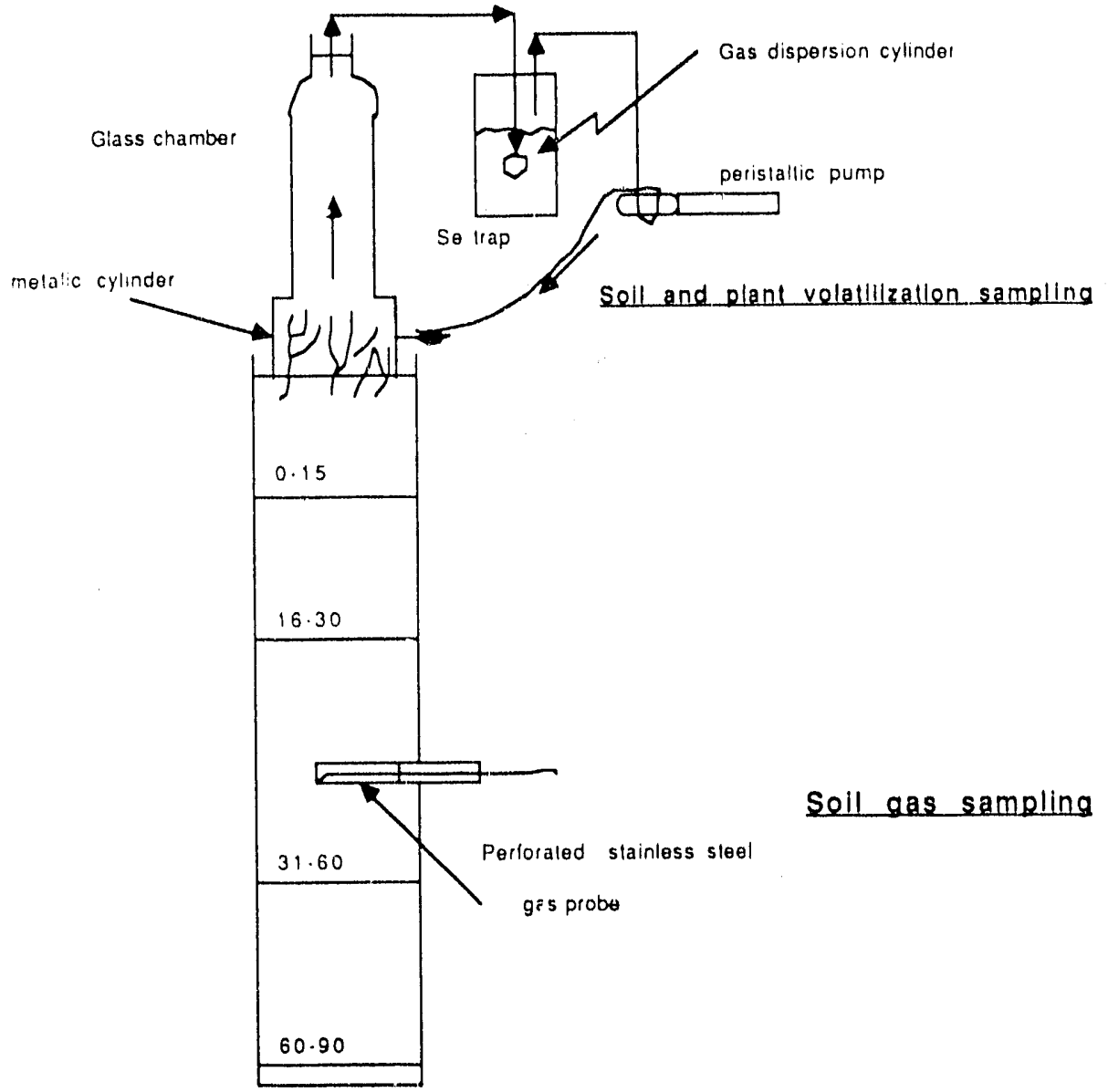

Figure 4.40. Schematic diagram of monitoring equipment for selenium volatilization from the soil surface and within the soil profile. 
analysis. Soil solution samples were collected one day after irrigation from various depths. The soil solution samples were sent to the laboratory for analysis as soon as possible and analyzed for selenite and total selenium. Effuent samples were collected for the duration of the irrigation interval when applicable and were analyzed for acid-extractable selenium.

To simulate subirrigation, water was applied continuously at a suction of approximately 50 $\mathrm{cm}$ from the lower end of another set of columns which had the same diameter as the surface irrigation columns but had a length of $50 \mathrm{~cm}$. A $20 \mathrm{ml}$ porous cup was used to apply the water at 50 $\mathrm{cm}$ suction. The depth of fill material in subirrigation columns was $15 \mathrm{~cm}$. Both bare and vegetated columns were tested. Saltgrass was planted in the columns. The subirrigation columns were monitored for surface volatilization only. The actual evaporation from bare columns and evapotranspiration was measured from the volume of water used in subirrigation. Saltgrass was clipped and nitrogen-phosphorus-potassium fertilizer was applied on 7-1-89.

\subsubsection{Results}

The distribution of selenium in the soil profile before irrigation for the filled and non-filled sediments is shown in Figure 4.41. The distribution of water extractable selenium in the soil before wetting and after wetting (microgram $/ \mathrm{kg}$ ) and selenium concentration in the soil solution (microgram/liter) for triweekly surface irrigated columns after appliu. on of 3.8 (3-9-89) and 26.5 (4-27-89) $\mathrm{cm}$ of irrigation water for both filled and non-filled sediments are shown in Figure 4.42. Selenium concentration increased in the surface layer following the upward wetting process. It was then dissipated by volatilization and leaching process after surface irrigation initiated. The concentration of selenium in soil solution for both filled and non-filled sediments irrigated biweekly after application of 26.5 (4-27-89), 54.0 (6-8-89), and 77.0 (7-19-89) cm of irrigation water are presented in Table 4.27. Selenium concentration in soil solution decreased with time for both filled and non-filled sediments, perhaps due to volatilization and immobilization processes. The concentration of selenium in soil solution for filled sediments irrigated biweekly and triweekly are presented in Table 4.28. Selenium concentration was generally higher for triweekly irrigation compared with the biweekly irrigation. Similar results were obtained for the 

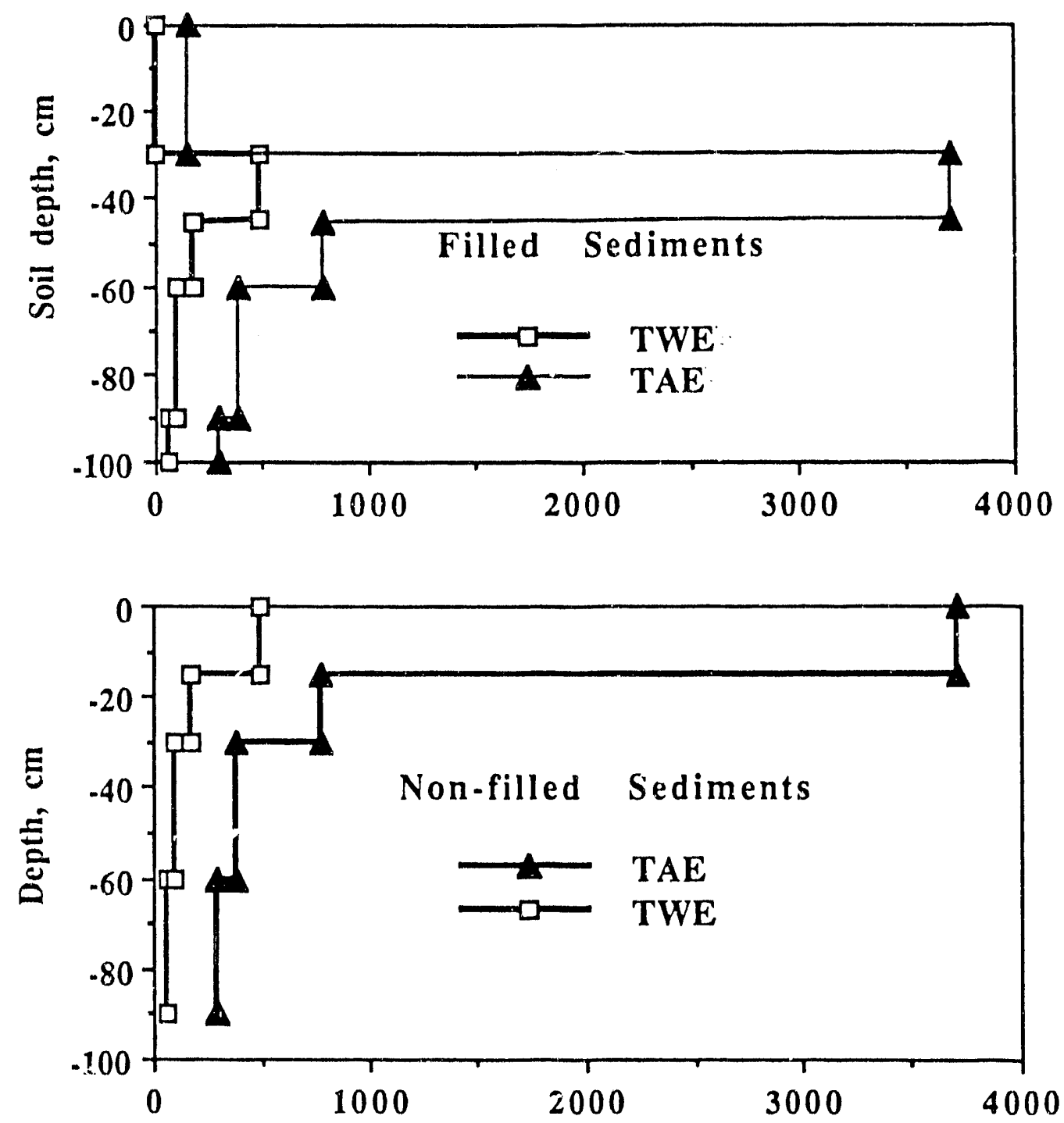

Total Acid and water-extractable Se, Microgram/Kg

Figure 4.41. Total water extractable (TWE) and acid-extractable (TAE) selenium in the sediments after air-drying. 

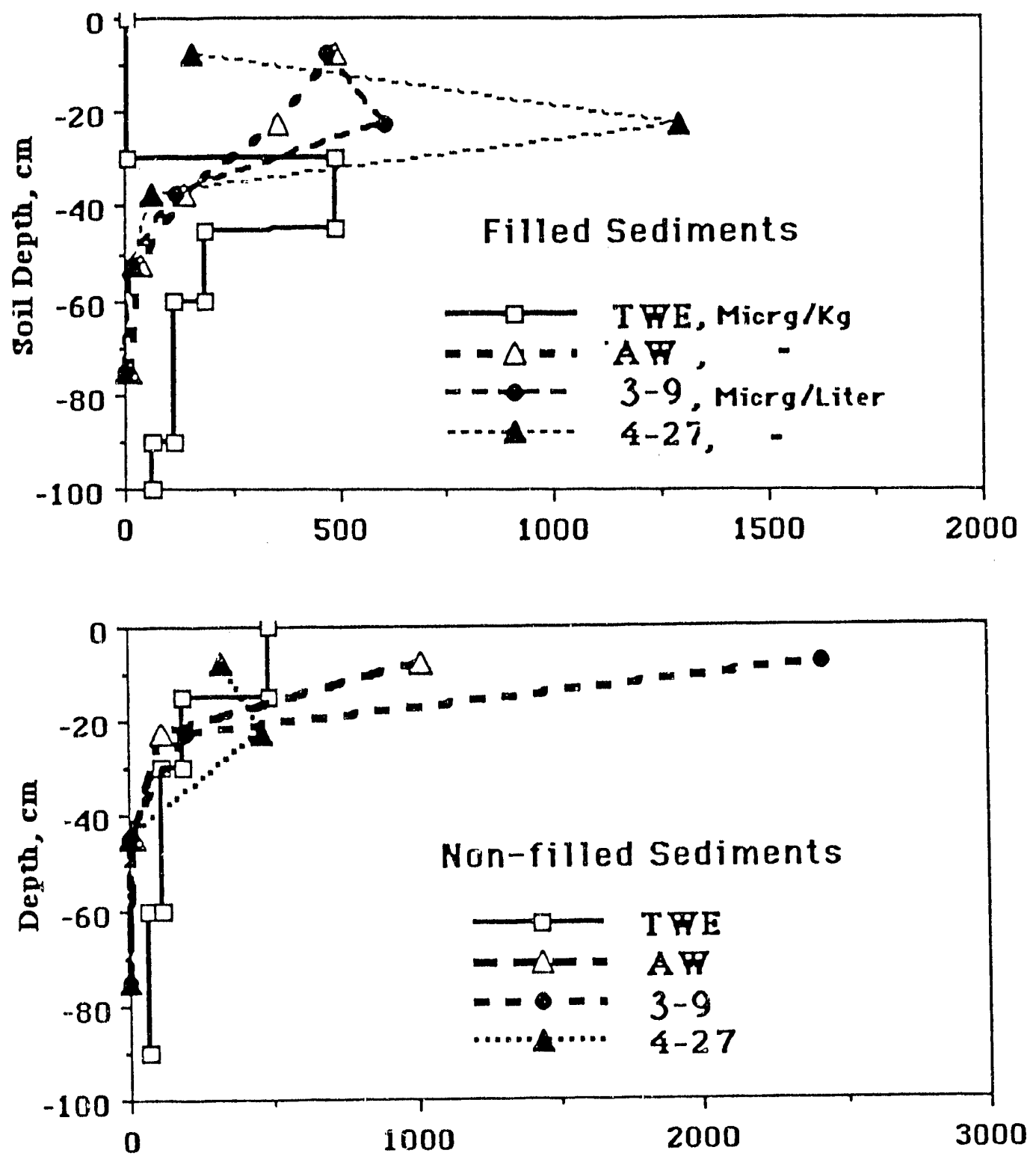

Figure 4.42. Original water-extractable selenium (TWE), selenium after wetting (AW) and following $3.8 \mathrm{~cm}(3-9-89)$ and $26.5 \mathrm{~cm}(4-27)$ water application in non-filled (Exp. IX) and filled (Exp. XII) sediments. 
Table 4.27. Concentration of selenium in soil solution $(\mu \mathrm{g} / \mathrm{l})$ for filled $(\mathrm{F})$ and non-filled (NF) sediments. Biweekly irrigation.

\begin{tabular}{|c|c|c|c|c|c|c|}
\hline \multirow{2}{*}{$\begin{array}{c}\text { Date } \\
\text { Column No./ } \\
\text { Depth }\end{array}$} & \multicolumn{2}{|c|}{$4 / 27 / 89$} & \multicolumn{2}{|c|}{$6 / 8 / 89$} & \multicolumn{2}{|c|}{$7 / 19 / 89$} \\
\hline & $\begin{array}{c}\text { II } \\
\text { (F) }\end{array}$ & $\begin{array}{l}\text { VIII } \\
\text { (NF) }\end{array}$ & $\begin{array}{c}\text { II } \\
(\mathrm{F})\end{array}$ & $\begin{array}{c}\text { VII } \\
\text { (NF) }\end{array}$ & $\begin{array}{c}\text { II } \\
\text { (F) }\end{array}$ & $\begin{array}{l}\text { VIII } \\
\text { (NF) }\end{array}$ \\
\hline-7.5 & 65 & 1080 & 0.2 & 359 & 2.7 & 128 \\
\hline-22.5 & 1344 & 668 & 21 & 1132 & 4.0 & 247 \\
\hline-37.5 & 42 & & 17 & & 5.2 & \\
\hline-45.0 & & 28 & & NA & & NA \\
\hline-52.5 & 9.7 & & 15 & & 18 & \\
\hline-75.0 & 1.7 & 16 & 2.0 & NA & 9.6 & 11 \\
\hline
\end{tabular}

NA not analyzed

Table 428 . Concentration of selenium in soil solution $(\mu \mathrm{g} / \mathrm{l})$ for filled sediments irrigated biweekly (BW) and triweekly (TW).

\begin{tabular}{|c|c|c|c|c|c|c|}
\hline \multirow{2}{*}{$\begin{array}{c}\text { Date } \\
\text { Column No./ } \\
\text { Depth }\end{array}$} & \multicolumn{2}{|c|}{$4 / 27 / 89$} & \multicolumn{2}{|c|}{$6 / 8 / 89$} & \multicolumn{2}{|c|}{$7 / 19 / 89$} \\
\hline & $\begin{array}{c}\text { II } \\
(\mathrm{BW})\end{array}$ & $\begin{array}{c}\text { VIII } \\
\text { (TW) }\end{array}$ & $\stackrel{\text { II }}{(\mathrm{BW})}$ & $\begin{array}{c}\text { VII } \\
\text { (TW) }\end{array}$ & $\underset{(\mathrm{BW})}{\mathrm{II}}$ & $\begin{array}{l}\text { VIII } \\
\text { (TW) }\end{array}$ \\
\hline-7.5 & 65 & 152 & 0.2 & 0.9 & 2.7 & 38 \\
\hline-22.5 & 134 & 1295 & 21 & 9.8 & 4.0 & 31 \\
\hline-37.5 & 42 & 61 & 17 & 30 & 5.2 & 39 \\
\hline-45.0 & & 29 & & & & \\
\hline-52.5 & 9.7 & 18 & 15 & 17 & 18 & 48 \\
\hline-75.0 & 1.7 & 2.8 & 2 & 5.3 & 9.6 & 12 \\
\hline
\end{tabular}


non-filled sediments. The concentration of selenium in soil solution for triweekly irrigation increased from 6-8-89 to 7-19-89 due to addition of fertilizer perhaps as a result of increased biological activity.

Selenium volatilization from the soil surface measured on 4-27-89, after irrigation (Figure 4.43), was the highest for sediments with saltgrass which were irrigated triweekly by surface irrigation and was minimum for the sediments with saltgrass which were irrigated weekly (surface irrigated columns had received $26.5 \mathrm{~cm}$ and subirrigated columns had used 16.4 and $3.5 \mathrm{~cm}$ of water for the vegetated and bare columns, respectively). Addition of fill material to the top of the columns reduced the volatilization rate drastically. Selenium volatilization was lower for subirrigation than for surface irrigation. The soil surface stayed dry for the subirrigation columns and lack of moisture was perhaps the limiting factor for lower volatilization rate in bare columns. For both surface irrigation and subirrigation with saltgrass, more volatilization was observed in nonfilled sediments than with filled sediments. The same was true for bare columns with subirrigation. As shown in Figure 4.44, for surface irrigation selenium volatilization was higher after irrigation (4-27-89) th:n before irrigation (4-25-89) for the low frequency irrigation (triweekly), while more selenium volatilization was observed before irrigation than after irrigation in the high frequency irrigation (weekly). Thus, indicating the effect of moisture regirne on mechanisms of volatilization and diffusion of gas from soil to the atmosphere. Average selenium volatilization before and after irrigation following application of 3.8 (3-9-89), 26.5 (4-27-89), 54.0 (6-8-89), and $77.0(7-19-89) \mathrm{cm}$ of irrigation water for both filled and non-filled sediments are shown in Table 4.29. Volatilization rate decreased with time, perhaps due to a lower soluble selenium concentration and microbial activity. The rate of volatilization measured on 7-19-89 was higher than that measured on 6-8.89 due to application of fertilizer.

Mass of selenium volatilized over the 8 month period (assumed period of active volatilization) was calculated by integrating the measured values over time and extrapolated to the 8 month period (Figure 4.45). The maximum amount of selenium volatilized was 8 gram/acre/ 8 months for the triweekly irrigated non-filled sediments. 


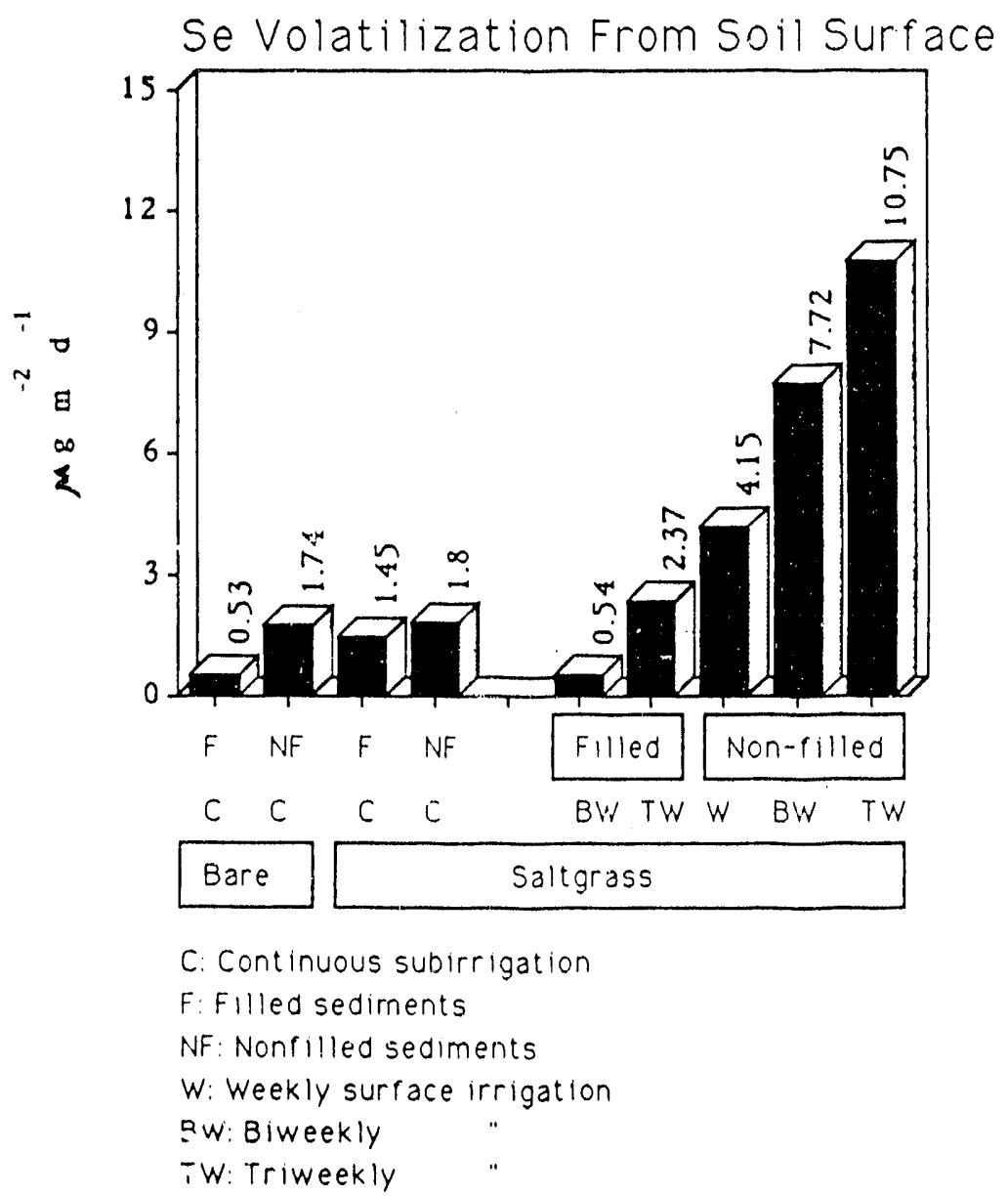

Figure 4.43. Rate of selenium volatilization (microgram $\mathrm{m}^{-2} \mathrm{~d}^{-1}$ ) on $4 / 27 / 89$. 


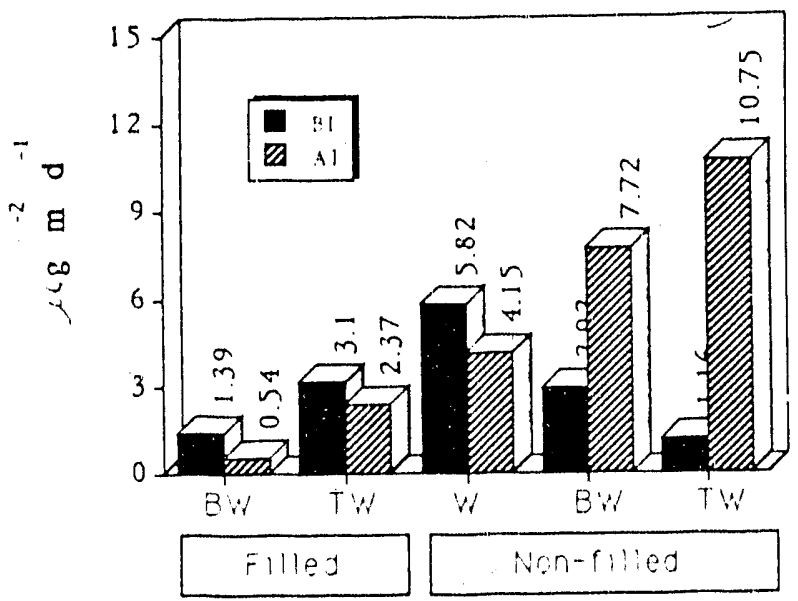

Figure 4.44. Selenium volatilization from soil surface before (BI) and after (AI) irrigation for filled and non-filled sediments irrigated weekly (W), biweekly (BW) and triweekly (TW).

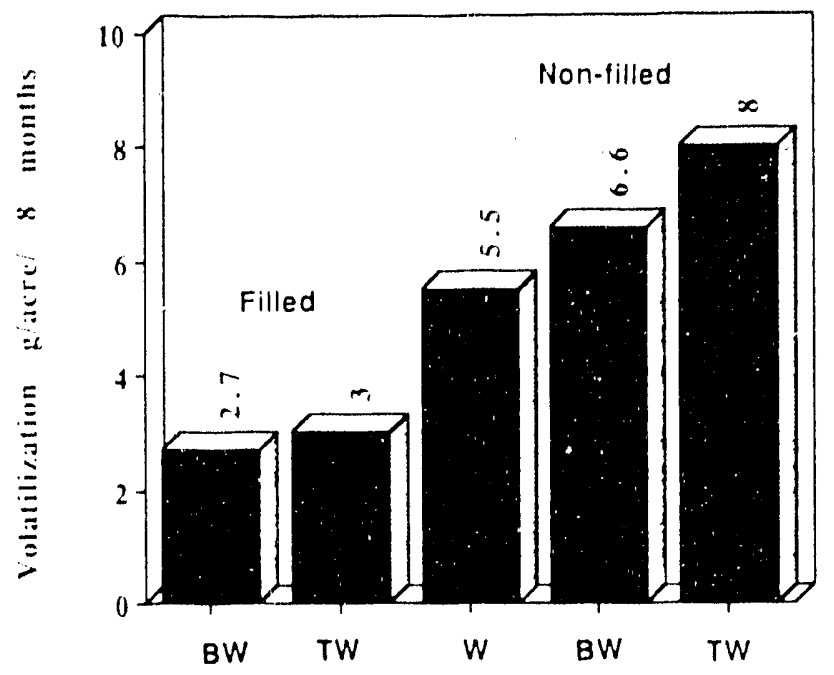

Figure 4.45. Selenium volatilization from the soil surface for filled and non-filled sediments. 
Table 4.29. Average rate of selenium volatilization from soil surface $\mu \mathrm{g} / \mathrm{m}^{2}$-day)

\begin{tabular}{|c|c|c|c|c|c|c|}
\hline \multirow{3}{*}{ Date } & \multirow{3}{*}{ No. Days } & \multicolumn{2}{|c|}{ Filled $(\mathrm{F})$} & \multicolumn{3}{|c|}{ Non-filled (NF) } \\
\hline & & BW & TW & W & BW & TW \\
\hline & & & & & & \\
\hline $3 / 28 / 89$ & & 6.6 & 4.4 & 8.2 & 10.6 & 7.2 \\
\hline $4 / 27 / 89$ & & 1.0 & 2.7 & 5.0 & 5.3 & 6.0 \\
\hline & 42 & & & & & \\
\hline $6 / 8 / 89$ & & 2.7 & 2.7 & 2.7 & 0.6 & 4.3 \\
\hline $7 / 19 / 89$ & 42 & 1.5 & 1.7 & 7.6 & 6.0 & 15.5 \\
\hline
\end{tabular}

Selenium volatilization measured from within the soil profile indicates that selenium can be volatilized from the deeper layers and volatilization rate is influenced by wetting and drying cycles. Figure 4.46 shows the selenium volatilization rate measured within the columns after the columns had received $26.5 \mathrm{~cm}$ of irrigation water. Maximum volatilization rate occurred near the soil surface for the non-filled sediments and decreased with soil depth. The volatilization was more after irrigation than before irrigation. There was more volatilization in the biweekly irrigated column than the triweekly irrigated column. Selenium volatilization in the filled sediments increased with depth of fill material and the maximum occurred at the interface between the fill material and sediments which coincides with the location of maximum selenium concentration measured in soil solution (see also Figure 4.42).

Profile-averaged rate of selenium volatilization within the soil profile for filled sediments irrigated biweekly and triweekly after application of $26.5,54.0$, and $77.0 \mathrm{~cm}$ of irrigation water are presented in Figure 4.47. Selenium volatilization rate was higher for biweekly irrigation compared with triweekly irrigation. Average rate of volatilization declined from 4-27-89 to 6-8-89 but increased following application of fertilizer. Average selenium volatilization for non-filled sediments for weekly, biweekly, and triweekly irrigation after application of 26.5, 54.0, and 77.0 of irrigation water are presented in Figure 4.48. Similar to the filled sediments, selenium volatilization was the highest for biweekly irrigation. Rate of volatilization increased with application of fertilizer. Comparing Figure 4.47 and 4.48 , profile-averaged selenium 


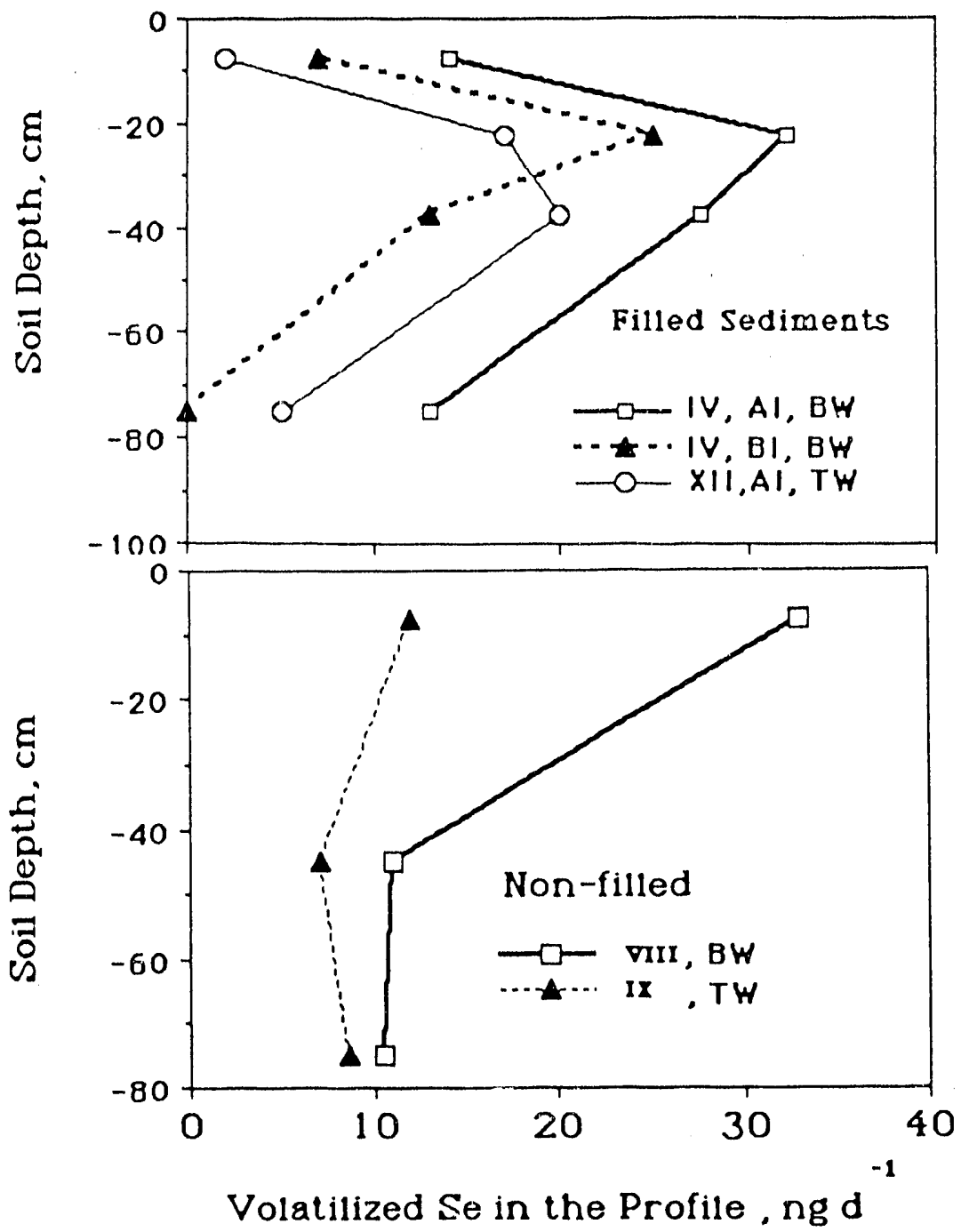

Figure 4.46. Volatilized selenium in the filled sediments irrigated biweekly (BW) or triweekly (TW), before (BI) and after (AI) irrigation. 


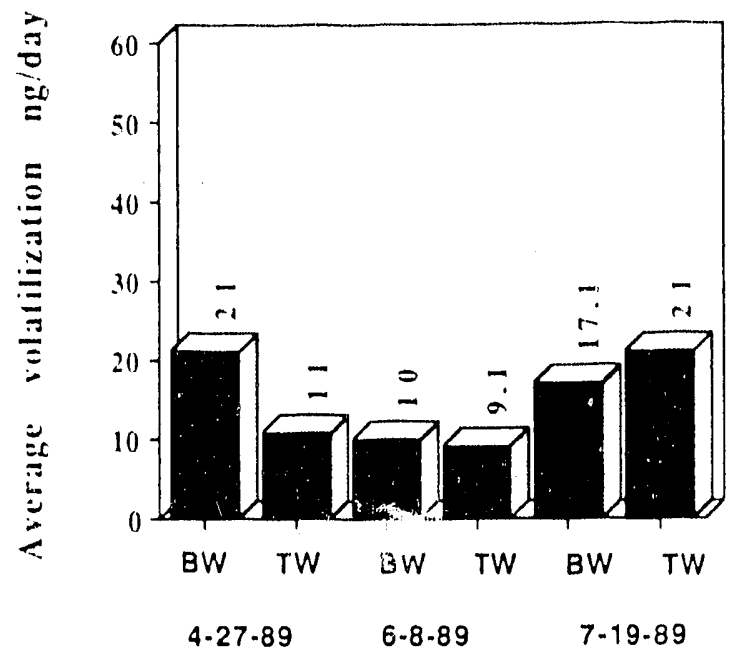

Figure 4.47. Average rate of selenium volatilization within the soil profile for filled sediments.

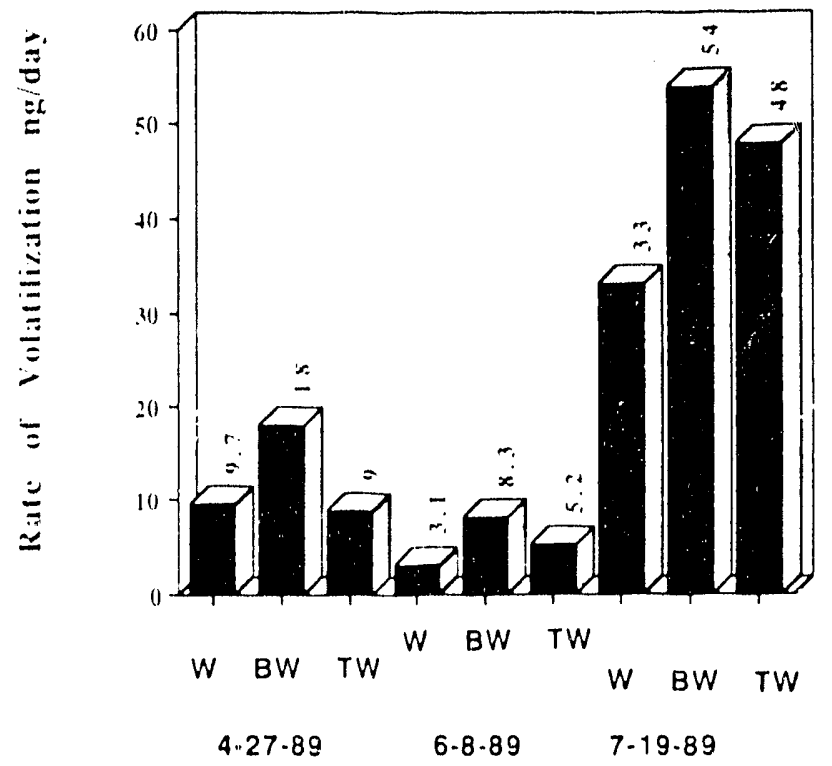

Figure 4.48. Average rate of selenium volatilization within the profile for non-filled sediments. 
volatilization appeared to be higher for filled sediments than non-filled sediments. However, due to the limited number of sampling points along the length of the column, this may be an artifact of the sampling procedure. Also, inferences about selenium dissipation rates, based on the quantity of volatile selenium residing in the profile, are premature due to a limited understanding of the factors affecting transport of volatile selenium from the soil to the atmosphere (see Section 4.9).

In summary, the study findings indicate that volatilization occurs both from the soil surface and within the profile and the rate seem to be dependent on the moisture regime, presence of plants, and fill material. It also indicates the importance of irrigation frequency and the drying and wetting cycles on the mechanisms of volatilization and diffusion. Optimizing these factors to provide for the most rapid rate of dissipation requires further investigation. 


\title{
4.6. SALT AND BORON TOLERANCE OF PROSPECTIVE FORAGE SPECIES FOR RECLAMATION OF SELENIUM - CONTAMINATED SOILS
}

\author{
D. R. Parker and A. L. Page, \\ Department of Soil and Environmental Sciences, \\ University of Califomia, Riverside
}

The focus of this study is on perennial forage species as candidate crops for vegetation of Kesterson soils. The rationale for this focus include (i) rapid establishment and initiation of selenium removal, (ii) potential persistence of the crop, (iii) potential for a deep and extensive root system that will bring subsoil selenium to the surface, and (iv) disposal options that include use as a feed additive or soil amendment on the east side of the San Joaquin Valley where soils are selenium-de ficient.

The primary c. iteria for crop selection are tolerance of the adverse soil conditions present at Kesterson, especially the elevated levels of salinity, boron, and other trace elements. In addition, plants that take up significant quantities of selenium may be desirable for enhancement of selenium dissipation strategies. Candidate plants were selected based on reported tolerance to salinity, or in a few cases, reportedly high selenium uptake potential. In no instance were we able to obtain complete information regarding salinity tolerance, B tolerance, and selenium uptake characteristics from the literature. Consequently, the objectives for this phase of the study were to carefully evaluate the salinity and B tolerance of a number of promising perennial grasses and legumes, and to initiate studies on growth and selenium uptake in Kesterson soils.

\subsubsection{Materials and Methods}

All seeds were obtained from reliable commercial sources (generally certified seed) or governmen/university germplasm repositories. Grass species selected for study included tall wheatgrass (Elysrigia pontica), streambank wheatgrass (E. lanceolatus), basin wildrye (Leymus cinerius), Russian wildrye (Psathyrostchys juncea), alkali sacaton (Sporobolus airoides), tall 
fescue (Festuca arundinacea), Indian ricegrass (Oryzopsis hymenoides), and alkaligrass (Puccinellia distans). Legumes selected included strawberry clover (Trifolium fragiferrum), California burclover (Medicago polymorpha), koa haole (Leucaena leucocephala), and four species of Astragalus: A. bisulcatus, A. falcatus, A. ponticus, and A. racemosus.

Germination tests were conducted by placing three 9.cm disks of Whatman No, 1 filter paper in a disposable $10 \times 1.5 \mathrm{~cm}$ petri dish, and moistening the filter paper with $6 \mathrm{~mL}$ of the test solution. Twenty-five seeds were placed on the filter paper, and the dish was covered and placed in a constant-temperature incubator in the dark. Each day, evaporative losses were estimated by weighing a 'blank' (no seeds) dish, and the appropriate amount of deionized water added to each dish. Germination was considered to have occurred when the emerging radicle was $\geq 0.5 \mathrm{~cm}$ in length.

In conjunction with information in the literature, preliminary experiments were conducted to determine the optimum time, temperature, and pretreatment for germination of each line/cultivar tested. Optimal germination times were taken to be the time required to achieve $85-95 \%$ of maximal germination; this approach yielded both near-maximum germination in the controls and high uniformity among radicle lengths. The conditions imposed for the salinity and boron tolerance tests are presented in Table 4.30, along with the percent germination in the control (zero added salinity or B) solutions. Mechanical scarification of the legume seeds was done by gently rubbing the seeds between two sheets of either 80 or 180 grit sandpaper. The $O$. hymenoides seed was scarified by soaking in $67 \% \mathrm{H}_{2} \mathrm{SO}_{4}$ for $40 \mathrm{~min}$. In addition, this species required the inclusion of $100 \mu \mathrm{M}$ gibberilic acid $\left(\mathrm{GA}_{3}\right)$ in the germination solutions. Even with these treatments, however, germination of the cultivar 'Nezpar' was too low (Table 4.30) to yield any reliable tolerance information.

The germination response of each line/cultivar to salinity was evaluated using 8 salinity levels with three replications. Solutions contained a basal level of $0.5 \mathrm{mM} \mathrm{CaCl}_{2}$ and added salts at 0 to $400 \mathrm{meq} / \mathrm{L}$. Salts were a mixture of $\mathrm{Ca}, \mathrm{Mg}, \mathrm{Na}, \mathrm{Cl}$, and $\mathrm{SO}_{4}$ designed to mimic soil solutions representative of those occurring at Kesterson (Table 4.31). The resulting electrical con- 
Table 4.30. Summary of germination conditions.

\begin{tabular}{|c|c|c|c|c|c|}
\hline Species & Cultivar/Line & Pretreatment & Temp. & Time & $\begin{array}{l}\text { Germination } \\
\text { in Controls }\end{array}$ \\
\hline & & & ${ }^{\circ} \mathrm{C}$ & $\mathrm{h}$ & $\%$ \\
\hline $\begin{array}{l}\text { Trifolium } \\
\text { fragiferrum }\end{array}$ & $\begin{array}{l}\text { Salina } \\
\text { O'Connors } \\
\text { Palestine } \\
\text { PI } 24515 \\
\text { PI } 206919 \\
\text { PI } 284267 \\
\text { PI } 325500\end{array}$ & $\begin{array}{l}180 \text { sandpaper } \\
180 \text { sandpaper } \\
180 \text { sandpaper } \\
180 \text { sandpaper } \\
180 \text { sandpaper } \\
180 \text { sandpaper } \\
180 \text { sandpaper }\end{array}$ & $\begin{array}{l}20 \\
20 \\
20 \\
20 \\
20 \\
20 \\
20\end{array}$ & $\begin{array}{l}72 \\
72 \\
72 \\
72 \\
72 \\
72 \\
72\end{array}$ & $\begin{array}{l}90 \\
91 \\
80 \\
82 \\
97 \\
89 \\
88\end{array}$ \\
\hline $\begin{array}{l}\text { Medicago } \\
\text { polymorpha }\end{array}$ & $\begin{array}{l}\text { Circle Valley } \\
\text { Serena } \\
\mathrm{T}-604\end{array}$ & $\begin{array}{l}180 \text { sandpaper } \\
180 \text { sandpaper } \\
180 \text { sandpaper }\end{array}$ & $\begin{array}{l}20 \\
20 \\
20\end{array}$ & $\begin{array}{l}50 \\
50 \\
50\end{array}$ & $\begin{array}{l}55 \\
59 \\
89\end{array}$ \\
\hline $\begin{array}{l}\text { Leucaena } \\
\text { leucocephela }\end{array}$ & $\mathrm{K}-8$ & 80 sandpaper & 25 & 38 & 93 \\
\hline $\begin{array}{l}\text { Elytrigia } \\
\text { pontica }\end{array}$ & $\begin{array}{l}\text { Alkar } \\
\text { Jose } \\
\text { Orbit }\end{array}$ & & $\begin{array}{l}20 \\
20 \\
20\end{array}$ & $\begin{array}{c}96 \\
96 \\
160\end{array}$ & $\begin{array}{l}75 \\
84 \\
71\end{array}$ \\
\hline $\begin{array}{l}\text { Elytrigia } \\
\text { lanceolatus }\end{array}$ & Sodar & & 25 & 116 & 76 \\
\hline Leymus cinerius & Magnar & & 20 & 240 & 49 \\
\hline $\begin{array}{l}\text { Psathyrostachys } \\
\text { juncea }\end{array}$ & $\begin{array}{l}\text { Bozoisky } \\
\text { Vinall }\end{array}$ & & $\begin{array}{l}20 \\
20\end{array}$ & $\begin{array}{l}120 \\
120\end{array}$ & $\begin{array}{l}59 \\
77\end{array}$ \\
\hline $\begin{array}{l}\text { Sporobolus } \\
\text { airoides }\end{array}$ & Salado & & 25 & 90 & 52 \\
\hline $\begin{array}{l}\text { Festuca } \\
\text { arundinacea }\end{array}$ & $\begin{array}{l}\text { Fawn } \\
\text { Johnstone }\end{array}$ & & $\begin{array}{l}25 \\
25\end{array}$ & $\begin{array}{l}116 \\
119\end{array}$ & $\begin{array}{l}80 \\
87\end{array}$ \\
\hline Oryzopsis & Paloma & $67 \% \mathrm{H}_{2} \mathrm{SO}_{4}, 40 \mathrm{~min}$ & 25 & 89 & 67 \\
\hline hymenordes & Nezpar & $67 \% \mathrm{H}_{2} \mathrm{SO}_{4}, 40 \mathrm{~min}$ & 25 & 168 & 19 \\
\hline
\end{tabular}


Table 4.31. Screening solution used for evaluating the germination response to salinity. All solutions contained a basal $\mathrm{CaCl}_{2}$ level or $0.5 \mathrm{mM}$.

\begin{tabular}{|c|c|c|c|c|c|c|}
\hline \multirow[t]{2}{*}{ Treatment } & \multirow[t]{2}{*}{$\begin{array}{l}\% \text { of full } \\
\text { strength }\end{array}$} & \multirow[t]{2}{*}{ Ion } & \multicolumn{2}{|c|}{ Amount added } & \multirow{2}{*}{$\begin{array}{l}\begin{array}{l}\text { Total } \\
\text { added }\end{array} \\
\text { meq } / L\end{array}$} & \multirow{2}{*}{$\frac{\mathrm{EC}}{\mathrm{dS} / \mathrm{m}}$} \\
\hline & & & $\mathrm{m} M$ & $\mathrm{meq} / \mathrm{L}$ & & \\
\hline 1 (control) & 0 & na & na & na & na & 0.14 \\
\hline \multirow[t]{2}{*}{2} & 10 & $\begin{array}{l}\mathrm{Ca} \\
\mathrm{Mg} \\
\mathrm{Na}\end{array}$ & $\begin{array}{l}1 \\
4 \\
30\end{array}$ & $\begin{array}{l}2 \\
8 \\
30\end{array}$ & & \\
\hline & & $\begin{array}{l}\mathrm{SO}_{4} \\
\mathrm{Cl}\end{array}$ & $\begin{array}{l}10 \\
20\end{array}$ & $\begin{array}{l}20 \\
20\end{array}$ & 40 & 4.06 \\
\hline \multirow[t]{2}{*}{3} & 20 & $\begin{array}{l}\mathrm{Ca} \\
\mathrm{Mg} \\
\mathrm{Na}^{2}\end{array}$ & $\begin{array}{l}2 \\
8 \\
60\end{array}$ & $\begin{array}{l}4 \\
16 \\
60\end{array}$ & & \\
\hline & & $\begin{array}{l}\mathrm{SO}_{4} \\
\mathrm{Cl}\end{array}$ & $\begin{array}{l}20 \\
40\end{array}$ & $\begin{array}{l}40 \\
40\end{array}$ & 80 & 7.51 \\
\hline \multirow[t]{2}{*}{4} & 30 & $\begin{array}{l}\mathrm{Ca} \\
\mathrm{Mg} \\
\mathrm{Na}\end{array}$ & $\begin{array}{l}3 \\
12 \\
90\end{array}$ & $\begin{array}{l}6 \\
24 \\
90\end{array}$ & & \\
\hline & & $\begin{array}{l}\mathrm{SO}_{4} \\
\mathrm{Cl}\end{array}$ & $\begin{array}{l}30 \\
60\end{array}$ & $\begin{array}{l}60 \\
60\end{array}$ & 120 & 10.8 \\
\hline \multirow[t]{2}{*}{5} & 40 & $\begin{array}{l}\mathrm{Ca} \\
\mathrm{Mg} \\
\mathrm{Na}\end{array}$ & $\begin{array}{l}4 \\
16 \\
120\end{array}$ & $\begin{array}{l}8 \\
32 \\
120\end{array}$ & & \\
\hline & & $\begin{array}{l}\mathrm{SP}_{4} \\
\mathrm{C}\end{array}$ & $\begin{array}{l}40 \\
80\end{array}$ & $\begin{array}{l}80 \\
80\end{array}$ & 160 & 13.9 \\
\hline \multirow[t]{2}{*}{6} & 60 & $\begin{array}{l}\mathrm{Ca} \\
\mathrm{Mg} \\
\mathrm{Na}\end{array}$ & $\begin{array}{l}6 \\
24 \\
180\end{array}$ & $\begin{array}{l}12 \\
48 \\
180\end{array}$ & & \\
\hline & & $\begin{array}{l}\mathrm{SO}_{4} \\
\mathrm{Cl}\end{array}$ & $\begin{array}{l}60 \\
120\end{array}$ & $\begin{array}{l}120 \\
120\end{array}$ & 240 & 19.8 \\
\hline \multirow[t]{2}{*}{7} & 80 & $\begin{array}{l}\mathrm{Ca} \\
\mathrm{Mg} \\
\mathrm{Na}^{2}\end{array}$ & $\begin{array}{l}8 \\
32 \\
240\end{array}$ & $\begin{array}{l}16 \\
64 \\
240\end{array}$ & & \\
\hline & & $\mathrm{SO}_{4}$ & 80 & 160 & & \\
\hline \multirow[t]{2}{*}{8} & 100 & $\begin{array}{l}\mathrm{Ca} \\
\mathrm{Mg} \\
\mathrm{Na}\end{array}$ & $\begin{array}{l}10 \\
40 \\
300\end{array}$ & $\begin{array}{l}20 \\
80 \\
300\end{array}$ & & 20.8 \\
\hline & & $\begin{array}{l}\mathrm{SO}_{4} \\
\mathrm{Cl}\end{array}$ & $\begin{array}{l}100 \\
200\end{array}$ & $\begin{array}{l}200 \\
200\end{array}$ & 400 & 30.6 \\
\hline
\end{tabular}


ductivities (EC's), corrected to $25^{\circ} \mathrm{C}$, ranged from 0.1 to $30.6 \mathrm{dS} \mathrm{m}^{-1}$ (Table 4.31). The number of germinated seeds was expressed as a percentage of the number germinated in the control treatments (see last column in Table 4.30). Germination responses to buron were evaluated using a similar procedure. The test solutions contained a basal level of $0.5 \mathrm{mM} \mathrm{CaCl}_{2}$ and $0,0.4,0.8$, $1.2,1.6,2.4,3.2$, or $4.0 \mathrm{mM} \mathrm{B}$ as $\mathrm{H}_{3} \mathrm{BO}_{3}$, with three replications per treatment.

For evaluation of salinity effects cn seedling growth, 16 lines were seeded into 10-L pots containing \#16 washed quartz sand in the gieenhouse. Seed pretreatments were as before (Table 4.30). The pots were placed over 100- or 120-L tanks containing the reservoir of complete nutrient solution which was automatically siphoned into the pots six times per day. Excess solution drained back into the tanks. Pots were overseeded initially and, after emergence, thinned back to six plants per pot for legumes, and 15 plants per pot for grasses. There were three replications for all treatments.

When the emerged seedlings were about $2.5 \mathrm{~cm}$ high, salinity treatments were initiated. This consisted of $i$ dding $20 \%$ of the total salts for each treatment every other day, such that it took eight days to reach the desired salinity level. Treatments were the same as in the germination studies, 0 to $400 \mathrm{meq} / \mathrm{L}$ added salts, and EC's ranged from 0.5 to $30 \mathrm{dS} / \mathrm{m}$. Weekly conductivity determinations were made on each solution. Solution $\mathrm{pH}$ was maintained at 6.5 to 7.5 via semi-weekly measurements and adjustments. Twenty-six days after completion of the salt additions, all plants were harvested by clipping at $2 \mathrm{~cm}$ above the sand surface. Plants were then oven-dried and weighed to obtain dry matter yields of tops. All yields are expressed as a percentage of the control (zero added salt) yield.

A very similar experiment was then performed using the same $E$ concentratiols as in the germination studies. As with $t^{h}:$ salinity experiment, the B was gradually added in $20 \%$ increments every two days until the final concer 'rations were achieved. Plants were also harvested 5 days after completion of the $B$ additions.

Sigmoidal response curves were generally used to characterize each line's sensitivity to salinity or B. Most often data were fit to the. Wribull-type function (model 1) 


$$
\% \mathrm{C}=100 \cdot \exp -\left[(\alpha \mathrm{x})^{\beta}\right]
$$

where $x$ is salinity in $\mathrm{dS} \mathrm{m}^{-1}$ or $[\mathrm{B}]$ in $\mathrm{mM}$, and $\alpha$ and $\beta$ are adjustable parameters. With selecter data that did not fit the above model well, an altemative (model 2) was used

$$
\% \mathrm{C}=100 \cdot \exp \left(\alpha \mathrm{x}-\beta \mathrm{x}^{2}\right)
$$

where $x, \alpha$, and $\beta$ have the same meaning as before. This model accommodates slight growth stimulations at low levels of $x$.

All data sets were fit to the above models using a general purpose nonlinear least-squares regression algorithm. For B, many of the data sets were fit to a simple linear regression model (model 3)

$$
\% \mathrm{C}=\alpha+\beta \mathrm{x}
$$

where $x$ is the $B$ concentration in $m M$, and a nonsignificant value of the coefficient $\beta$ indicates no response to the B treatments. A few of the data sets were fit to the function (model 4)

$$
\% \mathrm{C}=100 \cdot\left(1-\alpha \mathrm{x}^{2}\right)
$$

where $\mathrm{x}$, and $\alpha$ have the same meaning as before.

Values of $t$ (parameter estimate/standard error estimate) were compared with tabulated tvalues to estimate the probability ior $\mathrm{H}_{0}: \alpha(\operatorname{or} \beta)=0$.

Soil unsples were collected from low-lying, unclled sites at ponds 4 and 11 at Kesterson. The sites were vegetated with Sesuvium verrucosum (Pond 4) or Cressa truxillensis (Pond 11). Bulk soil samples, taken by horizon to a depth of one meter, were thoroughly mixed, and stored without drying at $4^{\circ} \mathrm{C}$. Saturated paste extracts of the topsoil horizons were made, and $\mathrm{pH}, \mathrm{EC}$, and soluble B determined. Total selenium content was determined via the sequential digestion procedure of Bahktar et al. (1989), 'nd selenium analysis by hydride-vapor ICPES.

A "quick screen" for plant emergence and growth was performed on all 30 plant lines currently in our collection. Plastic "conetainers" $(20.5 \mathrm{~cm}$ by $4.0 \mathrm{~cm}$ diam.) were packed with soil and sown with 10 (grasses) or 6 (legume) seeds. The cones 'vere flaced in th greenhouse, watered as needed, and any leachate was collected and returned to the conetainer. Emergence was monitored for 3 to 4 weeks. Three soils were used for each line: the topsoil samples from 
ponds 4 and 11, and a Hanford sandy loam as a control treatment. There were four replications for each soil.

\subsubsection{Results}

The germination responses of three tall wheatgrass cultivars to salinity are depicted in Figure 4.49 , and are representative of all lines tested. All data sets were successfully fit to either model 1 or 2 . For comparisons between lines, the $\mathrm{EC}$ required for $50 \%$ germination $\left(\mathrm{EC}_{50}\right)$ was computed based on the best-fit regression model, and ranged from 5.1 to $2.9 .9 \mathrm{dS} / \mathrm{m}$. Results of the salinity screening are summarized in Tables 4.32 and 4.33 .

Most lines exhibited little or no inhibition of germination due to $\mathrm{B}$; the minimum germination observed was 53\% of control. Typical significant and nonsignificant responses to $\mathrm{B}$ are presented in Figures 4.50 and 4.51 , respectively. The results of these experiments are summarized in Tables 4.34 and 4.35 .

Based on the preceding, lines were selected for further evaluation of tolerance during seedling growth in thic greenhouse. Due to the minimal adverse effect of $B$ on germination, salinity tolerance alone was used to select the best cultivar(s) of each species for continued study. In addition to the 11 lines thus selected, the four species of the genus Astragalus were included. The Astragalus were not screened for salt or B tolerance during termination due to very limited seed supplies. Also included was one grass species, Puccinellia distans, for which we were not able to obtain sufficient germination for reliable screens. The resulting list of candidate lines is given in Table 4.36 .

Yield data were regressed against average EC values for the growth period using either model 1 or model 2 as described above. Fits to the models were generally good (Table 4.36), although more experimental error was incurred here than with the germination studies. As before, $\mathrm{EC}_{50}$ values were computed as the single index of salinity tolerance. Among the grasses, tall wheatgrass ('Orbit'), alkali sacaton ('Salado'), and alkaligrass ('Faults') exhibited superior tolerance to salinity with $\mathrm{EC}_{50}$ values of 25 to $30 \mathrm{dS} / \mathrm{m}$. Among the legumes, two Astragalus 


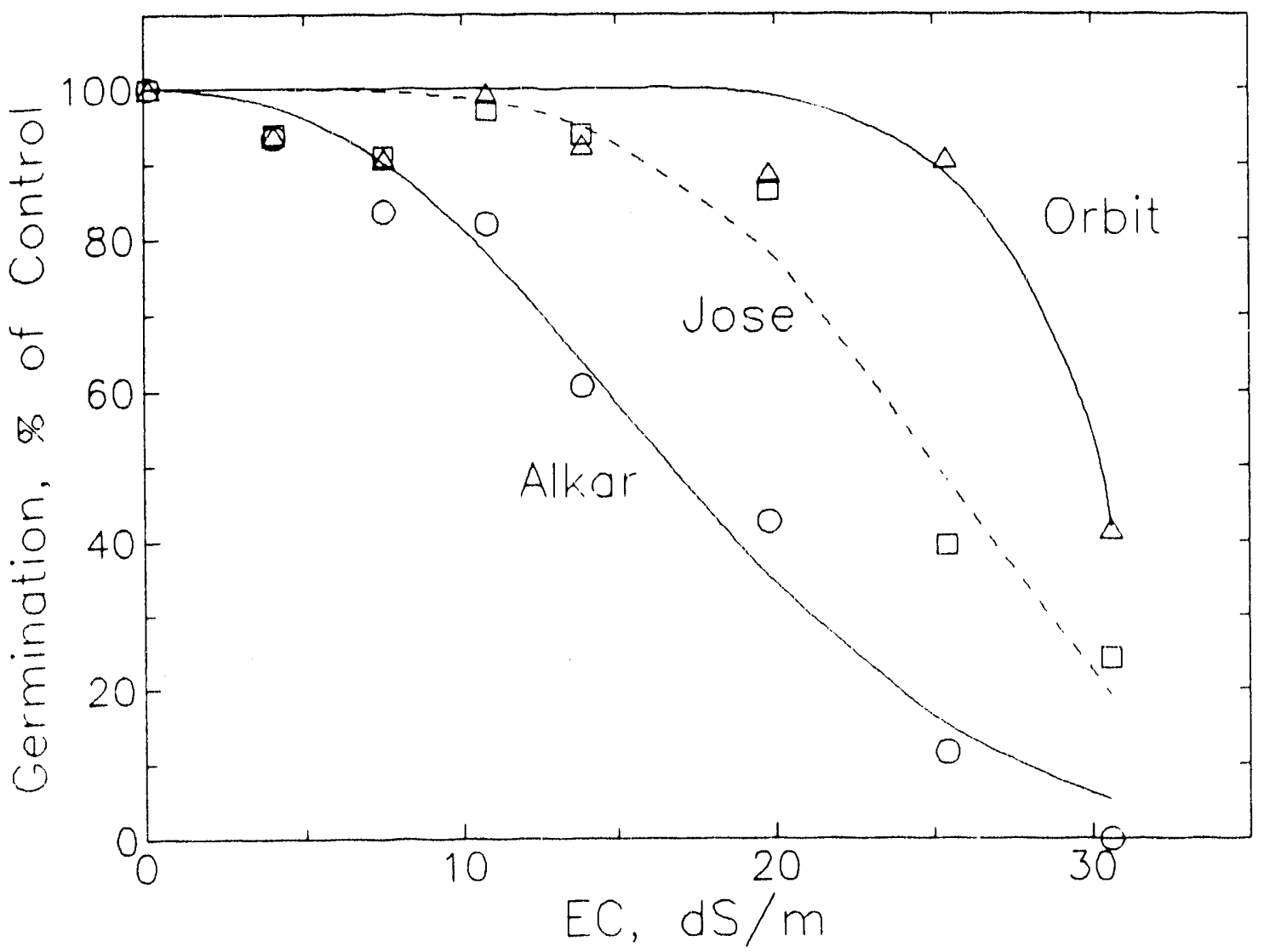

Figure 4.49. Representative germinaiion responses to salinity for three tall wheatgrass cultivars. Symbols indicate experimental observations and lines represent best-fit regression models from Table 4.33. 
Table 4.32. Regression analyses for the germination response of the legumes to salinity in the range 0.14 to $30.6 \mathrm{dS} / \mathrm{m}$. All coefficients are significant at $\mathrm{p} \leq 0.001$.

\begin{tabular}{|c|c|c|c|c|c|c|c|}
\hline Species & Cultivar & Model & $r^{2}$ & Coefficient & Value & $\mathrm{SE}$ & $\mathrm{EC}_{50}$ \\
\hline \multirow[t]{7}{*}{$\begin{array}{l}T . \text { fragifertum } \\
\text { (strawberry clover) }\end{array}$} & Salina & 1 & 0.966 & $\stackrel{\alpha}{\beta}$ & $\begin{array}{l}0.1644 \\
2.00\end{array}$ & $\begin{array}{l}0.0072 \\
0.255\end{array}$ & $\begin{array}{r}\mathrm{dS} / \mathrm{mm} \\
5.1\end{array}$ \\
\hline & O'Connors & 1 & 0.984 & $\stackrel{\alpha}{\beta}$ & $\begin{array}{l}0.1083 \\
3.405\end{array}$ & $\begin{array}{l}0.0023 \\
0.337\end{array}$ & 8.3 \\
\hline & Palestine & 1 & 0.956 & $\underset{\beta}{\alpha}$ & $\begin{array}{l}0.0906 \\
2.308\end{array}$ & $\begin{array}{l}0.0035 \\
0.309\end{array}$ & 9.4 \\
\hline & PI 204515 & 1 & 0.985 & $\stackrel{\alpha}{\beta}$ & $\begin{array}{l}0.1011 \\
4.411\end{array}$ & $\begin{array}{l}0.0020 \\
0.494\end{array}$ & 9.1 \\
\hline & PI 206919 & 1 & 0.972 & $\stackrel{\alpha}{\beta}$ & $\begin{array}{l}0.0609 \\
3.061\end{array}$ & $\begin{array}{l}0.0017 \\
0.309\end{array}$ & 14.6 \\
\hline & PI 284267 & 1 & 0.968 & $\begin{array}{l}\alpha \\
\beta\end{array}$ & $\begin{array}{l}0.0716 \\
3.039\end{array}$ & $\begin{array}{l}0.0022 \\
0.381\end{array}$ & 12.4 \\
\hline & PI 325500 & 1 & 0.951 & $\stackrel{\alpha}{\beta}$ & $\begin{array}{l}0.1031 \\
2.960\end{array}$ & $\begin{array}{l}0.0041 \\
0.484\end{array}$ & 8.6 \\
\hline \multirow{3}{*}{$\begin{array}{l}\text { M. polymorpho } \\
\text { (California } \\
\text { burclover) }\end{array}$} & $\begin{array}{l}\text { Circle } \\
\text { Valley }\end{array}$ & 2 & 0.930 & $\begin{array}{l}\alpha \\
\beta\end{array}$ & $\begin{array}{l}0.0779 \\
0.0084\end{array}$ & $\begin{array}{l}0.0149 \\
0.0014\end{array}$ & 14.8 \\
\hline & Serena & 1 & 0.903 & $\stackrel{\alpha}{\beta}$ & $\begin{array}{l}0.0490 \\
3.653\end{array}$ & $\begin{array}{l}0.0022 \\
0.701\end{array}$ & 18.5 \\
\hline & $T-604$ & 1 & 0.971 & $\stackrel{\alpha}{\beta}$ & $\begin{array}{l}0.1396 \\
2.728\end{array}$ & $\begin{array}{l}0.0049 \\
0.351\end{array}$ & 6.3 \\
\hline $\begin{array}{l}\text { Leucaena } \\
\text { leucocephela } \\
\text { ('soa haole) }\end{array}$ & $K-8$ & 1 & 0.943 & $\stackrel{\alpha}{\beta}$ & $\begin{array}{l}0.0917 \\
1.555\end{array}$ & $\begin{array}{l}\vdots .0048 \\
0.200\end{array}$ & 8.6 \\
\hline
\end{tabular}


Table 4.33. Regression analyses for the germination response of the grasses to salinity in the range 0.14 to $30.6 \mathrm{dS} / \mathrm{m}$. All coefficients are significant at $\mathrm{p} \leq 0.01$ or $\mathrm{p} \leq 0.001$.

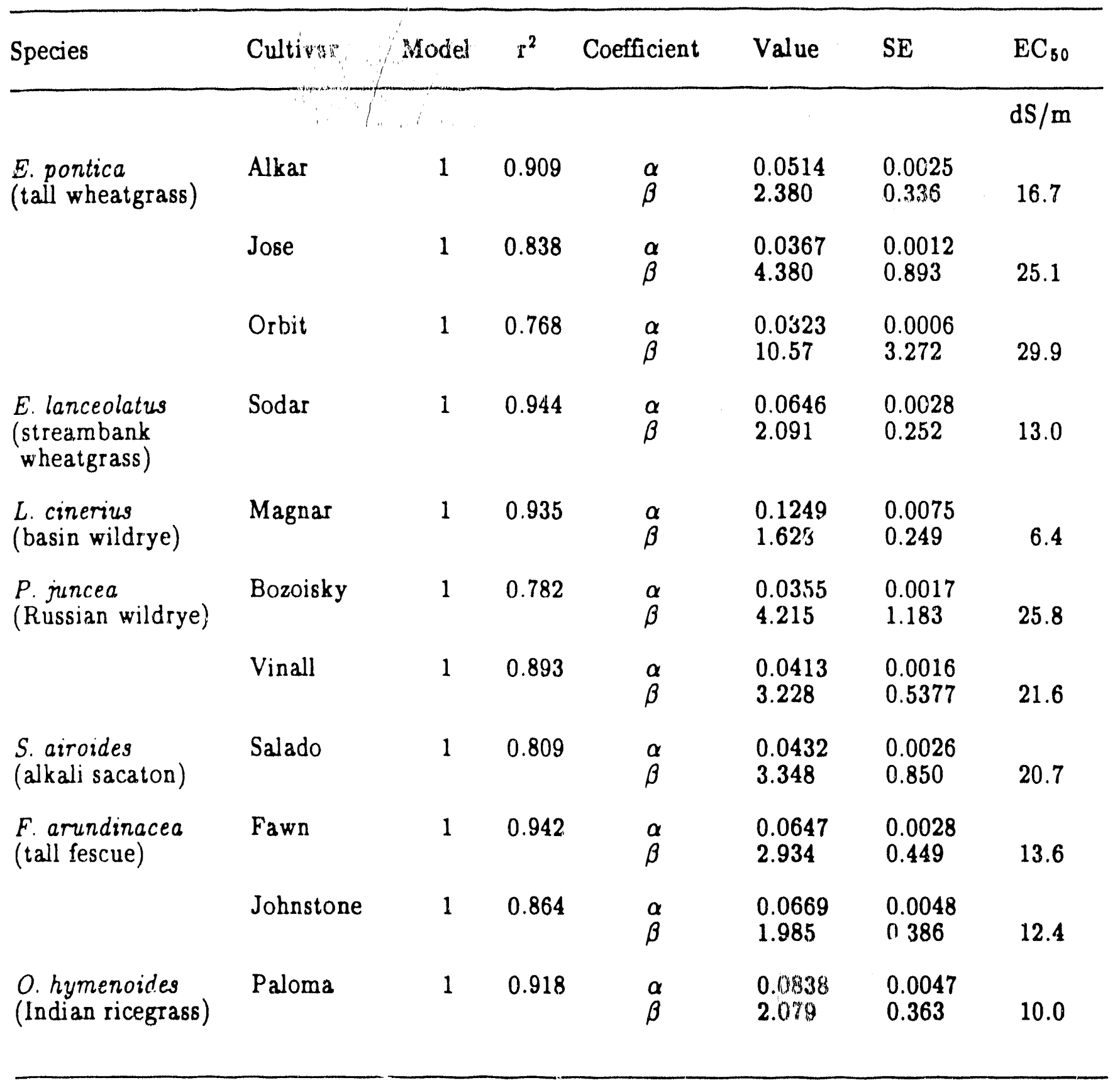




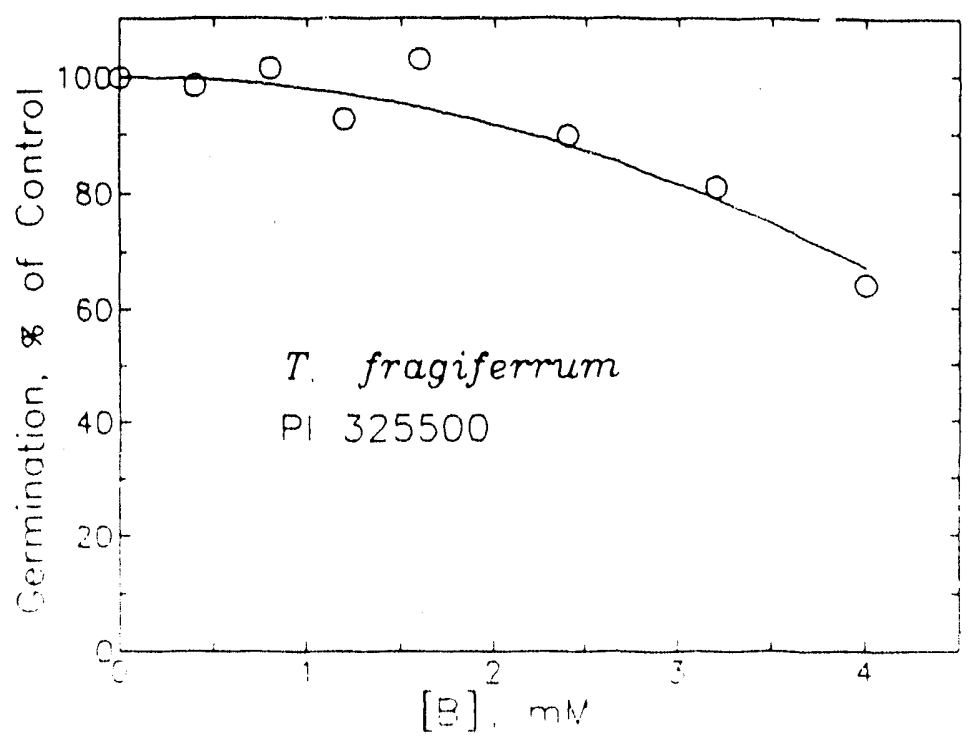

Figure 4.50. Typical significant germination response to B concentration. Symbols indicate experimental observations and line represents best-fit regression model using model 4 .

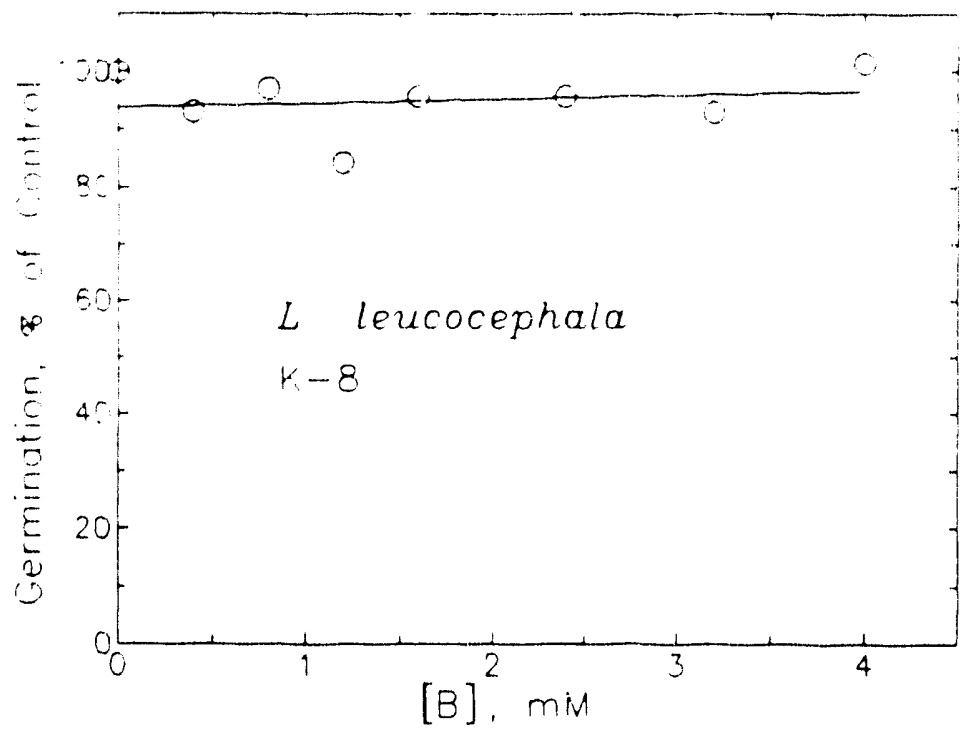

Figure 4.51. Typical nonsignificant germination response to B concentration. Symbols indicate experimental observations and line represents best-fit regression model usinf, model 3. 
Table 4.34. Regression analyses for the germination response of the legumes to boron in the range 0 to $4.0 \mathrm{mM}$.

\begin{tabular}{|c|c|c|c|c|c|c|c|}
\hline Species & Cultivar & Model & $\mathrm{I}^{2}$ & Coefficient & Value & $\mathrm{SE}$ & Significance ${ }^{\dagger}$ \\
\hline \multirow[t]{7}{*}{$\begin{array}{l}T . \text { fragiferrum } \\
\text { (strawberry clover) }\end{array}$} & Salina & 3 & 0.395 & $\begin{array}{l}\beta \\
\alpha\end{array}$ & $\begin{array}{l}-8.94 \\
93.9\end{array}$ & 2.36 & $* *$ \\
\hline & O'Connors & 3 & 0.476 & $\begin{array}{l}\beta \\
\alpha\end{array}$ & $\begin{array}{l}-8.60 \\
100.9\end{array}$ & 1.92 & $* * *$ \\
\hline & Palestine & 3 & 0.273 & $\begin{array}{l}\beta \\
\alpha\end{array}$ & $\begin{array}{l}-4.74 \\
99.4\end{array}$ & 1.65 & $*$ \\
\hline & PI 204515 & 3 & 0.259 & $\begin{array}{l}\beta \\
\alpha\end{array}$ & $\begin{array}{l}-4.08 \\
98.3\end{array}$ & 1.47 & $*$ \\
\hline & PI 206919 & 3 & 0.183 & $\begin{array}{l}\beta \\
\alpha\end{array}$ & $\begin{array}{l}-1.67 \\
96.9\end{array}$ & 0.75 & $*$ \\
\hline & PI 284267 & 3 & 0.116 & $\begin{array}{l}\beta \\
\alpha\end{array}$ & $\begin{array}{l}-2.32 \\
98.2\end{array}$ & 1.37 & NS \\
\hline & PI 325500 & 4 & 0.623 & $\alpha$ & 0.021 & 0.0027 & $* * *$ \\
\hline \multirow{3}{*}{$\begin{array}{l}\text { M. polymorpha } \\
\text { (California } \\
\text { burclover) }\end{array}$} & $\begin{array}{l}\text { Circle } \\
\text { Valley }\end{array}$ & 3 & 0.018 & $\begin{array}{l}\beta \\
\alpha\end{array}$ & $\begin{array}{l}-1.64 \\
97.9\end{array}$ & 2.55 & NS \\
\hline & Serena & 3 & 0.112 & $\begin{array}{l}\beta \\
\alpha\end{array}$ & $\begin{array}{l}-5.81 \\
125.9\end{array}$ & 3.495 & NS \\
\hline & $\mathrm{T}-604$ & 3 & 0.005 & $\begin{array}{l}\beta \\
\alpha\end{array}$ & $\begin{array}{l}-0.41 \\
94.4\end{array}$ & 1.18 & NS \\
\hline $\begin{array}{l}\text { Leucaena } \\
\text { leucocephala } \\
\text { (koa haole) }\end{array}$ & $K-8$ & 3 & 0.031 & $\begin{array}{l}\beta \\
\alpha\end{array}$ & $\begin{array}{l}0.66 \\
94.0\end{array}$ & 1.52 & NS \\
\hline
\end{tabular}

$\dagger^{*}, * *, * * *$ indicate significant coefficients at $p \leq 0.05,0.01$, or 0.001 , respectively. NS = nonsignificant coefficient. 
Table 4.35. Regression analyses for the germination response of the grasses to boron in the range 0 to $4.0 \mathrm{mM}$.

\begin{tabular}{|c|c|c|c|c|c|c|c|}
\hline Species & Cultivar & Model & $r^{2}$ & Coefficient & Value & $\mathrm{SE}$ & Significance ${ }^{\dagger}$ \\
\hline \multirow[t]{3}{*}{$\begin{array}{l}\text { E. pontica } \\
\text { (tall wheatgrass) }\end{array}$} & Alkar & 3 & 0.008 & $\begin{array}{l}\beta \\
\alpha\end{array}$ & $\begin{array}{l}-0.98 \\
109.1\end{array}$ & 2.38 & NS \\
\hline & Jose & 3 & 0.020 & $\begin{array}{l}\beta \\
\alpha\end{array}$ & $\begin{array}{l}0.87 \\
102.2\end{array}$ & 1.29 & NS \\
\hline & Orbit & 3 & 0.071 & $\begin{array}{l}\beta \\
\alpha\end{array}$ & $\begin{array}{l}-2.46 \\
94.5\end{array}$ & 1.18 & NS \\
\hline $\begin{array}{l}\text { E. lanceolatus } \\
\text { (streambank wheat }\end{array}$ & $\begin{array}{l}\text { Sodar } \\
\text { (rass) }\end{array}$ & 4 & 0.303 & $\alpha$ & 0.0114 & 0.0027 & $* * *$ \\
\hline $\begin{array}{l}\text { L. cinerius } \\
\text { (basin wildrye) }\end{array}$ & Magnar & 3 & 0.000 & $\begin{array}{l}\beta \\
\alpha\end{array}$ & $\begin{array}{l}0.58 \\
90.9\end{array}$ & 2.86 & NS \\
\hline \multirow{2}{*}{$\begin{array}{l}P . \dot{y} \text { juncea } \\
\text { (Russian wildrye) }\end{array}$} & Bozoisky & 4 & 0.104 & $\alpha$ & 0.0118 & 0.0045 & * \\
\hline & Vinall & 3 & 0.019 & $\begin{array}{l}\beta \\
\alpha\end{array}$ & $\begin{array}{l}2.27 \\
121.8\end{array}$ & 3.48 & NS \\
\hline $\begin{array}{l}\text { S. airoides } \\
\text { (alkali sacaton) }\end{array}$ & Salado & 3 & 0.004 & $\begin{array}{l}\beta \\
\alpha\end{array}$ & $\begin{array}{l}0.72 \\
98.1\end{array}$ & 2.36 & NS \\
\hline \multirow[t]{2}{*}{$\begin{array}{l}\text { F. arundinacion } \\
\text { (tall fescue) }\end{array}$} & Fawn & 3 & 0.071 & $\begin{array}{l}\beta \\
\alpha\end{array}$ & $\begin{array}{l}-2.18 \\
100.2\end{array}$ & 1.68 & NS \\
\hline & Johnstone & 3 & 0.003 & $\begin{array}{l}\beta \\
\alpha\end{array}$ & $\begin{array}{l}-0.65 \\
94.1\end{array}$ & 2.67 & NS \\
\hline $\begin{array}{l}\text { O. hymenoides } \\
\text { (Indian ricegrass) }\end{array}$ & Paloma & 3 & 0.269 & $\begin{array}{l}\beta \\
\alpha\end{array}$ & $\begin{array}{l}-5.85 \\
89.7\end{array}$ & 2.06 & $* *$ \\
\hline
\end{tabular}

$\dagger * * *, * * *$ indicate significant coefficients at $p \leq 0.05,0.01$, or 0.001 , respectively. NS $=$ nonsignificant coefficient. 
Table 4.36. Regression analyses for the seedling growth response to salinity in the range 0.4 to 30 $\mathrm{dS} / \mathrm{m}$. All coefficients are significant at $\mathrm{p} \leq 0.05$ or less.

\begin{tabular}{|c|c|c|c|c|c|c|c|}
\hline Species & Cultivar & Model & $r^{2}$ & Coefficient & Value & SE & $\mathrm{EC}_{50}$ \\
\hline & & & & & & & $\mathrm{dS} / \mathrm{m}$ \\
\hline $\begin{array}{l}\text { E. pontica } \\
\text { (tall wheatgrass) }\end{array}$ & Orbit & 1 & 0.865 & $\stackrel{\alpha}{\beta}$ & $\begin{array}{l}0.0315 \\
2.345\end{array}$ & $\begin{array}{l}0.0042 \\
0.860\end{array}$ & 27.2 \\
\hline $\begin{array}{l}\text { E. lanceolatus } \\
\text { (streambank wheatgr }\end{array}$ & $\begin{array}{l}\text { Sodar } \\
\text { rass) }\end{array}$ & 1 & 0.945 & $\stackrel{\alpha}{\beta}$ & $\begin{array}{l}0.0634 \\
1.354\end{array}$ & $\begin{array}{l}0.0054 \\
0.243\end{array}$ & 12.0 \\
\hline $\begin{array}{l}\text { L. cinerius } \\
\text { (basin wildrye) }\end{array}$ & Magnar & 1 & 0.881 & $\stackrel{\alpha}{\beta}$ & $\begin{array}{l}0.0462 \\
1.922\end{array}$ & $\begin{array}{l}0.0051 \\
0.555\end{array}$ & 17.9 \\
\hline $\begin{array}{l}\text { P. junced } \\
\text { (Russian wildrye) }\end{array}$ & Bozoisky & 1 & 0.978 & $\stackrel{\alpha}{\beta}$ & $\begin{array}{l}0.0446 \\
1.307\end{array}$ & $\begin{array}{l}0.0022 \\
0.129\end{array}$ & 16.9 \\
\hline $\begin{array}{l}\text { S. airoides } \\
\text { (alkali sacaton) }\end{array}$ & Salado & 2 & 0.787 & $\stackrel{\alpha}{\beta}$ & $\begin{array}{l}0.026 \\
0.00167\end{array}$ & $\begin{array}{l}0.0105 \\
0.001\end{array}$ & 29.6 \\
\hline $\begin{array}{l}\text { F. arundinacea } \\
\text { (tall fescue) }\end{array}$ & Fawn & 1 & 0.985 & $\stackrel{\alpha}{\beta}$ & $\begin{array}{l}0.0581 \\
1.464\end{array}$ & $\begin{array}{l}0.0024 \\
0.134\end{array}$ & 13.4 \\
\hline $\begin{array}{l}\text { O. hymenoides } \\
\text { (Indian ricegrass) }\end{array}$ & Paloma & 1 & 0.867 & $\stackrel{\alpha}{\beta}$ & $\begin{array}{l}0.066 \\
1.652\end{array}$ & $\begin{array}{l}0.0092 \\
0.541\end{array}$ & 12.1 \\
\hline $\begin{array}{l}\text { P. distaris } \\
\text { (alkaligrass) }\end{array}$ & Faults & 2 & 0.897 & $\stackrel{\alpha}{\beta}$ & $\begin{array}{l}0.0334 \\
0.0024\end{array}$ & $\begin{array}{l}0.0102 \\
0.00054\end{array}$ & 25.3 \\
\hline \multirow[t]{2}{*}{$\begin{array}{l}\text { T. fragifertum } \\
\text { (strawberry clover) }\end{array}$} & Palestine & 1 & 0.975 & $\stackrel{\alpha}{\beta}$ & $\begin{array}{l}0.057 \\
2.661\end{array}$ & $\begin{array}{l}0.0027 \\
0.407\end{array}$ & 15.3 \\
\hline & PI 206919 & 2 & 0.970 & $\begin{array}{l}\alpha \\
\beta\end{array}$ & $\begin{array}{l}0.0393 \\
0.00529\end{array}$ & $\begin{array}{l}0.0134 \\
0.00107\end{array}$ & 15.7 \\
\hline $\begin{array}{l}\text { M. polymorpha } \\
\text { (California burclover) }\end{array}$ & Serena & 1 & 0.957 & $\stackrel{\alpha}{\beta}$ & $\begin{array}{l}0.052 \\
2.435\end{array}$ & $\begin{array}{l}0.0032 \\
0.456\end{array}$ & 16.5 \\
\hline $\begin{array}{l}\text { Leucaena } \\
\text { leucocephala } \\
\text { (Koa haole) }\end{array}$ & $\mathrm{K}-8$ & 1 & 0.961 & $\begin{array}{l}\alpha \\
\beta\end{array}$ & $\begin{array}{l}0.0503 \\
1.678\end{array}$ & $\begin{array}{l}0.0036 \\
0.285\end{array}$ & 16.0 \\
\hline A. bisulcatus & PI 241039 & 1 & 0.794 & $\stackrel{\alpha}{\beta}$ & $\begin{array}{l}0.0428 \\
2.896\end{array}$ & $\begin{array}{l}0.0044 \\
1.158\end{array}$ & 20.6 \\
\hline 1. falcatus & PI 314062 & 1 & 0.884 & $\stackrel{\alpha}{\beta}$ & $\begin{array}{l}0.0686 \\
1.989\end{array}$ & $\begin{array}{l}0.0085 \\
0.655\end{array}$ & 12.1 \\
\hline A. ponticus & PI 325208 & 1 & 0.915 & $\stackrel{\alpha}{\beta}$ & $\begin{array}{l}0.136 \\
0.996\end{array}$ & $\begin{array}{l}0.0222 \\
0.288\end{array}$ & 5.1 \\
\hline A. racemosus & PI 315671 & 2 & 0.742 & $\stackrel{\alpha}{\beta}$ & $\begin{array}{l}0.0513 \\
0.003\end{array}$ & $\begin{array}{l}0.0174 \\
0.00095\end{array}$ & 26.0 \\
\hline
\end{tabular}


species (A. bisulcatus and A. racemosus) considered to be primary selenium-accumulators also demonstrated very good salinity tolerance (Table 4.36). The other (non-Astragalus) legumes tested all showed only moderate salinity tolerance with $\mathrm{EC}_{50}$ values of 15 to $17 \mathrm{dS} / \mathrm{m}$ (Tablc 4.36).

The yield response to B were quite varied. Where inhibition of growth was severe, the B concentration required for $50 \%$ relative yield $\left([\mathrm{B}]_{50}\right.$ ) was computed (Table 4.37 ). This parameter was obtainable for six lines, and ranged from 0.8 to $3.4 \mathrm{mM}$. Two lines ('Magnar' basin wildrye and $A$. racemosus) exhibited significant yield declines with increasing $\mathrm{B}$, but relative yields werc $>50 \%$ (Table 4.37). The remaining eight lines showed no significant decreases in yield with increasing [B] up to $4.0 \mathrm{mM}$ (Table 4.37).

Saturated paste extracts of the topsoil samples collected from ponds 4 and 11 had very high EC and B levels, at least in comparison with normal criteria (Table 4.38). These values are, however, consistent with other observations made in low-lyi!s, sites at Kesterson. The total selenium values ranged from $2.8 \mathrm{mg} / \mathrm{kg}$ (Pond 11 ) to $13.2 \mathrm{mg} / \mathrm{kg}$ (Pond 4). Other preliminary analyses suggest that these soils have elevated levels of other trace elements, most notably Mo and $U$ (sce Section 4.8). Additional characterization of these soils samples is underway.

In the "quicis screen" experiment, emergence and growth of 28 out of 30 lines occurred within two weeks in the Hanford soil. In both Kesterson soils, however, no plants emerged within three to four weeks of planting, presumably due to the high salinity or trace element concentrations found in these soils.

\subsubsection{Discussion}

Of the candidate plants scremed for salinity and B tolerance, the following five appear the most promising: tall wheatgrass ('Orbit'), alkali sacaton ('Salado'), alkaligrass ('Faults'), and two astragalus species, $A$. hisulcatus and $A$. racemosus. All exhibited $\mathrm{EC}_{50}$ values greater than $20 \mathrm{dS} / \mathrm{m}$ during seedling growth, and during termination where tested. Boron concentrations up to $4.0 \mathrm{mM}$ had little or no adverse effect on seedling growth or germiniticn of these lines. That 
Table 4.37. Regression analyses for the seedling growth response to boron in the range 0 to $4.0 \mathrm{mM}$.

\begin{tabular}{|c|c|c|c|c|c|c|c|}
\hline Species & Cultivar & Model & $r^{2}$ & Coefficient & Value ${ }^{\dagger}$ & $\mathrm{SE}$ & {$[B]_{s 0}$} \\
\hline & & & & & & & $\mathrm{m} M$ \\
\hline $\begin{array}{l}\text { E. pontica } \\
\text { (tall wheatgrass) }\end{array}$ & Orbit & 3 & 0.012 & $\begin{array}{l}\beta \\
\alpha\end{array}$ & $\begin{array}{l}0.973^{n s} \\
83.3^{-1}\end{array}$ & $\begin{array}{l}3.57 \\
7.66\end{array}$ & $>4.0$ \\
\hline $\begin{array}{l}\text { E. lancealatus } \\
\text { (streambank wheatgr }\end{array}$ & $\begin{array}{l}\text { Sodar } \\
\text { rass) }\end{array}$ & 3 & 0.628 & $\begin{array}{l}\beta \\
\alpha\end{array}$ & $\begin{array}{l}-11.74^{*} \\
83.7\end{array}$ & $\begin{array}{l}3.69 \\
7.9\end{array}$ & 2.9 \\
\hline $\begin{array}{l}\text { L. cinerius } \\
\text { (basin wildrye) }\end{array}$ & Magnar & 2 & j.420 & $\begin{array}{l}\beta \\
\alpha\end{array}$ & $\begin{array}{l}0.407^{* *} \\
0.108^{*}\end{array}$ & $\begin{array}{l}0.105 \\
0.035\end{array}$ & $>4.0$ \\
\hline $\begin{array}{l}P . \text { juncea } \\
\text { (Russian wildrye) }\end{array}$ & Bozoisky & 3 & 0.081 & $\begin{array}{l}\beta \\
\alpha\end{array}$ & $\begin{array}{l}-2.05^{\mathrm{ns}} \\
83.6\end{array}$ & $\begin{array}{l}2.82 \\
6.1\end{array}$ & $>4.0$ \\
\hline $\begin{array}{l}\text { S. airoides } \\
\text { (alkali sacaton) }\end{array}$ & Salado & 3 & 0.558 & $\begin{array}{l}\beta \\
\alpha\end{array}$ & $\begin{array}{l}14.2^{*} \\
98.3\end{array}$ & $\begin{array}{l}5.2 \\
11.1\end{array}$ & $>4.0$ \\
\hline $\begin{array}{l}\text { F. orundinacea } \\
\text { (tall fescuc) }\end{array}$ & Fawn & 1 & 0.448 & $\stackrel{\alpha}{\beta}$ & $\begin{array}{l}0.097_{\mathrm{as}} \\
1.397_{\mathrm{ns}}\end{array}$ & $\begin{array}{l}0.101 \\
1.199\end{array}$ & $>4.0$ \\
\hline $\begin{array}{l}\text { O. hymenoides } \\
\text { (Indian ricegrass) }\end{array}$ & Paloma & 1 & 0.727 & $\underset{\beta}{\alpha}$ & $\begin{array}{l}0.2097^{*} \\
1.026^{*}\end{array}$ & $\begin{array}{l}0.0629 \\
0.3846\end{array}$ & 3.3 \\
\hline $\begin{array}{l}\text { P. distons } \\
\text { (alkaligrass) }\end{array}$ & Faults & 3 & 0.212 & $\begin{array}{l}\beta \\
\alpha\end{array}$ & $\begin{array}{l}17.33^{\mathrm{ns}} \\
129.7\end{array}$ & $\begin{array}{l}13.66 \\
29.3\end{array}$ & $>4.0$ \\
\hline \multirow[t]{2}{*}{$\begin{array}{l}\text { T. fragiferrum } \\
\text { (strawberry clover) }\end{array}$} & Palestine & 3 & 0.490 & $\begin{array}{l}\beta \\
\alpha\end{array}$ & $\begin{array}{l}-9.55^{\mathrm{ns}} \\
94.7\end{array}$ & $\begin{array}{l}3.98 \\
11.1\end{array}$ & $>4.0$ \\
\hline & PI 206919 & 3 & 0.389 & $\begin{array}{l}\beta \\
\alpha\end{array}$ & $\begin{array}{l}-8.13^{\mathrm{nB}} \\
103.7^{-1}\end{array}$ & $\begin{array}{l}4.16 \\
8.9\end{array}$ & $>4.0$ \\
\hline $\begin{array}{l}\text { M. polymorpha } \\
\text { (California burclover }\end{array}$ & Serena & 1 & 0.994 & $\stackrel{\alpha}{\beta}$ & $\begin{array}{l}0.878^{* * *} \\
0.869^{* * *}\end{array}$ & $\begin{array}{l}0.0356 \\
0.0559\end{array}$ & 0.8 \\
\hline $\begin{array}{l}L . \\
\text { leucocephala } \\
\text { (koa haole) }\end{array}$ & $\mathrm{K}-8$ & 1 & 0.947 & $\underset{\beta}{\alpha}$ & $\begin{array}{c}0.205^{* * *} \\
1.01^{* * *}\end{array}$ & $\begin{array}{l}0.027 \\
0.163\end{array}$ & 3.4 \\
\hline A. birulcatus & PI 241039 & 3 & 0.794 & $\begin{array}{l}\beta \\
\alpha\end{array}$ & $\begin{array}{l}-4.54^{\mathrm{ns}} \\
115.0^{-1}\end{array}$ & $\begin{array}{l}4.81 \\
10.3\end{array}$ & $>4.0$ \\
\hline A. falcatus & PI 314062 & 1 & 0.921 & $\stackrel{\alpha}{\beta}$ & $\begin{array}{c}0.424^{* * *} \\
1.233^{* *}\end{array}$ & $\begin{array}{l}0.047 \\
0.251\end{array}$ & 1.8 \\
\hline A. ponticus & PI 325208 & 1 & 0.833 & $\underset{\beta}{\alpha}$ & $\begin{array}{c}0.310^{* * *} \\
1.627^{*}\end{array}$ & $\begin{array}{l}0.045 \\
0.527\end{array}$ & 2.6 \\
\hline A. racemosus & PI 315671 & 4 & 0.716 & $\alpha$ & $0.0138^{* *}$ & 0.0023 & $>40$ \\
\hline
\end{tabular}

$\dagger_{*}^{* * *}, * * *$ indicate significant coefficients at $p \leq 0.05,0.01$, or 0.001 , respectively. ns $=$ nonsignifir.ant coefficient. 
Table 4.38. Properties of the topsoil samples collected from Kesterson Reservoir.

\begin{tabular}{|c|c|c|c|c|c|}
\hline \multirow[b]{2}{*}{ Sample } & \multicolumn{4}{|c|}{ Saturated Paste Extract } & \multirow[b]{2}{*}{$\mathrm{Se}_{\mathrm{T}}^{\dagger}$} \\
\hline & $\mathrm{pH}$ & EC & {$[\mathrm{B}]^{\dagger}$} & $\operatorname{SAR}^{\dagger}$ & \\
\hline & & $\mathrm{dS} / \mathrm{m}$ & $\mathrm{mg} / \mathrm{L}$ & & $\mathrm{mg} / \mathrm{kg}$ \\
\hline Pond 4 & 7.7 & 33.5 & 22.4 & 41 & 13.2 \\
\hline Pond 11 & 7.6 & 38.4 & 47.9 & 51 & 2.8 \\
\hline
\end{tabular}

$\dagger$ Preliminary analysis, not subject to $Q A / Q C$ procedures. 
these two Astragalus species exhibited superior salinity and B tolerance has encouraging implications for the possibility of obtaining significant plant uptake of selenium from Kesterson soils. Both species are I ported to be among the group of primary selenium accumulators.

The failure to obtain any emergerice or growth, with any candidate line, in both Kesterson topsoil samples suggests that more sophisticated management of these soils may be required. At this juncture, we are inclined to attribute this failure to excessive salinity, under the assumption that the EC's at moderate soil moisture contents (i.e., field capacity) were substantially higher than those observed in saturated paste extracts. One possible approach is to apply enough water to leach salts out of the seed zone, but not out of the soil profile. If the surface soil salinity can be reduced enough to permit germination and emergence, the more tolerant plants may be able to persist as the salt gradually migrates back towards the soil surface. We are presently conducting preliminary experiments using the "conetainers" to address this question.

Altematively, the high trace element levels in these soils, either alone or in concert, may be precluding plant growth. Pending the outcome of the aforementioned studies, we will attempt to ascertain whether this is the case. One possible approach is to "dilute" the Kesterson soils with varying proportions of the Hanford sandy loam (i.e., a "clean" soil). By identifying the critical mixture composition at which growth is inhibited, and by analyzing the plant tops and roots, we may be able to identify the most growth-limiting element(s).

If plants can be successfully reared in the Kesterson soils, we will proceed with our original objective of quantifying selenium uptake by the plants. This information will be critical for the assessment of selenium dissipation strategies that can be employed at Kesterson. 


\title{
4.7. VOLATILIZATION OF SELENIUM FROM DIFFERENT TYPES OF PLANTS FOR THE REMOVAL OF SELENIUM FROM KESTERSON RESERVOIR
}

\author{
Norman Terry, M. Rao and C. Carlson, \\ Department of Plant Biology', \\ University of Califomia, Berkeley
}

\subsubsection{Objectives}

The main objectives of this project are (i) to detennine the rates of volatilization of selenium (Se) for a range of plant species including, selenium accumulators, crop plants and native species, and (ii) to determine the relationship of seleniurn volatilization to sclenium uptake and partitioning. This is to assess the selenium mass balance for a particular species when grow'n under high selenium conditions.

\subsubsection{Plant Materials and Methods}

The selenium accumulators include Astragalus bisulcatus, Astragalus hamosus and Astragalus cymbicarpos. The selenium nonaccumulator crops include cotton (Acala SJ-2), and barley (UC 337). The range plant species include Atriplex numularia and Brassica juncea. Plants were grown in solution culture throughout growth with sodium selenate (equivalent to $20 \mu \mathrm{M}$ Se or 1.6 $\mathrm{mg} s e(L)$ in $1 / 2$ Hoagland solution. For Astragalus species, $50 \mu \mathrm{M} \mathrm{P}$ was used in the nutrient solution. Higher $\mathrm{P}$ concentrations in the nutrient solution were found to be toxic to Astragalus species. The plants were grown in growth chambers at $500 \mu \mathrm{mol} \cdot \mathrm{m}^{-2} \cdot \mathrm{s}^{-1}$ photon flux density (PFD), $25^{\circ} \mathrm{C}$ and 16 hour photoperiod.

We sandardized the optimum giowing conditions for all of the plant species mentioned above. We have developed a gas exchange system for measuring the selenium volatilization rates from an intact plant for a prolonged time under controlled environmental conditions (light, air temperature, leaf temperature and relative humidity). This whole plant gas exchange system 
measures the selenium volatilization rates very accurately. The system comprises a plant chamber made with plexiglass (courtesy Prof. L. J. Waldron) and a light source (water-cooled xenon-arc illumination system) which is attached to a conventional leaf gas exchange system. The rate of air flow in the system is maintained at $61 / \mathrm{min}$. A small fan built inside the plant chamber circulates air. The leaf temperature is monitored by using a thermocouple.

Selenium volatilization rates were measured by passing the air over the whole plant into an alkaline peroxide solution ( $100 \mathrm{ml}: 80 \mathrm{ml}$ of $0.05 \mathrm{~N} \mathrm{NaOH}+20 \mathrm{ml}$ of $30 \% \mathrm{H}_{2} \mathrm{O}_{2}$ ) for 2 days. Prior to placing the plant into the correction chamber, we provided $20 \mu \mathrm{M}$ Se in half-Hoagland solution, i.e., the original solution was replaced with fresh solution. To analyze selenium from the trap, samples were boiled to drive off the residual $\mathrm{H}_{2} \mathrm{O}_{2}$ (using a hot plate for $15 \mathrm{~min}$ ), allowed to cool and made up to $100 \mathrm{ml}$ volume. We took $25 \mathrm{ml}$ aliquot from the above sample and auded to $25 \mathrm{ml}$ of concentrated $\mathrm{HCl}$ (final concentration $6 \mathrm{~N}$ ). We then boiled the sample for $1 \mathrm{~h}$, allowed it to cool and made it up to $50 \mathrm{ml}$ with distilled $\mathrm{H}_{2} \mathrm{O}$. Total selenium in the sample was estimated by using AAS/hydride generation method (courtesy Prof. Harvey Doner).

After determining the rate of selenium volatilization, the plant was removed from the chamber and scparated into roots, stems and leaves. Leaf area/plant was determined using a Delta-T devices leaf area meter so that selenium volatilization rates could be expressed per unit leaf area. The plant samples were dried at $50^{\circ} \mathrm{C}$, weighed and tissue selenium concentrations were determined using AAS/hydride generation method.

\subsubsection{Results}

Selenium volatilization rates have been monitored for 7 test plants, including 3 selenium accurnulators, 2 range and 2 crop species. The seleni,um accumulator, Astragalus bisulcatus was the champion volatilizer, volatilizing more selenium than any other species tested $(0.45$ $\mu \mathrm{g}$ selenium $\cdot \mathrm{plant}^{-1} \cdot \mathrm{day}^{-1} ; \quad 25.6 \mu \mathrm{g}$ selenium $\cdot \mathrm{m}^{-2}$ leaf area $\cdot \mathrm{day}^{-1} ; 407 \mu \mathrm{g}$ selenium $\cdot \mathrm{Kg}^{-1}$ leai dry wt. day ${ }^{-1}$ ). We were surprised to find however, that the two crop plants, cotton and barley, volatilized much more selenium per plant than the remaining two accumulator species, Astragalus hamosus and Astragalus cymbicarpos (Figure 4.52). Although the selenium 


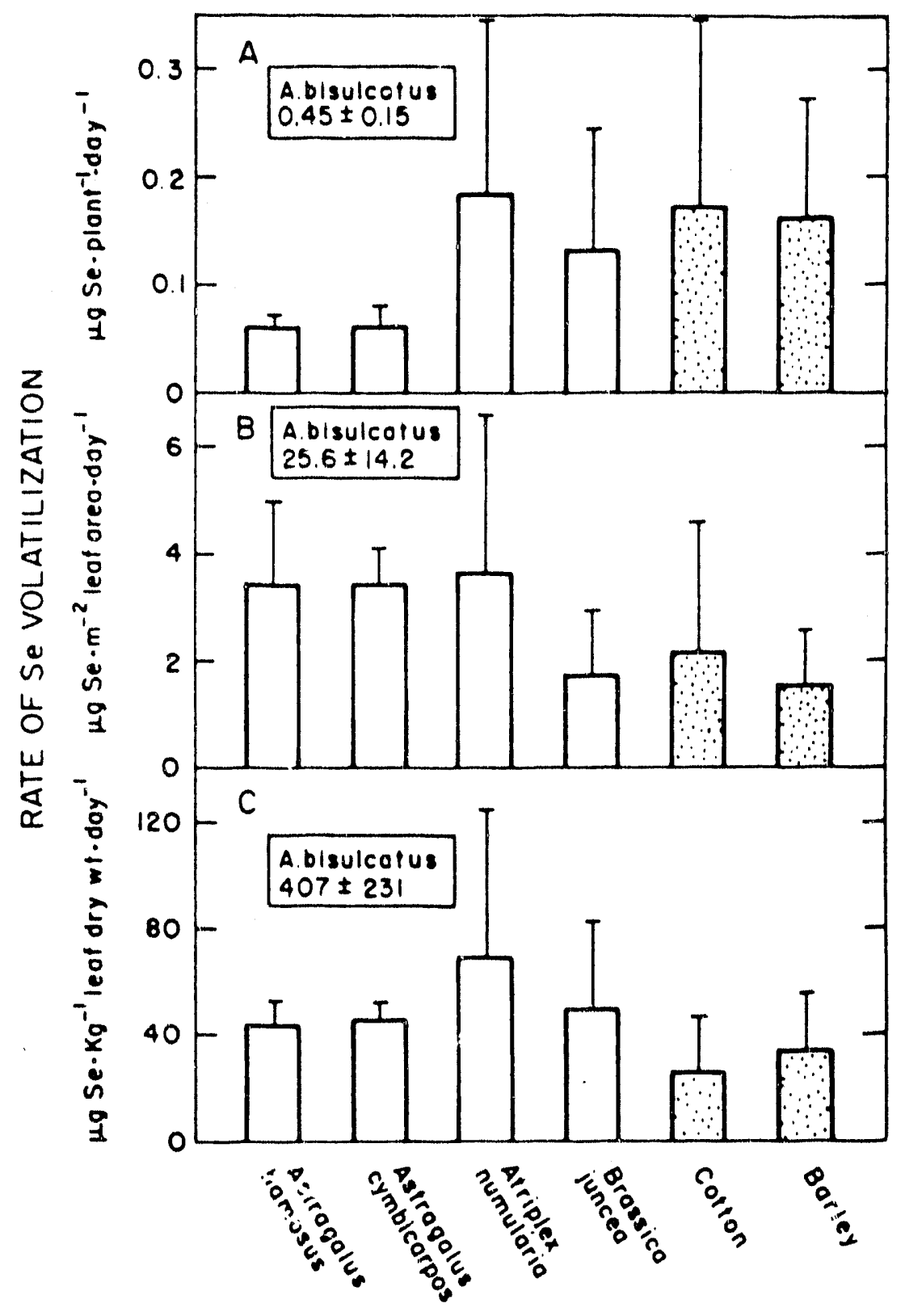

Figure 4.52. The rates of sel slium volatilization for 7 different plant species including selenium accumulator: (Astragalus bisulcatus, Astragalus hamosus, Astragalus cymbicarpos), range plants (Atriplex numularia, Brassica juncea) and crop species (cotton, barley). Plants were grown in growth chambers in $1 / 2$ Hoagland solution with 20) $\mu \mathrm{M}$ sodium selenate. Values are mean \pm S.D. for 3 replications. 
accumulator species outperformed the crop plant species on a per unit leaf area basis (Figure 4.52), the crop plants had faster growth rates and greater total leaf areas (Table 4.39) so that the rates of selenium volatilized per plant by the crop plants were comparable to those of the 2 range species. (The crop plants were grown for 5 weeks compared to 6 to 7 weeks for the accumulator plants).

There seems to be little relation between the rate of selenium volatilization and the amount of selenium present in the leaf. In barley, large amounts of selenium were transported to leaves (Figure 4.53a), yet the rate of selenium volatilization per area was the lowest of all the species tested here (Figure 4.52b). Cotton has lower leaf selenium concentration (Figure 4.53a), but volatilized selenium at a faster rate per area than barley. Similarly, there appeared to be little evidence that the rates of volatilization among the 6 species (excluding A. bisulcatus) were correlated with the total uptake of selenium per plant in each case (Figure 5.42 and Table 4.39). A. bisulcatus, however, had the highest concentration of selenium in leaves and this was correlated with the highest rate of selenium volatilization (Figures 4.52 and 4.53 ).

Barley is an interesting crop species in terms of its potential ability to remove selenium from soils, because it volatilized selenium at rates comparable to the other species except for $A$. bisulcatus (Figure 4.52). This was due in part to the high rate of expansion of the total leaf surface which was exhibited by barley. Furthermore, barley accumulated high concentrations of selenium in leaf tissue (Figure 4.52). This in tum could potentially contribute to the removal of selenium from seleniferous soils since leaves and stem could be harvested and removed from the site. 
Table 4.39. Plant growth and selenium uptake for 7 different plant species. Plants were grown in growth chambers in $1 / 2$ Hoagland solution with $20 \mu \mathrm{M}$ sodium ielenate. Valucs are mean \pm S.D. for 3 replications.

\begin{tabular}{|c|c|c|c|c|}
\hline Plant Species & $\begin{array}{c}\text { Age } \\
\text { (days) }\end{array}$ & $\begin{array}{l}\text { Total dy matter } \\
(\mathrm{g} \cdot \mathrm{plant}-1)\end{array}$ & $\begin{array}{l}\text { Total Lsaf Area } \\
\text { (cm².plant-1) }\end{array}$ & $\begin{array}{l}\text { Se uptake plant }{ }^{-1} \\
\text { (mg.plant }-1 \text { ) }\end{array}$ \\
\hline$\frac{\text { Astragalus }}{\text { bisulcatus }}$ & $45 \pm 9$ & $2.92 \pm 1.58$ & $212 \pm 100$ & $2.94 \pm 1.36$ \\
\hline$\frac{\text { Astragalus }}{\text { hamosus }}$ & $43 \pm 3$ & $3.7 \pm 1.23$ & $200 \pm 58$ & $1.26 \pm 0.31$ \\
\hline$\frac{\text { Astragalus }}{\text { cymbicarpos }}$ & $47 \pm 3$ & $2.68 \pm 1.19$ & $176 \pm 103$ & $1.31 \pm 0.85$ \\
\hline$\frac{\text { Atriplex }}{\text { numularia }}$ & $39 \pm 2$ & $4.81 \pm 1.66$ & $519 \pm 199$ & $1.2 \pm 0.46$ \\
\hline$\frac{\text { Brassica }}{\text { juncea }}$ & $32 \pm 9$ & $3.74 \pm 0.74$ & $685 \pm 94$ & $3.29 \pm 1.28$ \\
\hline Cotton & $35 \pm 2$ & $9.85 \pm 4.42$ & $854 \pm 240$ & $3.35 \pm 2.91$ \\
\hline Barley & $38 \pm 2$ & $13.8 \pm 6.42$ & $1009 \pm 67$ & $4.03 \pm 0.88$ \\
\hline
\end{tabular}




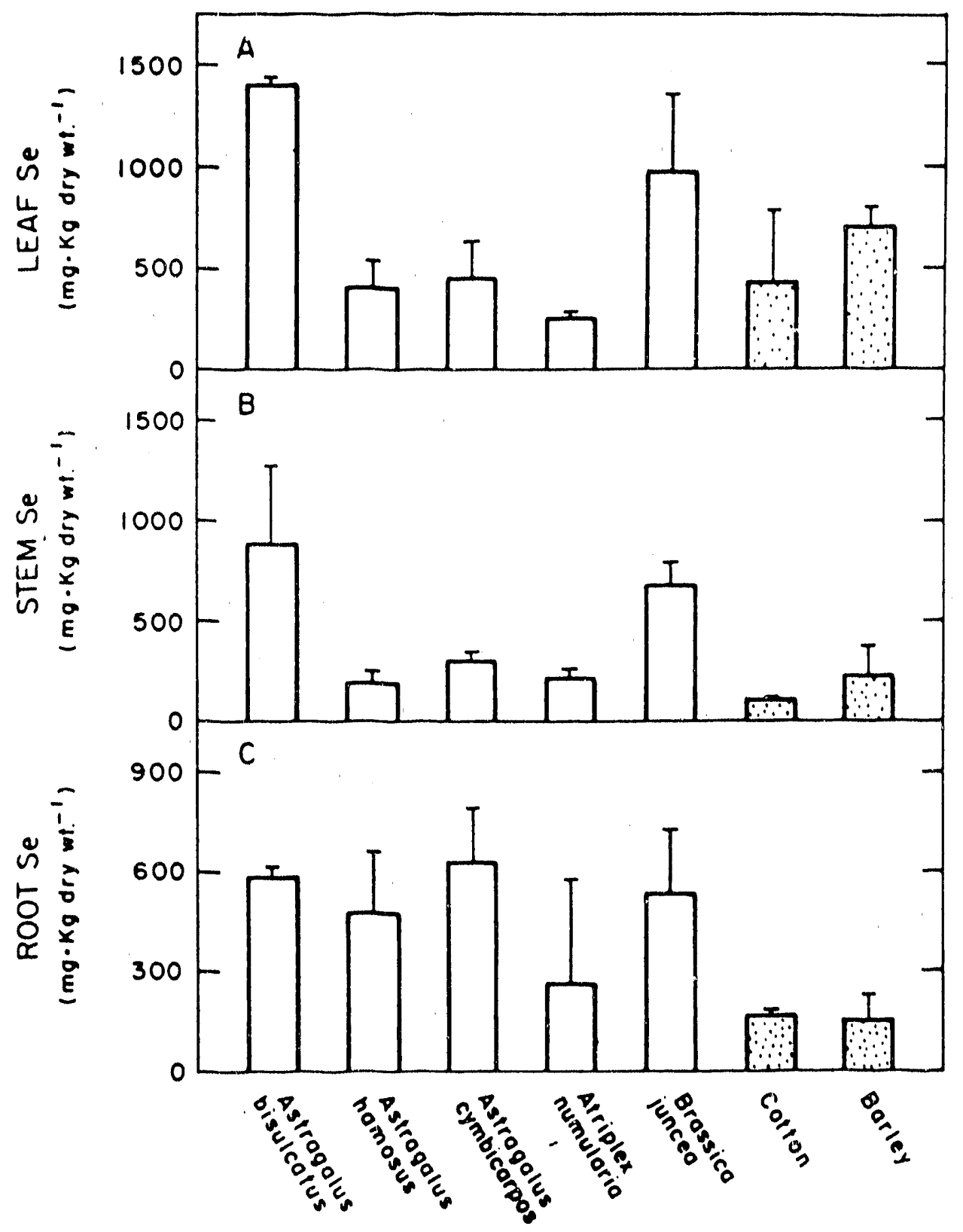

Figure 4.53. Tissue selenium levels in leaves (A), stems (B) and roots (C) for 7 different plant species. Plants were grown in growth chambers in $1 / 2$ Hoagland solution with $20 \mu \mathrm{M}$ sodium selenate. Values are mean \pm S.D. for 3 replications. 


\title{
4.8. SPATIAL DISTRIBUTION OF TRACE ELEMENTS IN RELATION TO SALINITY OF KESTERSON RESERVOIR SEDIMENTS
}

\author{
Gordon R. Bradford and Dariush Bakhtar \\ Department of Soil and Environmental Sciences \\ University of Califomia, Riverside
}

\subsubsection{Objective}

The principal objective of this effort is to measure concentrations of trace elements in relation to salinity of Kesterson sediments.

\subsubsection{Methods}

Thirty-six surface ( $<5 \mathrm{~cm}$ depth) sediment samples (three from each pond) were collected in October 1988 by John Fields (USBR). Four San Luis Drain sediment samples collected by the U.S.G.S. were included for total analyses. One-to-one $(\mathrm{m} / \mathrm{v})$ water extracts were prepared to separate and concentrate several trace elements. Aliquot \#2 was analyzed by hydride generation for selenium, arsenic, antimony, besmuth, germanium, tellurium and mercury. Aliquot \#3 was diluted and analyzed by direct nebulization. One-gram portions of each sample were dissolved by $\mathrm{HNO}_{3}, \mathrm{HCl}$, and $\mathrm{HF}$ treatment and analyzed for total trace element content.

Separate 1-gram portions of sediment samples were extracted with hot concentrated nitric acid and uranium was separated from other salts and particularly iron by passing a $5 \mathrm{NHNO}_{3}$ solution of the sample $(15 \mathrm{ml})$ through a $25 \mathrm{~cm} \times 6 \mathrm{~mm}$ I.D. glass column containing an anion exchange resin (AG1-X8 100-200 mesh nitrate form). This was followed by the addition of $8 \mathrm{ml}$ of $5 \mathrm{~N} \mathrm{HNO}_{3}$ to remove salts and then $15 \mathrm{ml}$ of deionized distilled water to remove uranium. The solution containing uranium was evaporated to $1.5 \mathrm{ml}$ and analyzed by ICAP-OES.

Three undisturbed sediment/soil profiles were sampled in Ponds 1, 4 and 9 of Kesterson Reservoir for characterization of the soil-water interactions controlling trace element solubility. 
Sequential 1:1 sediment water extracts were prepared from each profile and ana!; zed for trace and major elements.

\subsubsection{Results}

Figure 4.54 shows the sampling locations within Kesterson ponds. Due to usage patterns during the period from 1981 to 1986 lower numbered ponds would most likely have received the largest amount of drainage water. This is reflected by concentration data for total dissolved solids and selected elements shown in Figures 4.55 to 4.69. Areas of highest concentrations are outlined on most figures and frequently comprise parts of Ponds 1 through 4 and areas near the western boundary of Pond 10. Concentrations of soluble components, $1 /$ ith the exception of $\mathrm{Ca}$ and $\mathrm{Si}$, are often orders of magnitude higher in Ponds 1 to 4 compared to surrounding areas.

Nitric acid extracted levels of uranium in surface sediments of Kesterson (Figure 4.69) are close to the range of total uranium (1 - $4 \mathrm{mg} / \mathrm{kg}$ ) reported in normal soils (Harmensen and deHaan, 1980).

Figures 4.70 to 4.73 show the variability of trace element solubility with depth and sequence of extraction in a profile from Kesterson Pond 9. Vanadium and arsenic concentrations are higher by orders of magnitude in the third and fourth sequential water extracts compared to the first extract. This solubility pattern is in sharp contrast to that for molybdenum and selenium which shows the highest concentrations of these elements in the frst extractions. Occlusion of these elements with precipitates of major salts and/or association with clay particles are suggested as possible mechanisms controlling their solubility.

Relatively low ratios of total to water-soluble concentrations of turon, molybdenum and uranium (Table 4.40) suggest that these elements are in more soluble chemical forms in the surface sediments compared to other trace elements.

Table 4.41 lists correlation coefficients between selected trace elements and salinity indices in Kesterson sediment extracts. Relatively high positive correlation coefficients are observed for boron, selenium and strontium with magnesium, sodium and TDS. Positive associations of nickel 


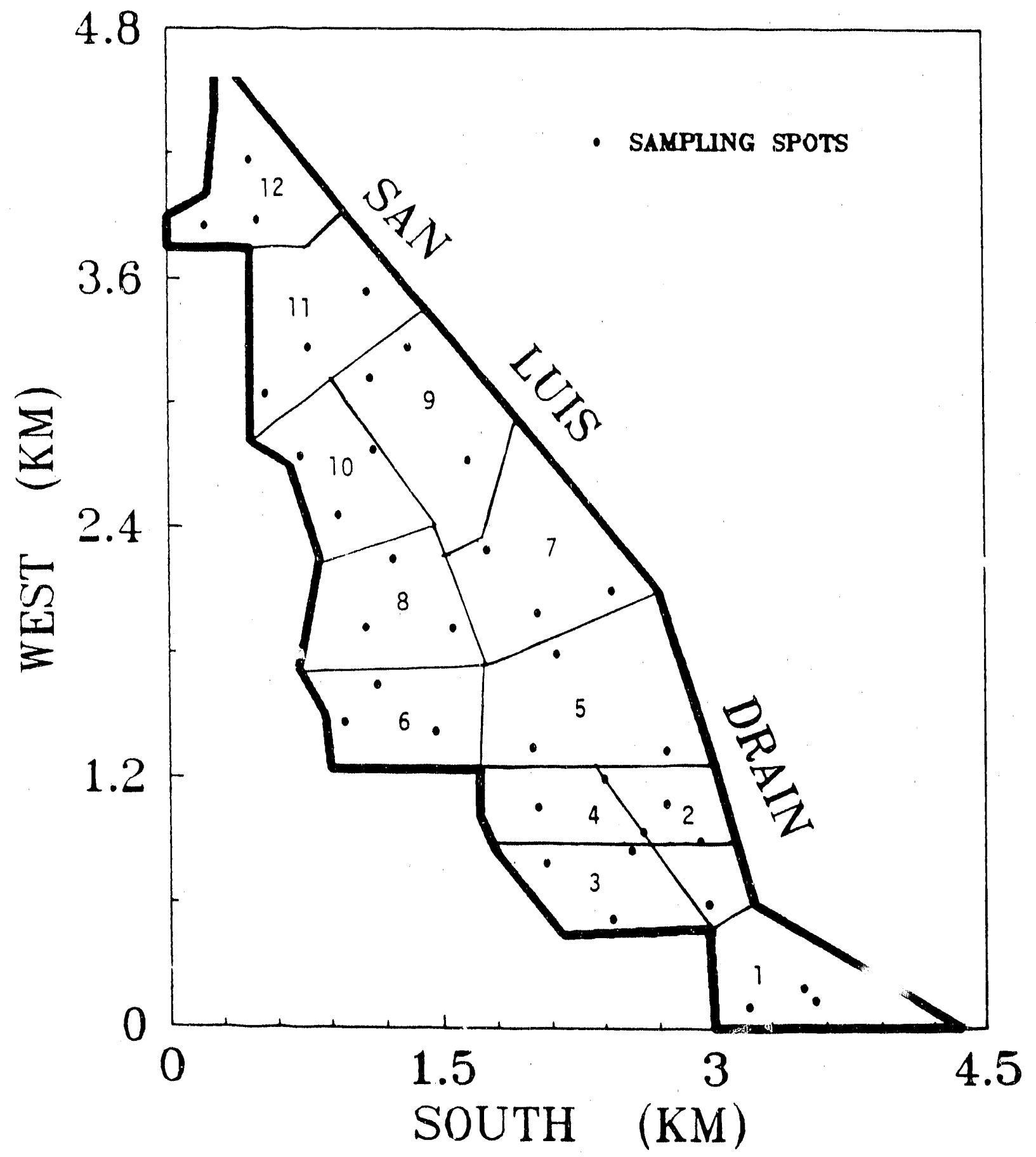

Figure 4.54. Configuration of Kesterson Reservoir. 


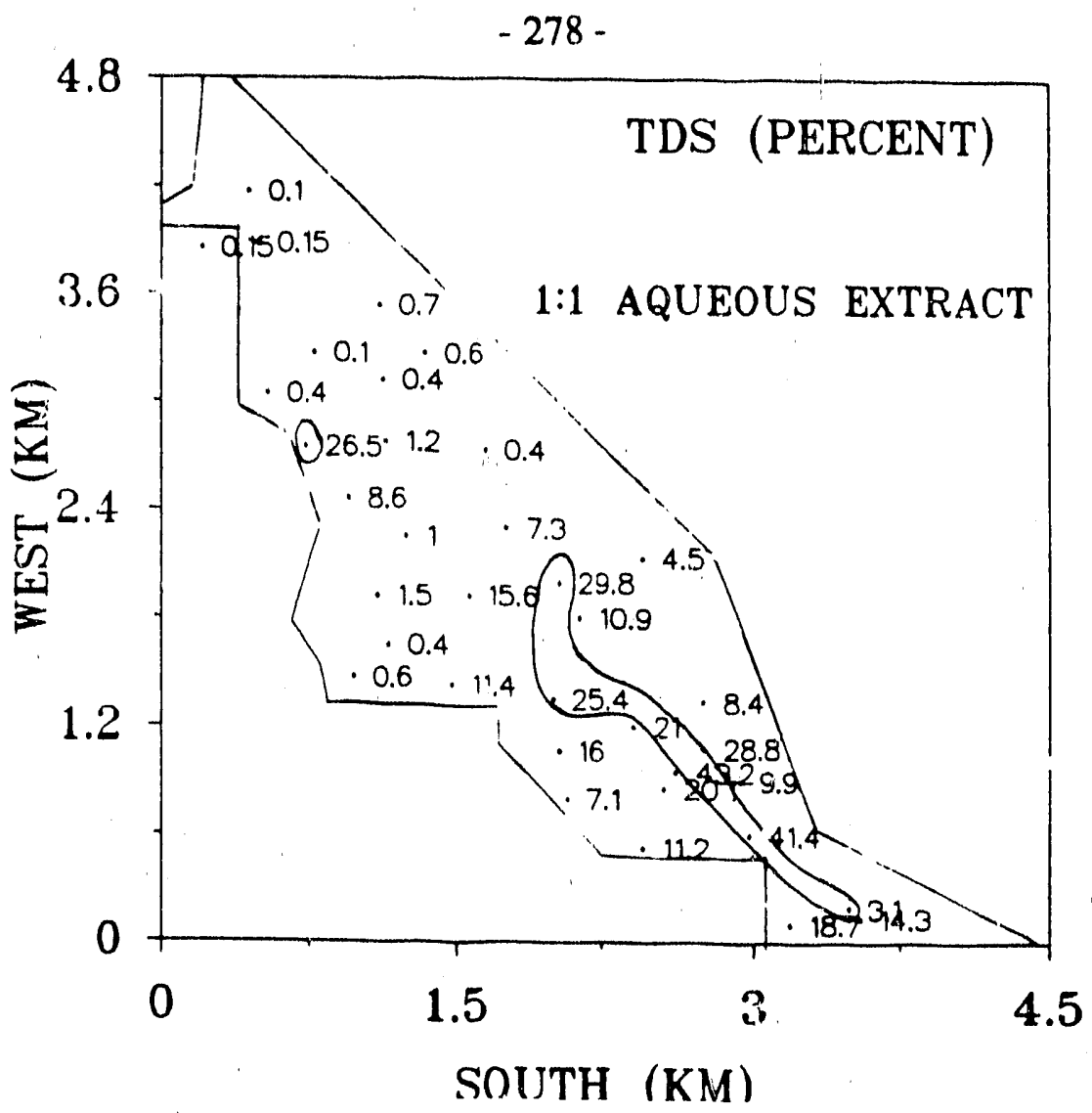

Figure 4.55. Distribution of total dissolved solids in surface sediments of Kesterson.

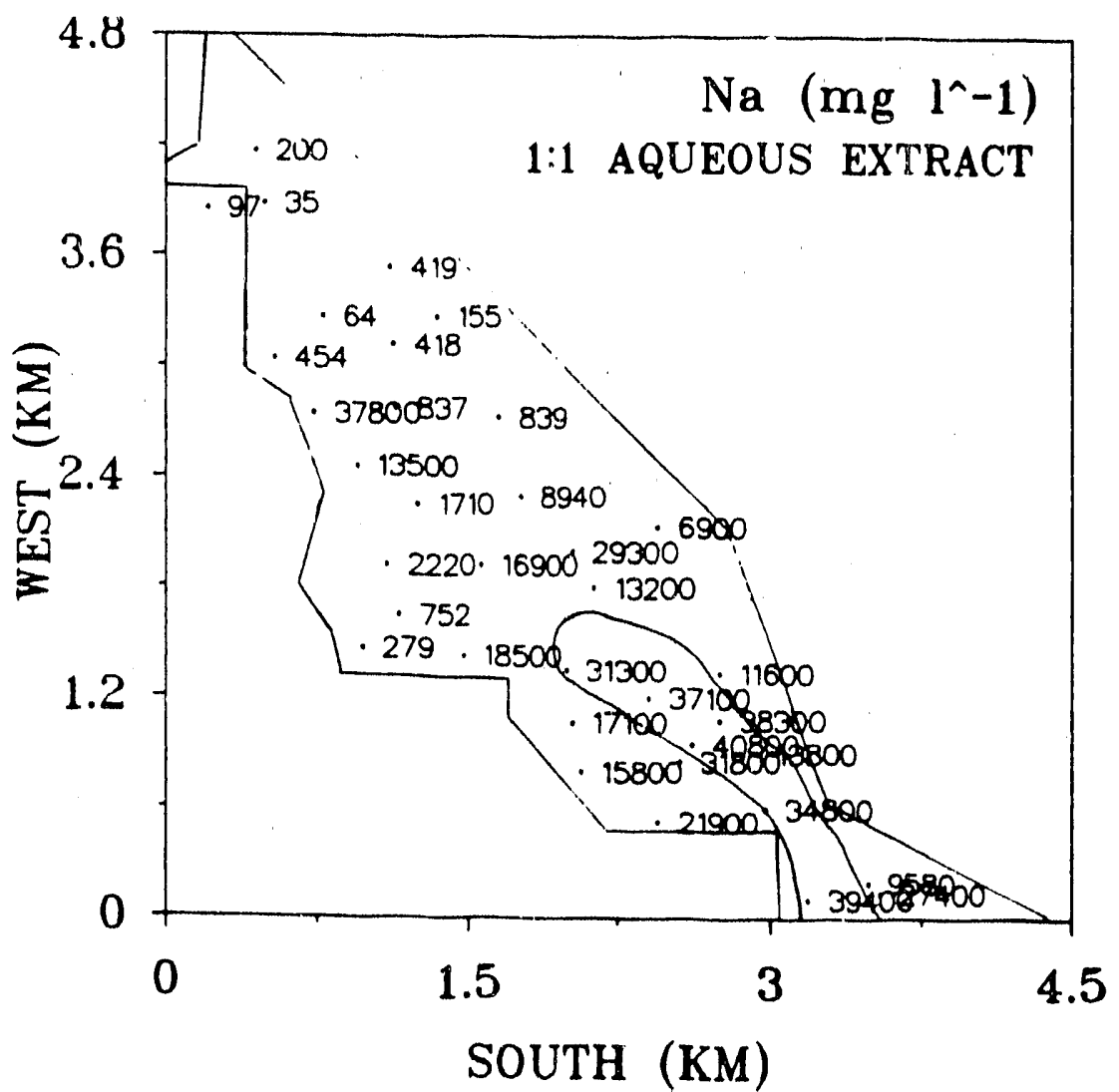

Figure 4.56. Distribution of sodium in surface sediment, of Kesterson. 


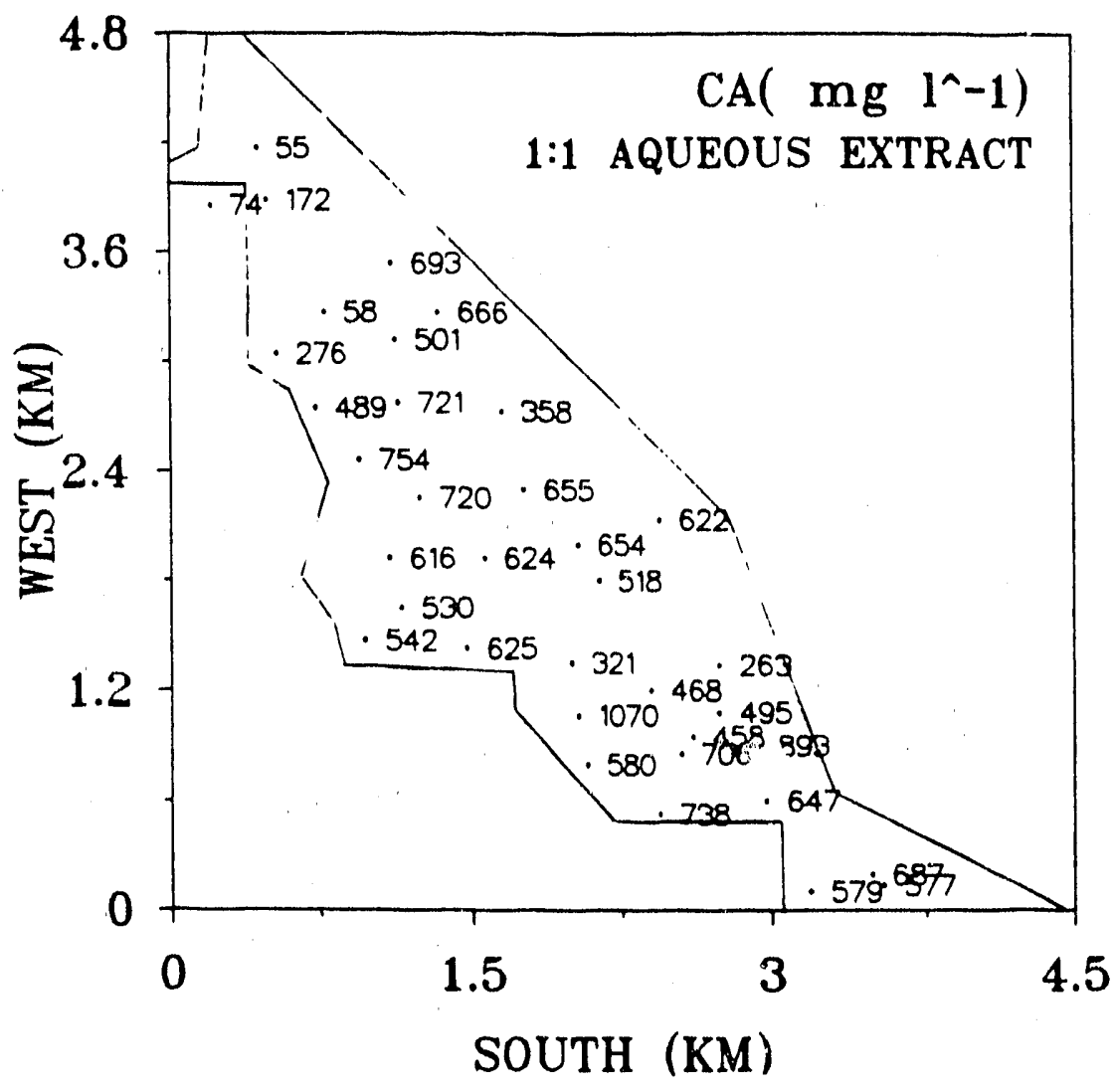

Figure 4.57. Distribution of calcium in surface sediments of Kesterson.

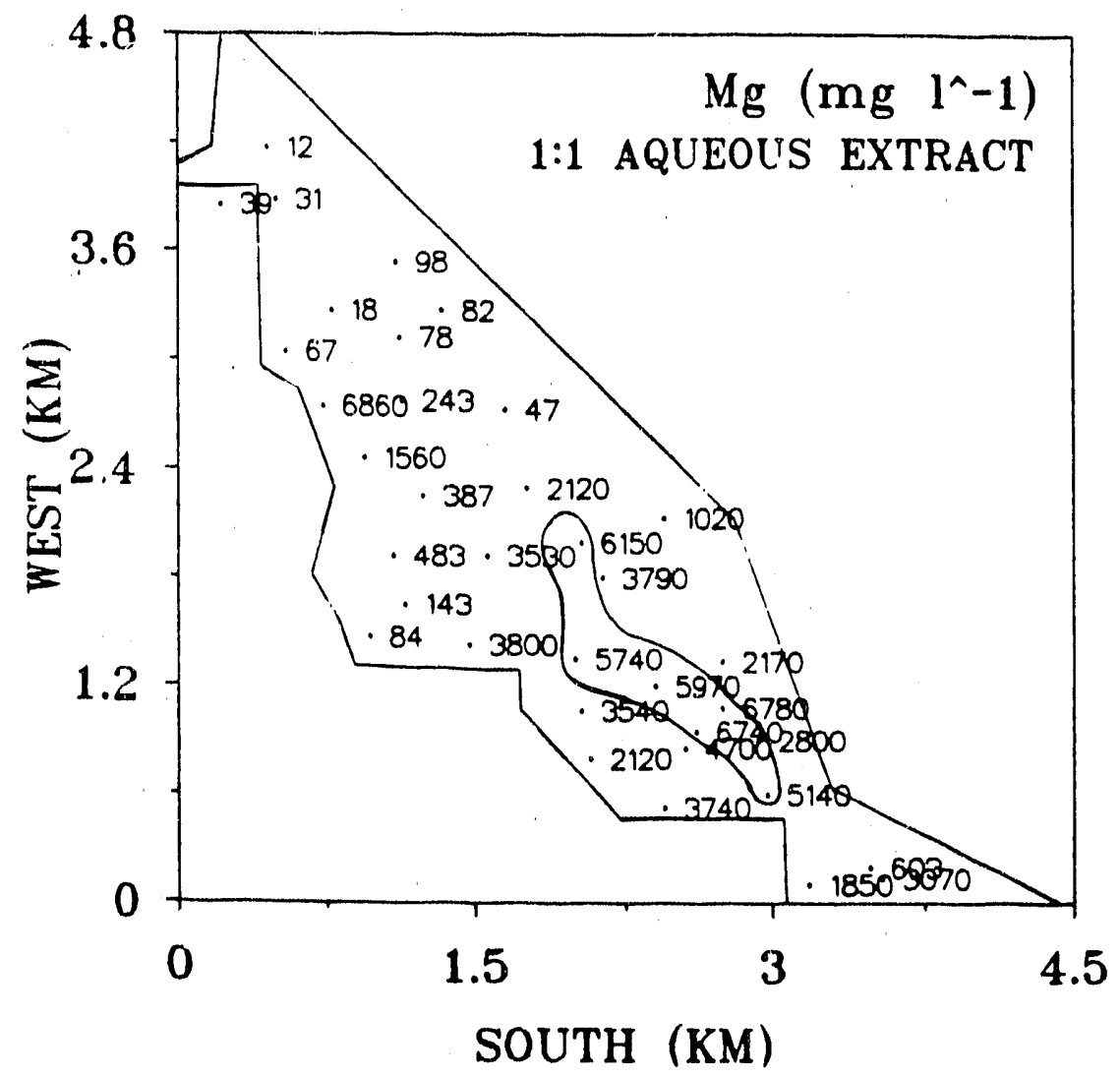

Figure 4.58. Distribution of magnesium in surface sediments of Kesterson. 
$-280-$

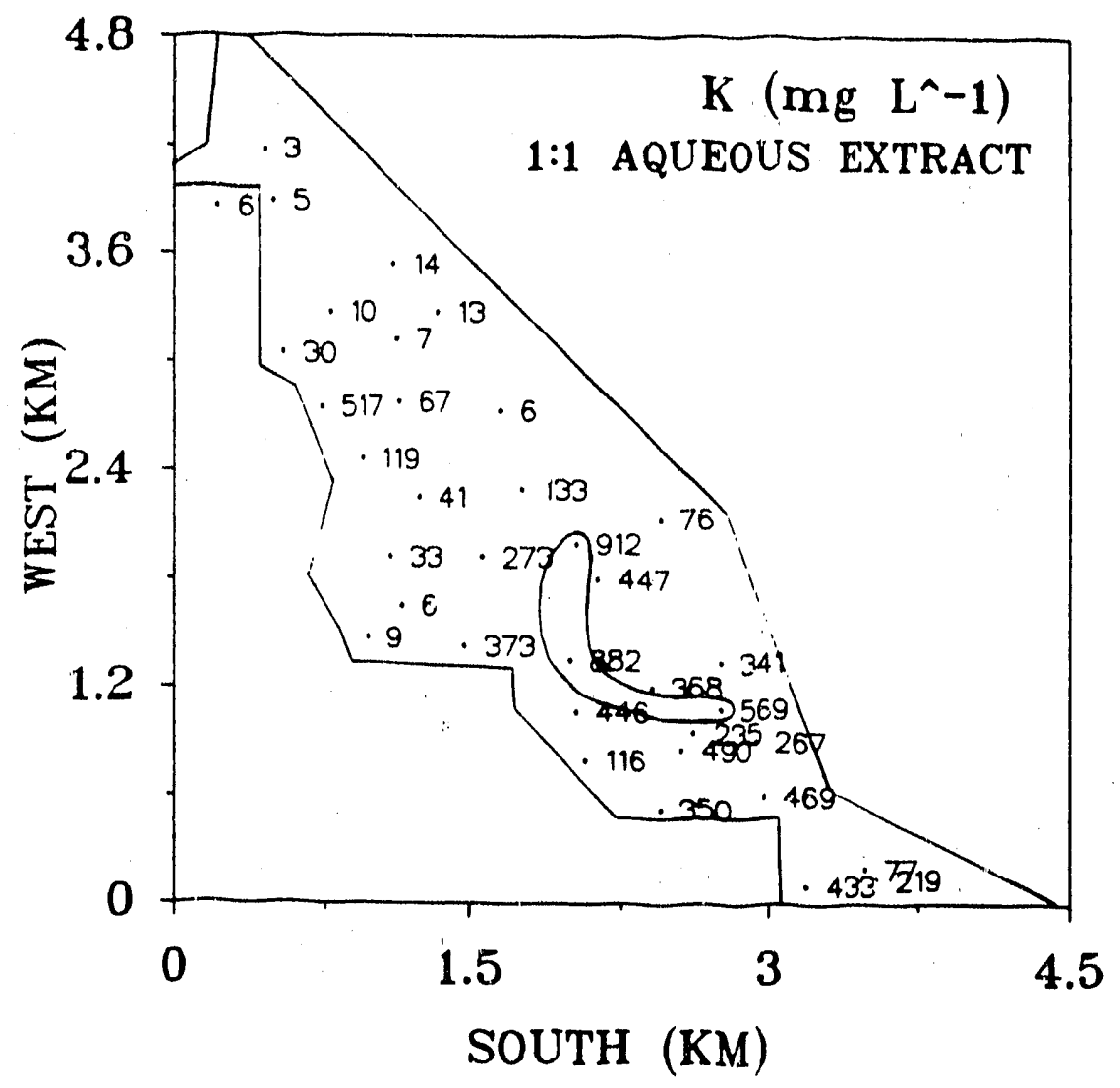

Figure 4.59. Distribution of potassium in surface sediments of Kesterson.

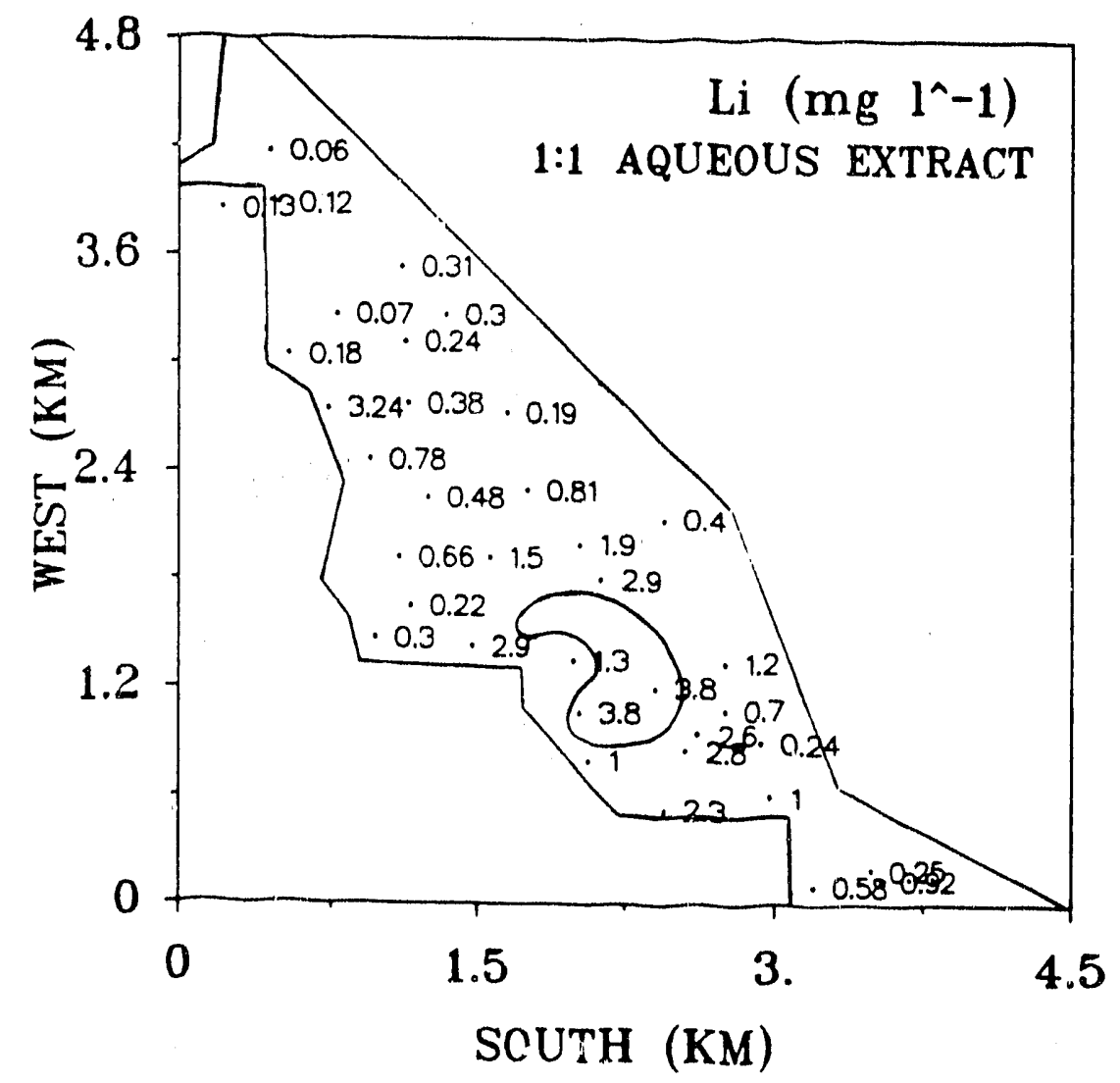

Figure 4.60. Distribution of lithium in surface sediments of Kesterson. 


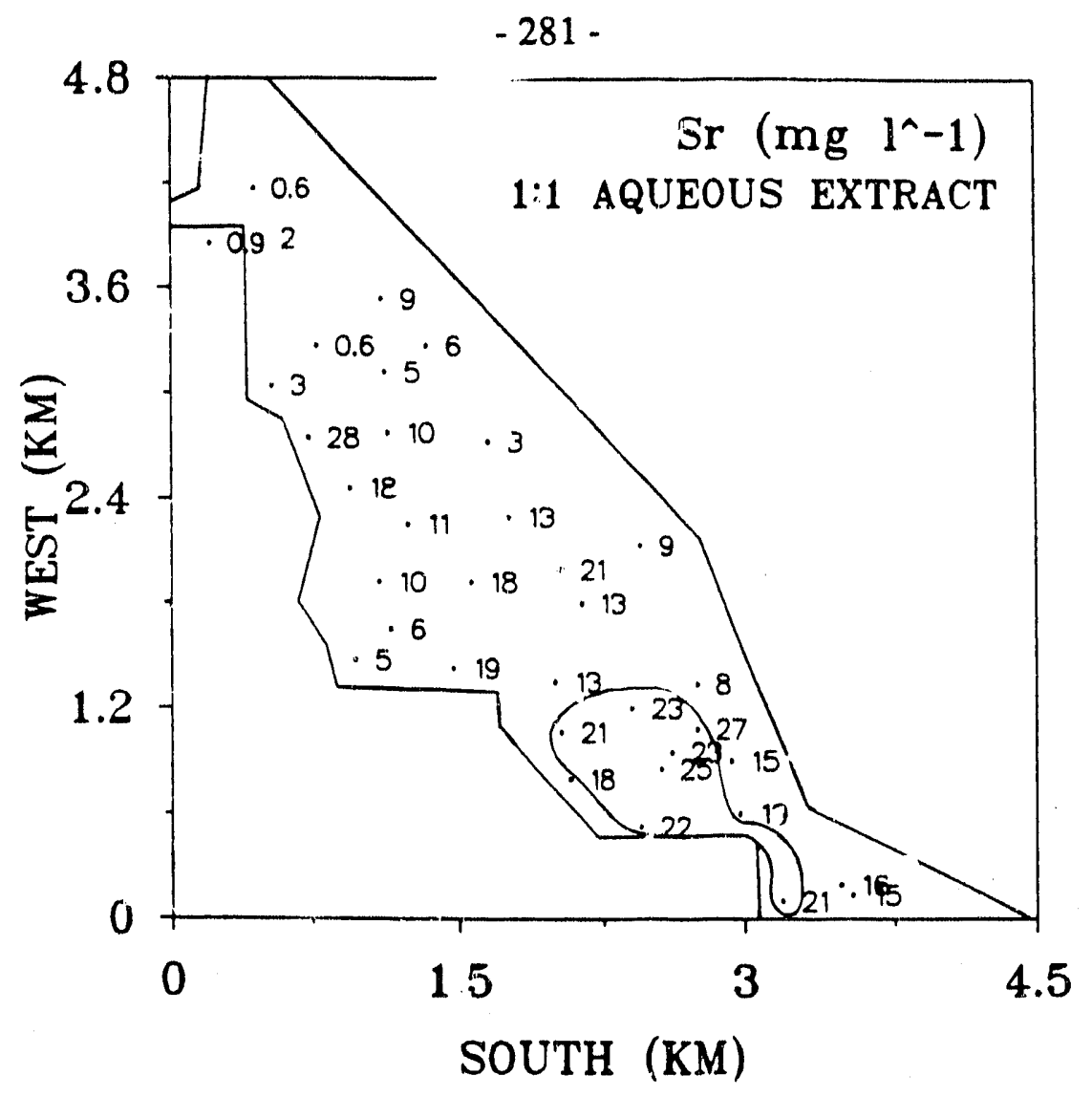

Figure 4.61. Distribution of strontium in surface sediments of Kesterson.

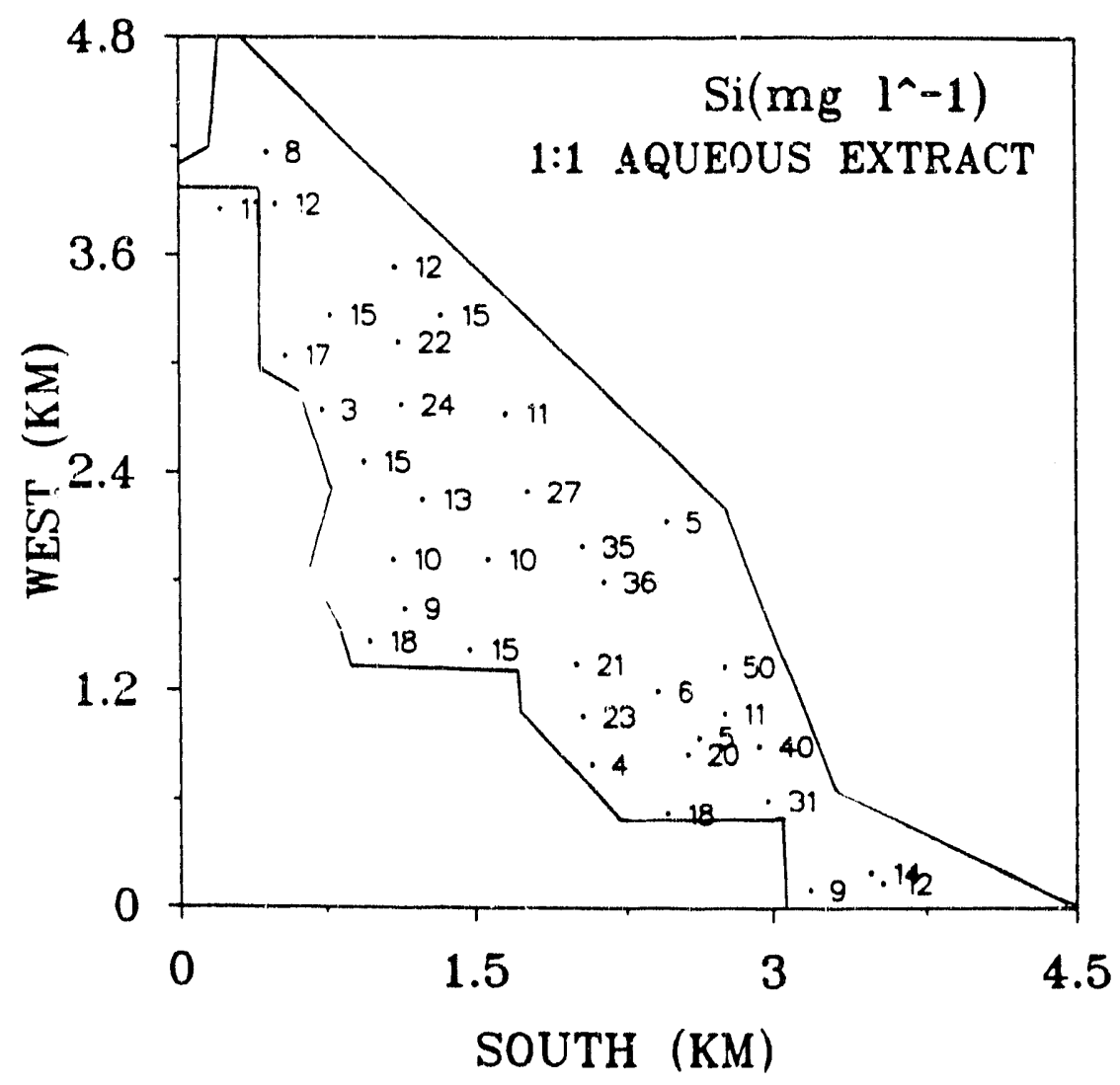

Figure 4.62. Distribution of silica in surface sediments of Kesterson. 
-282 -

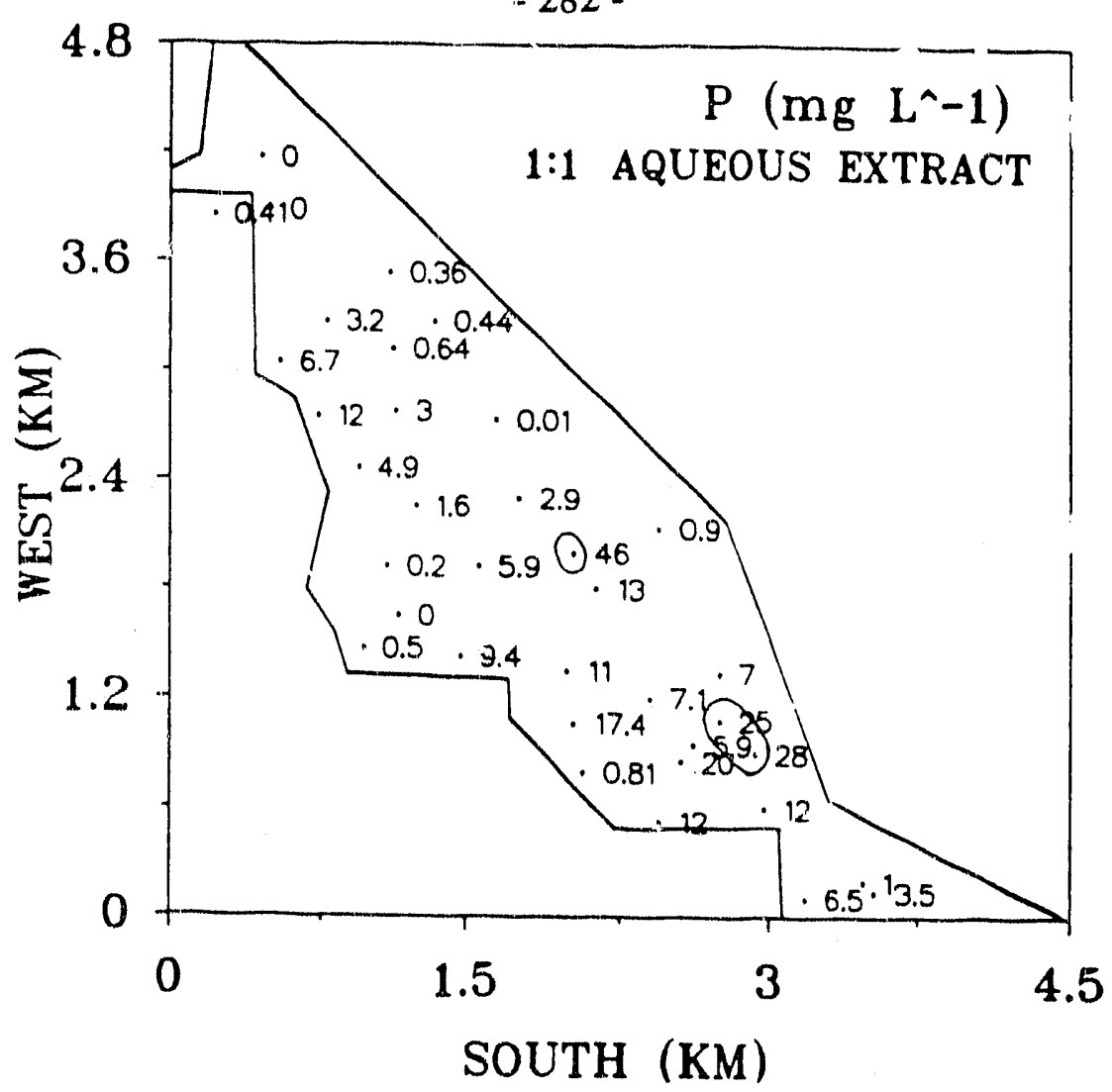

Figure 4.63. Distribution of phosphorus in surface sediments of Kesterson.

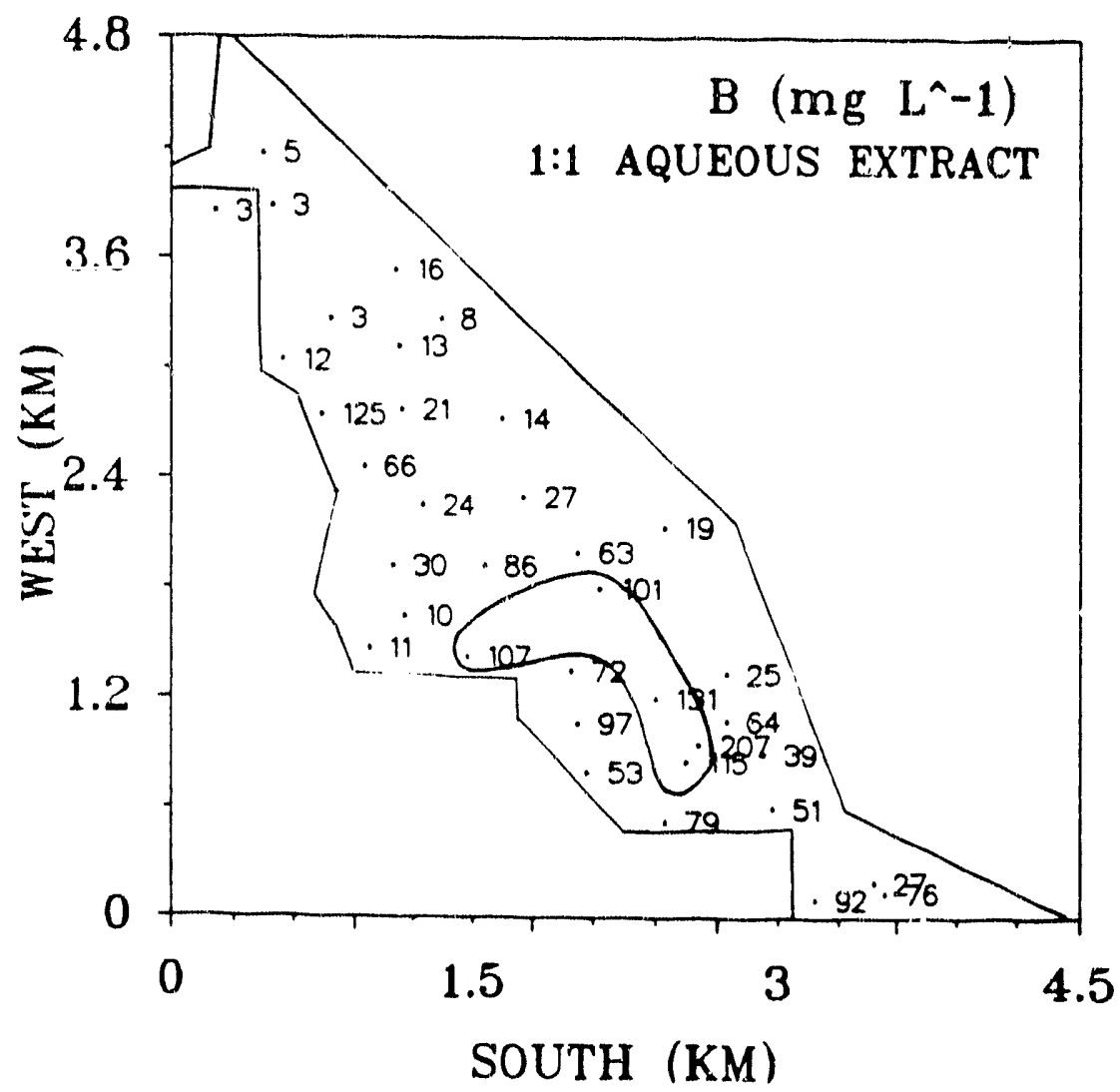

Figure 4.64. Distribution of boron in surface sediments of Kesterson. 
$-283-$

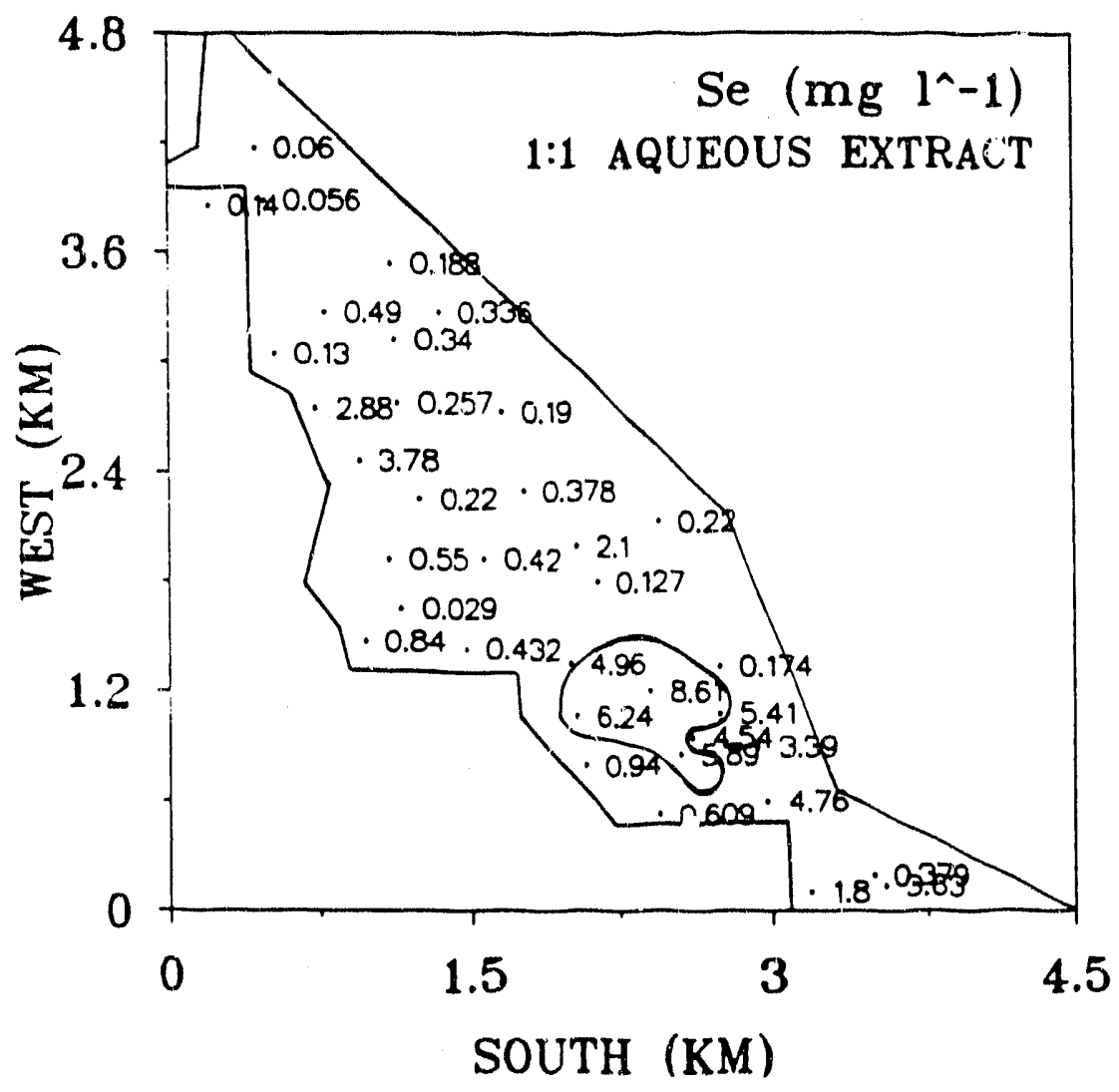

Figure 4.65. Distribution of selenium in surface sediments of Kesterson.

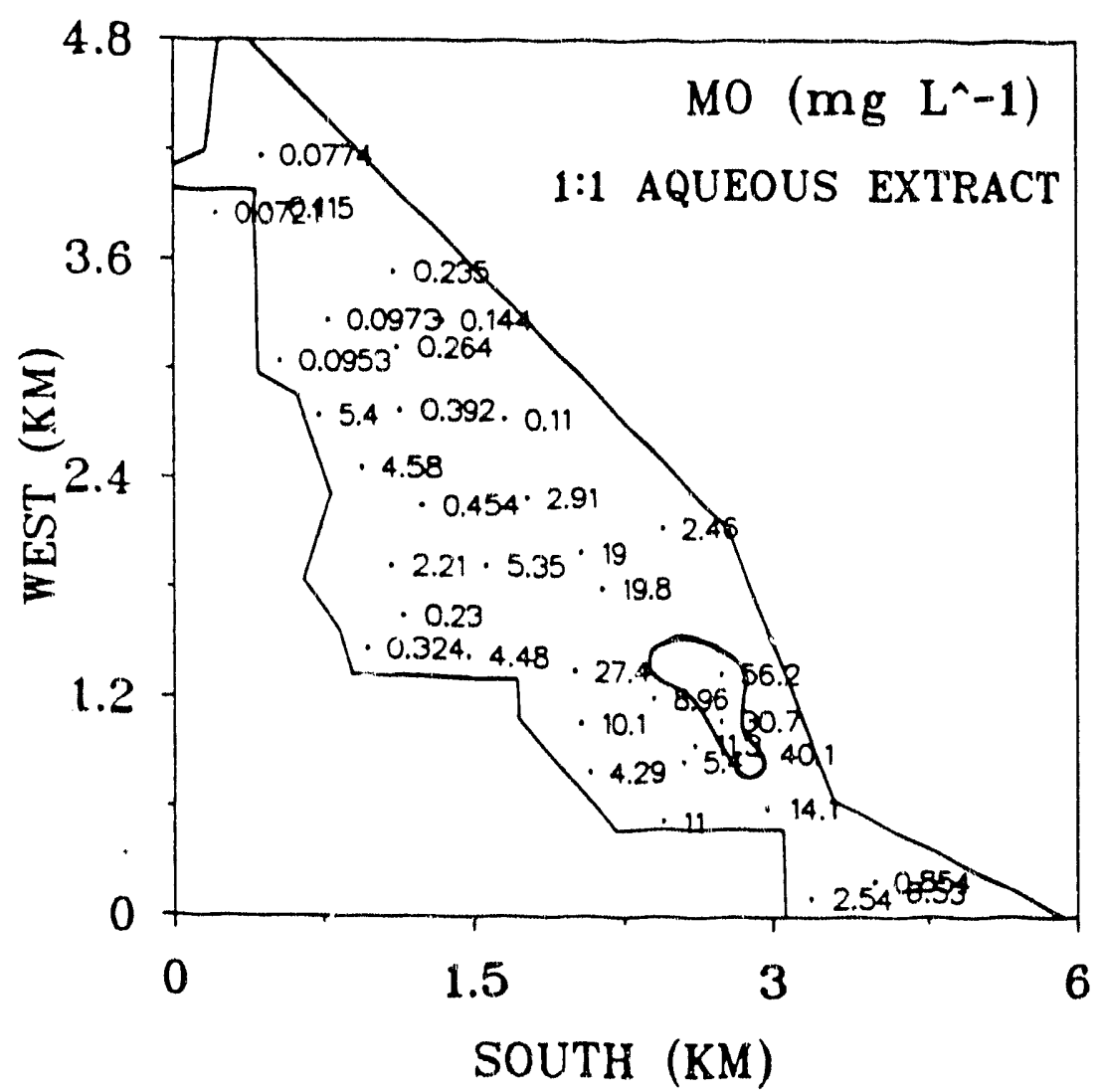

Figure 4.66. Distribution of molybdenum in surface sediments of Kesterson. 


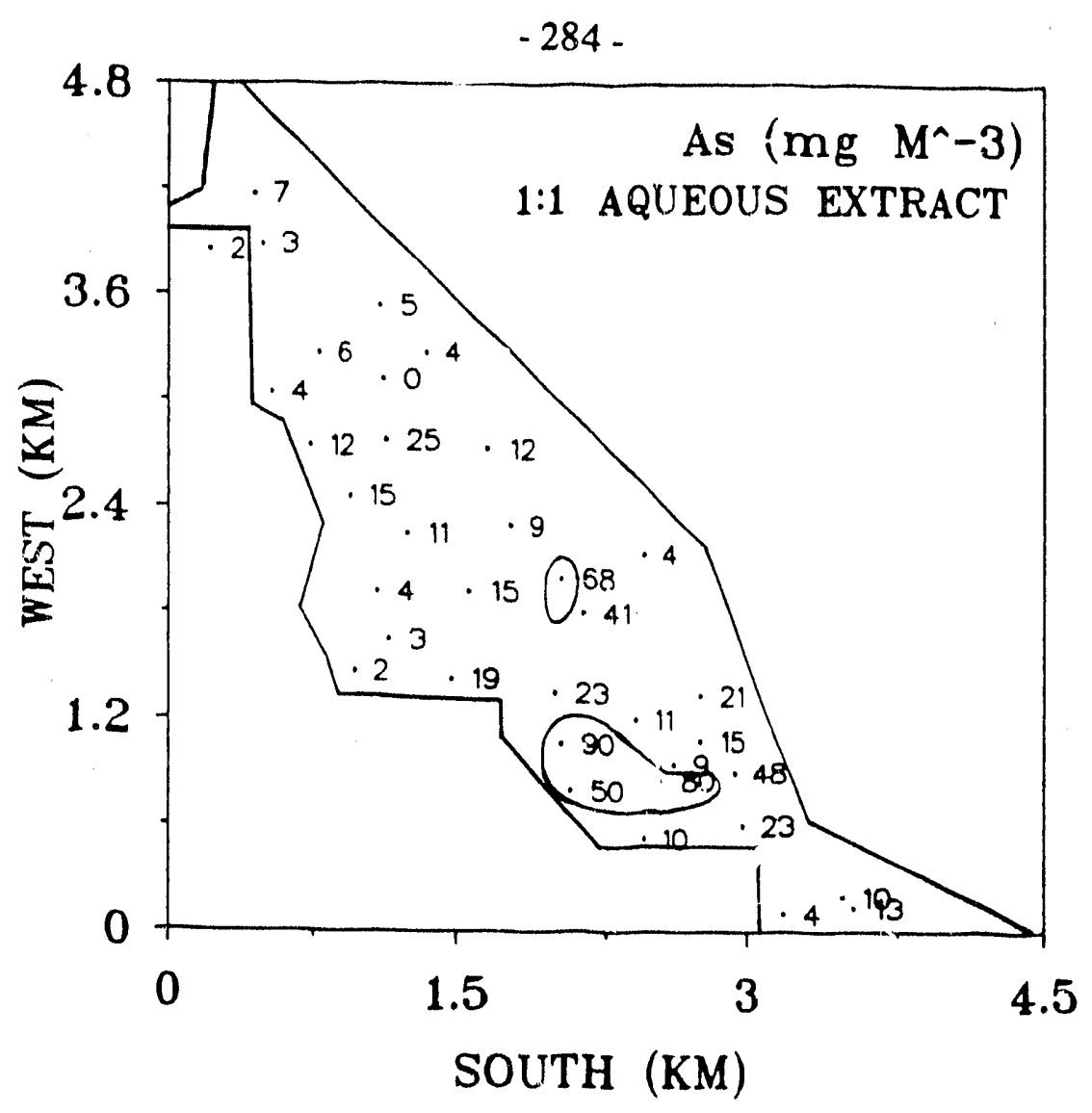

Figure 4.67. Distribution of arsenic in surface sediments of Kesterson.

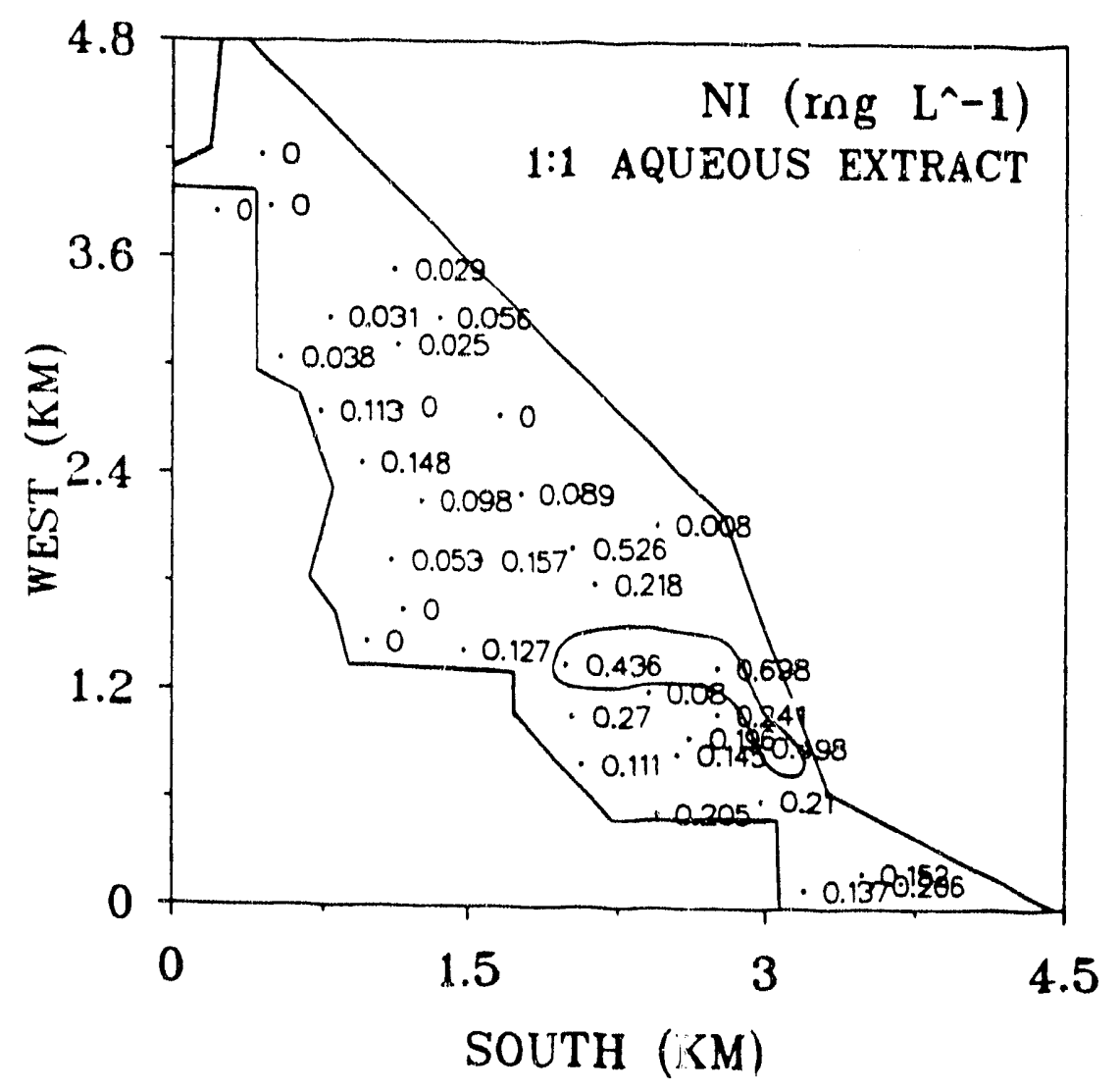

Figure 4.68. Distribution of nickel in surface sediments of Kesterson. 


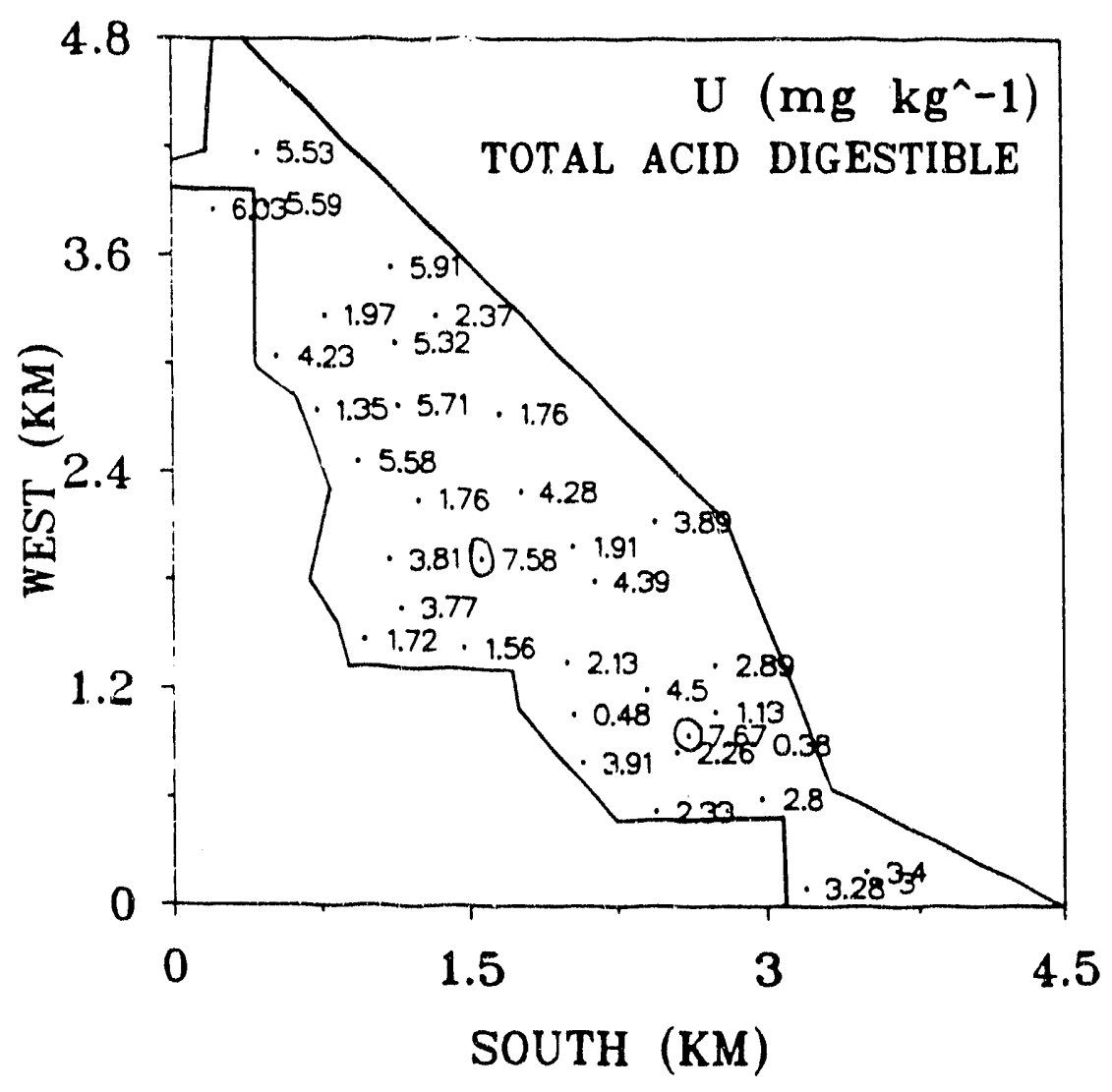

Figure 4.69. Distribution of uranium in surface sediments of Kesterson. 


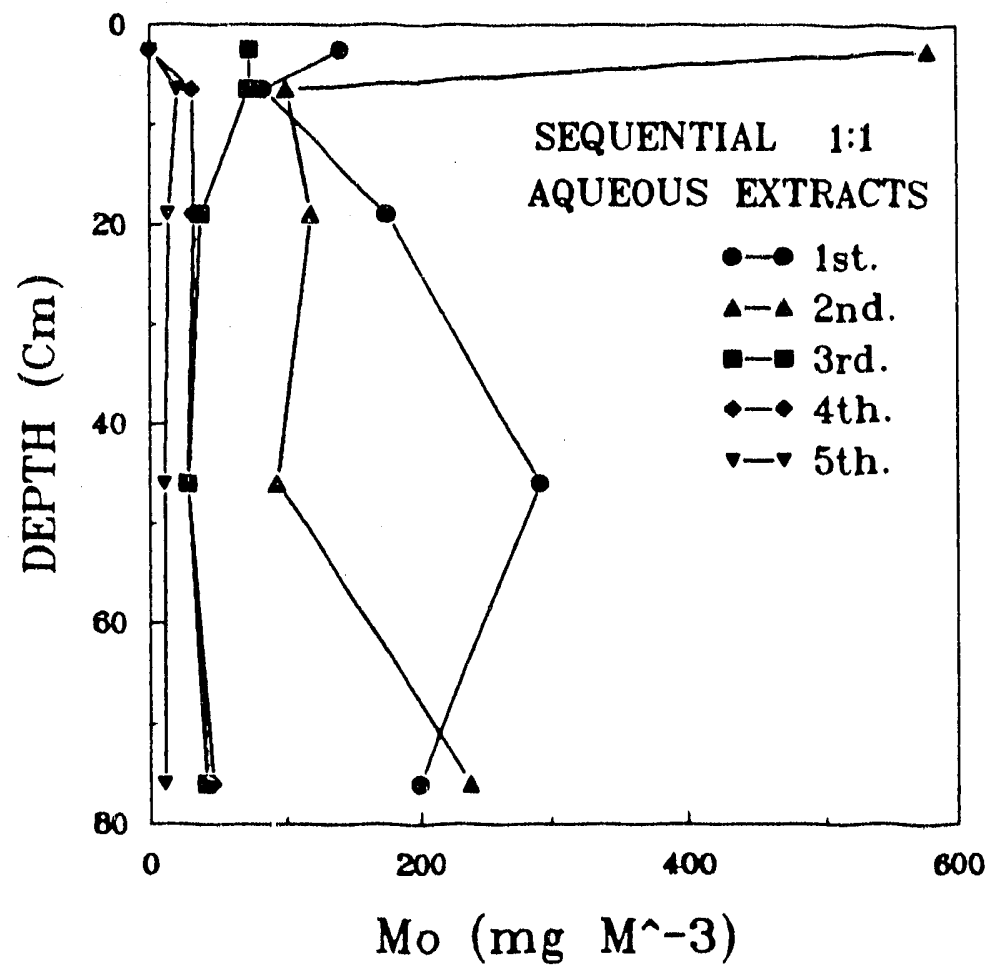

Figure 4.70. Distribution of molybdenum in a profile in cell 9, Kesterson.

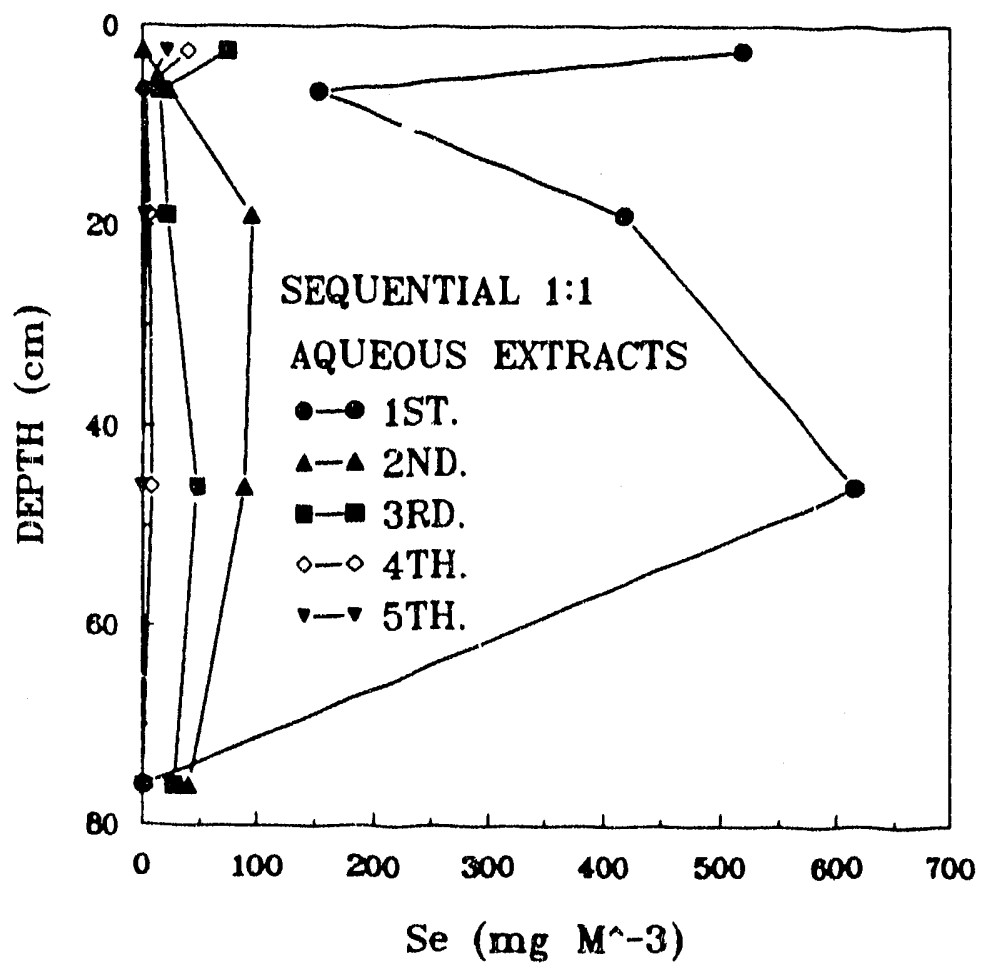

Figure 4.71. Distribution of selenium in a profile in cell 9, Kesterson. 


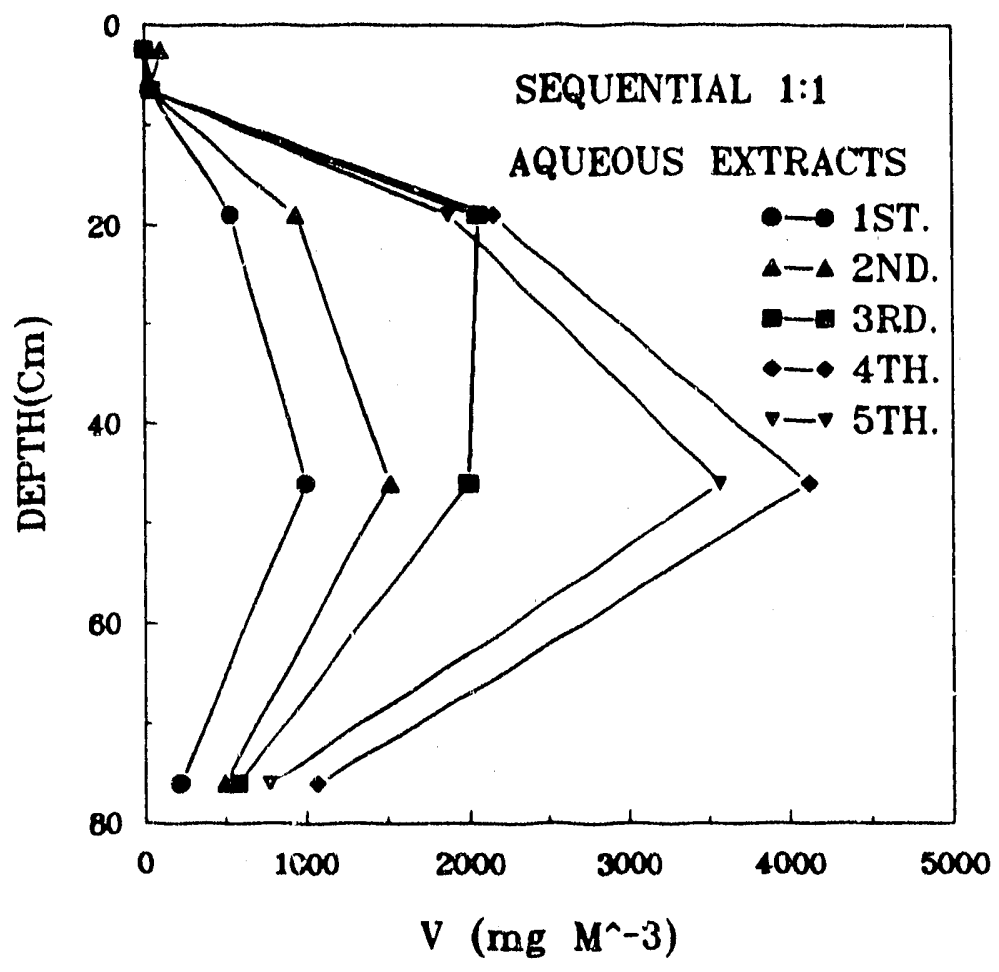

Figure 4.72. Distribution of vanadium in a profile in cell 9, Kesterson.

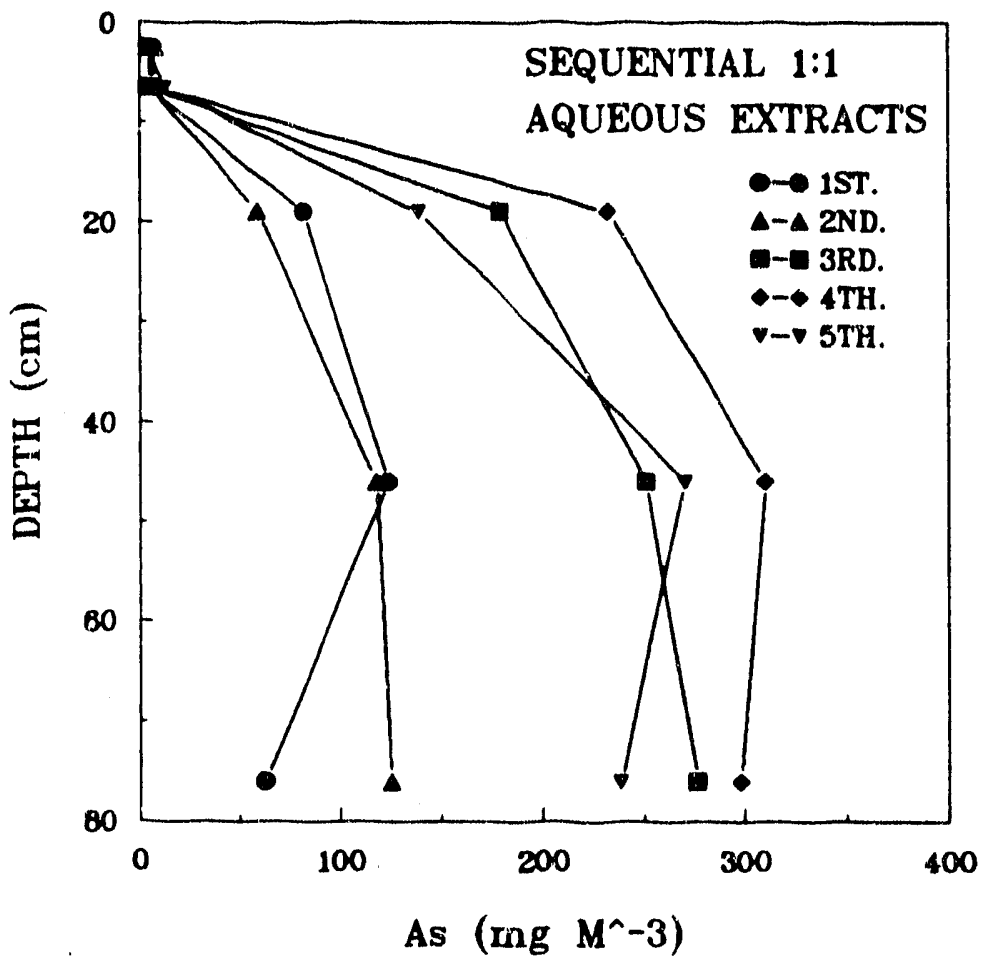

Figure 4.73. Distribution of arsenic in a profile in cell 9, Kesterson. 


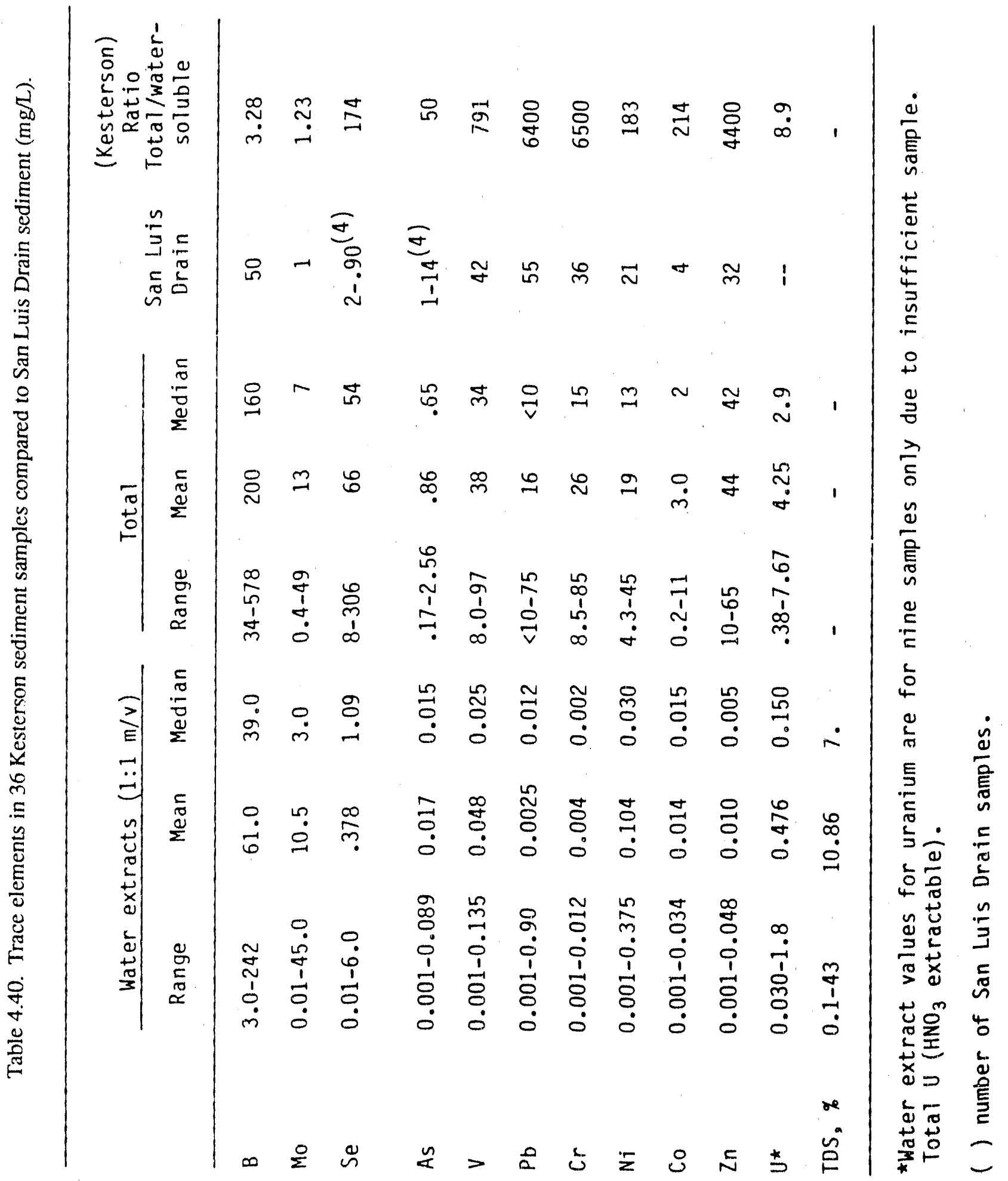


Table 4.41. Correlation coefficients between selected trace elements and sainity indices in Kesterson surface sediment aqueous $(1: 1 \mathrm{~m} / \mathrm{v})$ extracts.

\begin{tabular}{llllll}
\hline & $\mathrm{Ca}$ & $\mathrm{Mg}$ & $\mathrm{Na}$ & $K$ & $\mathrm{TDS}$ \\
\hline $\mathrm{As}$ & .48 & .42 & .32 & .55 & .34 \\
$\mathrm{~B}$ & .27 & .82 & .83 & .59 & .77 \\
$\mathrm{Li}_{\mathrm{M}}$ & .31 & .75 & .43 & .61 & .58 \\
$\mathrm{Mi}$ & .04 & .49 & .38 & .57 & .41 \\
$\mathrm{P}$ & .19 & .53 & .45 & .70 & .48 \\
$\mathrm{Se}$ & .32 & .67 & .55 & .79 & .59 \\
$\mathrm{Sr}$ & .27 & .73 & .75 & .58 & .71 \\
\hline
\end{tabular}


and phosphorus with potassium and lithium with magnesium are also evident.

Knowledge of specific element and salt concentration variability with distance and depth, chemical associations and factors controlling solubility is essential for effective management of salt-affected areas such as Kesterson. Analyses are planned for major anoins, DOC, and a'kalinity in sediment extracts. These data will be analyzed statistically to determine speciation and factors controlling solubility such as (a) soluble salt, (b) soluble organic complex, (c) exchangeable ic $n,(d)$ mineral solubility, and (c) coprecipitation with other minerals. 


\title{
4.9. DIFFUSIVE AND CONVECTIVE TRANSPORT OF VOLATILE SELENIUM THRO!GH KESTERSON RESERVOIR SOILS
}

\author{
Tetsu Tokunaga, \\ Earth Sciences Division, \\ Lawrence Berkeley Laboratory
}

Throughout this section the various gaseous selenium compounds will be referred to collec.. tively as volatile selenium. Using gas chromatography-mass spectrometry, Frankenberger and Karlson (1988) have determined that selenium volatilized from Reservoir soils used in their studies is predominantly dimethylselenide, with a minor fraction of dimethyldiselenide. Volatile selenium emissions in the work reported here were measured through hydride generation atomic absorption spectrometry of alkaline peroxide gas washing solutions (Weres et al., 1989a). Since no information on molecular structure of the recovered volatile species is obtained in this procedure, the selenium recovered throughout most of the work to be described is of undetermined composition. Thus reference will usually be made to "volatile selenium" rather than to a particular species such as dimethylselenide.

Volatilization of selenium from Reservoir soils is recognized as a significant pathway for depletion of the currently high selenium inventory (Frankenberger and Karlson, 1988). Currently there are considerable differences in estimates of volatilization rates obtained from different approaches. For example, estimates of volatile losses of selenium based on changes in surface soil concentrations are considerably larger thian depletion estimates based upon direct sampling of volatile emissions. 'This area of uncertainty will not be addressed here. Another large difference has been noted beiween methods of directly sampling volatilized selenium. In particular, sampling of volatilized selenium by pumping (evacuation) of the soil atmosphere into a surface headspace collector appears to yield higher estimates of emission rates than a method which relies primarily on diffusive transport into a headspace collector. The fact that forcing a convec- 
tive flow of soil air into a headspace sampler results in sampling an effective area larger than the projected area of the headspace chamber is recognized. This effect of extending the sampling area will not be considered in the present work. While there are numerous uncertainties in other aspects of the collection and recovery of volatilized selenium, a possible correlation between headspace pumping rate and volatile selenium emission rate was suggested by differences in results from the convection-based and diffusion-base techniques. Due to large differences in estimates of volatile selenium emission rates obtained from the two methods, it is warranted to systematically study the possible influence of measurement techniques on the observed volatilization rates. The work described in this section attempts to address the potential influence of soil air flow rates on measured volatile selenium emission rates. Emission rates obtained under a range of convective soil air flow rates and under static, diffusive conditions will be examined. It is unlikely that soil air flow rates imposed by the convective sampling method (in the range of 0.4 $\mathrm{m} / \mathrm{h}$, bulk gas flow velocity) are experienced under ordinary field conditions of interest. On the other hand, gaseous transport solely by molecular diffusion is probably inadequate to account for natural gas exchanges at the soil surface. The actual field environment is one where both convective and diffusive transport contribute to the release of volatile selenium off the soil surface. Ultimately, an evaluation of the emission rate dependence on gas flow velocity will be determined in ord $\mathrm{r}$ to more confidently interpret emission rates obtained from both convective and diffusive samplers.

If selenium volatilized within the soil profile were not subject to further interactions, the measured emission rates would be relatively insensitive to sampling diffiusively or convectively. Huwever, with the presence of other competing chemical is nctions or physical interactions the imposition of a forced convection through the soil gas phase can have suveral effects on the fate of volatilized selenium. The potential exchange of volatilized selenium between the soil gas phase and both solid phase surfaces and the liquid phase would provide such an interaction. The work of Zicve and Peterson (1985) demonstrated the large capacity for soils to adsorb dimethylselenide gas. As much as $4.6 \mu \mathrm{g} /(\mathrm{g}$ soil) was reported sorbed on a soil with high organic matter 
content (29\%). The mineral soils used in their study sorbed dimethylselenide in amounts of about $1 \mu \mathrm{g} /\left(\mathrm{g}\right.$ soil). This latter quantity would be equivalent to about $0.1 \mathrm{~g} / \mathrm{m}^{2}$ in a $0.1 \mathrm{~m}$ deep increment of low density soil. The soil in their study was equilibrated with as mucin as 2000 $\mu \mathrm{gSe} / \mathrm{m}^{3}$ concentrations in the gas phase. This concentration, equivalent to a partial pressure of about $0.06 \mathrm{~Pa}$ is within a range of partial pressures estimated from selenium emission data in the present study $\left(3 \times 10^{-3} \mathrm{~Pa}\right.$ up to $\left.0.8 \mathrm{~Pa}\right)$. Thus, a potentially high capacity to both store and release volatile selenium can be found in soils. This storage capacity can also complicate interpretation of volatile selenium emission data. While storage is attributable to both dissolution in the soil solution and to adsor-tic : 1 al surfaces (mineral and organic), the distinctions between these various forms of partitioning are merely speculative when working with macro-scale observations. Therefore, in this work the fostulatel storage of volatile selenium in condensed phases is referred to collectively as "adsorbed" only out of convenience.

A possible mechanism for an emission rate correlation with flow rate involves perturbing the local (pore scale) equilibrium between gas phase and sorbed phase volatile selenium. The direction of perturbation depends on the direction of the induced chemical potential difference of volatile selenium between the phases. Since a convective flow is likely to purge an initially volatile selenium-enriched gas phase, which is then replaced with air of lower selenium content, the local (pore scale) chemical potential gradient for volatile selenium would result in vaporization from the adsorbed phase. The rate of vaporization would to a first approximation be proportional to the depression of the local volatile selenium partial pressure relative to its local equilibrium value. This partial pressure depression would in tum be approximately proportional to the imposed convective air flow rate. If the initial adsorbed phase inventory is :arge relative to the quantity of volatile selenium emitted, convection-induced vaporization of volatile selenium may behave in a way which is indistinguishable from a steady microbial volatilization rate. An adsorbed dimethylselenide inventory on the order of that reported by Zieve and Peterson (1985) would satisfy this criterion.

The postulated interaction between adsorbed volatile selenium and soil air flow rate is 
amenable to testing, especially in the laboratory environment. After a period of incubation with adequate aeration and moisture, volatile selenium emission rates could be measured from a column of Kesterson Reservoir soil over a range of soil air flow rates (including zero flow, the diffusion limit). If the hypothesis is valid, increased air flow rates would yield higher rates of volatile selenium emission from the soil. Furthermore, when stepping up the air flow rate to a higher value, then maintaining the flow rate at the new level for an extended time, it is expected that an initial enhanced emission rate will gradually damp down to a quasi-steady rate. The initial pulse is associated with enhanced volatilization due to suddenly increased local chemical potential gradients. The enhancement is due to a transient release of adsorbed volatile selenium, and does not represent a sustainable source of volatilization. The quasi-steady emissioii rate should more accurately reflect microbial volatilization than the initial transient pulse associated with physical degassing from the condensed phase. Hysteresis in volatile selenium emission rates when cycling through a range of gas flow rates can be expected as an outcome of desorption during accelerated flow rates, and adsorption during deceleration of air flow rates. All of these features have now been tested at a preliminary level. In the following, a detailed description of the experimental design and a review of preliminary results are presented.

\subsubsection{Methods}

Soil from a cattail area bordered by fill material in Pond 4 was used for the column study. The soil sampled to a depth of $0.15 \mathrm{~m}$, included some moderately decomposed cattail sterns. Coarse crushing of the soil to pass through a $9.5 \mathrm{~mm}$ sieve was done to preserve some soil structure, yet also permit relatively homogeneous packing. The initial field water content was 0.110 $\mathrm{g} / \mathrm{g}$. Distilled water was added to bring the final soil water content up to $0.510 \mathrm{~g} / \mathrm{g}$. The ivetted soil was packed into the test column in 5 increments to assist in maintaining a uniform pracking density. The $0.196 \mathrm{~m}$ column has a cross-sectional soil area of $0.182 \mathrm{~m}^{2}$. The packed column had an equivalent dry bulk density of $0.833 \mathrm{Mg} / \mathrm{m}^{3}$. Based on a solid density measured as 2.43 $\mathrm{Mg} / \mathrm{m}^{3}$, the total porosity and air-filled porosity were calculated to be 0.657 and 0.232 respectively. 
The water-soluble selenium content of the soil was determined in two separate ways. In one method, duplicate samples of the soil were water-extracted at a 5:1 water:soil ratio. In another method, the soil was packed into a $0.11 \mathrm{~m}$ I.D., $(5 \mathrm{~m}$ length column into which a ceramic soil solution sampler with a $48 \mathrm{~mm}$ O.D., $60 \mathrm{~mm}$ length tip was inserted to obtain a vacuum extract of the soil at porosity and water content conditions identical to that of the test column described in Section 3.5. The 5:1 water extracts gave a soluble selenium concentration of $1435 \pm 40 \mu \mathrm{g}(\mathrm{kg} \mathrm{soil})^{-1}$. The vacuum extract soluble selenium concentration was equivalent to $1350 \pm 50 \mu \mathrm{g}(\mathrm{kg} \mathrm{soil})^{-1}$. Given a soluble selenium concentration of $1.40 \mathrm{mg}(\mathrm{kg} \mathrm{soil})^{-1}(1.40$ ppm soil), the test column inventory of water-soluble selenium would be equal to $3.12 \mathrm{mg}$. On a per unit area basis, this quantity is equivalent to $171 \mathrm{mg} \mathrm{m}^{-2}$.

The system used to monitor flow-cmission rate relations is depicted in Figure 4.74. The main components to the system are submerged in a constant temperature water bath. While the bath temperature can be maintained within $0.1^{\circ} \mathrm{C}$ of the target temperature, temperature fluctuations in the laboratory resulted in bath temperature fluctuations of up to $\pm 0.2^{\circ} \mathrm{C}$. Selenium-free gases (compressed air and nitrogen) are used as input gases. Inflow gas pressures are triple regulated, with the final regulation applied with a nullmatic regulator (item 4 in the figure). After pressure regulation, the gas flow is prehumidified (item 6), and thermally equilibrated (item 7) before entering the test column (item 1). Gas flow is routed either to the back port (item 9) in the case of flow-through (convection) experiments, or to the front port (item 8) in the case of diffusion experiments. In either case, gas is pumped out of the cell through a single outflow port (item 10). In the case of convective flow tests, the test chamber operates as a simple flowthrough cell. In the case of diffusion experiments, the front end plate can provide either a zeroconcentration boundary condition, or a well-stirred boundary condition. During volatilization measurements, outflow from the column is sent through a pair of alkaline peroxide traps (item 12) for collection of selenium. In more recent tests, only a single peroxide trap was used, since the backup trap never yielded more than $1 \%$ of the selenium obtained in the primary trap. A peristaltic pump (item 16) is used to pull gas from the test column through either the peroxide traps 


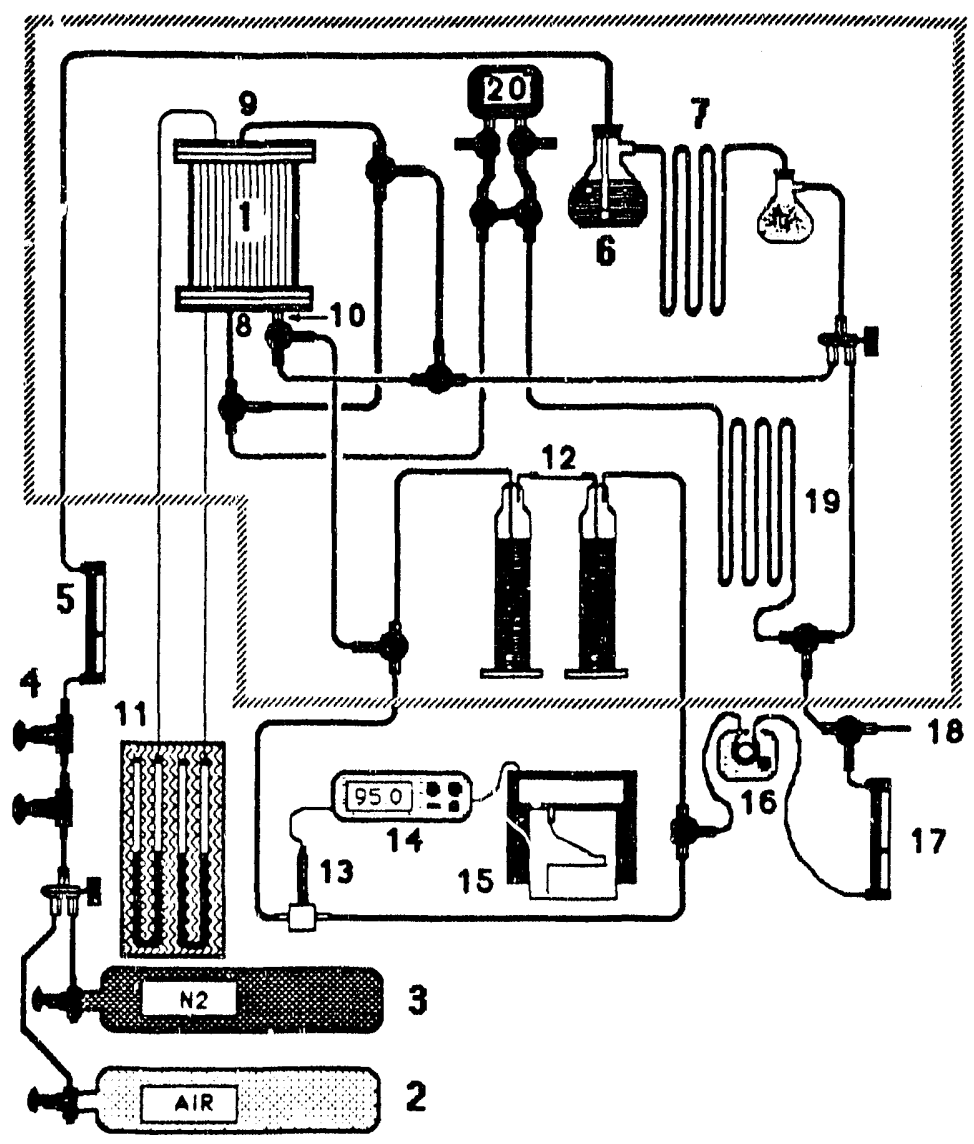

Figure 4.74. System for measuring volatile selenium emissions from soils under diffusive and convective conditions. 
or the oxygen analyzer system (items 13,14 , and 15, to be described later). Peristaltic pump flow rates and inflow regulators were balanced such that the test column gas phase was at atmospheric pressure (checked via water manometers, item 11), and fow rates were of the desired magnitude (checked through inflow and outflow flow meters, items 5 and 17). In most tests, the outflow gas is vented into the laboratory air after passing through the last flowmeter.

Several preliminary tests of the system were done prior to the experiments on the Kesterson Reservoir soil. Two of the more important tests will be mentioned here. Due to the manner in which ga is circulated across the column headspace during diffusion-limited runs (via iteins 8 and 10), the possibility that this cross flow would perturb diffusion-limited transport within the column was of concern. To insure that the system functioned properly in the diffusion mode, the counter diffusion of oxygen and nitrogen gas was monitored over a range of temperatures. For this pl'pose, the test cell was packed with a bundle of plastic straws to minimize convective mixing within the column. The column was equilibrated with air $(20.95 \%$ oxygen) and temporarily isolated from the rest of the system. An external closed loop connecting the oxygen electrode (item 13), peristaltic pump (item 16), return-flow heat exchanger (item 19), and supplemental mixing cell (item 20) was purged with nitrogen gas prior to an oxygen-nitrogen diffusion test. Diffusion experiments involved monitoring the transient oxygen concentration response when the loop was connected with the test cell. The oxygen-nitrogen binary diffusion coefficient (at atmospheric pressure, and at the regulated temperature) was then obtained through inversion of the oxygen wncentration data. Compazisons of measured oxygen-nitrogen diffusivities with data in the literature (Marrero and Mason, 1972) demonstrated agreements within 5\%, and commonly within $3 \%$. Thus, the diffusion mode of the system was considered functional.

A spike-recovery test using dimethylselenide gas was also performed. In this test, an aqueous sor:tion of dimethylselenide was prepared. Half of the sampie was placed in a sealed flask with an air inflow and outflow line (both of $1 / 4$ inch stainless steel tubing). The outflow line was connected to the alkaline peroxide traps via the test chamber. The flask headspace air was pumped through the test system and into the peroxide traps with the peristaltic pump while the 
aqueous dimethylselenide solution was evaporated on a hot plate. The air inlet line was formed into a coil which rested on the hotplate with the flask. The inclusion of an air inflow line served to prevent losses of dimethylselenide via counter diffusion out of a simple vent port. The line was heated to minimize sorption on the tubing walls. The half of the aqueous solution which was not introduced into the flask was directly oxidized by addition of alkaline peroxide solution, and served as the reference concentration. An essentially full spike recovery (102 $\pm 5 \%)$ was obtained from the test system alkaline peroxide traps.

\subsubsection{Results}

In one of the preliminary tests, a range of soil air flow velocities from 0 (diffusion only) up to $720 \mathrm{~mm} \mathrm{~h}^{-1}$ were performed at $25.0^{\circ} \mathrm{C}$, over a period of 15 hours (Figure 4.75). Individual flow rates were run for about 1 hour. Nine individual steady flow conditions were tested, including replicates of the 0 and $228 \mathrm{~mm} \mathrm{~h}^{-1}$ runs. This particular set of experiments was performed only 1 day after packing of the column. It was suspected that the microbial volatilization rates may not have attained a near steady-state which would be ideal for purposes of this work. Time trends in microbial volatilization rates would obscure interpretation of emission rate dependencies on any other variable which is monotonically increased or decreased. Therefore, the range of flow veiocities was covered in random sequence in this set of experiments. The order of the individual runs is shown in the sequential numbering of data points. While considerable scatter is observed in the data, a general correlation between flow velocity and volatile selenium emission rate is suggested. This flowrate effect has also been observed in recent experiments by 0 . Weres (Sonoma Research Co., Vineburg, CA. Oct. 1989 personal communication). From the sequence in which the runs were performed, it also appears that the volatile selenium emission rates exhibit hysteretic hehavior.

The possibility of hysteretic behavior indicated by the previous data set prompted a series of volatile selenium emission studies where flow velocities were quickly stepped through a scquence of increasing values up to a maximum flow rate, then stepped down sequentially back

to $0 \mathrm{~mm} \mathrm{~h}^{-1}$. The results of this test, shown in Figure 4.76, are qualitatively consistent with a 


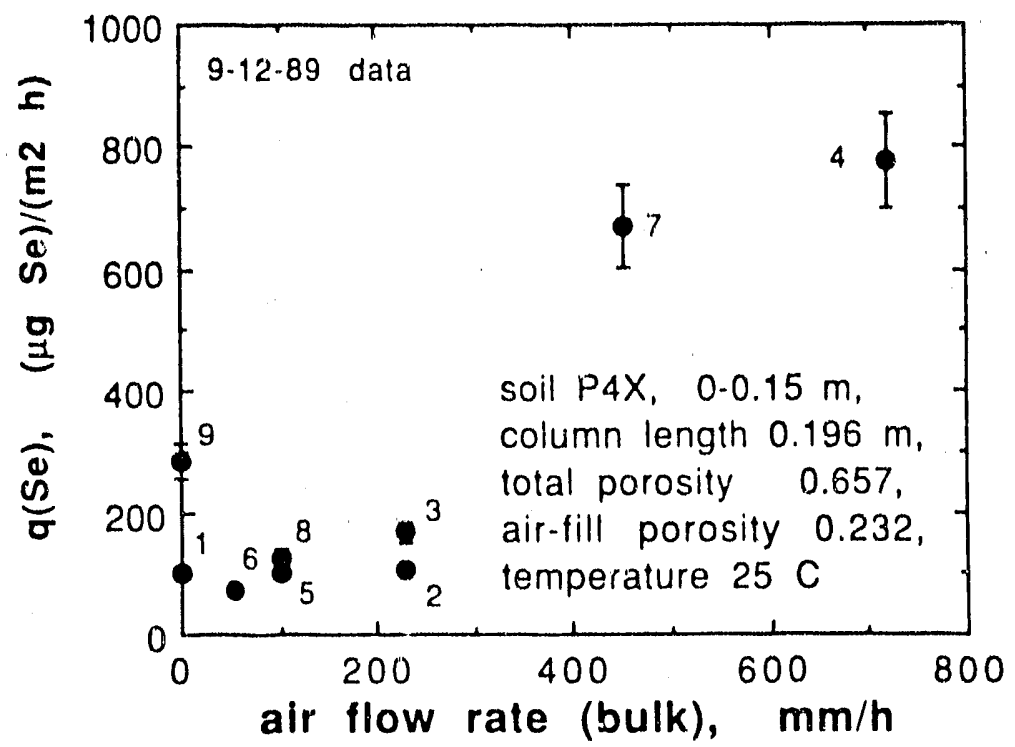

Figure 4.75. Laboratory volatile selenium emission rates from a Pond 4 soil, $(\mathrm{P} 4 \mathrm{X})$ at $25 \mathrm{C}$. Soil gas flow rates randomly varied from 0 to $720 \mathrm{~mm} / \mathrm{h}$.

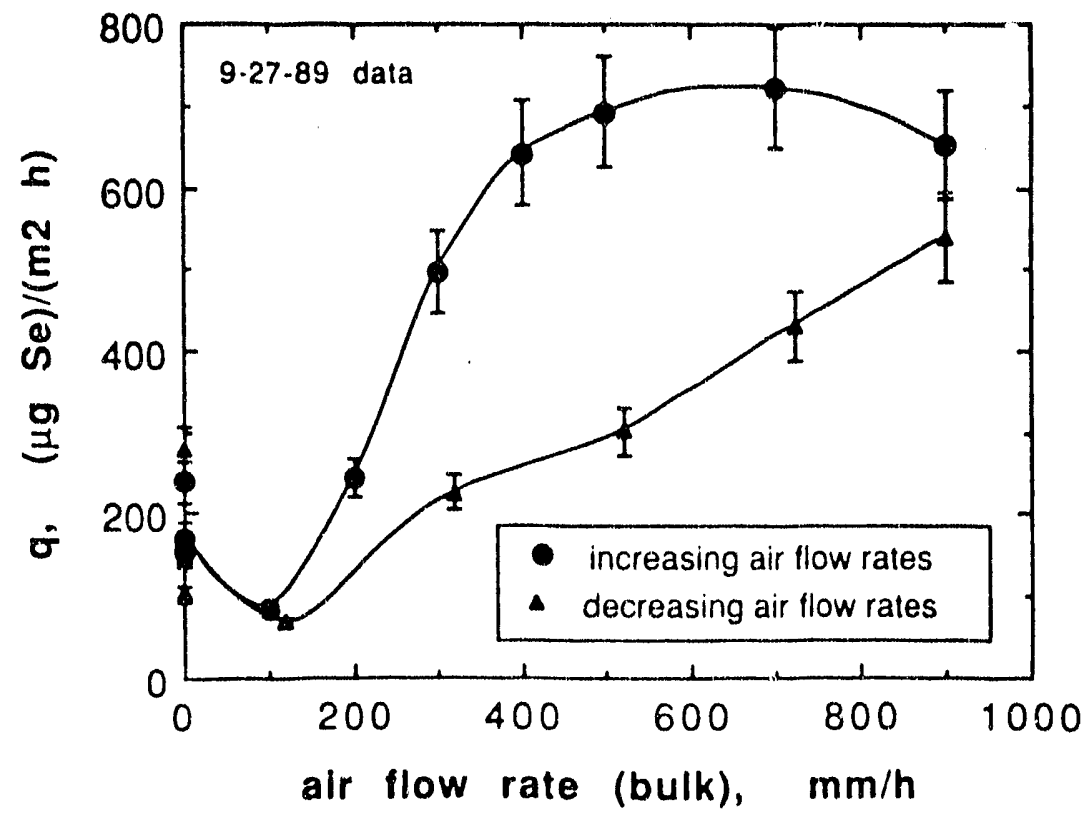

Figure 4.76. Hysteresis in volatile selenium emission rates under systen atically varied soil gas flow rates. Soil P4X, 25.2 C. 
model of desorption/adsorption behavior influencing the volatile selenium emission rates. In the following, a possible explanation of the behavior shown in Figure 4.76 is presented. The assumption is made that, over the course of the experiment ( 20 hours), the rate of selenium volatilization by microbes was practically constant. Several independert experiments support this assumption as a reasonable approximation. It is also assumed that the quantity of volatile selenium which is involved in the proposed adsorption/desorption mechanism is a relatively small fraction of the adsorbed/dissolved inventory of volatile selenium. Presently indirect evidence (to be presented later in this section) suggests that this assumption is valid. As the soil air flow rate is increased, the soil air phase becomes progressively more dilute with respect to volatile selenium. This depletion of volatile selenium from the gas phase should result in enhanced desorption of volatile selenium due to the induced chemical potential gradients at pore-scale gas-liquid interfaces. The higher flowv rates appear to more than compensate for the lower gas phase concentrations of volatile selenium during short periods of measurement, thus resulting in enhanced emission rates at higher flow rates. The same mechanisms, operating in the reverse direction may account for the hysteresis loop shown in Figure 4.76. When the flow rate is stepred down to a lower velocity, an increased concentration of volatile selenium in the soil occurs under the postulated constant generation rate. This increased concentration is partitioned between both the flowing gas and the effectively nonmobile surface and aqueous phases. Only the gas phase component is emitted from the soil column while surface and aqueous phases serve as sinks (during flow deceleration). The mechanisms suggested here are currently merely hypothetical. Furthermore, the local minima observed in both the increasing and decreasing air flow cycles can not presently be explained. Work is presently being conducted to test all components of the model.

In light of the results obtained from the flow velocity cycling experiment, it seemed worthwhile to study volatile selenium emission rates at fixed flow velocities for sustained periods of time. It was anticipated that, when a steady soil air flow as imposed on an initially static soil atmosphere, an approximately exponential decay of the volatile selenium emission rate from an 
initially high rate to a lower steady-state rate would be observed. Preliminary work has been completed on this aspect of the study, and is summarized here. The experiment consisted of monitoring volatile selenium emission rates over three flow velocities (inclusive of zero velocity). During the first 38 hours, no soil air flow was imposed. The soil column headspace was continuously swept to monitor diffusion-limited emission rates. This first stage was followed by a step-increase of the soil air flow rate up to $250 \mathrm{~mm} / \mathrm{h}$. Volatile selenium emission rates were continuously monitored for a period of 24 hours during this second stage. The third stage involved a further step-increase of the soil air flow rate to $500 \mathrm{~mm} / \mathrm{h}$, with volatile selenium emission rate monitoring for 38 hours. All work was performed at $25.2^{\circ} \mathrm{O} \pm 0.2^{\circ} \mathrm{C}$ and atmospheric pressure.

Results from the diffusion-limited stage are shown in Figure 4.77. The soil chamber had been maintained in a partially isolated condition for 3 days prior to the beginning of this test. The restricted venting during this period maintained the soil at atmospheric pressure, but hindered the diffusive exchange of volatile selenium, oxygen, and other gases between the soil and the labo atory atmosphere. The soil gas phase volatile selenium concentration increased during this period as a result of the restricted diffusion. This is reflected in the initial peak emission rate obtained by freely venting the column headspace to the selenium traps at the beginning of the experiment (Figure 4.7\%). The volatile selenium emissions rates slowly decline to approximately $250 \mu \mathrm{g} \mathrm{m}^{-2} \mathrm{~h}^{-1}$. At 28.5 hours, the headspace gas cycling rate was increased by a factor of 3 (from 7.5 to $22.5 \mathrm{~L} / \mathrm{h}$ ). It should be noted that no flow of air through the soil column as a whole was occurring during this stage. Some convective mixing of gases within the soil surface may have occurred, and could explain the associated local maxima in selenium emission rate. This increase appears to be transient.

The second stage consisted of imposing an air flow through the soil equal to $250 \mathrm{~mm} / \mathrm{h}$. The measured volatile selenium emission rates are shown as a function of elapsed time in Figure 4.78. Beginning with a rate of $200 \mu \mathrm{g} \mathrm{m}^{-2} \mathrm{~h}^{-1}$, emission rates increased steadily. The rate of increase diminished with time, but a steady state was not observed within 24 hours. The trend 


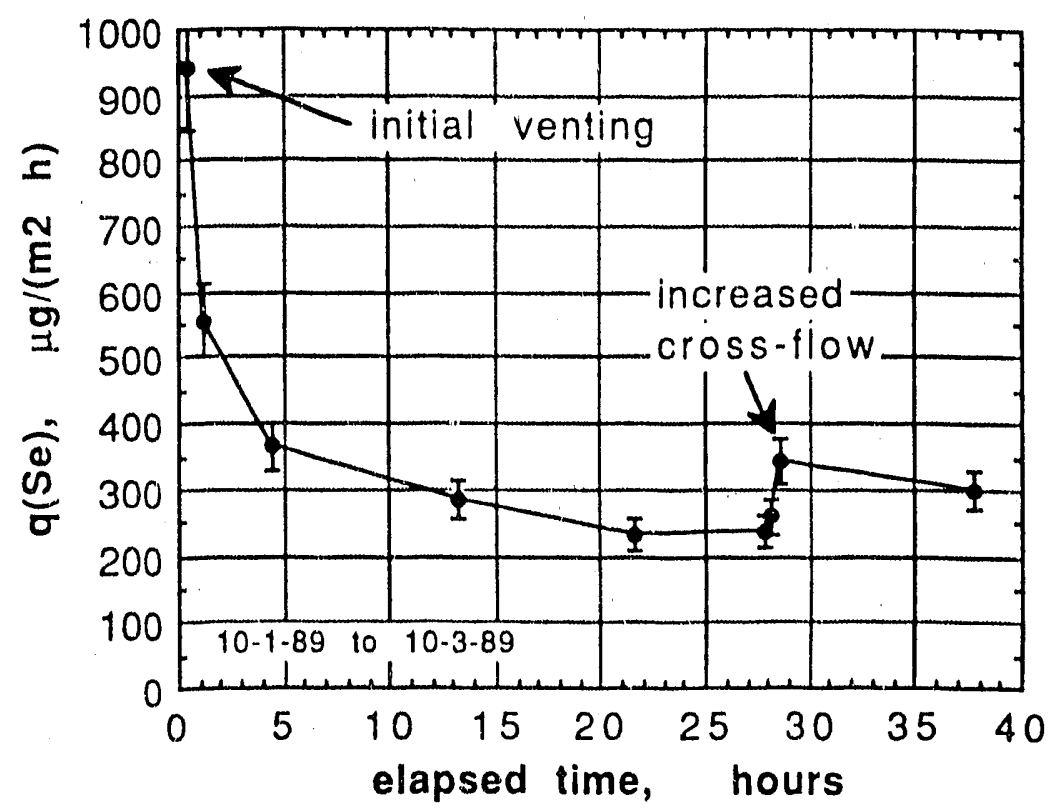

Figure 4.77. Volatile selenium emission rates under diffusion-limited conditions. Soil P4X, 25.2 C.

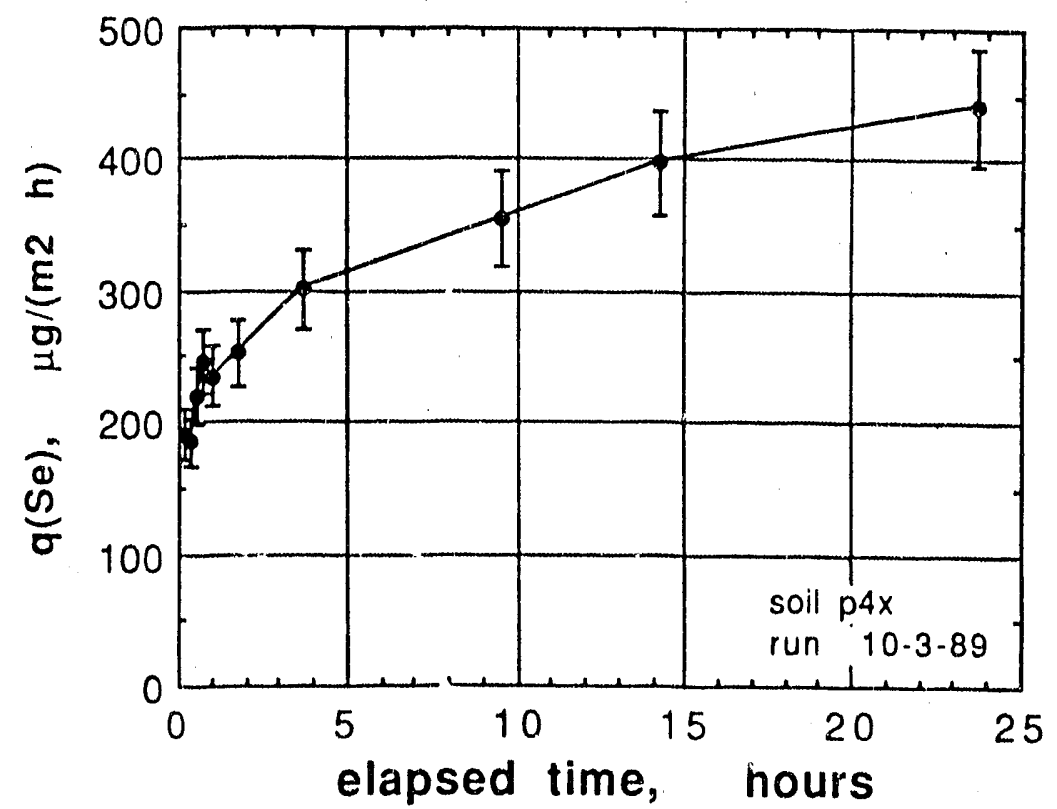

Figure 4.78. Volatile selenium emission rates under $250 \mathrm{~mm} / \mathrm{h}$ steady soil air flow rate. Soil P4X, 25.2 C. 
suggests a possible steady-state in the vicinity of $500 \mu \mathrm{g} \mathrm{m}^{-2} \mathrm{~h}^{-1}$ may have been reached with a longer testing time. However, this pattem is contrary to expectation, and to all other tests performed in this study to date. A possible explanation is that the imposition of the steady air flow increased the soil atmosphere oxygen activity (concentration), resulting in stimulation of fungal activity and hence selenium volatilization (Prof. M. Firestone, Dept. of Soil Science, U.C. Berkeley, personal communication, Oct. 13, 1989). The trend in Figure 4.78 remains to be explained, and is presented here for completeness and as an indication of the preliminary nature of this study. A repeat of the $250 \mathrm{~mm} / \mathrm{hr}$ experiment performed one month later exhibited an exponential decay to a steady-state volatile selenium emission rate of $270 \mathrm{\mu g} \mathrm{m}^{-2} \mathrm{~h}^{-1}$.

The final stage of this sequence involved stepping the soil air flow rate up to $500 \mathrm{~mm} / \mathrm{h}$. The results of volatile selenium emission monitoring during this stage are shown in Figure 4.79. An initially high rate (significantly higher than the last measurement taken for the $250 \mathrm{~mm} / \mathrm{h}$ case) of $700 \mu \mathrm{g} \mathrm{m}^{-2} \mathrm{~h}^{-1}$ declines (roughly exponentially) to an apparent steady-state rate of about $300 \mu \mathrm{g} \mathrm{m}^{-2} \mathrm{~h}^{-1}$. This pattern was expected from the perspe ttive of flow-induced desorption. From the perspective of this model, the quantity of volatile selenium desorbed during this stage can be obtained by integration of the instantaneous selenium emission rate curve, and subtracting out the steady-state component. This procedure results in an estimated areal equivalent desorption of $1.0 \mathrm{mg} \mathrm{m}^{-2}$ of volatile selenium. This amount is on the order of $1 \%$ of that estimated from the work of Zieve and Peterson (1985), and suggests that flow-induced desorption does not appreciably alter the surbed/dissolved volatile selenium ir ventory. If the desorbed quantities are relatively small, linear approximations can be applied in tests of different models of the system's response to soil air flow rates.

A possible practical implication of Figure 4.79 concerns the use of convective samplers for measuring field selenium volatilization rates. The results indicate that this technique may be used reliably only after pumping for long periods of time. The short-term (1 hour) measurements could be overestimating the actual microbial volatilization rates by about $200 \%$. Under isothermal conditions, a pre-pumping period of about 12 hours, followed by the actual gas collection, is 


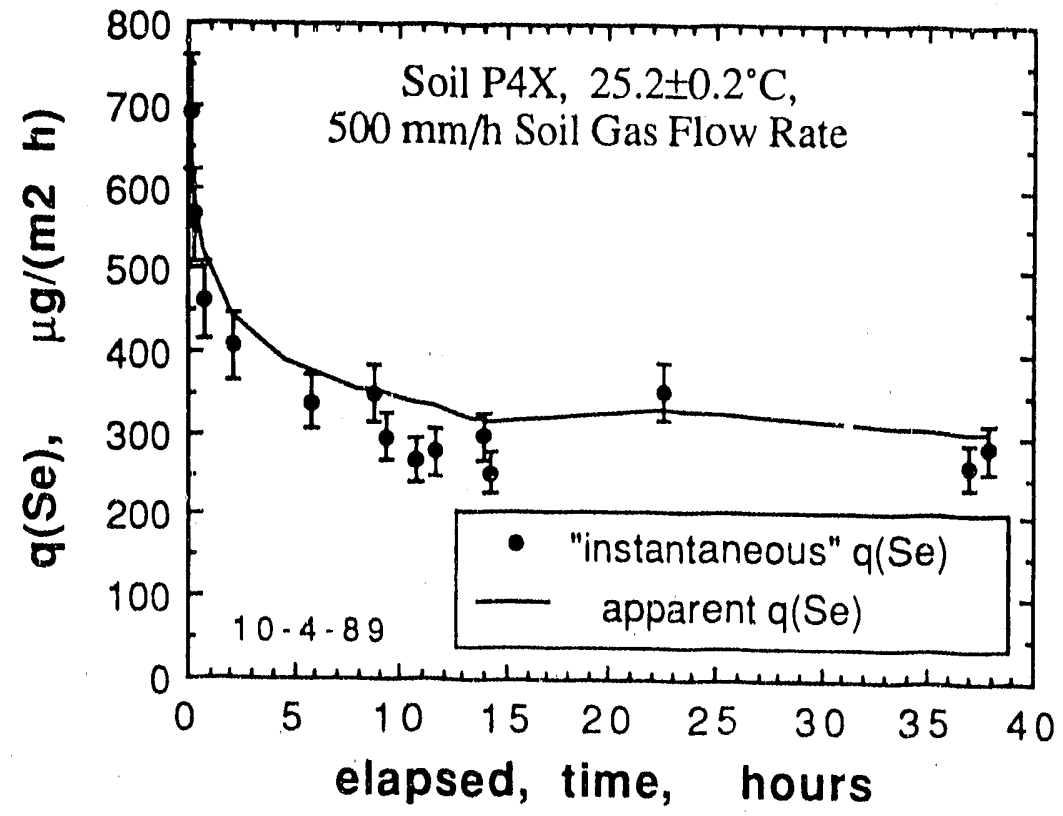

Figure 4.79. Volatile selenium emission rates under $500 \mathrm{~mm} / \mathrm{h}$ steady soil air flow rate. Soil P4X, 25.2 C. 
suggested from the data. Pre-pumping serves to eliminate the flow-induced inventory of volatile selenium, so that the rate-limiting microbial volatilization can be measured without interference. However, diumal temperature fluctuations introduce further complications which appear to make pre-pumping impractical.

On the other hand, lateral flow from the above-ground atmosphere leaking into the field sampler headspace will lessen the flow-induced bias by decreasing the extent of upwards flow of soil air. Recent studies by W. T. Frankenberger, Jr. (personal communication, April 1990) involving a sequence of short-time (10 minute) field gas collections in a single chamber suggest that flow-induced volatile selenium desorption does not occur to any significant exteni. However, the temperature was not controlled in the field test. A similar experiment with a field chamber over soils brought into the laboratory will be performed to help resolve this issue. While lateral leakage into a loosely fitted headspace sampler is advantageous from the standpoint of minimizing large convective disturbances, it also introduces ambiguous positive biases from effectively sampling an area large than that of the headspace. Both disadvantages of soil air convection and lateral leakage biases could conceivably be eliminated by providing an extra air inlet or by recirculating the headspace air. This approach was described in a newly designed sampler described in Section 4.1.

From another possible perspective, if the results of the $250 \mathrm{~mm} / \mathrm{h}$ flow stage (Figure 4.78 are in fact representative rather than anomalous, then sampling with any convection of soil air may yield data which are difficult to both reproduce and interpret.

It is emphasized that this work is in a preliminary stage, and requires considerable crosschecking of procedures and results. Along with modifications and extensior of the work described here, other potentially related areas of study are being pursued. Specifically, the literature in the areas of radon gas and volatile organic gas transport in soils is being reviewed for useful analogs to the volatile selenium case. 


\subsection{CHEMICAL ANALYSIS}

Development of improved analytical techniques for speciation of selenium in soil and pore water samples has been an integral part of the Kesterson Reservoir investigation since 1985. This year, we continued this effort along two lines, including development and application of soil fractionation techniques and application of techniques for separation of organo-selenium compounds in pore water. The results of these and related studies, along with discussion of our QA/QC statistics are presented in this section.

Major results from these investigations are summarized as follows:

(1) Approximately 60 percent of the selenium contained in the top six inches of soil is in refractory forms that are expected to resist transformation to more soluble or volatile forms. Further speciation and fractionation studies are in progress 10 identify the labile and refractory forms of selenium, and to determine rates of volatilization from the various pools of selenium.

(2) Phosphate extraction of soils indicates the presence of a significant pool of adsorbed selenite throughout the soil profile. Only a small fraction of the selenite (10\%) appears to be mobile.

(3) Pore waters collected by vacuum cup samplers do not have a significant fraction of organo-selenium compounds $(<5 \%)$. Consequently, selenate concentration in the pore water is accurately determined from the difference between the "total seleniurn" in the pore water and the selenite.

(4) A Reservoir-wide sampling of the top $0.15 \mathrm{~m}$ of soil (54 sampling sites) revealed that the average fractions of water extractable selenium in the fill, grassland, and former cattail areas of the Reservoir are $7 \%, 8 \%$ and $5 \%$ respectively. Average total 
selenium concentrations for es of the habitats are $2.1 \mathrm{mg} / \mathrm{kg}, 6.6 \mathrm{mg} / \mathrm{kg}$, and 17.3 $\mathrm{mg} / \mathrm{kg}$, respectively. However, within each habitat type there is a broad range of values. 


\title{
5.1. FRACTIONATION OF SELENIUM IN KESTERSON SOILS
}

\author{
A. Yee \\ Earth Sciences Division \\ Lawrence Berkeley Laboratory
}

\section{5:1.1. Objective}

Recent investigations on microbial volatilization of selenium by various workers (Weres, 1989, Frankenberger, 1988, and Karlson and Frankenberger, 1989) have shown great promise as one of the more attractive methods for removing selenium from the Kesterson soil. However, most of these investigations have focused on volatilization of labile fractions of selenium, which may only comprise about $50 \%$ of the selenium inventory in Kesterson soils. In order to estimate realistically the volatilization rate, improved knowledge of the distribution of selenium between the various soil fractions needs to be obtained, as well as, an improved understanding of the relative volatilization rates between the various species of selenium present in the Kesterson soils. To this end, we have attempted to characterize the Kesterson soil into two fractions, one containing labile and other containing refractory form of selenium. The procedure used is a modification that described by of Chao et al. (1989). In the coming year, volatilization experiments will be carried out in the laboratory to determine relative rates of volatilization for the labile and refractory pool of selenium. The effort described is a first-step to develop the methodology that will be used for these experiments.

\subsubsection{Experimental Procedure}

\subsubsection{Preparation of Soil}

A surface sample $(0-5 \mathrm{~cm})$ from pond 1 was collected and air dried. After grinding with a mortar and pestle the soil was mixed and sieved through a 44 mesh screen and then stored in a plastic container. 


\subsubsection{Sequential Extraction of Selenium}

The sequential extraction procedure used is illustrated in Figure 5.1. The soluble selenium was removed by sequential extraction with $0.1 \mathrm{M} \mathrm{KCl}$. Samples $(0.5 \mathrm{gm})$ were placed in an Oak Ridge type centrifuge cones to which $30 \mathrm{ml}$ of $0.1 \mathrm{M} \mathrm{KCl}$ were added. The cones were immersed in a $50^{\circ} \mathrm{C}$ shaking water bath and extracted for 30 minutes with moderate agitation. After cooling in an ice bath they were spun down in a Serval centrifuge for 15 minutes at 5,500 rpm. Supernatants was carefully withdrawn using a syringe. Extraction continued three more times. Then the soil was washed once with deionized water. The combined supernatant was collected in a $100 \mathrm{ml}$ volumetric llask, diluted to mark and then set aside for chemical analysis.

The potentially labile portion of the selenium which is associated with metal oxides, carbonates, and soluble organic matters was extracted sequentially with $0.1 \mathrm{M}$ potassium phosphate at $\mathrm{pH} 9.0,0.1 \mathrm{M}$ potassium EDTA at $\mathrm{pH} 9.0$, and $0.1 \mathrm{M}$ phosphoric acid at $\mathrm{pH} 1.0$. The order of extraction on some samples were reversed to see the effect of each solvent on the soil samples. Total selenium and the major cations from these extracts were monitored by hydride generation and ICP. The steps of the extraction procedure are the same as for the $\mathrm{KCl}$ extraction described above.

After the phosphate extractions the sample was digested with $3 \mathrm{ml}$ of concentrated nitric acid in a heated aluminum block overnight. Then selenium was repeatedly extracted with 10 to $20 \mathrm{ml} 6 \mathrm{~N} \mathrm{HCl}$ until the yellow color of iron no longer appear in the solution. The combined extrac:, which was collected in a $100 \mathrm{ml}$ volumetric flask, was diluted to mark for total selenium analysis.

\subsubsection{Results and Discussion}

From the sequential extraction we found the $\mathrm{KCl}$ soluble fraction to contain $7.6 \mathrm{ppm}$ selenium, the potentially labile fraction $8.6 \mathrm{ppm}$, and the refractory portion, $24.9 \mathrm{ppm}$ when extracted in the sequence of EDTA-buffer-phosphoric acid. When extracted in a different order, buffer-EDTA-phosphoric acid, the potential labile fraction was $7.7 \mathrm{ppm}$, and phosphoric acid- 
Sequential lixtraction Procedure

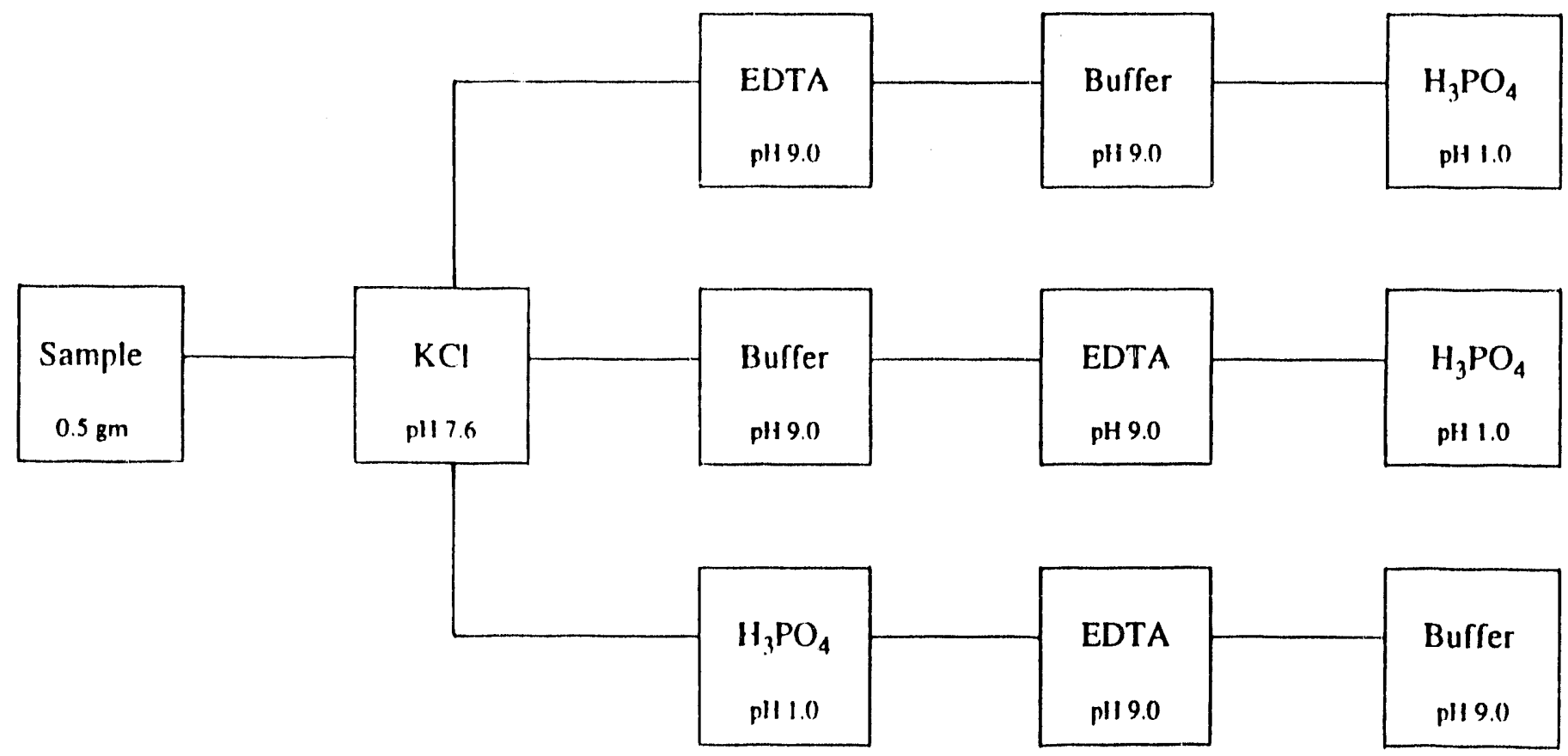

EDTA $=0.1 \mathrm{M}$, p 19.1$)$ potassium I:DTA

Buffer $=0.1 \mathrm{M}$, pll 9.0 potassium phospliale

$\mathrm{H}_{3} \mathrm{PO}_{4}=0.1 \mathrm{M}$

Figure 5.1. Sequentiai extraction procedure for Kesterson soil samples. 
EDTA-buffer, the potential labile fraction was $9.5 \mathrm{ppm}$ (see Table 5.1). The average total selenium content in the soil sample determined from sequential extraction was $40.7 \mathrm{ppm}$. This value compared well with both XRF analysis (42.5 ppm) and the acid extraction method of U.C. Riverside (40.2 ppm).

The average ICP results of the major elements indicate phosphoric acid and EDTA have similar extraction characteristics (Figure 5.2). Phosphoric acid, at pH 1.0 dissolved all the carbonates and metal oxides present in the samples and effectively released the selenium bound in the carbonate. Selenium extracted by phosphoric acid was predominantly in the selenite form. Phosphate buffer, at $\mathrm{pH}$ of 9.0 , functions as a chelating agent, and help extract selenium from the organic matter. At this alkaline pH it should not dissolve the metal oxides. EDTA, at pH 9.0, has dual functions; it chelates the metal ions and facilitates dissolution of organic matter, such as humic acid adsorbed from the mineral surfaces. Therefore, one would expect to get more selenium from EDTA extraction than from either phosphoric acid or from phosphate buffer, assuming there is a relatively large amount of organic matter in the soil samples.

The results of this preliminary investigation suggest that about $60 \%$ of the selenium in this soil sample was in a refractory form, presumably, not readily available for plant uptake or volatilization. This is in general agreement with early findings described by the LBL 1987 and 1988 annual reports. Additional fractionation work is now underway, along with volatilization experiments using one or a combination of these "pools" of selenium. 
Table 5.1. Sequential extraction of selenium using EDTA, phosphate buffer, and $\mathrm{H}_{3} \mathrm{PO}_{4}$.

Selenium $(\mathrm{mg} / \mathrm{kg})$

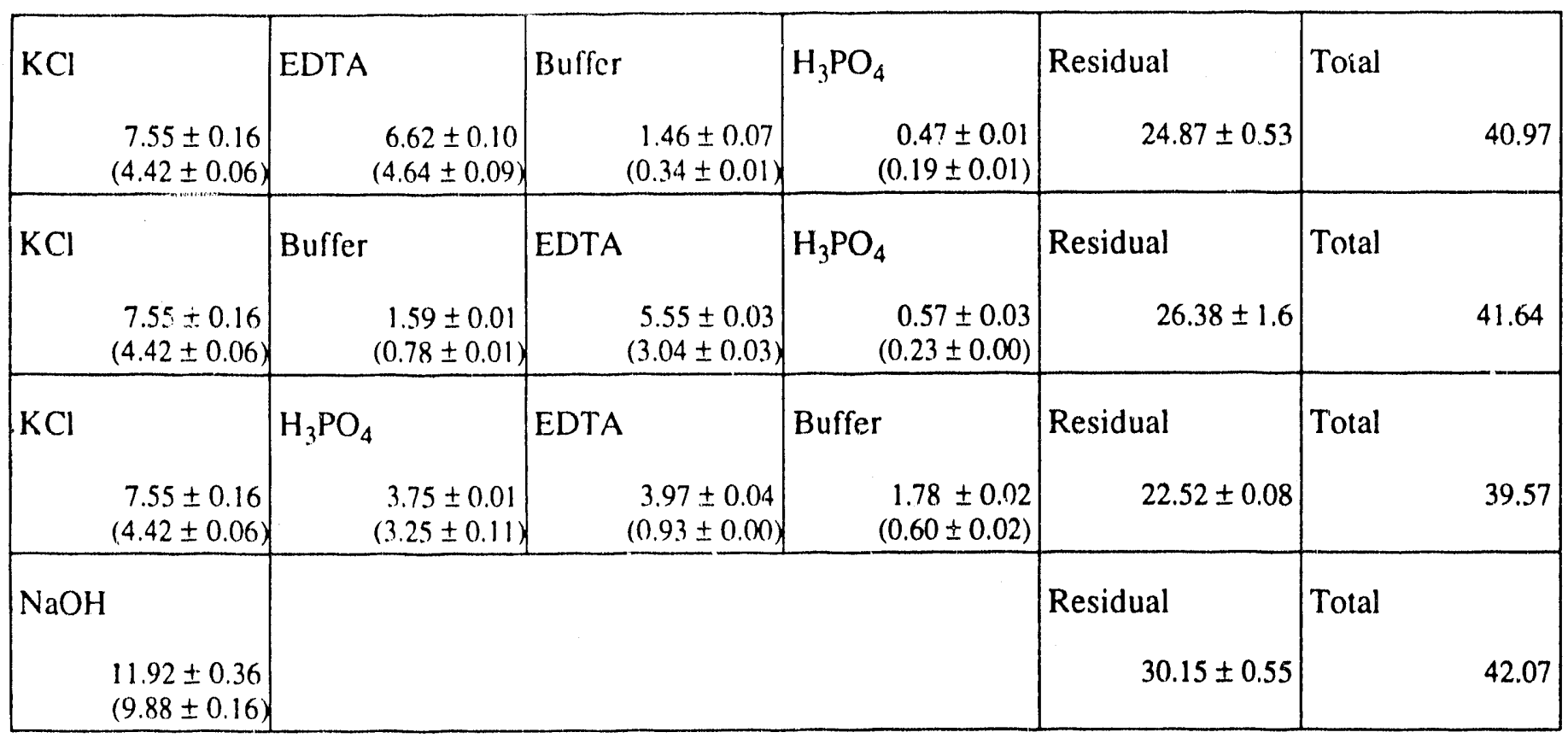

$(\quad)=\mathrm{SeO}_{3}^{2-}$ 


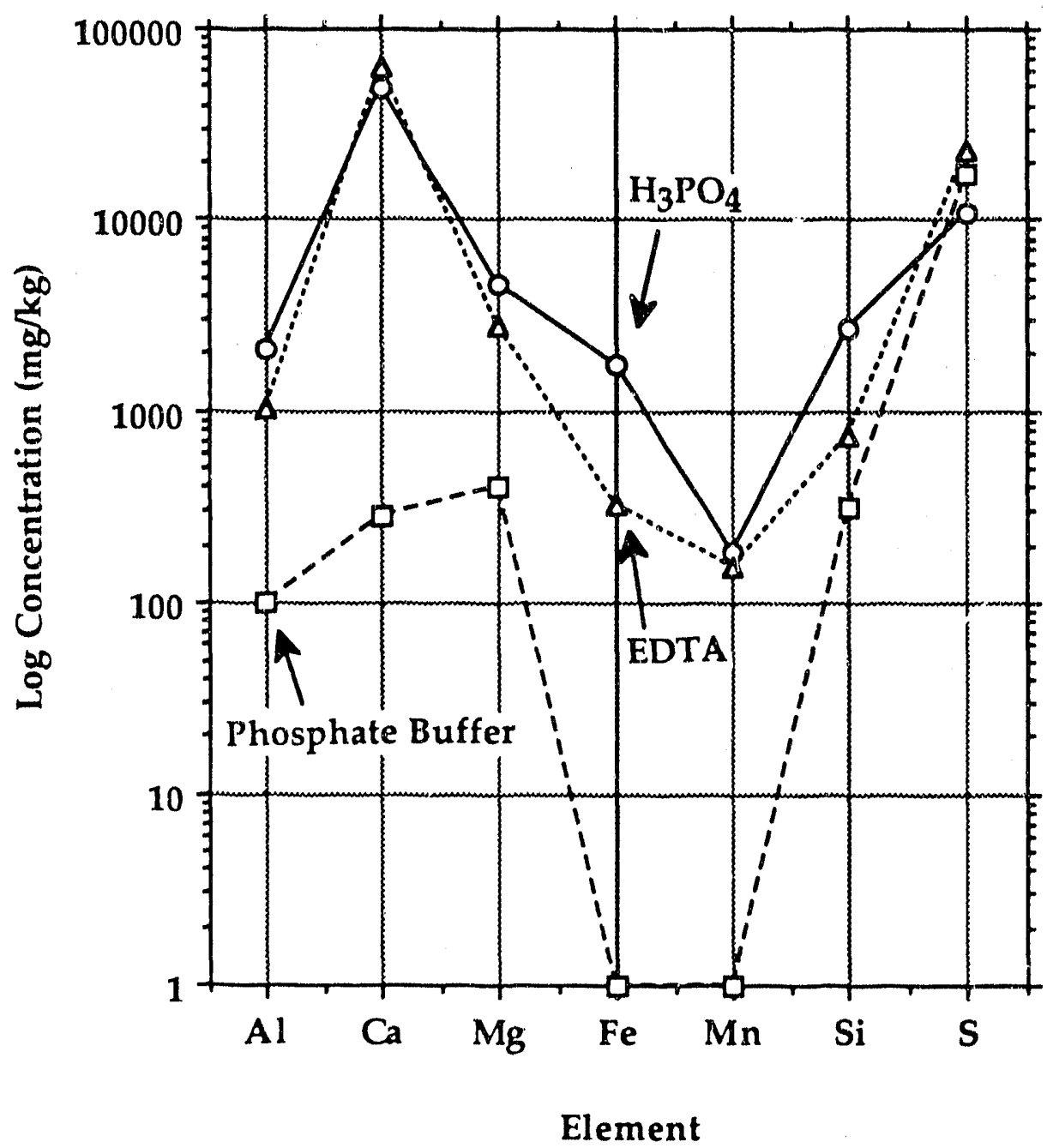

Figure 5.2. Comparisons of cations extracted by $0.1 \mathrm{~m} \mathrm{H}_{3} \mathrm{PO}_{4}, 0.1 \mathrm{~m}$ potassium phosphate buffer, and $0.1 \mathrm{~m}$ potassium EDTA. 


\title{
5.2. PHOSPHATE-EXTRACTABLE SELENITE AND ARSENATE
}

\author{
T. Tokunaga \\ Earth Sciences Division \\ Lawrence Berkeley Laboratory
}

In order to estimate the inventory of adsorbed selenite which may be susceptible to oxidation to selenate, a set of selenite extraction experiments have been performed. The approach used for this purpose utilizes the phosphate anion for displacing selenite into solution. Before proceeding to describe the approach taken, it is worth noting that the distinction between watersoluble and adsorbed (and/or precipitated) selenite is operationally defined, not only by the extraction technique for the adsorbed component which commonly receives attention, but also by the method for determining the water-soluble fraction. Extraction of the soil solution at field moisture, or as a saturation paste, or at any number of water:soil mass ratios will commonly yield essentially identical selenate contents. On the other hand, the water-extractable selenite content is sensitive to both water:soil ratios and mixing times.

\subsubsection{Method}

Phosphate extractions for selenite were performed using $1 \mathrm{mM}$ disodium phosphate $\left(\mathrm{Na}_{2} \mathrm{HPO}_{4}\right)$ equilibration solutions at neutral to slightly alkalins $\mathrm{pH}$. Samples were mixed in ratios of $10.00 \mathrm{~g}$ soil per $200.0 \mathrm{~g}$ phosphate solution for 24 hours in a reciprocating shaker (room temperature). Separate samples were water-extracted for soluble-selenium determination at a 5:1 water:soil mass ratio. After centrifugation, the samples were filtered $(0.45 \mu \mathrm{m})$ and analyzed for both selenite and total dissolved selenium by hydride generation atomic absorption spectrometry. Phosphate-extractable selenite was obtained by differences in selenite concentrations from the two extraction procedures. While the procedure is generally similar to phosphate-based selenite extraction step used in sequential extraction techniques reported by others (Fujii et al., 1988, 
Chao and Sanzolone, 1989), it differs primarily in the use of a lower concentration of phosphate (1 $\mathrm{mM}$ rather than $32 \mathrm{mM}$ up to $0.1 \mathrm{M}$ ). This modification was suggested by Prof. G. Sposito (U.C. Berkeley, Dept. of Soil Science, personal communication, March 1989), and serves to minimize chemical weathering of the solid phase while still utilizing the ligand exchange mechanism for displacing selenite with phosphate. Due to similarities in adsorption behavior of selenite, arsenate, and phosphate, the phosphate extracts were analyzed for arsenic as well. Experiments in which phosphate concentrations were varied from 0 through as much as $1 \mathrm{M}$, in duplicate, at fixed background $\left(\mathrm{NaCl}\right.$ and $\left.\mathrm{Na}_{2} \mathrm{SO}_{4}\right)$ electrolyte concentrations confirmed the occurrence of local plateaus in both extractable selenite and arsenate in the vicinity of $1 \mathrm{mM}$ phosphate (Figure 5.3). Blank solutions spanning the range of phosphate and background electrolyte concentrations were included in all analyses. Analysis for, and the detection of a large increase in dissolved silica with phosphate concentrations in excess of about $5 \mathrm{mM}$ was inter. preted as chemical weathering of the solid phase (Figure 5.3). In a separate set of tests, effectively $100 \%$ selenite spike recovery was confirmed using the present procedure. Using the method of Glaubig and Goldberg (1988), the arsenic extracted with $1 \mathrm{mM}$ phosphate was determined to be in the arsenate, $A s(V)$, oxidation state. Spike tests with sodium arsenate indicated that the $1 \mathrm{mM}$ phospitate extractions were not quantitatively reliable at high arsenate concentrations (above $500 \mu \mathrm{g} /(\mathrm{kg}$ soil)). Incomplete desorption and/or readsorption of some arsenate at high concentrations is suspected (e.g. Kheboian and Bauer, 1987, and Gruebel et al., 1988).

It should be noted that even with considerable circumstantial evidence that this procedure is effectively yielding adsorbed selenite, contribution to the selenite yield from dissolution of selenite minerals can not be completely ruled out. This is a deficiency in most all macroscopic analytical procedures (cf. Sposito, 1984, pp 122-128). Thus, while adsorbed selenite is the intended target of this method, the excess selenite yielded in phosphate solutions is more properly referred to as phosphate-extractable selenite. 


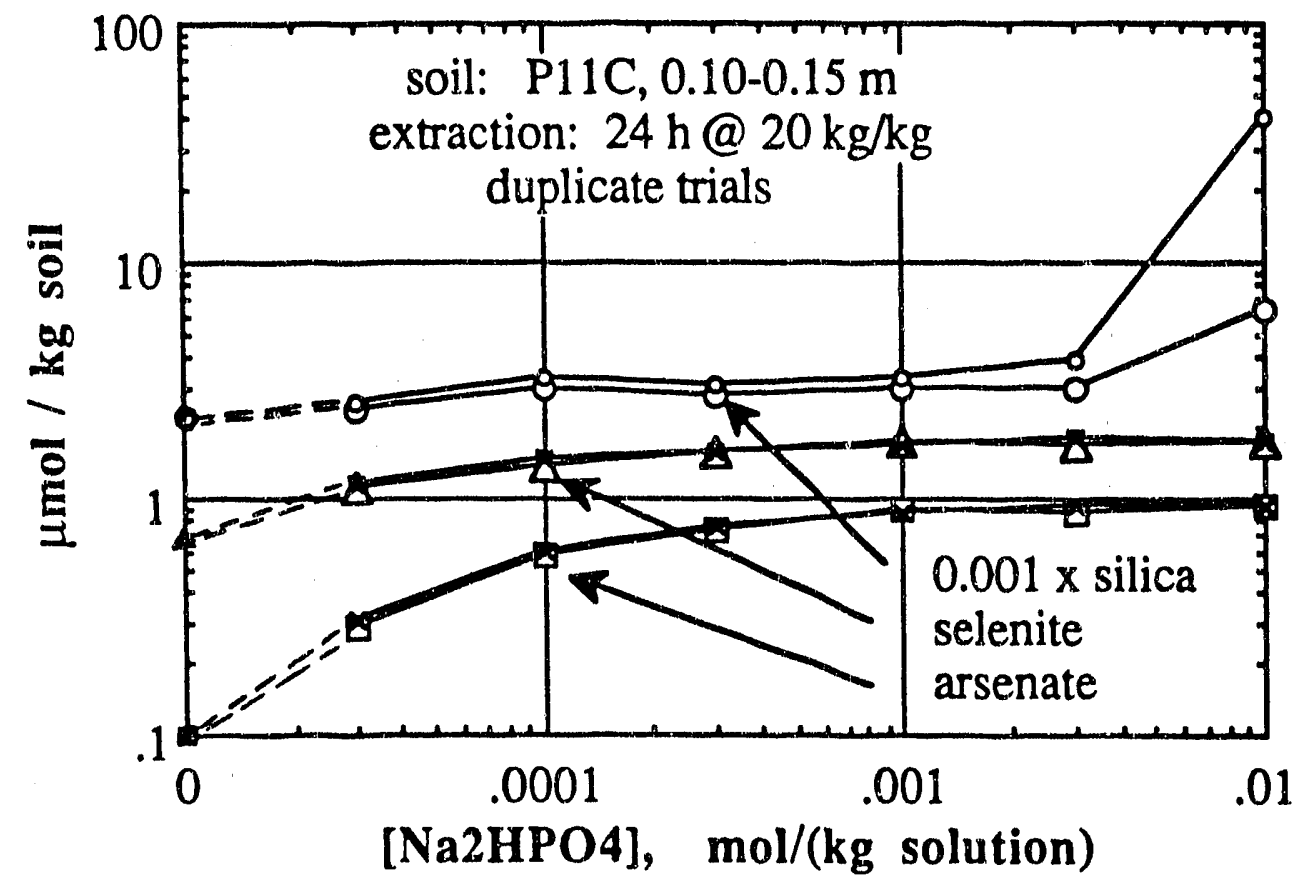

Figure 5.3. Dependence of extractable selenite, arsenate, and silica on phosphate concentration. 


\subsubsection{Soil Profile Data}

Profiles of water-soluble and phosphate-extractable selenite from the Pond 11 Control test plot are shown in Figure 5.4. It is evident from these profiles that while water-extractable selenite is a minor constituent in the total water-extractable selenium inventory, phosphate-extractable selenite comprises a much more significant fraction. Similar profiles, with and without phosphate, have been determined at other locations, both on and off the Reservoir. The on-site profiles exhibit generally similar pattems as that shown in Figure 5.4. The one off-site profile analyzed to date was low in both water-extractable and phosphate-extractable selenium.

Extractable arsenic profiles have been performed for several sites at the Reservoir, and at one off-site location within Kesterson National Wildlife Refuge. An example from Pond 9 is shown in Figure 5.5. Included in this piot are arsenic concentrations obtained from a variety of approaches. The data shown are from field soil solution samplers, water extracts (replicates of 5:1 extracts, and 20:1 extracts), phosphate extracts, and from XRF analysis. These profiles are typical of those measured at other locations on the Reservoir. Arsenic concentrations in soil pore waters are typically less than $50 \mu \mathrm{g} / \mathrm{L}$ (the drinking water standard for As). The soil solution As concentration plotted in Figure 5.5 was converted to a soil mass referenced concentration by assuming a field gravimetric water content of $0.25 \mathrm{~g} / \mathrm{g}$. The sensitivity of the watcr-extractable arsenic content to the water:soil ratio used is clearly depicted by the enhanced recoveries obtained in going from field-moist conditions $(=0.25: 1)$, to $5: 1$, and to $20: 1$. Roughly a 10 to 50 fold increase in extracted arsenic is commonly observed in changing from direct soil solution samples to 5:1 water extracts. Similar increased yields are obtained in comparing water extracts with phosphate extracts. In view of incomplete spike recoveries at higher concentrations, larger uncertainties are associated with the arsenate concentrations in excess of about $500 \mu \mathrm{g} /(\mathrm{kg}$ soil). The strong tendency for arsenate to sorb on soil particle surfaces has been observed in all sites where comparisons between direct soil solution samples and laboratory extracts have been possible. Also included in Figure 5.5 is the total soil arsenic content determined by XRF analysis. Unlike sclenium, neither the total soil arsenic or its various extractable forms are concentrated at 


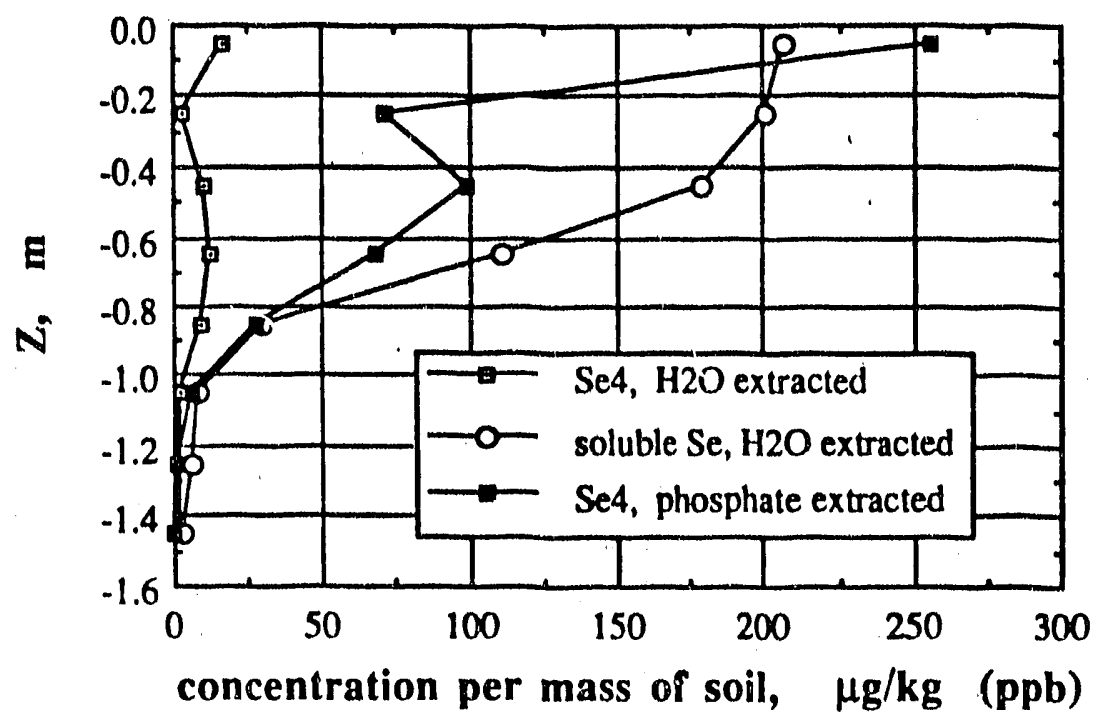

Figure 5.4. Site P11C, water-extractable and phosphate-extractable selenium.

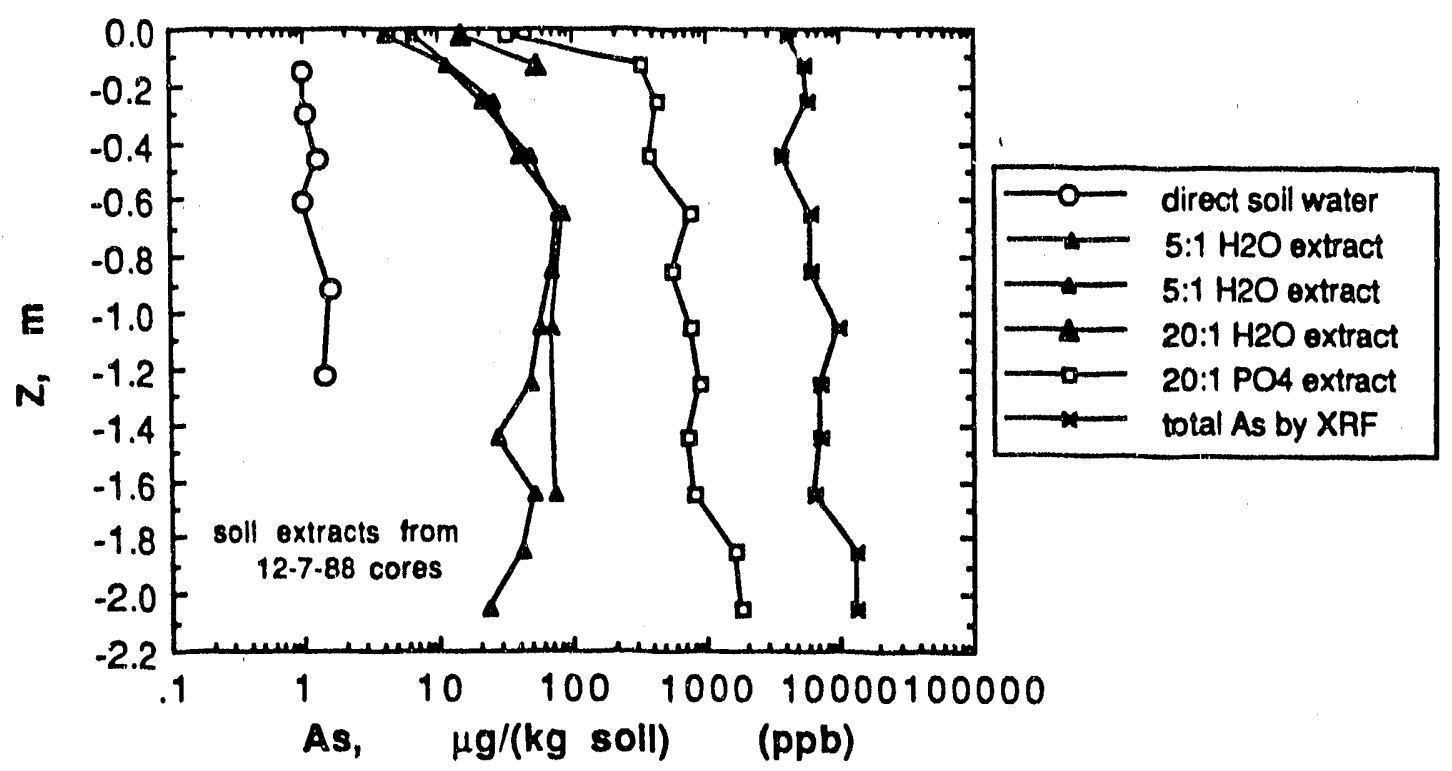

Figure 5.5. Site P9C, soluble arsenic, phosphate-extractable arsenic, and total arsenic. 
the soil surface in the Reservoir profiles sampled to date. On the contrary, the Reservoir profles analyzed to date exhibit arsenic concentration minima at the surface, and generally increase with depth. For comparison, water-extractable and phosphate-extractable arsenic profiles fror an off-site location are shown in Figure 5.6. This off-site profile was sampled within Kesterson National Wildlife Refuge, $1.1 \mathrm{~km}(0.7$ miles) directly north of the intersections of Ponds 11 and 12, and the San Luis Drain. While the extracted concentrations of arsenic are within the range observed at locations wi hin the Reservoir, the profiles have concentration maxima with the top meter of soil, unlike the Reservoir profiles. This may reflect slow leaching of arsenate while the Reservoir was in operation. More extensive analyses of both on-site and off-site profiles would be needed to test this concept. (The average extractable selenium content in the off-site profile was about $4 \mu \mathrm{g} /(\mathrm{kg}$ soil) (ppb) with a maximum value of $15 \mu \mathrm{g} / \mathrm{kg}$.) The soils analyzed to date have had total arsenic concentrations in the range of 1 to $20 \mathrm{mg} / \mathrm{kg}(\mathrm{ppm})$. These concentrations are within the normal range for uncontaminated soils. Ganje and Rains (1982) cite a range of 0.2 to $40 \mathrm{mg} / \mathrm{kg}$, with an average of about $5 \mathrm{mg} / \mathrm{kg}$ in common soils. All of the abovementioned factors, along with lack of detection of high arsenic concentrations in the original San Luis Drain waters indicate that drainwater contributions of arsenic to the Reservoir were minor.

From the perspective that oxyanion adsorption/desorption can occur through the common mechanism of ligand exchange in the cases or phosphate, selenite, arsenate, and molybdate (e.g. Hingston. 1981), it appears reasonable to test phosphate extraction techniques with the latter oxyanion as well. 


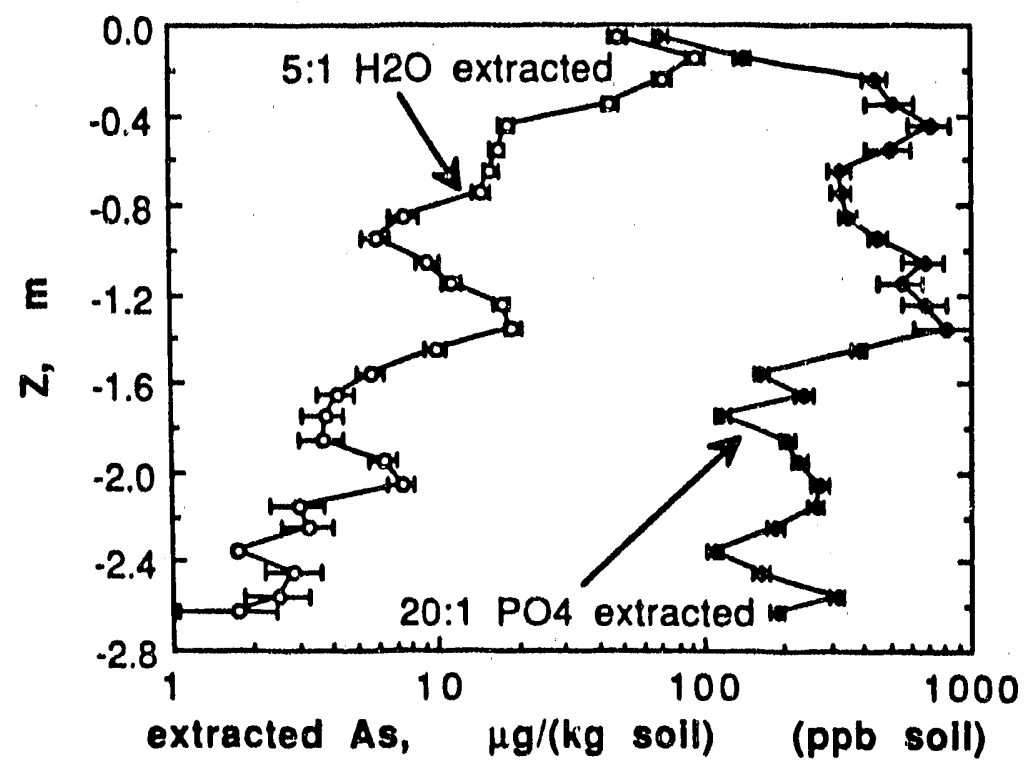

Figure 5.6. Off-site soil profiles of water-extractable and phosphate-extractable arsenic. 


\title{
5.3. ANALYSIS FOR ORGANIC SELENIUM IN WATER
}

\author{
A. Yee \\ Earth Sciences Division \\ Lawrence Berkeley Laboratory
}

The analytical methods we typically use to determine the concentration of selenium in the pore waters is a two step procedure that provides information regarding selenite and total selenium concentrations. In the most general sense, in alkaline environments, the total selenium represents the sum of selenate, selenite, plus any number of organoselenium compounds. Researchers studying soils in similar environments, in particular in the central valley, have concluded that selenate is the dominarit form of selenium present in pore water (Fio and Fujii, 1988). However in some samples, a significani fraction of organoselenium compounds have been observed. Due to the important role that speciation plays in the mobility, environmental availability, and toxicity of selenium, we have recently attempted to quantify the fraction of organoselenium compounds present in the pore-water samples collected from ceramic samplers in the vadose zone at Kesterson Reservoir. Pore water samples from 4 sites at the Reservoir were chosen for the initial screening. These included samples from the $0.15 \mathrm{~m}$ sampler at site UZ-5 in Pond 1 , the $0.3 \mathrm{~m}$ sampler site UZ-9 in Pond 1 , the $0.15 \mathrm{~m}$ sampler at UZ-8 in Pond 1 and the 0.15 m sampler at the Pond 10 gully site. In addition, two samples of a phosphate-extracted soil solution were evaluated.

\subsubsection{Methods}

Pore-water samples having selenium content $800-1000 \mathrm{ppb}$ were tested for the presence of organoselenium following the general procedure of Fio and Fujii (1988). Samples were first acidified to a pH of 2.2 and then $5 \mathrm{ml}$ aliquots were applied onto activated charcoal and XAD-8 columns followed by $5 \mathrm{ml}$ wash with $0.01 \mathrm{~N} \mathrm{HCl}$. The eluents were collected in $25 \mathrm{ml}$ volumetric 
flasks and then set aside for selenium determination. The adsorbed organoselenium, if present, were desorbed with $5 \mathrm{ml} 0.2 \mathrm{~N} \mathrm{NaOH}$ and the eluent collected in separate volumetric flasks. Selenium was determined by hydride generation atomic absorption spectrometry.

Since the XAD-8 resins adsorb only the hydrophobic type of selenium associated with humic acid, we introduced a cation exchange resin column to remove the hydrophilic type of selenium associated with proteins, peptides, and amino acids. The latter procedure is the well known method of amino acid analysis by Moore, et al. (1958).

The cation exchange columns were packed with AG 50x2 resin (Bio-Rad Lab). The 2\% cross link was selected over the usual $8 \%$ because it has larger porosity to accommodate the protein and peptide molecules, and it works equally well with smaller molecules like the amino acids. To get the highest exchange capacity the columns were converted to the hydrogen form and equilibrated with $0.01 \mathrm{~N} \mathrm{HCl}$ prior to use.

To test the effectiveness of these columns as adsorbers we passed standard solutions of selenite, selenate, and seleno-amino acids through the columns and collected the effluents in volumetric flasks for total selenium analysis. We found the activated charcoal columns irreversibly adsorbed selenite as well as selenate (see Tables 5.2 and 5.3); the same finding was also reported by Fio and Fujii (1988). Thereafter, charcoal columns were eliminated from the analysis procedure. XAD- 8 columns retained about $5 \%$ of the inorganic selenium and iess for the seleno-anino acids (see Table 5.2, 5.3 and 5.4). The small arnount of adsorption found was most likely due to slow equilibration of the trapped samples inside the resin matrix, and not due to actual column adsorption. In contrast, the cation exchange columns adsorbed the selenoamino acid very well, and recoveries were complete upon elution with $0.2 \mathrm{~N} \mathrm{NaOH}$.

\subsubsection{Results}

Analysis of the four pore water samples collected from Kesterson Reservoir are shown in Table 5.5. In each case, total selenium concentrations in the eluates were within the analyticai precision of the measurement techniques and the fraction recovered from the $\mathrm{NaOH}$ wash was 
small. The combination of these two factors indicates that organo-selenium compounds comprise only a small fraction (at most on the order of several percent) of tha selenium contained in pore water samples collected with the porous cup samplers. Consequently, for practical purposes, we may assume that the selenate fraction can be determined from the difference between the total soluble selenium and selenite.

Some caution is warranted in drawing this conclusion, because the vacuum extraction sampling procedure has the tendency to de-gas the solution as it enters the sample cup. Partitioning of the volatilized selenium between the soil solution and the void space of the samplers volume will be different than when the soil solution is in direct contact with the soil matrix. However, preliminary assessment suggests this is not a signi ant factor because the volatile species of selenium only comprise a small fraction of both the total and water extractable selenium in the soil.

A significant fraction of organically-bound selenium appears to be present in the phosphate-extracted soil solution (see Figure 5.4). Further analysis of the significance of this observation is underway. 
Table 5.2. Adsorption of selenite by activated charcoal (AC) and XAD. 8 resin columns. A 10 $\mu \mathrm{g} / \mathrm{l}$ standard was used for these trials.

\begin{tabular}{|lcccc|}
\hline & $\begin{array}{c}\mathrm{HCl} \text { wash } \\
(\mu \mathrm{g} / \mathrm{l})\end{array}$ & $\begin{array}{c}\text { Eluate } \\
\mathrm{NaOH} \text { wash } \\
(\mu \mathrm{g} / \mathrm{l})\end{array}$ & $\begin{array}{c}\text { Total Se } \\
(\mu \mathrm{g} / \mathrm{l})\end{array}$ & \% Recovery \\
\hline \hline AC column \#1 & 1.21 & 4.84 & 6.05 & 60.5 \\
$\mathrm{AC}$ column \#2 & 2.51 & 5.05 & 7.56 & 75.6 \\
XAD-8 column \#1 & 9.36 & 0.69 & 10.05 & 100.5 \\
XAD-8 column \#2 & 9.44 & 0.73 & 10.17 & 101.7 \\
\hline
\end{tabular}

Table 5.3.Adsorption of selenite by activated charcoal and XAD-8 columns. A $20 \mu \mathrm{g} / 1$ standard was used for theses trials.

\begin{tabular}{|lcccc|}
\hline & $\begin{array}{c}\text { Eluate } \\
\mathrm{HCl} \text { wash } \\
(\mu \mathrm{g} / \mathrm{l})\end{array}$ & $\begin{array}{c}\mathrm{NaOH} \text { wash } \\
(\mu \mathrm{g} /)\end{array}$ & $\begin{array}{c}\text { Total Se } \\
(\mu \mathrm{g} /)\end{array}$ & \% Recovery \\
\hline \hline AC Column\#1 & 7.77 & 6.99 & 14.76 & 73.8 \\
$\mathrm{AC}$ column \#2 & 7.21 & 9.32 & 16.53 & 83.0 \\
XAD-8 column \#1 & 19.33 & 0.77 & 20.10 & 101.0 \\
XAD-8 column \#2 & 19.48 & 0.86 & 20.34 & 102.0 \\
\hline
\end{tabular}

Table 5.4. Adsorption of selenoamino acids by XAD-8 and cation exchange resins.

\begin{tabular}{|c|c|c|c|c|}
\hline & \multicolumn{2}{|c|}{ Se-Cystine } & \multicolumn{2}{|c|}{ Se-Methionine } \\
\hline & $\begin{array}{c}\text { XAD-8 } \\
(\mu g / 1)\end{array}$ & $\begin{array}{c}\text { Ion-exchange } \\
(\mu \mathrm{g} / 1)\end{array}$ & $\begin{array}{c}\text { XAD-8 } \\
(\mu g / 1)\end{array}$ & $\begin{array}{c}\text { Ion-exchange } \\
\left(f^{\prime} g / 1\right)\end{array}$ \\
\hline Initial Conc. & 25.73 & 25.73 & 22.65 & 22.65 \\
\hline after acid wash & 25.64 & 0.38 & 22.96 & 0.28 \\
\hline after $\mathrm{NaOH}$ wash & 0.79 & 26.35 & 0.31 & 24.25 \\
\hline
\end{tabular}




\section{$-327-/ 328$}

Table 5.5. Analysis of pore-water samples for organoselenium compounds.

\begin{tabular}{|cccc|}
\hline Sample No. & $\begin{array}{c}\text { Total Se } \\
(\mu \mathrm{g} / \mathrm{l})\end{array}$ & $\begin{array}{c}\text { Pore-Water } \\
\text { After XAD-8 } \\
(\mu \mathrm{g} / \mathrm{l})\end{array}$ & $\begin{array}{c}\text { After Ion-exchange } \\
(\mu \mathrm{g} / \mathrm{l})\end{array}$ \\
\hline \hline 1. & 1,077 & 1,067 & 1,156 \\
2. & 944 & 886 & 1,025 \\
3. & 1,360 & 1,315 & 1,440 \\
4. & 1,904 & 2,036 & insuff. sample \\
\hline
\end{tabular}

Table 5.6. Analysis of phosphate extracted soil samples for organoselenium compounds.

\begin{tabular}{|c|c|c|c|c|c|}
\hline \multirow[b]{2}{*}{ Sample No. } & \multirow[b]{2}{*}{$\begin{array}{c}\text { Total Se } \\
(\mu \mathrm{g} / \mathrm{l})\end{array}$} & \multicolumn{2}{|c|}{ XAD-8 } & \multicolumn{2}{|c|}{ Ion-Exchange } \\
\hline & & $\begin{array}{c}0.01 \mathrm{~N} \mathrm{HCl} \\
(\mu \mathrm{g} / 1)\end{array}$ & $\begin{array}{c}\mathrm{NaOH} \text { wash } \\
(\mu \mathrm{g} / \mathrm{l})\end{array}$ & $\begin{array}{c}0.01 \mathrm{~N}-\mathrm{HCl} \\
(\mu \mathrm{g} / \mathrm{l})\end{array}$ & $\begin{array}{c}\mathrm{NaOH} \text { wash } \\
(\mu \mathrm{g} / 1)\end{array}$ \\
\hline 5. & 71.6 & 17.9 & 8.9 & 61.6 & 1.9 \\
\hline 6. & 20.7 & 16.4 & 4.1 & 34.8 & 0.7 \\
\hline
\end{tabular}




\title{
5.4. SYNOPTIC SURVEY OF WATER-EXTRACTABLE AND TOTAL SELENIUM CONCENTRATIONS IN KESTERSON SOILS
}

\author{
John Daggett and Salty Benson \\ Earth Sciences Division \\ Lawrence Berkeley Laboratory
}

Soil samples from each of three tri-sections covering Kesterson Reseryoir were collected by CH2M Hill (one below Gun Club Road; one covering former ponds 5, 6, 7, and 8; and one covering ponds 9,1011 and 12). Each tri-section contains six sites; each site contains three habitat types; and, each habitat type on every site was sampled in triplicate. LBL analyzed 54 samples (one sample for each habitat type from each site) for total water extractable selenium and water extractable selenite, and 52 samples for total selenium (54 less 2 due to sample depletion). The extracts used in the total water extractable selenium and water extractable selenite analyses were made using a 5:1 water to dry soil mass ratio following procedures described extensively in previous progress reports. Total selenium analyses were performed using $\mathrm{x}$-ray fluorescense. The three habitat types are:

- fill (a filled area);

- grasslands (a salt grass or uplands area); and,

- open (an area previously populated by cattails).

Eighteen samples of each soil/habitat type were analyzed.

Histograms showing the distribution of total selenium concentration and water extractable selenium concentration for each soil/habitat type are given in Figures 5.7 and 5.8. Figure 5.7 shows that the total selenium concentration in most of the fill samples lies in the range of 0 to 2 parts per million parts dry solid mass. (Note: all concentrations listed here will be units of parts per million parts dry solid mass unless noted otherwise.) The rest of the fill samples are roughly clustered around the 4 to $6 \mathrm{ppm}$ range. The grasslands and open data plotted in Figure 5.7 have a broader distribution with the open samples weighted more towards the higher values. The histo- 


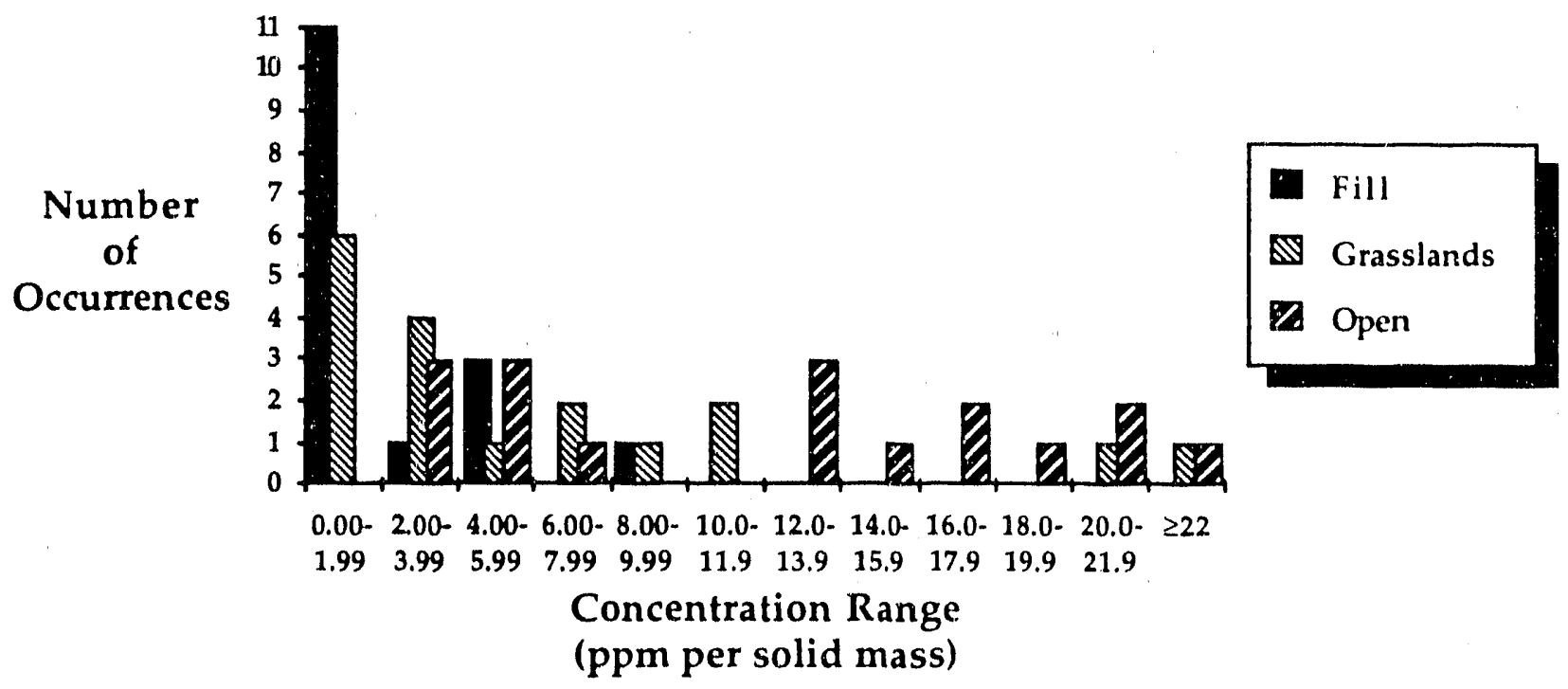

Figure 5.7. Comparison of the distribution of total selenium concentrations for each habitat type.

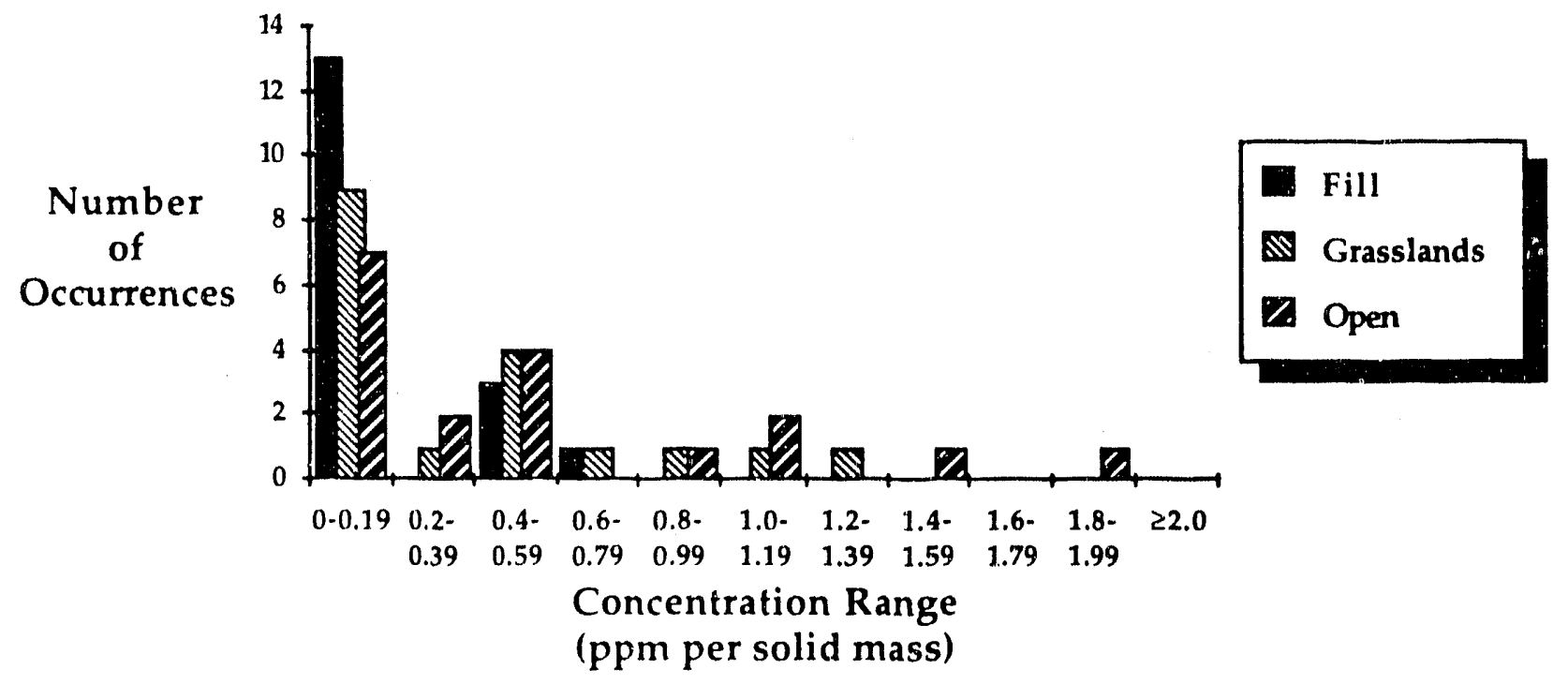

Figure 5.8. Comparison of the distribution of water extractable selenium concentrations for each habitat type. 
grams of water extractable selenium shown in Figure 5.8 indicate distributions similar to the total selenium histograms in Figure 5.7.

In order to assess if selenium levels could be correlated with habitat types, average values and $95 \%$ confidence limits on these averages are compared in Figures 5.9, 5.10, and 5.11. The water extractable fractions of total selenium for each soil/habitat type are shown in Figure 5.9 to be $7.0 \%, 7.7 \%$, and $4.6 \%$ for the fill, grasslands, and open soil/habitat types respectively. However, due to the range of variability present, these values are not significantly different at the $95 \%$ confidence limit. Note that the average extractable fraction values for the fill in Figure 5.9 have not included data for which the XFF values were equal to zero. Figures 5.10 and 5.11 show the averages of the total selenium and extractable selenium concentration data from each soil/habitat type. The averages of total selenium are $2.1,6.6$, and $17.3 \mathrm{ppm}$ for the fill, grasslands, and open soil/habitat type respectively, and the averages of extractable selenium are $0.16,0.4$, and 0.54 ppm in the same order. On average, $27 \%, 21 \%$, and $11 \%$ of the soluble selenium in the fill, grasslands, and open soil/habitat types respectively is in the form of selenite. Figure 5.11 illustrates the extractable selenium/selenite relationship for each soil/habitat type; the average concentration of water extractable selenite is $0.029,0.054$, and $0.05 \mathrm{ppm}$ for each soil/habitat type, ordered as above. Selenate is the major fraction of water extractable selenium.

Taken together, Figures 5.7 through 5.12 indicate that the average levels of selenium at Kesterson Reservoir listed in ascending order with respect to soil/habitat type are fill, grasslands, and open. The water extractable fraction of the selenium inventory is not statistically different in any of the soil/habitat types. This is more clearly seen in Figure 5.13 where water extractable selenium vs. total selenium is shown. Figure 5.13 exhibits no definite patterns to speak of.

A broad range ( $0 \mathrm{ppm}$ to $9 \mathrm{ppm})$ in selenium concentration in the fill material was not anticipated. However, upon considering the the various factors which effect the composition of the fill material, this range is not unexpected. There are many factors which contribute to the variability of the composition of the fill material including: 


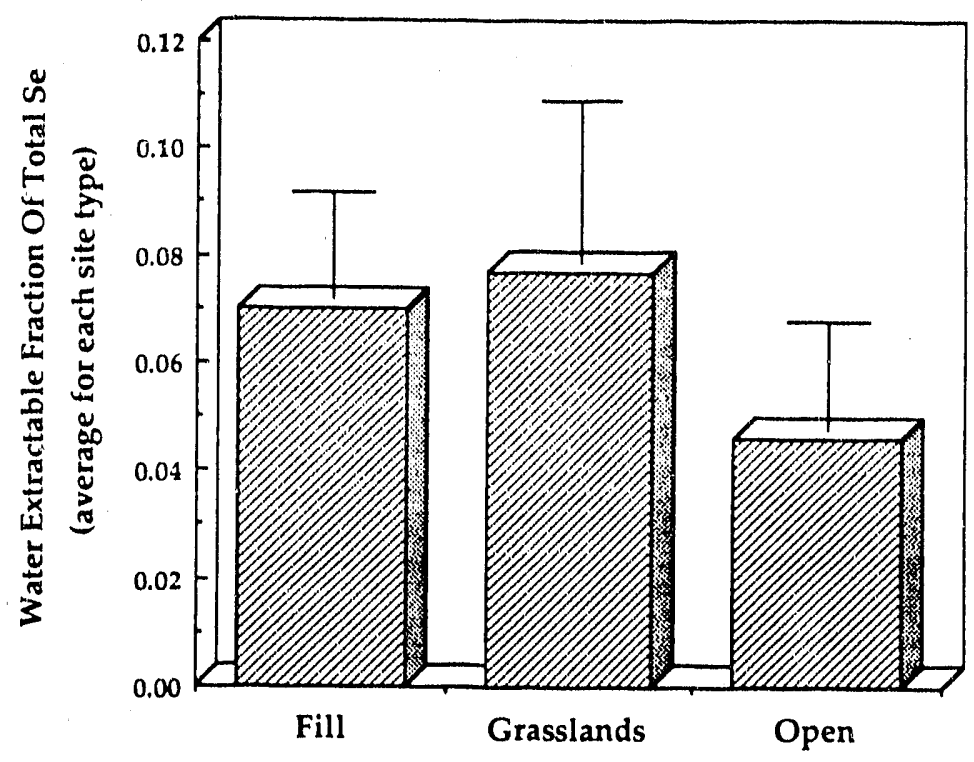

Figure 5.9. Water extractable fraction of total selenium vs. habitat type. Error bars show the upper half of the range in which there is $95 \%$ confidence.

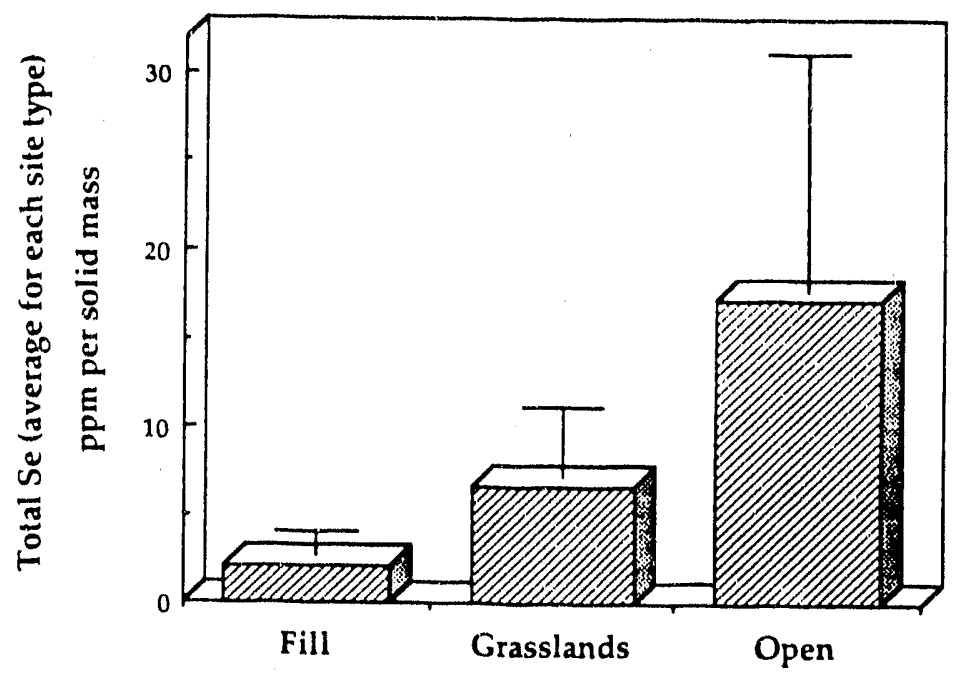

Figure 5.10. Total selenium vs. habitat type. Error bars show the upper half of the range in which there is $95 \%$ confidence. 


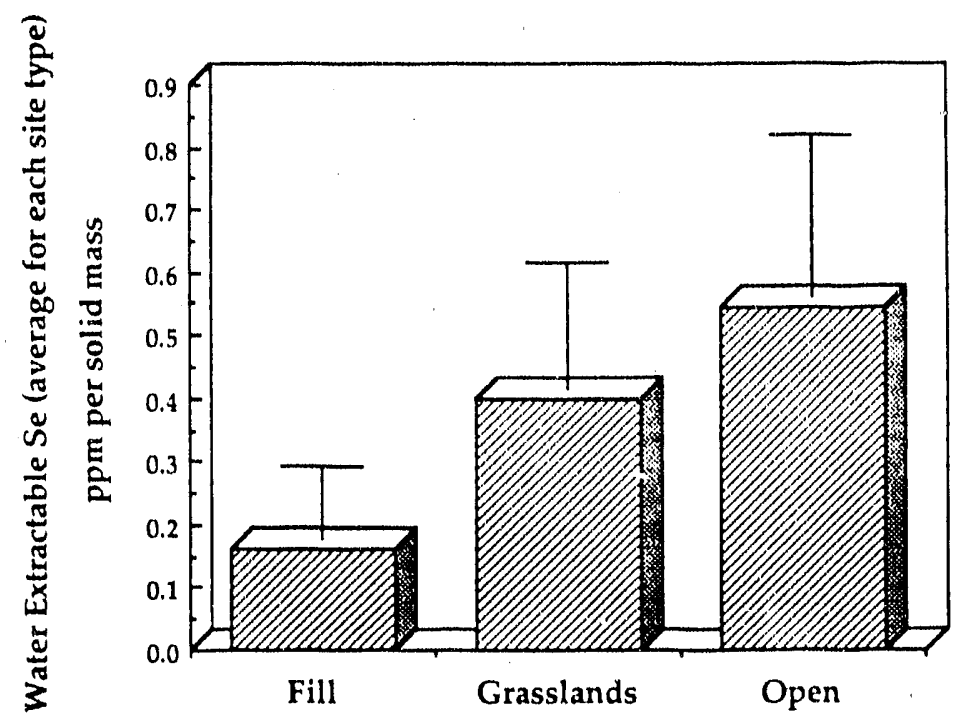

Figure 5.11. Water extractable selenium vs. habitat type. Error bars show the upper half of the range in which there is $95 \%$ confidence.

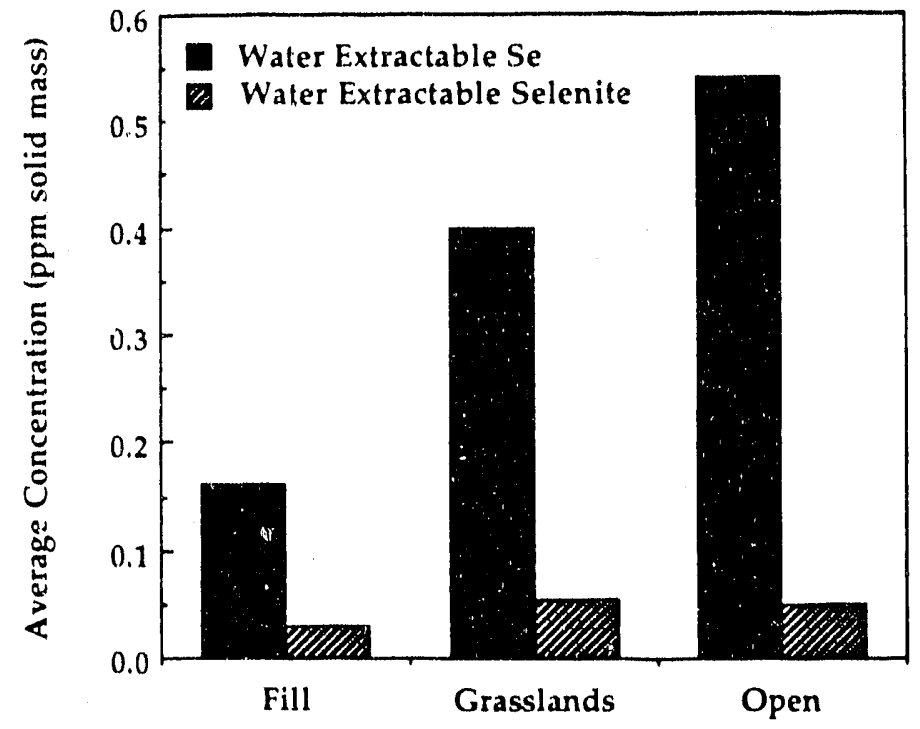

Figr:e 5.12. Water extractable selenium and selenite for each habitat type. 


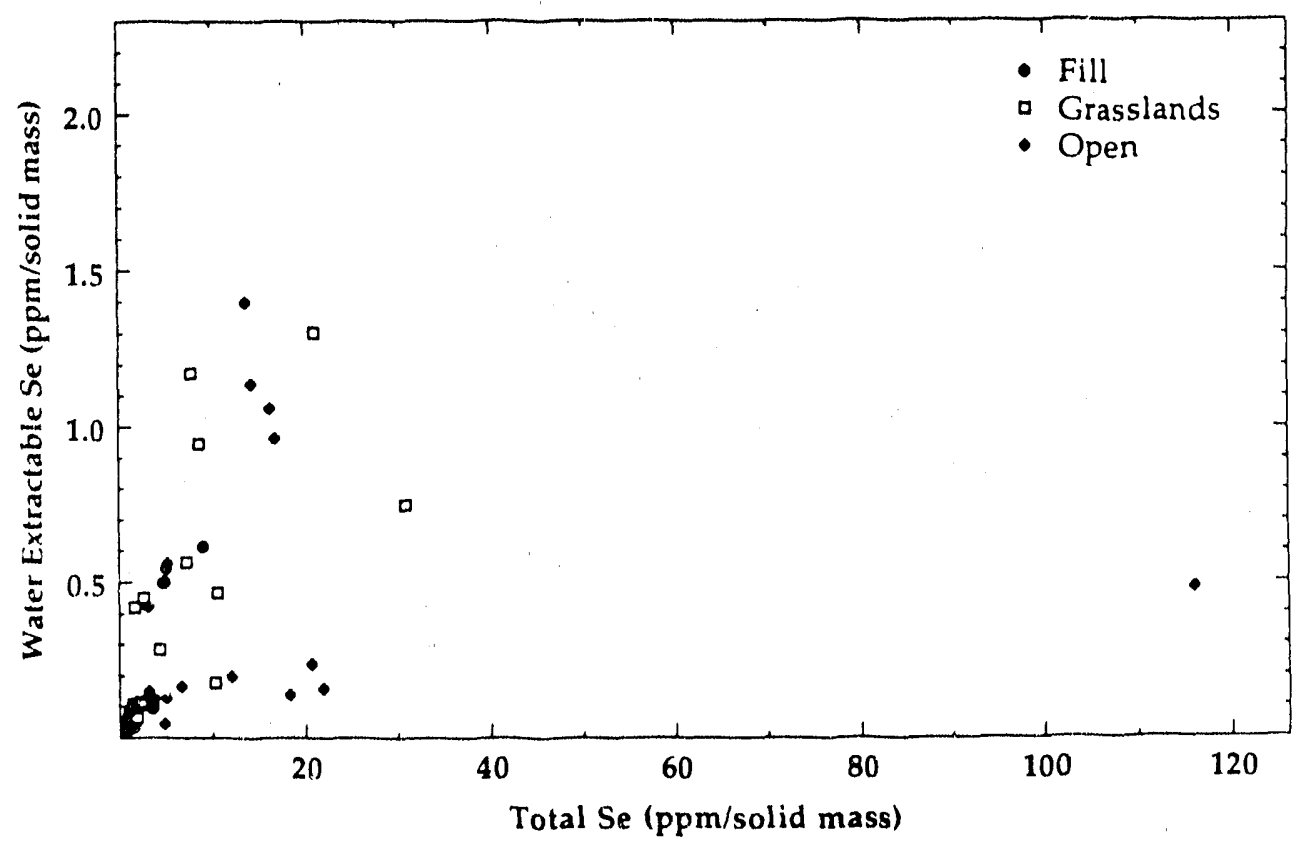

Figure 5.13. Water extractable selenium vs. total selenium for each habitat type. 
- in situ material on the reservoir has been displaced by earth moving equipment;

- some sampling sites were located at a boundary between two different soil types;

- multiple sources of fill material applied to the reservoir, and;

- uncertainty in the depth of fill material.

Data from the fill sites were reviewed to assess the rate of evapotranspiration accumulation of selenium in the surface-most $0.15 \mathrm{~m}$ of soil. Only 12 of the 18 samples could clearly be identified as off-site fill dirt with a sufficiently large fill depth to create an unmixed sample. In these samples the extractable selenium and water extractable selenite concentrations are $40 \pm 20$ ppb and $11 \pm 7 \mathrm{ppb}$ per dry solid mass. Changes in these values upon subsequent sampling will be monitored. 


\title{
5.5. QUALITY CONTROL AND QUALITY ASSURANCE FOR CHEMICAL ANALYSIS IN THE KESTERSON PROGRAM
}

\author{
Leon Tsao, Quality Assurance Manager \\ Earth Sciences Division \\ Lawrence Berkeley Laboratory
}

\subsubsection{Introduction}

A quality assurance program for the LBL Kesterson effort has been in place for over two years. We now have a large body of statistics and can demonstrate improvement in operation and have increased confidence over time in the selenium measurements made. In the last year we have extended the quality assurance program to iriclude boron analyses.

As an external system of control we are required to participate in the San Joaquin Valley Drainage Program Analytical Round-robin Program operated by the Department of Land, Air and Water Resources at the University of California, Davis. Results of this program for 1989 are not yet available.

\subsubsection{Measurement Statistics}

Analytical chemistry has a number of means to judge the quality of the measurements made. Here we are considering the entire measurement process which includes the performance of the analyst and preparation of samples prior to measurement. This means that blind quality control samples must be used. We use standard solutions to gauge accuracy and precision, duplicates to gauge precision with the natural matrix, blanks to gauge contamination and spiked samples or known addition to gauge interference.

\subsubsection{Operations}

Selenium analysis is performed by hydride generator AAS. Samples are feed untreated into

the instrument to measure selenite $\left(\mathrm{SeO}_{3}{ }^{-2}\right)$ concentration. Total selenium is here defined as the 
sum of selenite and selenate. It is analyzed by treating a $5.0 \mathrm{ml}$ sample with $0.2 \mathrm{ml}$ of a $2 \% \mathrm{w} / \mathrm{v}$ solution of ammonium persulfate and $5.0 \mathrm{ml}$ of concentrated $\mathrm{HCl}$. Our studies indicate that the concentration of organic forms of selenium in ground water and soil-water samples is usually not significant (see Section 5.3). Boron analysis is performed by inductively coupled plasma AAS. Samples are feed untreated into the instrument. For both selenium and boron analyses it is often necessary, after an initial reading, to dilute samples to bring them into the linear calibration range of the instrument.

The analyst prepares and runs control standards consisting of standards, blanks and spiked samples every tenth sample analyzed. In addition, $15 \%$ of the sample load consists of blind quality control samples prepared by the Quality Assurance Manager in containers intended to be indistinguishable from the others. These consist of standards, spiked samples, duplicates and blanks placed in the containers.

Calibration standard solutions with 10 and $20 \mathrm{ppb}$ selenium are prepared fresh daily from a 1000 ppm (as selenite) selenium reference standard obtained from the Ricca Chemical Company. Blind standards containing both selenite and selenate are prepared from a stock solution which is itself prepared from a high concentration or "super" stock solution, which is itself prepared from dry sodium selenite and sodium selenate. The blind standard solutions are also used for spiking samples.

Boron analyses are made by inductively coupled plasma AAS. Control samples are prepared in the same proportions as for selenium analyses. Sample sets for which both selenium and boron analyses have been requested have both selenium and boron in the control samples. Boron calibration standards of $5.00,10.00$ and $20.00 \mathrm{ppb} B$ are prepared from VWR Boron Reference Standard, lot $\mathrm{J} 8-04$, with 1000 ppm boron as $\mathrm{H}_{3} \mathrm{BO}_{3}$ in water.

\subsubsection{Blanks}

It is important to distinguish between the instrument limit of detection and the whole process limit of detection. The instrument limit of detection is determined by analyzing a series of 
standards prepared to contain known amounts of the analyte. The whole process limit is determined by analyzing blanks prepared blind in the same manner as any research sample. In the case of total selenium analyses contamination can occur during sample preparation. Splashing and incomplete cleaning of reaction tubes are the most likely causes.

The whole process limits of detection for selenite and total selenium are $0.25 \mathrm{ppb}$ and 0.87 ppb respectively. For boron it is $1.199 \mathrm{ppm}$.

\subsubsection{Selenium Standards}

We have established standards with both selenite and selenate because speciation of selenium has been important in many of the studies we have performed. Because selenite solutions with concentrations in the range of $40 \mathrm{ppb}$ or less oxidize rapidly we make up each standard from a concentrated stock. We report statistics on total selenium rather than selenate because it is a direct analytical measurement. Selenate concentrations may be derived from selenite and selenate but this should incorporate the error of both direct measurements. The ratio of selenite to total selenium is useful for control.

The standard deviation in these measurements includes errors in formulating these standards each time. One identifiable source of error is in the adjustable pipettes used. This is $0.36 \%$ relative deviation in the range used.

Statistics on 308 determinations using a $10 \mathrm{ppb}$ calibration standard give a value of 10.04 $\mathrm{ppb}$ with a standard deviation of $0.14 \mathrm{ppb}$. Statistics on 381 determinations using a $20 \mathrm{ppb}$ calibration standard give a value of $20.05 \mathrm{ppb}$ with a $0.16 \mathrm{ppb}$ standard deviation. The calibration values are within one standard deviation of the nominal value of standards prepared from the Ricca solution. These statistics have been accumulated over several years and indicate our accuracy over that time.

Table 5.7 gives the relative deviations of series of repeat measuremerits of sets of standard solutions run during the last part of fiscal 1988 and the first part of fiscal 1989. They were run blind to the analyst and, for total selenium, subject to all sample preparation procedures. They 
indicate that our precision varies with the concentration of selenium and that we have generally had a slight improvement over time. Table 5.8 contains statistics for a similar set of standards run in 1989. The smaller number of analyses of selenite for the more recent set of standards is the resuli of researchers request for analyses of total selenium only in many of the recent sets, and not due to rejection of more points. The greater relative differences of total selenium measurements in all standards, in spite of more analyses being performed, is most likely due to divergence generated by sample preparation.

Table 5.7. Selenium standard statistics $(5 / 11 / 88-3 / 22 / 89)$

\begin{tabular}{|l|r|r|r|r|r|r|r|r|}
\hline & \multicolumn{9}{|c|}{ Se+4 } & \multicolumn{3}{c|}{$\Sigma$ Se } \\
\hline Label & Conc. & r.d.* & No. of analyses & $95 \%$ c.i. & Conc. & No. of anaiyses & r.d.* & $9.5 \%$ c.i. \\
\hline \hline Se VII a & 4.50 & $6.2 \%$ & 37 & $12.6 \%$ & 9.69 & 40 & $10.4 \%$ & $21.0 \%$ \\
Se VII b & 9.13 & $4.1 \%$ & 43 & $8.3 \%$ & 19.15 & 46 & $7.3 \%$ & $14.8 \%$ \\
Se VII c & 18.42 & $3.9 \%$ & 35 & $7.9 \%$ & 37.86 & 39 & $6.9 \%$ & $13.9 \%$ \\
Se VIII a & 50.05 & $6.2 \%$ & 40 & $12.5 \%$ & 97.97 & 41 & $4.4 \%$ & $8.8 \%$ \\
Se VIII b & 98.27 & $5.1 \%$ & 37 & $10.3 \%$ & 190.75 & 39 & $5.6 \%$ & $11.3 \%$ \\
\hline
\end{tabular}

*r.d. = relative difference

Table 5.8. Selenium standard statistics (1/24/89 - 9/21/89)

\begin{tabular}{|c|r|r|r|r|r|r|r|r|}
\hline & \multicolumn{9}{|c|}{$\mathrm{Se}^{+4}$} & \multicolumn{5}{c|}{$\Sigma$ Se } \\
\hline Label & Conc. & r.d.* & No. of analyses & $95 \%$ c.i. & Conc. & No. of analyses & r.d.* & $95 \%$ c.i. \\
\hline \hline Se IX a & 4.57 & $6.3 \%$ & 28 & $12.8 \%$ & 9.29 & 42 & $9.7 \%$ & $19.6 \%$ \\
Se IX b & 8.90 & $5.8 \%$ & 34 & $11.8 \%$ & 18.09 & 41 & $5.9 \%$ & $11.9 \%$ \\
Se IX c & 17.71 & $4.2 \%$ & 30 & $8.6 \%$ & 35.61 & 44 & $7.2 \%$ & $14.5 \%$ \\
Se X a & 49.13 & $4.7 \%$ & 36 & $9.5 \%$ & 94.96 & 44 & $5.1 \%$ & $10.4 \%$ \\
Se X b & 100.46 & $3.7 \%$ & 30 & $7.5 \%$ & 195.43 & 46 & $4.9 \%$ & $9.8 \%$ \\
\hline
\end{tabular}

*r.d. = relative difference 


\subsubsection{Boron Standards}

For boron, Table 5.9 gives the relative deviations of series of repeat measurements of different sets of standard solutions with different boron concentrations. All standards are prepared from the same stock solution.

Table 5.9. Boron standard statistics

\begin{tabular}{|l|c|c|c|c|}
\hline Standard & Conc. (ppm) & r.d.* & No. of analyses & $95 \%$ c.i. \\
\hline \hline B I a & 2.354 & $12.7 \%$ & 24 & $26.2 \%$ \\
B I b & 4.659 & $7.1 \%$ & 23 & $14.7 \%$ \\
B I c & 9.172 & $16.6 \%$ & 16 & $35.0 \%$ \\
\hline
\end{tabular}

*relative difference

The wider confidence intervals for boron are due to fewer determinations done to begin with and the need to reject a substantial number of points due to technical problems with our ICP. The problems have beer. cleared up but it is still necessary to wait while we accumulate more statistics.

\subsubsection{Spike Recoveries}

A persistent drawback in our spike recovery measurements has been the difficulty in knowing a priori what the selenium concentrations of many samples are. Ideally the spike of analyte added is equal to the amount of the original analyte. Spikes less than $1 / 4$ or more than 4 of the original analyses are not statistically meaningful. Though we attempted 155 selenite and 199 total selenium spiked sample analyses, only 44 selenite analyses and 60 total selenium analyses were in a statistically meaningful range Our average recovery for a selenite spike was $88.2 \%$ and for a total selenium spike it was $84.4 \%$. We believe this is significant and andication of unknown organiss complexing with selenium.

For boron spike recoveries the same problem of appropriate spike lnvel occurred. Out of 44 spike recovery analyses, only 24 had spikes within the meaningful concentration range. The average spike recovery for boron was $94.7 \%$. 


\subsubsection{Duplicates}

Duplicates provide a measure of our analytical precision which includes factors such as foaming, which repeated measurements of standards do not reflect. The average relative difference for duplicate selenite analyses performed in 1989 was $5.4 \%$ and for duplicate total selenium analyses $14.2 \%$. Duplicates for which both values were less than the whole-process detection limit w'ere discarded. As with measurements of standards, the greater relative differences of total selenium duplicates compared to selenite is most likely due to divergence generated by sample processing. The average relative difference for duplicate boron analyses was $4.3 \%$. 


\section{REFERENCES}

\subsection{GENERAL REFERENCES}

Lawrence Berkeley Laboratory Progress Report 1, 1985, LBID-1101, Berkeley, CA. Lawrence Berkeley Laboratory Progress Report 2, 1986, LBID-1188, Berkeley, CA. Lawrence Berkeley Laboratory Progress Report 3, 1986, LBID-1213, Eerkeley, CA. Lawrence Berkeley Laboratory Progress Report 4, 1986, LBID-1250, Berkeley, CA. Lawrence Berkeley Laboratory Progress Report 5, 1987, LBID-1291, Berkeley, CA. Lawrence Berkeley Laboratory Progress Report 6, 1987, LBID-1312, Berkeley, CA. Lawrence Berkeley Laboratory Annual Report, 1987, LBL-24250, Berkeley, CA. Lawrence Berkeley Laboratory Progress Repor: 7, 1988, LBID 1404, Berkeley, CA. Lawrence Berkeley Laboratory Progress Repon 8, 1988, LBID-1420, Berkeley, CA. Lawrence Berkeley Laboratory Annual Report, 1988, LBL-26438, Berkeley, CA. Lawrence Berkeley Laboratory Progress Report 9, 1989, LBID-1483, Berkeley, CA. Lawrence Berkeley Laboratory Progress Report 10, 1989, LBID-1518, Berkeley, CA.

\subsection{HYDROLOGY AND GEOPHYSICS}

Benson, S.M., 1988. Characterization of the hydrologic and transport properties of the shallow aquifer under Kesterson Reservoir, Merced County, Califomia. PhD Dissertation, University of Califomia, Berkeley.

Goldstein, N. E., S. L. Pillsbury, J. S. Daggett and S. M. Benson, 1989. Contaminant plume monitoring adjacent to the Kesterson Reservoir, Califomia, Lawrence Berkeley Laboratory Report, LBL-26557, Berkeley, California.

Hanson, B. R. and M. E. Grismer, 1987. A geophysical approach to evaporation pond siting and drainage design survey: 1986-1987 Technical Progress Report, U. C. Salinity Drainage Task Force, Division of Agriculture and Natural Resources, University of Califomia, Davis.

Long, R.H., 1988. Transport of selenium and chloride through a shallow pond sediment at Kesterson Reservoir. Master's Thesis, University of California, Berkeley.

Mandle, R.J., and A.L. Kontis, 1986. Directions and rates of groundwater movement in the vicinity of Kesterson Reservoir, San Joaquin Valley, Ca. U. S. Geological Survey Water Resources Investigations, Report 86-4196.

Narasimhan, T.N., and P.A. Witherspoon, 1976. An integrated finite difference method for fluid flow in porous media. Water Resources Research, 12(1), 57-64, 1976.

Scheidegger, A. E., 1957. The physics of flow through porous media. University of Toronto Press.

Zawislanski, P.T., 1989. Bare suil evaporation at Kesierson Reservoir, Merced County, California; estimation by physical and chemical methods. Master's Thesis, University of California, Berkeley. 


\subsection{VADOZE ZONE}

Balistrieri, L. S., and T. T. Chao, 1987. Selenium adsorption by goethite, Soil Sci. Soc. Amer. J., $51,1145-1151$.

Barraclough, P. B. and P. B. Tinker, 1981. The determination of ionic diffusion coefficients in field soils. I. Diffusion coefficients in sieved soils in relation to water content and bulk density, J. Soil Sci., 32, 225-236.

Barraclough, P. B. and P. B. Tinker, 1982. The determination of ionic diffusion coefficients in field soils. I. Diffusion of bromide ions in undisturbed soil cores, J. Soil Sci., 33, 13-24.

Bar-Yosef, B. and D. Meek, 1987. Selenium sorption by kaolinite and montmorillonite, Soil Science, 144 (1), 11-19.

Benson, S.M., 1988. Characterization of the hydrologic and transport properties of the shallow aquifer under Kesterson Reservoir, Merced County, California. PhD Dissertation, University of California, Berkeley.

Black, T. A., W. R. Gardner and G. W. Thurtell, 1969. The prediction of evaporation, drainage, and soil water storage for a bare soil, Soil Sci. Soc. Amer. Proc., 33, 655-660.

Boast, C. W., 1986. Evaporation from bare soil measured with high spatial resolution, in Methods of Soil Analysis, Part 1 - Physical and Mineralogical Methods, A. Klute, ed., 2nd ed., Agronomy, 9, 889-900.

Boast, C. W., and T. M. Robertson, 1982. A Rmicro-lysimeterU method for determining evaporation from bare soil: Description and laboratory evaluation, Soil Sci. Soc. Am. J., 46, 689-696.

Bresler, E., W. D. Kemper and R. J. Hanks, 1969. Infiltration redistribution, and subsequent evaporation of water from soil as affected by wetting rate and hysteresis, Soil Sci. Soc. Amer. Proc., 33, 832-840.

Bresler, E., B. L. McNeal and D. L. Carter, 1982. Saline and Sodic Soils: Principles-DynamicsModeling, Springer-Verlag, Berlin.

Davis, G. H., J. H. Green, F. H. Olmsted and D. W. Brown, 1959. Ground-water conditions and storage capacity in the San Joaquin Valley, Califomia, U. S. Geol. Surv Water Supply Paper $1469,287 \mathrm{p}$.

Deverel, S. J., and R. Fujii, 1988. Processes affecting the distribution of selenium in shallow groundwater of agricultural areas, western San Joaquin Valley, Califomia, Water Resour. Res., 24 (4), 516-524.

Feddes, R. A., S. P. Neumann, and E. Bresler, 1975. Finite element analysis of two-dimensional flow in soils considering water uptake by roots: II. Field applications, Soil Sci. Soc. Amer. Proc., 39, 231-237.

Fio, J. L. and R. Fujii, 1988. Comparison of methods to determine selenium species in saturation extracts of soils from the western San Joaquin Valley, Califomia, Geol. Surv. Open-file Report 88-458, $16 \mathrm{p}$.

Flaschka, H. A., A. J. Barnard, Jr., and P. E. Sturrock, 1969. Quantitative Analytical Chemistry, Vol. I, Bames and Noble.

Flexser, S., 1988. Lithologic composition and variability of the sediments underlying Kesterson Reservoir as interpreted from shallow cores, LBL-25586, Lawrence Berkeley Laboratory, Berkeley, California.

Frankenberger, W. T. and U. Karlson, 1988. Dissipation of soil selenium by microbial volatilization at Kesterson Reservoir, Final Report to the U.S. Bureau of Reclamation.

Fujii, R., S. J. Deverel and D. B. Hatfield, 1988. Distribution of selenium in soil in agricultural fields, western San Joaquin Valley, California, Soil Sci. Soc. Am. J., 52 (5), 1274-1283. 
Gardner, H. R., 1973. Prediction of evaporation from homogeneous soil based on the flow equation, Soil Sci. Soc. Amer. Proc., 37, 513-516.

Gardner, W. R. and M. Fireman, 1958. Laboratory studies of evaporation from soil columns in the presence of a water table, Soil Science, 85, 244-249.

Hadas, A. and D. Hillel, 1968. An experimental study of evaporation from uniform soil columns in the presence of a water table, Trans. 9 th Int. Cong. Soil Sci., 85, 228-232.

Hadas, A. and D. Hillel, 1972. Steady-state evaporation through non-homogeneous soils from a shallow water table, Soil Science, 113 (2), 65-73.

Harradine, F., 1950. Soil Survey of Western Fresno County, University of Califomia Press, Berkeley.

Hillel, D., 1980a. Fundamentals of Soil Physics, Academic Press, New York.

Hillel, D., 1980b. Applications of Soil Physics, Academic Press, New York.

Hillel, D., 1975. Simulation of evaporation from bare soil under steady and diumally fluctuating evaporativity, Soil Science, 120 (3), 230-237.

Hillel D., 1976. On the role of soil moisture hysteresis in the suppression of evaporation from bare soil under diumally cyclic evaporativity, Soil Science, 122, 309-314.

Jackson, R. D., B. A. Kimball, R. J. Reginato and F. S. Nakayama, 1973. Diurnal soil-water evaporation: Time-depth-flux pattems, Soil Sci. Soc. Amer. Proc., 37, 505-509.

Koorevar, P., G. Menelik and C. Dirksen, 1983. Elements of Soil Physics, Elsevier, Amsterdam, The Netherlands.

Lindsay, W. L., 1979. Chemical Equilibria in Soils, Wiley, New York.

Long, R. H., 1988. Analysis of selenium and chloride movement through a shallow pond sediment at Kesterson Reservoir, M.S. thesis, University of California, Berkeley.

MacFarlane, D. S., J. A. Cherry, R. W. Gillham and E. A. Sudicky, 1983. Migration of contaminants in groundwater at a landfill: A case study, 1. Groundwater flow and plume dileneation, J. Hydrol., 63 (1,2), 1-29.

McNeal, J. M. and L. S. Balistrieri, 1989. Geochemistry and occurence of selenium, An overview, in Selenium in Agriculture and the Environment, Soil Sci. Soc. Am. Spec. Publ. No. 23, L. W. Jacobs, ed., American Society of Agronomy, Madison, Wisconsin, pp. 1-14.

Moore, R. E., 1939. Water conduction from shallow water tables, Hilgardia, 12, 383-426.

Narasimhan, T.N., and P.A. Witherspoon, 1976. An integrated finite difference method for fluid flow in porous media. Water Resources Research, 12(1), 57-64, 1976.

Passerat de Sillans, A., L. Bruckler, J. L. Thony, and M. Vauclin, 1989. Numerical modeling of coupled heat and water flows during drying in a stratified bare soil - Comparison with field observations, J. Hydrol., 105, 109-138.

Penman, H. L., 1948. Natural evaporation from open water, bare soil and grass, Proc. Roy. Soc., 193, 120-145.

Pinner, A. and P. H. Nye, 1982. A pulse method for studying effects of dead-end pores, slow equilibration and soil structure on diffusion of solutes in soil, J. Soil Sci., 33, 25-35.

Porter, L. K., W. D. Kemper, R. D. Jackson, and B. A. Stewart, 1960. Chloride diffusion in soils as influenced by moisture content, Soil Sci. Soc. Amer. Proc., 24, 460-463.

Qayyum, M. A. and W. D. Kemper, 1961. Salt-concentration gradients in soils and their effects on moisture movement and evaporation, Soil Science, 93, 333-342.

Reynolds, W. D., and G. K. Walker, 1984. Development and validation of a numerical model simulating evaporation from short cores, Soil Sci. Soc. Am. J., 48, 960-969.

Rhoades, J. D., 1978. Monitoring soil salinity, A review of methods, in Establishment of water quality monitoring programs, L. G. Everett and K. D. Schmidt eds., Am. Water Resour. Assoc., Minneapolis. 
Rhoades, J. D., 1984. Principles and methods of monitoring soil salinity, Soil Salinity under Irrigation: Processes and Management, I. Shainberg and J. Shalhevet, eds., Springer-Verlag, Berlin Heidelberg.

Ripple, C. D., J. Rubin, and T. E. A. van Hylckama, 1972. Estimating steady-state evaporation rates from bare soils under conditions of high water table, U. S. Geol. Surv. Water-Supply Paper 2019-A, and others.

Salhotra, A. M., E. E. Adams, and D. R. F. Harleman, 1985. Effect of salinity and ionic composition on evaporation: Analysis of dead sea evaporation pans, Water Resour. Res., 21 (9), 1336-1344.

Seidell, A., 1958. Solubilities, 1, 4th ed. American Chemical Society, D. van Nostrand Co., Princeton, New Jersey, 1958.

Sposito, G., 1984. The Surface Chemistry of Soils, Oxford University Press, New York.

Staple, W. J., 1969. Comparison of computed and measured moisture redistribution following infiltration, Soil Sci. Soc. Am. Proc., 33, 840-847.

Staple, W. J., 1970. Predicting moisture distributions in rewette 1 soils, Soil Sci. Soc. Amer. Proc., $34,387-392$.

Staple, W. J., 1971. Boundary conditions and conductivities used in the isothermal model of evaporation from soil, Soil Sci. Soc. Am. Proc., 35, 853-855.

Taylor, J. R., 1982. An Introduction to Error Analysis: The Study of Uncertainties in Physical Measurements, University Science Books, Mill Valley, California.

USDA Soil Conservation Service, 1952. Soil survey of the Los Banos area, California, Series 1939.

van Bavel, C. H. M., 1961. Lysimetric measurements of evapotranspiration rates in the eastern United States, Soil Sci. Soc. Amer. Proc., 25, 138-141.

Van De Pol, R. M., P. J. Wierenga and D. R. Nielsen, Solute movement in a field soil, Soil Sci. Soc. Am. J., 40, 473-480.

Veihmeyer, F. J. and F. A. Brooks, 1954. Measurements of cumulative evaporation from bare soil, Trans. Am. Geoph. Union, 35 (6).

Weres, O., A. F. White, H. A. Wollenberg and A. Yee, 1985. Geochemistry of selenium at Kesterson Reservoir: Possible remedial measures, Earth Sciences (Lawrence Berkeley Laboratory PUB-431), 8(3), 1-8.

Zawislanski, P. T., 1989. Bare soil evaporation at Kesterson Reservoir, Merced County, California: Estimation by physical and chemical methods, M.S. thesis, University of Califomia, Berkeley.

\subsection{SOIL AND VEGETATION}

Allaway, W. H. and E. E. Cary, 1964. Determination of selenium in biological materials, Anal. Chem. 36, 1359-1362.

Carter, D. D., W. H. Allaway and E. E. Cary, 1968. Selenium content of forage and hay crops in the Pacific Northwest, Agron, J., 60, 532-534.

Chao, T. T. and R. F. Sanzolone, 1989. Fractionation of soil selenium by sequential partial dissolution, Soil Sci. Soc. Am. J., 53, 385-391.

$\mathrm{CH}_{2 \mathrm{M}}$ Hill and Jones and Stokes Associate, 1980. Waste classification report, Kesterson Reservoir, September 1986, U. S. Bureau of Reclamation Mid-pacific Region.

Drake, C., A. B. Grant and W. J. Hartly, 1960. Selenium and animal health, Part I and II. N. Z Vet. J., 8, 4-10. 
Davis, E. B. and J. H. Watkinson, 1969. Uptake of native and applied selenium by pasture species, effects of sulphate and soil type on uptake by clover, N.Z. J. Agric., 9, 641-652.

Dodd, J. D. and R. T. Coupland, 1966. Vegetation of saline areas in Saskatchewan, Ecology, 47, 958-968.

Epstein, E., 1972. Mineral Nutrition of Plants: Principles and Perspectives, John Wiley and Sons, New York.

Fio, J. L. and R. Fujii, 1988. Comparison of methods to determine selenium species in saturation extracts of soils from the Western San Joaquin Valley, California. U.S. Geological Survey, Open File Report 88-458.

Frankenberger, W. T. Jr. and U. Karlson, 1988. Dissipation of soil selenium by microbial volatilization at Kesterson Reservoir, Final Report. U. S. Dept. of the Interior, Bureau of Reclamation, Sacramento.

Fujii, R., S. J. Deverel and D. B. Hatfield, 1988. Distribution of selenium in soils of agricultural fields, Soil Sci. Soc. Am. J., 52, 1274-1283.

Ganje, T. J. and D. W. Rains, 1982. Arsenic. Methods of Soil Analysis, Part 2-Chemical and Microbiological Properties, 2nd edition.

Gissel-Nielsen, G. and B. Bisbjerg, 1970. The uptake of applied selenium by agricultural plants, 2. The utilization of various selenium compounds, J. Ecology, 61, 473-494.

Harmensen, K. and deHaan, F. A. M., 1980, Occurrence and behavior of uranium and thorium in soil and water, Neth. J. Agric. Sci., 28, 40-62.

Hingston, F. J., 1981. A neview of anion adsorption. Adsorption of Inorganics at Solid-liquid Interfaces, Anderson, M. A. and A. J. Rubin, editors, Ann Arbor Science Publishers Inc., Ann Artor.

Horst, G. L. and N. B. Beadle, 1984. Salinity effects germination and growth of tall fescue cultivars, Hort. Sci., 109, 419-422.

Marrero, T. R. and E. A. Mason, 1972. Gaseous diffusion coefficients. 1972. J. Chem. Phys. Reference Data 1, 3-118.

Page, A. L., R. H. Miller and D. R. Keeney, editors. Agronomy, No. 9, Part 2, Am. Soc. Agronomy, Madisen.

Powell, J. W., 1978. Report on the lands of the arid region of the United States. Government Printing Office, Washington, D. C., $400 \mathrm{pp}$.

Rosenfeld, I. and O. A. Beath, 1964. Selenium: Geobotany, Biochemistry, Toxicity, and Nutrition, Academic Press, New York.

Rozema, J., E. Rozema-Dijst, A. H. J. Freijsen and J. J. L. Huber, 1978. Population differentiation with Festuca rubra L. with regard to soil salinity and soil water, Oecologia, 34, 329-341.

Wu, L., 1981. The potential for evolution of salinity tolerance in Agrostis stolonifera L. and Agrostis tenuis Sibth., New Phytol. 89, 471-486.

Zieve, R. and P. J. Peterson, 1985. Sorption of dimethylselenide by soils, Soil Biol. Biochem. 17, $105-107$.

\subsection{CHEMICAL ANALYSES}

Chao, T. T. and R. F. Sanzolone, 1989. Fractionation of soil by sequential partial dissolution, Soil Sci. Soc. Am. J., 53, 385-392.

Fio, J. L. and R. Fujii, DATE. Comparison of methods to determine selenium species in saturation extracts of soils from the Western San Joaquin Valley, Califomia, USr.S Open File Report 88-458, 
Frankenburger, W. T., 1988. Dissipation of soil selenium by microbial volatilization at Kesterson Reservoir, Final Report for USBR.

Karlson, U. and W. T. Frankenburger, 1989. Accelerated rates of selenium volatilization from Califomia Soil, Soil Sci. Soc. Am. J., 53, 749-753.

Glaubig, R. A. and S. Goldberg, 1988. Determination of inorganic arsenic(III) and arsenic(III plus V) using automated hydride-generation atomic-absorption spectrometry, Soil Sci. Soc. Am. J., 52, 536-537.

Gruebel, K. A., J. A. Davis and J. O. Leckie, 1988. The feasibility of using sequential extraction techniques for arsenic and selenium in soil and sediments, Soil Sci. Soc. Am. J., 52, 390397.

Kheboian, C. and C. F. Bauer. 1987. Accuracy of selective extraction procedures for metal speciation in model aquatic sediments, Anal. Chem. 59, 1417-1423.

Moore, S., D. H. Speckman, W. H. Stein, 1958. Chromatography of amino acids on sulfonated polystyrene resins, Anal. Chem., 30, 1185-1190.

Sposito, G. 1984. The Surface Chemistry of Soils, Oxford Univ. Press, New York.

Weres, O., 1989. Removal of selenium from San Luis Drain sediments, Final Report to USBR. 

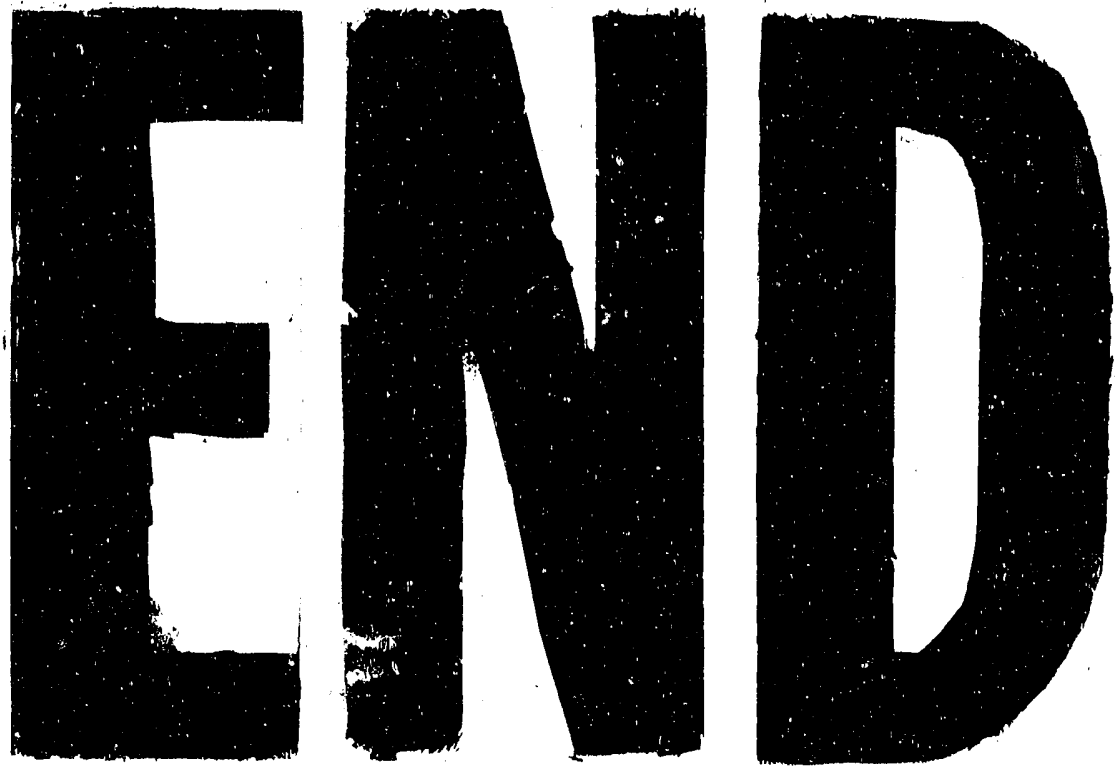

4
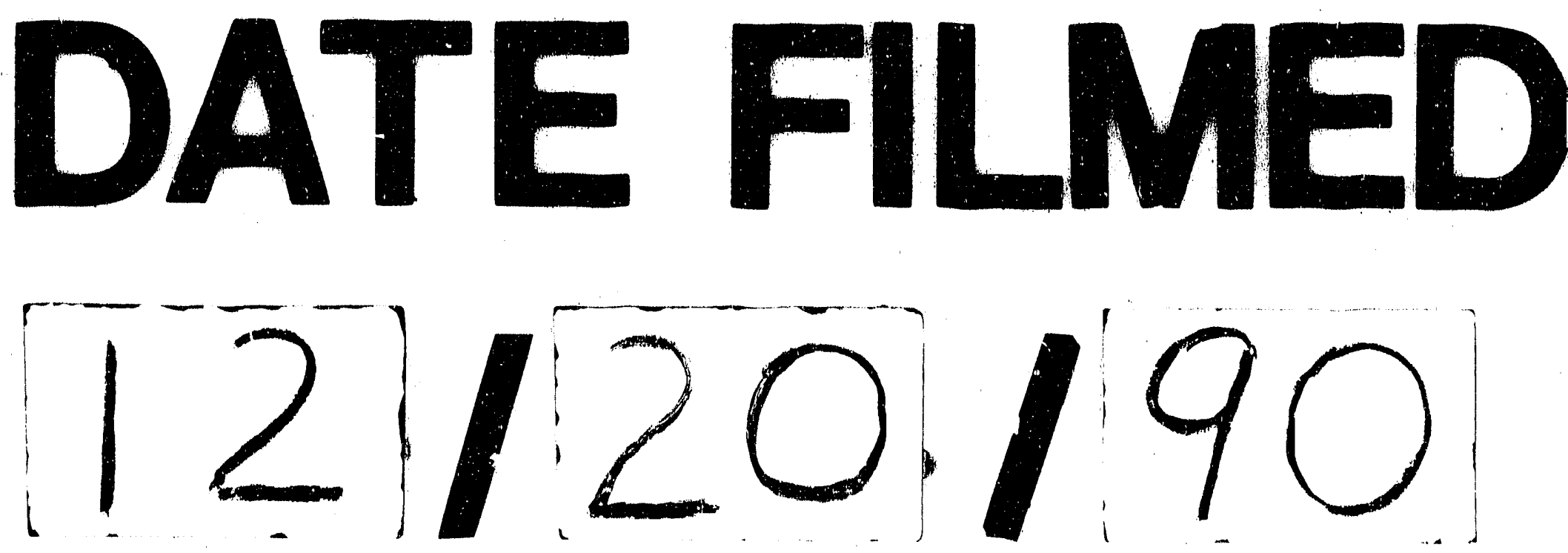
